\title{
West African food system
}

\section{resilience}

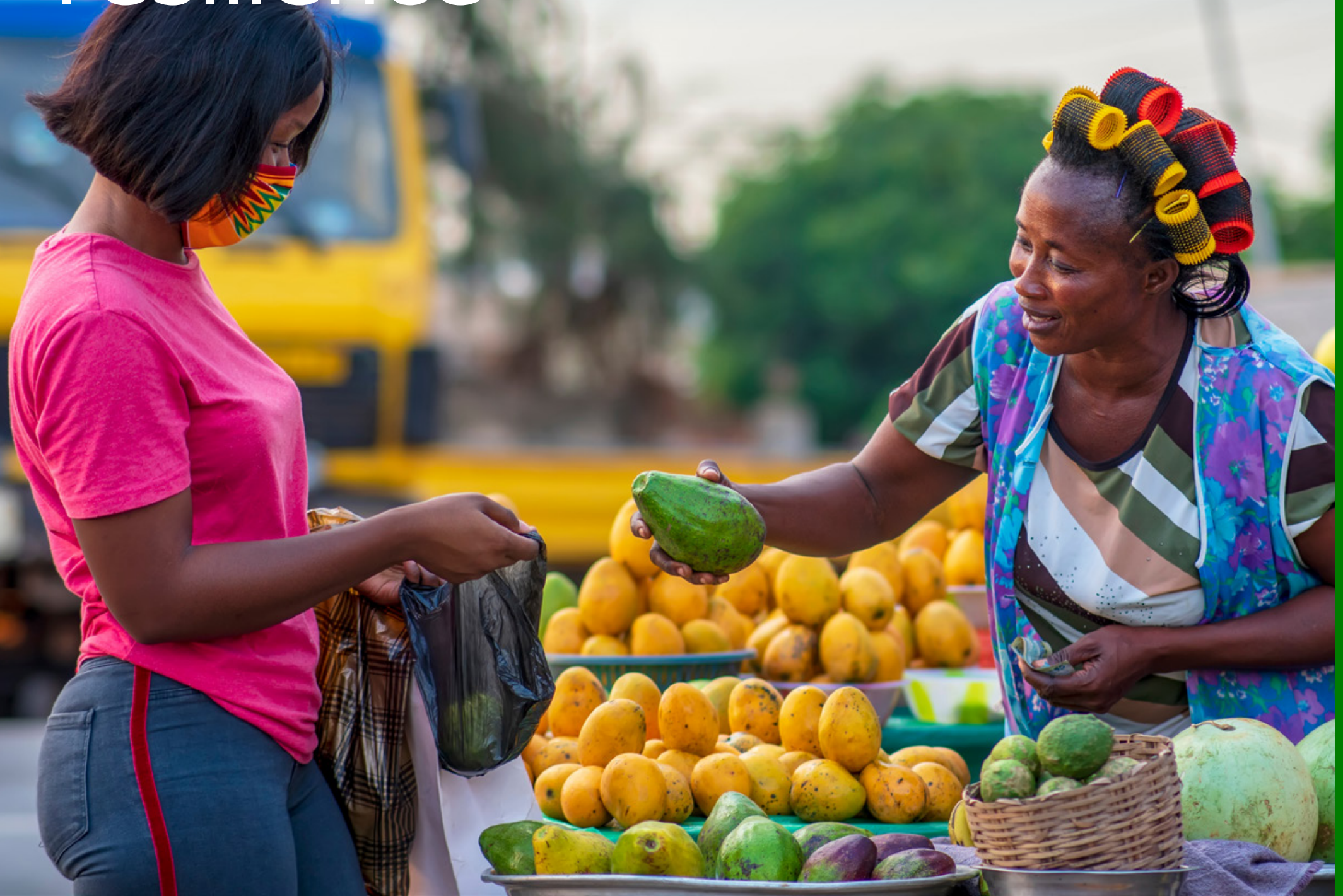

Authors: Bart de Steenhuijsen Piters, Joost Nelen, Bertus Wennink, Verina Ingram, Fabien Tondel, Froukje Kruijssen and Jenny Aker

Preface

\section{Executive Summary}

(1) Background and understanding food systems resilience

Regional drivers of West
Africa's food systems

(3) Regional organisations

(4) Agro-pastoralism-based
food systems

(5) Grains-and-legumes-based

5 food system

(6) Rice-and-horticulture-based food systems

(7) Coastal maritime fisheries food system

(8) Tropical mixed tree and

8 food crops systems

9 Toward enhanced resilience of West African food systems

Acknowledgements

Colophon 


\section{Preface}

COVID-19 is an extreme event that we will remember for a lifetime. But it is by no means the only shock of our time that puts global food security under pressure. Climate change, the increase in pandemics due to animal disease transfer and biodiversity loss will further increase pressure on existing food systems. Resilient, sustainable food systems, striking a balance between social, economic and environmental impacts, must be the answer. And that requires a different approach than 'producing more food'; it requires thinking in systems thinking and 'producing food in a better way'.

Early 2020 the World Bank and the Netherlands Ministry of Foreign Affairs approached Wageningen University and Research with the question: How resilient are West African food systems and how to strengthen their resilience? The World Bank was in the process of developing a regional programme for that purpose and expressed its interests to Wageningen University \& Research to obtain evidenced-based insights that could be used during its consultations and formulation. Wageningen University \& Research quickly set up a dedicated team, and invited experts from the Royal Tropical Institute (KIT), European Centre for Development Policy Management (ECDPM) and Mr. Joost Nelen to join.

Diving into the world of West African food systems and their resilience does not provide one with a univocal answer to the questions raised by the World Bank. The systems prove to be very diverse and respond in very different ways to shocks such as provoked by the COVID-19 pandemic. Whereas some systems show higher levels of resilience, others show important vulnerabilities to specific shocks. Income and power disparities between stakeholders in the systems, such as defined by gender differences, appear to be important, explaining why people's livelihoods are sometimes threatened, while other people have buffers and capacities to respond.

The study draws a rich and nuanced picture of West African food system resilience, with clear challenges and leverage points for enhancing capacities to respond to future shocks. I hope that the publication will also inform and inspire you, either to dive deeper into West African food systems and their resilience, or to undertake any action to support them.

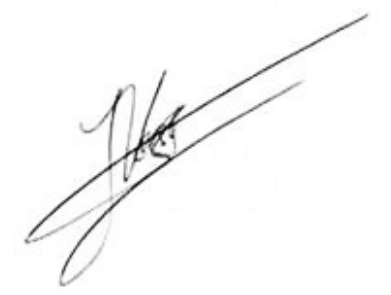

Prof. dr. ir. J.G.A.J. (Jack) van der Vorst

Managing Director Social Sciences Group (SSG)

Wageningen University \& Research

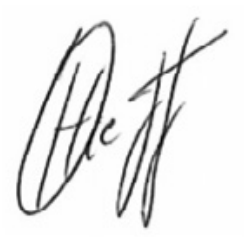

\section{Ir. O. (Olaf) Hietbrink}

Business Unit Manager Wageningen Economic Research Wageningen University \& Research
(1) Background and understanding

(2) Regional drivers

(3) Regional organisations

(4) Agro-pastoralism-based

(5) Grains-and-legumes-based

(6) Rice-and-horticulture

(7) Coastal maritime fisheries

(8) Tropical mixed tree and food crops systems

9) Toward enhanced resilience

Do you want to know more about WUR's food systems resilience research agenda? Download the whitepaper or contact: Bart de Steenhuijsen Piters. 


\section{Executive Summary}

The West African region supplies most of the food for its growing population, which now exceeds 400 million. West African countries meet most of the region's needs for coarse grains, tuber and root crops, vegetables, fruits, and meat (excluding some areas of fast-growing consumption such as chicken). Generic data and their interpretations obscure the region's food systems, which have evolved over hundreds of years. These systems, often poorly understood by outsiders, exist in complex relationships between people and natural environments, with both short value chains and long ones supplying distant consumer markets.

Food security figures have improved slightly across West Africa. In 2002 all countries in the region reported that at least 10-40 percent of their households were severely to moderately food insecure. Rates of severe to moderate food insecurity vary between the respective countries and range from 6 to above 25\%. The data show that food insecurity prevails despite generic data on the ability of food systems to feed West African consumers. This is due to increasing disparities between socioeconomic and gender segments in society.

Over the past century, West Africa's food systems have shown various degrees of resilience in responding to external and internal shocks. These food systems have also shown resilience to the drivers of and long-term changes to the social and ecological systems in which they are embedded. But there are limits to the region's capacity for absorption, adaptation, and response, which is challenging food system balance and efforts to ensure an affordable, sufficient, and accessible supply of healthy food for West Africa.

It is against this background that the World Bank and its regional partners formulate a regional programme to enhance the resilience of agriculture and food systems in West Africa. This study was conducted in contribution to the design and formulation of the support facility. Acknowledging the rich diversity in food systems in the region, five important food systems were selected to understand how they contribute to food system outcomes, experience a variety of vulnerabilities, and develop over time diverse and inherent forms of resilience. After detailed analysis of the five food systems, two major questions could be answered:

\section{What is the status of regional food system resilience in West Africa?}

\section{How can food system resilience in West Africa be enhanced through regional institutions?}

The most prominent conclusions from the study are: Consumer demands for food have risen gradually over the past decades in West Africa and are projected to rise further due to increasing population, income, and economic growth. Food systems have kept pace with these increasing demands which have been met by domestic and regional production. Important exceptions are rice, dairy, and poultry, though West African food systems have adequate potential to meet consumer demand for these products.

Although the food supply looks positive in absolute numbers, these figures do not explain the high rate of malnutrition observed among the various populations of West Africa. The numbers are alarming in terms of persistent undernutrition and rising levels of obesity. High rates of child stunting across all five food systems indicate the severity of food insecurity irrespective of the food system. Undernutrition and foodborne disease prevalence are explained by food system outcomes in terms of the affordability, accessibility, and safety of food. In other words, undernutrition is also an expression of socioeconomic poverty and is strongly associated with highly accentuated social disparities and the agroeconomic exclusion of people, notably women, observed across West Africa. Food safety issues and postharvest losses are observed in many food value chains, notably fresh vegetables and animal products (dairy and fish). These health risks hamper the consumption of the more diverse foods needed for healthy diets.

Food systems of West Africa differ significantly in their response to these threats. Food systems that depend on global markets, such as rice and poultry, and export-oriented cash crops, such as cotton, cacao, and palm oil (as drivers of mixed-crop systems), are more
(1) Background and understanding

(2) Regional drivers

(3) Regional organisations

(4) Agro-pastoralism-based

(5) Grains-and-legumes-based

6) Rice-and-horticulture

(7) Coastal maritime fisheries

8 Tropical mixed tree and food crops systems

9 Toward enhanced resilience 
vulnerable to economic shocks than food systems that depend on informal, domestic, and regional markets, such as livestock

products, coarse grains, and pulses. In contrast, food systems that are based on the extraction of food from natural resources, such as fisheries and pastoralism, are less resilient to climate variation when their historically evolved production systems are constrained by new drivers of change, such as industrial fisheries, encroachment on pastoral lands, and national policies restricting pastoralist mobility. Secured access to key natural resources is a prerequisite for the survival of the systems.

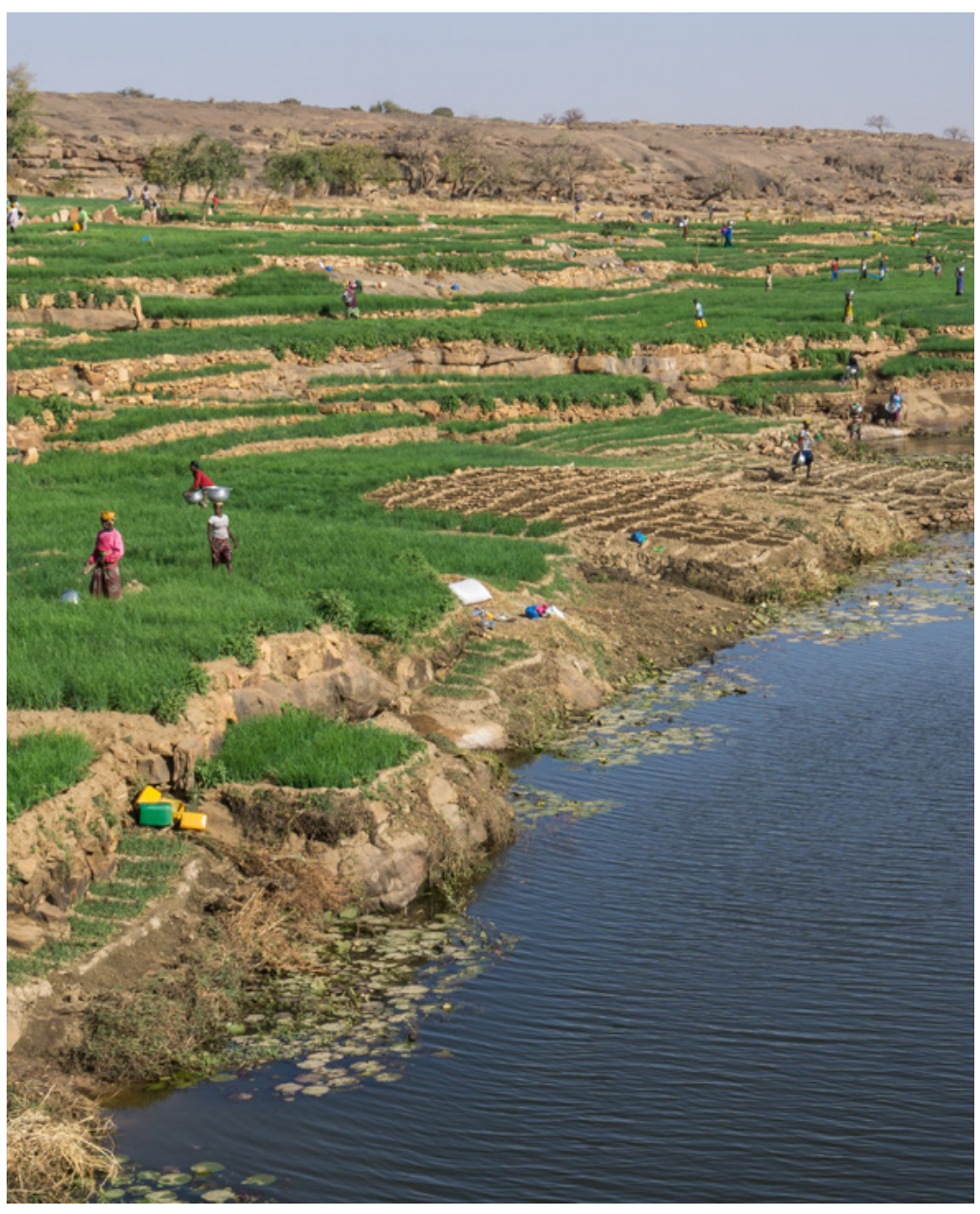

Two systems show greater climate resilience due to access to widely available natural resources. In some countries, the mixed-grainand-legumes-based system can still expand to the southern Sudan areas, which are the last abundant land reserves with relatively low population density. The rice-and-horticulture-based systems can build on largely available surface water and groundwater reserves to sustain current irrigated lowland systems. However, there are important nuances: expansion to and clearance of Sudan areas is already taking place in an unsustainable way, at the expense of forest resources, meaning the region's real water potential is unknown and possibly overestimated. Lastly, these two systems risk encroaching on the other systems and increasing their exposure to climate events and economic shocks.

Regional conflict hampers the safe and efficient flow of crop and livestock products, as well as wage labourers seeking opportunities elsewhere. There is much debate about the root causes of conflict in the Sahel region, but there is general agreement that land and water scarcity, combined with deteriorating natural resource management agreements between users, has contributed much to the current situation. In spite of ample progress in terms of natural resource legislation and decentralisation of government, enforcement has been weak, resulting in a status quo of competing claims on natural resources and confusion about rights among users. Moreover, local governments have not been sufficiently empowered, in terms of capacities and financial resources, which has limited their ability to intervene or provide community services. For these reasons, the authority of local governments has eroded over time, resulting in lack of a social contract and, in particular situations, a vacuum of power. Resolving conflict and addressing its root causes should be a top priority when pursuing enhanced food systems resilience. Mobilising community agencies, enforcing municipalities to reestablish social contracts, and addressing land tenure issues in cooperation with interest groups are among the most prominent and urgent interventions required.

Family farms still constitute the backbone of all food systems. Commercial - mainly informal - value chains, supplying the urban centres with food, include an estimated 20-30 percent of rural households, depending on the system and area. The other
(1) Background and understanding

(2) Regional drivers

(3) Regional organisations

(4) Agro-pastoralism-based

(5) Grains-and-legumes-based

6) Rice-and-horticulture

(7) Coastal maritime fisheries

(8) Tropical mixed tree and food crops systems

9) Toward enhanced resilience 
approximately 80-70 percent of households are engaged in seasonal/wage labour or other petty business for income generation, complemented with crop production and livestock keeping for self-provisioning. These households only bring produce to the market in situations of immediate cash needs or exceptional cases of access production. Currently, earnings from local wage labour and remittances from seasonal and regional migration to areas with demand for cheap labour are the most common tools households use to respond to food and nutrition insecurity. As such, these households are frequently net consumers of locally produced food.

In the short run, no significant shifts in economic development are foreseen in West Africa, such as creating new manufacturing and services industries that absorb massive numbers of workers. Thus, solutions to improve the livelihoods of poorer rural households must be sought in more enumerative labour and more diverse, sustainable farming for self-provisioning and selling of surplus in times of overproduction. The latter differs from more commercial farming in terms of extensive capital and labour practices but is geared toward securing access to diverse food year-round. The agroservices needed to achieve these objectives must be subsidised from public sources.

Regional markets are key to improving economic resilience.

Functioning regional markets are conducive to efficient trade flows, lowering transaction costs while protecting domestic production against market distortions triggered by the volatility of global food markets. Because of asymmetrical supply/demand in large areas, intraregional trade is crucial to satisfy rising demand. ECOWAS has made good progress with policies for establishing regional markets, enhancing the free flow of goods between countries, and regulating the import of products from global markets. However, despite this progress, endorsement of trade agreements and application of instruments such as CETs have been weak. The application of higher CETs on imports of strategic food such as rice, milk powder, or poultry might propel domestic production and trade. Until now, ECOWAS states have decided to keep such imports at the lower tariffs of 5 or 10 percent, which hardly prevents disturbances of domestic production by imports.
Trade restrictions negatively affect the resilience of food systems. Historically, the people of West Africa have traded their products across the region, and current national boundaries, drawn under colonial rule, have not significantly changed this dynamic. Even when nations decide to close their borders, they remain permeable to informal trade flows. Yet, such restrictions impose transaction costs, making regional food products much more expensive than needed and reducing their competitiveness with foreign imports.

These restrictions neither serve producers, who are limited in their offset on local markets of their production, nor help poorer urban consumers access basic food ingredients for healthy diets. Trade restrictions also negatively affect the resilience of food systems in economic terms and increase system vulnerability to unforeseen shocks that cannot be absorbed through regional displacement of food stocks and surpluses. Cross-border mobility is an essential part of agro-pastoralism-based food systems, which require seasonal transhumance and transport of animals to regional consumer markets. This implies that ECOWAS regional trade policy and agreements need to be endorsed.

The COVID-19 pandemic is a wake-up call for economic and food access vulnerability. The pandemic has had, to date, variable impacts on food systems. Food systems that are dependent on global markets have proven less resilient, and hence more vulnerable, to economic shocks. The pandemic has renewed debates on the importance of domestic and regional food markets. There are clear opportunities for import substitution to have positive economic and social impacts for rain-fed rice, peri-urban vegetables, poultry, dairy, grains and legumes, and fish. Food systems differ in their resilience to climate shocks. Such shocks are not new, and many populations have developed coping mechanisms when confronted with natural shocks. But the frequency and severity of these shocks have increased, which has reduced household resilience through the depletion of capital reserves and food stocks. Moreover, crop production and livestockkeeping practices and the innovation capacity of producers cannot keep pace with climate changes. This constraint is amplified by other food system bottlenecks, such as declining soil fertility, land and water scarcity, and food system drivers such as increased demands for food and income from agriculture. These challenges
(1) Background and understanding

(2) Regional drivers

(3) Regional organisations

(4) Agro-pastoralism-based

(5) Grains-and-legumes-based

6) Rice-and-horticulture

(7) Coastal maritime fisheries

8 Tropical mixed tree and food crops systems

9 Toward enhanced resilience 
can only be addressed by matching the innovation capacity of producers with regional research capacity, together seeking climate smart responses to production constraints.

Chronic inadequate diets, leading to micronutrient deficits, affect more people's health in West Africa than seasonal low calorie intake. Healthy nutrition is key to enhancing people's capacity to respond to shocks. Although the discourse around development and food insecurity has shifted toward nutrition, national policies and interventions still focus on staple crops and production quantities. There are some important technical interventions, such as enriching cereals, but these alone will not make the difference. More important are the current efforts of policy makers and agricultural researchers to expand perspectives on food security (such as extending nutrition questions from the health and food aid sectors to agriculture), change and target education (such as for women in agricultural households), and include vegetables, dairy, meat, and fish in agricultural policies for food and nutrition security.

Regional organisations can enhance the resilience of food systems In particular, they can build on the emerging track record of ECOWAS in establishing a regional agricultural policy framework and coordinating responses to regional food crises. Technical organisations such as CILSS have extensive experience in providing knowledge, advice, and coordination support for the implementation of programs to improve food security and manage climate risks. Yet, regional cooperation in West Africa still depends mainly upon the interests of national actors, which greatly limits what regional organisations can actually do beyond formal regional policies and agreements. To promote food systems resilience, for which many factors are locally specific, care must be taken in formulating regional interventions, notably at the ECOWAS level. Such interventions should build on regional policy and programmatic experiences with proven traction among member states, be it in the fields of agri-food trade, research and innovation, transboundary natural resources management, or social protection. Where there is traction for regional action, supporting the development of existing regional institutions, policy instruments such as the ARAA, and networks of nonstate actors should be the preferred approach to ensure the sustainability of outcomes.

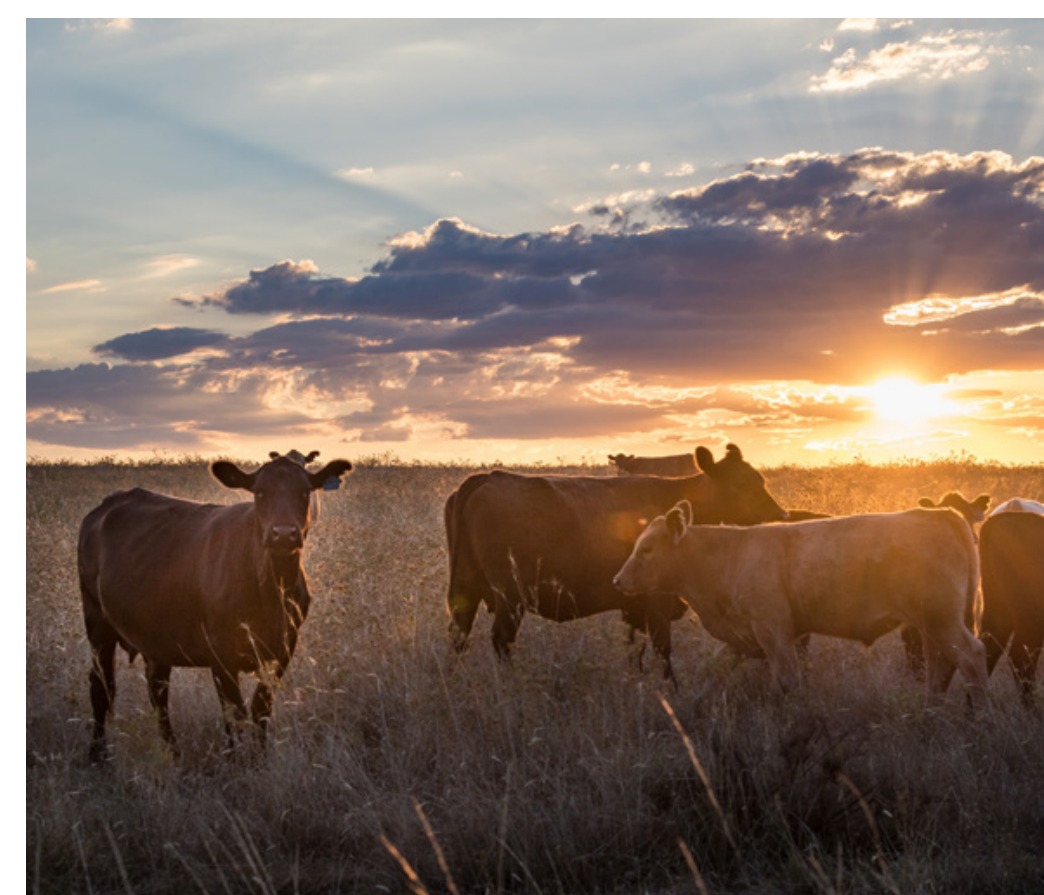

(1) Background and understanding

(2) Regional drivers

(3) Regional organisations

(4) Agro-pastoralism-based

(5) Grains-and-legumes-based

(6) Rice-and-horticulture

(7) Coastal maritime fisheries

(8) Tropical mixed tree and food crops systems

9) Toward enhanced resilience

Finally, this study has shown that the West African region is rich in its diversity of food systems. These systems provide most of the food consumed in the region. The diversity in food systems is an important asset when enhancing regional capacity to respond to shocks and stressors. This advantage will only be put to value when the food systems interact and are able to exchange food products, inputs but also knowledge and information. The capacity to innovate in one system may well create solutions for another system. Yet, historical, constructive interactions between systems may be constrained by new challenges, such a climate change, the emergence of pandemics like COVID-19 and political instability. Constrained interaction must be seen as a serious threat to regional food system resilience. In that respect, regional institutions have a key role to play to reestablish and strengthen interactions between food systems in West Africa. 


\section{Background and understanding food systems resilience}

By Bart de Steenhuijsen Piters and Joost Nelen

1.1 Background to the study

1.2 Defining food systems

1.3 Understanding food system resilience

1.4 Scope and approach to this study 1.5 Limitations to this study $\underline{\text { References }}$

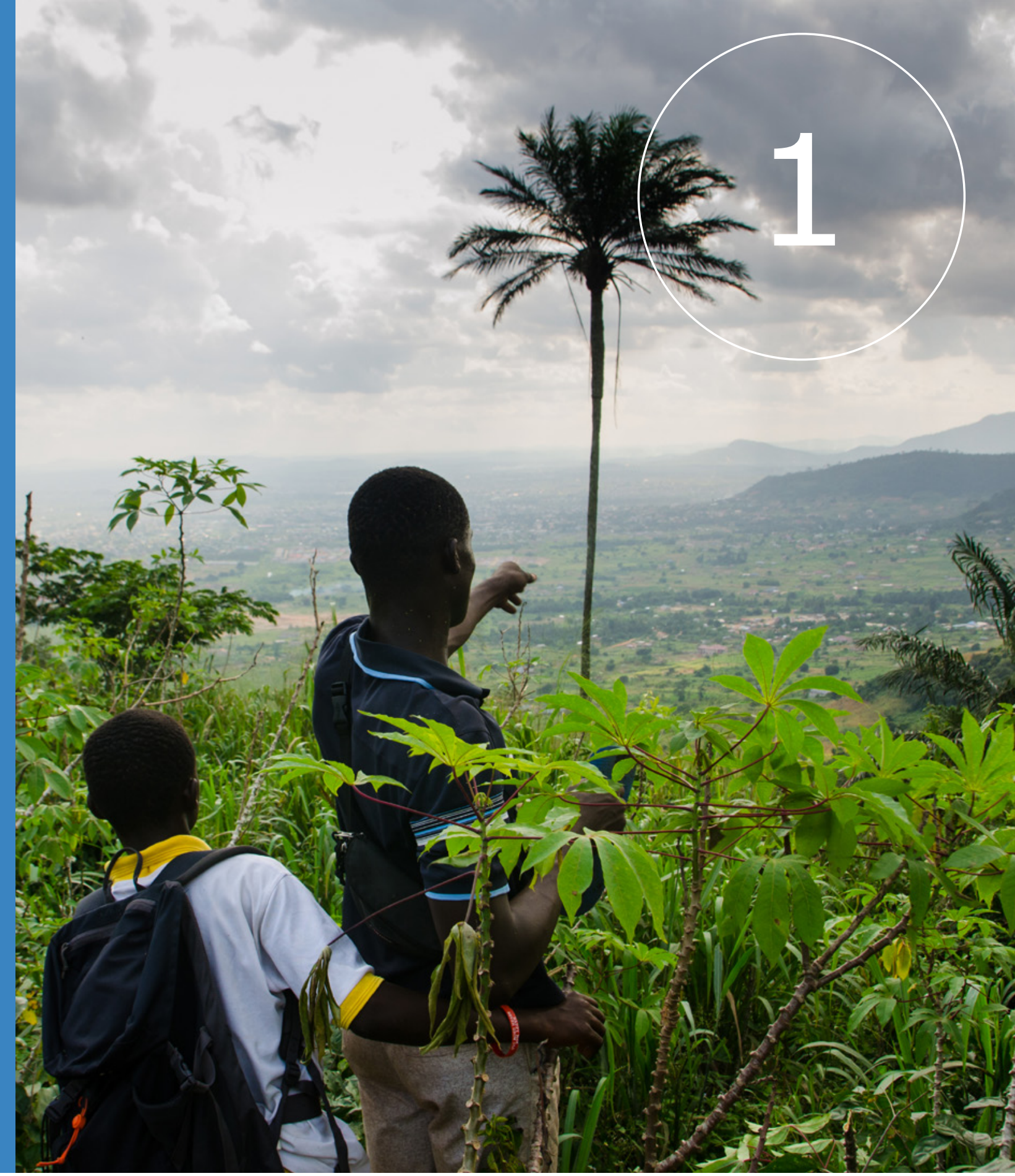

$\oplus \oplus$ 


\subsection{Background to the study}

West Africa keeps on surprising the world with reports and forecasts on food security and climate change resilience ranging from alarming to positive. The region supplies most of the food for its growing population, which now exceeds 400 million. West African countries meet most of the region's needs for coarse grains, tuber and root crops, vegetables, fruits, and meat (excluding some areas of fast-growing consumption such as chicken). Generic data and their interpretations obscure the region's food systems, which have evolved over hundreds of years. These systems, often poorly understood by outsiders, exist in complex relationships between people and natural environments, with both short value chains and long ones supplying distant consumer markets. Internal stakeholders and outsiders have created institutions to steer these food systems into directions they consider desirable, while public policies often magnify food insecurity through regressive and even distortive agriculture support programs for cash and subsistence crops. Private interests frequently push food systems into unsustainable and illegal practices, threatening resource availability for future generations and undermining the ecosystems in which these systems exist.

Over the past century, West Africa's food systems have shown various degrees of resilience in responding to external and internal shocks. These food systems have also shown resilience to the drivers of and long-term changes to the social and ecological systems in which they are embedded. But there are limits to the region's capacity for absorption, adaptation, and response, which is challenging food system balance and efforts to ensure an affordable, sufficient, and accessible supply of healthy food for West Africa.

Food security figures have improved slightly across West Africa. ${ }^{1}$ In 2002 all countries in the region reported that at least 10-40 percent of their households were severely to moderately food insecure. In 2017 rates of severe to moderate food insecurity varied between 6 percent and 14 percent in coastal countries such as Ghana, Benin, the Gambia, and Nigeria as well as in Sahel countries such as Mali, Senegal, and Mauritania. However, countries such as Côte d'Ivoire,
Togo, Guinea, Burkina Faso, and Niger continued to have high rates of severe to moderate food insecurity, between 15 percent and 25 percent, while parts of the Southwest Atlantic (Guinea-Bissau, Sierra Leone, and Liberia) had rates above 25 percent. The data show that food insecurity in West Africa is not merely a feature of Sahel countries, although recent conflicts have worsened food insecurity in Mali, Burkina Faso, and Niger (map 1.1). Besides the Southwest Atlantic nations, coastal countries such as Nigeria, Togo, and Côte d'Ivoire also struggle with systemic food insecurity.

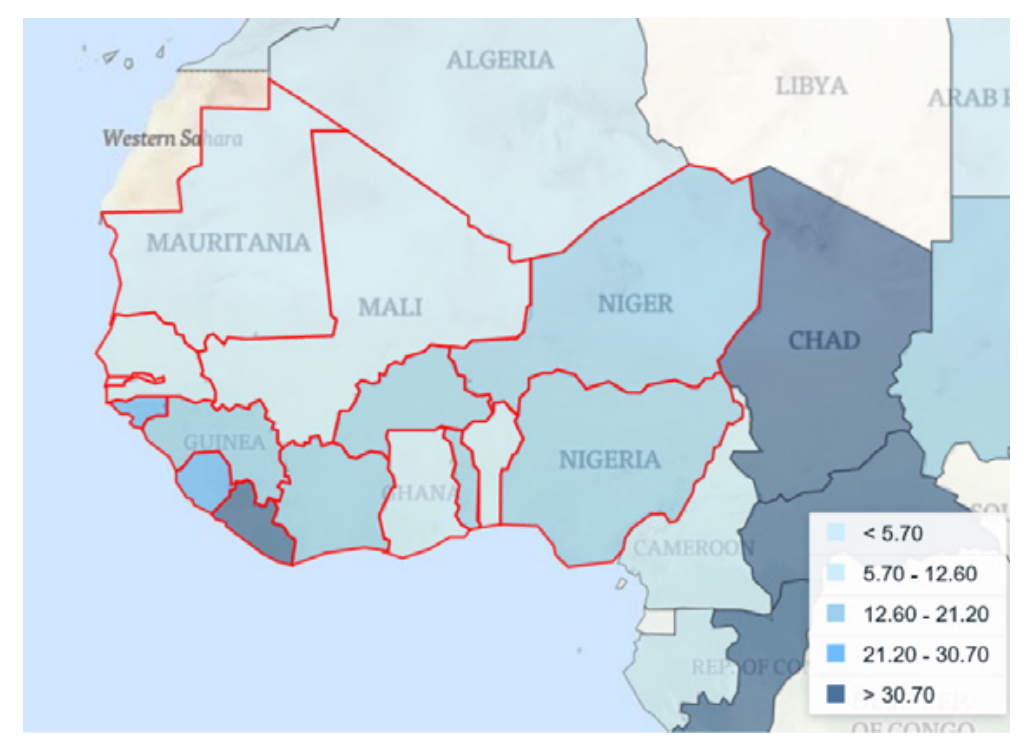

Map 1.1 Percentage of Households in West Africa with Severe to Moderate Food Insecurity, 2020

Source: World Bank Open Data, World Bank, Washington, DC (accessed August 31, 2020).

Nutritional outcomes in West Africa have been problematic for decades, though the situation has improved slightly in the twentyfirst century. According to data from between 2014 and 2019, the prevalence of wasting declined to 5-10 percent in all countries, with the exception of Niger and Mauritania (figure 1.1). Prevalence of stunting remains relatively high in the region, between 14 and 30 percent. Rates in Niger are particularly worrying (above
Background and

understanding

1.1 Background to the study

1.2 Defining food systems

1.3 Understanding food system resilience

1.4 Scope and approach to this study

1.5 Limitations to this study References

(2) Regional drivers

(3) Regional organisations

(4) Agro-pastoralism-based

(5) Grains-and-legumes-based

6) Rice-and-horticulture

(7) Coastal maritime fisheries

8 Tropical mixed tree and food crops systems

9 Toward enhanced resilience 
45 percent), and some coastal countries, such as Nigeria and Benin, continue to report relatively high figures (37 percent and

32 percent, respectively). The prevalence of anemia is still very high in West Africa; in most West African countries it has reached 43 percent or more (only Liberia is below 35 percent). Obesity is high in urban centres, but this trend is far from generalised, as all West African countries report obesity rates below 5 percent.

Fragility and conflict disrupt food production and livelihoods, while food and nutrition insecurity contributes to regional migration and competition over natural resources. Population growth and urbanisation present economic opportunities but also raise pressure on production to deliver sufficient food with lower per capita endowments of natural resources, including land. Climate change exerts increasing pressure on the supply side of food production as adverse trends in temperature and precipitation are manifested by more frequent and larger-scale extreme events. However, with reference to yield gap studies conducted, food production could be two to three times higher than average levels from previous

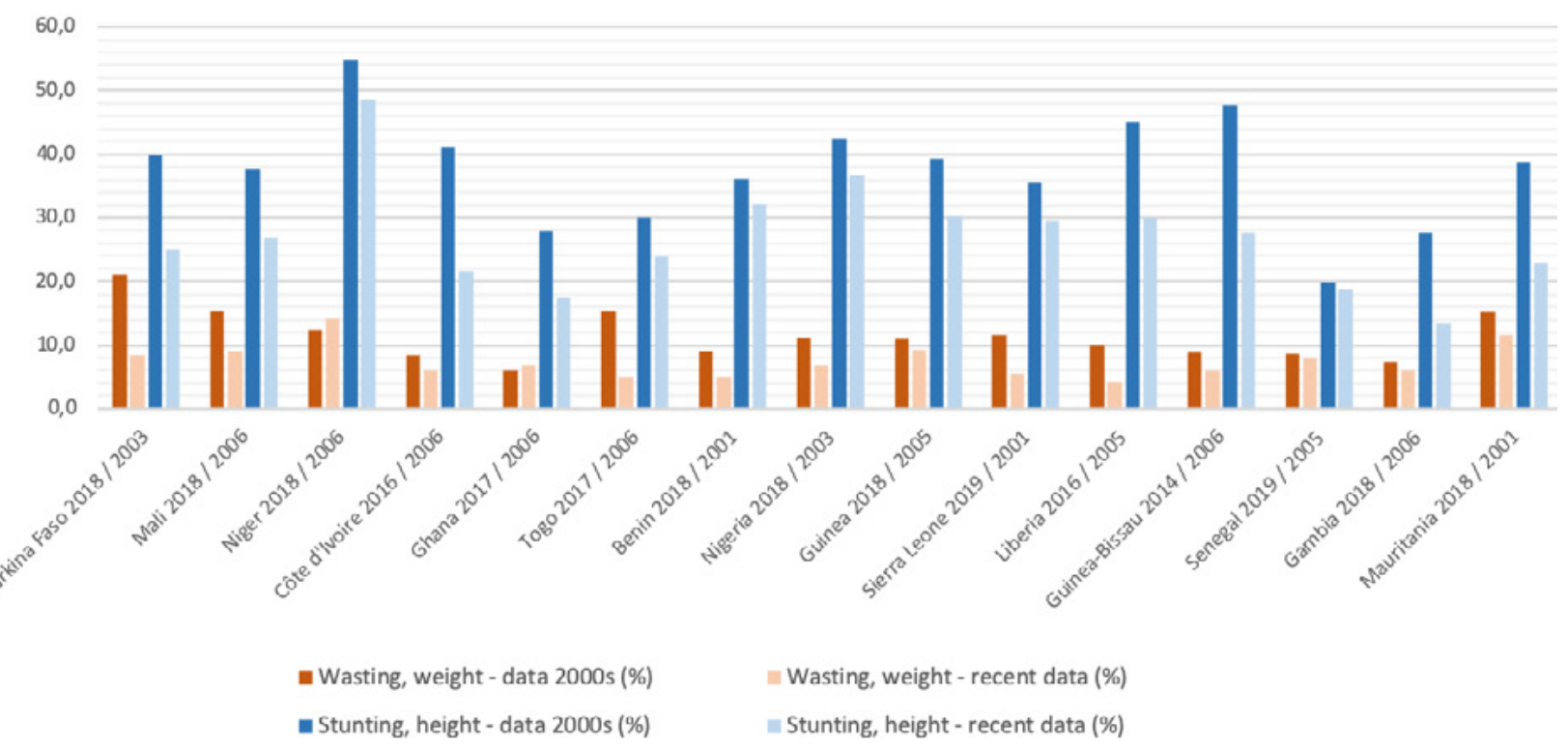

Figure 1.1 Prevalence of Wasting and Stunting in West Africa for Children under Age Five, 2001-19 Source: World Bank Open Data, World Bank, Washington, DC (accessed August 31, 2020). decades. Increases in agricultural productivity can have twice the impact in reducing extreme poverty than productivity gains in other sectors, provided that access to inputs (knowledge, financing, agricultural inputs) and environmental sustainability are secured.

Changes in West Africa's consumer markets are occurring at unprecedented speed as a function of urbanisation, improved infrastructure, the emerging middle class, and globalising consumer behavior. Food systems must keep pace with these changes, which is often very difficult when facing multiple challenges in the production and consumption environments. The double burden of malnutrition and obesity among urban consumers requires enhanced commercialisation of nutrient-rich foods, particularly safe vegetables. Moreover, food systems must absorb new generations of young people who have no economic option other than to farm or engage in agribusiness. Further, production systems must become more sustainable to secure future access to critical production assets while enhancing their resilience.
Background and

understanding

1.1 Background to the study

1.2 Defining food systems

1.3 Understanding food system resilience

1.4 Scope and approach to this study

1.5 Limitations to this study References

(2) Regional drivers

(3) Regional organisations

(4) Agro-pastoralism-based

(5) Grains-and-legumes-based

6) Rice-and-horticulture

(7) Coastal maritime fisheries

Tropical mixed tree and

8 food crops systems

9 Toward enhanced resilience 
The COVID-19 pandemic has clearly and painfully underscored West Africa's dependency on global food markets for grains such as rice and wheat and for animal products such as poultry, dairy, and fish, as well as for agricultural inputs. This dependency was already stressed during the 2008 global food crisis, but despite regional policies of open markets, imports of some food products of critical importance to daily consumer diets have remained relatively high. Amplified by growing impacts of the COVID-19 pandemic, calls for more domestic food value chains are increasing. But can West Africa feed itself by catalyzing its domestic production and markets?

Understanding West Africa's variety of food systems is critical when discussing these challenges. It would be easy to conclude that the magnitude of these challenges outweighs the opportunities, but that would be premature and fail to acknowledge the dynamics and viability of these food systems. To this purpose, five major food systems were analyzed. Together, these allow for understanding some of the complexity of, drivers of, and opportunities in West African food and nutrition challenges

\subsection{Defining food systems}

Food systems comprise all the processes associated with food production and food utilisation: growing, harvesting, packing, processing, transporting, marketing, consuming, and disposing of food remains (including fish). All these activities require inputs and result in products and services, income and access to food, as well as environmental impacts (van Berkum, Dengerink, and Ruben 2018). A food system operates in and is influenced by social, political, cultural, technological, economic, and natural environments.

A food systems approach is a useful conceptual framework for understanding how the food we consume is produced; exploring how this influences our economy, environment, and society at large; and identifying the important drivers behind it. A food systems approach (figure 1.2) may be used to analyze the relationships between different parts of the system and its diverse outcomes, such as food availability, access, and utilisation. Such an

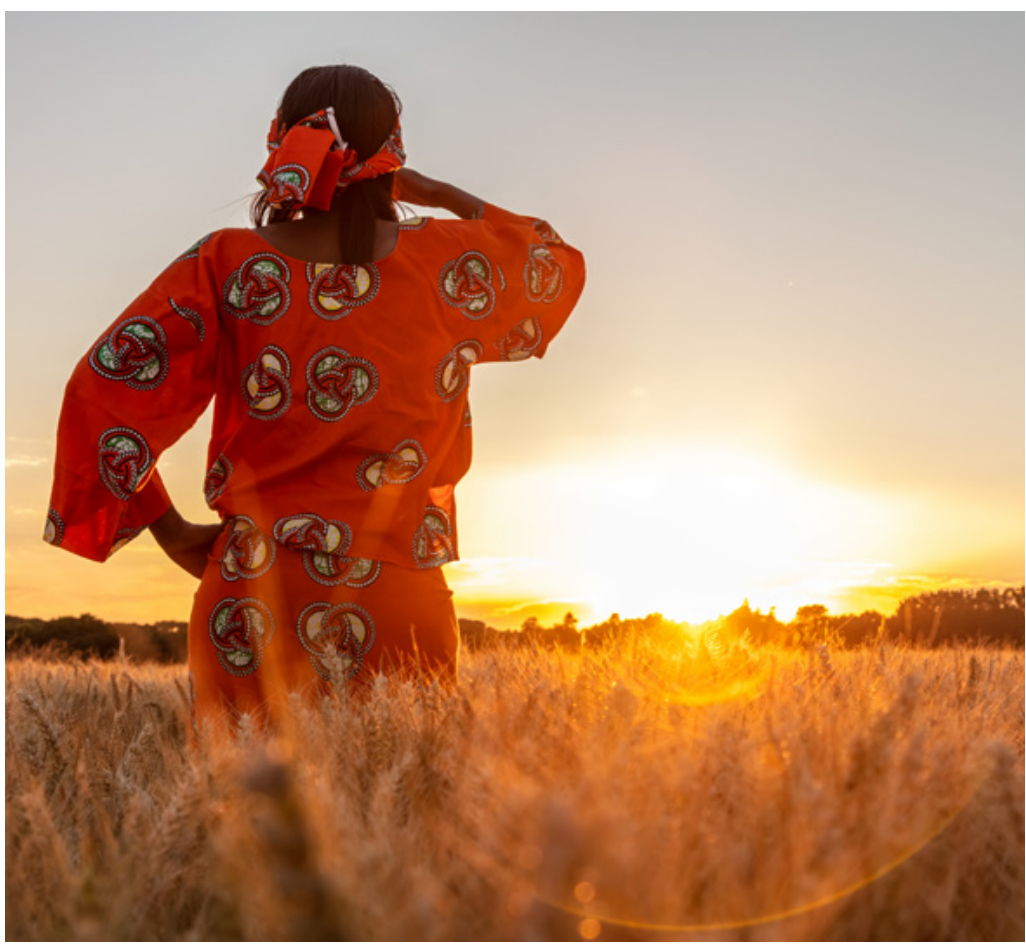

approach may also be used to examine other important outcomes such as income, employment, and sustainability and resilience. Drivers of change can be socioeconomic or environmental. They link a food system to distant (regional or global) systems and create feedback loops between parts of the system. An example is the socioeconomic and environmental interactions resulting in the spread of COVID-19, which has affected food systems across the globe.

Researchers use food systems analysis to examine the parts of a system and system behavior at different scales when subjected to different drivers. These drivers may range from deliberate policy interventions and strategic influences by powerful stakeholder groups pursuing their interests to responses to unexpected or unintended shocks, such as long-term climate changes and the effects of the COVID-19 pandemic. Food systems behavior includes the response capacity to absorb shocks, also known as resilience.
Background and understanding

1.1 Background to the study

1.2 Defining food systems

1.3 Understanding food system resilience

1.4 Scope and approach to this study

1.5 Limitations to this study References

(2) Regional drivers

(3) Regional organisations

(4) Agro-pastoralism-based

(5) Grains-and-legumes-based

6) Rice-and-horticulture

(7) Coastal maritime fisheries

Tropical mixed tree and food crops systems

9 Toward enhanced resilience 


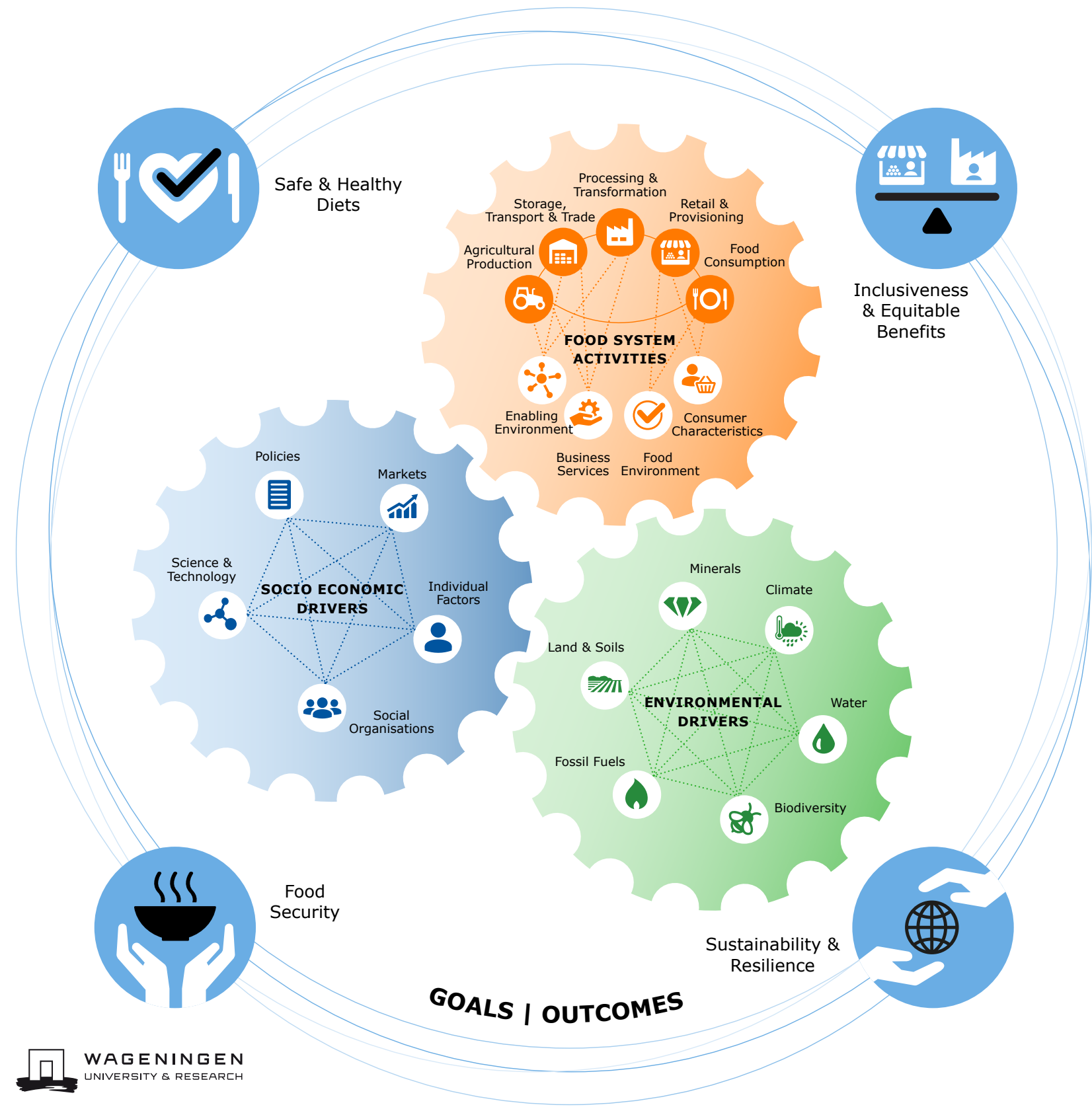

Background and understanding

1.1 Background to the study

1.2 Defining food systems

1.3 Understanding food system resilience

1.4 Scope and approach to this study

1.5 Limitations to this study References

(2) Regional drivers

(3) Regional organisations

(4) Agro-pastoralism-based

(5) Grains-and-legumes-based

(6) Rice-and-horticulture

(7) Coastal maritime fisheries

(8) Tropical mixed tree and

8 food crops systems

(9) Toward enhanced resilience

Figure 1.2 Food Systems Framework

Source: van Berkum, Dengerink, and Ruben 2018 


\subsection{Understanding food system resilience}

The Intergovernmental Panel on Climate Change (IPCC) defines resilience as "the ability of a social or ecological system to absorb disturbances while retaining the same basic structure and ways of functioning, the capacity of self-organisation, and the capacity to adapt to stress and change" (Engle et al. 2014). Food systems can be understood as complex organised and unorganised interactions between people and nature. Food system resilience refers to these interactions and how the system responds to disturbances through its absorption capacity. With so much uncertainty and complexity and with multiple unpredictable and interconnected drivers of change, how can food systems be made more resilient and sustainable? The solution is optimising parts of the system for specific risks and improving the general resilience capacity of the whole system. An important dimension of systems resilience is including gender and vulnerable groups from an ethical viewpoint and understanding human resource mobilisation and social and political stability.

Four types of resilience considered relevant here and affecting food systems are as follows: (1) climate resilience, (2) economic resilience, (3) sociopolitical resilience, and (4) food access resilience (figure 1.3).

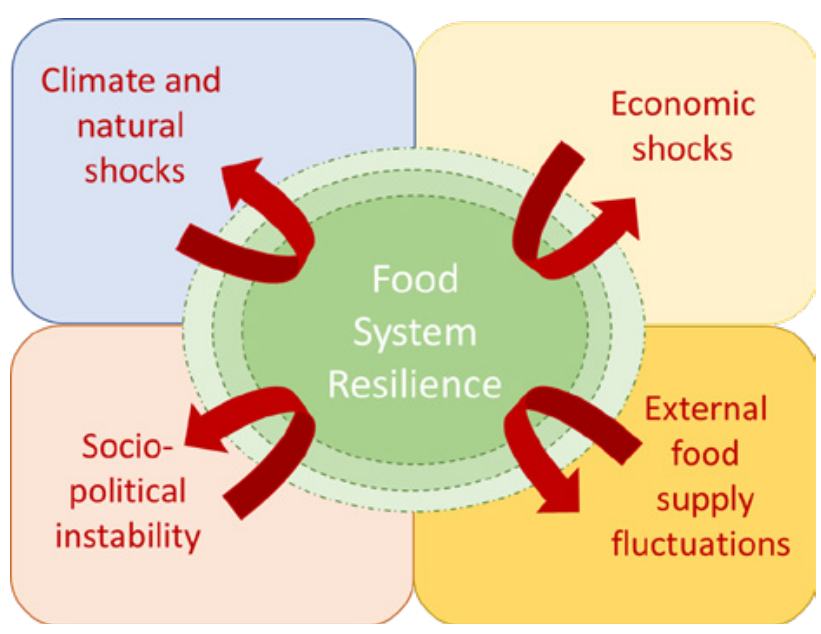

Figure 1.3 Four Impacts That Food Systems Must Absorb
Climate resilience has two components, one driven by nature and the other by human action and interaction (Keim 2008). An example of nature-based climate resilience is how ecosystems respond to long drought spells, such as through natural selection of drought-tolerant plant species. An example of human action affecting climate resilience would be social institutions or organisations facilitating response and recovery procedures. Building human resilience focuses on human populations and decreasing human vulnerability in the face of climate change and extreme weather events. Vulnerability to climatic disturbances has two sides: the first deals with the degree of exposure to dangerous hazards, known as susceptibility, while the second is the capacity to recover from disasters, known as resilience.

Economic resilience is a community's ability to foresee, adapt to, and leverage changing economic conditions to its advantage. Economic resilience is the ability to recover quickly from a disturbance, withstand the disturbance, or avoid the disturbance altogether. Disturbances may include economic downturns, such as national or global economic impacts on demand for local goods and spending or downturns of particular industries critical to local economic activities. Other disturbances or external impacts include unforeseen fluctuations in global trade, natural or man-made disasters (for example, conflict), or extreme events from the changing climate.

Sociopolitical resilience refers to the ability to foresee, adapt to, and leverage abrupt or unforeseen changes in political and civil stability in the context of food systems. Major elements of building and maintaining food systems resilience are social organisation, political and civil stability, and social services. Well-organised communities are less likely to suffer from disaster-related mortality and are therefore viewed as more disaster resilient. Political and civil instability increases the vulnerability of people to disturbances. Climate resilience literature indicates that an indirect source of resilience lies in the strength of a community's social services and social safety nets. This is an especially critical aspect of resilience in socioeconomically disadvantaged communities, cities, and nations. Places with stronger systems of social security and community safety nets have better climate resiliency (Satterthwaite 2013) for
Background and understanding

1.1 Background to the study

1.2 Defining food systems

1.3 Understanding food system resilience

1.4 Scope and approach to this study

1.5 Limitations to this study References

(2) Regional drivers

(3) Regional organisations

(4) Agro-pastoralism-based

(5) Grains-and-legumes-based

6) Rice-and-horticulture

(7) Coastal maritime fisheries

8 Tropical mixed tree and food crops systems

9 Toward enhanced resilience 
several reasons. First, better social services for citizens translate to better access to health care, education, and emergency services. Second, stronger social service systems generally increase the overall ownership of relevant economic assets correlated with access to healthy food, such as land.

Food system resilience increases consumers' ability to secure access to sufficient and safe foods needed for heathy diets. Food systems experience fluctuations, such as seasonality in food supplies, and forecasting makes it possible to prepare for these. Other fluctuations may be abrupt and unforeseen, such as those during the COVID-19 pandemic or the market and trade distortions

\section{has}

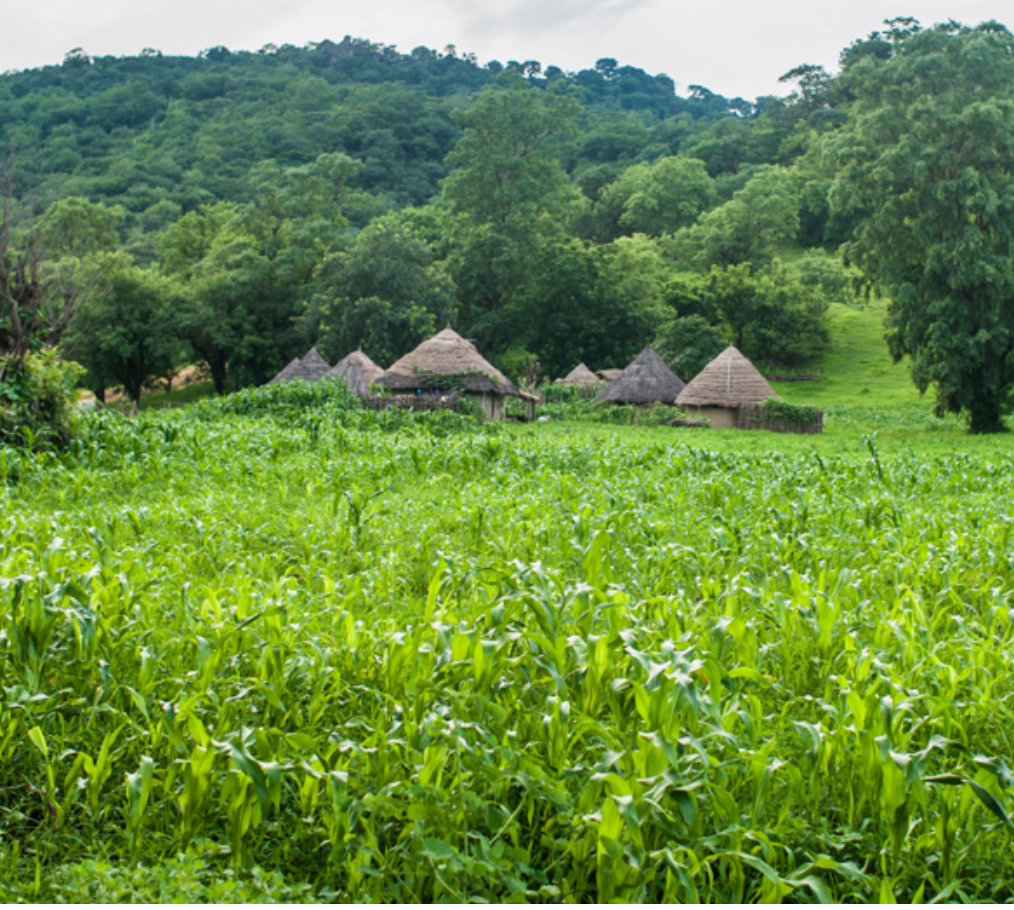

witnessed during the 2008 global food crisis. The World Bank reported that global food prices rose 83 percent over the following three years, and the FAO cited a 45 percent increase in the world food price index in 20202 . These food price increases have affected the most vulnerable, mainly urban, segments of society, which depend on food markets for their daily diet. Therefore, we define food access resilience as "the ability to foresee, adapt to, and leverage abrupt or unforeseen changes in access and affordability of food required to secure healthy diets."

The ability to absorb disturbances is not equally distributed within food systems. The level of socioeconomic disparity within systems affects the resilience of specific segments in society. Exclusion of poorer households and women from production assets makes them much more vulnerable than well-endowed households and men. Disparities between ethnic groups, households, and genders may be so pronounced that even a food system that is generally considered resilient, such as to climate or economic change, may contain specific socioeconomic segments that are highly vulnerable. A comparison of West African food systems based on their ability to absorb disturbances involves the four forms of resilience and two structural intrasystem disparities (figure 1.4).

$$
\begin{aligned}
& \text { Food system resilience } \\
& \text { Climate variability resilience } \\
& \text { Economic resilience } \\
& \text { Sociopolitical resilience } \\
& \text { Food access resilience }
\end{aligned}
$$

Intrasystem disparities

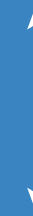

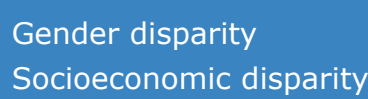

Figure 1.4 Food System Resilience and Intrasystem Disparities

\subsection{Scope and approach to this study}

The authors of this study selected five important regional food systems in West Africa to understand how they contribute to food system outcomes, experience a variety of vulnerabilities, and develop over time diverse and inherent forms of resilience (map 1.2). Of course, there are more food systems in the region,
Background and understanding

1.1 Background to the study

1.2 Defining food systems

1.3 Understanding food system resilience

1.4 Scope and approach to this study

1.5 Limitations to this study References

(2) Regional drivers

(3) Regional organisations

(4) Agro-pastoralism-based

(5) Grains-and-legumes-based

(6) Rice-and-horticulture

(7) Coastal maritime fisheries

(8) Tropical mixed tree and food crops systems

9 Toward enhanced resilience 
but the selected systems represent the region's diversity, major populations, and supply of important food groups to both rural and urban consumers. The authors chose these five archetypal West African food systems based on a study by Garrity, Dixon, and Boffa (2017). Because food systems entail more than farming systems, the authors included in this study the importance of food value chains that supply urban consumers across the West African region, drivers of food systems changes, and system interactions. This yielded the following five food systems for analysis:

- (agro)pastoralism-based food systems

- grains-and-legumes-based food system

- rice-and-horticulture-based food systems

- coastal maritime fisheries food system

- tropical mixed tree and food crops systems

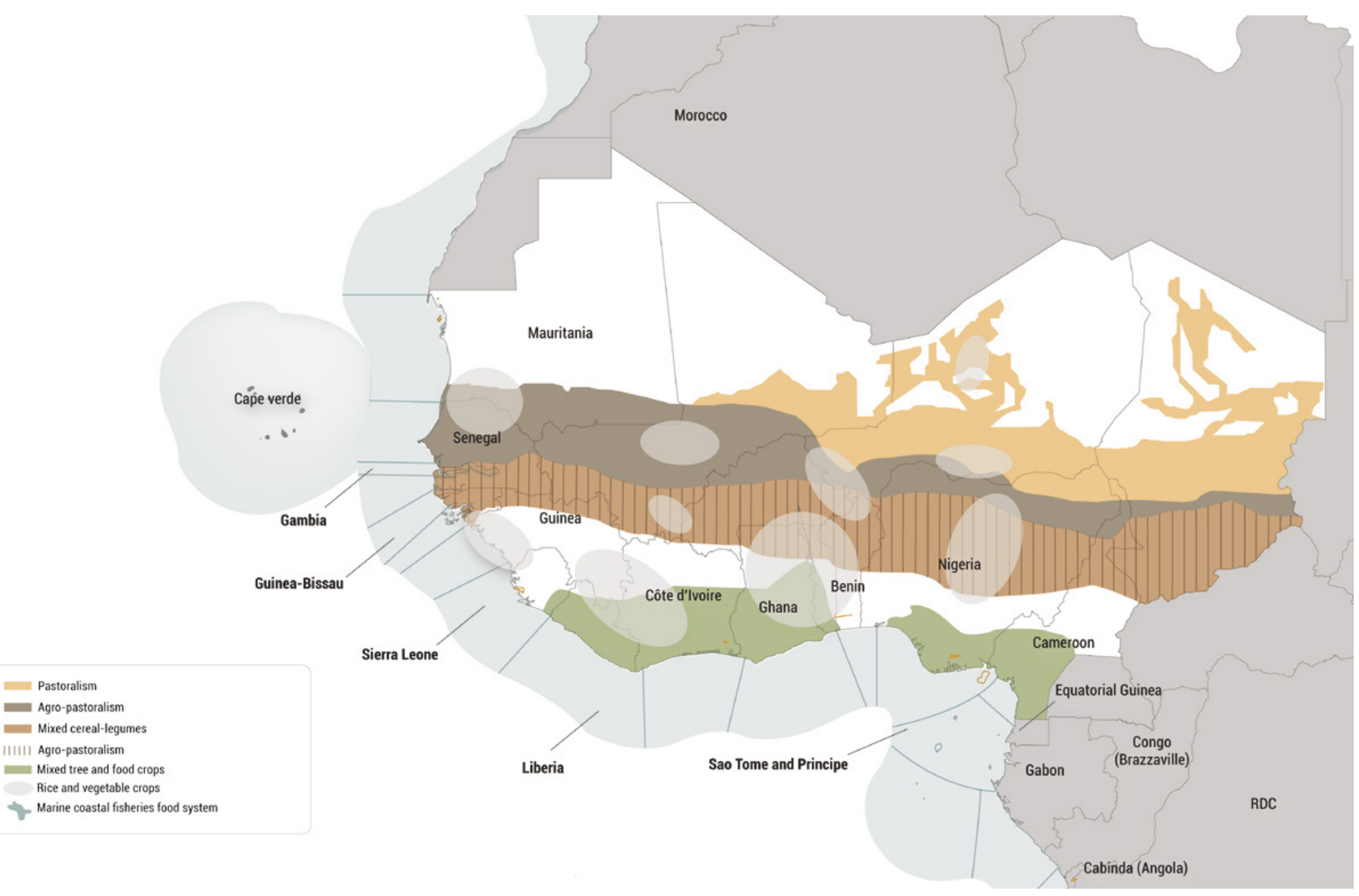

Background to the study

1.2 Defining food systems

1.3 Understanding food system resilience

1.4 Scope and approach to this study

1.5 Limitations to this study References

(2) Regional drivers

(3) Regional organisations

(4) Agro-pastoralism-based

(5) Grains-and-legumes-based

6) Rice-and-horticulture

(7) Coastal maritime fisheries

8 Tropical mixed tree and food crops systems

9 Toward enhanced resilience 
Food system outcomes refer not only to the food and nutrition security of households but also to sustainability, economic value, and contribution to economic development and employment, as well as to what degree these outcomes are equally accessible to or distributed over different segments in society. Food systems are also understood as socioeconomic and political constructions that are reflected in the livelihoods and behavior of people. In this study, the authors paid special attention to the role of regional institutions in enhancing food systems resilience. For each of the five key food systems, the authors identified the following:

- definition, demography, and geography of the food system

- regional consumption and production trends

- livelihoods of producer communities

- production system, including food system outcomes such as household food and nutrition security, income, trade and employment, sustainability, and equity and inclusion

- institutional drivers, including trends, risks, and resilience, such as climate variability resilience, economic resilience, sociopolitical resilience, and food access resilience

- food system impacts of the COVID-19 pandemic

- agency and development interventions

- leverage points for future interventions

Once the authors identified these issues for each of the five food systems, they addressed the following overall questions:

- What is the status of regional food system resilience in West Africa?

- How can food system resilience in West Africa be enhanced through regional institutions?

Each food system was matched with a highly seasoned expert with long-standing experience and networks in the respective system. The study authors collected and processed key publications and data and critically reviewed draft versions of the food system analysis multiple times. Consultations with additional experts, often from the region, filled any data gaps. The authors also identified regional economic and environmental drivers and analyzed their impacts on the food systems. Two specific substudies were conducted: one on the role of regional institutions and the other on known impacts of the COVID-19 pandemic on West African food

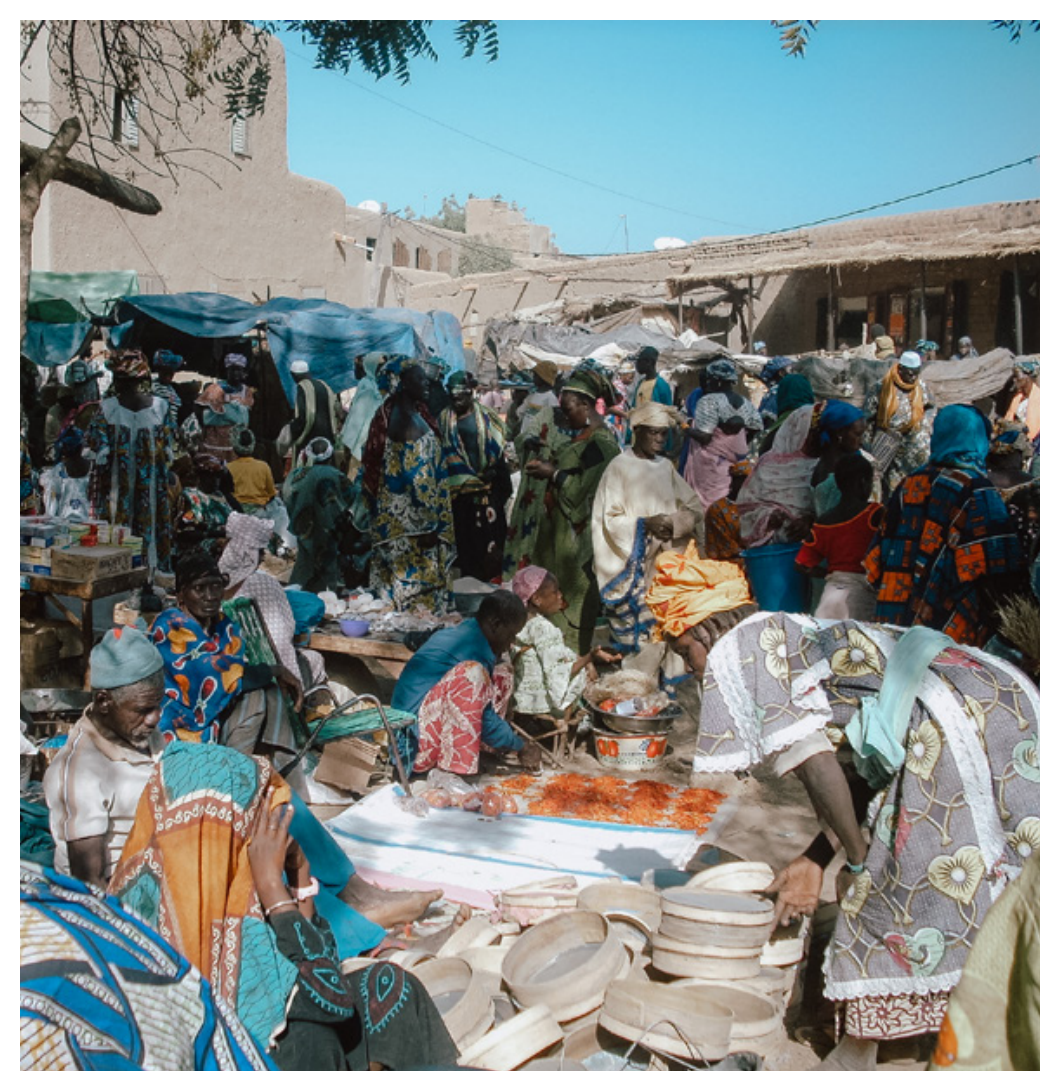

systems. In this substudy, the authors attempted to investigate potential implications of COVID-19 and the ensuing policy responses for the selected food systems, and indicate possible leverage points to alleviate negative impacts. The study was limited to the five selected food systems. The lean framework included the following four dimensions of analysis to explore the impacts of COVID-19: - primary production

- market linkages

- consumption and nutrition

- crosscutting themes (environment, demography, and urban-rural dimension)

Because the COVID-19 crisis was in the early stages at the time of the analysis, reliable evidence was scarce to capture the impact of
Background and understanding

1.1 Background to the study

1.2 Defining food systems

1.3 Understanding food system resilience

1.4 Scope and approach to this study

1.5 Limitations to this study References

(2) Regional drivers

(3) Regional organisations

(4) Agro-pastoralism-based

(5) Grains-and-legumes-based

(6) Rice-and-horticulture

(7) Coastal maritime fisheries

8 Tropical mixed tree and

8 food crops systems

9 Toward enhanced resilience 
COVID-19 on the five food systems. The authors used gray literature and webinars, as well as interviews with key experts in West Africa, to collect data and information. The result is a snapshot of the impact of COVID-19 on the five food systems with limited potential to predict the long-term effects of such an unforeseen global situation.

\subsection{Limitations to this study}

This study had several limitations. A few are noted here as follows:

- The authors collected data on the impact of COVID-19 on specific food systems through interviews with knowledgeable people in the region. Nevertheless, the information was scattered and often anecdotal, which permitted identification of plausible food system impacts only.

- The authors excluded Nigeria because of its dominance in terms of production and trade volumes as well as its economic and political uniqueness, which overshadowed the food system metrics and processes related to the other West African countries.

- Information about the economic importance of intermediate value chain actors, from farm gate collectors to wholesalers and retailers, was difficult to find for each food system. This was partially due to the informal nature of these economic sectors. Regional food production data, particularly on the value of livestock products and minor food crops, were also difficult to obtain.

- The authors had to rely on older data and projections in cases in which no recent census data were available.

- The five food systems cross borders and often do not relate to the same geographical units of analysis, which to some degree affected the precision of estimates made in this study.

\section{Notes}

1 Data in this section are from World Bank Open Data, World Bank, Washington, DC (accessed August 31, 2020), https://data.worldbank.org. Data were checked using FEWS NET Data Centre, USAID, Washington, DC (accessed November 30, 2020).

\section{References}

Engle, Nathan L., Ariane de Bremond, Elizabeth L. Malone, and Richard H. Moss. 2014. "Towards a Resilience Indicator Framework for Making ClimateChange Adaptation Decisions." Mitigation and Adaptation Strategies for Global Change 19: 1295-1312.

Folke, Carl. 2006. "Resilience: The Emergence of a Perspective for SocialEcological Systems Analyses." Global Environmental Change 16 (3): 253-67.

Garrity, Dennis, John Dixon, and Jean-Marc Boffa. 2017. "Understanding African Farming Systems as a Basis for Sustainable Intensification." In Sustainable Intensification in Smallholder Agriculture, edited by Michael Phillips, Ingrid Oborn, Richard Thomas, Bernard Vanlauwe, Kwesi Atta-Krah and Willemien Brooijmans, pp. 58-70. New York: Routledge.

Keim, Mark E. 2008. "Building Human Resilience: The Role of Public Health Preparedness and Response as an Adaptation to Climate Change." American Journal of Preventive Medicine 35 (5): 508-16.

Nelson, Donald R., W. Neil Adger, and Katrina Brown. 2007. "Adaptation to Environmental Change: Contributions of a Resilience Framework." Annual Review of Environment and Resources 32 (1): 395-419.

Satterthwaite, David. 2013. "The Political Underpinnings of Cities' Accumulated Resilience to Climate Change." Environment and Urbanisation 25 (2): 381-91.

van Berkum, Siemen, Just Dengerink, and Ruerd Ruben. 2018. The Food Systems Approach: Sustainable Solutions for a Sufficient Supply of Healthy Food. Wageningen Economic Research Memorandum 2018-064. The Hague: Wageningen Economic Research.
Background and understanding

1.1 Background to the study

1.2 Defining food systems

1.3 Understanding food system resilience

1.4 Scope and approach to this study

\subsection{Limitations to this study} References

(2) Regional drivers

(3) Regional organisations

(4) Agro-pastoralism-based

(5) Grains-and-legumes-based

6) Rice-and-horticulture

(7) Coastal maritime fisheries

(8) Tropical mixed tree and

8 food crops systems

9 Toward enhanced resilience 


\section{Regional drivers of West Africa's food systems}

By Bertus Wennink, Jenny Aker, and Joost Nelen

\subsection{Brief history of food systems in West Africa}

2.2 Population and migration

$\underline{2.3 \text { Economic drivers and monetary policy }}$

2.4 Environmental drivers

2.5 Conflict and insecurity

$\underline{2.6 \text { Technological drivers }}$

$\underline{2.7 \text { Regional consumer trends }}$

References

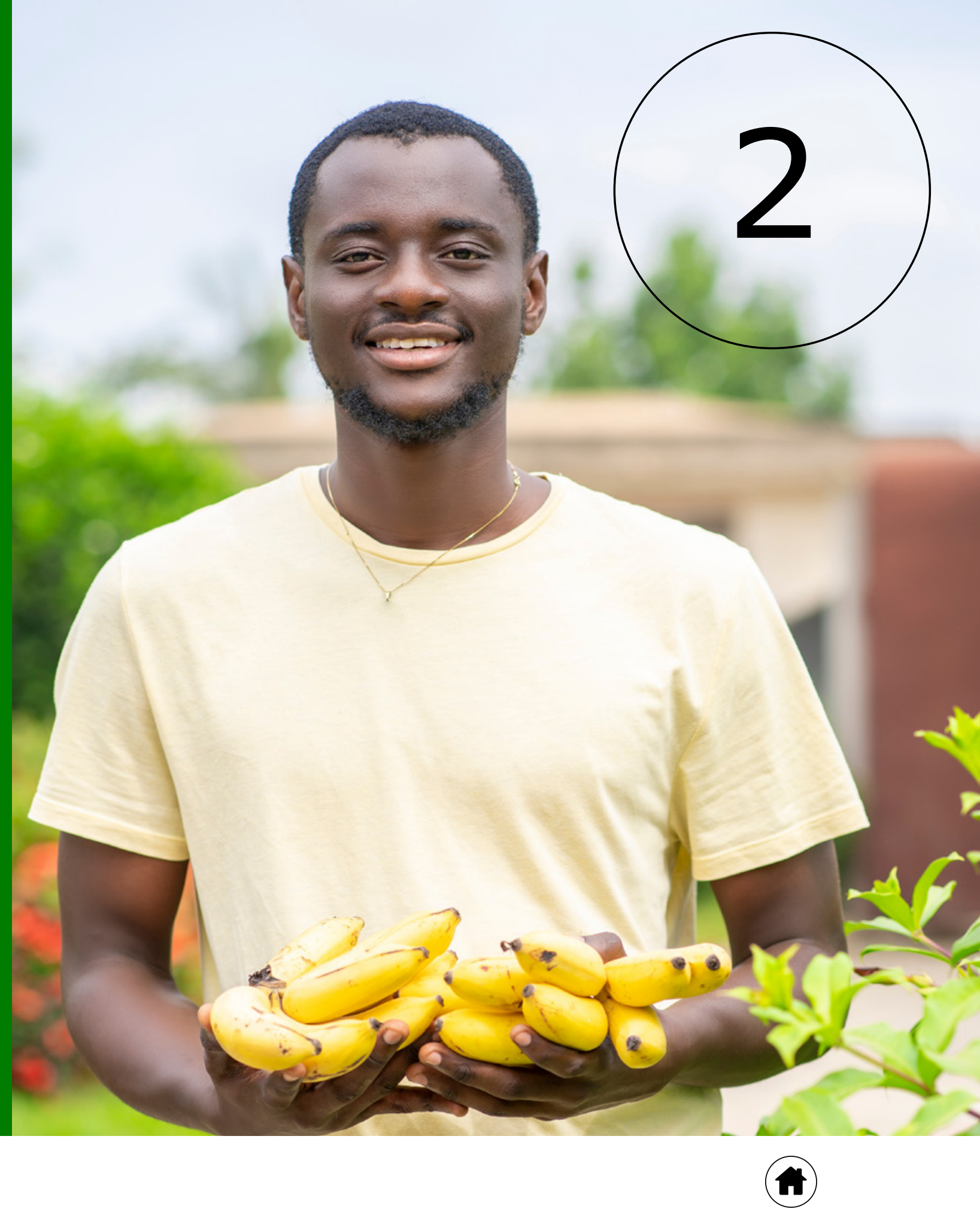


Most of the national borders within present-day West Africa were established in the wake of the 1884-85 Berlin Conference, which ignited the "scramble for Africa" (Miles 2005). The placement of these borders often reflected the opposing territorial interests of the French and British colonial administrations within West Africa. For example, the final border that emerged between Niger and Nigeria in 1906 divided ethnicities, natural resources, roads, markets, and villages. This led to the creation of political borders that developed distinct political, institutional, and financial structures, even if they were in close geographic proximity.

Food systems know no borders. Climatic shocks in Nigeria affect production systems in Niger and elsewhere. The use of water from Senegal River affects agriculture in the Gambia. Pastoralists from the Saharan zone travel thousands of miles south to find pasture for their livestock. As a result, the study of any food system requires a regional focus, understanding the drivers that influence the

countries and specific food systems. This chapter presents six main drivers of West African food systems: population, economic drivers, environmental drivers, conflict, technology, and consumer trends. The next chapter is dedicated to the role of regional economic institutions, which have been important in shaping today's food systems. To provide context for these, the following section briefly describes the history of food systems in West Africa.

\subsection{Brief history of food systems in West Africa}

West Africa's food systems have a long history dating back many centuries (table 2.1). West Africa has had kingdoms and empires with sophisticated governance models and trade routes across various regions. The information in this section is mainly based on works by Elbehri (2013) and Maur and Shepherd (2015). The following paragraphs summarise extracts from their publications.

\section{Commodities Key stakeholders}

\section{Period}

Precolonial

\section{Colonial (1920s-1960)}

Postindependence (1960-1980)

Poststructural adjustment (1980-2000)

Post-Millennium Development Goals (2000-07)

Post-food crisis (2007-now)

\section{Value chain models}

In-kind trade of food products and

interexchange with other goods such as salt

State-supported private-led value chains focusing on exportable raw commodities State-controlled (parastatal) integrated value chains for exportable raw commodities

State retreat from commodity chains and emergence of nontraditional export food products

New priorities for food importsubstitution value chains, with focus on food security; liberalisation of statecontrolled commodities

New initiatives to support production and Rice, millet, sorghum, and maize supply of staple food crops; alignment of Meat and fish new policies and investment strategies focusing on staple foods

\section{Coarse grains, meat, fish, and tubers Traders}

Cocoa, cotton, coffee, and groundnuts Parastatals and private companies

Cocoa, cotton, coffee, and groundnuts Parastatals

Selected high-value export products Private companies (horticulture)

Rice, maize, and cassava

Private companies and agribusiness (inputs)

Multiple private (including producer organisations) and state-based players; public-private partnerships
(1) Background and understanding

Regional drivers

\subsection{Brief history}

2.2 Population and migration

2.3 Economic drivers and monetary policy

2.4 Environmental drivers

2.5 Conflict and insecurity

2.6 Technological drivers

2.7 Regional consumer trends

References

(3) Regional organisations

(4) Agro-pastoralism-based

(5) Grains-and-legumes-based

6) Rice-and-horticulture

(7) Coastal maritime fisheries

Tropical mixed tree and

8 food crops systems

9) Toward enhanced resilience

Table 2.1 Key Epochs in West Africa Relating to Value Chain Development Source: Adapted from Elbehri (2013) and Maur and Shepherd (2015). 
2.1.1 Colonial period (1920s-60)

Colonial administrations introduced new crops suitable for the region's agroecological conditions. They organised value chains to supply processing and consumption centres in Europe. State agencies and private companies organised smallholder farmers to supply raw materials and manage the entire supply.

2.1.2 Postindependence (1960-80)

After independence, West African nations nationalised some state agencies but upheld the same structures for managing the supply chains. For example, France had created the French Company for the Development of Textile Fibres (CFDT), which became, among others, Sofitex in Burkina Faso, CMDT in Mali, and CIDT in Côte d'Ivoire. CFDT continued to collabourate with these national parastatals. Another example is the Ghana Cocoa Board, which was an offspring of the British colonial West African Produce Control Board, responsible for purchasing cocoa from the West African territories under British colonial administration.

These state agencies also managed the supply of production inputs and crops produced by smallholders. Export revenues were needed to finance rural and agricultural development. Focusing on a few export commodities that provided most agricultural export revenues (mainly coffee, cocoa, and cotton) left agriculture poorly diversified. From the mid-1970s onward, the national governments saw declining international prices for export commodities and the rise of competing regions, such as Southeast Asia. Also, given population growth in the 1960s and changing consumption patterns, the West African region became a net food importer. Structural adjustment programs that involved liberalising and restructuring production to market across the agricultural sector led to the state's gradual withdrawal from supervising and managing the sector.

2.1.3 Poststructural adjustment (1980-2000)

Increasing European demand for fresh fruits and vegetables, the rise of supermarkets, and technological advances that facilitated shipping perishable products all created opportunities for new export commodities. Private companies took the lead in organising the supply chains of high-value export horticulture products in the liberalised agricultural sector. While this led to agricultural diversification, many farmers and local processors were de facto excluded, given difficulties in complying with conditions and standards required by traders and consumers in, for instance, Europe.

2.1.4 Post-Millennium Development Goals and post-food crisis (2000-present)

Because of sustained population growth ${ }^{1}$ and changing consumption patterns, but also increased purchasing power, the share of food imported by the West African region remains great ${ }^{2}$ despite its great agricultural production potential. In fact, food output through agricultural production has not kept pace with demand for food. The growth of agricultural production has been mainly the result of the increased area under cultivation; much less (only an estimated one-third) came from increased yields (Hollinger and Staatz 2015).

Rising world food prices and the subsequent food crisis in 2007-08 in West Africa drew attention to unlocking the region's staple food potential. This potential involves not only production but also regional trade, which is key to the food supply. The food crisis was also an incentive for regional bodies such as the Economic Community of West African States (ECOWAS) and West African Economic and Monetary Union (WAEMU) to take up and strengthen their coordination role in shaping and implementing national and regional policies for agricultural development and investments, including market development for agricultural inputs and outputs, with a strong focus on staple foods. These staple food policies are aimed at achieving food security as well as income generation. Furthermore, their value chains do not generate revenues that governments can directly capture, and they are risky for private actors because of low margins of return and inherent production and marketing perils. Hence, many public-private partnership policies promote value chain investments.
(1) Background and understanding

Regional drivers

\subsection{Brief history}

2.2 Population and migration

2.3 Economic drivers and monetary policy

2.4 Environmental drivers

2.5 Conflict and insecurity

2.6 Technological drivers

2.7 Regional consumer trends

References

(3) Regional organisations

(4) Agro-pastoralism-based

(5) Grains-and-legumes-based

6) Rice-and-horticulture

(7) Coastal maritime fisheries

Tropical mixed tree and

8 food crops systems

9 Toward enhanced resilience 


\subsection{Population and migration}

As of 2020, West Africa had an estimated population of 400 million, representing 40 percent of the population of Sub-Saharan Africa.

The population of Nigeria represents half of the population in West Africa. Approximately 47 percent of the population lives in urban areas, which is expected to increase over the next 30 years (figure 2.1). Despite this, most West African households reside close to urban areas, with 84 percent of the rural population living within a 90-kilometer radius of an urban centre (Curiel et al. 2017). This urban concentration is primarily visible in the coastal and savannah regions, which house 75 percent of the population, as compared to the relatively less dense population of Sahelian areas (SWAC 2009). ${ }^{3}$

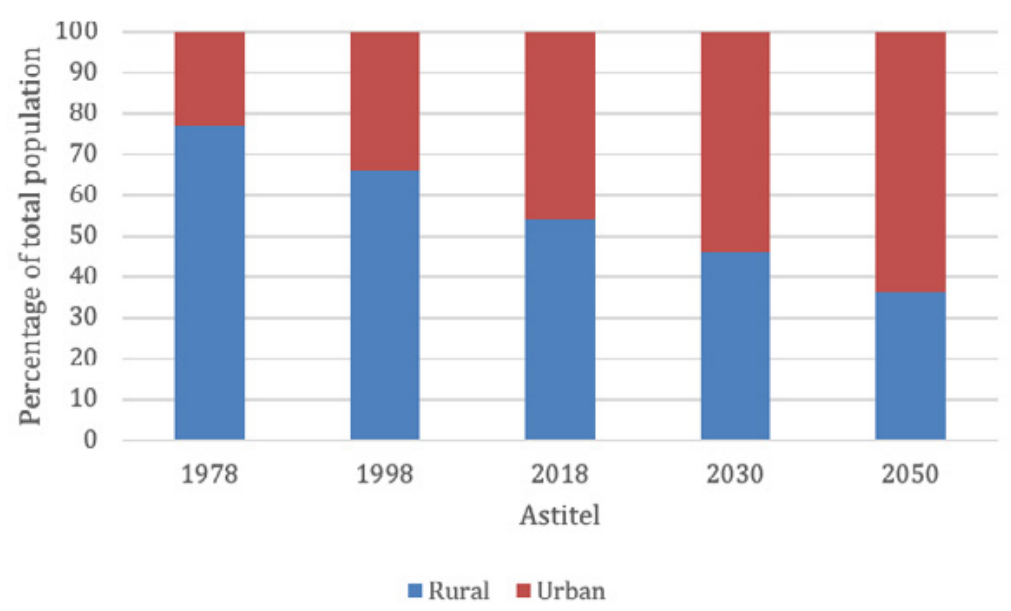

Figure 2.1 Urban-Rural Division of Population in West Africa, 1978-2050 Source: FAOSTAT, Food and Agriculture Organisation, Rome (accessed August 31,2020 ).

Overall, average population growth was 2.6-2.8 percent during the 1980-2019 period, with the Sahelian region of West Africa experiencing unprecedented population growth (figure 2.2). Over the next 20 years, the populations of Burkina Faso, Chad, Mali, Mauritania, and Niger are projected to increase by twofold, which would imply an increase from 80 million to 160 million inhabitants by 2040 (ADB 2018). By comparison, growth in the coastal countries of West Africa is expected to increase by a factor of 1.8 .

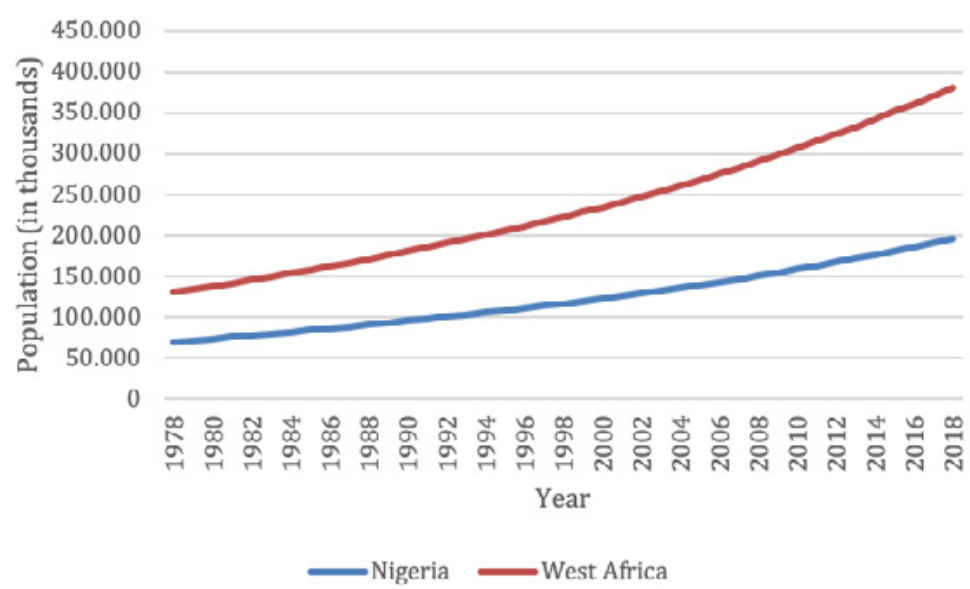

Figure 2.2 Comparison of Populations of West Africa and Nigeria, 1978-2018 Source: FAOSTAT, Food and Agriculture Organisation, Rome (accessed January 27, 2021)

Migration within Africa involves large movements of migrants both within and from the region. More than 21 million Africans lived in another African country as of 2019 (IMO UN Migration 2019). These trends are similar within West Africa, with internal and regional migration provides millions of households with job opportunities and income. While much of the international policy focus has been on international migration from Sub-Saharan Africa to Europe and the United States, regional and domestic migration far exceeds international migration. In 2016, an estimated 84 percent of migration was to countries within the region, with regional migration seven times greater than flows to other parts of the world. Although bilateral migration flows vary considerably by country, Nigeria, Côte d'Ivoire, and Ghana, with their well known "migration corridors," are the primary destinations for migrants from the Sahelian and other coastal countries (ICPMD and IOM 2015). ${ }^{4}$ Migration often includes seasonal migration, whereby households return to their farms during the rainy season (Aker et al. 2020). ${ }^{5}$
(1) Background and understanding

Regional drivers

2.1 Brief history

2.2 Population and migration

2.3 Economic drivers and monetary policy

2.4 Environmental drivers

2.5 Conflict and insecurity

2.6 Technological drivers

2.7 Regional consumer trends

References

(3) Regional organisations

(4) Agro-pastoralism-based

(5) Grains-and-legumes-based

6) Rice-and-horticulture

(7) Coastal maritime fisheries

(8) Tropical mixed tree and

8 food crops systems

9 Toward enhanced resilience 
Overall, these dual drivers - population growth and seasonal migration - have several implications for food systems in West Africa. First, rapid population growth over the past four decades has increased land use under agricultural cultivation. In fact, data show that the area under cultivation in West Africa has doubled between 1975 and 2013 (CILSS 2016; Cotillon 2017). Second, whereas small-scale farmers in West Africa have traditionally dealt with poor rains and degraded soils by shifting into extensive agriculture, increasing population density has resulted in shorter fallow periods and has reduced the availability of arable land for both agriculture and pasture, necessitating agricultural intensification (Woittiez et al. 2015). Third, the exchange of labour across the region, both between rural and urban areas and across countries, has implications for labour availability and hence production in different food systems, as well as for food consumption (ADB 2018).

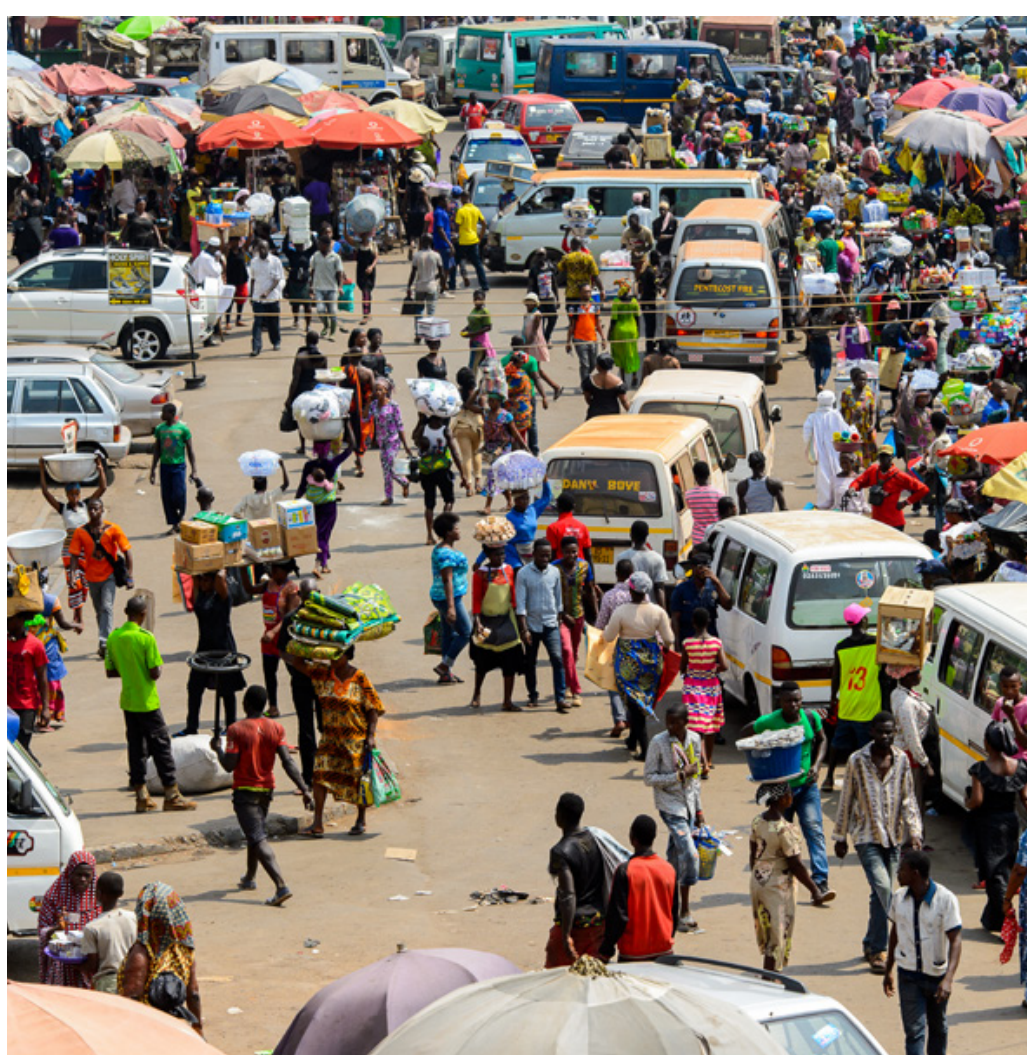

\subsection{Economic drivers and monetary policy}

Despite the reduction in extreme poverty across Sub-Saharan Africa from 56 percent in 1990 to 43 percent in 2012, West Africa is still home to some of the poorest countries in the world (Beegle et al. 2016; ADB 2018; World Bank 2015). Forty-three percent of the population lives below $\$ 1.90$ a day, with 60 percent of citizens living on less than $\$ 1.25$ a day (ADB 2018) (figure 2.3). Among the 15 countries in West Africa, 12 are the lowest ranked on the UN's Human Development Index (HDI), each with a ranking lower than 160 (UN HDR 2020). ${ }^{6}$
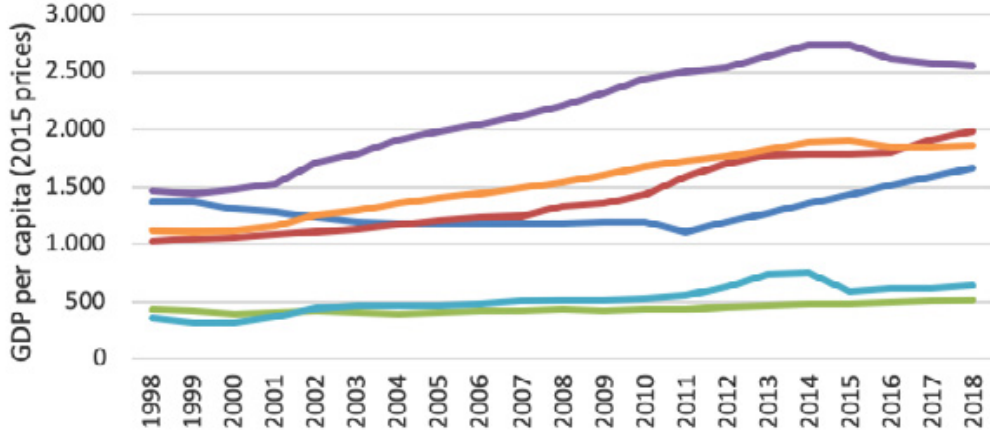
Year

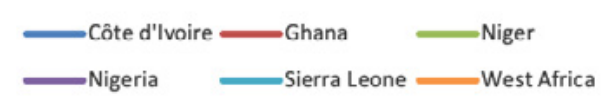

Figure 2.3 GDP Per Capita in West Africa, 1998-2018

Source: FAOSTAT, Food and Agriculture Organisation, Rome (accessed January 27, 2021)

While persistent poverty is due to a number of political, economic, geographic, and social factors, the economies in West Africa share some defining features. First, while West Africa has experienced gross domestic product (GDP) growth over the past decade, this has greatly depended upon the primary sector (defined as agriculture and primary commodities), with high volatility and a significant downturn in 2016. ${ }^{7}$ This GDP growth has not necessarily coincided with income redistribution: the Gini coefficient has ranged between 40 and 46 since 1985 (ADB 2018). Second, in most
(1) Background and understanding

Regional drivers

2.1 Brief history

2.2 Population and migration

2.3 Economic drivers and monetary policy

2.4 Environmental drivers

2.5 Conflict and insecurity

2.6 Technological drivers

2.7 Regional consumer trends

References

(3) Regional organisations

(4) Agro-pastoralism-based

(5) Grains-and-legumes-based

6) Rice-and-horticulture

(7) Coastal maritime fisheries

Tropical mixed tree and

8 food crops systems

9 Toward enhanced resilience 
countries across the region, the service sector's share in the economy is the largest, and the manufacturing sector's share is the smallest (ADB 2018). While the contribution of each sector and subsector varies by country, agriculture (including livestock raising, forestry, and fishing) accounts for approximately 25 percent of GDP, ranging from 8 percent in Cape Verde to 70 percent in Liberia (ADB 2018; (figure 2.4). ${ }^{8}$ Third, four economies - Nigeria, Ghana, Côte d'Ivoire, and Senegal - account for 90 percent of the region's GDP, with Nigeria accounting for 70 percent of regional GDP alone (ADB 2018). Thus, the economic performance of Nigeria has strong impacts on the economies, and hence food systems, of other countries within the region. Finally, average inflation in West Africa rose from 8.2 to 13.3 percent between 2014 and 2017, similar to the rates of inflation across Sub-Saharan Africa (ADB 2018).

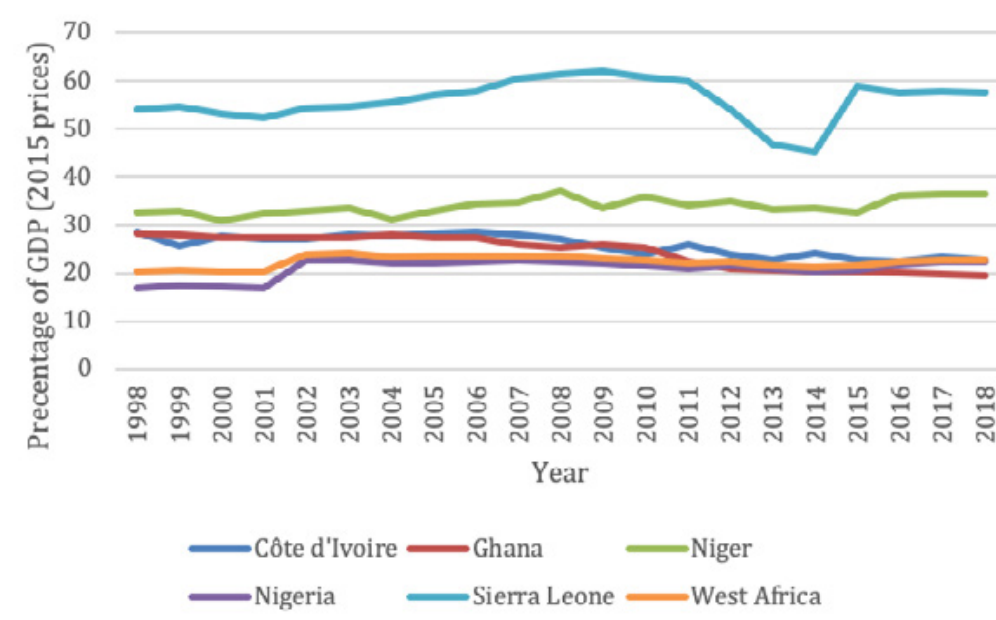

Figure 2.4 Agricultural Share of GDP in West Africa, 1998-2018 Source: FAOSTAT, Food and Agriculture Organisation, Rome (accessed January $\overline{27,2021)}$.

Note: Data reflect agriculture, forestry, and fishing, value added.

Agriculture, livestock raising, and fishing remain the main sources of employment in West Africa, accounting for approximately 58 percent of the population (ADB 2018). Family and seasonal labour covers almost all agriculture-related production, and the informal sector is responsible for more than 73 percent of the off-farm workforce in rural areas. Yet the food economy goes beyond strict agriculture, livestock raising, and fishing: 40 percent of the gross value added comes from off-farm activities, mostly found in the informal sector - a figure that is likely to rise (Bricas, Tchamda, and Mouton 2016; Weng 2016). Much of GDP growth in West Africa has come from increased primary commodities production, which does not necessarily lead to productive employment (ADB 2018; Aryeetey and Baah-Boateng 2007). Productive employment is defined as "employment yielding sufficient returns to labour to permit a worker and his/her dependents a level of consumption above the poverty line" (ILO 2012, 3).

Overall, employment in West Africa has two defining features. First, households must generate their income from a variety of subsectors, including agriculture and small and medium enterprises (Mueller and Chan 2015). Second, this employment is primarily informal and hence subject to a high degree of volatility, often following agricultural cycles (ADB 2018).

ECOWAS, created in 1975 as a political and economic union (see chapter 3), organises the 15 West African countries, comprised of Anglophone, Francophone, and Lusophone countries. Within ECOWAS, WAEMU, a smaller subregional customs and currency union, includes former French and French-speaking colonies, with the exception of Guinea-Bissau, which is Portuguese speaking. ${ }^{9}$

A key feature of WAEMU is its common currency: the CFA franc. While the CFA was originally pegged to the French franc, since the creation of the European Union (EU), it has been pegged to the euro. As a result, the French Treasury guarantees the CFA under a fixed exchange rate, dependent upon the deposit of $50 \%$ of WAEMU's foreign exchange reserves into the French central bank (Tchatchouang 2015).

The CFA has long been a subject of debate in terms of political, economic, and social advantages and disadvantages (Bangake and Eggoh 2009; Strong 2018). A number of researchers have assessed the impact on economic performance of membership in the CFA
(1) Background and understanding

Regional drivers

2.1 Brief history

2.2 Population and migration

2.3 Economic drivers and monetary policy

2.4 Environmental drivers

2.5 Conflict and insecurity

2.6 Technological drivers

2.7 Regional consumer trends

References

(3) Regional organisations

(4) Agro-pastoralism-based

(5) Grains-and-legumes-based

6) Rice-and-horticulture

(7) Coastal maritime fisheries

(8) Tropical mixed tree and food crops systems

9 Toward enhanced resilience 
zone. Overall, these researchers have concluded that inflation is lower (Boccara and Devarajan 1993) and price stability is higher in the CFA zone compared to in the non-CFA zone (Sy 2016; Yehoue 2007), especially during the 2007-08 global financial crisis. Despite arguments in favor of the CFA for higher income growth and increased trade, the empirical evidence on these outcomes is mixed (Bangake and Eggoh 2017; Carrère 2004; Coulibaly and Davis 2013; Gnimassoun 2019; Masson and Pattillo 2004; Nitsch 2002; Patillo, Tsangarides, and van den Boogaerde 2008). More recently, Strong (2018) used a rigorous impact evaluation approach to assess the impact of Mali's membership in the CFA zone, finding that CFA membership had strong and positive impacts on GDP per capita, inflation, and foreign direct investment (FDI) but no impact on trade with France. In theory, improved price stability should increase trade and facilitate money transfers across the region, thereby improving the functioning of food systems.

Beyond its common currency, WAEMU is considered "the furthest along the path toward integration" of all the regional groupings in Africa. With a primary goal to "develop a competitive common market based on the free flow of persons, goods, services, and capital," WAEMU has adopted a common customs union and external tariff, as well as combined indirect taxation regulations (U.S. Department of State ${ }^{10}$; Sy 2016). Yet, while WAEMU has typically had the highest level of intraregional exports in SubSaharan Africa, its share of intraregional exports has fallen behind that of the Southern Africa Development Community (SADC) since 2009 (figure 2.5). Nevertheless, the region still has high and growing interregional trade, including imports and exports.

Each country outside of WAEMU, which are member of ECOWAS (the Gambia, Ghana, Liberia, Nigeria, and Sierra Leone) has its own currency. While these states proposed a common currency (the West African Monetary Zone, or WAMZ) by 2020, the launch date has been postponed several times since the concept arose in the early 2000s. ECOWAS formally agreed to name the future common currency "eco" in July 2019, but this has recently been further complicated by plans to change the name of the CFA to Eco as well.

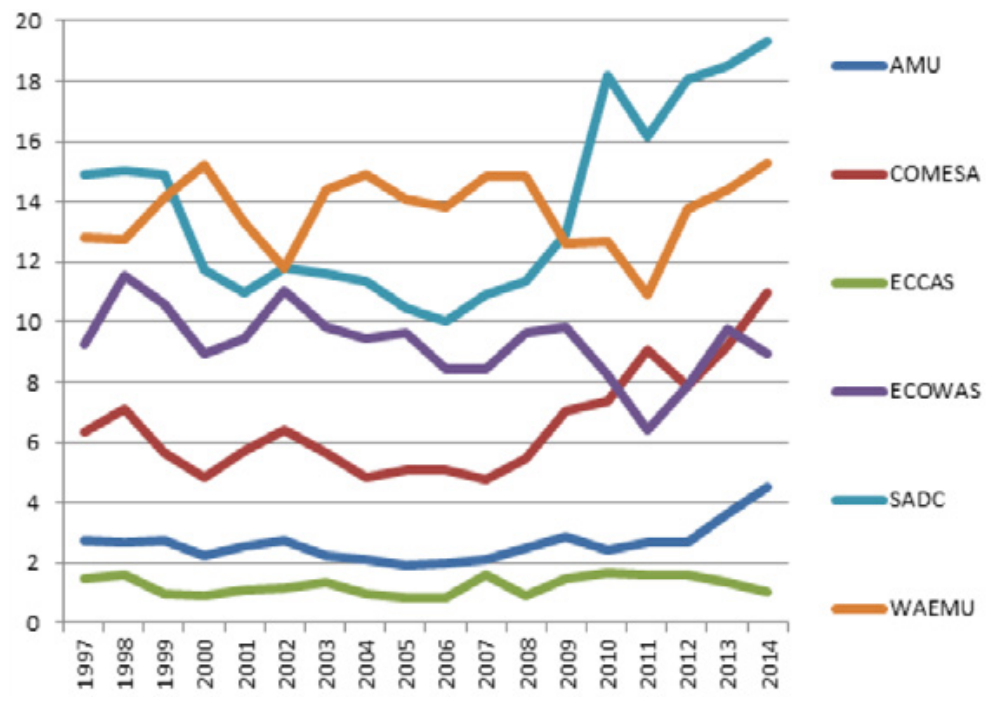

Figure 2.5 Intraregional Exports as a Share of Total Exports for African Currency Unions, 1997-2014

Source: Brookings Institute 2016.

Note: AMU: Arab Maghreb Union; COMESA: Common Market for Eastern and Southern Africa; ECCAS: Economic Commission of Central African States; ECOWAS: Economic Community of West African States; SADEC: Southern African Development Community; WAEMU: West African Economic and Monetary Union.

\subsection{Environmental drivers}

Since 1990, the environmental landscape has changed markedly in West Africa. Rainfall has become more erratic, land under agricultural use has augmented, the size of landholdings has decreased, land and resource degradation has amplified, and water resources have been used extensively. All of these have important implications for food system functioning.

\subsubsection{Land}

The rapid growth of West Africa's population has contributed to the transformation of its land use over the past four decades. As agriculture is the primary source of food, the area under agricultural
(1) Background and understanding

Regional drivers

2.1 Brief history

2.2 Population and migration

2.3 Economic drivers and monetary policy

\subsection{Environmental drivers}

2.5 Conflict and insecurity

2.6 Technological drivers

2.7 Regional consumer trends

References

(3) Regional organisations

(4) Agro-pastoralism-based

(5) Grains-and-legumes-based

6) Rice-and-horticulture

(7) Coastal maritime fisheries

Tropical mixed tree and

8 food crops systems

9 Toward enhanced resilience 
cultivation grew by 25 percent between 1980 and 2018 (figure 2.6). This has coincided with the loss of forests, woodlands, savannah, and steppes. The area under forestland declined by nearly 20 percent (figure 2.7 ). ${ }^{11}$

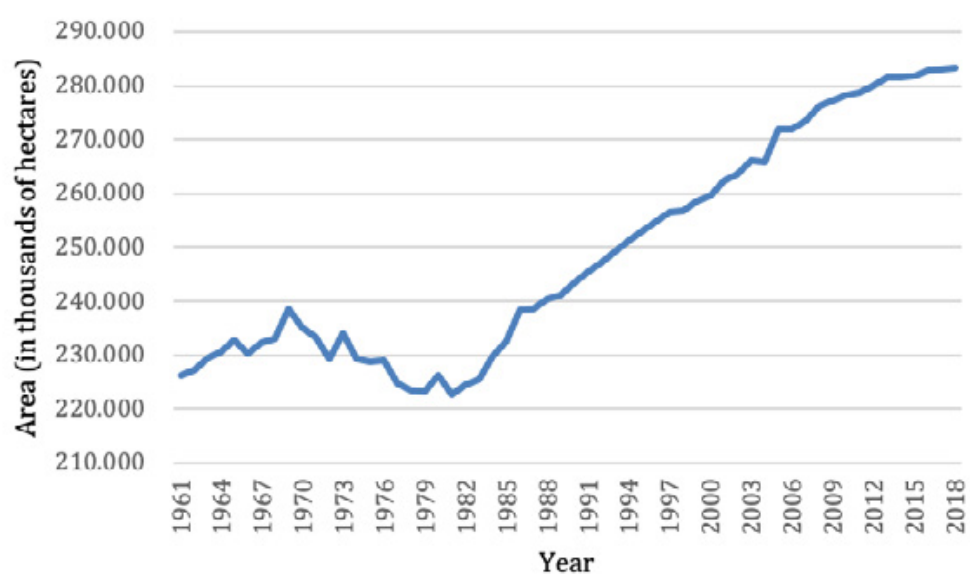

Figure 2.6 Agricultural Land Area in West Africa, 1961-2018

Source: FAOSTAT, Food and Agriculture Organisation, Rome (accessed January 27, 2021)

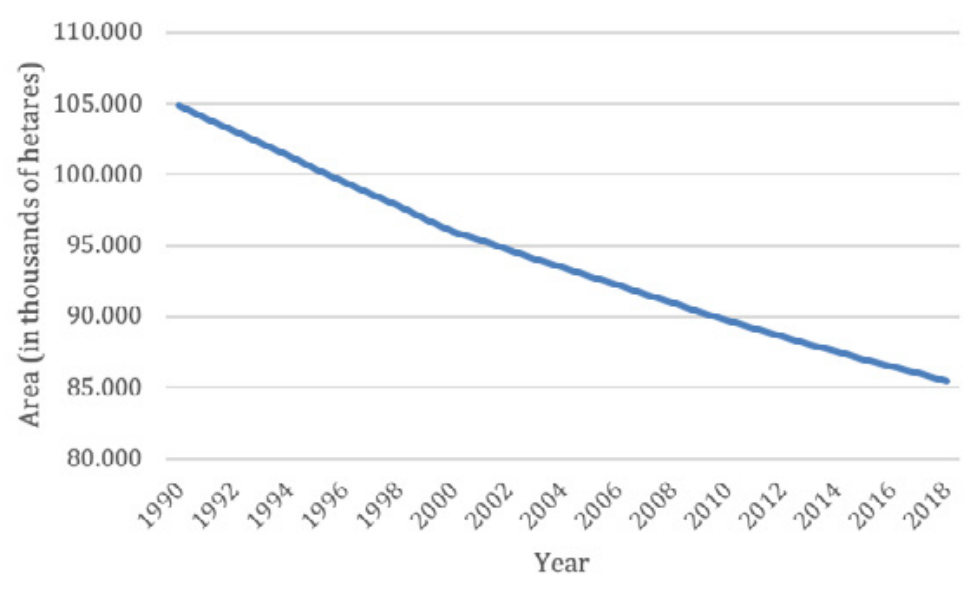

Figure 2.7 Forestland Area in West Africa, 1990-2018

Source: FAOSTAT, Food and Agriculture Organisation, Rome (accessed January $\overline{27,2021}$.
Data from wide-ranging remote-sensing studies show that this process gained pace from the mid-1970s onward. The area of forests, woodlands, savannah, and steppes declined to approximately 14 percent of the total area between 1975 and 2013. During this period, an estimated 20 percent of Sahelian short grass and savannah and 25 percent of forest were lost (CILSS 2016).

Industries such as mining, oil and gas, and industrial plantations have also led to changes in land use (Godfray et al. 2010; USAID 2013a). The primary impacts of these industries are degrading natural vegetation and topsoil, polluting surface and groundwater, and increasing standing water, leading to negative health impacts. Artisanal mining has a similar impact, although it is often concentrated in one area.

\subsubsection{Climate}

West Africa, specifically its Sahelian region, is vulnerable to climate change, which directly affects the national economies that depend mostly on agriculture, livestock raising, and fisheries. There is general agreement about a probable increase in temperature in West Africa. Mean annual temperatures are expected to rise by $1.5^{\circ} \mathrm{C}$ to $2.3^{\circ} \mathrm{C}$ between 2000 and 2050 (Zougmoré et al. 2015). Although the Sahelian region has encountered large rainfall deficits, especially in the 1970s, 1980s, and 1990s, the different climate change scenarios for West Africa are less conclusive about rainfall in the future. According to some studies (as cited by Zougmoré et al. 2018), mean annual rainfall in West Africa may decline by 4 percent by 2050 , reducing the duration of the cropping season by 20 percent and causing a decrease of up to 40 percent in yields of cereal crops. Other studies are more nuanced and provide projections per crop (as cited by Zougmoré et al. 2015). However, there is consensus on growing interannual variability with more frequent and more or less localised extremes, such as drought and flooding. The expected impacts of climate change on livestock and agriculture in West Africa vary according to the agroecological zones and are the result of interactions with demographic change and economic development (RCPA 2015; Zougmoré et al. 2015; Zougmoré et al. 2018).
(1) Background and understanding

Regional drivers

2.1 Brief history

2.2 Population and migration

2.3 Economic drivers and monetary policy

\subsection{Environmental drivers}

2.5 Conflict and insecurity

2.6 Technological drivers

2.7 Regional consumer trends

References

(3) Regional organisations

(4) Agro-pastoralism-based

(5) Grains-and-legumes-based

6) Rice-and-horticulture

(7) Coastal maritime fisheries

(8) Tropical mixed tree and

8 food crops systems

9 Toward enhanced resilience 
During the twentieth century, sea levels in the coastal countries rose an average of 1.7 millimeters per year, with an expected acceleration in the future. The predicted global rise in sea level by 30 centimeters in 2100 will also affect the coastal zones of West Africa by flooding, increased coastal erosion and augmentation of salinity. This will affect not only large coastal urban agglomerations with more than one million inhabitants but also small and poor coastal communities that depend on mangroves for their livelihoods (fisheries, agriculture, and tourism). These mangroves attenuate the negative effects of climate change (flooding, coastal erosion), but they are threatened by agricultural expansion and intensive salt production (RCPA 2015; Zougmoré et al. 2018).

The transformation of land use in combination with predicted climate change has different consequences for the diverse agroclimatic zones in West Africa.

The Sahara-Sahelian zone ${ }^{12}$ has an average annual precipitation below 450 millimeters per year and a rainy season that lasts between 50 and 110 days per year. The pastoralist food system prevails in this zone. In the northern fringe of this zone (with less than 250 millimeters per year), the duration of the rainy season varies more than 30 percent from one year to another. Therefore, this zone represents two major climate-related risks for the pastoralist food system: structurally low annual precipitation and unpredictable variations in rainfall (RCPA 2015).

Specific impacts of climate change on livestock include changes in grazing land availability, quality of forage resources, access to water, greater heat stress leading to a decline in productivity, and emerging and re-emerging animal diseases, which determine the species and breeds of livestock that can be kept. Combined with an observed encroachment by agriculture, mainly for cultivation of rice and vegetables in river valleys and lowlands, it reduces the possibilities for pastoralists to move their herds to these refuge areas during the dry season (Zougmoré et al. 2015).

Years of drought in the Sahel devastated the herds of the pastoralists that rely on transhumance for their livelihoods. Drought also affected farmers and their households. Nevertheless, they continued to produce, and the well-off households managed to sell surplus production and invested revenues in livestock. According to ICG $(2020,3)$, "This period is the origin of a crisis of marginalisation for pastoral communities, which partly explains the appeal of jihadist rhetoric to many Fulani nomads." Furthermore, national policies emphasising food sovereignty and modernisation of agriculture were more beneficial to farmers than to pastoralists. Climate change certainly affects pastoralists' livelihoods, but the enhanced resilience of the pastoralist food system needs to equally take into account access to pastoral resources and the political choices made (ICG 2020).

The Sudano-Sahelian zone has an annual precipitation between 450 and 800 millimeters per year. This is the zone par excellence for crop-based food systems associated with sedentary livestock keeping, such as the grains-and-legumes-based food system that prevails in central and southern Burkina Faso and Mali, southern Niger, and eastern Senegal.

According to case studies (see RCPA 2015) and literature reviews (Sultan et al. 2017; Zougmoré et al. 2018), yields of the major staple food cereals - millet, sorghum, and maize - may decrease by up to 20-40 percent of current yield because of climate change. However, different climate models using various parameters such as temperature, rainfall, and $\mathrm{CO}_{2}$ emissions result in a wide display of crop yield responses. Some researchers (see RCPA 2015) argue that the increasing concentration of atmospheric $\mathrm{CO}_{2}$ has a fertiliser effect and, combined with technological improvements, will positively affect cereal crop yields. Others reason that the combined effects of environmental changes have a net negative impact on crop yields (Sultan et al. 2017; Zougmoré et al. 2015). Projections of yield change based on crop model analysis, combined with different climate models, indicate that only rain-fed rice shows a modest increase in yields ( 0.9 percent). The yields for other rain-fed crops are expected to decrease by 5.5 percent for maize, 13.9 percent for sorghum, 6.8 percent for groundnuts, and 5.0 percent for soybeans (Zougmoré et al. 2015).

In this food system zone, land pressure has increased over the last four decades in the traditional agricultural basins of central Mali,
(1) Background and understanding

Regional drivers

2.1 Brief history

2.2 Population and migration

2.3 Economic drivers and monetary policy

2.4 Environmental drivers

2.5 Conflict and insecurity

2.6 Technological drivers

2.7 Regional consumer trends

References

(3) Regional organisations

(4) Agro-pastoralism-based

(5) Grains-and-legumes-based

6) Rice-and-horticulture

(7) Coastal maritime fisheries

Tropical mixed tree and

8 food crops systems

9 Toward enhanced resilience 
central Burkina Faso, and southern Niger. This has led to smaller plots, reduced time under fallow, and encroachment onto forestland and rangeland, resulting in increased land degradation and reduced yields (Woittiez et al. 2015). However, large areas within the Sahe and Sudan zones in Burkina Faso, Mali, and Niger show significant signs of "re-greening," or "the transformation of degraded landscapes into productive and resilient farmland through widespread adoption of agroforestry and related sustainable land management practices" (Reij and Winterbottom 2015, 11). Because of the empowerment of local groups and communities, farmers now use simple techniques on a large scale, including farmer-managed natural regeneration, wherein farmers regenerate and multiply valuable trees that are already part of their traditional agroforestry systems. Besides strengthening grassroots organisations, national policies that allow for and foster grassroots initiatives are equally decisive in the scaling up of re-greening initiatives (Smale et al. 2018)

In the Sudano-Guinean zone, annual precipitation varies between 800 and 1,200 millimeters, and food systems are dominated by sorghum, maize, legumes, and, increasingly, root crops, often combined with cotton (southern Burkina Faso and Mali, northern Côte d'Ivoire, Ghana, Togo, and Benin). Climate change (rising temperature, erratic rainfall) might have the same effect as in the

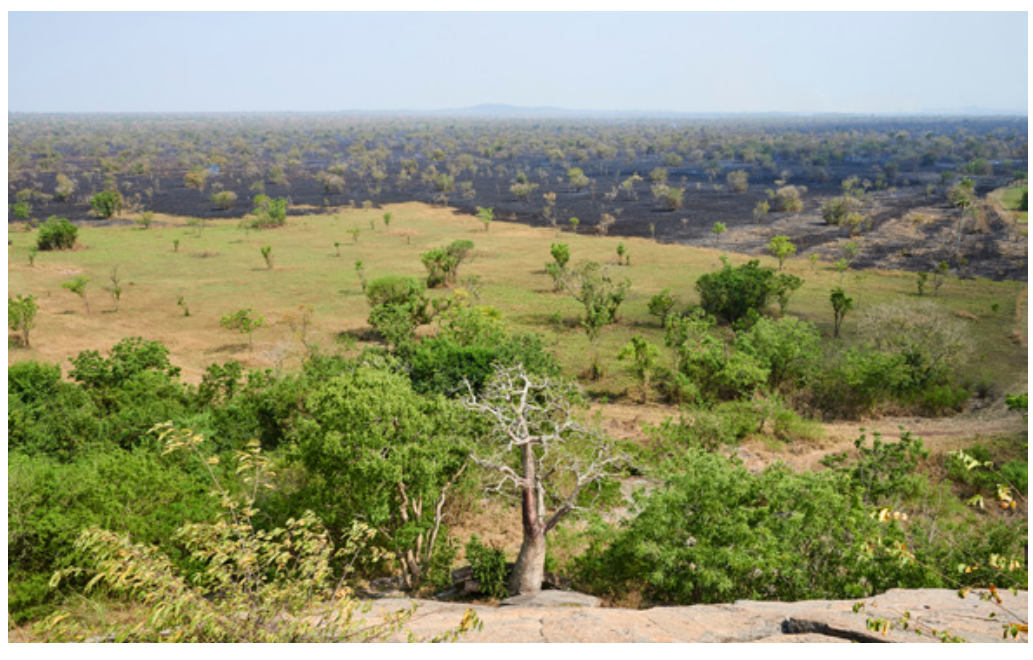

Sudano-Sahelian zone but with less negative impact on the yields of cereal crops (Sultan et al. 2017).

Rapid agricultural colonisation followed the reduction of diseases such as onchocerciasis and trypanosomiasis in the 1970 and 1980s, opening an estimated 20 million hectares of arable land during that period (SWAC 2009). Yet this also accelerated encroachment on forests and river borders. As with the Sudano-Sahelian zone, pressure on land increases with a corresponding deterioration of the soil's capacity to replenish its pool of nutrients and subsequent declining crop yields. However, this zone still has some land buffers left through long fallow land reserves.

The scale of the additional fertilisation and production practices (manuring, new external inputs, association of farming and livestock practices) are insufficient to thwart land degradation. This also affects livestock and forestry, as the farmers' strategy follows an agricultural rationale. Forestlands and rangelands are considered agricultural land reserves instead of strategic areas to protect livestock and tree production (pastures and forests are relegated to border areas). The primary exception is the Guinean savannahs of Guinea, Côte d'Ivoire, Ghana, and to a lesser extent Togo and Benin, which all have relatively abundant forestland and rangeland.

West Africa's coastal and Guinean tropical forest zones include almost 60 percent of the West African population and contribute to more than one-third of GDP for the region (Croitoru 2019). There are still major gaps in knowledge about the impacts of climate change on forests in West Africa and hence the adaptation strategies to use (Zougmoré et al. 2015).

For the coastal zone, as mentioned, the combination of urbanisation, increased temperatures, rising sea levels, and surging storms has increased flooding and coastal erosion and has damaged the critical mangrove ecosystems. As for the tropical mixed tree and food crops systems, crop suitability models predict that, in the case of decrease in rainfall, the current cocoa-growing zones in Ghana and Côte d'Ivoire will become less suitable for production. In addition, the suitable area itself will shrink, particularly the areas bordering the savannahs of the current forest belt. However,
(1) Background and understanding

Regional drivers

2.1 Brief history

2.2 Population and migration

2.3 Economic drivers and monetary policy

2.4 Environmental drivers

2.5 Conflict and insecurity

2.6 Technological drivers

2.7 Regional consumer trends

References

(3) Regional organisations

(4) Agro-pastoralism-based

(5) Grains-and-legumes-based

6) Rice-and-horticulture

(7) Coastal maritime fisheries

8 Tropical mixed tree and

8 food crops systems

9 Toward enhanced resilience 
climatic suitability for cocoa will increase in some higher-elevation areas, such as the Kwahu Plateau of Ghana, because of the temperature increase, but to a very limited extent. The climatic suitability might more importantly increase in the southwest of Côte d'Ivoire, already an important cocoa-producing area. The predicted increase in evaporation would make this very wet area more suitable for cocoa production and especially for the postharvest processing and conservation operations (Läderach et al. 2013).

\subsubsection{Water}

The three primary basins in the West Africa region are the Niger River (shared across 10 riparian countries), the Volta River (six countries), and the Senegal River (four countries). ${ }^{13}$ Overall, there

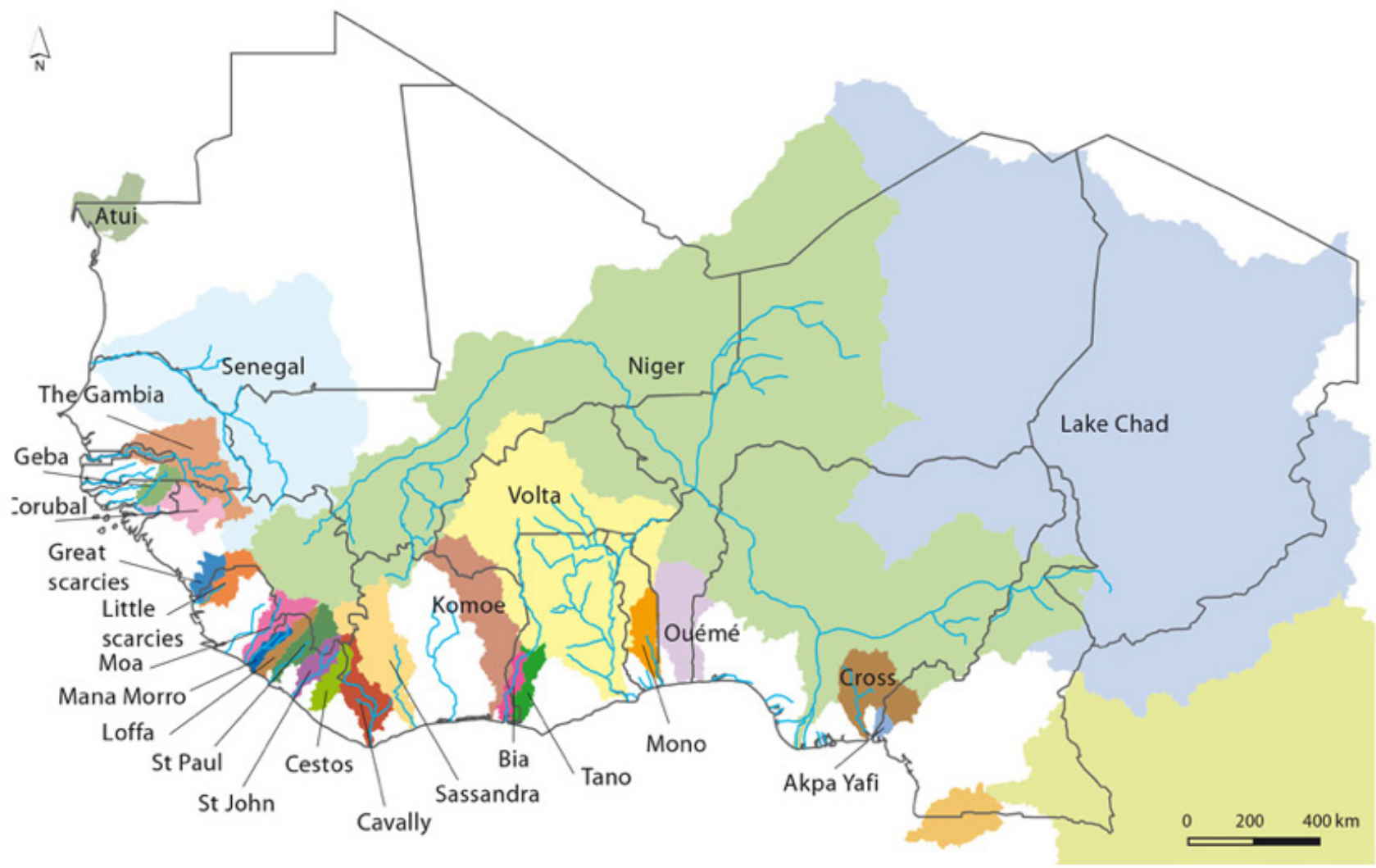

are 11 transboundary river basins in West Africa (map 2.1). Over the course of the second half of the twentieth century, West Africa's rivers experienced an overall decline in water supply (USAID 2013b). In general, annual per capita water availability for West Africa's population has decreased in the twenty-first century, with Burkina Faso and Niger showing an annual supply volume that is currently below the international scarcity standard of 1,700 cubic meters per inhabitant per year (figure 2.8). When considering the sustained population growth and the countries' political ambitions in agricultural and industrial development, this trend will surely continue and soon bring countries such as Ghana and Togo into a situation of water scarcity.
(1) Background and understanding

Regional drivers

2.1 Brief history

2.2 Population and migration

2.3 Economic drivers and monetary policy

\subsection{Environmental drivers}

2.5 Conflict and insecurity

2.6 Technological drivers

2.7 Regional consumer trends

References

(3) Regional organisations

(4) Agro-pastoralism-based

(5) Grains-and-legumes-based

6) Rice-and-horticulture

(7) Coastal maritime fisheries

Tropical mixed tree and

(8) food crops systems

9) Toward enhanced resilience 


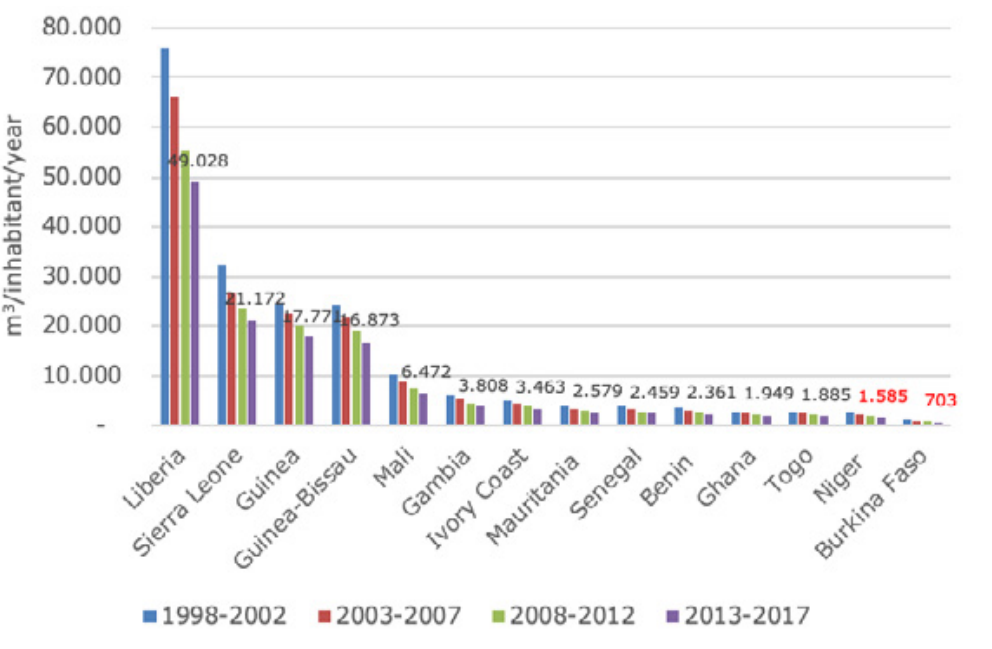

Figure 2.8 Availability of Total Renewable Water Resources Per Capita for West African Countries, 1998-2017

Source: FAO AQUASTAT, Food and Agriculture Organisation, Rome (accessed August 30, 2020).

This decline in water resources is due to both climatic and nonclimatic stressors. For climatic stressors, changes in temperature and rainfall have variable impacts on surface water levels in the region. The climate projections for annual rainfall do not show consistent trends for the West Africa region. There is a consensus that greater inter- and intra-annual variability will remain a major challenge with consequences that may be aggravated by reduction of total rainfall (Zougmoré et al. 2015).

While the relationship between precipitation, runoff, and water supplies is highly complex and context specific, it is estimated that river flows will decline by 20-40 percent by 2050 based upon climatic projections (USAID 2013b, 17). The river basins in the Sahel, such as the Niger, Senegal, and Gambia River basins, will be most vulnerable to climate change. Beyond these climatic factors, nonclimatic factors also play an important role in the depletion of water supplies and interact with many of the factors mentioned. Population growth, increased land under agricultural use, inadequate water and river basin management, groundwater decline, and inefficient water provision all exacerbate the effect of climatic factors on water flows in West Africa (USAID 2013b).

Each of the West African countries shares at least one watercourse with one of its neighbours. Together these transboundary basins cover 71 percent of the total surface area of the region. Therefore, many countries are dependent on the water resources of neighbouring countries for their water supply (ECOWAS and SWAC 2006).

\subsection{Conflict and insecurity}

In the 1990s and 2000s, the civil wars in Liberia and Sierra Leone as well as the internal crisis and war in Côte d'Ivoire, were the primary security concerns in the West African region. Since the 2010s, however, several new security crises have emerged in the region. The roots of the current insecurity and tensions lie in what the UN and World Bank (2018) call four "arenas of contestation": access to political power and governance; exclusion of land, water, and extractive resources; access to basic services; and access to justice and security. These crises have given rise to violent conflicts, primarily in the Sahelian countries of West Africa, related to three types: (1) violent extremism related to al-Qaeda in the Islamic Maghreb (AQIM) and Boko Haram, (2) conflicts related to rebellions, and (3) community self-defense and the actions of militia (UN and World Bank 2018)

According to the UN, violence has increased substantially since, with more than 12,000 events and 50,000 fatalities through June 2019 (SWAC 2020a, 15). While a majority of this violence has occurred in Nigeria (one-third of the violent events and half of the fatalities between 1997 and 2019 occurred in Nigeria), other localised areas of violence include the border regions between Mali, Burkina Faso, and Niger, as well as between Niger, Chad, and Nigeria. In fact, 40 percent of violence and fatalities have occurred within 100 kilometers of the land borders (OECD 2020a, 16), where conflict has remained largely local but increasingly violent.

The increased intensity of violence in West Africa has important implications for security and human life in the region. As of 2019,
(1) Background and understanding

Regional drivers

2.1 Brief history

2.2 Population and migration

2.3 Economic drivers and monetary policy

2.4 Environmental drivers

2.5 Conflict and insecurity

2.6 Technological drivers

2.7 Regional consumer trends

References

(3) Regional organisations

(4) Agro-pastoralism-based

(5) Grains-and-legumes-based

6) Rice-and-horticulture

(7) Coastal maritime fisheries

Tropical mixed tree and

8 food crops systems

9 Toward enhanced resilience 
there were 4.5 million people displaced and 12.2 million people suffering from food insecurity within the West Africa region (OCHA $2020,3)$. The cycle of violence puts increasing pressure on households and hosting communities within the region, with increased pressure on land and water resources in hosting communities.

While farmer-herder conflicts are on the rise in West Africa, the growing political violence along the border regions has increasingly disrupted pastoralists' way of life, in particular traditional

pastoralists. This has been primarily focused on the areas between Chad and Nigeria, as well as between Mali, Burkina Faso, and Niger (UNOWAS 2018).

\subsection{Technological drivers}

2.6.1 Agricultural technologies

According to the latest data available through the IFPRI-ASTI database, the spending on agricultural in West Africa doubled between the late 1990s and 2014, following a long period of stagnation. In 2014 West Africa in all spent some $\$ 950$ million on agricultural research, with Nigeria and Ghana accounting for more than half of this total. The region also employed more than 5,600 full-time researchers in agricultural and related sciences, compared with 3,200 in 2000. Other countries showed stagnated or even declining levels of investments during the 2000-14 period (Stads and Beintema 2017). In terms of investments as a percentage of agricultural GDP, this varies between 0.2 and 0.9 percent for the West Africa region (without Nigeria). ${ }^{14}$

While improved technologies and substantial investments have been made in agricultural research and extension, reliable data on agricultural technology adoption and usage for the West Africa region are not available. Seeds and fertiliser adoption rates are relatively low in West Africa (Kpadonou et al. 2019), but important long-term subsidy programs introduced after the 2008 food crisis seemed to kick-start the effective use of inputs with a fourfold increase of volumes of nitrogen between 2007 and 2017

(figure 2.9). Volumes used in 2017 varied considerable between countries, with Nigeria, Mali, and Burkina Faso standing out with, respectively, 0.45 million, 0.15 million, and 0.06 million tons of nutrient nitrogen.

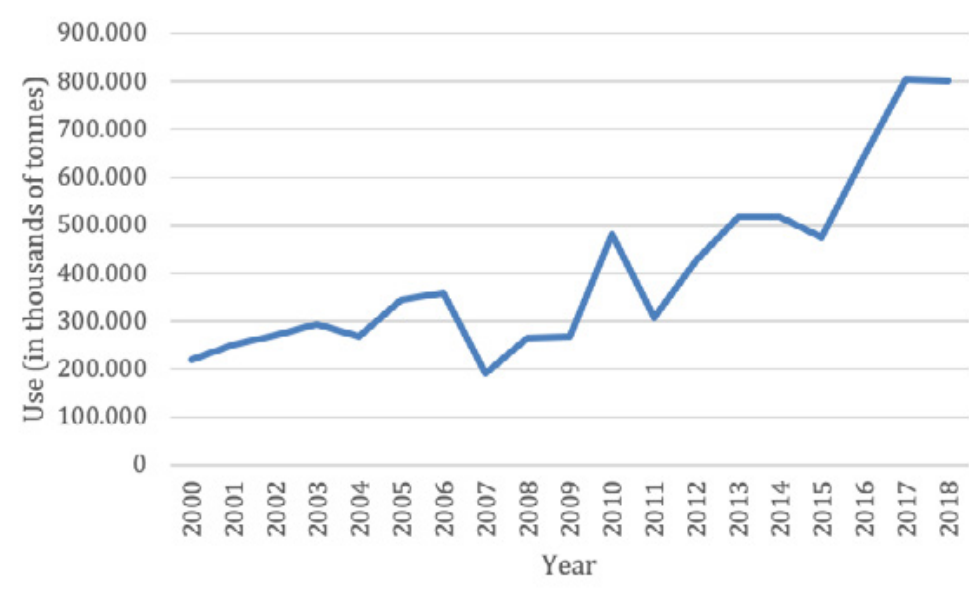

Figure 2.9 Evolution of Agricultural Use of Nutrient Nitrogen in West Africa, 2000-2018

Source: FAOSTAT, Food and Agriculture Organisation, Rome (accessed January 27, 2021).

Soil degradation is a problem particularly in the Sahel. It is possible to achieve sustained yield improvements there through intensive agricultural practices that increase the level and duration of water stored within the soil, restore organic matter content, and replenish soil nutrients. Yet in situ rainwater conservation is poorly suited to the semiarid areas of Africa, where soil cover materials such as mulch compete with livestock fodder (Aker 2015). In such contexts, microcatchments - small structures constructed within a field to collect soil runoff and increase the nutrient content of the soil - are the most appropriate rainwater-harvesting technology. The most common Sahelian catchment systems are zaï/tassa (soil pits), demi-lunes (half-moons), and banquettes. Yet sustained adoption of such techniques remains low despite substantial investments in the twenty-first century. In West Africa, it is estimated that less than 10 percent of small-scale farmers use microcatchments on any part of their land (calculations by Aker 2015, based on WOCAT Global
(1) Background and understanding

Regional drivers

2.1 Brief history

2.2 Population and migration

2.3 Economic drivers and monetary policy

2.4 Environmental drivers

2.5 Conflict and insecurity

2.6 Technological drivers

2.7 Regional consumer trends

References

(3) Regional organisations

(4) Agro-pastoralism-based

(5) Grains-and-legumes-based

6) Rice-and-horticulture

(7) Coastal maritime fisheries

Tropical mixed tree and

8 food crops systems

9) Toward enhanced resilience 
Database on SLM). ${ }^{15}$ However, the experiences with re-greening and fertiliser subsidies indicate that the appropriate policies (for example, community participation and targeted subsidies) can enhance technology adoption (Smale et al. 2018).

2.6.2 Information and communications technology

The number of unique mobile subscriptions was 185 million at the end of 2018 , representing $48 \%$ of the population. This percentage is expected to be $54 \%$ by 2025 (GSMA 2019). Farmers can now contact people across cities and countries, know agricultural prices in distant markets in real time, discover what job opportunities are available at a lower cost, and access targeted government services (Dalerg Advisors and CTA 2019). Mobile phone technology has brought new opportunities for financial inclusion to West Africa. The rise of the mobile phone has been accompanied by emerging financial applications, which have allowed people access to certain financial services in light of their exclusion from formal financial institutions. An average 35 percent of the adult population of West Africa owns an account at a financial institution or mobile money service provider (figure 2.10).
(1) Background and understanding

Regional drivers

2.1 Brief history

2.2 Population and migration

2.3 Economic drivers and monetary policy

2.4 Environmental drivers

2.5 Conflict and insecurity

2.6 Technological drivers

2.7 Regional consumer trends

References

(3) Regional organisations

(4) Agro-pastoralism-based

(5) Grains-and-legumes-based

6) Rice-and-horticulture

(7) Coastal maritime fisheries

Tropical mixed tree and

8 food crops systems

9 Toward enhanced resilience

Figure 2.10 Account Ownership at a Financial Institution or with a Mobile Money Service Provider in West Africa, 2017. Percentage of Population Age 15 or Older per Country and Group of Countries

Source: World Development Indicators Database, World Bank, Washington, DC (accessed August 31, 2020). 


\subsection{Regional consumer trends}

Major studies reveal that changes over time in consumer habits and preferences have altered West Africa's food systems. Current

consumption patterns may belie preconceived ideas (Bricas et al. 2016; Staatz and Hollinger 2016). First, purchased goods at food markets dominate consumption, even in rural areas. Although self-provision is still common, urban and rural inhabitants face increasingly similar food security issues. The domestic food market is now much larger than export markets. The domestic market, which primarily concerns local and regional products, is a significant driver of agricultural development.

Urban centres are still highly dependent on wheat and rice imports, and to a lesser extent on milk powder, poultry, and fish imports, but the idea that West Africa will remain dependent on other regions for food no longer holds true. West Africa's wide range of agroclimatic zones creates many opportunities to expand the availability of food to consumers and farmers' access to profitable markets through regional trade. Still, rapid population growth and urbanisation are putting tremendous strain on the market and transportation infrastructure upon which the West African agro-food system depends (Bricas et al. 2016).

While the composition of major food groups has not changed in terms of human consumption, with the exception of starchy roots and tubers (figure 2.11), dietary habits have changed slightly with economic growth and urbanisation.

As for cereals and vegetables, demand for wheat, rice, and vegetables has increased, while relatively fewer coarse grains are consumed, especially in urban areas (figure 2.12). Between the 1960 s and 2010s, rice and wheat consumption increased by a factor of 8 and 15, respectively, and vegetable consumption tripled. West Africa imports 40 percent of its rice and over 90 percent of its wheat consumed, amounting to an annual import bill for rice around $\$ 3-\$ 4$ billion (see chapter 6). According to De Fraiture $(2014,1)$, "Even if the demand curves flatten out, rice, wheat and vegetable consumption may triple, quintuple and triple, respectively, by 2050."

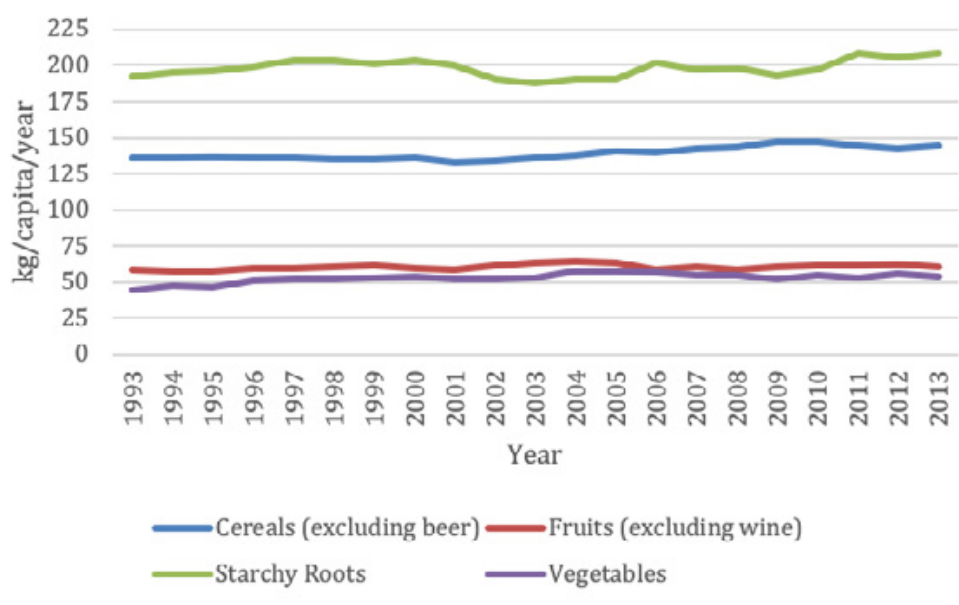

Figure 2.11 Per Capita Consumption of Food Groups in West Africa, 1993-2013

Source: FAOSTAT, Food and Agriculture Organisation, Rome (accessed January $\overline{28,2021}$.

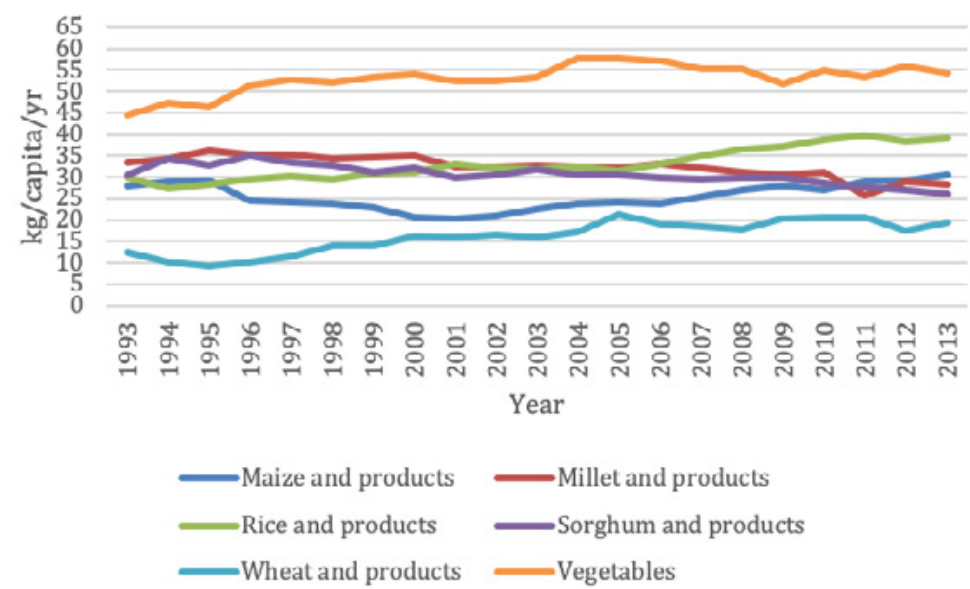

Figure 2.12 Cereal Consumption Per Capita in West Africa, 1993-2013 Source: FAOSTAT, Food and Agriculture Organisation, Rome (accessed January 28, 2021).
(1) Background and understanding

Regional drivers

2.1 Brief history

2.2 Population and migration

2.3 Economic drivers and monetary policy

2.4 Environmental drivers

2.5 Conflict and insecurity

2.6 Technological drivers

2.7 Regional consumer trends

References

(3) Regional organisations

(4) Agro-pastoralism-based

(5) Grains-and-legumes-based

6) Rice-and-horticulture

(7) Coastal maritime fisheries

(8) Tropical mixed tree and

8 food crops systems

9 Toward enhanced resilience 
The consumption of animal products has risen gradually (figure 2.13). People consume more fish and milk products (each above 15 kilograms per capita per year). Poultry is primarily responsible for the growth in meat consumption, while the consumption of bovine, mutton, and goat meat has remained stable or has grown slightly.

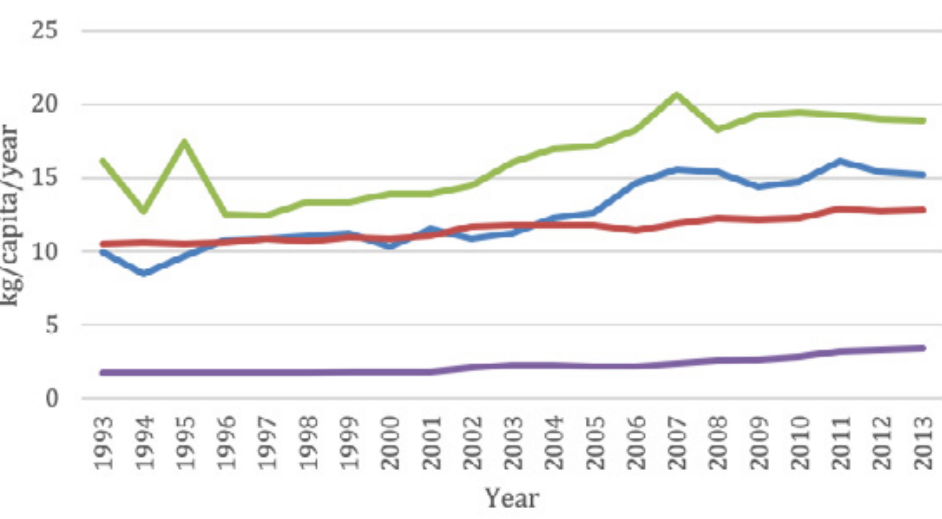

— Fish and seafood $—$ Meat $—$ Milk (excluding butter) $\longrightarrow$ Poultry Meat

Figure 2.13 Animal Product Consumption Per Capita in West Africa, 1993-2013

Source: FAOSTAT, Food and Agriculture Organisation, Rome (accessed February 1, 2021)

Diet diversification in staples, toward more perishable products, is strongest in coastal countries and big cities but is spreading slowly to smaller towns and rural areas. A middle-class urban population of more than 70 million people in 2015 requires safer, cleaner, and higher quality food. However, 75 percent of the population is still very poor such that affordability and costs remain the determinant factor. Another trend is the demand for more swiftly or easily managed foods within households as well as restaurants at marketplaces. The demand for convenience might indicate the changing role (more work outside the house), or even the increased multitasking, of women. Rice and wheat exemplify this trend. The share of processed or prepared maize versus unprocessed grains rose from 2 to 7 percent in rural Niger and in Mali and from 70 percent to 84 percent in urban Ghana and Côte d'Ivoire. In the latter countries, the share of processed maize has grown to 50 percent or more in rural areas (Staatz and Hollinger 2016).

Domestic production of strategic food has kept pace with rising demand, except for countries with the fastest-growing demands, which now depend on considerable imports, such as rice, wheat (figure 2.14), milk, poultry, and fish/seafood (figure 2.15). Wheat and rice are almost 100 percent responsible for cereal imports in West Africa. The region has little potential for wheat, but rice has become a strategic food crop (see chapter 6 ). Rice production has risen swiftly, as has maize and cassava production, but the region still depends partly on imports. Poultry represents the vast majority of meat imports (see chapter 4 ). Fish and seafood imports have outstripped domestic fishing (see chapter 7 ).

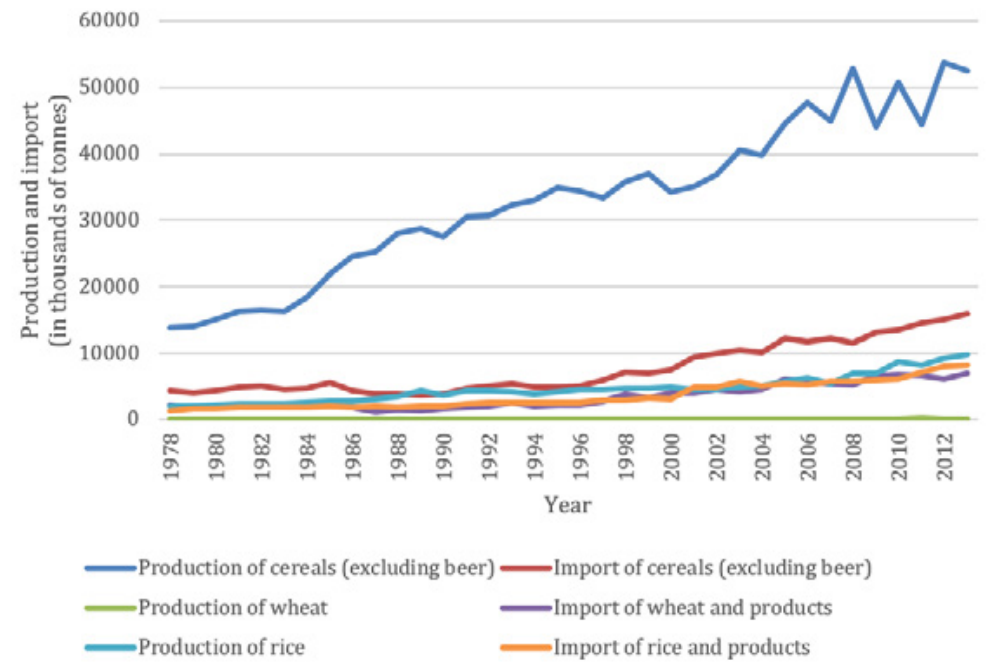

Figure 2.14 Cereal Production and Imports in West Africa, 1978-2013 Source: FAOSTAT, Food and Agriculture Organisation, Rome (accessed February 1, 2021).
(1) Background and understanding

Regional drivers

2.1 Brief history

2.2 Population and migration

2.3 Economic drivers and monetary policy

2.4 Environmental drivers

2.5 Conflict and insecurity

2.6 Technological drivers

2.7 Regional consumer trends

References

(3) Regional organisations

(4) Agro-pastoralism-based

(5) Grains-and-legumes-based

6) Rice-and-horticulture

(7) Coastal maritime fisheries

Tropical mixed tree and food crops systems

9 Toward enhanced resilience 


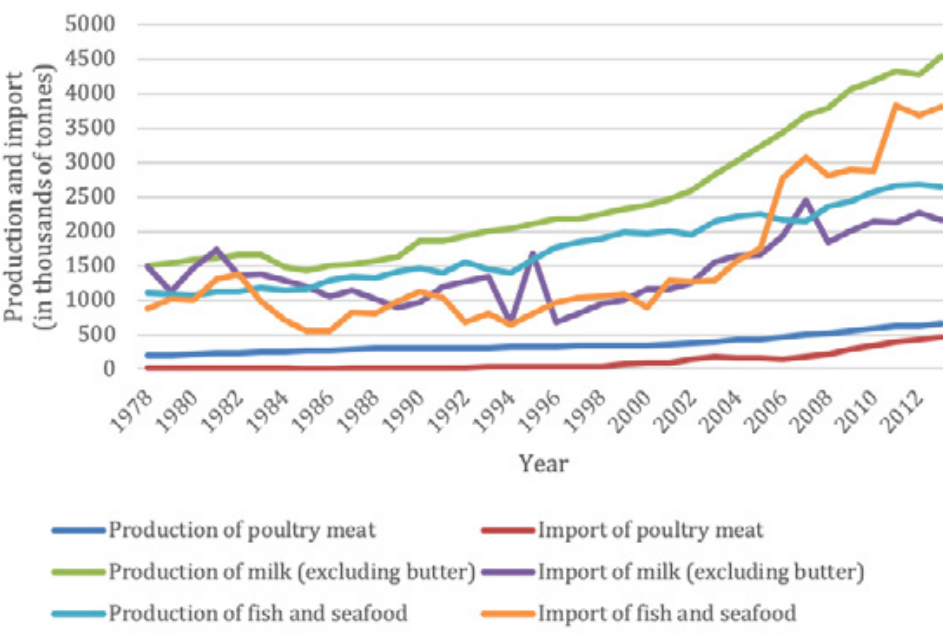

Figure 2.15 Production and Imports of Animal Products in West Africa, 1978-2013

Source: FAOSTAT, Food and Agriculture Organisation, Rome (accessed February 1, 2021)

Staatz $(2015,1)$ remarked,

While there has been a proliferation of retailing and fast-food formats in urban areas, the transformation of agro processing, which has a largely dualistic structure in the region, has been slower. Large-scale industrial processors dominate in many of the more dynamic industries, especially in rapidly growing processed, packaged and convenience foods and beverages. But because they often have problems obtaining reliable supplies of local raw products of consistent quality, they frequently rely on imported inputs.

There is a booming local agro-food sector dominated by family farms and mainly family-run small and medium enterprises. This mostly informal sector, which is not widely recognised by the authorities, is and remains responsible for overall food production, processing, and trade (especially based on domestic staples). It is also a major supplier of jobs, especially for women, in both rural and urban areas (Pozo-Vergnes and Vorley 2015; Lançon and Wade 2016). However, the quality of their output is variable, and wage levels are generally low.

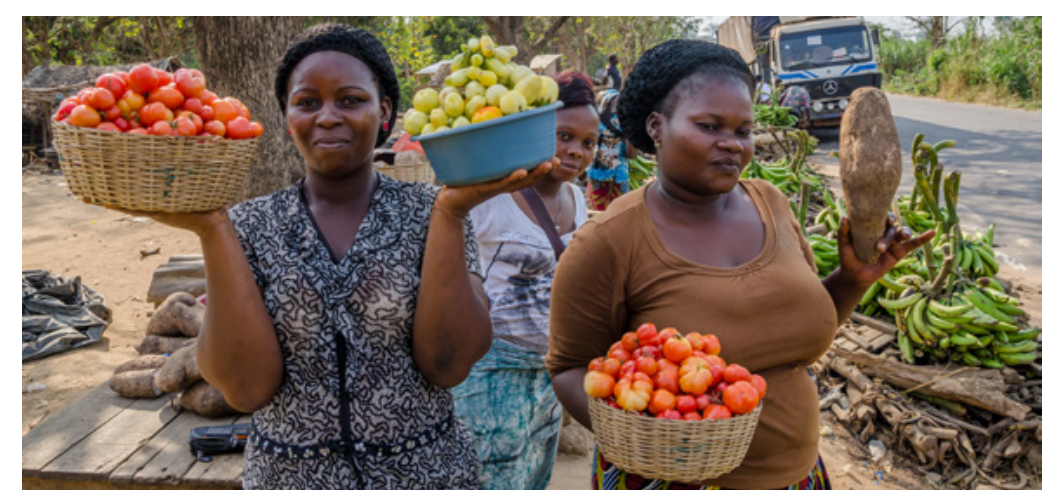

Looking at the food markets, constraints of accessibility to food appear more worrying for poor people than the problems of competitiveness of local products. Modernising existing informal wholesale and retail markets through improved transport and storage, adequate market infrastructures, and loans to small and medium enterprises that are active in trade and processing remain the main recommendations (Bricas et al. 2016).

Without denying the necessity that production must follow rising demand, these trends imply greater attention to the postharvest segments of the food chains: storage and conservation, wholesaling, and retailing. It also underscores the importance of national and ECOWAS policies on a wide range of strategic foods. In other words, public concerns about food insecurity can no longer be restricted to the staple grains, although these account for a major share of caloric intake. Tubers and plantains, legumes, animal products (meat, dairy, and fish), oils, fruits, and vegetables now play a strategic role from a nutritional, economic, and cultural point of view (Bricas et al. 2016).

Although malnutrition due to moderate-severe food insecurity still occurs, on average, in 10 to 15 percent of West Africa's population, the region's overall caloric intake of 2,600 to 2,700 kilocalories per person per day approaches the world average of 2,800 kilocalories per person per day (figure 2.16). Affordability and accessibility are as key to food and nutrition security as agroecological potential and food availability.
(1) Background and understanding

Regional drivers

2.1 Brief history

2.2 Population and migration

2.3 Economic drivers and monetary policy

2.4 Environmental drivers

2.5 Conflict and insecurity

2.6 Technological drivers

2.7 Regional consumer trends

References

(3) Regional organisations

(4) Agro-pastoralism-based

(5) Grains-and-legumes-based

6) Rice-and-horticulture

(7) Coastal maritime fisheries

(8) Tropical mixed tree and

8 food crops systems

9 Toward enhanced resilience 


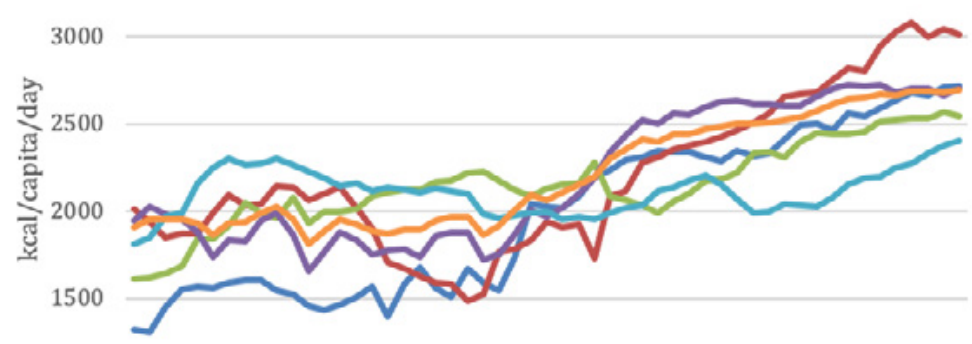

1000

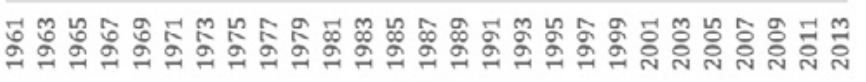

Year

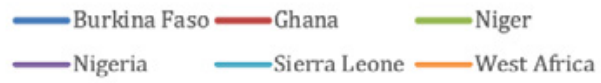

Figure 2.16 Calorie Intake in West African Countries, 1961-2013

Source: FAOSTAT, Food and Agriculture Organisation, Rome (accessed February 1, 2021)

Dietary diversity, a key element of nutrition security, is a determinant for the population's well-being. Poor people's diets tend to be high in starch (for example, roots and tubers such as cassava and cereals such as maize and rice) and low in dairy, meat, and vegetables. Several studies have specified that poor diets, leading to micronutrient deficiencies (for example, of iron, zinc, and iodine) affect more people's health than seasonal low calorie intake (De Fraiture 2014).

The food insecurity discourse changes in favor of more attention to nutrition, although many national policies in West Africa still focus on production and productivity of staple crops. Some positive results have been achieved in crop breeding by enriching cereals and roots with micronutrients and vitamins. Although enriching makes a contribution, it will not make the difference. More important are the current efforts of policy makers and agricultural researchers to broaden their view to include vegetables, dairy, meat, and fish in development policies for food and nutrition security.
Notes

1 The population of West Africa grew by 2.7 percent annually between 1990 and 2018, from 181 million to 381 million. Data retrieved.

Most agricultural imports, close to 90 percent until 2020, are food products, compared to just above 80 percent during most of the 1990 s. All food commodity sectors, with the exception of fruits and vegetables, are responsible for the increasing food trade deficit. Cereals are by far the eading item in the food import basket (Hollinger and Staatz 2015; see figure 2.14)

3 For example, Benin, Burkina Faso, Côte d'Ivoire, and Togo have high rates of population density, with Togo having population density rates thre times higher than those of the rest of Sub-Saharan Africa (data retrieved from World Development Indicators Database, World Bank, Washington, DC; accessed August 31, 2020). The Sahelian countries are those primarily located in the Sahelian zone of West Africa - namely, Burkina Faso, Cape Verde, the Gambia, Guinea-Bissau, Mali, Mauritania, and Niger. Chad is either part of the West or Central Africa region, although it is a member of the Permanent Interstate Committee for Drought Control in the Sahel (CILSS). It should be noted that the northern parts of many of the coastal countries in West Africa (for example, Benin, Togo, and Ghana) have climatic conditions that are similar to those of the Sahelian countries.

4 The primary destination for Burkina Faso and Mali is Côte d'Ivoire. The primary destination for Benin, Ghana, Mali, Togo and Niger is Nigeria. The primary destination for Liberia and Sierra Leone is Guinea. The primary destination for Senegal is the Gambia and France. The Burkina Faso-Côte $d^{\prime}$ Ivoire migration corridor is the second largest in Africa, following the corridor between Algeria and France (IMO UN Migration 2019).

5 While regional statistics are difficult to obtain, many of the regiona and domestic migration patterns across West Africa can be typified by the example of Niger. Between 2008 and 2017, 50 percent of Nigerien households had a migrant. The majority of these (40 percent) were seasonal migrants traveling for work during the dry season as opposed to migrating permanently (Aker et al. 2020). Further, 27 percent of migrants worked internally within Niger, with 15 percent migrating to Nigeria and 21 percent migrating to other destinations within West Africa - namely, Côte d'Ivoire, Ghana, and Senegal. Data on the drivers of migration in Niger show that migration is correlated with household size, education, and wealth. Perhaps surprisingly, climatic shocks (such as drought) are negatively correlated with the likelihood of migration.

6 United Nations Human Development Report (UN HDR) 2020 Human Development Data Centre (accessed 31 August 2020).

7 Foreign exchange comes from mining and agro-industrial crops. Countries that depend upon natural resources from the mining sector such as Nigeria (oil and gas), Niger (gas and uranium), Ghana (gold and oil), and
(1) Background and understanding

Regional drivers

2.1 Brief history

2.2 Population and migration

2.3 Economic drivers and monetary policy

2.4 Environmental drivers

2.5 Conflict and insecurity

2.6 Technological drivers

2.7 Regional consumer trends

References

(3) Regional organisations

(4) Agro-pastoralism-based

(5) Grains-and-legumes-based

6) Rice-and-horticulture

(7) Coastal maritime fisheries

(8) Tropical mixed tree and food crops systems

9 Toward enhanced resilience 
Burkina Faso and Mali (gold), are vulnerable to commodity price shocks. The agriculture sector depends on cocoa and rubber (Côte d'Ivoire and Ghana), cotton (Burkina Faso, Mali, Côte d'Ivoire, and Benin), oil palm (Ghana, Benin, and Côte d'Ivoire), and cashew (Benin and Guinea-Bissau).

8 This structural transformation seems to be different from that in other regions, where a decline in agriculture coincides with an increase in industry. In West Africa, the decline in agriculture seems to be associated with an increase in services (ADB 2018; data retrieved from World Development Indicators Database, World Bank, Washington, DC; accessed August 31, 2020).

9 WAEMU member states include Benin, Burkina Faso, Côte d'Ivoire, Guinea-Bissau, Mali, Niger, Senegal, and Togo. Six other countries (Cameroon, Central African Republic, Chad, Republic of Congo, Equatorial Guinea, and Gabon) also use the CFA franc and compose the Central African Economic and Monetary Community. Among these countries, Equatorial Guinea and Guinea-Bissau are former Portuguese colonies.

10 U.S. Department of State. Archive. Fact Sheet. West African Economic and Monetary Union (WAEMU).

11 Data from FAOSTAT, Food and Agriculture Organisation, Rome (accessed August 31, 2020). Data are not available for the years before 1990.

12 In the literature, the Sahara-Sahelian and Sudano-Sahelian zones are indicated as "pastoral" and "agropastoral" areas. Annual rainfall in the Sahel lies between approximately 250 and 600 millimeters, while in the Sudan it increases up to 800 millimeters.

13 Two other important river basins are the Chad (eight countries) and the Comoé (four countries).

14 The Gambia, Ghana, and Senegal invested 0.9 percent of their agricultural GDP in research in 2016; Benin (2016), Burkina Faso (2014), Côte d'Ivoire (2016), Liberia (2011), and Mauritania (2016), 0.5-0.6

percent; and Guinea (2016), Mali (2016), Niger (2016), Sierra Leone (2016), and Togo (2016), 0.2-0.3 percent. Guinea-Bissau did not invest in research according to latest data available (2011). Data in this section retrieved from ASTI (database), International Food Policy Research Institute, Washington, DC, (accessed August 31, 2020).

15 Global Database on Sustainable Land Management (accessed September 15, 2009).

\section{References}

ADB (African Development Bank). 2018. West Africa Economic Outlook 2018 Macroeconomic Developments and Poverty, Inequality, and Employment; Labour Markets and Jobs. Abidjan, Côte d'Ivoire: ADB.

Aker, Jenny C. 2015. "Are Rainwater Harvesting Techniques Profitable for Small-Scale Farmers? A Study on the Impacts of Adopting Rainwater Harvesting Techniques in Niger." Centre for International Environment \& Resource Policy, January 26, 2015.

Aker, Jenny C., Silvia Prina, and C. Jamilah Welch. 2020. "Migration, Money Transfers, and Mobile Money: Evidence from Niger." AEA Papers and Proceedings 110: 589-93.

Aryeetey, Ernest, and William Baah-Boateng. 2007. "Growth, Investment and Employment in Ghana." Working Paper No. 80, Policy Integration Department, ILO, Geneva.

Bangake, Chrysost, and Comlanvi Jude Eggoh. 2009. "The Impact of Currency Unions on Trade: Lessons from CFA Franc Zone and Implications for Proposed African Monetary Unions." Savings and Development 33 (1): $61-72$.

Beegle, Kathleen G., Luc Christiaensen, Andrew Dabalen, and Isis Gaddis. 2016. Poverty in a Rising Africa. Washington, DC: World Bank.

Boccara, Bruno, and Shantayanan Devarajan. 1993. "Determinants of Inflation among Franc CFA Countries in Africa." Policy Research Working Paper WPS 1197, World Bank, Washington, DC.

Bricas, Nicolas, Claude Tchamda, and Florence Mouton, eds. 2016. L'Afrique à la conquête de son marché alimentaire intérieur. Enseignements de dix ans d'enquêtes auprès des ménages d'Afrique de I'Ouest, du Cameroun et du Tchad. Collection Études de I'AFD 12. Paris: AFD.

Carrère, Céline. 2004. "African Regional Agreements: Impact on Trade with or without Currency Unions." Journal of African Economies 13 (2): 199-239.

CILSS (Permanent Interstate Committee for Drought Control in the Sahel). 2016. Landscapes of West Africa. A Window on a Changing World. Reston, VA: USGS.

Cotillon, Suzanne E. 2017. The Landscapes of West Africa. 40 Years of Change. US Geological Survey Fact Sheet 2017-3005. Reston, VA: USGS.

Coulibaly, Issiaka, and Junior Davis. 2013. "Exchange Rate Regimes and Economic Performance: Does CFA Zone Membership Benefit Their Economies?" MPRA Paper No. 54075, Université Paris-Est Créteil, Créteil, France.
(1) Background and understanding

Regional drivers

2.1 Brief history

2.2 Population and migration

2.3 Economic drivers and monetary policy

2.4 Environmental drivers

2.5 Conflict and insecurity

2.6 Technological drivers

2.7 Regional consumer trends

\section{References}

(3) Regional organisations

(4) Agro-pastoralism-based

(5) Grains-and-legumes-based

6) Rice-and-horticulture

(7) Coastal maritime fisheries

Tropical mixed tree and

8 food crops systems

9 Toward enhanced resilience 
Croitoru, Lelia, Juan José Miranda Montero, and Maria Sarraf. 2019. The Cost of Coastal Zone Degradation in West Africa: Benin, Cote d'Ivoire, Senegal, and Togo (English). Washington, DC: World Bank Group.

Curiel, Rafael Pietro, Philippe Heinrigs, and Inhoi Heo. 2017. Cities and Spatial Interactions in West Africa: A Clustering Analysis of the Local Interactions of Urban Agglomerations. West African Papers No. 5. Paris: OECD.

Dalerg Advisors, and CTA. 2019. The Digitalization of African Agriculture Report 2018-2019. Wageningen, the Netherlands: CTA.

De Fraiture, Charlotte. 2014. "Water and Food Trends in West Africa: Drivers and Change." Irrigation in West Africa: Current Status and a View for the Future, edited by R. E. Namara and H. Sally, 1-20. Colombo, Sri Lanka: IWMI.

ECOWAS (Economic Community of West African States) and SWAC (Sahel and West Africa Club Secretariat, Organisation for Economic Co-operation and Development). 2006. Transboundary River Basins: Atlas on Regional Integration in West Africa. Abuja, Nigeria: ECOWAS.

Elbehri, Aziz, and Marwan Benali. 2013. "A Historical Comparative Analysis of Commodity Development Models in West Africa and Implications for Staple Food Value Chains." In Rebuilding West Africa's Food Potential: Policies and Market Incentives for Smallholder-Inclusive Food Value Chains, edited by Aziz Elbehri, 43-81. Rome: FAO/IFAD.

Gnimassoun, Blaise. 2019. "Is WAEMU Integration Growth-Enhancing?" Revue d'économie politique 129 (3): 355-90.

GSMA (Global System for Mobile Communications Association). 2019. The Mobile Economy. West Africa 2019.

Hollinger, Frank, and John M. Staatz, eds. 2015. Agricultural Growth in West Africa: Market and Policy Drivers. Rome: ADB/FAO.

ICG (International Crisis Group). 2020. "The Central Sahel: Scene of New Climate Wars?" Crisis Group Africa Briefing No. 154, ICG, Brussels.

ICMPD (International Centre for Migration Policy Development) and IOM (International Organisation for Migration). 2015. A Survey on Migration Policies in West Africa. 2nd ed. Vienna: ICMPD.

International Labour Office (ILO). (2012) Understanding Deficits of Productive Employment and Setting Targets: A Methodological Guide. Geneva: ILO.

IOM and UN Migration. 2019. World Migration Report 2020. Geneva: IOM.

Kpadonou, Rivaldo A. Baba, Tom Owiyo, Bruno Barbier, Fatimata Denton, Franck Rutabingwa, and Andre Kiema. 2017. "Advancing Climate-SmartAgriculture in Developing Drylands: Joint Analysis of the Adoption of Multiple
On-Farm Soil and Water Conservation Technologies in West African Sahel." Land Use Policy 61 (February 2017): 196-207.

Läderach, P., A. Martinez-Valle, G. Schroth, and N. Castro. 2013. "Predicting the Future Climatic Suitability for Cocoa Farming of the World's Leading Producer Countries, Ghana and Côte d'Ivoire." Climate Change 119: 841-54.

Lançon, Frédéric and Idrissa Wade. 2016. Urbanisation, Changing Tastes and Rural Transformation in West Africa. London: IIED.

Masson, Paul, and Catherine Pattillo. 2004. "A Single Currency for Africa?" Finance and Development, December 2004, 8-15.

Maur, Jean-Christophe, and Ben Shepherd. 2015. Connecting Food Staples and Input Markets in West Africa: A Regional Trade Agenda for ECOWAS Countries. Report No. 97279-AFR. Washington, DC: World Bank.

Miles, William F. S. 2005. "Development, Not Division: Local Versus Externa Perceptions of the Niger-Nigeria." Journal of Modern African Studies 43 (2): 297-320.

Mueller, Bernd and Man-Kwun Chan. 2015. Wage Labour, Agricultural-based Economies and Pathways out of Poverty. Taking Stock of the Evidence. LEO Report \#15. Washington, DC: USAID.

Nitsch, Volker. 2002. "Comparing Apples and Oranges: The Effect of Multilateral Currency Unions on Trade Is Small." Technische Universität Darmstadt, March 4, 2002.

OCHA (United Nations Office for the Coordination of Humanitarian Affairs). 2020. Sahel Crisis: Overview of Humanitarian Needs and Requirements. Humanitarian Program Cycle 2020. Published May 2020.

Pattillo, Catherine, Charalambos Tsangarides, and Pierre van den Boogaerde. 2008. "Growth and Convergence in the CFA Franc Zone." In The CFA Franc Zone: Common Currency, Uncommon Challenges, edited by Anne Gulde and Charalambos Tsangarides, 299-334. Washington, DC: IMF.

Pozo-Vergnes, Ethel del and Bill Vorley. 2015. Global or Local Food Chains? Uncovering the Dilemmas in Senegal and Peru. London: IIED.

Reij, Chris, and Robert Winterbottom. 2015. Scaling Up Regreening: Six Steps to Success. A Practical Approach to Forest and Landscape Restoration. Washington, DC: World Resources Institute.

RPCA. 2015. Climat, changement climatique \& resilience. Cartes \& faits. Paris: $\mathrm{CSAO} / \mathrm{OCDE}$

Smale, Melinda, Gray Tappan, and Chris Reij. 2018. "Farmer-Managed Restoration of Agroforestry Parklands in Niger." In Fostering Transformation and Growth in Niger's Agricultural Sector, edited by Fleur Wouterse and Ousmane Badiane, 19-34. Wageningen: Wageningen Academic Publishers.
(1) Background and understanding

Regional drivers

2.1 Brief history

2.2 Population and migration

2.3 Economic drivers and monetary policy

2.4 Environmental drivers

2.5 Conflict and insecurity

2.6 Technological drivers

2.7 Regional consumer trends

\section{References}

(3) Regional organisations

(4) Agro-pastoralism-based

(5) Grains-and-legumes-based

6) Rice-and-horticulture

(7) Coastal maritime fisheries

Tropical mixed tree and

8 food crops systems

9 Toward enhanced resilience 
Staatz, John. 2015. Impact of Urbanisation on West African Food Systems. The Sahel \& West Africa Week. 26-30 October 2015. Milan, Italy.

Staatz, John, and Frank Hollinger. 2016. West African Food Systems and Changing Consumer Demands. West African Papers 4. Paris: OECD.

Stads, Gert-Jan and Nienke Beintema. 2017. An Assessment of the Critical Financial, Human and Institutional Capacity Issues Affecting Agricultural Research in West Africa: Synthesis and Policy Considerations. Washington, DC: IFPRI and World Bank.

Strong, Christine. 2018. "Did Mali Benefit from Joining the CFA Zone? An Analysis Using the Synthetic Control Method." SSRN, August 14, 2018.

Sultan, Benjamin, Philippe Roudier, and Seydou Traoré. 2017. "The Impacts of Climate Change on Crop Yields in West Africa. In Rural Societies in the

Face of Climatic and Environmental Changes in West Africa, edited Benjamin. Sultan, Richard Lalou, Mouftaou Amadou Sanni, Amadou Oumarou, and Mame Arame Soumaré, 199-251. Paris: IRD.

SWAC (Sahel and West Africa Club Secretariat, Organisation for Economic Co-operation and Development). 2009. Regional Atlas on West Africa. Paris: OECD.

SWAC (Sahel and West Africa Club Secretariat, Organisation for Economic Co-operation and Development). 2020a. The Geography of Conflict in North and West Africa. Paris: OECD.

SWAC (Sahel and West Africa Club Secretariat, Organisation for Economic Co-operation and Development). 2020b. "Severe Food Security Has Tripled in the UMEAO Area." Maps \& Facts, no. 91.

Sy, Amadou N. R. 2016. "The Role of the CFA Franc in the Economic Integration of the West Africa Region." PowerPoint presentation at the Second International Conference on Sustainable Development in Africa, Dakar, Senegal, November 26-27, 2015.

Tchatchouang, Jean-Claude. 2015. "The CFA Franc Zone: A Biography." In The Oxford Handbook of Africa and Economics. Vol. 2: Policies and Practices, edited by Célestin Monga and Justin Yifu Lin, 114-29. Oxford, UK: Oxford University Press.

Traoré, Jean Abel. 2013. "Revisiting the Determinants of Informal Sector in Burkina Faso." Economic Research Guardian 3(2): 111-45.

UN (United Nations) and World Bank. 2018. Pathways for Peace: Inclusive Approaches to Preventing Violent Conflicts. Washington, DC: World Bank.

UNOWAS (United Nations Office for West Africa and the Sahel). 2018. Pastoralism and Security in West Africa and the Sahel: Towards Peaceful Coexistence. Dakar: UNOWAS.
USAID (United States Agency for International Development). 2013a. West Africa Environmental Threats and Opportunities Assessment. Washington, DC: USAID.

USAID (United States Agency for International Development). 2013b. Climate Change and Water Resources in West Africa: Transboundary River Basins. Washington, DC: USAID.

Weng, X. 2015. The Rural Informal Economy: Understanding Drivers and Livelihood Impacts in Agriculture, Timber and Mining. London: IIED.

Woittiez, Lotte, Katrien Descheemaeker and E. Ken Giller. 2015. Adoptability of Sustainable Intensification Technologies in Dryland Smallholder Farming Systems of West Africa. Research Report 64. Telangana, India: ICRISAT

Yehoue, Etienne B. 2007. "The CFA Arrangements. More Than Just an Aid Substitute?" IMF Working Paper 07/19, IMF, Washington, DC, January 1, 2007.

Zougmoré, R., A. S. Traoré, and Y. Mbodj, eds. 2015. "Overview of the Scientific, Political and Financial Landscape of Climate-Smart Agriculture in West Africa." Working Paper 118, CGIAR Research Program on Climate Change, Agriculture and Food Security, Copenhagen, Denmark, June 15, 2015.

Zougmoré, Robert B., Samuel T. Partey, Mathieu Ouédraogo, Emmanue Torquebiau, and Bruce M. Campbell. 2018. "Facing Climate Variability in Sub-Saharan Africa: Analysis of Climate-Smart Agriculture Opportunities to Manage Climate-Related Risks." Cahiers Agricultures 27 (3): 34001.
(1) Background and understanding

Regional drivers

2.1 Brief history

2.2 Population and migration

2.3 Economic drivers and monetary policy

2.4 Environmental drivers

2.5 Conflict and insecurity

2.6 Technological drivers

2.7 Regional consumer trends

\section{References}

(3) Regional organisations

(4) Agro-pastoralism-based

(5) Grains-and-legumes-based

6) Rice-and-horticulture

(7) Coastal maritime fisheries

(8) Tropical mixed tree and

8 food crops systems

9 Toward enhanced resilience 


\section{Regional organisations}

By Fabien Tondel and Bruce Byiers

3.1 Formal regional agri-food processes and policies 3.2 Regional political economy issues References

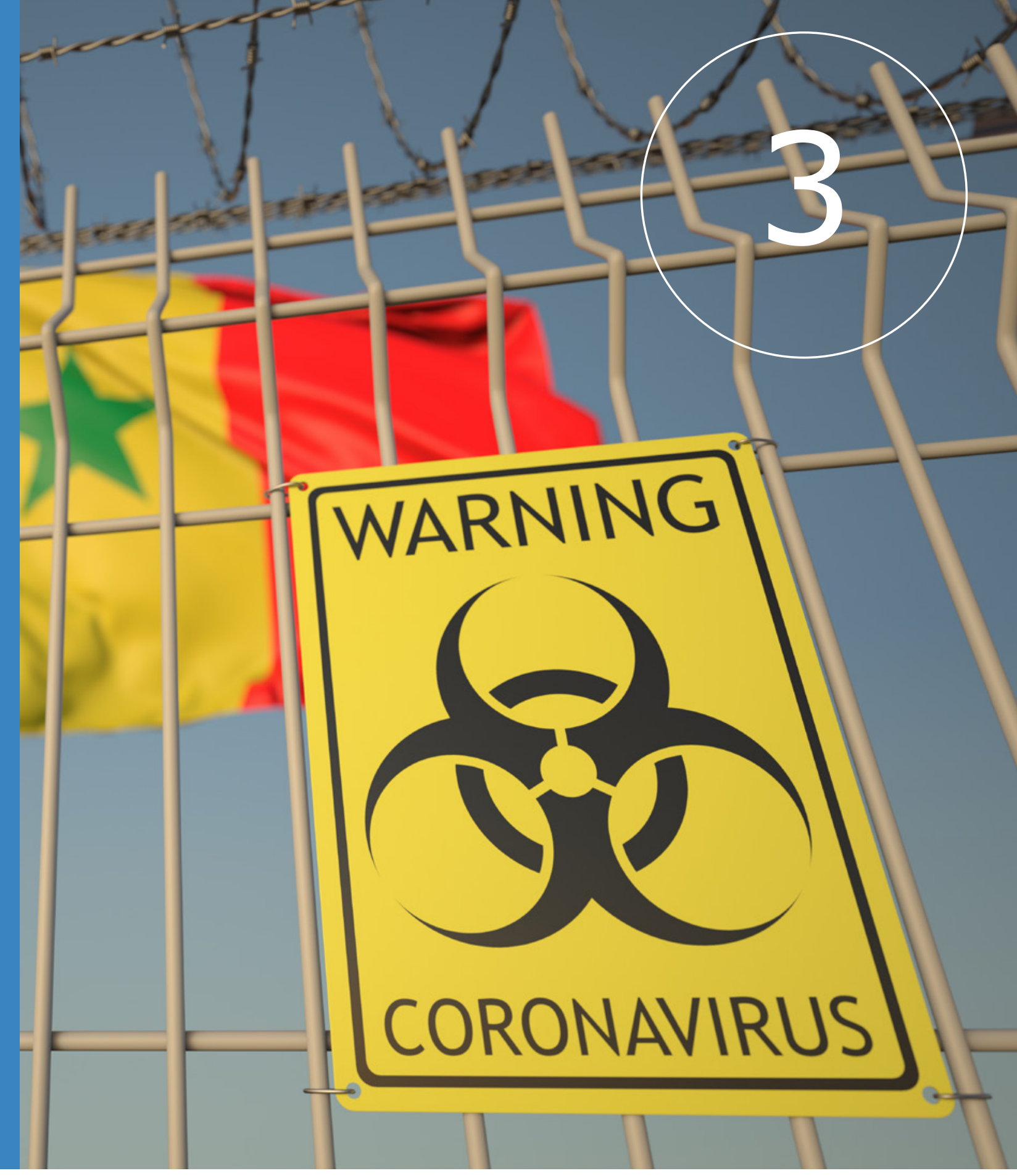




\subsection{Formal regional agri-food processes and policies}

Since 2005, in West Africa, the Economic Community of West African States (ECOWAS) has led regional organisation in the areas of agriculture and food. Among the eight regional economic communities (RECs) recognised by the African Union (AU), ECOWAS was established first in 1975. As the mandate of ECOWAS expanded over the next four decades, various institutions, organs, and systems were put in place to implement its regional integration agenda. Although ECOWAS still largely depends on donors for funding to implement its policies, it is the only African REC with its own resources generated from a ommunity levy on imports, which are used to finance its operational costs and some of its programs.

\subsubsection{ECOWAS agricultural policy}

Following consultation with stakeholders led by the ECOWAS Commission, heads of state and government adopted the ECOWAS agricultural policy (ECOWAP) in 2005. The overarching objective of the ECOWAP was to "contribute in a sustainable way to meeting the food needs of the population, to economic and social development, to the reduction of poverty in the Member States, and thus to reduce existing inequalities among territories, zones and nations" (ECOWAS 2005, p. 5). The process leading to ECOWAP was accompanied by the Comprehensive Africa Agriculture Development Programme (CAADP). The AU launched CAADP in 2002 in response to the underdevelopment of the agricultural sector and the rising risk of food insecurity throughout Africa, with the objective of supporting smallholder farmers. ${ }^{1}$ Building on the common agricultural policy of the West African Economic and Monetary Union (WAEMU), a subgroup of eight mostly Francophone countries, the process leading to ECOWAP/CAADP progressed rather slowly.

The 2008 food price crisis resulted in strong mobilisation of national governments, regional organisations, stakeholders, and development partners around the ECOWAP/CAADP and in an acceleration of the process. As ruling elites felt threatened by food price hikes and ensuing urban riots, new resources were quickly mobilised, and a flurry of national and regional initiatives were launched. In this context, the CAADP set higher standards for policy making and programming processes, inclusive of nonstate stakeholders, evidence-based policy planning, and coordination between sectors, which improved the quality of agricultural and food policies at the national and regional levels.

West African governments responded to the crisis with measures to increase cereal production, usually with the stated objective of attaining national self-sufficiency. Those policies emphasised farm production with heavy reliance on input subsidies. Although effective in boosting agricultural output, such an approach neglected productivity growth and the removal of obstacles to marketing and the development of value chains, especially downstream activities. It also remained ambiguous about the trade-off between supporting subsistence farming and encouraging a shift toward more commercially oriented agriculture. National investment plans elabourated through the CAADP/ECOWAP process gave little attention to creating incentives for private investment in agri-food production, processing, and distribution. Yet, in West Africa, the negative effects of the 2008 crisis were largely due to the poor performance of agri-food markets and trade and to issues of access to food for vulnerable households rather than to food availability. It would then take several years for market issues, including regional market integration, to gain more visibility in the regional policy agenda with the notions of competitiveness and coordination of actors in agri-food value chains.

3.1.2 ECOWAP implementation progress

A number of programs emerged to implement ECOWAP/CAADP. Rice was selected as a strategic sector, which led to the Regional Offensive for the Sustainable Revival of Rice Production in West Africa, launched in 2014. (Initially, the Rice Offensive was copiloted by the WAEMU Commission). This initiative aimed to increase rice production and modernise the supply chain. After 2008, many West African governments strongly supported the rice sector through investments in irrigation, processing, and storage infrastructure, and through spending on input and credit subsidies for producers. Yet, as most of the rice output in West Africa is from rain-fed farms, those policies mainly benefited only a minority of rice producers with access to irrigated land. (This was also the case for maize, albeit to a lesser extent.) In addition, both national and regional
(1) Background and understanding

(2) Regional drivers

Regional organisations

3.1 Formal regional agri-food processes and policies

3.2 Regional political economy issues References

(4) Agro-pastoralism-based

(5) Grains-and-legumes-based

6) Rice-and-horticulture

(7) Coastal maritime fisheries

(8) Tropical mixed tree and

8 food crops systems

9 Toward enhanced resilience 
programs paid little attention to the regulation of overseas imports and complementarities in production within cross-border market catchment areas. In Burkina Faso, for example, the National Rice Development Strategy formulated after the 2008 crisis did not take into account the regional dimension of the rice sector, not even ECOWAS trade policies.

In 2015 ECOWAS set the common external tariff (CET) for rice at 10 percent as its member states sought to safeguard their populations' access to rice. The Network of Farmer Organisations and Agricultural Producers in West Africa (ROPPA), the leading representative of West African farmers' interests, which played a key role in the formulation of the ECOWAP, strongly but unsuccessfully advocated for a higher import tariff on rice. National trade policies continued to dominate as some member states (Ghana and Nigeria in particular) applied different customs duties and additional levies. Discrepancies in import tariffs and trade regulations between countries have driven illegal transshipments of overseas rice. Smuggling between Benin and Nigeria is a notable example, among other cases that have become entrenched in local economies and politics. While providing opportunities for rent seeking by actors controlling transshipment channels, frequent changes in the Nigerian trade policy have also created instability in the domestic rice market as well as in neighbouring countries. A recent example is the 2019 ban on land imports of rice and other products.

Livestock was also selected as a strategic sector, which led to the ECOWAS West African livestock development action plan. As part of ECOWAP 2025 and the second regional agricultural investment program of ECOWAS (PRIA-SAN), two major initiatives have been launched. The first is the Regional Investment Program for Livestock Development in Coastal Countries (PRIDEC), which complements programs targeting Sahelian countries, notably the Regional Support Project for Sahel Pastoralism (PRAPS). The second is the local milk offensive, the objective of which is to promote investment in the local milk sector. The regional dialog on the livestock sector has progressed under the growing influence of networks of livestock keepers organisations, in particular the Réseau Billital Maroobé (RBM), Association pour la Promotion de I'Élevage au Sahel et en
Savane (APESS), and the Confédération des Fédérations Nationales de la Filière Bétail Viande de I'Afrique de l'Ouest (COFENABVI-AO), as well as the security concerns raised by intensifying farmerpastoralist conflicts in recent years.

There are regional regulatory frameworks regarding the movement of livestock across borders and an international transhumance certificate. However, coastal and Sahelian countries do not always have the same perspective on these issues, which leads to poorly coordinated national regulations. The approach of the Sahelian countries to transhumance has been somewhat accommodative, with a historical tendency to let the herds graze where pastoral conditions are best, as long as tensions with local communities remain limited. Coastal states have become increasingly stringent as they try to better control the movement of transhumant livestock, partly due to increasing pressures on land resources. Thus, in practice there is little harmonisation in how ECOWAS countries regulate the mobility of livestock (APESS 2015). Each tends to take ad hoc, inadequately communicated measures, sometimes against regional agreements and regulations (Thébaud 2017).

A third notable initiative is the establishment of the Regional Food Security Reserve as an instrument to manage food crises,

complementing national and local community stocks of staple foods. The Regional Reserve is made of two components: national stocks of staple foods pooled among member states (one-third) and a common financial reserve (two-thirds). The primary use for the grain stocks is to address humanitarian crises. A first physical stock of more than 11,000 tonnes of cereals (maize, millet, sorghum, and rice) was assembled in 2017 in four member states (including Nigeria) by pooling parts of their national stocks (OECD/SWAC, 2018). Since that time, the stock has been expanded to about 30,000 tonnes. It was first used the same year to respond to a food crisis in northeastern Nigeria and again in 2018 in several countries. Some producer organisations have offered to supply commodities to the Regional Reserve. The operations of the Regional Reserve follow the Charter for Food Crisis Prevention and Management (PREGEC), a set of principles agreed upon by member states. The fact that ECOWAS has so far succeeded in putting in place this instrument is a sign that the regional organisation has to certain extent gained
(1) Background and understanding

(2) Regional drivers

Regional organisations

3.1 Formal regional agri-food processes and policies

3.2 Regional political economy issues References

(4) Agro-pastoralism-based

(5) Grains-and-legumes-based

6) Rice-and-horticulture

(7) Coastal maritime fisheries

8 Tropical mixed tree and

8 food crops systems

9 Toward enhanced resilience 
buy-in from national political leaders and is capable of collective action.

The ECOWAS Commission has proven to have the institutional capacity and political leadership to lead regional agricultural and food policy processes; convene public, business, and civil society actors to carry out multistakeholder consultations (in particular through the Advisory Committee for Agriculture and Food), and produce sound regional policies and regulations. The CAADP process advanced faster in West Africa than in any other region in Africa, both at the country and regional levels. The commission has been able to commit significant financial resources of its own to support those processes, though it still relies heavily on international donors (including for the Regional Reserves). The operationalisation of the fledgling Regional Food and Agriculture Fund in 2019, which is intended to support the Regional Reserve and implement programs and projects of ECOWAP, has so far been modestly funded from the ECOWAS budget (Inter-réseaux Développement rural, 2018). The commission has shown a significant level of bureaucratic capability, including in the establishment of the Regional Agency for Agriculture and Food (RAAF) in 2013, which is in charge of overseeing programs and projects.

ECOWAS can rely on science and technical expertise from several regional and international organisations whose mandates partially overlap with its own. In particular, the Permanent Interstate Committee for Drought Control in the Sahel (CILSS), a longestablished organisation of West African states, has provided critical information and tools for promoting agricultural development, sustainable natural resources management, and managing food crises. Established in 1973 following a major drought in the Sahel, it has played an important role in the prevention and management of food crises in West Africa and currently coordinates the main regional mechanism for this purpose, PREGEC. Although CILSS still depends on international funding, over time it has gained its own scientific and technical expertise. It also provides critical agroclimatic information (with the AGRHYMET Centre); contributes to market and food security assessments, though it is sometimes limited by the data that member states are able, or willing, to produce; conducts socioeconomic research (with the Institut du
Sahel); and delivers training services for technical staff in national administrations. Building on its role in the process of reforming cereal markets in the 1980s, CILSS supported the ECOWAP process and was an early promoter of the regional food reserves as an instrument to address emergency food assistance needs.

The ECOWAS Commission also benefits from a range of expertise based in the region that can support the implementation of the ECOWAP, including the West and Central Africa Council for Agriculture Research and Development (CORAF), ${ }^{2}$ the Centre International de Recherche-Développement sur I'Élevage en zone Subhumide (CIRDES), the Regional Animal Health Centre (RAHC), AfricaRice, the International Institute of Tropical Agriculture (IITA), and the West and Central Africa Network Agricultural and Rural Advisory Services (RESCAR-AOC). ${ }^{3}$

Yet, despite some real capacity issues to carry out implementation, the ECOWAS Commission has had little power and incentives to implement the ECOWAP/CAADP and other regional policies, agreements, or protocols affecting agriculture and food. One illustration of this weakness is the fact that the ECOWAP has not led to any major regional cooperation initiatives on export commodities (cocoa, coffee, cotton, cashew, groundnut, or palm oil) to generate more value from raw agricultural products destined to either international markets or emerging consumer markets in the region. Despite multiple common challenges and opportunities in the fisheries and aquaculture sector (shared stocks; illegal, unregulated, and unreported fishing; and trade), little progress has been made on the ECOWAS fisheries and aquaculture regional policy.

Such is also the case for trade policy. In the framework of the ECOWAS Trade Liberalisation Scheme (ETLS), the ECOWAP aims to remove barriers to intraregional trade so as to enhance flows of food commodities and livestock from producing areas to consumption markets and create investment opportunities for agricultural producers and other stakeholders of the private sector. Although customs duties for agricultural products have been largely eliminated, in principle there are still many nontariff barriers to trade, notably between WAEMU and non-WAEMU countries. Traders and transporters often must go through multiple border posts and
(1) Background and understanding

(2) Regional drivers

Regional organisations

3.1 Formal regional agri-food processes and policies

3.2 Regional political economy issues References

(4) Agro-pastoralism-based

(5) Grains-and-legumes-based

6) Rice-and-horticulture

(7) Coastal maritime fisheries

(8) Tropical mixed tree and

8 food crops systems

9 Toward enhanced resilience 
redundant border-crossing procedures, and pay bribes to go through borders, which increases travel time and transport costs. During food crises, governments often impose export restrictions to protect domestic consumers.

\subsection{Regional political economy issues}

3.2.1 From regional ambitions to practice

Much of what has been discussed here regards formal processes or institutions. This is the more visible aspect of regional policies and commitments that aim to promote and shape agri-food systems in West Africa, taken through regional organisations at the request of and in agreement with heads of state.

However, these more formal dynamics are accompanied by less visible dynamics that relate to informal ways of working within and between states, whether within government or the private sector, and that affect policy implementation and outcomes. State-business relations, rent seeking, and rent distribution often shape which regional agendas are implemented and how, with variations across sectors or value chains, as well as how national elites perceive "national interests." These can run counter to regional agreements, frustrating those pushing the formal agenda. Further, country leaders seek to satisfy different agendas through different regional structures, all combining to create a complex, dynamic context of regional agricultural policy outcomes within and between countries.

Beyond these less visible incentives and interests, regional policies and external support primarily focus on formal activities, actors, and processes, with a danger of ignoring the often hidden losers from particular policies, including women smallholders and the large number of informal economic activities that provide a basis for livelihoods in West Africa. Many market intermediaries involved in cross-border agri-food supply chains, livestock flows linked to transhumance and marketing, and even the processing sector largely operate in the informal sector. These entities are rarely represented in formal regional policy fora yet must be understood and taken into account when designing and supporting regional approaches to agri-food systems.

\subsubsection{Between-state relations}

ECOWAS and WAEMU are the key formal bodies through which regional policies are made, with seemingly growing coordination and alignment. The fact that the ECOWAS CET was largely based on the WAEMU CET, for example, is evidence of how the two regional bodies interact and can complement one another. But inconsistencies between the two remain, as mentioned. Although partly a question of alignment, these differences also reflect divergence in objectives among countries.

As work on the political economy of ECOWAS suggests, the WAEMU group often operates as a bloc within ECOWAS (Vanheukelom 2017). This reflects another important characteristic of the region: the importance of Nigeria in supporting or undermining regional initiatives. In the case of the CET, a new tariff band was added at Nigeria's insistence. In 2019 Nigeria was also undermining the ETLS through its unilateral border closures, ostensibly to address smuggling. Yet, this measure was also linked to tensions between the Beninese and Nigerian ruling political and economic elites. The WAEMU grouping is therefore also a form of solidarity among the mainly Francophone states, allowing common positions to be sought prior to discussion through ECOWAS (even if this has not so far affected Nigeria's unilateral trade policy). Different monetary and exchange rate policies between WAEMU countries, whose currency is pegged to the euro, and other ECOWAS countries also make it difficult to develop and integrate the regional market. The lack of currency convertibility in Ghana and Nigeria, for example, has created black markets for foreign exchange, which favor informal trade and affect the structure of economies of neighbouring countries.

Similarly, ECOWAS member states deal with, discuss, and finance agri-food system-related issues through a range of other regional fora: Mali, Burkina Faso, and Niger are also members of the Liptako-Gourma Authority, which prioritises agricultural and pastoral issues for cooperation among states. Membership of other regional bodies, such as the Mano River Union, and other river and lake basin management organisations, such as for the Niger, Volta, and Senegal Rivers, also clearly affect agri-food systems through their role in governing river water for irrigation, often competing with hydroenergy demands (Medinilla 2019).
(1) Background and understanding

(2) Regional drivers

Regional organisations

3.1 Formal regional agri-food processes and policies

3.2 Regional political economy issues References

(4) Agro-pastoralism-based

(5) Grains-and-legumes-based

6) Rice-and-horticulture

(7) Coastal maritime fisheries

(8) Tropical mixed tree and

8 food crops systems

9 Toward enhanced resilience 
Although regional bodies can be seen as technical bodies, they also, unavoidably, reflect politics between their member states, with potential implications for how policies are formed or implemented in other regional fora, such as ECOWAS. Further, they are heavily reliant on external finance, thus offering their members multiple options to finance regional and cross-border projects in the agriculture and related sectors.

3.2.3 Regional commitments and national politics

ECOWAP is a clear example of regional food security commitments made in the spirit of solidarity among states following a crisis. After 2008, with technical and financial support, policy-makers undertook a technocratic process of preparing regional and national compacts. However, even before the crisis had passed, political priorities lay with national self-sufficiency, implying different levels of real engagement in the regional process between producers and suppliers of different goods and between landlocked and coastal states, as well as state-business involvement in trade in key goods. With weak monitoring and enforcement of regional commitments, it is generally easier for leaders to sign on to regional commitments than to implement them, especially those related to multiple overlapping regional bodies.

Functioning of agri-food markets is not just about technical and logistical issues but also about rents, power relations between different groups between and within countries, and control of markets. Of course, these differ between value chains, not just because of the different nature of production and trade but also because of the relative capacity for production based on imports, state-business relations around import trade, location of production versus that of principal markets (hinterland to coast), and how these interact with domestic power relations and politics. Understanding these factors helps shed light on the Nigeria's unilateral decision to close its borders as well as the fact that regional commitments in the context of ECOWAP have only partially translated into implementation by member states.

As such, the degree of implementation of the ECOWAS agricultural and trade policies continues to reflect national level interests, often related to dominant concerns about national food sovereignty and the relations between political elites and well-connected influential economic operators.

3.2.4 Within states: sector actors and interests

Political traction in regional food security or agricultural policies varies depending on the political and cross-border characteristics of particular products. Because rice is an important staple food that is largely imported, rice-related policies affecting market access and production play out mainly at the national level because of political elites' protectionist and social stability concerns. Politically connected importers, cross-border trade networks, and rent-seeking mechanisms involve both private and public actors, thus hindering the market and trade reforms implied by the Rice Offensive.

Rice in Burkina Faso illustrates these dynamics clearly, as urban rice consumption is still increasing and the country has potential for rice production but still has low productivity, maintaining a dependency on imported rice. The stakes for powerful and well-connected cartels in national-level rice imports remain substantial. Burkina Faso relies on regional and overseas imports of food to satisfy part of the food consumption of its rapidly urbanising population (Vanheukelom 2017).

Regional rice dynamics contrast with those of the livestock sector, where a different picture emerges, one less affected by imports. Ruminant livestock in West Africa rely on extensive production systems that derive their viability from cross-border mobility of cattle from the hinterland north to the urbanised south. This mobility, based on natural complementarities between agroecological zones and on informal rules that regulate exchanges between pastoralists and farmers, is firmly rooted in history and tradition. However, it has been increasingly hampered by encroachment on pastoral resources due to the extension of farmland and urbanised areas. Climate change and the increasing incidence of extreme weather add strain on these relations.

Although livestock inherently involves cross-border dynamics and processes with strong regional policy implications, a range of structures and informal institutions still play a key role in how the value chain operates and where money is made. For example, the
(1) Background and understanding

(2) Regional drivers

Regional organisations

3.1 Formal regional agri-food processes and policies

3.2 Regional political economy issues References

(4) Agro-pastoralism-based

(5) Grains-and-legumes-based

(6) Rice-and-horticulture

(7) Coastal maritime fisheries

(8) Tropical mixed tree and

8 food crops systems

9 Toward enhanced resilience 
livestock meat value chain in the central trade basin (Côte d'Ivoire, Burkina Faso, and Mali) has been strongly shaped by the politicomilitary crises of the early twenty-first century in Côte d'Ivoire. During the first crisis, the Forces Nouvelles controlled the northern half of the country, enabling a network of traders to consolidate their positions in livestock trading with the south. As a result, these traders wield considerable power over the value chain, not least through the COFENABVI-AO.

The resulting concentration of trading activities in the hands of a few operators after the war, who also invest in other stages of the value chain, now risks marginalising herders and informal smallscale intermediaries. These underlying dynamics around the control of production and trade networks pose problems for reforming the formal rules for domestic markets and regional cross-border movement in favor of the inclusion of herders and small-scale traders in the value chain. It also makes it more difficult for new innovative actors to enter the livestock meat market. In combination with the issues highlighted previously, these developments risk damaging the livelihoods of vulnerable populations and possibly the local milk sector, which in West Africa is closely linked to pastoral and agropastoral systems. Alongside formal regional policy processes, those dynamics in market structures are seen in other agri-food sectors in the context of weak formal regulatory institutions at the national level.

In both the rice and livestock value chains and subsectors, therefore, there is an intricate mix of state and nonstate actors involved. While there is a cross-country and regional characteristic to the livestock subsector in particular, state-business relations in the countries are such that there is weak organised pressure behind regional cooperation. These dynamics are likely to play out differently for different subsectors, but nonetheless remain fundamental to regional agri-food policy processes. Understanding and monitoring the underlying political and economic factors is critical for anticipating blockages to reforms and investments in regional agri-food systems due to vested interests but also for identifying areas where the interests of different actors may align as economic and political conditions shift.
Notes

1 In 2003, to support the implementation of the CAADP, the African heads of state pledged through the Maputo Declaration on Agriculture and Food Security in Africa to allocate at least 10 percent of national budgets to the agricultural sector.

2 CORAF covers ECOWAS and the Economic Community of Central African States (ECCAS).

3 RESCAR-AOC is affiliated with the African Forum for Agricultural Advisory Services and the Forum for Agricultural Research in Africa.

\section{References}

APESS (Association pour la Promotion de l'Élevage au Sahel et en Savane). 2015. Éviter la crise de l'élevage: Point de vue de I'APESS sur la situation de l'élevage en Afrique de I'Ouest depuis 2005.

ECOWAS (Economic Community of West African States) Commission. 2005. Twenty-eighth session of the Authority of Heads of State and Government. Decision A/DEC.11/01/05 adopting an agricultural policy for the Economic Community of West African States - ECOWAP. Accra, 19 January 2005.

Inter-réseaux Développement rural. 2018. "I'Afrique de l'Ouest est-elle mieux préparée face aux crises alimentaires ?" Grain de sel, no. 76.

Medinilla, Alfonso, and Martin Ronceray, with Amagoin Keita and Brahima Fomba. 2019. Entre coopération et contestation les intérêts maliens dans la gestion des fleuves transfrontaliers du Sahel. Document de réflexion No. 247. Maastricht, the Netherlands: ECDPM.

OECD/SWAC (Organisation for Economic Co-operation and Development, Sahel and West Africa Club Secretariat). 2018. West Africa Brief No. 258. Paris: OECD.

Thébaud, B. 2017. Pastoral and Agropastoral Resilience in the Sahel: Portrait of the 2014-2015 and 2015-2016 Transhumance (Senegal, Mauritania, Mali, Burkina Faso and Niger). Copenhagen: Nordic Consulting Group. In collabouration with ISRA-BAM and CIRAD.

Vanheukelom, J. 2017. "Understanding the Economic Community of West African States: Political Traction with Africa's Oldest Regional Organisation." Background paper, ECDPM, Maastricht, the Netherlands.
(1) Background and understanding

(2) Regional drivers

Regional organisations

3.1 Formal regional agri-food processes and policies

3.2 Regional political economy issues

\section{References}

(4) Agro-pastoralism-based

(5) Grains-and-legumes-based

6) Rice-and-horticulture

(7) Coastal maritime fisheries

8 Tropical mixed tree and

8 food crops systems

9 Toward enhanced resilience 


\section{Agro-pastoralism- based food systems}

By Joost Nelen

\subsection{Definitions}

4.2 Demography and geography

4.3 Regional consumption and production trends

4.4 Livelihoods of agro-pastoralists

4.5 Production systems

4.6 Food system outcomes

4.7 Institutional drivers

4.8 Risks and resilience

4.9 Food system impacts of and responses to the COVID-19 pandemic

4.10 Agency and development paradigms

4.11 Summing up: toward leverage points for future interventions

References

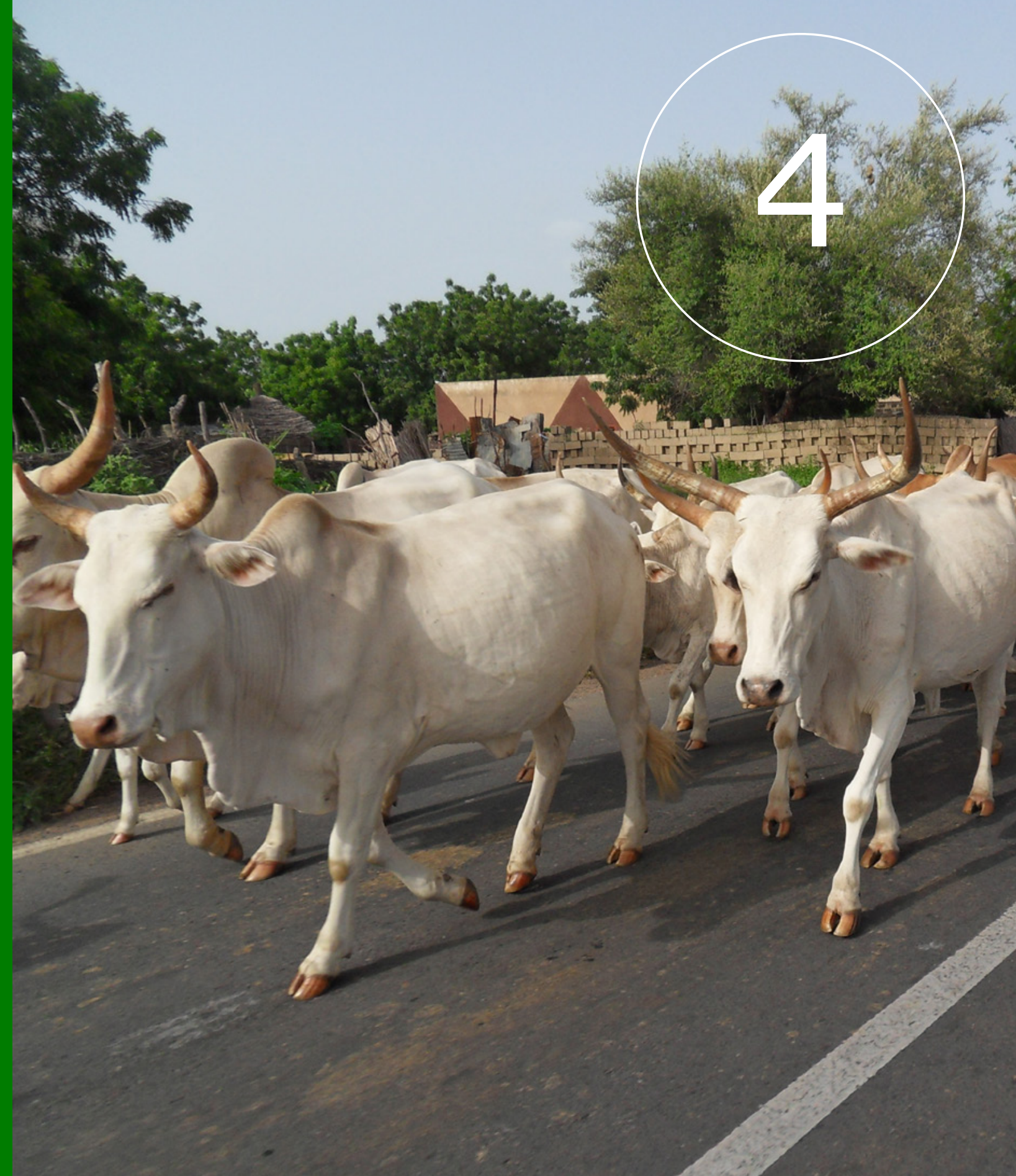


This chapter contains a description and an analysis of pastoralismand agro-pastoralism-based food systems in West Africa. The chapter has 11 sections. The first section defines pastoral and agropastoral systems, followed by a discussion of their demography and geography. Section 4.3 describes production and consumption trends; section 4.4, livelihoods; and section 4.5, production systems. Section 4.6 covers the various system outcomes, section 4.7 addresses institutional drivers, and section 4.8 identifies trends, risks, and systems resilience. Section 4.9 indicates some effects of the COVID-19 pandemic, followed by a section on agency and development paradigms. The final section outlines some conclusions about leverage points for enhanced resilience of agro-pastoralismbased food systems.

\subsection{Definitions}

Definitions of pastoralism are not uniform and vary from a strict definition of a livelihood based on transhumance or nomadism to the broader involvement of all households practicing some form of mobile livestock keeping (Inter-réseaux 2017). All definitions imply a degree or proportion of grazing and travel mobility, combined with other activities (Ickowicz et al. 2012; Krätli et al. 2015; see also Turner and Schlecht 2019). Pastoralism and agro-pastoralism imply livelihoods wherein mobile livestock keeping remains the principal source of food and revenue. Hence, this chapter relies on a stricter notion of agro-pastoralism than most other studies, which can include all dryland crop-livestock systems (see Boffa et al. 2020; Inter-réseaux 2018). Pastoralism is more frequent in West Africa's dryland areas (typically the Sahara-Sahel zone). Agro-pastoralism refers to livelihoods in the Sahel-Sudan zone, and even in the Sudan-Guinea zone in coastal countries, where all or part of a family has settled for at least part of the year. However, it excludes animal husbandry and livestock rearing in mixed crop-based systems by 'agrobreeders'. Besides in the Sahel areas, examples of agro-pastoralism are found in the cotton and groundnut belts of Senegal, Mali, and Burkina Faso.

Pastoralism has both socioeconomic and sociocultural features (see section 4.2 ), though these may not necessarily overlap anymore.
People may identify as pastoralist but live in town away from the herds. Absentee livestock ownership is on the rise, whereby

livestock keeping is outsourced to herders such as hired labourers or relatives. It is therefore important to distinguish livestock management from ownership. In this food systems analysis, the definition is closely tied to the socioeconomic characteristics of pastoralism and agro-pastoralism (hereafter referred to as 'agropastoralism'), where forms of transhumance and herd management remain key activities associated with, but not limited to, livestock ownership.

When referring to agro-pastoralism-based food systems, the author refers to all related value chains, institutions, and agencies specific to these systems and their contribution to the diets of nonpastoralist consumers. The food system attains its characteristics and internal logic through feedback loops between its components. As such, resilience is created to respond to external shocks. Therefore, agro-pastoralism-based food systems are defined here as food systems based on agro-pastoralist livelihoods and production systems wherein a form of transhumance or nomadism is still significant and through which livestock products are produced for household consumption and external consumer markets.

\subsection{Demography and geography}

Depending on the definition of pastoralism, researchers report between 17 and 25 million agro-pastoralists in West Africa, including Nigeria (AU 2010; FAO 2018; UNECA 2017; UNOWAS 2018). ${ }^{1}$ Agro-pastoralists amount to 17 percent of the population of Sahel countries. The agro-pastoralist population is growing at an estimated rate of 2.5 to 3.0 percent per year, similar to rates in other Sahelian countries. Livestock growth is variable, around 3.3 percent per year over the past 18-20 years, but exceeded 2.5 percent per year over a longer period, including during a major drought in the 1980 s (see also section 4.3). Agro-pastoralism covers a wide area in West Africa (map 4.1).
(1) Background and understanding

(2) Regional drivers

(3) Regional organisations

Agro-pastoralism-based

4.1 Definitions

\subsection{Demography and} geography

4.3 Regional consumption and production trends

4.4 Livelihoods of agro-pastoralists

4.5 Production systems

4.6 Food system outcomes

4.7 Institutional drivers

4.8 Risks and resilience

4.9 The COVID-19 pandemic

4.10 Agency and development paradigms

4.11 Summing up References

(5) Grains-and-legumes-based

6) Rice-and-horticulture

(7) Coastal maritime fisheries

8 Tropical mixed tree and

8 food crops systems

9 Toward enhanced resilience 


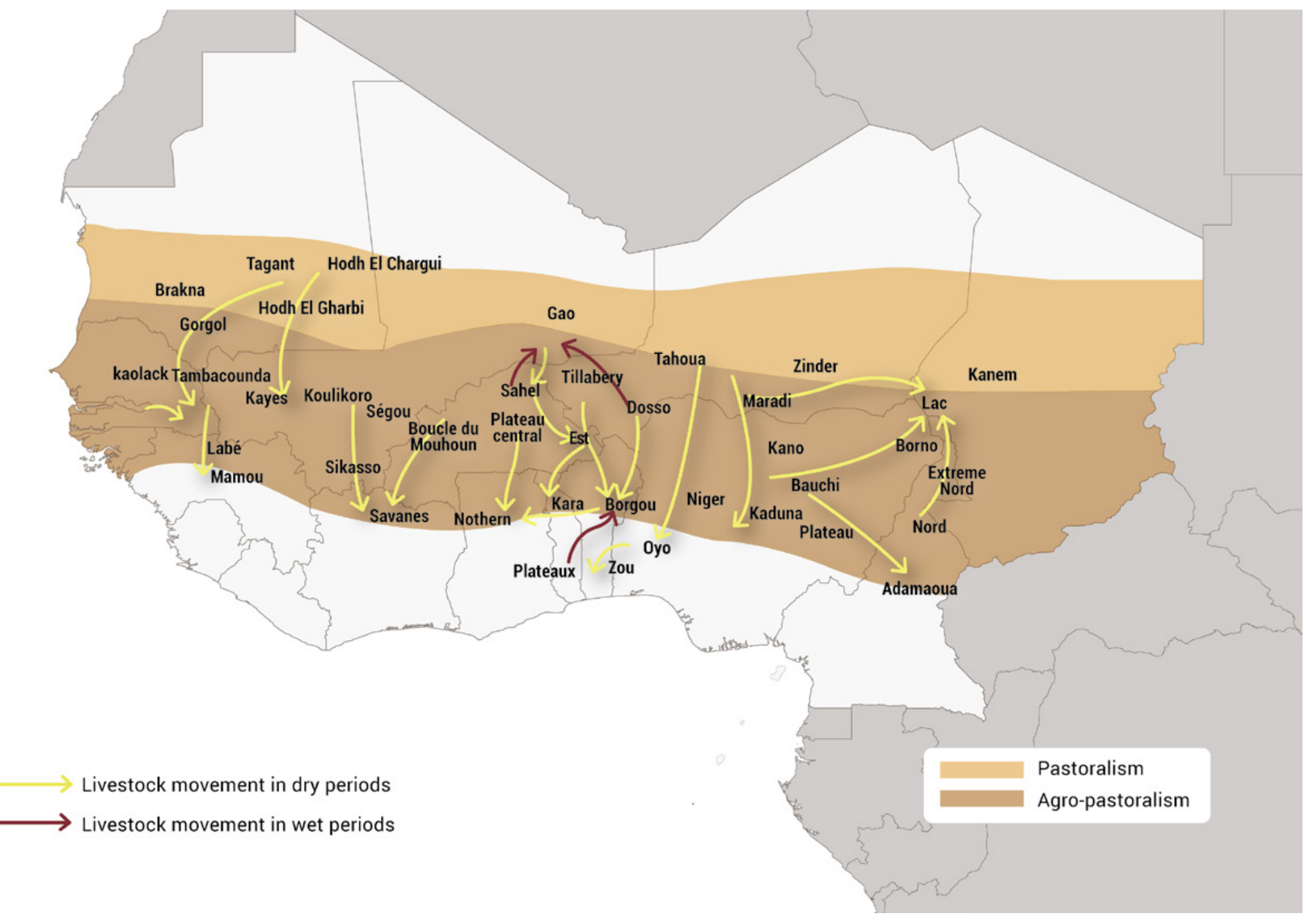

Map 4.1 Pastoral and Agro-pastoral Areas in West Africa

Source: OECD/SWAC (2009)

(1) Background and understanding

(2) Regional drivers

(3) Regional organisations

Agro-pastoralism-based

4.1 Definitions

4.2 Demography and geography

4.3 Regional consumption and production trends

4.4 Livelihoods of

agro-pastoralists

4.5 Production systems

4.6 Food system outcomes

4.7 Institutional drivers

4.8 Risks and resilience

4.9 The COVID-19 pandemic

4.10 Agency and development paradigms

4.11 Summing up References

(5) Grains-and-legumes-based

6) Rice-and-horticulture

(7) Coastal maritime fisheries

8 Tropical mixed tree and

8 food crops systems

9 Toward enhanced resilience 


\subsection{Regional consumption and production trends}

In West Africa around 57 and 163 million heads of cattle and small ruminants, respectively, were raised in $2018 .^{2}$ These figures exclude Nigeria, which raised 21 million heads of cattle and 122 million small ruminants. Of all animals raised in West Africa, excluding Nigeria, the Sahel countries (Burkina Faso, Mali, Niger, Senegal, and Mauritania) produced 72 percent of heads of cattle and 79 percent of small ruminants in $2018 .{ }^{3}$ Agro-pastoralist systems contain 61-67 percent of both cattle and small ruminants and, of course, 100 percent of dromedaries (Corniaux et al. 2018; Inter-Réseaux
2018; Nugteren and Le Côme 2016). Between the 1980s and 2014, the bovine population in West Africa multiplied by 2.5 , and the caprine population almost quadrupled to 100,000 million (Didier et al. 2019). The annual growth rate for both cattle and small ruminants has remained at 3.3 percent since 2002 . The growth rate for agro-pastoralist livelihoods lies around 2.7-2.9 percent. Since the late 1980s, other households have also invested in ruminants, and livestock has expanded to more humid areas. The 2013 meat supply was 3.68 million tons, of which ruminants composed 2 million tons. Meat imports were around 556,000 tons, most of which was poultry (462,000 tons) (figure 4.1 ).

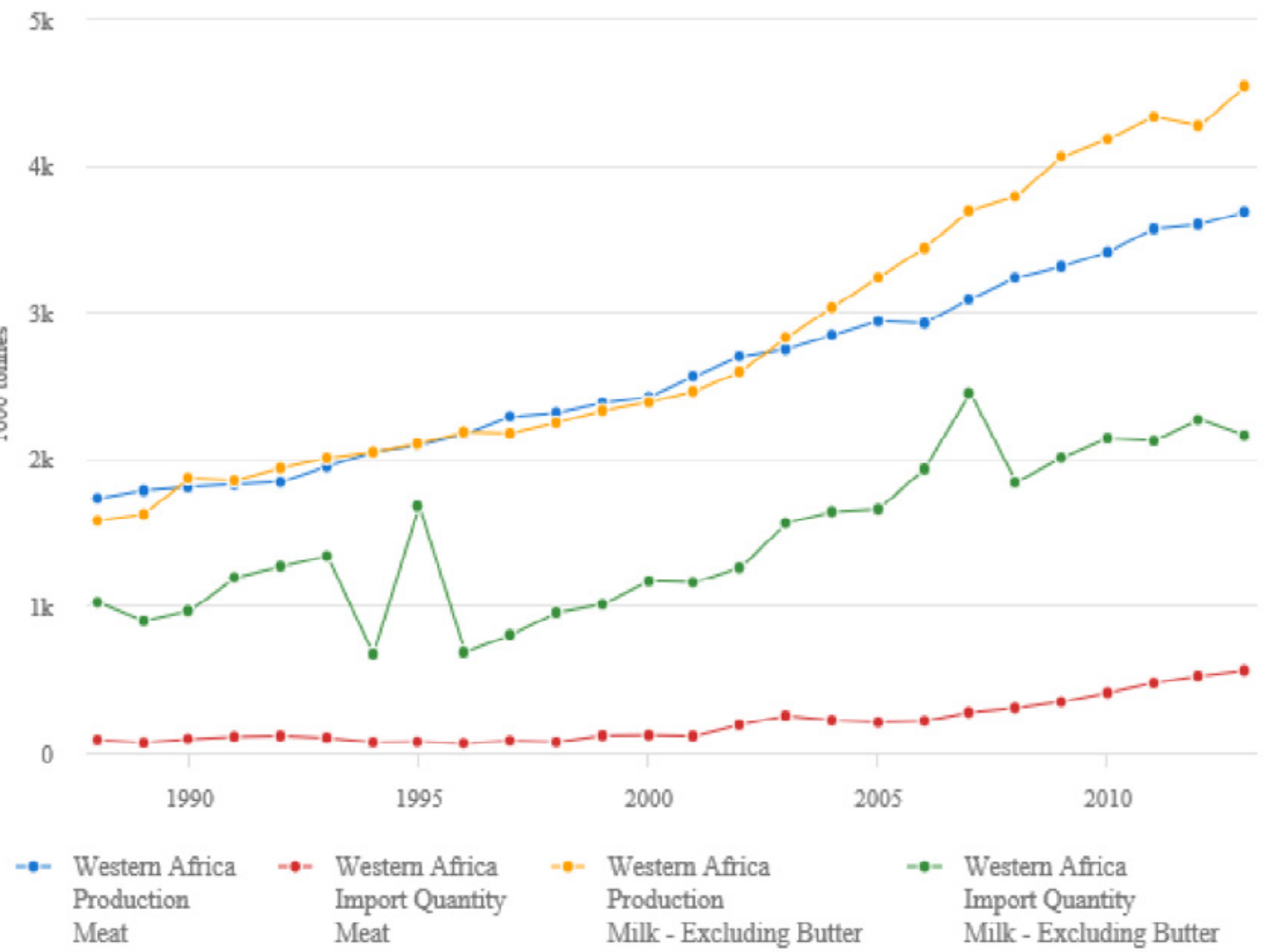

Figure 4.1 West African Meat and Milk Production and Import Quantities, 1988-2013

Source: FAOSTAT, Food and Agriculture Organisation, Rome (accessed August 31, 2020).

(1) Background and understanding

(2) Regional drivers

(3) Regional organisations

Agro-pastoralism-based

4.1 Definitions

4.2 Demography and geography

\subsection{Regional consumption} and production trends

4.4 Livelihoods of agro-pastoralists

4.5 Production systems

4.6 Food system outcomes

4.7 Institutional drivers

4.8 Risks and resilience

4.9 The COVID-19 pandemic

4.10 Agency and development paradigms

4.11 Summing up References

(5) Grains-and-legumes-based

6) Rice-and-horticulture

(7) Coastal maritime fisheries

8 Tropical mixed tree and food crops systems

9 Toward enhanced resilience 
The average consumption of animal meat varies in the countries between 10 and 20 kilograms per habitant per year (an average of 13 kilograms per habitant per year), which is far below the averages in the European Union, United States, and Southern Cone Common Market (Mercosur), which exceed 75 kilograms per habitant per year. ${ }^{4}$ There are differences between wealth groups, such that the rich classes spend 6 to 10 times more on meat than the poorest households (Bricas et al. 2016). Three zones can be distinguished here: First, in the Sahel countries (Burkina Faso, the Gambia, Mali, Mauritania, Niger, Senegal, and Nigeria), the meat of ruminants represents 36-76 percent of the value of consumed animal products, but with the exception of Burkina Faso, the value of poultry does not exceed 20 percent (Bricas et al. 2016). ${ }^{5}$ Next, the coastal countries are divided into the Gulf of Guinea (Benin, Côte d'Ivoire, and Ghana), where 12-39 percent of the animal products' value comes from ruminants (mainly beef), 4-12 percent from poultry, and the rest from other sources such as bush meat; in the Southwest Atlantic coast (Guinea, Liberia, Sierra Leone, and Togo), ruminants and poultry each take 8-25 percent of the value of consumed animal products. In the coastal zones, aquatic products are most important. ${ }^{6}$ The agro-pastoralist system delivers a major portion of ruminant meat for the first two zones. Ghana, Côte d'Ivoire, and Nigeria are the main importers of this meat from the Sahel.

Far more than self-provisioning, food markets supply 86 percent of consumed meat (as a weighted average for 230,000 households in 15 West African countries) (Bricas et al. 2016). In rural areas, 75 percent originates from purchase. In those areas, the share of market purchase is particularly high for beef ( 92 percent), relatively low for poultry (45 percent, or less than 20 percent in rural areas of such countries as Burkina Faso, Guinea, and Sierra Leone), 62 percent for small ruminants, and 66 percent for pigs. Almost all meat in urban areas is bought at marketplaces ( 95 percent of consumption).

Dairy products have different sources, from scattered local production and trade by agro-pastoralists to suburban value chains around dairy factories (4.54 million liters in 2013) to milk powder imports (2.16 million liters in 2013) (Inter-réseaux 2017). Milk plays a strong role in food security and subsistence for agropastoralists. Local production and consumption of dairy products is variable outside agro-pastoral areas: up to 80 percent in rural Sahel-Sudan areas to less than 20 percent in coastal areas. Milk consumption increases with population growth, and consumption per capita varies from 15 to 25 kilograms per habitant per year in coastal areas and from 30 to 60 kilograms per habitant per year in the Sahel (Inter-réseaux 2017). Especially in urban environments and coastal areas, milk powder is important. Fatted milk (degreased milk completed with vegetable fats such as palm oil) has become important because it is cheaper than fresh milk and more affordable for poor households. In 201750 percent of imported milk powder was fat filled. Nevertheless, there is considerable room for growth for local dairy products with collabouration between producers and industrial and semi-industrial processors (Corniaux 2015; Corniaux and Duteurtre 2018)

Local milk production has grown considerably in the past two decades. The agro-pastoralist systems form the heart of this production. Nevertheless, it is unlikely that within current circumstances the agro-pastoralist system can follow rising demand for several reasons. Corniaux (in Inter-réseaux 2017, 18) stated "From 1960 to 2015 consumption has been multiplied by 4.7, while production has grown by 4.1." Further, the mobile system is hampered by reduction in availability of and access to pastoral natural resources (see section 4.8). Growth of herds in the more humid (Sudan) areas is oriented at animals for traction and meat as much as, or even more than, for milk due to the influence of agrobreeders and absentee owners. Milk farms exist but hardly contribute to local milk collection because of their limited number and high investment risk. Numerous mini dairy industries have been created, especially in the Sahel countries, covering less than 5 percent of milk production, with capacities of 50-250 liters per day. Milk multinationals have installed industries since 2010, including Danone, Nestlé, Sodiaal, Lactalis, Arla, Glanbia, and Friesland-Campina in Nigeria. The big dairy industries depend considerably on milk powder, especially in the dry season. Some make genuine efforts to collect local milk (Sodiaal, Lactalis, Friesland-Campina) because of diversification of supply or corporate responsibility or both (Inter-réseaux 2017).
(1) Background and understanding

(2) Regional drivers

(3) Regional organisations

Agro-pastoralism-based

4.1 Definitions

4.2 Demography and geography

\subsection{Regional consumption} and production trends

4.4 Livelihoods of agro-pastoralists

4.5 Production systems

4.6 Food system outcomes

4.7 Institutional drivers

4.8 Risks and resilience

4.9 The COVID-19 pandemic

4.10 Agency and development paradigms

4.11 Summing up References

(5) Grains-and-legumes-based

6) Rice-and-horticulture

(7) Coastal maritime fisheries

8 Tropical mixed tree and

8 food crops systems

9 Toward enhanced resilience 


\subsection{Livelihoods of agro-pastoralists}

Agro-pastoralist livelihoods are based on the extended family as the production and decision unit for re- and destocking, sales,

investments, and expenses. Agro-pastoralists are mostly members of broad social communities with proper languages and distinct cultural identities linked to livestock keeping or nomadism. The distinction between a household and a larger community is often small. Gonin and Gautier $(2015,5)$ observed a persistence of socioprofessional and sociocultural differences despite long-standing community interactions and a convergence of production activities:

Historically, FulBe people [also Fulani or Peuhl] were by far the biggest cattle owners in Burkina Faso. FulBe people still herd $70 \%$ of the total cattle population... although they own only $55 \%$ of national livestock and represent only $11 \%$ of herders. As such, in social representations, FulBe are seen as pastoralists even when they have been settled for decades on land they currently use to grow crops, and they are still contrasted with other ethnic groups who are considered to be farmers.... Even though farmers usually entrust the care of their herd to sedentary FulBe (Bassett 1994), the social and political permanency that opposes farmer and herder communities is strange since both combine farming and herding activities. Despite the convergence of the two rural systems, FulBe people are nevertheless considered by others (and by themselves) culturally and economically herders, even if the majority are now sedentary and share closed territoriality with farmers. Due to this social and cultural permanency, and due to very different practices typical of pastoral mobility (Turner et al. 2014), the legacy of two co-existing territorial systems is still very meaningful.

Traditionally, livelihoods are characterised by a distribution of tasks and income. Men tend to be more oriented toward keeping large ruminants and dromedaries, while women are more focused on small ruminants. Women and young men may own productive capital (livestock), which are often integrated into bigger herds (Ickowicz et al. 2012). Livestock trade and subproducts such as skins and hides are mainly the responsibility of adult men, while women have activities such as dairy trade and services in nearby food markets. Young men are involved as herders and may be accompanied by women, as in the case of family transhumance.

Contemporary pastoralist livelihoods have become diversified. In the Sahel-Sudan areas, mobile livestock farming is not a pastoralist privilege. Agrobreeders as well as agro-pastoralists can outsource their "bush" herds to salaried herders who are not necessarily members of the extended family. In the case of agro-pastoralists, these herders generally are recruited by wealthy families living closely to urban centres. Case studies in the cotton and groundnut cereal belts confirm the socioprofessional interaction and the mixing of practices.

Livelihoods are subject to various external influences, such as (agricultural) land encroachment, climate shocks and conflict, mobility restrictions enforced by governments (see sections 4.6 and 4.8 ), and internal aspirations, for example, of young people. Due to population growth, a segment of young people have left the production system to settle in towns - for example, desiring more stable access to services or jobs) - while the extended family remains. ${ }^{8}$ Literacy rates are low, especially among women. Access to basic services (education and health) is a challenge in most rural areas but even more complex in transhumant or nomad environments.

Researchers have tried to identify the total number of livestock needed for different pastoralist households. They have estimated the living minimum of tropical livestock units (TLUs) in a household economy of six to seven persons to be 50-80 as permanent stock in pastoralism, and 20-30 in agro-pastoralism (in Nugteren and Le Côme, 2016; Manoli et al, 2014 on Senegal). ${ }^{9}$ Thébaud et al. (as cited in Nugteren and Le Côme 2016; also De Haan et al. 2016) estimate 3-5 TLUs per active person. Other reports of smaller herds indicate either livestock mixed with other livelihoods (such as mixed-cereal-based systems) or livestock of impoverished agropastoralist households, which are incapable of keeping a minimum level of livestock (Boffa et al. 2020).
(1) Background and understanding

(2) Regional drivers

(3) Regional organisations

Agro-pastoralism-based

4.1 Definitions

4.2 Demography and geography

4.3 Regional consumption and production trends

\subsection{Livelihoods of} agro-pastoralists

4.5 Production systems

4.6 Food system outcomes

4.7 Institutional drivers

4.8 Risks and resilience

4.9 The COVID-19 pandemic

4.10 Agency and development paradigms

4.11 Summing up References

(5) Grains-and-legumes-based

6) Rice-and-horticulture

(7) Coastal maritime fisheries

8 Tropical mixed tree and

8 food crops systems

9) Toward enhanced resilience 
A significant portion of agro-pastoralist households in the SaharaSahelian zone belong to the poor and very poor wealth categories (Dixon and Holt 2010; AGVSAN 2014; ENSAN 2018). ${ }^{10}$ Figures for Mali and Burkina Faso vary between 45 and 60 percent of households. ${ }^{11}$ The middle or medium groups compose a considerable part of the households, representing 20 to 35 percent. The better-off households compose 10 to 20 percent. The share of better-off households is higher in purely pastoralist environments than in mixed agro-pastoralist environments, where the medium group is far larger. Livestock is the main asset. Medium and betteroff households have at least 35 heads of cattle and more than 70 dromedaries (the composition depends on the area), as well as $50-100$ heads of small ruminants. Poor and very poor households do not have enough livestock (hardly any cattle and 10-25 heads of small ruminants) to get sufficient revenues from sales. Whereas medium and better-off households can get 80 percent or more from sales of livestock, livestock sales for the poor or very poor represent 15-25 percent of revenues. Instead, these households must sell their labour (herding, in agriculture) to make enough income.

\subsection{Production systems}

Extensive pastoralist livestock rearing is based on using natural resources (water, pasture, salty soils), generally without improving them. Dongmo et al. $(2012,1)$ stated that for agro-pastoralism,

the herding territory is mainly composed of three subelements endowed with different access rights: the "attachment territory" and "peripheral territory", with rangelands that are exploited by "house herds" [or "milk herds"] on a daily basis, and the "territories distant from the residential area" that serve for transhumance and the relocation of a second group of herds known as the "bush herd". These territories and herds are managed by mobilising local knowledge and juggling a combination of factors, including the availability of plant biomass on different pastoral units, access rights and agreements with local stakeholders regarding resources, the date the rains arrive and the progress of sowing and harvesting in the fields.
Complementary sources, such as fodder, might also be used. Fattening of ruminants based on nearby pastures and feed has developed rapidly in more humid Sudan areas. Although this has become economically viable, it will not replace mobile systems in volume and in meat quality (van der Lee et al. 2014). Another reason is that sedentary breeders, thus, can avoid the harassment that transhumant pastoralists often encounter.

Pastoralist systems enable higher production per hectare than sedentary or ranching systems by careful selection of productive natural resources (Breman and De Wit as cited in De Haan 2016 and van der Lee et al. 2014; Inter-réseaux 2018). Sedentary systems are more productive in terms of animal production per head of livestock but have higher economic costs for meat production (CFAF 750 per kilogram versus CFAF 2,500 per kilogram) (Inter-réseaux 2017; Inter-réseaux 2018). Despite several state efforts supporting sustainable sedentary or ranching livestock systems funded by the German Agency for International Cooperation (GIZ) and World Bank, these systems never took off in West Africa. Private ranching often implies land acquisition through capital investments by urban elites, excluding pastoralists. These systems also depend on natural resources outside the ranches. ${ }^{12}$

Between 60 and 80 percent of livestock have been located in the more humid Sahel-Sudan areas since the 1990s (Inter-réseaux 2017; Inter-réseaux 2018; Touré et al. 2012). In Burkina Faso, "farmers who invest the money they make on cash crops in cattle... now own 45 percent of national livestock and represent 89 percent of livestock owners" (Gonin and Gautier 2015, 5). Apart from the growth of agrobreeder herds, an important change since the 1970 s has been the displacement of the so-called "Fulani" herds towards the Sudan areas. Narratives suggest that climate shocks are behind the migration. The droughts of the 1970 s and 1980s would have forced pastoralists, supported by national policies or not, to seek pastoral resources in the south, which had previously been avoided because of the risk of trypanosomiasis and onchocerciasis and the poor grass quality. Bassett and Turner $(2006,33)$ add nuance to this view: ${ }^{13}$
(1) Background and understanding

(2) Regional drivers

(3) Regional organisations

Agro-pastoralism-based

4.1 Definitions

4.2 Demography and geography

4.3 Regional consumption and production trends

4.4 Livelihoods of agro-pastoralists

\subsection{Production systems}

4.6 Food system outcomes

4.7 Institutional drivers

4.8 Risks and resilience

4.9 The COVID-19 pandemic

4.10 Agency and development paradigms

4.11 Summing up References

(5) Grains-and-legumes-based

6) Rice-and-horticulture

7) Coastal maritime fisheries

(8) Tropical mixed tree and

8 food crops systems

9 Toward enhanced resilience 
This "sudden push" hypothesis places Sahelian herds in savanna pastures in a matter of a 1-3 years. This stimulusresponse model runs counter to our observations and understanding of the social and ecological processes

influencing FulBe herd movements.... The southerly expansion of FulBe herds has proceeded according to a more complex temporal frame that includes generational, biological, and social historical timeframes and periodicities... These mobility patterns are linked to contingent factors such as cattle diseases, drought, and political instability, as well as to more structural and adaptive features such as the establishment of social networks, herding contracts, and cattle cross-breeding. Shifts in livestock ownership and the social differentiation among herders are important variables for understanding changes in herd movements.

In addition, van der Lee et al. $(2014,5)$ write,

During the droughts, part of the animals was sold by desperate pastoralists to investors, who then hired caretakers to manage the herds. This change in ownership resulted in changes of traditional grazing practices. Nevertheless, migration continues to be essential to maintain productivity of pastoralist systems, leading to new challenges and opportunities for pastoralist re-organisation.

Changed ownership and migration to new areas could reorient production to favour meat and traction at the expense of milk cows, although this is more likely in mixed crop-based systems of agrobreeders (Thébaud and Diallo. as cited in Nelen, Traoré, and Coulibaly 2015). The community interactions and mixing of practices do not necessarily mean that the systems converge:

One should not forget that compared to northern pastoralists' areas, livestock rearing is of recent date in the cotton-grain belts. With the exception of agro-pastoralists, livestock and grazing areas seem to have remained the closing entry in management of farming systems: the division of family labour is not adapted to bigger herds, nor to their composition. For instance, keeping older, male animals has benefits for agriculture (traction), but can lead to poor monetary value of herds if we look from a livestock rearing perspective. The indefinite status of forest- and grazing lands favours land clearing. (Nelen, Traoré, and Coulibaly 2015, 8)14

\subsection{Food system outcomes}

In this section, multiple food system outcomes are considered, including household food and nutrition security, income, trade and employment, sustainability, and equity and inclusion.

\subsubsection{Household food and nutrition security}

The main diets of people with agro-pastoralist livelihoods are based on cereals and meat enriched with milk. The direct availability of milk for young children is one of the system's advantages. However, milk consumption mainly concerns the medium and better-off households, where dairy products satisfy 30 percent of food needs. For poor or very poor households, the share of milk is lower, around 10 percent (Dixon and Holt 2010). ${ }^{15}$ Nutritional habits hardly change over time: households consume calories in the form of cereals, animal proteins, and fats daily, and eat vegetables, fruits, and pulses two to four times per week (AGVSAN 2014; ENSAN Mali 2018 (2016); ENSAN 2013; VIA 2015). ${ }^{16}$ Rice has joined millet and sorghum as a staple grain in sedentary environments (part of the pastoralist family is settled). Because of asymmetric supply of and demand for staple foods, such as grains and pulses, and livestock in the Sahara-Sahelian zones, pastoralists depend strongly on food markets. Households in the more humid Sudano-Sahelian areas do not have this constraint. The wealthier agro-pastoralists can rely, partly or entirely, on proper staple food production. In-kind payment and food received from relatives are frequent sources that may apply to 10 to 25 percent of households, mostly the very poor or vulnerable ones. The share of food aid fluctuates, but remains low, except for people in refugee camps (AGVSAN 2014; ENSAN Mali 2018 (2016); ENSAN 2013; VIA 2015).

Chronic food insecurity prevails in pastoralist areas: 24-30 percent of the pastoralist population finds itself in the severe-to-moderate range (ENSAN 2018). ${ }^{17}$ Households in the moderate category might
(1) Background and understanding

(2) Regional drivers

(3) Regional organisations

Agro-pastoralism-based

4.1 Definitions

4.2 Demography and geography

4.3 Regional consumption and production trends

4.4 Livelihoods of agro-pastoralists

4.5 Production systems

4.6 Food system outcomes

4.7 Institutional drivers

4.8 Risks and resilience

4.9 The COVID-19 pandemic

4.10 Agency and development paradigms

4.11 Summing up References

(5) Grains-and-legumes-based

6) Rice-and-horticulture

(7) Coastal maritime fisheries

8 Tropical mixed tree and

8 food crops systems

9 Toward enhanced resilience 
have enough energy intake (calories), but malnutrition persists. The severe group is insecure for both energy and nutrition. Food insecurity climbs to 40 percent or more in Sahara-Sahelian nomadic environments. This malnutrition is related to poverty; a lack of access to diverse food, health, drinking water, and hygiene; and changed consumption habits, such as the replacement of healthier sources with white rice, processed vegetables, and condiments. Moreover, only recently has the so-called "harmonised monitoring" of households begun to account for pastoralist vulnerability by observing herd dynamics. ${ }^{18}$ Previously, the monitoring system had overlooked that livestock is the main asset, that restocking takes far more time than in agricultural cropping cycles, and that land tenure security may not exist for pastoralist populations moving outside of traditional lands or farms (see also Ancey et al. 2009). Further, pastoralists are confronted with asymmetric seasondependent supply and demand between animals and food. The aforementioned living minimum ratio and natural resource availability and access are fair indicators of agro-pastoralist resilience. Agro-pastoralist families in Sudanese areas that combine livestock and cropping (mostly food but rarely cash crops) are more successful in self-provisioning than their counterparts, such as agrobreeders and pastoralists.

There has been growing awareness of the linkages between livestock and a household's food security and nutrition. For pastoral communities the "hungry," or soudure, season is not necessarily a result of a gap in cereals but is linked to reduced access to fodder and natural resources. The availability and quality of rangelands affects animal health conditions and, subsequently, milk and livestock production. A declining forage base can therefore lead to rising household malnutrition levels (Dominguez-Salas 2019; FAO 2018; Ickowicz 2012). Forage importance is demonstrated by estimates that 44 percent of families' expenditures go to animal feed, 7 percent to veterinary services, 4 percent to telephone costs, 7 percent to access to natural resources (water and pasture), and 22 percent to human food (Corniaux et al. 2018; Inter-réseaux 2018).

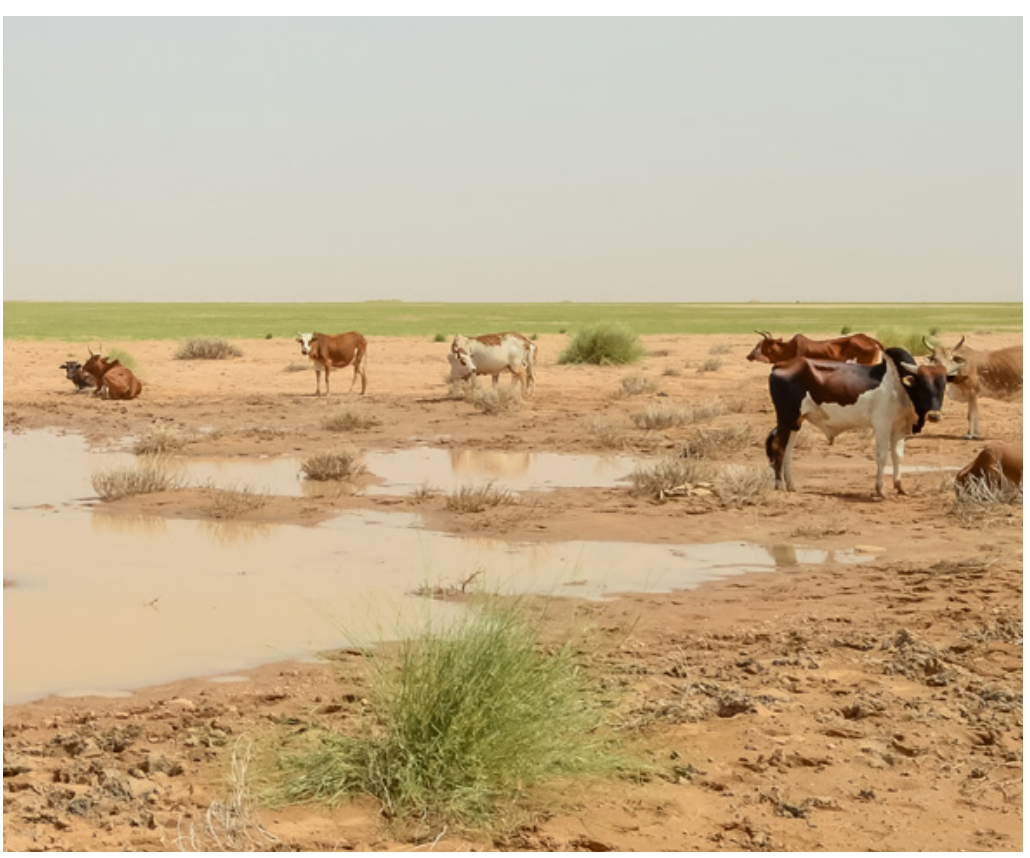

4.6.2 Income, trade, and employment

Animal production and goods contribute 12-19 percent of the GDP of Sahel countries but less than 6 percent of coastal countries. Tondel $(2019,1)$ reports, "According to data from CILSS and USAID, intra-regional trade flows of livestock (75\% cattle, $25 \%$ small ruminants) were estimated at nearly $\$ 400$ million per year for the 2013-2015 period, six times more than for cereals." ${ }^{\prime 19}$ However, researchers have been cautious in giving figures about traded volumes and values: "Intraregional livestock trade is highly informal; its true magnitude is not captured in official statistics and therefore unknown" (Valerio et al. 2020, 2). Available data give different volumes and values. The gross production value of cattle in 2016 was $\$ 2.470$ billion and small ruminants, $\$ 1.763$ billion (2004-06 constant). ${ }^{20}$ Nigeria was responsible for $\$ 1.101$ billion in cattle and $\$ 933$ million in small ruminants, and the Sahel interior (Mali, Niger, and Burkina Faso) for $\$ 979$ million in cattle and $\$ 603$ million in small ruminants. The production data have to be taken with caution: as table 4.1 shows, there is no correlation between stocks and production values per country.
(1) Background and understanding

(2) Regional drivers

(3) Regional organisations

Agro-pastoralism-based

4.1 Definitions

4.2 Demography and geography

4.3 Regional consumption and production trends

4.4 Livelihoods of agro-pastoralists

4.5 Production systems

4.6 Food system outcomes

4.7 Institutional drivers

4.8 Risks and resilience

4.9 The COVID-19 pandemic

4.10 Agency and development paradigms

4.11 Summing up References

(5) Grains-and-legumes-based

6) Rice-and-horticulture

(7) Coastal maritime fisheries

8 Tropical mixed tree and

8 food crops systems

9 Toward enhanced resilience

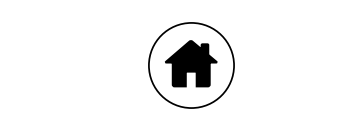




\begin{tabular}{|c|c|c|c|c|}
\hline \multirow[b]{2}{*}{ Region } & \multicolumn{2}{|r|}{$\begin{array}{r}\text { Gross value } \\
\text { (US\$, millions) }\end{array}$} & \multicolumn{2}{|c|}{$\begin{array}{r}\text { Stocks } \\
\text { (heads, millions) }\end{array}$} \\
\hline & Cattle & Sheep/goat & Cattle & Sheep/goat \\
\hline West Africa & 2,470 & 1,763 & 74.196 & 269.847 \\
\hline Nigeria & 1,101 & 933 & 20.581 & 115.836 \\
\hline Rest of West Africa & 1,369 & 830 & 53.615 & 154.011 \\
\hline Mali & 408 & 406 & 10.941 & 38.041 \\
\hline Burkina Faso & 138 & 81 & 9.457 & 24.580 \\
\hline Niger & 433 & 116 & 12.783 & 27.997 \\
\hline Sahel interior & 979 & 603 & 33.181 & 90.618 \\
\hline Côte d'Ivoire & 178 & 68 & 1.649 & 3.260 \\
\hline Ghana & 38 & 71 & 1.815 & 11.484 \\
\hline Guinea-Conakry & 131 & 17 & 6.758 & 5.231 \\
\hline Coast & 347 & 156 & 10.222 & 19.975 \\
\hline Sahel and coast & 1,326 & 759 & 43.403 & 110.593 \\
\hline
\end{tabular}

Table 4.1 Estimated Production of Ruminants (Value and Stock) in West Africa, 2016

Source: FAOSTAT, Food and Agriculture Organisation, Rome (accessed June 30, 2020).

Note: Values in US\$, millions (2004-06 constant).

FAOSTAT trade data related to West African agro-pastoralism are probably too conservative or too low, and they have not been used as reference. Local references (see, for example, Simonet et al. 2018) cannot be extrapolated or aggregated to the West African level. Several countries have livestock market information websites, which mostly give very generic data. ${ }^{21}$ The past five years opendata websites have made it possible to collect socioeconomic data on livestock keeping and trade. ${ }^{22}$ Again, the data are not always up to date, and the dilemma over the reliability of livestock trade data remains.

Agro-pastoralism-based food systems are the major suppliers of livestock products to consumers in urban centres in West Africa (Inter-Réseaux 2018; Kamuanga et al. 2008; Nugteren and Le Côme 2016; Simonet et al. 2018; van der Lee et al. 2014). There is a thriving domestic and regional trade in livestock products supporting local livelihoods and contributing to national economic growth. For example, 30 percent of ruminants in Burkina Faso are exported to coastal countries. Well-established regional markets are linked across the Sahel and between the Sahel and coastal zones, with Nigeria, Ghana, and Côte d'Ivoire as the primary destinations (Tondel 2019; Valerio et al. 2020). Livestock is traded through a robust network of collection, regrouping, and final markets, with traders serving as intermediaries between producers and consumers.

There is significant growth potential for regional trade in livestock products. This is largely due to a growing urban population, particularly in the coastal countries. West Africa imports very little red meat (less than 5 percent for beef, sheep, and goat) but has poultry and milk powder imports over 30 percent (figure 4.1 ) (Corniaux et al. 2018). Agro-pastoral systems have thus far met West Africa's urban demands of ruminants in terms of volume and price. Nevertheless, imports in coastal countries have risen slowly, and even if the product is different-chicken rather than beef-this change affects market conditions for, and market shares of products (Nugteren and Le Côme 2016). Other studies indicate a rising divide in demand and supply of livestock products driven by population and income growth, migration and urbanisation, sustaining the argument of the high potential for intraregional livestock trade (Valerio et al. 2020).

Most of the intraregional trade is livestock on hoof (cattle and small ruminants). Mobility not only determines the capacity of pastoralists to produce but is also essential for trade. Movements of livestock on hoof allow "the animals to gradually 'finish', providing the food they need during the journey before being sold at markets at reception zones" (Inter-réseaux 2018, 6) (map 4.2).23 Due to regulations, encroachment of corridors and routes, conflicts, and harassment of herders, transport by van has risen swiftly, especially from Burkina Faso to Ghana and Côte d'Ivoire (70 percent for the latter). Valerio et al. (2020) report that 58 percent of monitored movements between 2013 and 2017 in the central trade corridor (Burkina Faso to coast) were international, with vehicles used in 94 percent of the cases. Yet the quality of the living animals declines because of
(1) Background and understanding

(2) Regional drivers

(3) Regional organisations

Agro-pastoralism-based

4.1 Definitions

4.2 Demography and geography

4.3 Regional consumption and production trends

4.4 Livelihoods of agro-pastoralists

4.5 Production systems

4.6 Food system outcomes

4.7 Institutional drivers

4.8 Risks and resilience

4.9 The COVID-19 pandemic

4.10 Agency and development paradigms

4.11 Summing up References

(5) Grains-and-legumes-based

6) Rice-and-horticulture

(7) Coastal maritime fisheries

8 Tropical mixed tree and

8 food crops systems

9 Toward enhanced resilience 
disease and stress during transport. More than half of profit margins of meat is made upstream of slaughter, through fattening, if necessary; sales; cross-border transport; and trade (Tondel 2019). Transport, handling costs, and illegal taxes may represent more than 50 percent of the costs of cross-border trade in live cattle (Valerio et al. 2020). This has a profound negative impact on profit margins for both the producers and the traders.

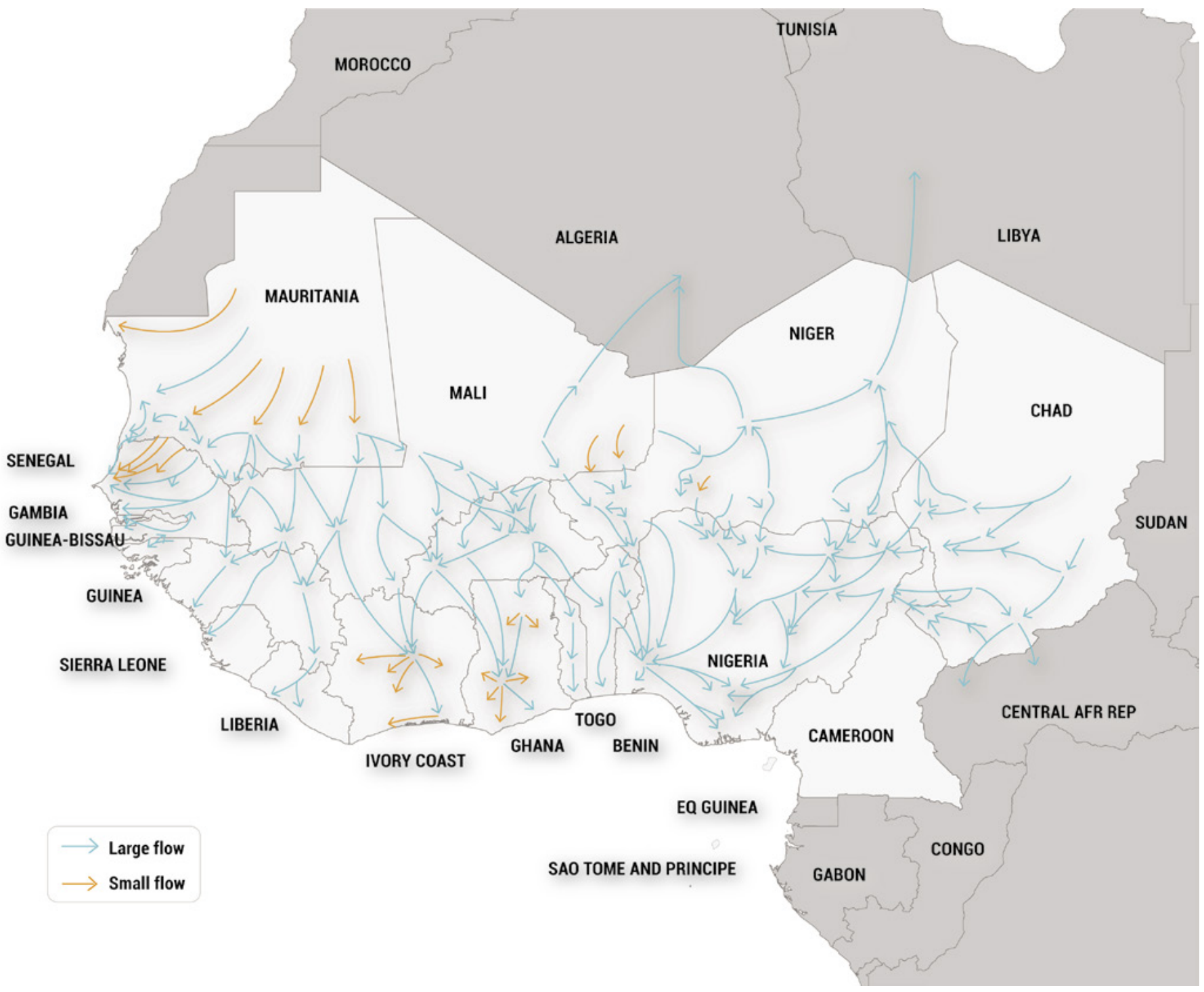

Map 4.2 Production and Market Flows for Livestock in West Africa (no year)

Source: FEWS NET Data Centre, USAID, Washington, DC (accessed August 31, 2020).

(1) Background and understanding

(2) Regional drivers

(3) Regional organisations

Agro-pastoralism-based

4.1 Definitions

4.2 Demography and geography

4.3 Regional consumption and production trends

4.4 Livelihoods of agro-pastoralists

4.5 Production systems

4.6 Food system outcomes

4.7 Institutional drivers

4.8 Risks and resilience

4.9 The COVID-19 pandemic

4.10 Agency and development paradigms

4.11 Summing up References

(5) Grains-and-legumes-based

(6) Rice-and-horticulture

(7) Coastal maritime fisheries

8 Tropical mixed tree and food crops systems

9) Toward enhanced resilience 
Except for health and hygiene measures, it is uncertain whether external investments will improve these often closed, well-organised circuits. The narrative that Sahel countries can add value to their meat products through slaughterhouses and transporting frozen carcasses must be made more nuanced (Inter-réseaux 2018). Such a narrative fails to consider that existing systems supply coastal countries' markets with fresh meat at low prices and support numerous people in extensive supply chains. Traders and wholesalers rely on the physical appearance of the live animal for quality estimations. Finally, most West African consumers lack the purchasing power to buy beef products, both currently and in the future. Frozen carcasses would target a small market for specialty products (such as supermarkets and butchers) and would compete with imports originating outside West Africa. Improved

slaughterhouses in the Sahel could eventually be important for big domestic markets if purchasing power rises.

While dairy products are important, they remain secondary products in bigger agro-pastoral production systems, especially in the more humid Sudanese areas. Dairy's informal markets provide higher prices to agro-pastoralists and lower prices to consumers than small-scale processing (van der Lee et al. 2014). Changing production conditions (higher milk yields), increased demand, and greater cash needs could alter the situation. But as of 2020 , creating new rural employment and providing additional income were the main benefits of small-scale dairy processing. Most dairy production continues to serve nearby food markets, providing better local prices to women traders than semi-industrial dairy factories aiming to serve bigger areas and cities.

There is considerable room for growth, which deserves specific attention. But it is unlikely in the short term that local production will replace all imports in urban and coastal centres (Corniaux 2015; Nugteren and Le Côme 2016). ${ }^{24}$ Because of high demands and numerous scattered production and consumption centres, milk imports do not necessarily weaken local milk chains. Milk powder can be part of additional supply strategies of industries and miniindustries. However, the low level of the common external tariff (CET) at 5 percent makes imports cheap, which does not favour the development of local production and processing. The situation is double-edged: Poor people partly or entirely depend on fat-filled milk powder and likely do not have the budget to follow price increase. Instead, they will buy microdoses and reduce the amount they consume. Reduction of local taxation, such as of value-added taxes, might be of help (Corniaux 2015; Corniaux and Duteurtre 2018).

4.6.3 Environmental sustainability

There is concern over livestock production and its links to global greenhouse gas (GHG) emissions, especially methane. Yet different livestock production systems are not equivalent. In pastoral systems, from the point of view of GHG evaluations, ${ }^{25}$ a livestock unit (TLU, defined as a 250-kilogram live-weight animal)

would emit over a year nearly fifty percent less methane than the regional norms proposed by the Intergovernmental Panel on Climate Change. Regarding gas emissions, the net result of the sylvo-pastoral ecosystem would generally balance out over the year; the emissions are probably compensated by carbon storage [in range lands] after a whole year. (Inter-réseaux $2018,8)^{26}$

Inherently, the effects of pastoralism on natural degradation are low. The Sahelian pastoral production systems are viewed as nearly optimal in the use of available natural resources (Hesse et al. 2013; Krätli et al. 2013, 2015). If not constrained in mobility, pastoralism

contributes to preservation of natural savannah rangelands and their forage resources, avoiding overgrazing and undergrazing. It even encourages the regeneration of several species as a result of seed dispersal.... Degraded pasture lands often go hand in hand with sedentary livestock farming sites. (Inter-réseaux 2018, 8)

Yet the situation has changed or is changing. Risks of overstocking or overgrazing and soil compaction increase if external factors determine herd management, such as through the influence of absentee owners lacking affinity with land management or reduced mobility of herds and people. In large areas, the risks have become reality through large herds of absentee owners, encroachment on
(1) Background and understanding

(2) Regional drivers

(3) Regional organisations

Agro-pastoralism-based

4.1 Definitions

4.2 Demography and geography

4.3 Regional consumption and production trends

4.4 Livelihoods of agro-pastoralists

4.5 Production systems

4.6 Food system outcomes

4.7 Institutional drivers

4.8 Risks and resilience

4.9 The COVID-19 pandemic

4.10 Agency and development paradigms

4.11 Summing up References

(5) Grains-and-legumes-based

6) Rice-and-horticulture

(7) Coastal maritime fisheries

8 Tropical mixed tree and

8 food crops systems

9 Toward enhanced resilience 
traditional refuge areas for livestock, or, more recently, conflicts in the Sahel, such as in central Mali, the Gourma area of Mali, Burkina Faso, Niger, and the Diffa region in Niger. Additional fodder mechanisms could partly attenuate the risks. ${ }^{27}$

The situation is different in the southern Sahel-Sudan areas of West Africa, where agro-pastoralism fits into a broader picture of several systems using the same natural resources. Land degradation occurs because of rising pressure on and competition over resources, fragmented mobility patterns, and different ways of keeping livestock (Ickowicz et al. 2012; Nelen, Traoré, and Coulibaly 2015; Touré et al. 2012; Turner and Schlecht 2019). Besides the effects of a higher density of transhumance herds, on which there is no consensus, ${ }^{28}$ the areas showcase the double effect of mixed, crop-based systems of agrobreeders, which both expand the arable land and invest in cattle herds with an agricultural rationale. ${ }^{29}$ That is, herds are seen as living capital that exploits remaining forestlands and rangelands (located more and more often at the fringes of the terroirs), which farmers consider agricultural reserves rather than strategic pastoral resources. Viewed this way, agricultural encroachment has had a higher impact on land degradation than agro-pastoralist livestock keeping.

The literature shows how degradation is intertwined with climate variability, pastoral resource availability, and competition over them, as well as with different herd and land management practices. Gonin (2016) states that most responses focus on agriculture and livestock association or intensification and on conflict resolution, but relatively few focus on access conditions. He sees a tendency in land tenure "based on reciprocity of access rights" toward "a regime where tenure security is based on the exclusive appropriation of production spaces" (Gonin 2016, 1).

4.6.4 Equity and inclusion

Agro-pastoralism's capacity to absorb shocks and adapt to external drivers has eroded since the 1970s (Bonnet and Guibert 2012; De Haan 2016; FAO 2018; Touré et al. 2012). Growing social differentiation and inequalities have been reported within the pastoralists communities as a result of increasing poverty through loss of assets (livestock above all) and reduced mobility (Bonnet and Guibert 2012; De Haan 2016; FAO 2018; Touré et al. 2012; Catley and Aklilu 2013; Dixon and Holt 2010). Poor and very poor households depend on selling labour to wealthier groups or on in-kind loans of these groups. Seasonal labour and migration of youth have become major sources of revenue.

As mentioned in section 4.4, agrobreeders as well as agropastoralists can entrust their bush herds to third parties (salaried herders). This practice has existed for decades, such as in Mali and Burkina Faso since the 1970s (Bassett 1994). These herders are often impoverished pastoralists who are increasingly older (over 50) or very young (under 20) (Ouoba-Ima 2018). A more recent practice involves absentee owners hiring herders without affinity or connection with the pastoral system (Turner 2009), putting production and trade decisions outside pastoralist households. In 2014 van der Lee et al. reported that 40-60 percent of cattle in the Sudan areas of Mali belonged to absentee owners. The management of bush herds appears more difficult than for "house herds" or "milk herds," which is generally entrusted to sedentary herders who are members of or close to the family. If the salaries of the two categories are comparable, the latter can take greater advantage of the herd's products, such as milk or calves or both. In addition, they are less exposed to conflicts.

Yet the agro-pastoralist population is growing, and people have left or want to leave the production systems, as these are under pressure or cannot absorb more persons. ${ }^{30}$ These changes widen the asset gap between wealthy and poor groups and make it more difficult for the poor to continue their pastoralism-based livelihoods (FAO 2018) because livestock declines per capita. Several scenarios show a prolonged rise of vulnerability and socioeconomic

differentiation if no specific policies and programs are implemented (De Haan 2016).

At the same time, the narrative of the rural exodus, wherein young people leave rural areas, must be made more nuanced. First, in such situations, the core of the family remains intact (Inter-réseaux 2015). ${ }^{31}$ In addition, the rural-urban divide has become artificial (Stührenberg as cited in Inter-réseaux 2015, 4-5):
(1) Background and understanding

(2) Regional drivers

(3) Regional organisations

Agro-pastoralism-based

4.1 Definitions

4.2 Demography and geography

4.3 Regional consumption and production trends

4.4 Livelihoods of agro-pastoralists

4.5 Production systems

4.6 Food system outcomes

4.7 Institutional drivers

4.8 Risks and resilience

4.9 The COVID-19 pandemic

4.10 Agency and development paradigms

4.11 Summing up References

(5) Grains-and-legumes-based

6) Rice-and-horticulture

(7) Coastal maritime fisheries

(8) Tropical mixed tree and

8 food crops systems

9 Toward enhanced resilience 
Many young people born in rural areas move to town on a seasonal or temporary basis.... School attendance, the diversification of the activities of rural people, the return to the village of city dwellers confronted with the urban economic crisis, in particular young people,... the development of transport and information technology, have led to a rapprochement of urban and rural lifestyles.... Often, rural youth is equated with young farmers. However, jobs in rural areas have diversified considerably, which particularly affects young people and women.... More than half of young workers in rural areas have an activity other than agriculture in Africa (processing, taxi, petty trade, etc.).

Literature on youth is on the increase, but there is relatively little documentation on young pastoralists. Ancey et al. (2020) state that migration and mobility are still part of the path to maturity, without leaving the extended family. ${ }^{32}$ They state that "the (urban) migrations of young pastoralists are poorly identified by the public authorities" (ix-x). Further,

while public authorities fear the marginality and delinquency of young migrants, professional organisations highlight the labour question.... The difficulty in public debate and action is explained by the lack of data, weak inter-sectoral coordination, the focus of the political agenda on employment, migration and security, at the expense of rural transformations and the role of rural-urban links; the frequent political solutions for "managing youth migration" don't correspond with reality, if they aim to "retain" young people or "settle" pastoralists. (Ancey et al. 2020,ix-x)

Finally, as stated, livestock keeping, trading in livestock, and marketing meat involve large numbers of young people and women. Also, the preparation and sale of offal are mainly carried out by women. The milk trade is an important source of income for agro-pastoral women, who may quickly find themselves marginalised by the development of industrial dairy chains. They may be targeted in nongovernmental organisation (NGO) initiatives, but women rarely have a voice in formal policy circles.

\subsection{Institutional drivers}

National governments in Sahelian countries and Côte d'Ivoire previously provided public services such as water facilities, cattle dipping against tick-borne diseases, or livestock auctions and markets. Often initiated in colonial times, postindependence governments continued to both construct facilities and finance their operations and maintenance at subsidised prices. After the big droughts of the 1970 s and 1980s, several states (such as Senegal and Burkina Faso) initiated programs for ranching with inadequate or mixed results (Greenough and Neya 2016; Hochet and Guissou 2010; Manoli et al. 2014; Nelen, Traoré, and Ouattara 2004; Touré et al. 2012).

With the onset of structural adjustment and the collapse of state services in the 1980s and 1990s, a vacuum often emerged in pastoralist areas. In the more settled urban and agricultural environments, communities or the private sector filled the void. In the first decade of the twenty-first century, political decentralisation laws and processes in Sahel countries offered opportunities to claim and develop more adapted facilities and secure natural resources. In the same period, Sahel governments showed greater awareness of the importance of livestock mobility for dryland ecosystems. For example, legislation in Burkina Faso, Guinea-Conakry, Mali, Niger, and Mauritania (and currently Benin) sets out pastoralists' rights to move their animals within and across national borders (Interréseaux 2018; Thébaud and Hesse 2006). Countries like Niger invest considerably in pastoral hydraulics, such as wells and boreholes.

However, the outcomes of national land (tenure) policies and of territorialisation (such as by decentralisation) have been ambiguous, which can be more in favour of farmers and agrobreeders than of agro-pastoralists. Gonin and Gautier (2015) exemplify this for Burkina Faso, concluding that

(1) the livestock territories that were created by the state to facilitate herd mobility are now usually controlled by farmerherders; (2) at local scale, the territorialities of permanently settled farmers who capitalise on livestock are reinforced despite the fact that their herding action space extends
(1) Background and understanding

(2) Regional drivers

(3) Regional organisations

Agro-pastoralism-based

4.1 Definitions

4.2 Demography and geography

4.3 Regional consumption and production trends

4.4 Livelihoods of agro-pastoralists

4.5 Production systems

4.6 Food system outcomes

4.7 Institutional drivers

4.8 Risks and resilience

4.9 The COVID-19 pandemic

4.10 Agency and development paradigms

4.11 Summing up References

(5) Grains-and-legumes-based

6) Rice-and-horticulture

(7) Coastal maritime fisheries

Tropical mixed tree and

8 food crops systems

9 Toward enhanced resilience 
beyond the boundary of their village territory; and (3) at the regional scale, these policies weaken pastoralists' reticular territorialities, which are based on socio-spatial relations built up with farmers to acquire and secure access to water, pastures and stock routes between the anchored pastoral territories.... The state now wishes to develop new pastureland territories under its own control or under the control of the municipalities; but their intentions do not match current herding practices. The fragmentation of reticular FulBe territorialities at regional scale is to a large extent due to the extensive cropping practices, but it is reinforced by these top-down territories devised at local scale. The articulation between dry season pasturelands in the south and rainy season pasturelands in the north has been destroyed by 50 years of rural policies that deny the efficiency of pastoralism. (Gonin and Gautier 2015, 10)

Turner and Schlecht $(2019,14)$ nuanced the effects of territorialisation on pastoralism stating, "Widespread characterizations are misleading and contribute to the lack of progress in pastoral development."

After the creation of national and regional farmer platforms of which the Network of Farmers Organisations and Agricultural Producers in West Africa (ROPPA) is well established, agro-pastoralists have worked as well on stronger representation. Partly due to the nature of their profession, agro-pastoralists do not have the same unionist tradition as farmers of cotton, groundnut, and grain (such as rice). Agro-pastoralists have slowly developed professional organisations, instead of merely cultural or ethnic ones, that led to the creation of both national and regional associations, such as the 'Réseau Billital Maroobè' (RBM), the 'Association pour la Promotion de l'Elevage au Sahel et en Savane' (APESS) or the 'Confédération des Fédérations Nationales de la Filière Bétail Viande' (COFENABVI) for trade, in the early twenty-first century. As relatively young organisations, they cover a wide range of topics and need to be active on the local, national, and regional levels. Some national associations, however, are dominated by big livestock keepers and traders but do not necessarily take into account pastoralists' or women's needs and vulnerability.

\subsection{Risks and resilience}

There are multiple risks related to the agro-pastoralist-based food systems. Population growth has direct effects on available natural resources and opens opportunities for market growth through urban demand. Mobility of livestock and people has always been the adequate response to cope with erratic rainfall. Another response to droughts is selling of livestock, albeit at unfavorable prices (Bonnet and Guibert 2012; De Haan 2016; de Leeuw et al. 2020; FAO 2018; Inter-réseaux 2017; Hesse et al. 2013; Krätli et al. 2013).

Multiple use of land resources is widespread in agro-pastoral areas, where land is governed by a mix of statutory and customary rules and institutions. As secondary rights holders for common resources, pastoralist women and men increasingly lack secure land tenure rights. Rangelands have changed over time due to (1) expansion of settlement, agriculture, and ranching onto natural rangelands, and (2) converting forestland into grassland or replacing abandoned farmland or rangeland with forests (FAO 2018). The dominant trend remains agricultural encroachment onto rangelands, which may or may not be justified by statutory law. Natural grass degradation, increasing risk of animal and zoonotic diseases (Corniaux et al. 2018), and more extreme climate events (CILSS 2016; Touré et al. 2012) have further undermined the production systems. As mentioned, the diminishing forage base reinforces a trend toward more nutritional vulnerability for both animals and pastoralists.

Most of the trends and risks mentioned in previous sections have their roots as equally in poor national and local governance as in agrophysical or climate conditions. Land tenure insecurity exemplifies this. In all Sahel-Sudan areas, rising land pressure and higher land values undermine customary tenure regimes, with the risk of reducing a wide range of access and property rights to mere private ownership and titles. The countries have legislation recognising different rights, common pool resources, and livestock mobility, but practice often shows otherwise. The commons are exposed to land acquisitions, and land speculation is allowed. Secondary rights holders, such as women and pastoralists, risk being excluded from key resources. The struggle of the central state to manage and protect resources has been a constant in the past
(1) Background and understanding

(2) Regional drivers

(3) Regional organisations

Agro-pastoralism-based

4.1 Definitions

4.2 Demography and geography

4.3 Regional consumption and production trends

4.4 Livelihoods of agro-pastoralists

4.5 Production systems

4.6 Food system outcomes

4.7 Institutional drivers

4.8 Risks and resilience

4.9 The COVID-19 pandemic

4.10 Agency and development paradigms

4.11 Summing up References

(5) Grains-and-legumes-based

6) Rice-and-horticulture

(7) Coastal maritime fisheries

8 Tropical mixed tree and

8 food crops systems

9 Toward enhanced resilience 
five decades. Decentralisation has the potential to break the impasse and bring natural resource management back to control at the local level. However, it has not yet fulfilled its promise, in large part because of lack of transfer of competencies and finances from the central government to local institutions (Hesse et al. 2013). ${ }^{33}$

As for the promotion of dairy products, the abolition of quotas in Europe amplifies an existing trend wherein the import of milk powder has become structural and favours the establishment of large foreign companies rather than of local industries. The increase in imported milk-in particular, refattened milk powder-has implications in terms of quality and price, both of which are much lower than those of locally processed milk. The low level of taxation of milk powder in the ECOWAS market ( 5 percent for the CET) encourages these imports (Inter-réseaux 2017).

A bias toward more sedentary and agricultural systems is found in practical measures (see section 4.7). Government officials' limited understanding of pastoralist systems means that legislation is likely to be implemented in an unduly technocratic and centralised way. In practice, this continues a process of curtailing pastoralist mobility. Moreover, while the various regional integration processes across Africa permit the free movement of people and goods, pastoralists still face many practical difficulties when moving their animals across borders (Tondel 2019; Valerio et al. 2020). Last but not least, violence, displacement, and militarisation affect pastoral livelihood systems. In some countries, levels of exclusion have led to frustration and sometimes to armed conflict between pastoralists and local militia, which exacerbate poverty levels among all households and affect the most vulnerable community members, such as women and children (FAO, UNICEF, and WFP 2018; UNECA 2017; UNOWAS 2018).

4.8.1 Climate variability and sociopolitical resilience

Greater climate variability has had an impact on livelihoods, it is difficult to separate climate from other drivers influencing resilience, such as socioeconomic development, demography, resource

management, and local institutions. First, different scenarios exist for the Sahel (Dosio et al. 2020; Sidibé et al. 2020), wherein some predict, for example, a "drier west" and a "wetter central Sahel."
After an inventory of 1,250 households, Mertz et al. $(2010,1)^{34}$ conclude,

climate factors, mainly inadequate rainfall, are perceived by 30-50 percent of households to be a cause of decreasing rainfed crop production, whereas a wide range of other factors explains the remaining 50-70 percent. Climate factors are much less important for decreasing livestock production and pasture areas.

The inherent resilience of agro-pastoralism to respond successfully to climate shocks is progressively undermined by mobility constraints and land tenure insecurity. ${ }^{35}$ Pastoralism has become dependent on access to resources in more humid Sudan areas, where it encounters competition and where different production systems contribute to land degradation. Local institutions do not necessarily favor mobile livestock keeping, which could contribute to further undermining. Pastoralism might be dominant in SaharaSahelian areas, but pastoralists often have little political voice in areas where different production systems meet. ${ }^{36}$

\subsubsection{Economic resilience}

Demand for ruminant meat and dairy has been growing. As stated agro-pastoralism is capable of meeting demand for ruminant meat due to its robust production and trade systems. To a lesser degree, this applies to the delivery of dairy products. Intensification, such as more inputs, feed, and means of production, has the potential to raise production but cannot replace natural resources (pastures). The capacity to improve production and trade depends on access to these resources as well as on mobility and unimpeded circulation of people and animals. In light of market triggers, facilitating economic resilience is as much a question of technological incentives as of sociopolitical recognition and protection of the system.

\subsubsection{Food access resilience}

As stated in section 4.6, pastoralist households in Sahel areas have to cope with asymmetric supply and demand of staple food (grains, legumes) and animal products. They face unfavourable trade terms between products or relatively high staple food prices. Livestock keeping and food and nutrition security are related. The availability
(1) Background and understanding

(2) Regional drivers

(3) Regional organisations

Agro-pastoralism-based

4.1 Definitions

4.2 Demography and geography

4.3 Regional consumption and production trends

4.4 Livelihoods of agro-pastoralists

4.5 Production systems

4.6 Food system outcomes

4.7 Institutional drivers

4.8 Risks and resilience

4.9 The COVID-19 pandemic

4.10 Agency and development paradigms

4.11 Summing up References

(5) Grains-and-legumes-based

6) Rice-and-horticulture

(7) Coastal maritime fisheries

8 Tropical mixed tree and

8 food crops systems

9 Toward enhanced resilience 
and quality of fodder or pastures affect animal production and, subsequently, milk and livestock production. A declining forage base can therefore lead to rising household malnutrition levels. Agropastoralist families in Sudan areas that combine livestock and cropping (mostly food, rarely cash crops) are more successful in self-provisioning than pastoralists and are more food resilient.

4.8.4 Adaptations to reduce vulnerability

In response to greater climate variability and socioeconomic shocks, pastoralism and agro-pastoralism have made a series of adaptations over the past four decades (Ickowicz et al. 2012; Menghistu et al. 2020). The pastoralist livestock production system has shown significant changes in herd composition, with more small ruminants and fewer cattle raised due to decreasing access by pastoralists to pasture lands. In Saharan areas, dromedary numbers have increased. They purchase and provide supplementary feed (fodder, crop residues, concentrate), destock herds, or diversify livestock species. Changes in mobility patterns have occurred, with longer distances and longer periods outside the home areas (terroirs d'attache). Herd routes are moving southward to more humid areas in search of fodder and water. These changes are accompanied by rising tensions or conflicts between users' groups, such as livestock keepers and sedentary farmers, due to competition over water points and pastures. Building on these elements, pastoralists have responded to external shocks through three key socioeconomic strategies:

- Moving up includes getting bigger herds or evolving to more commercial practices that target higher-value markets, including exports. This strategy requires assets, specialised labour and inputs, and political influence and is only possible for a minority of wealthy households.

- Diversification of revenues is probably the most accessible strategy for most pastoralist households. Under this strategy, the composition of herds changes and new markets are addressed. Farm and livestock by-products (such as dairy by women) receive a more prominent place next to raising and selling animals. Family members can have nonagricultural sources of income. Eventually, this entails more sedentary ways of life for part of the family, though mobile livestock remains the key asset.

- Moving out involves the household leaving the pastoralist production system and looking for other sources of income. It often implies that the household leaves the area and settles in towns. Young people may still remain as herders without owning livestock.

With respect to these strategies, de Leeuw et al. (2020,318) argue,

The two most promising poverty escape pathways are intensification of the farming system through greater market orientation, secure access to natural resources and to supplemental feeds, and second, an exit from agriculture through education and development of alternatives for the young and pastoral dropouts. Other less prospective options are diversification of the farming system and obtaining off-farm income.

\section{The agro-pastoralist livestock production system has}

responded to increased volatility in rainfall patterns by crop diversification, changes in sowing and harvesting dates, and selecting crop species and varieties - all adapted to shorter growing cycles (for example, drought resistance or precocious varieties of millet, sorghum, cowpea) and changing or supplementing livestock feed. Although transhumance remains dominant, raising sedentary fattened cattle and small ruminants is on the increase. Because of reduced rangelands, more herd mobility in dry seasons outside the familiar areas is observed. Over the past three decades, there have been rising tensions or conflicts between users' groups due to conflicting interests in the commons and competition over remaining land and water points. A dominant response strategy by agro-pastoralists is diversification of revenues and income sources, including farm, horticultural, and livestock products. While livestock and agriculture remain critical for income generation, nonfarm activities that lead to asset accumulation (for example, housing, land, and livestock) and salaried employment are at least as effective at moving households out of poverty. ${ }^{37}$ Menghistu et al. (2020) mention in a review of 130 papers that besides household income, institutional or government support, and land tenure security, access to information (extension on inputs as well on weather, prices, and biomass) is a determinant factor for adaptation.
(1) Background and understanding

(2) Regional drivers

(3) Regional organisations

Agro-pastoralism-based

4.1 Definitions

4.2 Demography and geography

4.3 Regional consumption and production trends

4.4 Livelihoods of agro-pastoralists

4.5 Production systems

4.6 Food system outcomes

4.7 Institutional drivers

4.8 Risks and resilience

4.9 The COVID-19 pandemic

4.10 Agency and development paradigms

4.11 Summing up References

(5) Grains-and-legumes-based

6) Rice-and-horticulture

(7) Coastal maritime fisheries

8 Tropical mixed tree and

8 food crops systems

9 Toward enhanced resilience 


\subsection{Food system impacts of and responses to} the COVID-19 pandemic

According to key experts interviewed, agro-pastoralists risk being seriously affected by the preventive measures taken by the various governments of West Africa against the COVID-19 pandemic.

Overall, the 2020 restrictions amplified tendencies and risks that already had major effects on the agro-pastoralist system. The movement restriction jeopardises the possibility of providing feed and water to the herds with a direct effect on the productivity of the system, both in terms of traded meat and secondary milk. This results in an accumulation of animals in specific grazing areas and close to borders, inducing health risks both for humans and for their animals. Furthermore, it puts an extra pressure on local natural resources, hampering the future production of these areas. To cope, farmers invest in animal feed and reduce the number of animals. A vast majority of households were put into a precarious situation by the COVID-19 crisis: there were an estimated 81 percent vulnerable agro-pastoralist households with a daily income under $\$ 1.90$ per day (sample of 1,935 households in eight countries) (APESS 2020). To cope with the situation, individuals complement their incomes with off-farm jobs ( 61 percent men and 45 percent women). In the context of current and potential conflict, tensions are rising between herders, as well as between herders and farmers.

Regarding the input supply, prices for feed have rapidly increased in several countries in West Africa. Mobility restrictions have affected the dynamic of all supply chains both for live animals and for trucks supplying the markets. Furthermore, several major animal markets shut down in March and April 2020, reducing the market network of an area that had already partially closed to prevent terrorist attacks before the COVID-19 crisis. As markets close and numerous pastoralists become engaged in destocking, animal prices have dropped significantly. While impacting supply to major cities, this has also threatened the livelihood of many households relying on these markets. The largely informal character of trade prevents gaining a clear understanding of the impacts. The situation seemed to improve once mobility restrictions were relaxed.
Like the meat market, the milk market also faced challenges during the restrictions. The collection of local milk was hampered, and enterprises relying on local milk were strongly impacted and had to reorganise their milk collection and increase their use of milk powder. As Europe began overproducing (seasonal peak combined with decreased consumption in Europe during the COVID-19 crisis), milk powder prices remained low. Hence, West African dairy industries, regardless of their size, began using more milk powder than before. These events threaten the emerging local dairy sector which various government entities may not support (as the 55 organisations of the campaign "Mon lait est local" are arguing).

Consumption of meat has decreased since a shift toward strategic staple food has been observed. Dairy products, mainly relying on milk powder, remained available for consumers in most cities. Pastoralists' nutritional status, however, has been threatened, with women and children the most at risk. Indeed, a large part of pastoralists' revenue is used to buy cereals for the family. Hence, a reduction of revenue directly threatens their nutritional status. Furthermore, by threatening milk productivity of their herds, the COVID-19 crisis directly threatens children's nutritional status. Pastoralist organisations call for major support (such as feed) from their governments and humanitarian organisations, both for families as well as for their herds (APESS 2020).

\subsection{Agency and development paradigms}

As stated in section 4.7, West African institutions have progressively taken into account pastoralism in policies. In 2010, the AU issued the Policy Framework for Pastoralism in Africa, addressing the interrelated goals of sustainable pastoral resource management, equitable and secured access to pastoral resources, and peace and security. The framework also emphasises supporting and harmonising policies across the regional economic communities and member states as a prerequisite for ensuring action at the required scale. Since pastoralism is one of the largest agricultural subsectors in terms of wealth creation in West Africa, livestock raising and trade are identified as priority market chains for the ECOWAS and WAEMU regions, based on criteria such as competitiveness, social
(1) Background and understanding

(2) Regional drivers

(3) Regional organisations

Agro-pastoralism-based

4.1 Definitions

4.2 Demography and geography

4.3 Regional consumption and production trends

4.4 Livelihoods of agro-pastoralists

4.5 Production systems

4.6 Food system outcomes

4.7 Institutional drivers

4.8 Risks and resilience

4.9 The COVID-19 pandemic 4.10 Agency and development paradigms

4.11 Summing up References

(5) Grains-and-legumes-based

6) Rice-and-horticulture

(7) Coastal maritime fisheries

8 Tropical mixed tree and

8 food crops systems

9 Toward enhanced resilience 
and economic advantages, food security, income for producers, and existence of a structured professional environment. ${ }^{38}$ The

importance of these value chains is recognised the national and regional levels by regional development programs cofinanced by donor agencies, such as PRAPS (World Bank), PEPISAO (AFD), PREDIP (EU), PACBAO and PREPP (SDC), PRIDEC (ECOWAS), Trois Frontières (AFD), and MOPSS (Sida). All of these programs work on one or several of the above-mentioned criteria and issues. National and regional pastoralist organisations such as RBM and APESS participate in or own these programs.

Nevertheless, gaps persist. Even if policy makers have started to consult pastoralists in regional West African dialogue and debate, coordination among ministries concerned with pastoral issues is still lacking and fails to deliver coordinated pastoral development and policies grounded in local realities. Secondly, pastoralist institutions and pastoralist civil society associations still face insufficient capacity and voice in order to organise more permanent collective action, which is required at the national and local levels to enforce pro-pastoralist policies.

Interventions still cope with biased or changing assumptions. Hesse et al. $(2013,7)$ write,

The last 20 years have seen a radical improvement in our understanding of the dynamic nature of drylands, providing us with far greater insight into dryland production systems. Seminal work has demonstrated that drylands are better understood as disequilibrium environments, where climatic variability... is the norm rather than the exception.

Most development interventions still address risk as an absolute problem, aiming to reduce it such that risk management equals risk aversion. The first step is recognition that pastoralism and rain-fed farming deal differently with climate variability and can be seen as "risk-taking enterprises, wherein rewards are highest when risk is harnessed and managed... not when it is avoided" (Krätli et al. $2015,26)$. Then pastoralism can be seen as a productive, highly adaptive system, which goes further than recognition of pastoralism as viable but fragile with low potential. This view does not deny the problems presented in sections 4.8 and 4.9 ; rather, it underlines that mobility remains a fundamental pillar in the system, wherein use of natural resources can be completed but not replaced by additives.

The term "livestock mobility" requires further investigation as a

multidimensional concept that resists simple definitions and quantification. Shifting views of livestock mobility have been shaped less by empirical engagements with pastoral ecology and mobility and more by unexamined associations connecting ecology, mobility, livelihood, and institutions. Current scholarly views of livestock mobility reject earlier notions of it being contrary to modern development and instead point to it being an adaptation to high spatio-temporal variability and risks associated with unpredictable change, both tied to a pastoral or nomadic lifestyle. Pastoral land tenure in turn is seen as being incompatible to territorial forms that are overly rigid and constrain flexible response to unpredictable locations of water and fodder. These widespread characterizations are misleading and contribute to the lack of progress in pastoral development. (Turner and Schlecht 2019, 14)

Turner and Schlecht $(2019,14)$ emphasise that it is important to seek "clarity about the spatio-temporal specificities and motivations behind mobile herding practices" (see also section 4.7).

Agro-pastoralists respond to price rises and markets when they feel safe, having secured availability of rangelands, water, and corridors, as well as peace. If possible, herds are maintained at levels, allowing producers to ensure food access, to preserve stock for reproduction (keep the best animals), and to engage in transhumance (keeping the experienced animals), knowing that restocking of herds takes many years. There is no direct correlation between sales and droughts but rather a mix of reasons for sales: estimations of food and water scarcity (at short and seasonal terms), physical market access and cash and food needs, ${ }^{39}$ assessments of accessibility of distant refuge areas, and logistics to keep herds at the critical level. So, the cycle of stocking, sales, reinvestment, and possible herd growth is more an outcome of
(1) Background and understanding

(2) Regional drivers

(3) Regional organisations

Agro-pastoralism-based

4.1 Definitions

4.2 Demography and geography

4.3 Regional consumption and production trends

4.4 Livelihoods of agro-pastoralists

4.5 Production systems

4.6 Food system outcomes

4.7 Institutional drivers

4.8 Risks and resilience

4.9 The COVID-19 pandemic

\subsection{Agency and} development paradigms

4.11 Summing up References

(5) Grains-and-legumes-based

6) Rice-and-horticulture

(7) Coastal maritime fisheries

8 Tropical mixed tree and

8 food crops systems

9 Toward enhanced resilience 
careful economic planning and optimisation of various parameters based on long experience than a result of keeping large numbers of livestock for the sake of status or insurance - though the latter may occur if absentee owners are involved. These nuanced insights are understood, but not yet reflected in, most interventions, which tend to focus on productivity and maximising profits. It is uncertain if external (donor-supported) investments can improve trade circuits, with the exception of health and hygiene measures. Policies to reduce red tape and transaction costs might bear more fruit.

Two views seem to underlie policies for marketing:

livestock trade networks appear to be dominated by socially embedded business transactions, generating contrasting opinions on the market system's ability to respond to future increases in demand for livestock-derived products. On the one hand, the market structure is thought to constrain agricultural growth; on the other hand, it confers the system with resilience in an environment where disruptions and shocks to the market system - like climatic events and conflict - are frequent. Few attempts to formally describe the regional trade structure have been made to support either claim, partly because comprehensive data are lacking on livestock movements, production (allowing inferences on sales made), sales (allowing inferences on domestic vs. regional sales) and exports. (Valerio et al. 2020, 2)

As for nutrition, Dominguez-Salas et al. $(2019,786)$ write,

An important premise of many livestock projects (i.e. that income will ultimately improve nutrition security) is not supported by empirical studies, as changes in incomes do not immediately lead to a higher consumption of calories or more diverse diets.... Livestock interventions tend to be more oriented to productivity and small enterprise development than other agricultural interventions that tend to be more focused on subsistence producers and their dietary diversification. Government initiatives were perceived to focus frequently on increasing production of medium and large producers, rather than on vulnerable smallholders. ${ }^{40}$
There is an emerging asymmetry in policies and practices across and within countries. First, there is asymmetry between policies recognising pastoral mobility in Sahelian countries and coastal countries building barriers for movements of livestock and people (Inter-réseaux 2017). Border restrictions between and across countries have a negative impact on trade. Within countries, there are differences between central and remote or sparsely populated zones (often border or pastoral areas that have relatively poor basic services and human protection, such as against rising insecurity and violence). While fear for destabilisation of the Sahelian countries (regular insurrections, proliferation of armed groups) may be justified, some narratives and speeches put young pastoralists at the forefront as antagonists, assuming that pastoralists are participating in armed violence and terrorism or by presenting violent conflicts in a caricatured manner as ethnic and/or socioprofessional conflicts.

\subsection{Summing up: toward leverage points for} future interventions

Agro-pastoralism is an important food system in West Africa, which not only feeds and provides income and employment to people in areas considered marginal for other forms of economic activity but also provides the urban centres with livestock products. Although frequently debated, there is growing evidence and consensus that agro-pastoralism is, essentially, a sustainable production system for the arid areas of West Africa. Ickowicz et al. $(2012,288)$ write,

To cope with shocks and crisis but also to support changes, they [pastoralists] have developed various strategies based on the mobility of livestock and/or families, reorganisation and diversification of activities, reciprocity and social networks. These strategies have allowed them to reproduce their societies through several major political events and droughts in the Sahel.

Twenty-first-century agro-pastoralists have to deal with demographic growth, market demands and liberalisation, and security issues, combined with extreme climate variability, for which
(1) Background and understanding

(2) Regional drivers

(3) Regional organisations

Agro-pastoralism-based

4.1 Definitions

4.2 Demography and geography

4.3 Regional consumption and production trends

4.4 Livelihoods of agro-pastoralists

4.5 Production systems

4.6 Food system outcomes

4.7 Institutional drivers

4.8 Risks and resilience

4.9 The COVID-19 pandemic

4.10 Agency and development paradigms

\subsection{Summing up}

References

(5) Grains-and-legumes-based

6) Rice-and-horticulture

(7) Coastal maritime fisheries

8 Tropical mixed tree and

8 food crops systems

9 Toward enhanced resilience 
their coping strategies might not be sufficient anymore. The system is under pressure due to reduced access to land and water sources, related conflicts with sedentary farmers, climate change, and national policies of closing borders, thus hindering the mobility of herds, which is essential to the system. The COVID-19 pandemic has added another shock to this food system. Moreover, inequalities within pastoralist communities in terms of wealth, gender, and generations add to these constraints and result in the net migration of those who cannot make a living out of pastoralism.

Marketing policies, land tenure, land use management and regulations, and investments in infrastructures and services are the main priorities to enhance the capability of the food system to adapt to the recent changes. Besides explicit attention for maintaining mobility and pastoral land tenure security, other potential leverage points for future interventions are as follows:

- The twenty-first century has shown greater progress in policies and programs that are favourable to pastoralism. Nevertheless, they could still perceive better or take into account agropastoralist specificities when analysing context (such as investigating the dimension of mobility in current circumstances) and in response to issues of food security, climate change, insecurity, migration of youth, and rural transformation. The place of pastoralism in current territorial development, in Sahel and certainly Sudan areas, also merits more attention. This can partly be achieved by developing and using specific livelihood-based information and monitoring systems, by supporting livelihood resilience programming, and by addressing specific pastoralist dimensions, such as pastoralist land tenure security and mobility.

- Further addressing the cross-border and regional dimensions of pastoralism is important, as is recognising the viability of existing production systems and robust livestock supply/value chains. Due to the nature of the trade, this requires as much the enforcement of existing policies - ECOWAS trade and the ECOWAS Trade Liberalisation Scheme (ETLS), respect for the convention of free circulation, protection of natural resources and corridors - as large investments in infrastructure. Cross-border trade practices need to be improved, reducing transaction costs. Competing milk powder imports could be properly regulated such as through higher tariffs like the CET. However, such protection will hold only if local production and processing receive a boost. There is considerable room for expansion of local milk industries and collabouration fora between producers and dairy industries. - It is equally important to consider that most production (70 percent of meat and 80 percent of dairy) in the Sahel is oriented at domestic markets and consumed locally. In many cases, the responsibility to manage and regulate the local livestock and food markets has devolved to local authorities and, increasingly, livestock keepers' and traders' organisations. The same is true of promotion of local milk industries. Supporting decentralisation initiatives, including favourable tax systems, can be instrumental.

- Ensuring stronger linkages between local and higher-level peace initiatives and inserting pastoralists' voices are also important. It is necessary to reassess how local governance institutions around conflicts, land tenure, and natural resources management currently function.

- Supporting stronger agency for pastoralists also includes improving capacity, accountability, and responsiveness in governance institutions and in agro-pastoralist associations themselves.

Notes

1 De Haan et al. (2016) indicated 50 million agro-pastoralists in West Africa (potentially an overestimate), but the figure depends on the definitions of Sahel and pastoralism and agro-pastoralism.

2 Data in this section from FAOSTAT, Food and Agriculture Organisation, Rome (accessed June 30, 2020).

3 Estimations made using FAOSTAT and other sources as noted. Statistics often show data for all livestock raised in West Africa without specifying the origin or production system.

4 FAOSTAT, Food and Agriculture Organisation, Rome (accessed August $31,2020)$.

5 FAOSTAT gives roughly similar divisions of animal products but different estimations. Since these are based on domestic supply and do not necessarily reflect imports from Sahel countries, they have not been presented here.

6 According to Bricas et al. (2016), meat represents 43-92 percent of animal products in the Sahel group, while it represents $19-56$ percent of animal products in the two coastal zones.
(1) Background and understanding

(2) Regional drivers

(3) Regional organisations

Agro-pastoralism-based

4.1 Definitions

4.2 Demography and geography

4.3 Regional consumption and production trends

4.4 Livelihoods of agro-pastoralists

4.5 Production systems

4.6 Food system outcomes

4.7 Institutional drivers

4.8 Risks and resilience

4.9 The COVID-19 pandemic

4.10 Agency and development paradigms

\subsection{Summing up}

References

(5) Grains-and-legumes-based

6) Rice-and-horticulture

(7) Coastal maritime fisheries

8 Tropical mixed tree and

8 food crops systems

9 Toward enhanced resilience 
7 See, for example, Falconnier et al. $(2015,2018)$ and Sanogo et al (2010) on southern Mali, Ouoba-Ima (2018) and Gonin and Gautier (2015) on west and south Burkina Faso, Manoli et al. (2014) on central Senegal, and Bassett (1994) and Bassett and Turner (2006) on northern Côte d'Ivoire.

8 For more on young pastoralists in Burkina Faso and Chad, see Ancey et al. (2020), Magnani et al. (2020), and Rangé (2020).

9 For a 250-kilogram animal. TLU conversion factors according FAO are as follows: cattle $=0.70$, sheep and goats $=0.10$, pigs $=0.20$, and chicken $=$ 0.01

10 Besides national food surveys, data in this section from FEWS NET Data Centre, USAID, Washington, DC (accessed November 30, 2020).

11 The Niger and Senegal reports (VIA 2015 and ENSAN 2013) do not provide enough livelihood details.

12 On Niger, see Hilhorst, Nelen, and Traoré (2011). On the Ferlo region of Senegal, see Manoli et al. (2014) and Touré et al. (2012). On Burkina Faso, see Hochet and Guissou (2010) and Nelen, Traoré, and Ouattara (2004).

13 See also Bassett (1988) and Bassett (1994).

14 Case studies confirm different rationale in productions systems of the cotton belts. On Burkina Faso, see Bainville and Dufumier (2009). On Mali, see Dufumier (2005).

15 See also AGVSAN Burkina (2014) and ENSAN Mali (2018).

16 See also data in maps and livelihoods reports at FEWS NET.

17 FEWS NET Data Centre, USAID, Washington, DC (accessed August

$31,2020)$.

18 See FEWS NET guide of 2018.

19 On small ruminants in Niger, see also CNFA (2016).

20 A billion is 1,000 million. Data from FAOSTAT, Food and Agriculture Organisation, Rome (accessed June 30, 2020).

21 See, for example, simbmali.cilss.in, simbburkina.cilss.int, simaniger.cilss.int, and sim2g.net/liste-des-sim.

22 See, for example, burkinafaso.opendataforafrica.org, mali.opendataforafrica.org, niger.opendataforafrica.org, and cotedivoire.opendataforafrica.org.

23 See also Nugteren and Le Côme (2016) and Simonet et al. (2018).

24 In general, looking beyond agro-pastoralists' livelihoods, "Labour productivity of... smallholder dairy is higher than for crops and wage labour, but dairy is not for the resource poor, who will benefit more from goats or pigs.... Backyard and small scale poultry are the first and last resort for the poor, especially for women in societies where women's access to sheep and cattle is less acceptable" (Van der Lee et al. 2014).
25 Ecological efficiency is defined as the ratio between emissions and production (by weight of produce). As a consequence, systems with comparatively low production tend to be presented as having lower ecological efficiency and may emerge as a priority for mitigation even if their absolute net emissions are far lower than in intensified production systems. This is typically the case for pastoralism versus livestock breeding.

26 See also Van der Lee et al. (2014).

27 A nuance is that intensification (more inputs, feed, and means of production) has limited potential, as it cannot replace pastures, it will not shorten reproduction intervals, it will not change the best possible ratios of females to males and age groups, and it will not lower natural mortality rates in herds (Krätli et al. 2015)

28 On southern Mali, see, for example, Umutoni and Ayantunde (2018).

29 In analyzing perceptions of the effects of transhumant practices on natural resources among settled livestock keepers and transhumant pastoralists, Umutoni and Ayantunde $(2018,1)$ present an ambivalent picture. They note different views on the causes of degradation: "The differences in the perceptions of the host communities from the transhumant, particularly with respect to species richness, abusive cutting trees and spread of invasive species, indicate the challenge that will be faced in elabouration and development of local natural resource institutions acceptable to all natural resource users."

30 On the living minimum of livestock per person, see de Leeuw et al. (2020).

31 On pastoralists in Burkina Faso, see also Ouoba-Ima (2018).

32 On Burkina Faso and Chad, see also Rangé (2020) and Magnani et al. (2020).

33 See also Grain de Sel (2012) and Nelen, Traoré, and Coulibaly (2015).

34 Bassett and Turner (2006) give an overview of pastoralists' movements to southern as well as northern Sahel-Sudan areas, wherein rainfall and droughts are one cause among others. See also Hesse et al. (2013).

35 See section 4.6 .

36 Such as the grains-and-legumes-based and rice-and-horticulture-based systems. See also section 4.7 .

37 According to Mueller and Chan and to Higgins (as cited in SNV and KIT 2015), 80-90 percent of rural households are engaged in off-farm activities.

38 See also the Nouakchott Declaration on Pastoralism.

39 With modern technology (mobile-phone banking) and trustworthy dense banking systems, it should become easier to keep cash (different programs exist in Sahel countries).

40 See also FAO (2018)
(1) Background and understanding

(2) Regional drivers

(3) Regional organisations

Agro-pastoralism-based

4.1 Definitions

4.2 Demography and geography

4.3 Regional consumption and production trends

4.4 Livelihoods of agro-pastoralists

4.5 Production systems

4.6 Food system outcomes

4.7 Institutional drivers

4.8 Risks and resilience

4.9 The COVID-19 pandemic

4.10 Agency and development paradigms

\subsection{Summing up}

References

(5) Grains-and-legumes-based

6) Rice-and-horticulture

(7) Coastal maritime fisheries

8 Tropical mixed tree and

8 food crops systems

9 Toward enhanced resilience 


\section{References}

Ancey, V., A. Ickowicz, I. Touré, A. Wane, and A. T. Diop. 2009. "La vulnérabilité pastorale au Sahel : portée et limite des systèmes d'alerte basés sur des indicateurs." In L'élevage, richesse des pauvres : stratégies d'éleveurs et organisations sociales face aux risques dans les pays du Sud, 117-32. Versailles: Quae.

Ancey, V., C. Rangé, S. Magnani, and C. Patat. 2020. Jeunes pasteurs en ville - synthèse finale. Accompagner l'insertion économique et sociale des jeunes pasteurs - Tchad et Burkina Faso. Rome: FAO.

APESS. 2020. Note d'analyse des premiers impacts de la pandémie du COVID 19 sur les Exploitations Familiales. Membres de I'Association pour la Promotion de l'Élevage au Sahel et en Savane.

AU (African Union). 2010. Sécuriser, protéger et améliorer les vies, les moyens de subsistance, et les droits des communautés pastorales. Addis Ababa, Ethiopia: AU.

Bainville, S., and M. Dufumier. 2009. Diversité des exploitations agricoles en zone cotonnière du Burkina Faso. Synthèse des études régionales conduites entre avril et septembre 2009. Bobo-Dioulasso, Burkina Faso: UNPCB/ IDRBobo Dioulasso/ Montpellier Sup-Agro/ Agro Paris-Tech/ AFD.

Bassett, T. 1988. "The Political Ecology of Peasant-Herder Conflicts in the Northern Ivory Coast", In Annals of the Association of American Geographers, Volume 78 (Issue 3), p. 453-72.

Basset, T. J. 1994. "Hired Herders and Herd Management in Fulani Pastoralism (Northern Côte d'Ivoire)." Cahiers d'études africaines 34 (133-35): 147-73.

Bassett, T. J., and M. D. Turner. 2006. "Sudden Shift or Migratory Drift? FulBe Herd Movements to the Sudano-Guinean Region of West Africa." Human Ecology 35: 33-49

Boffa, J-M., J. Sanders, S. J.-B. Taonda, P. Hiernaux, M. Bagayoko, S. Ncube, and J. Nyamangara. 2020. "The Agropastoral Farming System: Achieving Adaptation and Harnessing Opportunities under Duress." In Farming Systems and Food Security in Africa: Priorities for Science and Policy under Global Change, edited by J. Dixon, D. P. Garrity, J.-M. Boffa, T. O. Williams, and T. Amede. New York: Routledge.

Bonnet, B., and B. Guibert. 2012. Vulnérabilités et efforts d'adaptation des familles de pasteurs face aux crises récurrentes : enseignements tirés de l'analyse de l'activité pastorale dans les trajectoires familiales. ANR "Vulnérabilité, Milieu, Climat et Société". Paris: ANR/ IRAM.

Bricas, N., C. Tchamda, and F. Mouton, eds. 2016. "L'Afrique à la conquête de son marché alimentaire intérieur. Enseignements de dix ans d'enquêtes auprès des ménages d'Afrique de l'Ouest, du Cameroun et du Tchad." Études de I'AFD 12: 132. Paris: Agence Française de Développement (AFD).
Catley, A., and Y. Aklilu. 2013. "Moving Up or Moving Out? Commercialisation, Growth and Destitution in Pastoralist Areas." In Pastoralism and Development in Africa: Dynamic Change at the Margins, edited by A. Catley, J. Lind, and I. Scoones, 85-97. New York: Routledge.

CILSS (Permanent Interstate Committee for Drought Control in the Sahel). 2016. Landscapes of West Africa: A Window on a Changing World. Reston, VA, USA: USGS.

CNFA (Cultivating New Frontiers in Agriculture). 2016. Value Chain and End Market Assessment - Small Ruminants. Resilience and Economic Growth in the Sahel-Accelerated Growth (REGIS-AG). Washington, DC: USAID.

Corniaux, C. 2015. L'industrie laitière en Afrique de l'Ouest : histoire stratégies et perspectives. Dakar, Senegal: Projet Milky Way for Development / PPZS/ CIRAD.

Corniaux, C. and G. Duteurtre. 2018. Pour une alliance renouvelée entre industriels et éleveurs laitiers en Afrique de I'Ouest. Note d'orientation 2. Dakar: Oxfam/ CIRAD.

Corniaux, C., B. Thébaud, A. Powell, A. Apolloni, and I. Touré, 2018. CrossBorder Livestock Mobility: Challenges for West-Africa. Policy Brief. Dakar, Senegal: FAO/ CIRAD.

De Haan, C. 2016. Prospects for Livestock-Based Livelihoods in Africa's Drylands. Washington, DC: World Bank, Washington DC, USA.

De Haan, C., E. Dubern, B. Garancher, and C. Quintero. 2016. Pastoralism Development in the Sahel: A Road to Stability? Washington, DC: World Bank.

De Leeuw, J., P. Osano, M. Said, A. Ayantunde, S. Dube, C. Neely, A. Vrieling, P. Thornton, and P. Ericksen. 2020. "The Pastoral Farming System: Balancing between Tradition and Transition." In Farming Systems and Food Security in Africa: Priorities for Science and Policy under Global Change, edited by J. Dixon, D. P. Garrity, J-M. Boffa, T. O. Williams, and T. Amede. New York: Routledge.

Didier, R., V. Alary, C. Corniaux, G. Duteurtre, and P. Lhoste. 2019.

Dynamique des élevages pastoraux et agropastoraux en Afrique intertropicale. Versailles: Quae.

Dixon, S., and J. Holt. 2010. Livelihood Zoning and Profiling Report: Mali (1) and Burkina Faso (2). FEG Consulting / United States Agency for International Development USAID)/ Famine Early Warning Systems Network (FEWS NET).

Dominguez-Salas, P., D. Kauffmann, C. Breyne, and P. Alarcon. 2019. "Leveraging Human Nutrition through Livestock Interventions: Perceptions, Knowledge, Barriers and Opportunities in the Sahel." Food Security 11: $777-96$

Dongmo, A., E. Vall, M. A. Diallo, P. Dugue, A. Njoya and J. Lossouarn. 2012. "Herding territories in Northern Cameroon and Western Burkina Faso: spatial arrangements and herd management". In Pastoralism 2, 26 (2012).
(1) Background and understanding

(2) Regional drivers

(3) Regional organisations

Agro-pastoralism-based

4.1 Definitions

4.2 Demography and geography

4.3 Regional consumption and production trends

4.4 Livelihoods of agro-pastoralists

4.5 Production systems

4.6 Food system outcomes

4.7 Institutional drivers

4.8 Risks and resilience

4.9 The COVID-19 pandemic

4.10 Agency and development paradigms

\subsection{Summing up}

\section{References}

(5) Grains-and-legumes-based

6) Rice-and-horticulture

(7) Coastal maritime fisheries

(8) Tropical mixed tree and

8 food crops systems

9) Toward enhanced resilience 
Dosio, A., A. G. Turner, A. T. Tamoffo, M. B. Sylla, C. Lennard, R. G. Jones, L. Terray, G. Nikulin, and B. Hewitson. 2020. "A Tale of Two Futures: Contrasting Scenarios of Future Precipitation for West Africa from an Ensemble of Regional Climate Models." Environmental Research Letters 15 (6): 064007.

Dufumier, M. 2005. Etude des systèmes agraires et typologie des systèmes de production agricole dans la région cotonnière du Mali. Bamako, Mali: Programme d'amélioration des systèmes d'exploitation en zone cotonnière (PASE)/ Compagnie Malienne de Développement des Textiles (CMDT)/ Institut National Agronomique Paris-Grignon (INAPG).

OECD/SWAC (2009), Atlas régional de I'Afrique de I'Ouest, Cahiers de I'Afrique de I'Ouest, OECD Publishing, Paris.

Falconnier, G. N., K. Descheemaeker, B. Traore, A. Bayoko, and K. E. Giller. 2018. "Agricultural Intensification and Policy Interventions: Exploring Plausible Futures for Smallholder Farmers in Southern Mali." Land Use Policy 70: 623-34.

Falconnier, G. N., K. Descheemaeker, T. A. Van Mourik, O. M. Sanogo, and K. E. Giller. 2015. "Understanding Farm Trajectories and Development Pathways: Two Decades of Change in Southern Mali." Agricultural Systems 139: 210-22.

FAO (Food and Agriculture Organisation). 2018. Pastoralism in Africa's Drylands: Reducing Risks, Addressing Vulnerability and Enhancing Resilience. Rome: FAO.

FAO (Food and Agriculture Organisation), UNICEF (United Nations Children's Fund), and WFP (World Food Programme). 2018. Sahel: Early Action and Scale-Up of Emergency Response 2018. Rome: FAO.

Gonin, A. 2016. "Les éleveurs face à la territorialisation des brousses : repenser le foncier pastoral en Afrique de I'Ouest." Annales de géographie, Armand Colin 2 (707): 28-50.

Gonin, A., and D. Gautier. 2015. "Shift in Herders' Territorialities from Regional to Local Scale: The Political Ecology of Pastoral Herding in Western Burkina Faso." Pastoralism: Research, Policy and Practice 5: 7.

Greenough, K., and O. Neya. 2016. Governance of Commons, Management of Pastoral Zones in Burkina Faso. Ouagadougou, Burkina Faso.

Hesse, C., S. Anderson, L. Cotula, J. Skinner, and C. Toulmin. 2013. Managing the Boom and the Bust, Supporting Climate Resilient Livelihoods in the Sahel. London: International Institute for Environment and Development (IIED).

Hilhorst, T., J. Nelen, and N. Traoré. 2011. Agrarian Change below the Radar Screen: Rising Farmland Acquisitions by Domestic Investors in West Africa. Results from a Survey in Benin, Burkina Faso and Niger. Amsterdam : Netherlands Development Organisation SNV/ Royal Tropical Institute (KIT)/ LANDac IS Academy.
Hochet, P., and C. Guissou. 2010. "Une politique d'adaptation climatique inachevée mais persistante, le cas de la zone pastorale du CEZIET de Samorogouan (Burkina Faso)." Sustentabilidade em Debate 1 (2): 59. Ouagadougou, Burkina Faso: Labouratoire Citoyennetés.

Ickowicz, A., V. Ancey, C. Corniaux, G. Duteurtre, R. Poccard-Chappuis, I. Touré, E. Vall, and A. Wane. 2012. Crop-Livestock Production Systems in the Sahel: Increasing Resilience for Adaptation to Climate Change and Preserving Food Security. Montpellier, France: UMR SELMET / CIRAD-INRA-SUPAGRO.

Inter-réseaux. 2015. "Jeunesses rurales africaines : contours, aspirations et perspectives." Grain de Sel, no. 71. Paris: Inter-réseaux Développement Rural.

Inter-réseaux. 2017. "Le pastoralisme a-t-il encore un avenir en Afrique de I'Ouest?." Grain de Sel, no. 73-74. Paris: Inter-réseaux Développement Rural.

Inter-Réseaux. 2018. Pastoral Livestock Farming in Sahel and West Africa: 5 Preconceptions Put to the Test. Projet Régional d'Appui au Pastoralisme au Sahel (PRAPS). Ouagadougou, Burkina Faso: CILSS / ECOWAS / WAEMUUEMOA/ World Bank.

Kamuanga, J. B., Mulumba, J. Somda, Y. Sanon, and H. Kagoné. 2008. Élevage et marché régional au Sahel et en Afrique de I'Ouest, Potentialités et défis. Paris: Club du Sahel et de I'Afrique de I'Ouest-OCDE/ CEDEAO.

Krätli, S., C. Huelsebusch, S. Brooks, and B. Kaufmann. 2013. "Pastoralism: A Critical Asset for Food Security under Global Climate Change." Animal Frontiers 3 (1): 42-50.

Krätli, S., B. Kaufmann, H. Roba, P. Hiernaux, W. Li, M. Easdale, and C. Hülsebusch. 2015. A House Full of Trap Doors: Identifying Barriers to Resilient Drylands in the Toolbox of Pastoral Development. London: IIED.

Magnani, S., M. Ouedraogo, A. Barry, and F. Dao. 2020. Jeunes pasteurs en ville - Contexte institutionnel des jeunes issus des populations pastorales. Perceptions, dispositifs et stratégies d'action publique au Burkina Faso. Rome: FAO.

Manoli, C., V. Ancey, C. Corniaux, A. Ickowicz, B. Dedieu, and C. H. Moulin. 2014. "How Do Pastoral Families Combine Livestock Herds with Other Livelihood Security Means to Survive? The Case of the Ferlo Area in Senegal." Pastoralism: Research, Policy and Practice 4 (3).

Menghistu, H. T., A. Z. Abraha, G. Tesfay, and G. T. Mawcha. 2020.

"Determinant Factors of Climate Change Adaptation by Pastoral/Agropastoral Communities and Smallholder Farmers in Sub-Saharan Africa: A Systematic Review." International Journal of Climate Change Strategies and Management 12 (3): 305-21.

Mertz, O., C. Mbow, J. Østergaard Nielsen, A. Maiga, D. Diallo, A. Reenberg A. Diouf, B. Barbier, I. Bouzou Moussa, M. Zorom, I. Ouattara, and D. Dabi. 2010. "Climate Factors Play a Limited Role for Past Adaptation Strategies in West Africa." Ecology and Society 15 (4): 25.
(1) Background and understanding

(2) Regional drivers

(3) Regional organisations

Agro-pastoralism-based

4.1 Definitions

4.2 Demography and geography

4.3 Regional consumption and production trends

4.4 Livelihoods of agro-pastoralists

4.5 Production systems

4.6 Food system outcomes

4.7 Institutional drivers

4.8 Risks and resilience

4.9 The COVID-19 pandemic

4.10 Agency and development paradigms

\subsection{Summing up}

\section{References}

(5) Grains-and-legumes-based

6) Rice-and-horticulture

(7) Coastal maritime fisheries

8 Tropical mixed tree and

8 food crops systems

9 Toward enhanced resilience 
Nelen, J., N. Traoré, and A. Coulibaly. 2015. "Changing Land Use, Tenure, Interdependency and Resilience: The Uncertain Fate of Grazing Lands in Farming Systems in Mali and Burkina." Paper presented at LANDac International Conference on Land Governance for Equitable and Sustainable Development, Utrecht, the Netherlands, July 8-10, 2015.

Nelen, J., N. Traoré, and M. Ouattara. 2004. From Colonisation to Consultation: Regulating the Use of a Pastoral Zone in Samorogouan, Burkina Faso. Issue Paper 129. Edinburgh, Great-Britain: SNV/ IIED.

Nugteren, H., and C. Le Côme. 2016. Libérer le potentiel du pastoralisme pour développer l'Afrique de I'Ouest [Unleashing the potential of pastoralism to develop West Africa]. Edited by F. Zaal, T. Hilhorst, and J. Sluijs. Amsterdam: SNV/ KIT.

Rangé. 2020. Jeunes pasteurs en ville - Réseaux et trajectoires migratoires des jeunes d'origine pastorale, Tchad, Burkina Faso. Rome: FAO.

Ouoba-Ima, S. 2018. "Caractéristiques socio-démographiques et dynamique de la transhumance des bouviers peuls de la Nouhao au Burkina Faso." VertigO 18 (2).

Sanogo, O. M., N. de Ridder, and H. van Keulen. 2010. "Diversité et dynamique des exploitations agricoles mixtes agriculture-élevage au sud du Mali." Cahiers agriculture 19 (3)

Sidibé, M., B. Dieppois, J. Eden, G. Mahé, J. E. Paturel, E. Amoussou, B. Anifowose, M. van de Wiel, and D. Lawler. 2020. "Near-Term Impacts of Climate Variability and Change on Hydrological Systems in West and Central Africa." Climate Dynamics 54: 2041-70.

Simonet, C., S. M. Traoré, S. Brunelin, and L. Royer. 2018. Marchés de bétail au sahel, intégration des marchés, rôle du climat et des conflits dans la formation des prix. Program 'Building Resilience and Adaptation to Climate Extremes and Disasters' (BRACED). London: DFID/UK-Aid.

SNV (Netherlands Development Organisation) and KIT (Royal Tropical Institute). 2015. Enhancing Rural Labour Productivity: Reaching the Rural Poor. Amsterdam: SNV/KIT.

Thébaud, B., and C. Hesse. 2006. "Will Pastoral Legislation Disempower Pastoralists in the Sahel?" Indigenous Affairs 1 (6): 14-23.

Tondel, F. 2019. Dynamiques régionales des filières d'élevage en Afrique de I'Ouest : Etude de cas centrée sur la Côte d'Ivoire dans le bassin commercial central. Political Economy Dynamics of Regional Organisations in Africa 241. Maastricht, the Netherlands: ECDPM.

Touré, I., A. Ickowicz, A. Wane, I. Garba, and P. Gerber. 2012. Atlas of Trends in Pastoral Systems in the Sahel 1970-2012. Rome: FAO/ CIRAD.

Turner, M. 2009. "Capital on the Move: The Changing Relation between Livestock and Labour in Mali, West Africa." Geoforum 40 (5): 746-55.

Turner, M. D., J. G. McPeak, and A. Ayantunde. 2014. "The Role of Livestock
Mobility in the Livelihood Strategies of Rural Peoples in Semi-arid West Africa." Human Ecology 42: 231-47.

Turner, M., and E. Schlecht. 2019. "Livestock Mobility in Sub-Saharan Africa: A Critical Review." Pastoralism: Research, Policy and Practice 9: 13.

Umutoni, C., and A. A. Ayantunde. 2018. "Perceived Effects of Transhumant Practices on Natural Resource Management in Southern Mali." Pastoralism 8 $(8)$

UNECA (United Nations Economic Commission for Africa). 2017. New Fringe Pastoralism: Conflict and Insecurity and Development in the Horn of Africa and the Sahel. Addis Ababa, Ethiopia: UNECA.

UNOWAS (United Nations Office for West Africa and the Sahel). 2018.

Pastoralisme et sécurité en Afrique de l'Ouest et au Sahel, vers une coexistence pacifique. Dakar, Senegal: UNOWAS.

Valerio, V. C., O. J. Walther, M. Eilittä, B. Cissé, R. Muneepeerakul, and G. A. Kiker. 2020. "Network Analysis of Regional Livestock Trade in West Africa." PLOS ONE 15 (5): e0232681.

Van der Lee, J., H. Schiere, R. Bosma, E. de Olde, S. Bol, and Jessica Cornelissen. 2014. Aid and Trade for Livestock Development and Food Security in West Africa. The Hague, the Netherlands: Wageningen Research University.

Food security surveys by National institutes of Early Warning Systems and World Food Program:

AGVSAN. 2014. Analyse Globale de la Vulnérabilité, de la Sécurité Alimentaire et de la Nutrition (AGVSAN) Burkina Faso. Rome, Italy: WFP (World Food Program)/ FEWS-Net.

ENSAN. 2013. Enquête Nationale sur la Sécurité Alimentaire et la Nutrition - ENSAN 2013, Données primaires collectées en juin 2013. Early Warning System-Système d'Alerte Précoce (EWS-SAP). Dakar, Senegal: SE/CNSA (Secrétariat Exécutif du Conseil National à la Sécurité Alimentaire)/ WFP/ UNICEF/ FAO/ OMS.

ENSAN. 2018 (2016). Enquête Nationale sur la Sécurité Alimentaire et la Nutrition, Septembre 2018 (Mars 2016) ENSAN Mali, Rapport de Synthèse. Early Warning System-Système d'Alerte Précoce (EWS-SAP). Bamako, Mali: Mali Food Security Cluster.

VIA, 2015. Enquête Conjointe sur la Vulnérabilité à I'Insécurité Alimentaires des Ménages au Niger (Décembre 2010 - Janvier 2015). Système d'Alerte Précoce et de Prévention des Catastrophes (SAP/PC). Niamey, Niger: INS (Institut National des Statistiques)/ WFP/ PNUD/ FAO/ Save the Children/ FEWS-Net.
(1) Background and understanding

(2) Regional drivers

(3) Regional organisations

Agro-pastoralism-based

4.1 Definitions

4.2 Demography and geography

4.3 Regional consumption and production trends

4.4 Livelihoods of agro-pastoralists

4.5 Production systems

4.6 Food system outcomes

4.7 Institutional drivers

4.8 Risks and resilience

4.9 The COVID-19 pandemic

4.10 Agency and development paradigms

\subsection{Summing up}

\section{References}

(5) Grains-and-legumes-based

6) Rice-and-horticulture

(7) Coastal maritime fisheries

(8) Tropical mixed tree and

8 food crops systems

9) Toward enhanced resilience 


\section{Grains-and- legumes-based food system}

By Bertus Wennink

\subsection{Definitions}

5.2 Demography and geography

5.3 Regional consumption and production trends

5.4 Livelihoods of producer communities

5.5 Production systems

5.6 Food system outcomes

5.7 Institutional drivers

5.8 Risks and resilience

5.9 Food system impacts of and responses to the COVID-19 pandemic

5.10 Agency and development interventions

5.11 Summing up: toward leverage points for future interventions

References

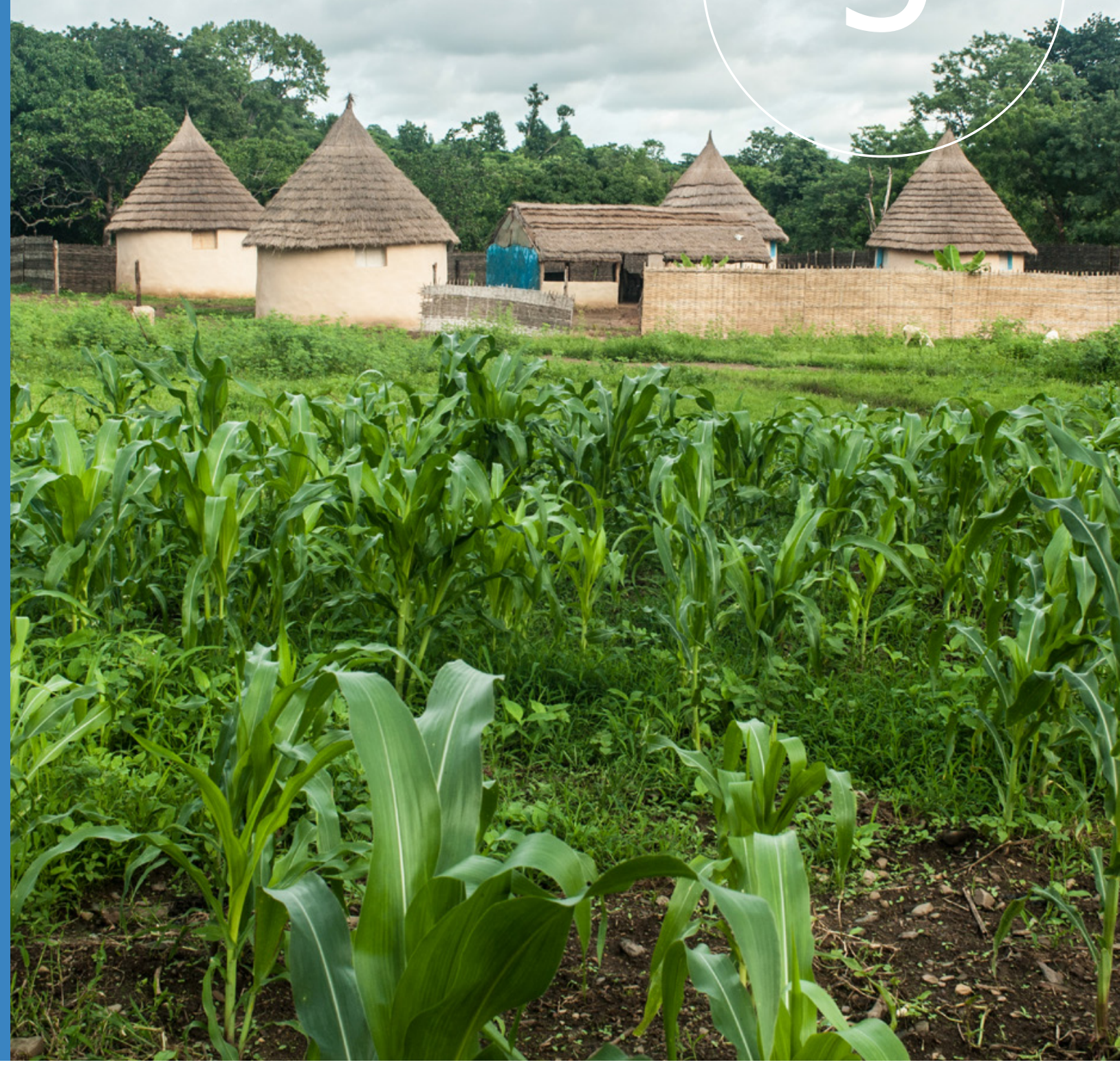

$\oplus \oplus$ 
This chapter contains a description and an analysis of food systems based on the production, trade, processing, and consumption of grains and legumes. The chapter has 11 sections. The first defines a grains-and-legumes-based food system, followed by a discussion in section 5.2 of their demography, location, and importance to livelihoods. Section 5.3 describes the trends in consumption and production, and section 5.4 details the livelihoods of people living in this food system. Section 5.5 covers the production system, and section 5.6 addresses multiple food system outcomes. Section 5.7 highlights the important institutional drivers of particular changes in the system, while section 5.8 identifies trends, risks, and systems resilience. Section 5.9 is an analysis of food system impacts of the COVID-19 pandemic. Section 5.10 contains an examination of past agency and development efforts to influence grains-and-legumesbased food system and lessons for the future. The final section outlines some conclusions about leverage points for enhanced resilience of the grains-and-legumes-based food system.

\subsection{Definitions}

Millet, sorghum, and maize are grown in rain-fed agricultural systems in a large area of West Africa, stretching from the Sahel zone (with millet as an important staple) to the Guinea zone (where maize is the dominant food crop, together with root crops) and the in-between Sudan zone (where all three cereals are being grown). The cereal-legume cropping system produces these coarse grains ${ }^{1}$ in association with legumes. Cowpea, groundnut, Bambarra groundnut, pigeon pea, and soybean are the most commonly cultivated legumes in West Africa, with mainly cowpea and groundnuts being associated with millet, sorghum, and maize in the Sudano-Sahelian zone. Farmers combine the production of these cereals and legumes through intercropping or rotation schemes, which has agronomic as well food benefits (Snapp et al. 2018).

The average annual rainfall in the Sudano-Sahelian agroclimatic zone ranges from 600 to 1,100 millimeters per year, but climatic change is causing frequent weather extremes with long periods of drought or high peaks in rainfall. In Burkina Faso and Mali, the Sudano-Sahelian zone has become the breadbasket for these countries given its suitability for producing coarse grains and legumes and the rural development investments made in the zone during the last four decades (Kaminksi 2008).

\subsection{Demography and geography}

Excluding Nigeria, the nations of Burkina Faso, Mali, and Niger are the most important millet- and sorghum-producing countries in West Africa. As for maize, Mali is the most important producer, followed by Ghana, Burkina Faso, and Benin. As of 2018, Niger was by far the most important cowpea-producing country in the region, followed by Burkina Faso and Ghana. ${ }^{2}$

The cereal-legume cropping system, which associates these crops through intercropping or relay cropping, is the typical agricultural production system in the Sudano-Sahelian zone. In the Sahel zone, millet is the dominant cereal as part of the agro-pastoralist production system, while maize takes over in the Soudano-Guinean zone, where it is associated with root crops (Kaminski 2008; Snapp, Rahmanian, and Batello 2018). The system involves a considerable portion of the populations of Burkina Faso, Mali, northern Ghana, Benin, southern parts of Niger along the border with Nigeria and Benin, and the central belt of Senegal. In Burkina Faso, Mali, and Niger, the Sudano-Sahelian zone overlaps with roughly 50 percent of the country's population. In general, population density varies in this food system zone, ranging from 15 to 85 people per square kilometer but generally exceeding the national population density in Burkina Faso, Mali, and Niger. In northern Ghana and Benin, the estimated population density varies between 40 and 85 people per square kilometer and remains below the national average of these countries. ${ }^{3}$

Altogether, an estimated 32 million people are at the heart of the grains-and-legumes-based food system and represent about

15 percent of West Africa's the total population, excluding Nigeria. ${ }^{4}$ This food system has both national and regional importance because millet, sorghum, maize, and cowpea are traded within and between West African countries (Maur and Shepherd 2015).
(1) Background and understanding

(2) Regional drivers

(3) Regional organisations

(4) Agro-pastoralism-based

5 Grains-andlegumes-based

\subsection{Definitions}

5.2 Demography and geography

5.3 Regional consumption and production trends

5.4 Livelihoods of producer communities

5.5 Production systems

5.6 Food system outcomes

5.7 Institutional drivers

5.8 Risks and resilience

5.9 The COVID-19 pandemic

5.10 Agency and development interventions

5.11 Summing up References

(6) Rice-and-horticulture

(7) Coastal maritime fisheries

(8) Tropical mixed tree and

8 food crops systems

9 Toward enhanced resilience 


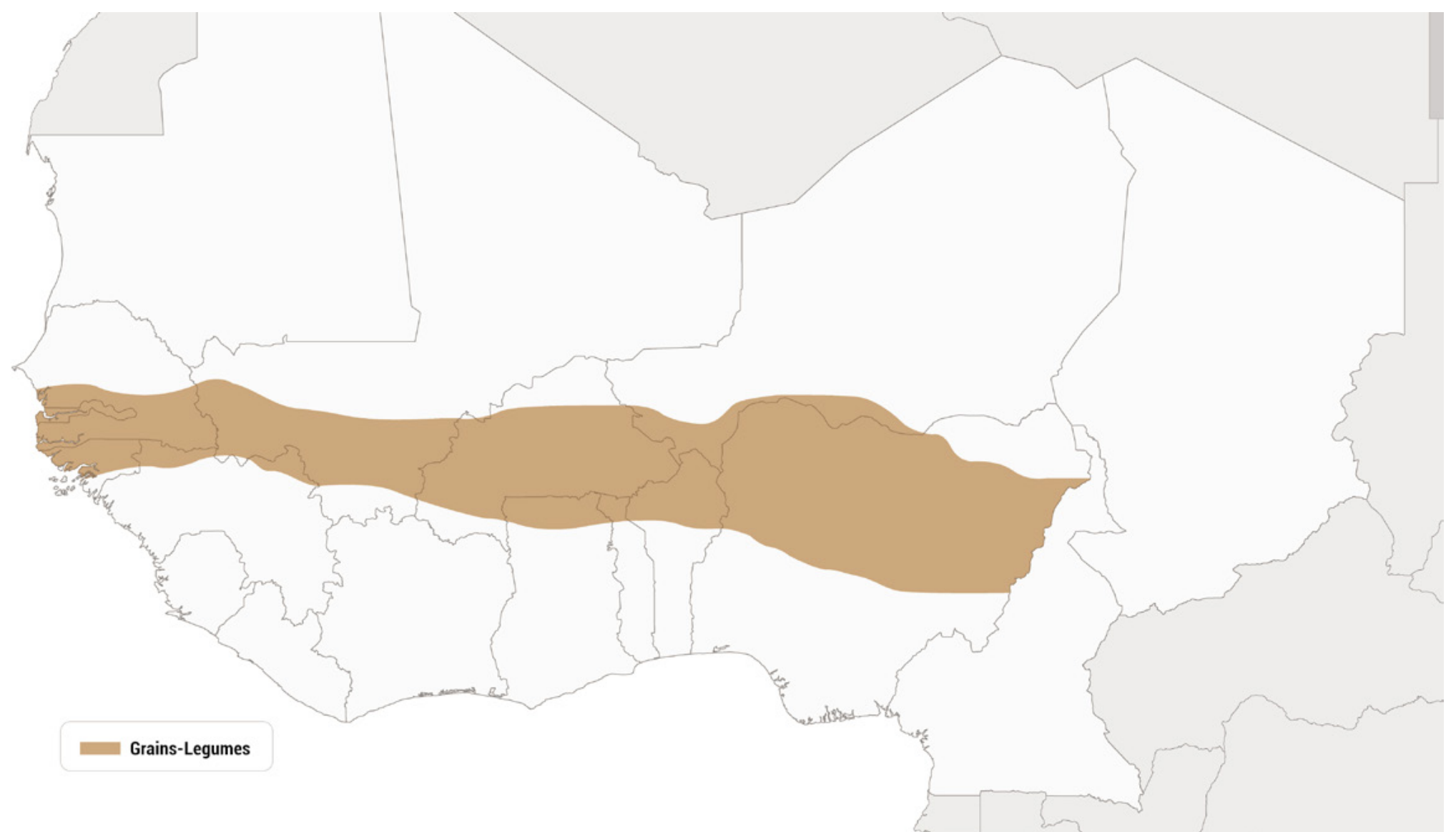

Map 5.1 Grains-and-legumes-based food system in West Africa

\subsection{Regional consumption and production trends}

In 2017 millet, sorghum, and maize represented 50 percent of the daily food intake (energy) in West Africa, with root crops accounting for 20 percent. In the Sahel countries (Burkina Faso, Mali, Niger, and Senegal), cereals accounted for 60 percent of the daily food intake, and root crops, only 2 percent. Millet, sorghum, and maize accounted for about 60 percent of the daily food intake through cereals, and rice, 30-40 percent. In Niger, millet alone represented 60 percent of the daily food intake through cereals. In the coastal countries (Benin, Côte d'Ivoire, Ghana, Guinea, Guinea-Bissau,
Liberia, Sierra Leone, and Togo), cereals were estimated to be 40 percent of the daily food intake, and root crops, 20-40 percent. In these countries, rice contributed $40-85$ percent of daily food intake through cereals. ${ }^{5}$

In West Africa, vegetal products contributed about 80 percent to the daily supply in proteins (quantity). Pulses represented 15 percent of this supply through vegetal products. In Niger (the top producer of cowpea in West Africa), pulses contributed 30 percent of daily supply through vegetal-based proteins. In Benin, Burkina Faso, Mali, Mauritania, Sierra Leone, and Togo, this percentage varied
(1) Background and understanding

(2) Regional drivers

(3) Regional organisations

(4) Agro-pastoralism-based

5 Grains-andlegumes-based

5.1 Definitions

5.2 Demography and geography

5.3 Regional consumption and production trends

5.4 Livelihoods of producer communities

5.5 Production systems

5.6 Food system outcomes

5.7 Institutional drivers

5.8 Risks and resilience

5.9 The COVID-19 pandemic

5.10 Agency and development interventions

5.11 Summing up References

6) Rice-and-horticulture

(7) Coastal maritime fisheries

Tropical mixed tree and

8 food crops systems

9 Toward enhanced resilience 
between 10 and 20 percent. In the other countries of the region, this percentage did not exceed 10 percent. $^{6}$

During the 2009-19 period, the regional production of cereals increased by 33 percent, with a 30 percent increase for sorghum, 17 percent decrease for millet, and 64 percent increase for maize. The regional production of cowpea almost doubled during the same period (figure 5.1).

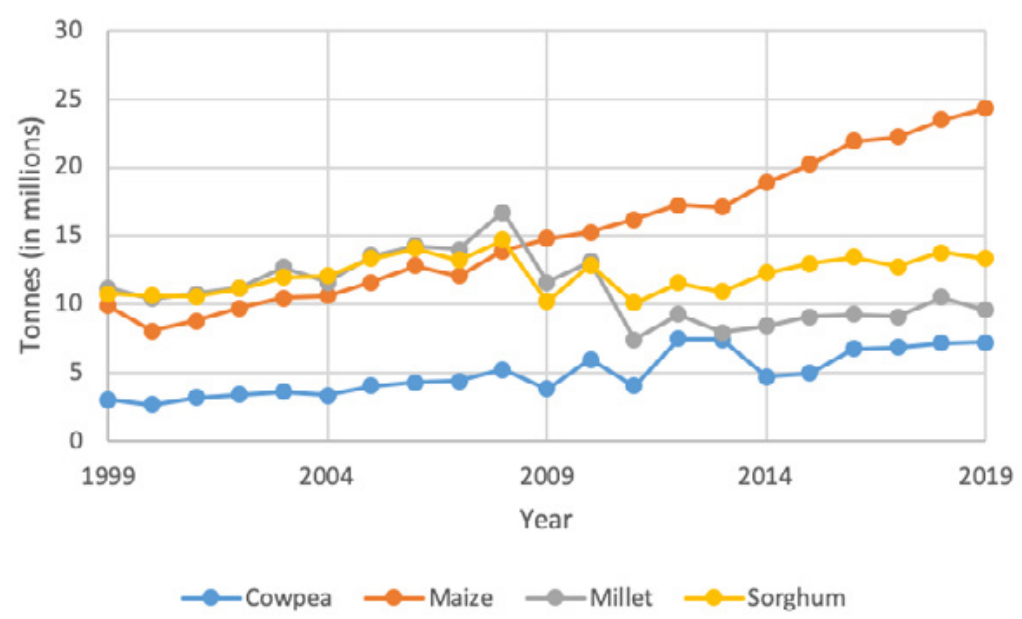

Figure 5.1 Production of Millet, Sorghum, Maize, and Cowpea in West Africa Source: FAOSTAT, Food and Agriculture Organisation, Rome (accessed February $\overline{2,2021}$ )

In 2018 the West Africa region produced about 22 million tons of maize, 14 million tons of sorghum, and 10 million tons of millet. Burkina Faso, Mali, and Niger were responsible for 66 percent of the region's millet production and in combination with Benin, Ghana, and Togo produced 48 percent of the region's sorghum. Mali was the most important producer of maize, with 16 percent of regional production, followed by Ghana with 10 percent, Burkina Faso and Benin with 8 percent each, and Côte d'Ivoire with 5 percent. Cowpea production reached 6 million tons in 2018, with Niger accounting for 40 percent of the region's production, followed by Burkina Faso and Ghana with 10 percent each. ${ }^{7}$

\subsection{Livelihoods of producer communities}

There are three main types of farmer households in the typica grains-and-legumes-based agricultural production system: (1) highly market-oriented large farmer households linked to global cotton markets, (2) mixed market-oriented and subsistence-based medium-sized farmer households, and (3) subsistence-based small farmer households (Douxchamps et al. 2016; Dufumier 2005; Toulmin and Guèye 2003; Woittiez et al. 2015). This farmer household typology, thoroughly described for Burkina Faso and Mali and, to a lesser extent, for Senegal and northern Ghana, sheds light on their food security situation and strategies.

Subsistence-based farmer households in Burkina Faso and Mali have up to 12 members, cultivate between 3 and 6 hectares, raise goats and sheep only, and lack any agricultural equipment. These households rely on crop and livestock production for their income and food. They undertake other income-generating activities such as farm labour and petty trade in order to buy food when their own staple food production does not allow for self-sufficiency (FEWS NET 2010a, 2010b).

The market-oriented farmer households are significantly larger, with 20 to 35 persons, and the area cultivated is higher, 6 to 20 hectares typically, although up to 40 hectares in parts of Burkina Faso and Mali. Besides small ruminants, these households have oxen for animal traction, manure, milk, and meat and are well equipped for agricultural operations possessing ploughs, carts, and even smal tractors. Depending on the agroecological conditions, they might have other assets, such as orchards, and access to inland valleys, where they grow rice and vegetables under rain-fed and small-scale irrigation conditions. In an average year, these households are self-sufficient in food and sell surplus staple food production (Dufumier 2005; FEWS NET 2010a, 2010b).
(1) Background and understanding

(2) Regional drivers

(3) Regional organisations

(4) Agro-pastoralism-based

5 Grains-andlegumes-based

5.1 Definitions

5.2 Demography and geography

5.3 Regional consumption and production trends

\subsection{Livelihoods of producer} communities

5.5 Production systems

5.6 Food system outcomes

5.7 Institutional drivers

5.8 Risks and resilience

5.9 The COVID-19 pandemic

5.10 Agency and development interventions

5.11 Summing up References

6) Rice-and-horticulture

(7) Coastal maritime fisheries

Tropical mixed tree and

food crops systems

9 Toward enhanced resilience 


\subsection{Production systems}

Traditionally, when arable land was still abundant, farmers in the main millet and sorghum production zones left their fields after harvest for several years and allowed the regeneration of natural vegetation to restore soil fertility. With increased pressure on land the fallow period was reduced or it was no longer possible to restock soil nutrients. The cultivation of legumes associated with cereals through intercropping or relay cropping (rotation) is now a common practice of farmers to restore soil fertility (Woittiez et al. 2015).

Legumes contribute to soil nutrient recapitalisation through biologically fixing atmospheric nitrogen and improving the biological turnover of phosphorous. With their abundant leaves covering the soil, legumes also reduce soil erosion. While millet, sorghum, and maize are important staples for the farmer households, with surplus being sold on local markets, pulses such cowpeas and beans are affordable sources of protein for the households. Another nonnegligible advantage of legumes is their use of foliage as fodder or mulch (Franke et al. 2018; Snapp et al. 2018; Sogoba et al. 2020).

The introduction of cash crops, notably cotton in Benin, Burkina Faso, Côte d'Ivoire, Mali, and to a lesser extent Ghana and Niger, has largely determined how vast portions of these food systems have evolved and their contribution to local and national economies and, in particular, to food security within and outside the production zone. Cotton became successful because of the agronomic and socioeconomic complementarities between the types of crops involved (Kaminski 2008).

Typical land allocation in the cotton-inclusive grains-and-legumesbased food system is 40 percent cotton, 25 percent sorghum or maize (with maize increasingly replacing sorghum), and 10 percent legumes, most often cowpea. Millet is grown more often northward in the Sahelian zones, in association with livestock in agropastoral areas. The main food crop for households is maize or sorghum, while cotton provides cash income and access to inputs. Farmers usually apply a one-year rotation of cotton with cereals, whereby cereals benefit from the rear effect of fertilisers applied on cotton during the preceding year (Kaminski 2008).

The prevailing organisation of the cotton supply was based on implicit contract farming arrangements between organised smallholder farmers and parastatals in charge of processing and marketing cotton. The parastatals delivered a comprehensive package of services (extension and advice, access to inputs and credit) to farmers who supplied cotton. Over time, governments delegated other rural development tasks to the cotton parastatals, such as literacy trainings and maintaining feeder roads. The overal farming and cropping systems benefitted from this comprehensive and integrated approach, its link with input supply, and the increased use of inputs. The result was improved agricultural production and yields (Asinyo et al. 2015; Hollinger and Staatz 2015).

Cattle have always been an integral element of these production systems as a source of protein and as part of a savings strategy. Agricultural extension services have promoted animal traction to expand cropping areas in general and the area under cotton in particular. With time, farmers have increasingly integrated cattle into their production systems, often hiring Fulani herders to manage their herds for them. Cattle are an indispensable part of the farming system for many farmer households. Besides animal traction, they provide manure in a zone where there is less room for fallow practices and contribute to the food and nutrition security of farmers' households (Elbehri et al. 2013; Hollinger and Staatz 2015).

Women and men often grow different crops or keep different livestock. They can also grow the same crops on distinct fields for local consumption and the market. Labour division though is often gender specific, but men and women do work together. Although gender roles are distinct, they are narrowly related and increasingly flexible (Gnisci 2016).

Governments have stimulated crop diversification among smallholder farmers to diminish their dependence on cotton for income and as a response to 2008 food trade disruptions. Crop
(1) Background and understanding

(2) Regional drivers

(3) Regional organisations

(4) Agro-pastoralism-based

5 Grains-andlegumes-based

5.1 Definitions

5.2 Demography and geography

5.3 Regional consumption and production trends

5.4 Livelihoods of producer communities

\subsection{Production systems}

5.6 Food system outcomes

5.7 Institutional drivers

5.8 Risks and resilience

5.9 The COVID-19 pandemic

5.10 Agency and development interventions

5.11 Summing up References

6) Rice-and-horticulture

(7) Coastal maritime fisheries

(8) Tropical mixed tree and

(8) food crops systems

9 Toward enhanced resilience 
diversification programs have introduced new high-yielding and marketable varieties of food crops such as rice, sorghum,

groundnuts, and cowpea as well as new crops such as maize. The latter has received significant attention in breeding and varietal creation because of growing urban demand and its high yielding potential. Maize has rapidly become part of local household diets and cropping systems. Increased demand due to population growth and changes in quality are the main drivers for the increase in production of millet, sorghum, maize, and cowpea. Several governments facilitated access to agricultural inputs for farmers through subsidised inputs, which also contributed to production increase. Nevertheless, a large part of the growth in production is due to bringing more land into production rather than improvements in crop yields or labour productivity (Elbehri et al. 2013; PAM 2014; Staatz and Hollinger 2016).

With the exception of maize in Mali, yields did not show a comparable increase during the 2014-18 period in Burkina Faso, Mali, and Niger. ${ }^{8}$ For instance, in the case of Mali, yields of these crops were considered much lower than the optimal, with yields gaps between 50 and 70 percent. Average actual yields for maize were 2.7 tons per hectare against its potential of 8 tons per hectare; millet, 0.9 against 2.5 tons per hectare; sorghum, 1.0 against 3.5 tons per hectare; and cowpea, 0.6 against 2 tons per hectare. As such, there is still great opportunity to reduce the yield gap by increasing actual yields through sustainable intensification (Kojo Kondo. AGRA Mali, pers. comm.).

\subsection{Food system outcomes}

5.6.1 Household food and nutrition security

In the twenty-first century, the West Africa region has increasingly imported rice and wheat (figure 5.2 and 5.3). As for millet, sorghum, and maize, the region principally relies on its own production, whereby cross-border trade between countries plays an important role (Maur and Shepherd 2015).

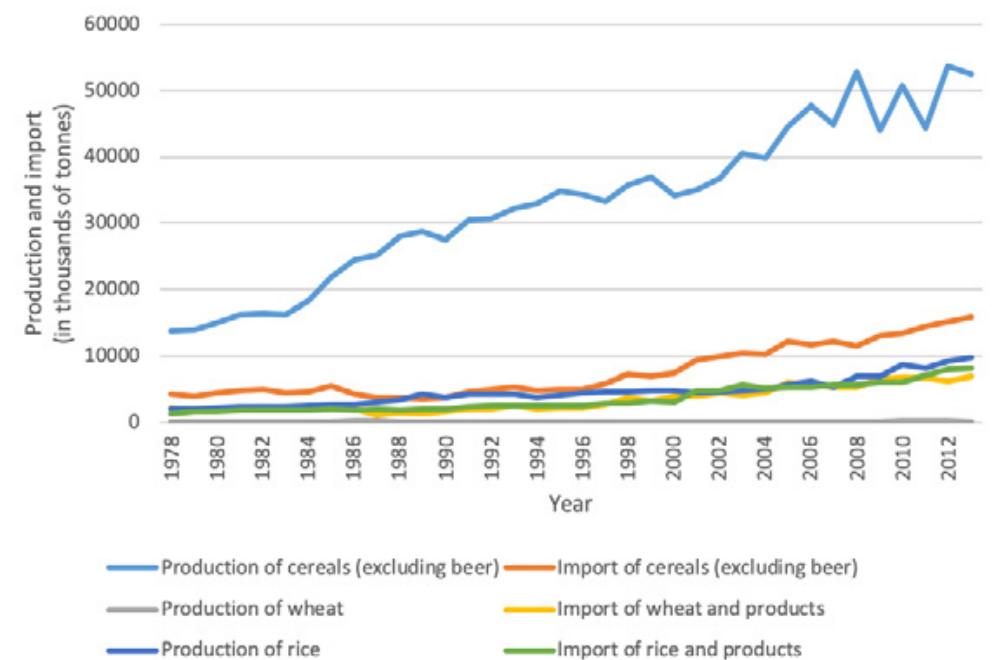

Figure 5.2 Production and Imports of Grain in West Africa, 1978-2013 Source: FAOSTAT, Food and Agriculture Organisation, Rome (accessed February 1, 2021).

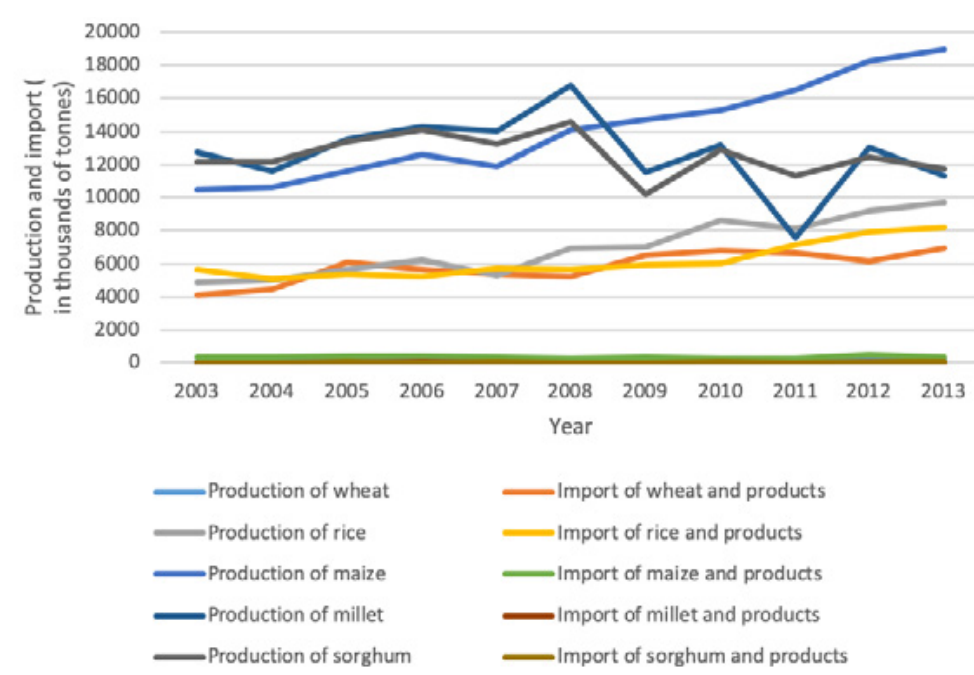

Figure 5.3 Production and Imports of Wheat, Rice, Maize, Millet, and Sorghum in West Africa, 2003-2013
(1) Background and understanding

(2) Regional drivers

(3) Regional organisations

(4) Agro-pastoralism-based

5 Grains-andlegumes-based

5.1 Definitions

5.2 Demography and geography

5.3 Regional consumption and production trends

5.4 Livelihoods of producer communities

5.5 Production systems

5.6 Food system outcomes

5.7 Institutional drivers

5.8 Risks and resilience

5.9 The COVID-19 pandemic

5.10 Agency and development interventions

5.11 Summing up References

6) Rice-and-horticulture

(7) Coastal maritime fisheries

(8) Tropical mixed tree and

food crops systems

9 Toward enhanced resilience 
According to the various historical data available for West African countries, the food supply has improved over the last four decades in terms of energy supply (grains). Burkina Faso, Ghana, Mali, and Nigeria showed a 50 percent increase in grain production between 1980 and 2009. Protein supply also augmented in most countries, in part because much of the protein consumed is cereal based (Staatz and Hollinger 2016). Mali, Niger, and Burkina Faso stand out with relatively low ratios for dependency on imports of cereals (table 5.1 and figure 5.4).

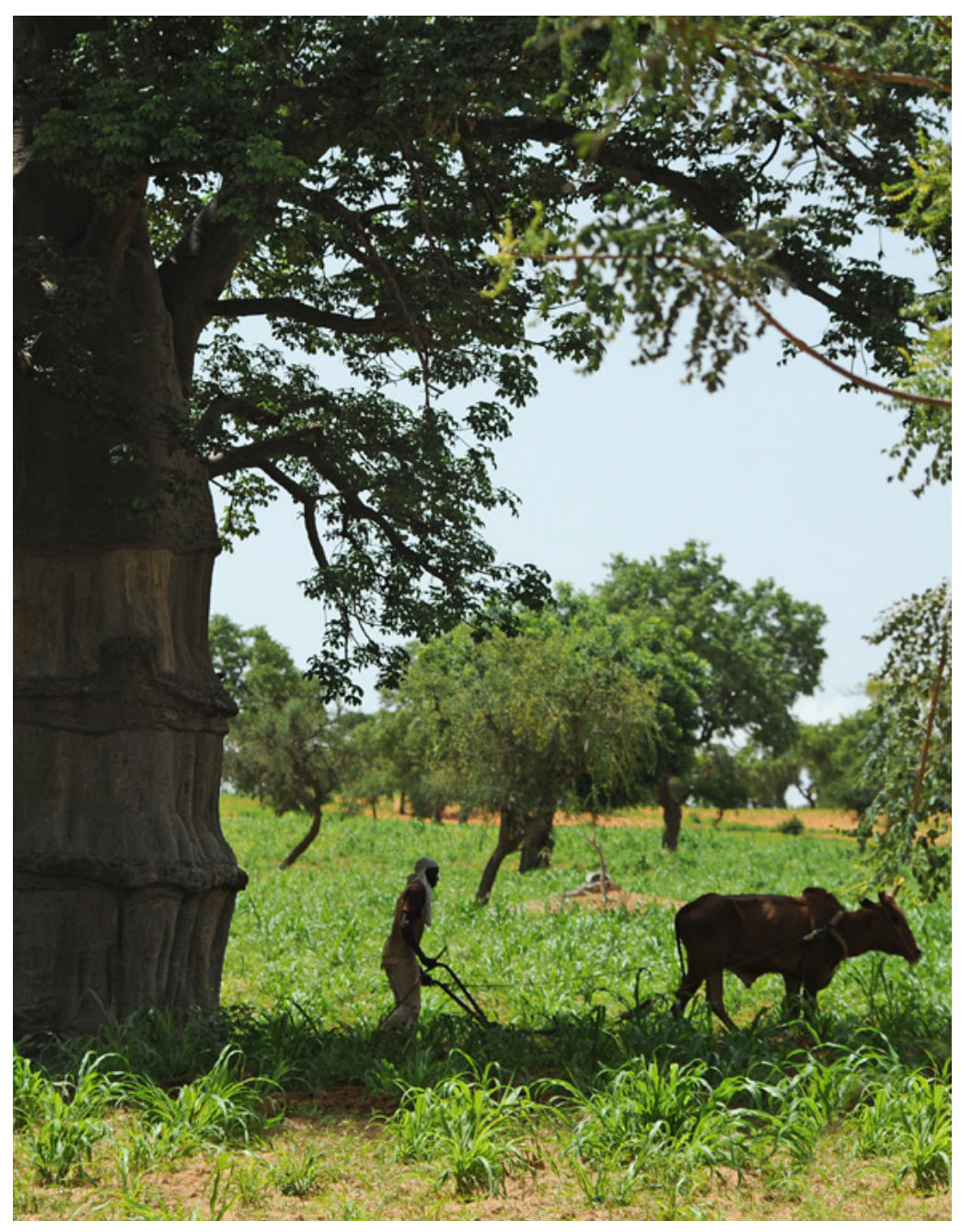

\begin{tabular}{lccc}
\hline Country & $\begin{array}{c}\text { Average dietary } \\
\text { energy supply } \\
\text { (kcal/cap/day) }\end{array}$ & $\begin{array}{c}\text { Average dietary } \\
\text { energy supply } \\
\text { adequacy (\%) }\end{array}$ & $\begin{array}{c}\text { Dietary energy } \\
\text { supply from } \\
\text { cereals, roots, } \\
\text { and tubers (\%) }\end{array}$ \\
\hline Benin & 2.786 & $127 \%$ & $71 \%$ \\
\hline Burkina Faso & 2.722 & $124 \%$ & $65 \%$ \\
\hline Côte d'Ivoire & 2.713 & $123 \%$ & $66 \%$ \\
\hline Ghana & 3.090 & $136 \%$ & $63 \%$ \\
\hline Guinea & 2.649 & $119 \%$ & $62 \%$ \\
\hline Guinea-Bissau & 2.220 & $100 \%$ & $63 \%$ \\
\hline Liberia & 2.228 & $101 \%$ & $66 \%$ \\
\hline Mali & 2.947 & $141 \%$ & $67 \%$ \\
\hline Mauritania & 2.781 & $124 \%$ & $51 \%$ \\
\hline Niger & 1.585 & $124 \%$ & $61 \%$ \\
\hline Senegal & 2.550 & $114 \%$ & $61 \%$ \\
\hline Sierra Leone & 2.433 & $110 \%$ & $64 \%$ \\
\hline The Gambia & 2.630 & $119 \%$ & $62 \%$ \\
\hline Togo & 2.506 & $113 \%$ & $71 \%$ \\
\hline
\end{tabular}

Table 5.1 Dimensions of Food Supply by Country for the West Africa Region, 2017

Source: FAOSTAT, Food and Agriculture Organisation, Rome (accessed August 31, 2020).

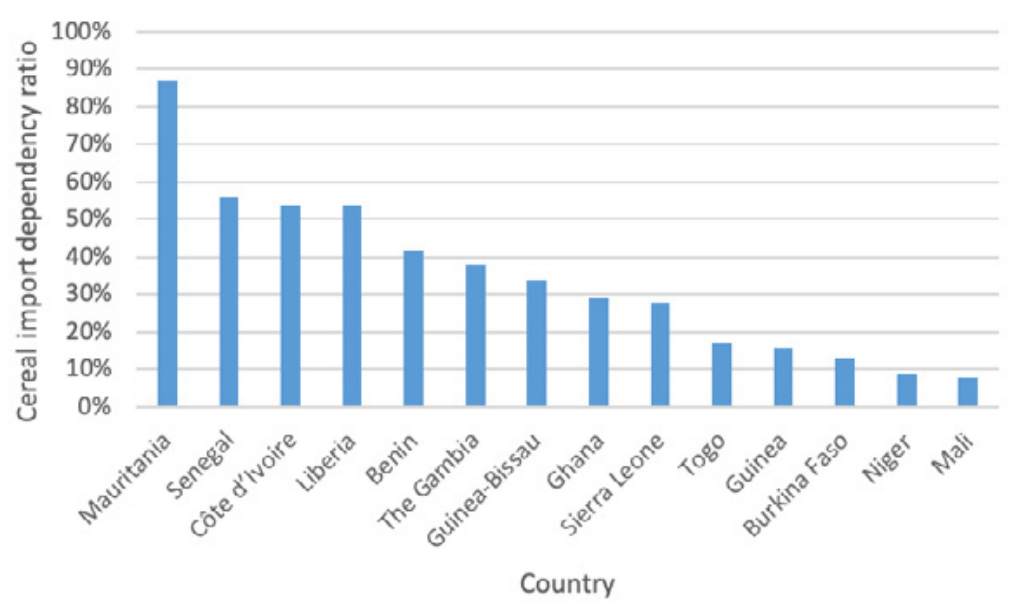

Figure 5.4 Cereal Import Dependency Ratio for Various Countries in West Africa, 2017

Source: FAOSTAT, Food and Agriculture Organisation, Rome (accessed August $\overline{31,2020)}$.
(1) Background and understanding

(2) Regional drivers

(3) Regional organisations

(4) Agro-pastoralism-based

5 Grains-andlegumes-based

5.1 Definitions

5.2 Demography and geography

5.3 Regional consumption and production trends

5.4 Livelihoods of producer communities

5.5 Production systems

5.6 Food system outcomes

5.7 Institutional drivers

5.8 Risks and resilience

5.9 The COVID-19 pandemic

5.10 Agency and development interventions

5.11 Summing up References

(6) Rice-and-horticulture

(7) Coastal maritime fisheries

(8) Tropical mixed tree and

food crops systems

9 Toward enhanced resilience 
Recent household surveys in Burkina Faso (2012), Northern Ghana (2012), Benin (2017), and Mali (2018) provide insight into the food and nutrition status of the population in the grains-and-legumesbased food system. Data show about 1 percent of the population (either persons or households) were in a severe food security situation in Burkina Faso and Mali, with 3 percent in Ghana and 8 percent in Benin. Estimates of the proportion of people in a limited food secure situation were 96 percent in Mali, 84 percent in Burkina Faso, 81 percent in Benin, and 79 percent in Ghana (table 5.2). In Burkina Faso and Mali, these percentages for food security in the grains-and-legumes-based food system were slightly higher than the average national percentages of people in a limited food secure situation for the respective countries.

\begin{tabular}{|c|c|c|c|c|}
\hline Region/country & $\begin{array}{c}\begin{array}{c}\text { Severe } \\
\text { food } \\
\text { insecurity }\end{array} \\
\end{array}$ & $\begin{array}{l}\text { Moderate } \\
\text { food } \\
\text { security }\end{array}$ & $\begin{array}{l}\text { Limited } \\
\text { food } \\
\text { security }\end{array}$ & $\begin{array}{l}\text { Food } \\
\text { security }\end{array}$ \\
\hline $\begin{array}{l}\text { Sudano-Sahelian zone, } \\
\text { Burkina Faso ( } 2012) \\
\text { (\% of population) }\end{array}$ & $<1 \%$ & $16 \%$ & $38 \%$ & $46 \%$ \\
\hline $\begin{array}{l}\text { Burkina Faso, country } \\
\text { (2012) (\% of population) }\end{array}$ & $1 \%$ & $18 \%$ & $43 \%$ & $38 \%$ \\
\hline $\begin{array}{l}\text { Sudano-Sahelian zone, } \\
\text { Mali (2018) } \\
\text { (\% of households) }\end{array}$ & $<1 \%$ & $4 \%$ & \multicolumn{2}{|c|}{$96 \%$} \\
\hline $\begin{array}{l}\text { Mali, country (2018) } \\
\text { (\% of households) }\end{array}$ & $<1 \%$ & $8 \%$ & \multicolumn{2}{|c|}{$92 \%$} \\
\hline $\begin{array}{l}\text { Sudan zone, Ghana } \\
(2012)(\% \text { of households) }\end{array}$ & $3 \%$ & $18 \%$ & $10 \%$ & $69 \%$ \\
\hline $\begin{array}{l}\text { Ghana, country ( } 2017) \\
\text { (\% of population) }\end{array}$ & \multicolumn{2}{|c|}{$50 \%$} & \multicolumn{2}{|c|}{-} \\
\hline $\begin{array}{l}\text { Sudan zone, Benin (2017) } \\
\text { (\% of households) }\end{array}$ & $3 \%$ & $14 \%$ & $42 \%$ & $39 \%$ \\
\hline $\begin{array}{l}\text { Benin, country (2017) } \\
\text { (\% of households) }\end{array}$ & $<1 \%$ & $9 \%$ & $43 \%$ & $48 \%$ \\
\hline
\end{tabular}

Table 5.2 Food Security of West African Regions and Countries Source: Calculations based on data from Hjelm and Dasori (2012) and PAM $(2014,2017,2018)$ and 2017 data from FAOSTAT, Food and Agriculture Organisation, Rome (accessed August 31, 2020).

Note: Data reflect Consolidated Approach to Reporting Indicators of Food Security (CARI), which include absolute food deficiency in the short and long terms.

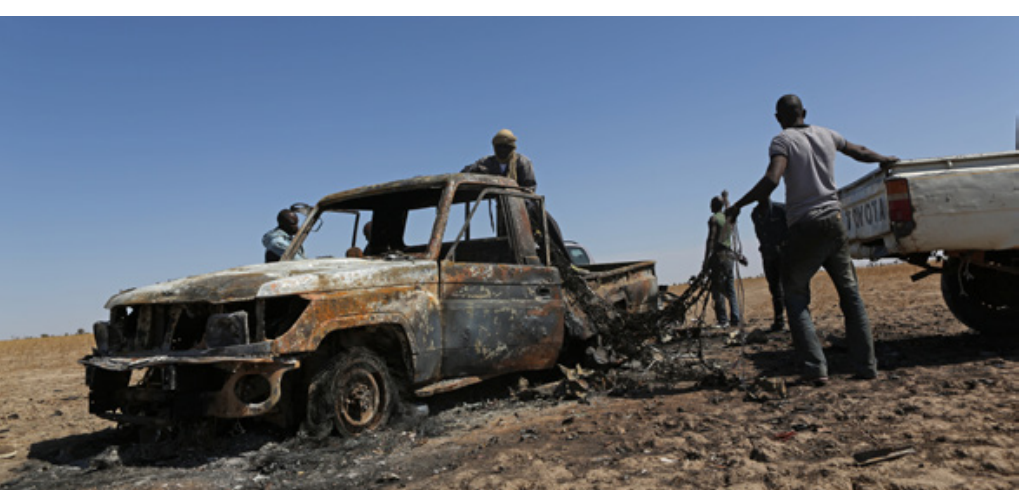

(1) Background and understanding

(2) Regional drivers

(3) Regional organisations

(4) Agro-pastoralism-based

5 Grains-andlegumes-based

5.1 Definitions

In Burkina Faso, about 75 percent of poor households have moderate to severe food insecurity, while 50 percent of the wealthier households are in a similar situation (PAM 2014). In Mali, in line with a better overall food security situation in the food system zone, 60 percent of the poorer households and 20 percent of the richer households are food insecure (PAM 2018). Yet persistent civil insecurity continues to aggravate the food insecurity situation for many people in the northern fringe of the food system zone in Burkina Faso, Mali, and Niger. The number of people suffering from severe food security has nearly tripled between the end of 2018 and the same period in 2019 because of civil insecurity, totaling 2.7 million people in the border regions between Burkina Faso, Mali, and Niger and in the border areas between Niger and Nigeria (SWAC/OECD 2020).

Households in Mali prefer maize as a grain staple food (59 percent of households), followed by local rice (49 percent), millet (34 percent), imported rice (29 percent), and sorghum (26 percent). In general, the larger farmer households with access to rain-fed lowland valleys also grow rice and vegetables for home consumption and sales to nearby markets. As for legumes, 95 percent of households prefer either cowpeas/beans or groundnuts (DARD 2019; Dufumier 2005; PAM 2018). Households in the food system zone score low on food diversity, frequency of meals, and nutrition quality. For example, 28 percent of households in Burkina Faso, 24 percent in Benin, and 22 percent in Mali show a poor or limited food consumption (table 5.3).
5.2 Demography and geography

5.3 Regional consumption and production trends

5.4 Livelihoods of producer communities

5.5 Production systems

5.6 Food system outcomes

5.7 Institutional drivers

5.8 Risks and resilience

5.9 The COVID-19 pandemic

5.10 Agency and development interventions

5.11 Summing up References

6) Rice-and-horticulture

(7) Coastal maritime fisheries

8 Tropical mixed tree and

food crops systems

9 Toward enhanced resilience

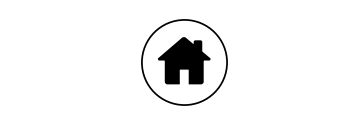




\begin{tabular}{|c|c|c|c|}
\hline \multirow[b]{2}{*}{ Region/country } & \multicolumn{3}{|c|}{ Percentage of households } \\
\hline & $\begin{array}{c}\text { Poor } \\
\text { consumption }\end{array}$ & $\begin{array}{l}\text { Limited } \\
\text { consumption }\end{array}$ & $\begin{array}{l}\text { Acceptable } \\
\text { consumption }\end{array}$ \\
\hline Burkina Faso, zone (2012) & $3 \%$ & $25 \%$ & $72 \%$ \\
\hline Burkina Faso, country (2012) & $5 \%$ & $27 \%$ & $68 \%$ \\
\hline Mali, zone (2018) & $7 \%$ & $15 \%$ & $78 \%$ \\
\hline Mali, country (2018) & $6 \%$ & $15 \%$ & $79 \%$ \\
\hline Benin, zone (2017) & \multicolumn{2}{|c|}{$24 \%$} & $76 \%$ \\
\hline Benin, country (2017) & \multicolumn{2}{|c|}{$14 \%$} & $86 \%$ \\
\hline
\end{tabular}

Table 5.3 Food Consumption Score of Households in Burkina Faso, Mali, and Benin

Sources: Calculations based on data from PAM (2014, 2017, 2018).

Note: Food consumption score (FCS) includes diversity of food, frequency of meals, and nutrition contribution.

Chronic malnutrition, particularly the prevalence of stunting in children under five years of age, remains high in this food system. While Burkina Faso showed a considerable decrease in the percentage of stunted children, from 32.8 percent in 2012 to 21.1 percent in 2018 , and Niger showed a decrease from 43.5 percent to 40.6 percent, Mali displayed an increase from 27.8 percent to 30.4 percent during the same period. For the West Africa region, the percentage of stunted children declined from 31.5 percent in 2012 to 29.2 percent in 2018 . This is mainly due to the increase in food secure households (FAO et al. 2019). However, poor nutrition is driven by a set of intricate factors, as shown by data from Niger, including inadequate availability of sufficient high-quality and diverse foods and insufficient purchasing power to access such foods. Furthermore, recurrent illness of children, exacerbated by poor hygiene, poor sanitation, and the disadvantaged position of women, together with high levels of early marriage and pregnancy, lead to an intergenerational cycle of malnutrition (SPRING 2018).

Data on national grains production and the percentage of households facing severe food insecurity in the food system in Burkina Faso, Mali, Ghana, and Benin could suggest that a majority of households can rely on their own food production and are somewhat food self-sufficient. Yet results from the mentioned household surveys and others in Burkina Faso and Mali draw a more nuanced picture. In Burkina Faso, for example, for 65 percent of all farmer households, local markets are the main source for food. For 31 percent, their own production is the main source, and for 4 percent the main sources are income from hired labour or petty trade for buying food and/or on food loans or gifts from family or friends (PAM 2014).

5.6.2 Income, trade, and employment

Farm households store and conserve coarse grains in both traditional and improved granaries. Storage in community warehouses is often part of cereal banks and warehouse receipt systems. Farmers use these storage facilities for collectively selling surplus cereal production, besides individual sales (PARM 2017). Cereal processing is limited to grinding of grains for making flour, mainly by individual women or women groups, for selling on local markets (Kaminsky et al. in Elbehri et al. 2013).

Postharvest and processing losses for cereals are relatively high, estimated at between 20 percent and 25 percent for harvest, trading, and processing. Losses are approximately 2 percent to 5 percent for transport and warehouse operations (AGRA 2014). This implies up to 30 percent in postharvest food losses. For cowpea, farmers estimate losses during threshing, winnowing, drying, and storage of beans to be about 20 percent. Losses of 10 to 20 percent mainly occur during transportation and storage (AGRA 2014; PAPSA 2020; REGIS-AG 2016).

After harvest, drying, and dehusking, households store cowpea beans in bags for conservation. Households increasingly use Purdue Improved Cowpea Storage (PICS) bags for improved storage. PICS bags are on sale in Burkina Faso and Niger, but the market is not saturated. Availability of these bags is limited because the manufacturing license delivered by Purdue University requires compliance with specific norms. The bags are also a significant investment for the poorer smallholder farm households in rura areas that have limited access to credit (AGRA 2014; PAPSA 2020; REGIS-AG 2016).
(1) Background and understanding

(2) Regional drivers

(3) Regional organisations

(4) Agro-pastoralism-based

5 Grains-andlegumes-based

5.1 Definitions

5.2 Demography and geography

5.3 Regional consumption and production trends

5.4 Livelihoods of producer communities

5.5 Production systems

5.6 Food system outcomes

5.7 Institutional drivers

5.8 Risks and resilience

5.9 The COVID-19 pandemic

5.10 Agency and development interventions

5.11 Summing up References

6) Rice-and-horticulture

(7) Coastal maritime fisheries

(8) Tropical mixed tree and

8 food crops systems

9 Toward enhanced resilience 
Because of growing urban demand for processed food, industrial transformation of maize (in particular) is rising but still has to compete with processing imported wheat, maize, and rice, which are being substituted for traditional grains such as millet and sorghum (Hollinger and Staatz 2015). Rural areas that are closely linked to urban agglomerations generally offer more productive off-farm opportunities in processing and trading staple food than in production. Availability of and access to local processing and trading infrastructure and services determine the demand for labour and skills (SWAC/OECD 2018).

West African traders in millet, sorghum, maize, and cowpea operate through a highly informal but well-coordinated international network that links to countries to regional West African markets. Despite the worsening security situation in parts of the Sahel, information continues to flow because of the mobile phone network. This facilitates communication between buyers and sellers across even longer distances and allows trade to continue (FEWS NET 2019).

After cereals are harvested, collectors, on behalf of traders, directly purchase grains from farm households and in local markets where farmers sell their produce. Large traders aggregate and store the purchased grains to sell to wholesalers, who have their own storage facilities and transportation. Wholesalers often deal with importers from neighbouring countries.

The West Africa region contains five principal market basins for millet, maize, and sorghum:

- a western basin centred in Senegal, mainly for local rice, millet, and sorghum

- a central basin comprising Côte d'Ivoire, Ghana, Togo, Mali, and Burkina Faso, mostly for maize

- an eastern basin including Nigeria, Benin, Niger, and Chad, representing 60 percent of regional trade flows, mainly for millet, sorghum, maize, and cowpeas and re-exportation of rice from Benin to Nigeria

- the Ibadan-Lagos-Accra conurbation (cities in Nigeria, Benin, Togo, and Ghana), mostly for maize and re-exported rice

- the Sahelian belt spanning Mauritania, Mali, Burkina Faso, Niger, and Nigeria, principally for millet and sorghum.
In-country trade flows of millet and sorghum in Burkina Faso and Mali generally transfer surplus from areas in the south to deficit areas in the north, with urban centres in the north serving as hubs from where cereals are distributed to smaller markets. During the lean season, Burkina Faso imports maize from Ghana and Côte d'Ivoire, which may follow the aforementioned distribution channels. In fact, the lean season in the Sudano-Sahelian zone corresponds to the maize harvesting season in the coastal countries. Niger depends on imports from Nigeria and Burkina Faso of millet (during the lean season), sorghum, and maize for addressing deficits in the country (AGRA 2014; CILSS 2016a; REGIS-AG 2016). ${ }^{9}$

Cowpea produced in Burkina Faso is mainly for household consumption but is increasingly sold to urban consumers and exported to Benin, Côte d'Ivoire, Ghana, Nigeria, and Togo. Niger exports cowpea to its southern neighbours Benin, Nigeria, and, to a lesser extent, Burkina Faso and Mali (CILSS 2016a; REGIS-AG 2016)..$^{10}$

There are no reliable data on the volume of regional market and trade flows of coarse grains and legumes (cowpea) in West Africa. This is because the vast majority of transactions are informal and involve small volumes, and unprocessed products are exempted from customs duties and are not captured by official statistics (SWAC/OECD 2013). Agroclimatic conditions, purchase prices in collection and aggregation markets, and transportation costs determine staple food prices. Marketing margins for grains are limited because of high transportation costs, rising insecurity, and the population's low purchasing power. Hence, profit is mainly the result of product turnover (FEWS NET 2019).

In 2015 coarse grains contributed an estimated 9 percent to the total value of agricultural production in West Africa. Considering the most important countries in the grains-and-legumes-based food system, millet, sorghum, and maize contribute a sizable percentage to the total value of agricultural production in Burkina Faso (35 percent), Niger (34 percent), and Mali (17 percent). Cowpea contributes 3 percent in Niger and 5 percent in Burkina Faso (table 5.4).
(1) Background and understanding

(2) Regional drivers

(3) Regional organisations

(4) Agro-pastoralism-based

5 Grains-andlegumes-based

5.1 Definitions

5.2 Demography and geography

5.3 Regional consumption and production trends

5.4 Livelihoods of producer communities

5.5 Production systems

5.6 Food system outcomes

5.7 Institutional drivers

5.8 Risks and resilience

5.9 The COVID-19 pandemic

5.10 Agency and development interventions

5.11 Summing up References

6) Rice-and-horticulture

(7) Coastal maritime fisheries

(8) Tropical mixed tree and

8 food crops systems

9 Toward enhanced resilience 


\begin{tabular}{|c|c|c|c|c|c|c|c|c|}
\hline \multirow[b]{2}{*}{ Countries } & \multicolumn{2}{|c|}{ Millet } & \multicolumn{2}{|c|}{ Sorghum } & \multicolumn{2}{|c|}{ Maize } & \multicolumn{2}{|c|}{ Cowpea } \\
\hline & $\begin{array}{c}\text { Value } \\
\text { (\$US, millions) }\end{array}$ & $\begin{array}{l}\text { Percentage } \\
\text { of total } \\
\text { agricultural } \\
\text { production (\%) }\end{array}$ & $\begin{array}{c}\text { Value } \\
\text { (\$US, millions) }\end{array}$ & $\begin{array}{l}\text { Percentage } \\
\text { of total } \\
\text { agricultural } \\
\text { production (\%) }\end{array}$ & $\begin{array}{c}\text { Value } \\
\text { (\$US, millions) }\end{array}$ & $\begin{array}{c}\text { Percentage } \\
\text { of total } \\
\text { agricultural } \\
\text { production (\%) }\end{array}$ & $\begin{array}{c}\text { Value } \\
\text { (\$US, millions) }\end{array}$ & $\begin{array}{c}\text { Percentage } \\
\text { of total } \\
\text { agricultural } \\
\text { production (\%) }\end{array}$ \\
\hline Benin & 6 & $<1 \%$ & 30 & $1 \%$ & 263 & $9 \%$ & - & - \\
\hline Burkina Faso & 196 & $8 \%$ & 262 & $11 \%$ & 381 & $16 \%$ & 179 & $5 \%$ \\
\hline Ghana & 23 & $<1 \%$ & 34 & $<1 \%$ & 186 & $5 \%$ & - & - \\
\hline Mali & 407 & $6 \%$ & 307 & $5 \%$ & 389 & $6 \%$ & 35 & $<1 \%$ \\
\hline Niger & 1,309 & $23 \%$ & 669 & $11 \%$ & 13 & $<1 \%$ & 199 & $3 \%$ \\
\hline West Africa & 2,308 & $3 \%$ & 2,071 & $2 \%$ & 3,232 & $4 \%$ & 1,095 & $1 \%$ \\
\hline
\end{tabular}

(1) Background and understanding

(2) Regional drivers

(3) Regional organisations

(4) Agro-pastoralism-based

5 Grains-andlegumes-based

5.1 Definitions

5.2 Demography and geography

Table 5.4 Production Value of Millet, Sorghum, Maize, and Cowpea and Their Contribution to Total Agricultural Production Value, 2015 Source: Data from FAOSTAT, Food and Agriculture Organisation, Rome (accessed August 31, 2020), and Our World in Data, Global Change Data Lab, Oxford, UK (accessed August 31, 2020).

\subsubsection{Environmental sustainability}

Population growth remains the main driver for land use change, mainly for agricultural purposes. Some areas are "saturated," with hardly any land left for further expansion, particularly the traditional areas of cotton production in central Burkina Faso and Mali and the southern areas of Niger. The main consequences are land degradation, declining soil fertility, biodiversity loss, and fewer nontimber forest products. The latter are additional food sources for poorer households and income sources for women (CILSS 2016b; Jalloh et al. 2011). Inherently poor soils that have reduced fallow periods are worsening land degradation and reducing crop yields. Highly degraded soils are also less responsive to fertilisers (Woittiez et al. 2015).

The countries in the Sudano-Sahelian zone are responsible for a very small share of GHG emissions, estimated at 0.25 percent, with the per capita emissions of four countries (Burkina Faso, Chad, Mali, and Niger) among the lowest 10 percent in the world. Including Nigeria, this share rises to 0.92 percent (Crola 2019). Nigeria (50 percent) and Cameroon ( 20 percent) by far dominated GHG emissions in 2014 for the enlarged West Africa region, ${ }^{11}$ followed by
Chad (5 percent), Côte d'Ivoire (4 percent), Mali (4 percent), and Ghana (4 percent). The main sources of GHG emissions for the enlarged West African region are land use change and forestry (32 percent), energy (27 percent), and agriculture (23 percent). In the agriculture sector, Nigeria is again leading the West African region (28 percent), followed by Mali, Niger, and Burkina Faso. Agriculture is the principal source of GHG emissions in Mali, Niger, and Burkina Faso (USAID 2019).

5.6.4 Equity and inclusion

In general, most of the wealthier households get their food from their own production, complemented with purchases of additional food items on the market. Poorer households depend more on markets, and very poor households depend on food or wages they receive from working as hired labour (for food) carried out for the wealthier farmers and on food loans and gifts (table 5.5).
5.3 Regional consumption and production trends

5.4 Livelihoods of producer communities

5.5 Production systems

\subsection{Food system outcomes}

5.7 Institutional drivers

5.8 Risks and resilience

5.9 The COVID-19 pandemic

5.10 Agency and development interventions

5.11 Summing up References

6) Rice-and-horticulture

(7) Coastal maritime fisheries

8 Tropical mixed tree and

(8) food crops systems

9 Toward enhanced resilience 


\begin{tabular}{lccc}
\multicolumn{1}{c}{$\begin{array}{c}\text { Country and } \\
\text { wealth category } \\
\text { of household }\end{array}$} & $\begin{array}{c}\text { Own } \\
\text { production }\end{array}$ & $\begin{array}{c}\text { Purchase on } \\
\text { local market }\end{array}$ & $\begin{array}{c}\text { Payment in kind } \\
\text { for work, loans } \\
\text { and gifts in kind }\end{array}$ \\
$\begin{array}{l}\text { Burkina Faso, poor } \\
\text { or very poor }\end{array}$ & $39 \%$ & $34 \%$ & $27 \%$ \\
\hline $\begin{array}{l}\text { Burkina Faso, rich or } \\
\text { very rich }\end{array}$ & $84 \%$ & $16 \%$ & $0 \%$ \\
\hline $\begin{array}{l}\text { Mali, poor or very } \\
\text { poor }\end{array}$ & $39 \%$ & $45 \%$ & $5 \%$ \\
\hline $\begin{array}{l}\text { Mali, rich or very } \\
\text { rich }\end{array}$ & $90 \%$ & $10 \%$ & $0 \%$ \\
\hline $\begin{array}{l}\text { Northern Ghana, all } \\
\text { households }\end{array}$ & $28 \%$ & $64 \%$ & - \\
\hline
\end{tabular}

Table 5.5 Importance of Food Sources for Households (Percentage of Households)

Sources: Calculations by the author based on data from FEWS NET (2010a, 2010b) and Hjelm and Dasori (2012).

The poorer subsistence-oriented households are unable to increase their production because of limited land, cattle (manure), family labour, and equipment. Either they use their cash income from off-farm activities to purchase their food or wealthier marketoriented households pay them in food for hired labour. During the lean period, the poorer farmers also take food loans, which they have to pay back during or just after the harvest period. This reduces their food stock for the following lean period (FEWS NET 2010a, 2010b; Save the Children Fund 2017).

To pay back their food loans, farmer households might sell part of their food production during or just after the harvest period, when prices are relatively low. The wealthier market-oriented farmer households have the means to invest in staple food and cash crop production. Income from sales of cash crops and surplus production of staple foods allow them to purchase more expensive and nutritious food. The poorest households thus depend on the wealthier ones for meeting their food needs. This dependence repeats itself every year and is particularly strong during the lean season, becoming weaker during and just after harvest (FEWS NET 2010a, 2010b; Save the Children Fund 2017).
While future perspectives are already less attractive for youths in the class of poorer subsistence-oriented farmer households, youths in general are confronted with difficulties accessing land in the saturated areas where arable land is increasingly scattered.

Ultimately, the land they inherit may be too small to earn a decent income from through farming. Although women have their own plots and are active in processing and trading grains and pulses, they have less control over household assets and income than men. In the case of the poorer subsistence-oriented farmer households in areas with increased land pressure and subsequent depletion of natural resources, women are more and more deprived from income-generating activities from nontimber products.

\subsection{Institutional drivers}

Regional trade is an important element of the grains-and-legumesbased food system. It matches demand and supply in domestically produced coarse grains and legumes through imports and exports by countries. Regional trade in cowpea grows because of the drought tolerance of the crop (Sahel conditions) and the growing demand for low-cost protein sources. Trade thus contributes to food security and is a growing source of income for West African farmers, processors, and traders (Maur and Shepherd 2015).

In many West African countries, transformation of the agricultural sector is at the heart of agricultural policies. The central assumption is that the transition from subsistence farming to more marketoriented farming will allow for feeding a growing population, increasing smallholder farmers' income and creating value addition and employment opportunities. The Partnership for Inclusive Agricultural Transformation in Africa (PIATA) of the Alliance for a Green Revolution in Africa (AGRA) supports the required policy reforms and the implementation of value chain development in 11 African countries, including Burkina Faso, Mali, Ghana, and Nigeria. In Burkina Faso and Mali, PIATA investments target the countries' breadbaskets (AGRA Country Teams Burkina Faso and Mali, pers. comm.).
(1) Background and understanding

(2) Regional drivers

(3) Regional organisations

(4) Agro-pastoralism-based

5 Grains-andlegumes-based

5.1 Definitions

5.2 Demography and geography

5.3 Regional consumption and production trends

5.4 Livelihoods of producer communities

5.5 Production systems

5.6 Food system outcomes

5.7 Institutional drivers

5.8 Risks and resilience

5.9 The COVID-19 pandemic

5.10 Agency and development interventions

5.11 Summing up References

6) Rice-and-horticulture

(7) Coastal maritime fisheries

Tropical mixed tree and

8 food crops systems

9 Toward enhanced resilience 
A key element of the cotton sector management by parastatals has been the organisation of farmers for handling operations in the supply of agricultural inputs and cotton. The increasing demand for staple foods, in combination with fewer certainties in the cotton sector, has prompted farmers to switch to staple foods such as cash crops, particularly maize. The experiences with organising cotton farmers have turned out to be fertile ground for farmers to organise themselves around the supply of staple foods. Ultimately, this has led to multitier networks not only at the subnational level but also at the regional level, such as ROPPA (ECOWAS and IRDR 2018). Because of their representativeness - with the financial and technical support from donors and international nongovernmental organisations (INGOs) - they are now acknowledged and essential interlocutors for national and regional policy makers. While their influence on policy making and implementation has increased, many local member organisations still struggle to be economically viable in the national staple food markets.

Institutional buyers, such as the World Food Programme (WFP) through Purchase for Progress (P4P), or national food security stocks, such as SONAGESS in Burkina Faso and OPAM in Mali, not only purchase grains and staples through large urban-based traders but also large farmer organisations, such as UGCPA/USCCPA in Dédougou, Burkina Faso, and Faso Jigi in Ségou, Mali. These organisations are able to purchase the required volumes through their network of farmers and ensure quality control as well as storage and transportation logistics while obtaining decent prices for famers (Commandeur and Casey 2016; ECOWAS and IRDR 2018; FEWS NET 2019).

\subsection{Risks and resilience}

5.8.1 Climate resilience

Although there is general agreement on the rise of temperature in the West African region - within a range of $1.5^{\circ} \mathrm{C}$ to $2.3^{\circ} \mathrm{C}$ until 2050 and varying across different geographical zones - projections for rainfall vary between a drop (23 millimeters per year) and a rise in rainfall (22 millimeters per year) for the same period (Zougmoré et al. 2015). Data since 2000 point to a greater variability of annual rainfall and a higher number and recurrence of localised climate extremes. From the 1970s until the beginning of the twenty-first century, West Africa experienced a sharp decrease in rainfall with long-lasting effects in the Sudano-Sahelian zone (RPCA 2015).

Climate variability poses an important challenge to the production of grains and legumes in West Africa because they are predominantly based on rain-fed systems. According to projections of yield change based on crop model analysis combined with different climate models, only rain-fed rice shows a modest increase in yields ( 0.9 percent). The yields for the other rain-fed crops are expected to decrease by 5.5 percent for maize, 13.9 percent for sorghum, 6.8 percent for groundnuts, and 5.0 percent for soybeans.

As a reaction to decreasing rainfall over the last decades, government and donor programs and projects have developed and disseminated technologies for land and water conservation, valorising indigenous knowledge and experience, combined with increased use of dry-resistant crop varieties and fertilisers. A few decades later, farmers in this food system, to various extents, have integrated these climate smart technologies in their agricultural practices (UNCCD 2019; Woittiez et al. 2015). Although changing practices by farmers serve multiple purposes and are interrelated, climate change, besides market opportunities, is an important driver of change in farming practices in the Sudano-Sahelian zone. Models indicate that perceived climate changes, such as more erratic rainfall, bring about changes in land use and management, including expanding cultivated areas and applying organic and mineral fertilisation (Ouédraogo et al. 2017).

However, it is important that farmers in the grains-and-legumesbased food system have access to a basket of technological options because of the considerable variation of outcomes of the different climate change, crop, and economic models (Zougmoré et al. 2015). Furthermore, adaptation strategies to changing conditions by smallholder farmers also vary according to household assets (Douxchamps et al. 2016). There are no one-size-fits-all solutions; therefore technology options need to take in account the different smallholder farmer strategies to ensure food security and household income, which will then become climate smart. Climate smart
(1) Background and understanding

(2) Regional drivers

(3) Regional organisations

(4) Agro-pastoralism-based

5 Grains-andlegumes-based

5.1 Definitions

5.2 Demography and geography

5.3 Regional consumption and production trends

5.4 Livelihoods of producer communities

5.5 Production systems

5.6 Food system outcomes

5.7 Institutional drivers

5.8 Risks and resilience

5.9 The COVID-19 pandemic

5.10 Agency and development interventions

5.11 Summing up References

6) Rice-and-horticulture

(7) Coastal maritime fisheries

(8) Tropical mixed tree and

(8) food crops systems

9 Toward enhanced resilience 
adaptation strategies improve the food security status of diversified and intensified farming households and can meet their food needs by increasing their current practice of adaptation strategies. Other household types, such as subsistence and extensive farmers, have to either upgrade to another type or change their livelihood strategies under the changing climate and demographic conditions (Douxchamps et al. 2016).

5.8.2 Economic resilience

Currently, West Africa's population is growing at an annual rate of 2.5 percent, which is expected to continue through the middle of the twenty-first century. Furthermore, urbanisation of the West African population will continue and might lead to 65 percent of the population living in urban areas by 2050 . Hence, demand for unprocessed and processed coarse grains and legumes will increase accordingly (Maur and Shepherd 2015; Staatz and Hollinger 2016).

The grains-and-legumes-based food system has the potential to address these challenges. First, the system has intrinsic agronomic (soil fertility management) and nutritious (energy and protein supply) complementarities. Second, enhanced linkages with agricultural inputs (subsidised fertilisers) as well as output markets (grains and pulses) are instrumental in sustainable agricultural intensification. Third, trends in the twenty-first century show increased production capacity of grains and pulses in response to rising demand, though closing yield gaps remains a challenge. Finally, yet importantly, production support services and value addition in the grains and pulses value chains provide business and employment opportunities for youths, who compose some 40 percent of the population (Maur and Shepherd 2015).

\subsubsection{Sociopolitical resilience}

Farmers in the Sudano-Sahelian zone are still expanding the area under cultivation. They are moving northward (Sahel zone), where the conditions are less suitable for agriculture and better for pastoralism. This creates conflicts with pastoralist communities around access to grazing areas. Farmers also are opening up new land in the south (Sudan zone) by clearing biodiverse woodlands and forests and thus, ultimately, undermining farmers' livelihoods and local economies - for example, based on firewood, fruits, and

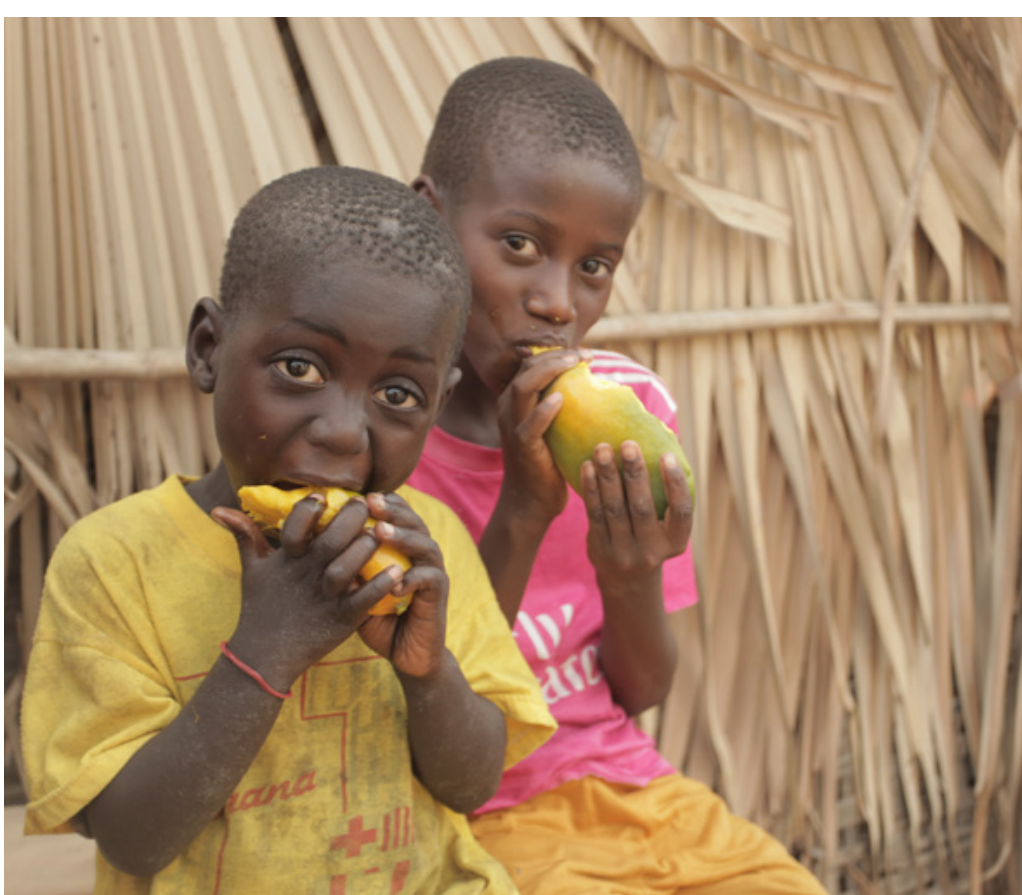

wild game (CILSS 2016b). The result has been a rise in conflicts between farmer households in the saturated areas over access to and use of existing farmland. As a result, many countries are now reviewing their land tenure policies, including local alternative dispute resolution mechanisms and decentralisation of land registration facilities. Within the larger context of decentralisation in West Africa, local governments undertake initiatives to prevent and resolve conflicts around water and land resources with a more prominent role for local communities.

Since 2012 the security situation in Sahel countries has worsened in parts of Niger, Burkina Faso, and Mali, with spillover effects in other areas. For instance, farmers in central Mali are not always able to cultivate their fields because of recurrent attacks and massacres. ${ }^{12}$ Moreover, the number of internally displaced persons (IDPs) has continued to increase: 851,000 in Burkina Faso, 250,000 in Mali, and 224,000 in Niger. ${ }^{13}$ Local communities host the majority of IDPs, which increases pressure on food resources and local
(1) Background and understanding

(2) Regional drivers

(3) Regional organisations

(4) Agro-pastoralism-based

5 Grains-andlegumes-based

5.1 Definitions

5.2 Demography and geography

5.3 Regional consumption and production trends

5.4 Livelihoods of producer communities

5.5 Production systems

5.6 Food system outcomes

5.7 Institutional drivers

5.8 Risks and resilience

5.9 The COVID-19 pandemic

5.10 Agency and development interventions

5.11 Summing up References

6) Rice-and-horticulture

(7) Coastal maritime fisheries

(8) Tropical mixed tree and

food crops systems

9 Toward enhanced resilience

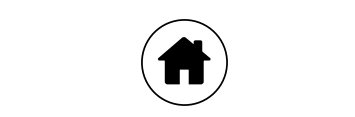


livelihoods in the short and long terms. IDPs in camps largely depend on a form of food aid, with camps not always being accessible because of the prevailing insecurity situation (SWAC/ OECD 2020).

5.8.4 Food access resilience

While availability of grains and pulses has increased in the twentyfirst century through improved production, accessibility varies with the increased social differentiation of farmer households in the grains-and-legumes-based food system. Markets are a source of food supply for all farmers, but the poorer subsistence farmers rely more than the wealthier market-oriented farmers on these markets. However, because their food production capacity and purchasing power are limited, they depend on off-farm activities for income and their social networks for additional food. As such, these households show problematic levels of food access resilience. In all households, women and children are particularly touched by food insecurity, which negatively affects their nutrition status (see chapter 5.6.1 and 5.6.4).

\subsection{Food system impacts of and responses to the COVID-19 pandemic}

The regional impact of COVID-19 on this food system was limited in 2020 , especially in rural areas. ${ }^{14}$ During the height of the pandemic in March-June 2020, many cities implemented lockdowns, but rural areas did not. Markets were still open and operational, and few limitations were imposed on domestic transportation of goods. However, the closure of domestic borders and the restriction of internal and cross-border movements limited people's access to regional markets as well as trade of goods. For example, exporting fresh fruit by cargo flights from Burkina Faso became problematic, and fresh fruit exports (mainly mango) from Mali to Senegal were also limited.

In the mixed-grains-and-legumes-based food system in the Sudano-Sahelian zone during the 2020 off-season, crops were expected to reach markets and provide substantial income to farmers. However, the closure of borders and the restriction of internal and cross-border movements may have limited people's access to markets The planting period begins in May-June for the 2020-21 agricultural season, but the COVID-19 pandemic has forced governments to reduce agricultural spending and prioritise spending related to health.

Cotton is the pillar of rain-fed grains-and-legumes-based food system in southern Burkina Faso and southern Mali, which are the breadbaskets of these countries. The cotton sector already faces several challenges, which include a low price in the world markets because of declining global demand from the garment industry, disruptions in international trade, and delays in input distribution. The challenges in the cotton sector will likely affect the entire food system during upcoming agricultural season (2020-21), as there may not be sufficient funds to pay for the inputs, machinery, and labour required for cotton and cereal production. Even if agro-inputs will be available with some delay, farmers have difficulties accessing loans to purchase these inputs at the beginning of the planting season. There is a general fear that agricultural production may be lower than expected in the 2020-21 agricultural season and consequently, that farmers might not be capable of repaying input loans. This poses a serious risk to the production of staple foods for the upcoming season.

Already vulnerable households maybe hit hardest by COVID-19 impacts. Overall, women are affected more than men due to their already more precarious situation in terms of household and farming responsibilities. In rural areas, inflow of labour and inputs is expected to decrease, whereas in urban areas, casual labour in particular may be affected, which in turn may affect the flow of remittances to relatives in rural areas. Indeed, in Burkina Faso and Mali, COVID-19-related restrictions, including closing down markets and evening curfews, have been related to decreasing household incomes in two ways: both earnings from casual work as well as incomes from the sale of agricultural products have decreased The restrictions have led to a drop in demand for cash crops such as cowpeas and peanuts, which are usually exported to Mali, Togo, and Benin. This drop in demand has, in the short term, led to a slight decrease in price and therefore a decrease in the household income of cowpea farmers.
(1) Background and understanding

(2) Regional drivers

(3) Regional organisations

(4) Agro-pastoralism-based

5 Grains-andlegumes-based

5.1 Definitions

5.2 Demography and geography

5.3 Regional consumption and production trends

5.4 Livelihoods of producer communities

5.5 Production systems

5.6 Food system outcomes

5.7 Institutional drivers

5.8 Risks and resilience

5.9 The COVID-19 pandemic

5.10 Agency and

development interventions

5.11 Summing up References

6) Rice-and-horticulture

(7) Coastal maritime fisheries

(8) Tropical mixed tree and

(8) food crops systems

9 Toward enhanced resilience 
With respect to consumption and nutrition, the shrinking sources of income and increased nonfood spending may ultimately lead to a deterioration in household food security. Children and pregnant women will also be most affected in terms of the prevalence of malnutrition. In addition, mistrust between households in relation to the prevalence of the disease may contribute to the erosion of socia networks that secure access to food for poorer households. ${ }^{15}$

\subsection{Agency and development interventions}

Since the 2008 food crisis, governments have designed systems for subsidising agricultural inputs (fertiliser and seeds) for staple food crops, including grains such as maize and sorghum. As a result, the region has increased its fertiliser consumption, with Ghana, Burkina Faso, and Mali showing considerable augmentation. At the start, many fertiliser companies were reluctant to invest in manufacturing, supply, and distribution facilities because of the unpredictable market size and fear of fraud with subsidies. However, the induced rise in fertiliser consumption allowed importers and local blending companies to achieve economies of scale and increase investments (Hollinger and Staatz 2015).

The first results of pilots of electronic vouchers for fertilisers in Burkina Faso and Mali demonstrated the potential to enhance the effectiveness (target groups), efficiency (transaction costs), and transparency of the systems (PAPSA 2020; World Bank 2019). However, the downside was more attention and funding for agricultural extension focusing on delivering inputs at short notice at the expense of agricultural advisory services aimed at improving farm management over the long term (Michel Havard, CIRAD Mali, pers. comm.).

Agricultural value chain development programs and projects tap into the increasing demand for staple foods in regional and local markets (processing and consumption) and link and match them with the supply side (inputs and production). Many of these initiatives target crops that contribute significantly to food security and farmer income, such as grains and pulses. Various approaches have been developed and implemented, such as lead firms and agribusiness clusters. Experiences point out some key issues: Farmer organisations often struggle to mobilise products (volumes) and ensure quality control. Access to finance (credits and

investment loans) for farmer organisations, processors, and traders remains a challenge. Finally, transaction costs continue to be high because of inadequate infrastructure. Access to finance is key for developing and expanding production, processing, and trading capacities. Experiences have resulted in testing and scaling up of value chain financing mechanisms, such as contract farming and warehouse receipt systems (2SCALE 2019; PAPSA 2020).

\subsection{Summing up: toward leverage points for future interventions}

The grains-and-legumes-based food system covers a diversity of farmer households, with each type having distinctive but linked livelihood strategies. In the current situation, the poorer households depend on the wealthier ones for their survival, and the wealthier on the poorer for labour. There is a net difference in development opportunities and pathways for the wealthier market-oriented and the poorer subsistence farmer households. The former have the assets to invest in sustainable intensification (closing yield gaps), to create food stocks, and to gain a decent income from farming; the latter have too little assets to make agriculture profitable. These poorer households require more off-farm income, such as employment in the agri-food sector). They can be food sovereign but necessitate enhanced food diversity (nutrition).

Enhancing access to improved seeds, varieties, and fertilisers contributes to significantly more production of cereals and, in many cases, higher yields. The various national subsidy mechanisms have been instrumental in kick-starting this process. They make fertilisers available to farmers and induce fertiliser companies to invest in manufacturing and distribution and, thus, enhance access to fertilisers. This seems particularly beneficial for market-oriented farmers, though it remains a challenge to make farmers pay the full commercial price for fertilisers once the subsidy mechanisms stop.
(1) Background and understanding

(2) Regional drivers

(3) Regional organisations

(4) Agro-pastoralism-based

5 Grains-andlegumes-based

5.1 Definitions

5.2 Demography and geography

5.3 Regional consumption and production trends

5.4 Livelihoods of producer communities

5.5 Production systems

5.6 Food system outcomes

5.7 Institutional drivers

5.8 Risks and resilience

5.9 The COVID-19 pandemic

\subsection{Agency and}

development interventions

5.11 Summing up

References

6) Rice-and-horticulture

(7) Coastal maritime fisheries

(8) Tropical mixed tree and

(8) food crops systems

9 Toward enhanced resilience 
Effective access to input loans for farmers through value-chainbased financing (for example, warehouse receipt systems) is essential. For grains, this requires higher volumes, value addition along the supply chain, and, ultimately, links with substantial and remunerative markets.

Agricultural intensification is only sustainably achieved within a food system environment that provides incentives such as access to new markets, agricultural extension services (quality inputs), and financial services (input credits). Intensification needs to fit first with the farmer's objectives, the context of the farmer's household, the availability of arable land and market opportunities, and the assets of the household. In case of a shortage of land, farmers will seek either to undertake off-farm activities or to intensify their production on the land still available. The latter option is attractive when remunerative markets are accessible because they are an incentive to improve production and yields. Whether and to what extent famers will adopt the required technologies mainly depends on the availability of the required assets (Douxchamps et al. 2016; Woittiez et al. 2016).

From a sustainability perspective, agricultural intensification also requires a holistic territorial approach in the saturated areas of the grains-and-legumes-based food system, where competition for access to and use of rangelands and forests increases. Sedentary farmers consider these lands as agricultural reserves, while pastoralists see them as rangeland and therefore a key element of their livestock production system. Furthermore, forestry and agroforestry products and practices are an integral part of farmers' livelihoods and production systems. Agroforestry also contributes to soil organic matter, which improves nutrient and water retention and soil structure (Zougmoré et al. 2015). Such a territorial approach includes community-based arrangements for access to and use of common natural resources such as grazing areas, woodlands, and forests (Binam et al. 2017; Touré 2018)

The private agro-food sector plays a key role in linking farmers with expanding grains and legume markets and in developing new markets. This leads to more employment opportunities for youths and members of subsistence farmer households (SWAC/OECD

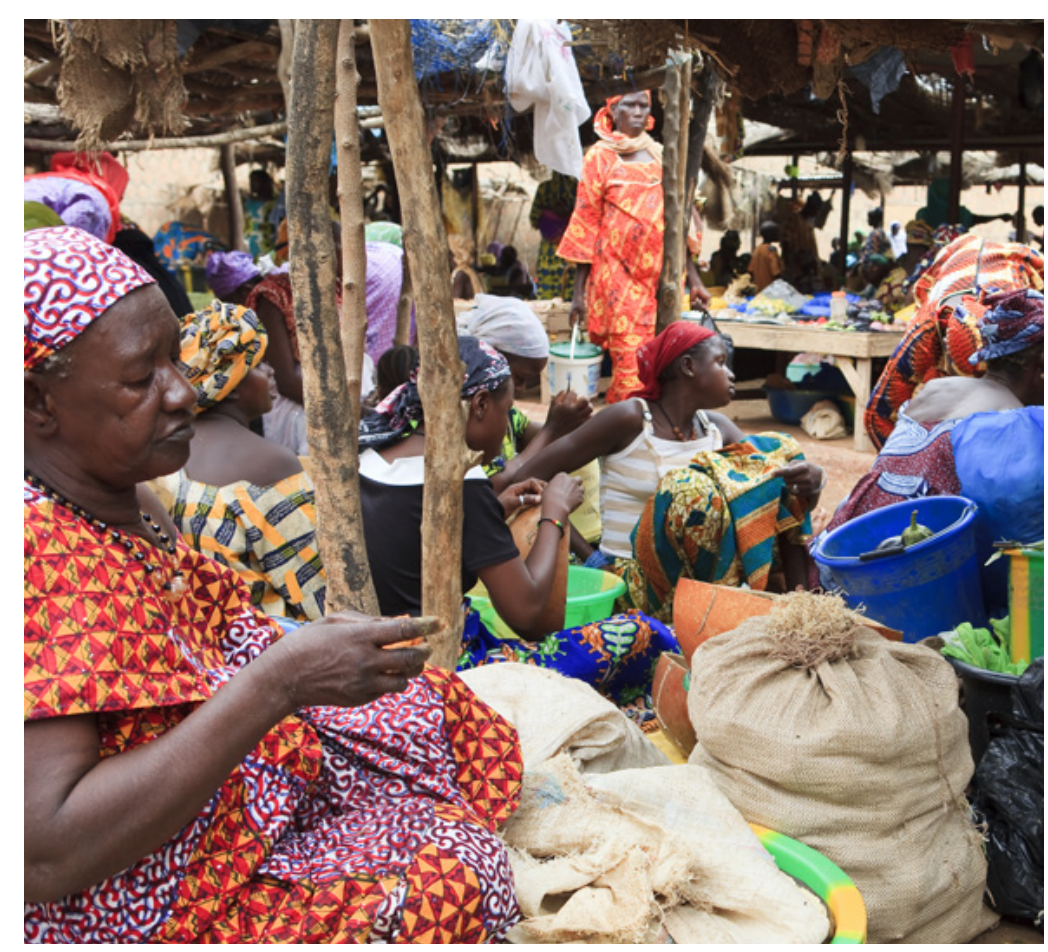

2018). The increasing involvement of the private sector is also an opportunity for reducing losses along the supply chain. There are considerable reductions of losses possible during storage, processing, and transport, with benefits for farmers, processors, and ultimately consumers. While technologies are available, the required knowledge and investments are barriers. Expanding and secured markets for produce and processed products are an incentive for the private sector, including farmers and their organisations, to make the necessary investments (Context 2014a, 2014b).

However, private investments in the agro-food sector still face structural constraints. First, the appropriate "hard" infrastructure, particularly rural roads and electricity, is lacking. Second, accessing "soft" infrastructure such as finance (loans for operations and investments) and skilled human resources is difficult (Maur and Shepherd 2015; WEF 2019, 122-125). Addressing these constraints
(1) Background and understanding

(2) Regional drivers

(3) Regional organisations

(4) Agro-pastoralism-based

5 Grains-andlegumes-based

5.1 Definitions

5.2 Demography and geography

5.3 Regional consumption and production trends

5.4 Livelihoods of producer communities

5.5 Production systems

5.6 Food system outcomes

5.7 Institutional drivers

5.8 Risks and resilience

5.9 The COVID-19 pandemic

5.10 Agency and

development interventions

5.11 Summing up

References

6) Rice-and-horticulture

(7) Coastal maritime fisheries

Tropical mixed tree and food crops systems

9 Toward enhanced resilience

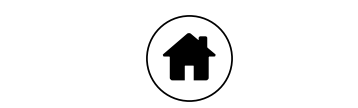


requires government investments in public goods based on thorough knowledge of remunerative local and regional markets and trade flows.

The interlinked national and regional trade networks of grains and pulses in West Africa allow for matching surplus and deficit areas and unlocking the potential of urban markets. In that respect, it is also interesting to notice cross-border initiatives at the subregional level, such as coordination of investments for improving irrigation schemes and upgrading feeder roads between the Sikasso region in Mali and the Cascades region in Burkina Faso (DGCT 2017). While investments are still needed to improve the regional roads, energy, and communications infrastructure, effective implementation of regional trade policies and rules for facilitating trade equally needs to be strengthened.

Various experiences show the positive effects of the innovative use of information and communication technologies on trade and information flows, such as linking sellers of cereals in surplus regions with buyers in insecure deficit areas or the use of e-vouchers in the input subsidy schemes. Overall, ICT reduces transaction costs in the supply of agricultural inputs and outputs and the handling of payments (loans and purchases) and greatly improves access to information (agricultural technologies and weather information) (PAPSA 2020; World Bank 2019). The rapid uptake of information technologies in rural areas pleads for more public-private investments in information and communications technology infrastructure and web-based applications.

Notes

1 Coarse grains generally refer to cereal grains other than wheat and rice. See website (accessed August 21, 2020).

2 Data in this section from FAOSTAT, Food and Agriculture Organisation, Rome (accessed August 31, 2020).

3 http://www.geo-ref.net/en/bfa.htm (last accessed May 15, 2020).

4 http://www.geo-ref.net/en/bfa.htm (last accessed May 15, 2020).

5 Data in this section from FAOSTAT, Food and Agriculture Organisation, Rome (accessed August 31, 2020)
6 Data in this section from FAOSTAT, Food and Agriculture Organisation, Rome (accessed August 31, 2020).

7 Nigeria is not included in these rankings and percentages. Data in this section from FAOSTAT, Food and Agriculture Organisation, Rome (accessed August $31,2 \overline{020}$ ).

8 FAOSTAT, Food and Agriculture Organisation, Rome (accessed August $31,2020)$.

9 Production and market flow data from FEWS NET.

10 Production and market flow data from FEWS NET.

11 Including Cameroon, Equatorial Guinea, Gabon, and São Tomé and Príncipe.

12 M. Maillard. « J'ai vu la crise se répandre comme une pieuvre dans la région » : des villages au Mali rasés par la violence et la famine. (accessed February 1, 2021)

13 Operations Portal Refugee Situations database, United Nations High Commissioner for Refugees, Geneva (accessed June 17, 2020).

14 Information in this section based on interviews with key experts in Burkina Faso and Mali and a literature review for Mali. See also de Roo, Wennink, and Boef (2020).

15 This information refers specifically to Burkina Faso.

\section{References}

AGRA (Alliance for a Green Revolution in Africa). 2014. Establishing the Status of Postharvest Losses and Storage for Major Staple Crops in Eleven African Countries (Phase II). Nairobi, Kenya: AGRA.

Asinyo, B., C. Frimpong, and E. Amankwah. 2015. "The State of Cotton Production in Northern Ghana." International Journal of Fiber and Textile Research 5 (4): 58-63. The State of Cotton Production in Northern Ghana.

Binam, J. N., F. Place, A. A. Djalal, and A. Kalinganire. 2017. "Effects of Local Institutions on the Adoption of Agroforestry Innovations: Evidence of Farmer Managed Natural Regeneration and Its Implications for Rural Livelihoods in the Sahel." Agricultural and Food Economics 5: 2.

CILSS (Permanent Interstate Committee for Drought Control in the Sahel). 2016a. "Intra-regional Trade Flows of Agricultural Products and Livestock in the Sahel and West Africa." Le Hub Rural.

CILSS (Permanent Interstate Committee for Drought Control in the Sahel). 2016b. Landscapes of West Africa. A Window on a Changing World. Reston, VA: USGS.
(1) Background and understanding

(2) Regional drivers

(3) Regional organisations

(4) Agro-pastoralism-based

5 Grains-andlegumes-based

5.1 Definitions

5.2 Demography and geography

5.3 Regional consumption and production trends

5.4 Livelihoods of producer communities

5.5 Production systems

5.6 Food system outcomes

5.7 Institutional drivers

5.8 Risks and resilience

5.9 The COVID-19 pandemic

5.10 Agency and development interventions

5.11 Summing up

\section{References}

6) Rice-and-horticulture

(7) Coastal maritime fisheries

(8) Tropical mixed tree and

8 food crops systems

9 Toward enhanced resilience 
Commandeur, D., and K. Casey. 2016. Marchés de demande structurée et petits exploitants: pertinence et accès. Bethesda, MD: SNV.

Context. 2014a. Multicrop Value Chain Phase II. Burkina Faso/Mali Sorghum and Millet. Seattle, US: Bill \& Melinda Gates Foundation.

Context. 2014b. Multicrop Value Chain Phase III. Burkina Faso/Mali Cowpea. Seattle, US: Bill \& Melinda Gates Foundation.

Crola, J.-D. 2019. Lutter contre les inégalités au Sahel pour répondre aux défis du développement et de la sécurité. London: Oxfam International.

DARD (Directorate of Agriculture and Rural Development). 2019. The ECOWAS Rice Fact Book, 2019. Abuja, Nigeria: ECOWAS.

de Roo, Nina, Bertus Wennink, and Walter de Boef. 2020. Rapid Country Assessment: Mali. The Impact of COVID-19 on the Food System.

Wageningen, the Netherlands: Wageningen University \& Research/KIT.

DGCT (General Directorate of Local Governments). 2017. Les conseils régionaux et le développement économique régional. Leçons tirées de leurs expériences et perspectives d'avenir. Bamako, Mali: MFDL.

Douxchamps, S., M. T. Van Wijk, S. Silvestri, A. S. Moussa, C. Quiros, N. Y. B. Ndour, S. Buahe, L. Somé, M. Herrero, P. Kristjanson, M. Ouédraogo, P. K. Thornton, P. Van Asten, R. Zougmoré, and M. C. Rufinob. "Linking Agricultural Adaptation Strategies, Food Security and Vulnerability: Evidence from West Africa." Regional Environmental Change 16: 1305-17.

Dufumier, M. 2005. Etude des systèmes agraires et typologie des systèmes de production agricole dans la région cotonnière du Mali. Bamako, Mali: PASE.

ECOWAS (Economic Community of West African States) and IRDR (Interréseaux Développement rural). 2018. "Les marchés institutionnels alimentaires en Afrique : Quelles évolutions et quelles contributions au développement?" Bulletin de synthèse souveraineté alimentaire, no. 26.

Elbehri, A., J. Kaminski, S. Koroma, M. Iafrate, and M. Benali. "West Africa Staple Food Systems: An Overview of Trends and Indicators of Demand, Supply, and Trade." In Rebuilding West Africa's Food Potential: Policies and Market Incentives for Smallholder-Inclusive Food Value Chains, edited by A. Elbehri, 1-43. Rome: FAO/IFAD.

FAO (Food and Agriculture Organisation). 2020. World Food and Agriculture Statistical Yearbook 2020. Rome: FAO.

FAO (Food and Agriculture Organisation), IFAD (International Fund for Agricultural Development), UNICEF (United Nations Children's Fund), WFP (World Food Programme), and WHO (World Health Organisation). 2019. The State of Food Security and Nutrition in the World 2019. Safeguarding against Economic Slowdowns and Downturns. Rome: FAO.
FEWS NET. 2010a. Livelihood Zoning and Profiling Report: Burkina Faso. Washington, DC: USAID.

FEWS NET. 2010b. Livelihood Zoning and Profiling Report: Mali. Washington, DC: USAID.

FEWS NET. 2019. Mali: Enhanced Market Analysis. June 2019. Washington, DC: USAID.

Franke, A. C., G. J. van den Brand, B. Vanlauwe, and K. E. Giller.

"Sustainable Intensification through Rotations with Grain Legumes in SubSaharan Africa: A Review." Agriculture, Ecosystems and Environment 261: 172-85.

Gnisci, D. 2016. Women's Roles in the West African Food System: Implications and Prospects for Food Security and Resilience. West African Papers 3. Paris: OECD.

Hjelm, L., and W. Dasori. 2012. Comprehensive Food Security \& Vulnerability Analysis. Ghana 2012. Focus on Northern Ghana. Accra, Ghana: WFP/MFA/ GSS.

Hollinger, Frank, and John M. Staatz, eds. 2015. Agricultural Growth in West Africa: Market and Policy Drivers. Rome: ADB/FAO.

Jalloh, A., E. R. Rhodes, I. Kollo, H. Roy-Macauley, and P. Sereme. 2011. Nature and Management of the Soils in West and Central Africa: A Review to Inform Farming Systems Research and Development in the Region. Dakar, Senegal: CORAF/WECARD.

Kaminski, Jonathan. 2008. Cotton-Cereal Farming Systems in West and Central Africa: Opportunities and Constraints for Revenue-raising Diversification and Marketing Strategies. FAO Working Paper under the AAACP Project. Rome: FAO, Economic and Social Department, Trade and Markets Division.

Kaminski, Jonathan, Aziz Elbehri, and Jean-Baptiste Zoma. "An Analysis of Maize Value Chain and Competitiveness in Burkina Faso: Implications for Smallholder-inclusive Policies and Initiatives." In Rebuilding West Africa's Food Potential: Policies and Market Incentives for Smallholder-Inclusive Food Value Chains, edited by A. Elbehri, 451-479. Rome: FAO/IFAD.

Maur, J.-C., and B. Shepherd. 2015. Connecting Food Staples and Input Markets in West Africa: A Regional Trade Agenda for ECOWAS Countries. Washington, DC: World Bank.

Platform for Agricultural Risk Management (PARM). 2016. Warehouse Receipt System in Sub-Saharan Africa: Making progress in market, finance and postharvest risks management (by B. Osman). PARM Policy Brief \#13. Rome: PARM/IFAD.
(1) Background and understanding

(2) Regional drivers

(3) Regional organisations

(4) Agro-pastoralism-based

5 Grains-andlegumes-based

5.1 Definitions

5.2 Demography and geography

5.3 Regional consumption and production trends

5.4 Livelihoods of producer communities

5.5 Production systems

5.6 Food system outcomes

5.7 Institutional drivers

5.8 Risks and resilience

5.9 The COVID-19 pandemic

5.10 Agency and development interventions

\subsection{Summing up}

\section{References}

6) Rice-and-horticulture

(7) Coastal maritime fisheries

Tropical mixed tree and

8 food crops systems

9 Toward enhanced resilience 
Ouédraogo, M., R. Zougmoré, A. S. Moussa, S. T. Partey, P. K. Thornton, P. Kristjanson, N. Y. B. Ndour, L. Somé, J. Naab, M. Boureima, L. Diakité, and C. Quiros. "Markets and Climate Are Driving Rapid Change in Farming Practices in Savannah West Africa." Regional Environmental Change 17: 437-49.

United Nations World Food Programme (PAM). 2014. Burkina Faso. Analyse globale de la vulnérabilité, de la sécurité alimentaire et de la nutrition (AGVSAN). Rome: PAM/VAM.

United Nations World Food Programme (PAM). 2017. Analyse Globale de la Vulnérabilité et de la Sécurité Alimentaire (AGVSA). République du Bénin. Données collectées en Juillet-Août 2017. Rome: PAM/VAM.

United Nations World Food Programme (PAM). 2018. Mali. Enquête nationale sur la sécurité alimentaire et nutritionnelle (ENSAN). Septembre 2018. Bamako, Mali: PAM.

PAPSA (Agricultural Productivity and Food Security Project). 2020. L'essor des petits producteurs agricoles au Burkina Faso. L'approche du Projet d'Amélioration de la Productivité agricole et de la Sécurité Alimentaire. Ouagadougou, Burkina Faso: PAPSA / Groupe de la Banque mondiale / GAFSP / KIT.

REGIS-AG (Resilience and Economic Growth in the Sahel - Accelerated Growth). 2016. Value Chain and End Market Assessment - Cowpea. Washington, DC: USAID.

RPCA. 2015. Climat, changement climatique \& resilience. Cartes \& faits. Paris: CSAO/OCDE.

Save the Children Fund. 2017. An Atlas of Household Economy Analysis Information across the Sahel. Dakar, Senegal: Save the Children West and Central Africa.

Snapp, Sieglinde, Maryam Rahmanian, and Caterina Batello. 2018. Pulse Crops for Sustainable Farms in Sub-Saharan Africa. Edited by Teodardo Calles. Rome: FAO.

Sogoba, Bougouna, Bouba Traoré, Abdelmounaime Safia, Oumar Baba Samaké, Gilbert Dembélé, Sory Diallo, Roger Kaboré, Goze Bertin Benié, Robert B. Zougmoré, and Kalifa Goïta, 2020. "On-Farm Evaluation on Yield and Economic Performance of Cereal-Cowpea Intercropping to Support the Smallholder Farming System in the Soudano-Sahelian Zone of Mali." Agriculture 10 (6): 214.

SPRING (Strengthening Partnerships, Results, and Innovations in Nutrition Globally). 2018. Drivers of Malnutrition in Niger: Analysis of Secondary Data Sources. Washington, DC: USAID.

Staatz, John, and Frank Hollinger. 2016. West African Food Systems and Changing Consumer Demands. West African Papers 4. Paris: OECD.
SWAC/OECD (Sahel and West Africa Club Secretariat, Organisation for Economic Co-operation and Development). 2013. Settlement, Market and Food Security. West African Studies. Paris: OECD/SWAC.

SWAC/OECD (Sahel and West Africa Club Secretariat, Organisation for Economic Co-operation and Development). 2018. "Rural Employment Diversification." Maps \& Facts, no. 68

SWAC (Sahel and West Africa Club Secretariat, Organisation for Economic Co-operation and Development). 2020b. "Severe Food Security Has Tripled in the UMEAO Area." Maps \& Facts, no. 91.

Torres, C., J. Van Seters, K. Karaki, and R. Kpadonou. 2017. An Exploratory Analysis of Measures to Make Trade Facilitation Work for Inclusive Regional Agro-food Value Chains in West Africa. Discussion Paper 214. Maastricht, the Netherlands: ECDPM.

Toulmin, C., and B. Guèye. 2003. Transformations in West African Agriculture and the Role of Family Farms. Issue Paper 123. London: IIED.

Touré, O. 2018. Sécurisation du foncier pastoral en Afrique de I'Ouest : Des modèles divers et riches d'enseignements. London: IIED.

2SCALE. 2019. Business as Unusual: Insights from the 2SCALE Program. Amsterdam: IFDC/BoP/ICRA/KIT.

UNCCD (United Nations Convention to Combat Desertification). 2019. The Global Land Outlook: West Africa Thematic Report. Bonn, Germany: UNCCD.

USAID (United States Agency for International Development). 2019. Greenhouse Gas Emissions in the West Africa Region: Numbers at a Glance. Washington, DC: USAID.

Woittiez, Lotte, Katrien Descheemaeker and E. Ken Giller. 2015. Adoptability of Sustainable Intensification Technologies in Dryland Smallholder Farming Systems of West Africa. Research Report 64. Telangana, India: ICRISAT.

World Bank. 2019. Numériser l'agriculture. Résultats des programmes de délivrance de bons électroniques (e-vouchers) au Mali, au Niger et en Guinée. Bilan économique AFCW3. Washington, DC: World Bank Group.

World Economic Forum (WEF). 2019. The Global Competitiveness Report 2019. Insight Report. Edited by Prof. Klaus Schwab. Geneva, Switzerland World Economic Forum

Zougmoré, R., A. S. Traoré, and Y. Mbodj, eds. 2015. "Overview of the Scientific, Political and Financial Landscape of Climate-Smart Agriculture in West Africa." Working Paper 118, CGIAR Research Program on Climate Change, Agriculture and Food Security, Copenhagen, Denmark, June 15, 2015.
(1) Background and understanding

(2) Regional drivers

(3) Regional organisations

(4) Agro-pastoralism-based

5 Grains-andlegumes-based

5.1 Definitions

5.2 Demography and geography

5.3 Regional consumption and production trends

5.4 Livelihoods of producer communities

5.5 Production systems

5.6 Food system outcomes

5.7 Institutional drivers

5.8 Risks and resilience

5.9 The COVID-19 pandemic

5.10 Agency and development interventions

\subsection{Summing up}

\section{References}

6) Rice-and-horticulture

(7) Coastal maritime fisheries

(8) Tropical mixed tree and

8 food crops systems

9 Toward enhanced resilience 


\section{Rice-and- horticulture-based food systems}

By Joost Nelen

\subsection{Definitions}

6.2 Demography and geography

6.3 Regional consumption and production trends

6.4 Livelihoods of producer communities

6.5 Production systems

6.6 Food system outcomes

6.7 Institutional drivers

6.8 Risks and resilience

6.9 Food system impacts of and responses to the COVID-19 pandemic

6.10 Agency and development interventions

6.11 Summing up: toward leverage points for future interventions

References
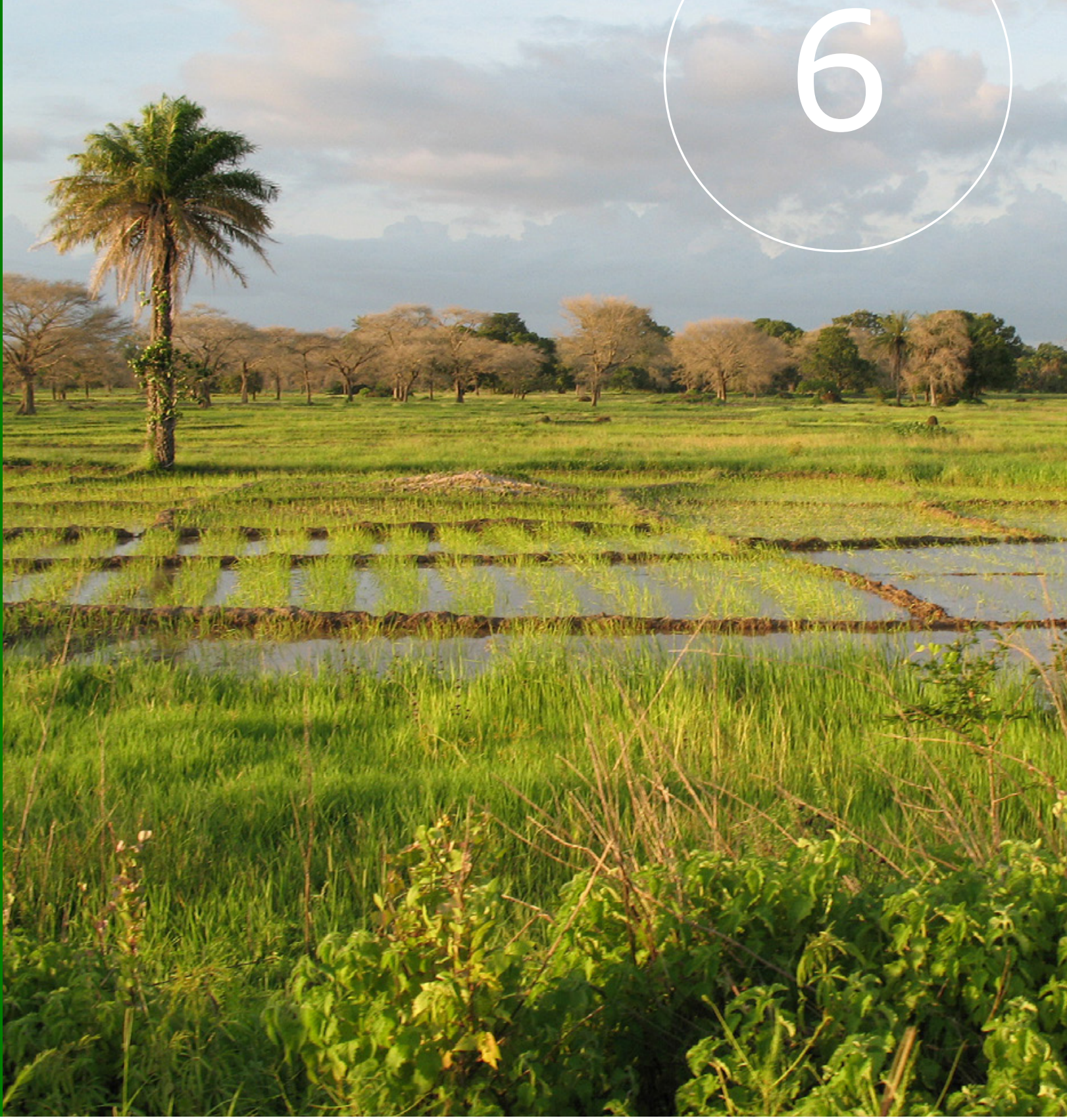
This chapter contains a description and an analysis of food systems based on the production, trade, processing, and consumption of rice and horticultural crops. The chapter has 11 sections. The first defines rice-and-horticulture-based food systems, followed by a discussion of their demography, location, and importance to livelihoods. Section 6.3 describes the trends in consumption and production, and section 6.4 details the livelihoods of people living in this food system. Section 6.5 covers the production system, while section 6.6 addresses multiple food system outcomes. Section 6.7 highlights important institutional drivers of changes in the system, while section 6.8 identifies trends, risks, and systems resilience, followed by an analysis of food system impacts of the COVID-19 pandemic in section 6.9. Section 6.10 contains an examination of past agency and development efforts to influence the rice-andhorticulture-based food system and lessons for the future. The final section outlines some conclusions about leverage points for enhanced resilience of the rice-and-horticulture-based food system.

\subsection{Definitions}

This chapter is focused on rice food systems in West Africa, which sometimes include horticulture crops. These two commodity groups are products of humid, sometimes irrigated environments and are often part of the same production systems. Vegetables such as tomatoes, potatoes, and onion are also included in some specific subsystems. Rain-fed rice is part of the broader grains-andlegumes-based food system (discussed in chapter 5) and mixed tree and food crops systems (discussed in chapter 8). Given their dominant place in terms of production, farmed area, and number of households growing the crops, rain-fed upland and lowland rice are mentioned in multiple sections of this chapter. Furthermore, they are included because data on rice and vegetables rarely mention their origins. Mangrove swamp rice and floating rice are briefly described. ${ }^{1}$

The scope of irrigated agriculture is broad, ranging from large-scale state or public-private schemes covering command areas or perimeters of more than 1,000 hectares to farmer community- or agribusiness-managed irrigation subsystems with a medium-scale (less than 1,000 hectares) or small-scale (less than 100 hectares) perimeter (Williams et al. 2020). Microscale irrigation subsystems (less than 1 hectare) for village gardening and urban or peri-urban farming, while important for nutritional security, are part of other food systems and therefore are not discussed here. Related value chains, institutions, and agencies specific to rice and horticulture food systems are discussed, as is how these contribute to consumer diets. Rice has become an indicator of urbanisation and dietary change during the past three decades, and rice is a strategic commodity for tackling food insecurity in the region.

\subsection{Demography and geography}

In West Africa over 3 million small-scale family farms, or 18 24 million people, are involved in rice and irrigated horticulture production. Nigeria counts for roughly half of these farms. ${ }^{2}$ Rice production involves up to 6 percent of the population, with the exception of Guinea, where it rises to 18 percent (DARD 2019). The systems can be found all over the region. As rain-fed rice and small-scale irrigation crops are part of larger systems, researchers have observed demographic growth of 2-3 percent per year and the same livelihoods as elsewhere in the Sudan-Sahelian (grains-andlegumes-based system) and Guinean zones (mixed tree and food crops systems). Population growth takes place at a slower pace in the Sahara-Sahelian horticulture areas, mainly found in Niger. In all rain-fed rice and small-scale systems, the commodities are the realm of women.

It is impossible to give a simple overview of the hundreds of medium- and small-scale irrigation areas in West Africa. Besides in Nigeria (Kano and Sokoto basins), the large-scale subsystems are concentrated in the Sahel. These include various irrigation offices along the Niger River in Mali, of which the Office du Niger is the largest, with 100,000 hectares irrigated, and more recently in Niger, such as at the Kandadji Dam. The same is observed in the Senegal River valleys for Mali (such as the Manantali area), Mauritania, and Senegal (Podor and Dagana), as well as along the Volta River affluents in Burkina Faso (such as at the Bagré area). The areas are densely populated and often constitute immigration poles. Already
(1) Background and understanding

(2) Regional drivers

(3) Regional organisations

(4) Agro-pastoralism-based

(5) Grains-and-legumes-based

Rice-and-horticulture

\subsection{Definitions}

\subsection{Demography and} geography

6.3 Regional consumption and production trends

6.4 Livelihoods of producer communities

6.5 Production systems

6.6 Food system outcomes

6.7 Institutional drivers

6.8 Risks and resilience

6.9 The COVID-19 pandemic

6.10 Agency and development interventions

6.11 Summing up References

(7) Coastal maritime fisheries

8 Tropical mixed tree and

8 food crops systems

9 Toward enhanced resilience 
in the 1930s, people from the French Sudan had moved to the more developed irrigation zones. The Mali Office du Niger is a well-known case.

Migration also took place in more recently developed areas with one major difference: Since 2000, national governments have developed a discourse of agribusiness promotion to attract foreign capital investment and new actors supposing to give a boost to agriculture. Irrigation schemes were the most coveted areas for leases of thousands of hectares for those new actors. Until now, these new farmers or agroenterprises partly met expectations: although there are examples of increased productivity, in most cases government policies led to land acquisition and speculation by companies and city-based elites (Brondeau 2019; Deininger et al. 2011; Hilhorst and Nelen 2012; Papazian 2012). ${ }^{3}$ As for rice and vegetables, agroenterprises remain a minority in number and in production volume. The bulk of rice production in West Africa originates from the numerous small- and medium-scale family farms.

(1) Background and understanding

(2) Regional drivers

(3) Regional organisations

(4) Agro-pastoralism-based

(5) Grains-and-legumes-based

ALGERIA

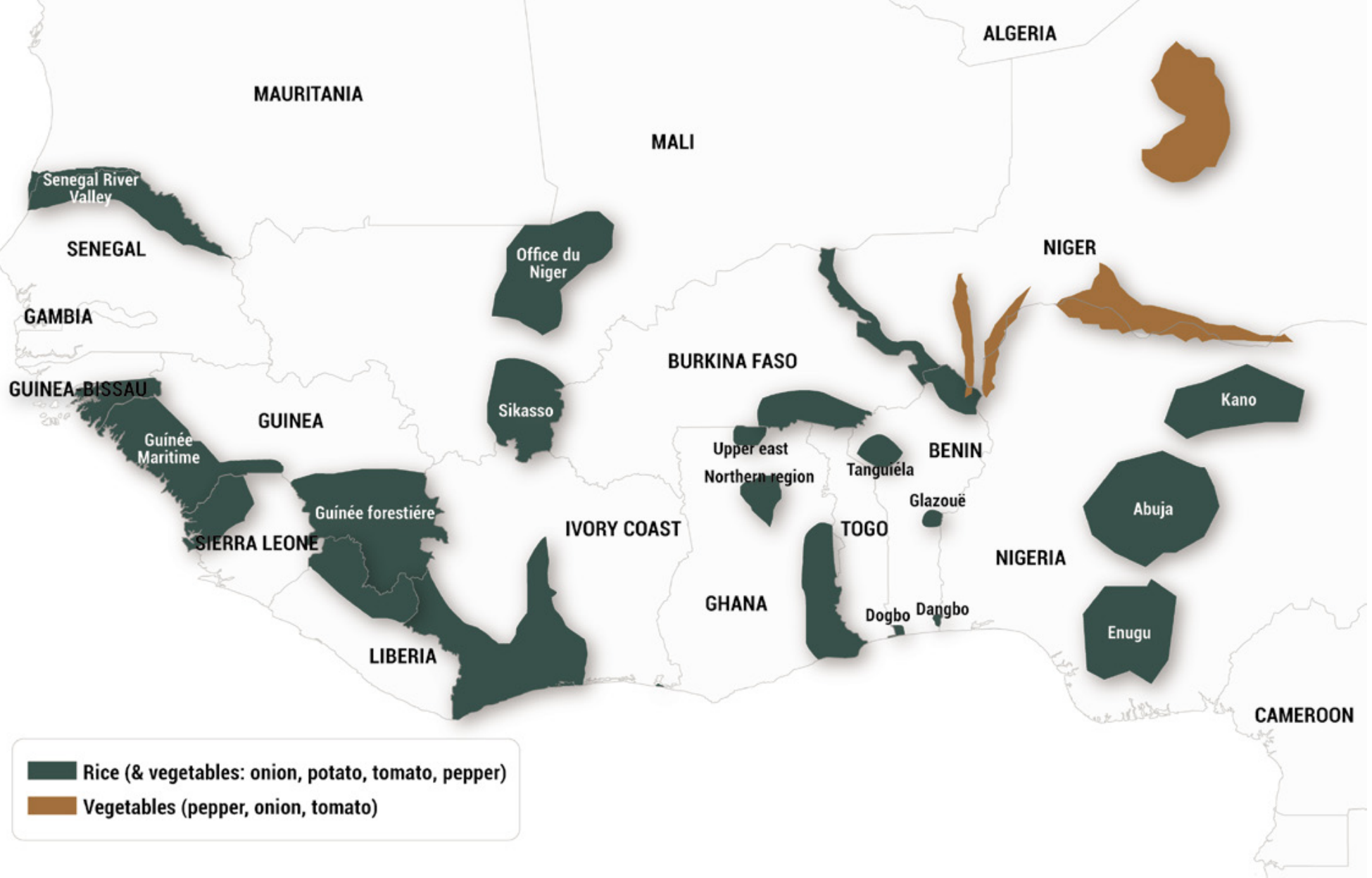

6 Rice-and-horticulture

6.1 Definitions

6.2 Demography and geography

6.3 Regional consumption and production trends

6.4 Livelihoods of producer communities

6.5 Production systems

6.6 Food system outcomes

6.7 Institutional drivers

6.8 Risks and resilience

6.9 The COVID-19 pandemic

6.10 Agency and development interventions

6.11 Summing up References

(7) Coastal maritime fisheries

8 Tropical mixed tree and food crops systems

9 Toward enhanced resilience 


\subsection{Regional consumption and production trends}

6.3.1 Rice

West Africa is the rice belt of Africa and has become one of the world's biggest rice consumers after Asia. Rice is a staple food for almost all West African households, including poor urban and rural households. Rice has become the most consumed cereal after sorghum and millet. From 2006 to 2011, 27 percent of all grain consumption in West Africa (excluding Nigeria) was rice (DAEWR 2012), a figure that only has risen in the past eight years. ${ }^{4}$ In terms of caloric intake, rice has overtaken individual coarse grains and can exceed 33 percent of calories for the urban poor (GRiSP 2013;
Soullier et al. 2020) (see also annex 6A). Since the 1970s, regional demand for rice has grown at 3-6 percent annually, driven by a combination of population growth and gradually becoming a substitute for coarse grains (DARD 2019)..$^{5}$ Important reasons for consumer shifts are urbanisation and behavioural change: milled rice is a convenient staple for swift meal preparation at home or at market restaurants, which benefits women, who often handle multiple tasks.

Given rice imports, price fluctuations can have direct impacts on West Africa. During the price spikes of 2008, urban populations in countries with high rice consumption levels spent 20-25 percent of

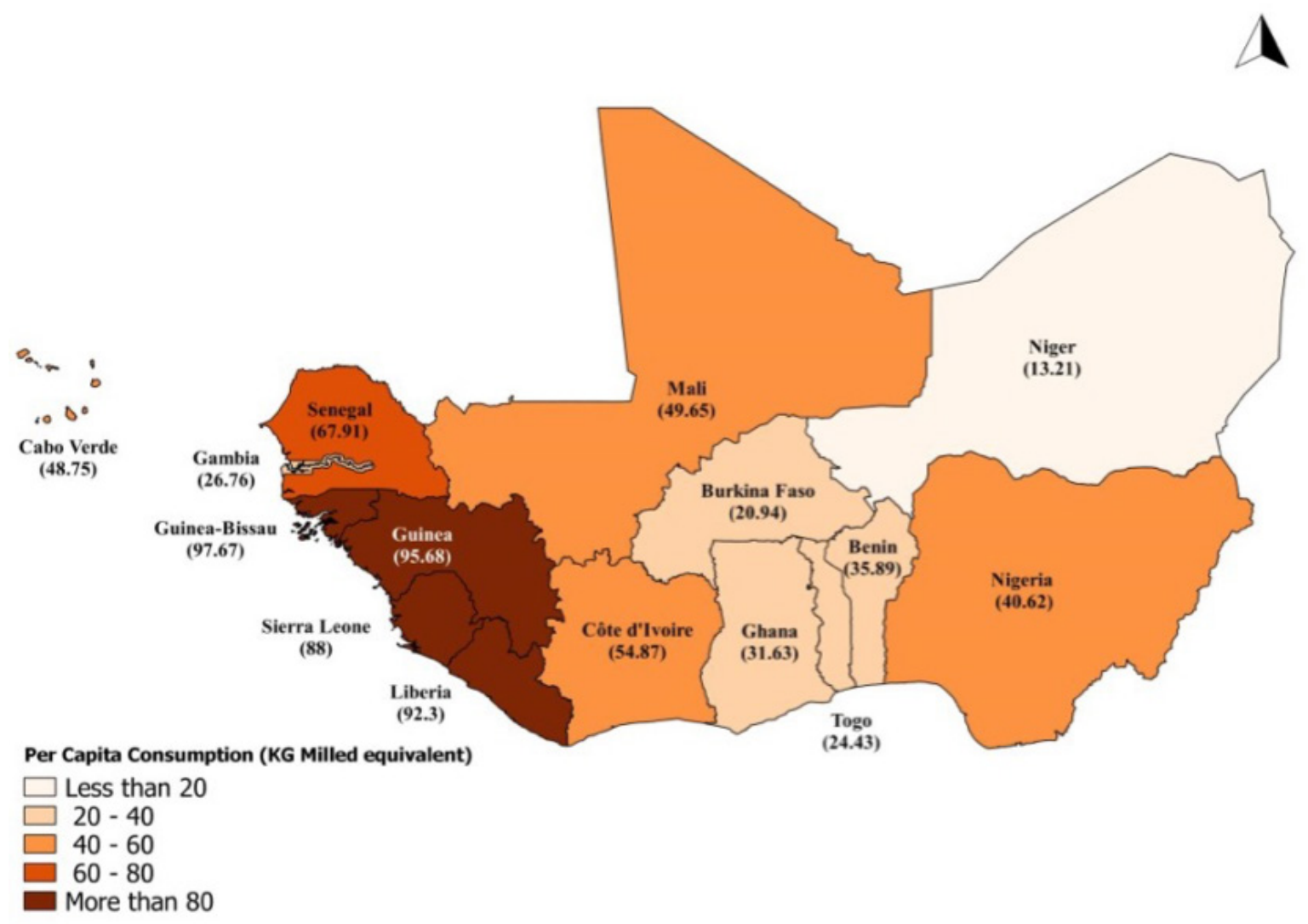

(1) Background and understanding

(2) Regional drivers

(3) Regional organisations

(4) Agro-pastoralism-based

(5) Grains-and-legumes-based

6 Rice-and-horticulture

6.1 Definitions

6.2 Demography and geography

6.3 Regional consumption and production trends

6.4 Livelihoods of producer communities

6.5 Production systems

6.6 Food system outcomes

6.7 Institutional drivers

6.8 Risks and resilience

6.9 The COVID-19 pandemic

6.10 Agency and development interventions

6.11 Summing up References

(7) Coastal maritime fisheries

8 Tropical mixed tree and food crops systems

9 Toward enhanced resilience

Map 6.2 Rice Consumption per Capita in West Africa (2017)

Source: DARD 2019. 
their income on rice (SWAC/OECD 2011). For Burkina Faso's poor, for example, rice purchases can

represent $45 \%$ of cash expenditures on cereals, a share that is substantially higher than for other income classes. Similar findings have been obtained in several other West African nations, demonstrating that rice availability and rice prices have become a major determinant of the welfare of the poorest segments of West African consumers.

(GRiSP 2013, 91-92)

There are regional consumption differences. Rice is most important in diets in countries on the Southwest Atlantic coast, where people consume more low-grade rice than in, for example, Nigeria or Mali. In comparison with the yearly average per capita consumption in West Africa of 220-50 kilograms of cereals and tubers, ${ }^{6}$ in 2017 people consumed over 90 kilograms of milled rice per capita in Guinea-Conakry and Guinea-Bissau, Liberia, and Sierra Leone, and over 65 kilograms per capita in Senegal. Less rice, around 4055 kilograms per capita, was consumed in Côte d'Ivoire, Mali, and Nigeria (DARD 2019). The other West African countries had consumption below 36 kilograms per capita, while in the Sahel consumption was under 21 kilograms per capita (map 6.2) (DARD 2019).

According to DARD $(2019,8)$,

In 2017 , the consumption of rice in West Africa was

15.86 million metric tons and is projected to grow to 22 million metric tons by 2025 based on the trends in the last five years. This is close to a 50 percent increase between 2017 and 2025 with per capita consumption equally expected to rise from $43 \mathrm{~kg}$ in 2017 to $49 \mathrm{~kg}$ in 2025.

Nigeria is the largest consumer of rice, leading at 7.75 million tons per year overall. Other large consumers are Guinea and Côte d'Ivoire, both over 1.200 million tons; Senegal, Ghana, and Mali at 0.900-1.075 million tons; and Sierra Leone and Liberia at 435,000665,000 tons. Consumption in other countries was less than 405,000 tons in 2017.7
Many factors apart from availability and origin determine what kind of rice is purchased. Such factors are accessibility (price),

characteristics (variety, texture, flavour, aroma), and quality (linked to processing technique, cleanness, homogeneity, and swelling and stickiness for cooking). The importance of these different factors varies within and between countries. Polished white rice is consumed most often in cities, while brown and parboiled rice is more common in rural areas. But these trends are not fixed and can change. In the Southwest Atlantic countries, Mali, and Nigeria to some extent, local polished and parboiled rice has become the norm, while in other countries imported varieties of perfumed or cheap white rice are the standard (Soullier et al. 2020). The latter trend is certainly due to insufficient domestic production. Yet big producers such as Guinea-Conakry, Sierra Leone, and Côte d'Ivoire still import large amounts of rice (DARD 2019). ${ }^{8}$ There are questions about the quality of locally milled rice (such as unclean, broken, mixed varieties called tout-venant), but there are also food safety questions about the quality of imported stocks. Nutritional value does not yet seem to be a determining factor: white rice is preferred above brown or parboiled. However, rice is unlikely to replace more nutritious coarse grains in the short term. ${ }^{9}$ Moreover, during the 2008 price spike, people easily returned to using coarse grains (SWAC/OECD 2011).

Data show that in 2018, West Africa produced 18.5 million tons of paddy (or 13 million tons milled equivalent), with a cultivated area of more than 9.1 million hectares. ${ }^{10}$ The average yield in the region, though it varies enormously by area and by subsystem, rose from 1.8 metric tons per hectare in 2003 to over 2 metric tons per hectare in 2018 (see country production and yields in annex 6A). Production has risen by 5.9 percent per year over the past decade (5 percent per year, 2000-2018). In 2018 Nigeria was the biggest producer ( 6.8 million tons, 3.35 million hectares), followed by Mali (3.17 million tons, 0.97 million hectares), Guinea ( 2.34 million tons, 1.86 million hectares), and Côte d'Ivoire ( 2.1 million tons, 0.78 million hectares). The other countries produced 920,000 tons or less (Sierra Leone on 796,000 hectares). Ghana produced little (769,000 tons on 272,000 hectares), considering its population and water reserves (figure 6.1).
(1) Background and understanding

(2) Regional drivers

(3) Regional organisations

(4) Agro-pastoralism-based

(5) Grains-and-legumes-based

Rice-and-horticulture

6.1 Definitions

6.2 Demography and geography

6.3 Regional consumption and production trends

6.4 Livelihoods of producer communities

6.5 Production systems

6.6 Food system outcomes

6.7 Institutional drivers

6.8 Risks and resilience

6.9 The COVID-19 pandemic

6.10 Agency and development interventions

6.11 Summing up References

(7) Coastal maritime fisheries

8 Tropical mixed tree and

(8) food crops systems

9 Toward enhanced resilience 


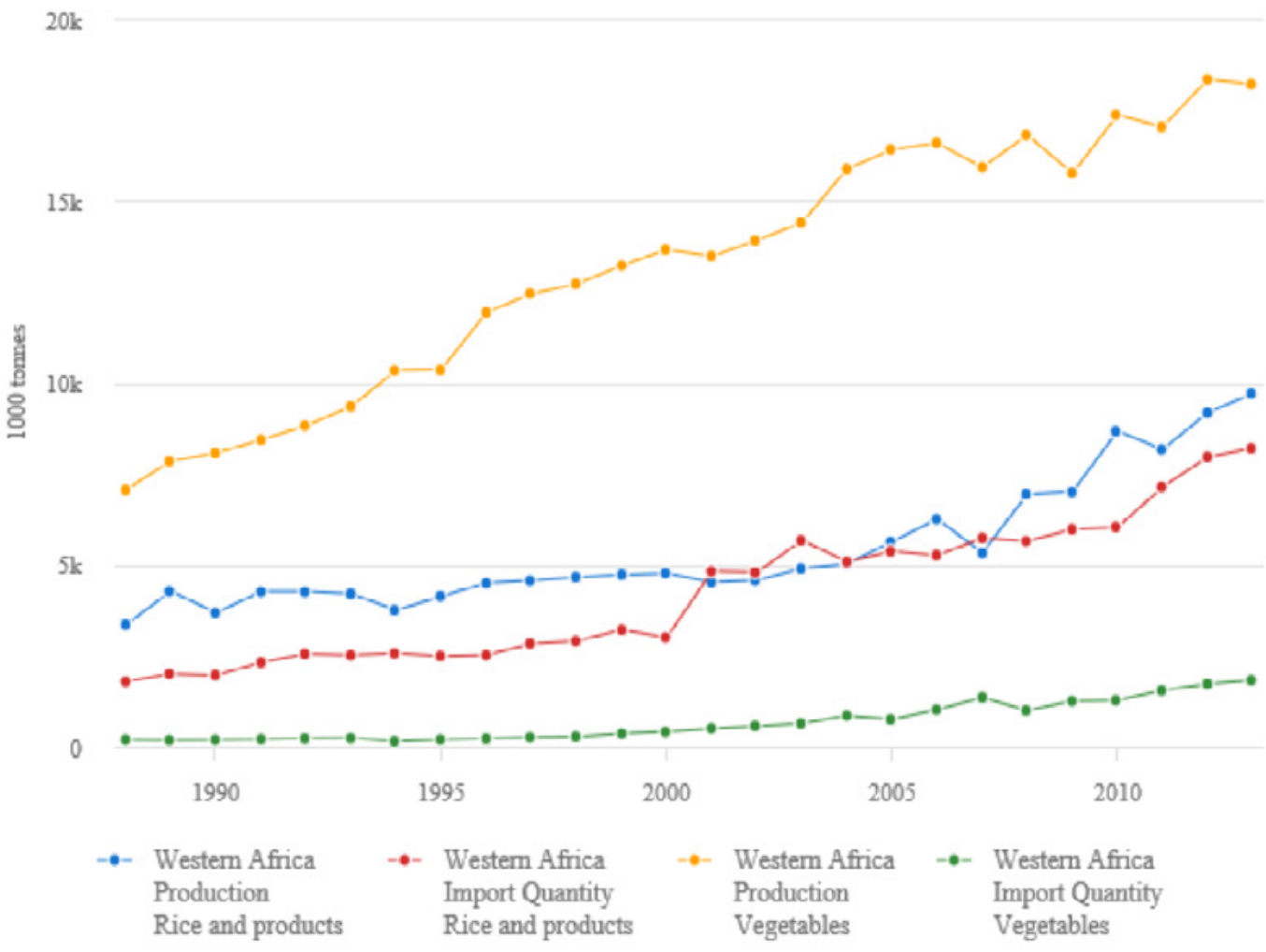

Figure 6.1 Rice and Vegetable Production and Imports in West Africa, 1988-2013

Source: FAOSTAT, Food and Agriculture Organisation, Rome (accessed August 27, 2020).

\subsubsection{Vegetables (horticulture)}

Onions, tomatoes, and leafy vegetables are part of the basic meal ingredients in most West African households. On average, people in West Africa consume between 50 and 60 kilograms per capita per year. ${ }^{11}$ Foods providing energy, such as cereals and tubers, can make up over 50 percent of food budgets of poor households, while vegetables represent 10 percent or less in Niger and Senegal (Bush 2018). Urbanisation and income growth have meant "increased demand for horticulture products-vegetables, fruits and spices. This growth in demand, both domestically and externally, is promoting horticulture production on medium- to large-scale irrigated farming systems" (Williams et al. 2020, 429). Some countries have found export market niches, but 90 percent of overall horticulture production goes to nearby food markets. ${ }^{12}$ In general, while food energy intake may be sufficient through self-provisioning and market access, nutritional security (dietary diversity) is not yet assured; horticulture has been focused on tomatoes, onions, potatoes, and peppers as the dominant cash crops.

Horticulture production has risen quickly alongside increasing rice production, at 4.2 percent per year in the past decade (2010-2018; 3.9 percent per year in 1998-2018). In 2018 West Africa produced around 26.4 million tons of primary vegetables on an estimated 4.43 million hectares, of which Nigeria had the biggest share at 16.4 million tons on 3.22 million hectares. Niger and Mali are the next highest at, respectively, 3.4 million and 2 million tons. Other
(1) Background and understanding

(2) Regional drivers

(3) Regional organisations

(4) Agro-pastoralism-based

(5) Grains-and-legumes-based

6 Rice-and-horticulture

6.1 Definitions

6.2 Demography and geography

6.3 Regional consumption and production trends

6.4 Livelihoods of producer communities

6.5 Production systems

6.6 Food system outcomes

6.7 Institutional drivers

6.8 Risks and resilience

6.9 The COVID-19 pandemic

6.10 Agency and development interventions

6.11 Summing up References

(7) Coastal maritime fisheries

(8) Tropical mixed tree and food crops systems

9 Toward enhanced resilience 
producing countries are below 850,000 tons each. ${ }^{13}$ Niger and Mali, both around 650,000 tons, dominate shallot onion production in the region, which has a total production of 1.6 million tons. Niger and Nigeria produce, respectively, 1.2 million and 1 million tons for dry onions (total production is 2.7 million tons). Behind Nigeria, which produces 1.36 million tons of potatoes and 4 million tons of sweet potatoes, Mali is a major producer of these crops (310,000 tons potatoes and around 700,000 tons of sweet potatoes). The total regional production for potatoes is 2.1 million tons and for sweet potatoes, 5.4 million tons. Tomato production ( 5.3 million tons total) is more spread out over the region: behind Nigeria (3.9 million tons), the nations of Ghana, Benin, Senegal, Niger, Burkina Faso, and Mali each produce between 150,000 and 400,000 tons per year.

\subsection{Livelihoods of producer communities}

According to typologies described in irrigated lowland areas (see section 6.5) in Burkina Faso, Mali and Senegal, there are three types of farming households (FHs): (1) FHs specialising in irrigation farming (rice and horticulture); (2) diversifying FHs, oriented at rain-fed and irrigated products (grains and others); and (3) smallholder FHs, which are poorly equipped and have a perimeter of less than 1 hectare (Bazin et al. 2017). Although the typology does not follow wealth groups at 100 percent (see section 6.6), the first two types generally represent the categories of medium to wealthy FHs, while the smallholder FHs and some of the specialising FHs represent poor to very poor household categories.

In general, besides rice and/or vegetables, millet and sorghum are

typically grown on the rain-fed land. The family owns about 9-10 TLU (tropical livestock unit). One or two adult household members work outside the farm in nearby towns, requiring the family to rely on hired labour for about 40-50 per cent of the farm work on the irrigated fields. (Williams et al. 2020, 426)

The more specialised FHs have the most off-farm income. Zorom et al. (as cited in Van der Wijngaart et al. 2019, 22) stated that farmers who "have some off-farm income are particularly interested in investing in agriculture if irrigation is made available, whereas other groups may be interested in improving first their access to credit for farm inputs with then a view on irrigation." The specialising or diversifying households (with 2 hectares or more) can afford more inputs and own both plows and oxen than the smallholder FHs. The wealthiest own motorised cultivators. Poor households hardly own proper equipment and ruminant livestock.

Diversification appears to be an indicator of wealth. Specialising FHs also have several revenue sources. The poorest, often migrant farmers, were least diversified and had to sell their labour (see section 6.6) (Bazin et al. 2017; Dixon and Holt 2010; Guèye 2014). In some cases, farmers start to concentrate on more lucrative horticulture crops. Huge differences in gross margins exist per area and per market. In Sahel countries, paddy/milled rice can give between $\$ 80$ and $\$ 180$ per ton (or about $\$ 430$ per hectare), while onions or tomatoes can give $\$ 50-\$ 155$ per ton (or about $\$ 1,000$ per hectare). ${ }^{14}$ Surveys in Burkina, Mali, and Senegal show that rice remains the overall primary source of revenue, while horticulture is most common among the wealthier diversifying or specialising $\mathrm{FHs}$.

The FHs might have relatively good market access and water services compared to their counterparts in other farming systems, but access to other services (extension, credit, insurance, and so on) is low to moderate. Nutrition insecurity prevails, and access to basic services-especially health, considering the disease risks associated with abundant water-is often insufficient. $\mathrm{FH}$ vulnerability also has monetary dimensions: water charges and taxes weigh heavily on family farms, which also face land fragmentation and water and land tenure insecurity, exacerbated by the aforementioned land acquisitions (Bazin et al. 2017; Dixon and Holt 2010; Guèye 2014). Emigration also takes place; as stated, most households have one or two members with off-farm revenues.
(1) Background and understanding

(2) Regional drivers

(3) Regional organisations

(4) Agro-pastoralism-based

(5) Grains-and-legumes-based

Rice-and-horticulture

6.1 Definitions

6.2 Demography and geography

6.3 Regional consumption and production trends

6.4 Livelihoods of producer communities

6.5 Production systems

6.6 Food system outcomes

6.7 Institutional drivers

6.8 Risks and resilience

6.9 The COVID-19 pandemic

6.10 Agency and development interventions

6.11 Summing up References

(7) Coastal maritime fisheries

8 Tropical mixed tree and

8 food crops systems

9 Toward enhanced resilience 


\subsection{Production systems}

Five production subsystems are part of the different food systems discussed here (box 6.1). Rain-fed upland rice (subsystem 1), lowland rice and vegetables (subsystem 2), and mangrove or floating rice (subsystem 4) are generally part of the grains-andlegumes-based system and mixed tree and food crops systems, or of specific agropastoral systems, such as in the inner Niger delta. Irrigated lowlands (subsystem 3 ) and irrigated horticulture (subsystem 5) are specific subsystems. Even though these latter two require specialisation and investments in rice or vegetables, the FHs produce a wider range of crops and animals. As mentioned, specialised agroenterprises are rare, and the bulk of rice and vegetable production originates from numerous diversifying family farms. In the irrigated subsystems, rice is the principal staple crop during the wet season. Diverse crops (rice, cereals, vegetables) are grown on the perimeter in the dry season. In general, the better-off households continue to grow rice in the dry season, while poorer households focus on vegetables (shallots, onions, and tomatoes, as well as cabbages and okra).

\section{Box 6.1 Rice and Horticulture Production Subsystems}

Five rice and horticulture subsystems characterise the West African landscape: ${ }^{15}$

1 Rain-fed upland rice in 2018 covered 43 percent of the total rice area, or over 4 million hectares, contributing an estimated 25 percent or more of regional production. Upland rice is part of larger farming systems and uses the same farming practice as other grains. Yields are low, around 1 ton per hectare, but rise to 2.5 tons per hectare under favourable conditions (fertile soils, sufficient rainfall, increased of labour and inputs). Nigeria, Sierra Leone, Côte d'Ivoire, Liberia,

Guinea-Conakry, and Guinea-Bissau are the main producers. Upland rice is part of the mixed tree and food crops system.

2 Rain-fed lowland rice and vegetables are grown in many floodplains, rivers, and inland valleys, covering 38 percent of the total rice area (over 3.7 million hectares), contributing an estimated $40-45$ percent of total rice production. However, no specific data are available on the share of horticulture per subsystem. This environment, an estimated 13 million hectares, offers the highest growth potential in hectares and in households (GRiSP 2013). The subsystem is located all over the region and has no or only partial water control. Only a small part of the lowlands is irrigated (less than 5 percent), accounting for 6 percent of total rice production. Depending on the level of technology, soil conditions, and socioeconomic factors, yields range between 2.5 and 5 tonnes per hectare. ${ }^{16}$ The same lowlands (often bas-fonds or fadamas) also produce horticulture crops, mainly onions, tomatoes, potatoes, peppers, and leafy vegetables that are sold in local markets (Dittoh et al. 2013). Women are responsible for production, processing, and trade of both crop groups. Rice and vegetables are part of both the grains-and-legumes-based and the mixed trees and food crops systems.

3 Irrigated lowlands occupy a small part of the total rice area (700,000-800,00 hectares, or 8 percent) but make a substantial contribution to regional production (about 21 percent), given high yields of 4-5 tons per hectare, which can rise to 6-8 tons per hectare in total water-controlled systems. Large-scale systems are located in the Sahel zones.

Government reports estimate that production could grow from less than 800,000 hectares to an optimistic 2.5-3 million hectares. Most FHs in the irrigated lowlands also grow horticulture market crops. ${ }^{17}$ Irrigation perimeters are oriented
(1) Background and understanding

(2) Regional drivers

(3) Regional organisations

(4) Agro-pastoralism-based

(5) Grains-and-legumes-based

Rice-and-horticulture

6.1 Definitions

6.2 Demography and geography

6.3 Regional consumption and production trends

6.4 Livelihoods of producer communities

\subsection{Production systems}

6.6 Food system outcomes

6.7 Institutional drivers

6.8 Risks and resilience

6.9 The COVID-19 pandemic

6.10 Agency and development interventions

6.11 Summing up References

(7) Coastal maritime fisheries

8 Tropical mixed tree and

8 food crops systems

9 Toward enhanced resilience

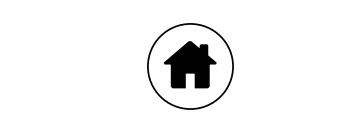


to sugar cane and/or industrial crops and are often allocated to private or state companies. Households might be involved in these areas as contract farmers (Brondeau 2019).

4 Mangrove and floating rice includes mangrove "swamp" rice and deepwater, or floating, rice. Mangrove swamp rice covers 3 percent of total rice area and 3 percent of total rice production, with average yields of 1 to 2.2 tons per hectare. Although West Africa has "approximately 1 million ha of possible cultivable mangroves, the high opportunity and labour costs and potentially negative environmental effects pose major constraints to area expansion" (GRiSP 2013, 94-95). These subsystems are found along the Southwest Atlantic coast. Deepwater or floating rice accounts for 4.5 percent of total area and 2 percent of total rice production, with average yields of 1 ton per hectare. According to GRiSP $(2013,95)$, "It is generally believed that, with the control of river flooding because of the construction of dams and with lower rainfall, areas under these ecosystems have probably declined during the last 20 years." Production is located in the inner Niger delta in Mali, Birnin Kebbi in Nigeria, and northern

Land is relatively abundant in West Africa. The choice of the crops and the cultivated area are largely dictated by the availability of water and fertilisers as well as market prices. A remarkable feature of West African irrigated agriculture is that nutrient management (organic matter, fertiliser) is as much, or even more, a determining productivity factor than water and climate (Van der Wijngaart 2019).

\subsection{Food system outcomes}

6.6.1 Household food and nutrition security

Rain-fed upland and lowland subsystems, as well as mangrove and floating rice subsystems, are part of broader systems. The same tendencies are observed for these systems as for households in the
Guinea. Mangrove and floating rice are part of larger systems including rain-fed crops, forest, and livestock products. There has been little research, extension, or development programs regarding this subsystem. With low use of inputs and mechanisation, yields are relatively low, as with upland rice, and are highly variable across sites and years. Research to improve these subsystems has made little progress.

5 Irrigated horticulture involves production under various forms of microirrigation (Dittoh et al. 2013). It can involve relatively large investments in modern (drip) irrigation equipment on plots between 1 and 5 hectares and even up to 10 hectares. The Sahel countries produce many products under microirrigation, and it is widespread in Niger, including the Sahara-Sahelian areas of Tahoua and Agadez (for onions and peppers), followed by Burkina Faso, Senegal, and Mali for tomatoes, beans, leafy vegetables, onions, and peppers. Irrigated horticulture shows a mix of male and female producers, as well as individuals, households, and small associations, though men dominate the bigger or betterequipped plots.

grains-and-legumes-based system and mixed tree and food crops systems. Also, in the lowland or horticulture irrigation areas (see subsystems 3 and 5 in box 6.1), the main diet is based on cereals, vegetables and legumes, and meat and fish. However, households consume fewer dairy products than those in adjacent agropastoral areas (ENSAN 2018; ENSAN 2013; VIA 2015). ${ }^{18}$ Rice is as much a staple for self-provisioning as a cash crop and may be sold to buy other cereals or food. The wealthier households can rely on proper staple food production but still buy some food. The poorer households can rely on proper production for 25-50 percent of their food needs and buy the rest. These figures might be too low however, as households have plots outside the irrigated perimeters. Poorer households, more often than wealthier ones, focus on vegetables in the dry season, when rice production can become too expensive.
(1) Background and understanding

(2) Regional drivers

(3) Regional organisations

(4) Agro-pastoralism-based

(5) Grains-and-legumes-based

Rice-and-horticulture

6.1 Definitions

6.2 Demography and geography

6.3 Regional consumption and production trends

6.4 Livelihoods of producer communities

6.5 Production systems

6.6 Food system outcomes

6.7 Institutional drivers

6.8 Risks and resilience

6.9 The COVID-19 pandemic

6.10 Agency and development interventions

6.11 Summing up References

(7) Coastal maritime fisheries

(8) Tropical mixed tree and

8 food crops systems

9 Toward enhanced resilience 
While food energy intake may be sufficient through self-provisioning and market access, nutritional security (dietary diversity) is not yet assured. Horticulture may be important but is focused on tomatoes, onions, potatoes, and peppers, which are the dominant cash crops. Therefore, nutrition insecurity prevails: 54 percent of households in the Office du Niger, for instance, remain vulnerable to food insecurity, and 7-8 percent are moderately to severely food insecure, which are the same rates as the rain-fed grain-legumes belts (ENSAN 2018). ${ }^{19}$

6.6.2 Income, trade, and employment

Although West African farmers have spectacularly improved their rice production in recent years, demand is still higher than production. The rice diet transition has stimulated local production and has led to a rapid increase in rice imports. The import of Asian and American rice, therefore, has increased over from 1975-2020. West Africa imports at a large scale: in 2017, imports of 9.2 million tons equaled 40 percent of total demand. ${ }^{20}$ Imports ranged from low levels of 10 percent of demand in Mali to 30 percent in Nigeria, Guinea-Conakry, Guinea-Bissau, and Sierra Leone to 50 percent in Côte-d'Ivoire and 60-70 percent in Ghana, Burkina Faso, Senegal, Benin, and Togo, with Niger using imports to meet 80 percent of rice demand. ${ }^{21}$ Postharvest losses can be high (dry weight losses between 11 and 14 percent). ${ }^{22}$ Yet data probably underestimate the available stocks at FHs (Wannehain and Janin 2012). Besides Nigeria, Côte d'Ivoire and Senegal are significant importers (over 1 million tons each). The rates change favourably with a simplified comparison between food consumption and milled production. Regional self-sufficiency reaches 81 percent when Nigeria and Mali are left out. ${ }^{23}$ Guinea, Côte-d'Ivoire, and Sierra Leone are selfsufficient, and Mali would be over 200 percent self-sufficient (see annex $6 \mathrm{~A}$ ). The gross value of West Africa's milled rice was estimated at $\$ 4.4-\$ 5.9$ billion per year in 2012-16 (versus $\$ 2$ billion in 2000-01), while imported rice was estimated between $\$ 3.6$ and $\$ 3.8$ billion per year in $2012-18$ (versus $\$ 480$ million in 2000-01)

This demonstrates that imports do not merely complete domestic supply deficits; consumption relates to availability and accessibility, urban and cultural preferences, and import policies (Hathie 2016;
Soullier et al. 2020; World Bank 2012). Rice is characterised by high market segmentation in numerous trade channels. In general, rain-fed upland and lowland rice is oriented at self-provisioning and nearby food markets. The irrigation systems target domestic markets and might informally serve neighbouring countries. According to Soullier et al. $(2020,2-3){ }^{24}$

Domestic rice in West Africa is mainly supplied by traditional value chains (VCs). These VCs proliferated after liberalisation and the decrease in state control of industrial mills. They are often made of several intermediaries owning little capital and managing small quantities. Traditional millers tend to purchase paddy through spot transactions, which do not include quality criteria and incentives for proper moisture rates, impurity rates, and varietal homogeneity. The traditional technologies used by millers include manual milling, as well as the simple huller, "monobloc" (one-pass mill) and "minirizeries."

Whereas local rice is distributed by retailers in informal markets and by local farmer-trader networks, imported rice is sold through a network of traders, groceries, and shops (DARD 2019; SWAC/OECD 2011).

More recently, upgrading value chains by semi-industrial milling has emerged. Soullier et al. (2020) found 57 operating rice mills with semi-industrial or industrial technologies in West Africa. They also found evidence of contract farming in eight countries, involving a minimum of 10,890 producers (at best 9 percent of farmers in each country), and vertical coordination in five countries (at best 2 percent per country) covering at least 29,240 hectares. Nigeria and Senegal dominate the landscape. These emerging value chains are due to three factors: (1) high import bills that increase pressure on favourable national investment policies, (2) sufficient availability of domestic (milled) rice, and (3) low cultural barriers or comparative advantage in demand. The mills have an aggregated capacity of 315 tons per hour. But it is difficult to quantify production, which is variable, and most mills function below capacity. Insufficient or variable supply has several causes: unrealistic, overoptimistic production projections, unfavourable contract terms or lack of understanding of farmers' livelihood strategies among millers,
(1) Background and understanding

(2) Regional drivers

(3) Regional organisations

(4) Agro-pastoralism-based

(5) Grains-and-legumes-based

Rice-and-horticulture

6.1 Definitions

6.2 Demography and geography

6.3 Regional consumption and production trends

6.4 Livelihoods of producer communities

6.5 Production systems

6.6 Food system outcomes

6.7 Institutional drivers

6.8 Risks and resilience

6.9 The COVID-19 pandemic

6.10 Agency and development interventions

6.11 Summing up References

(7) Coastal maritime fisheries

8 Tropical mixed tree and

8 food crops systems

9 Toward enhanced resilience 


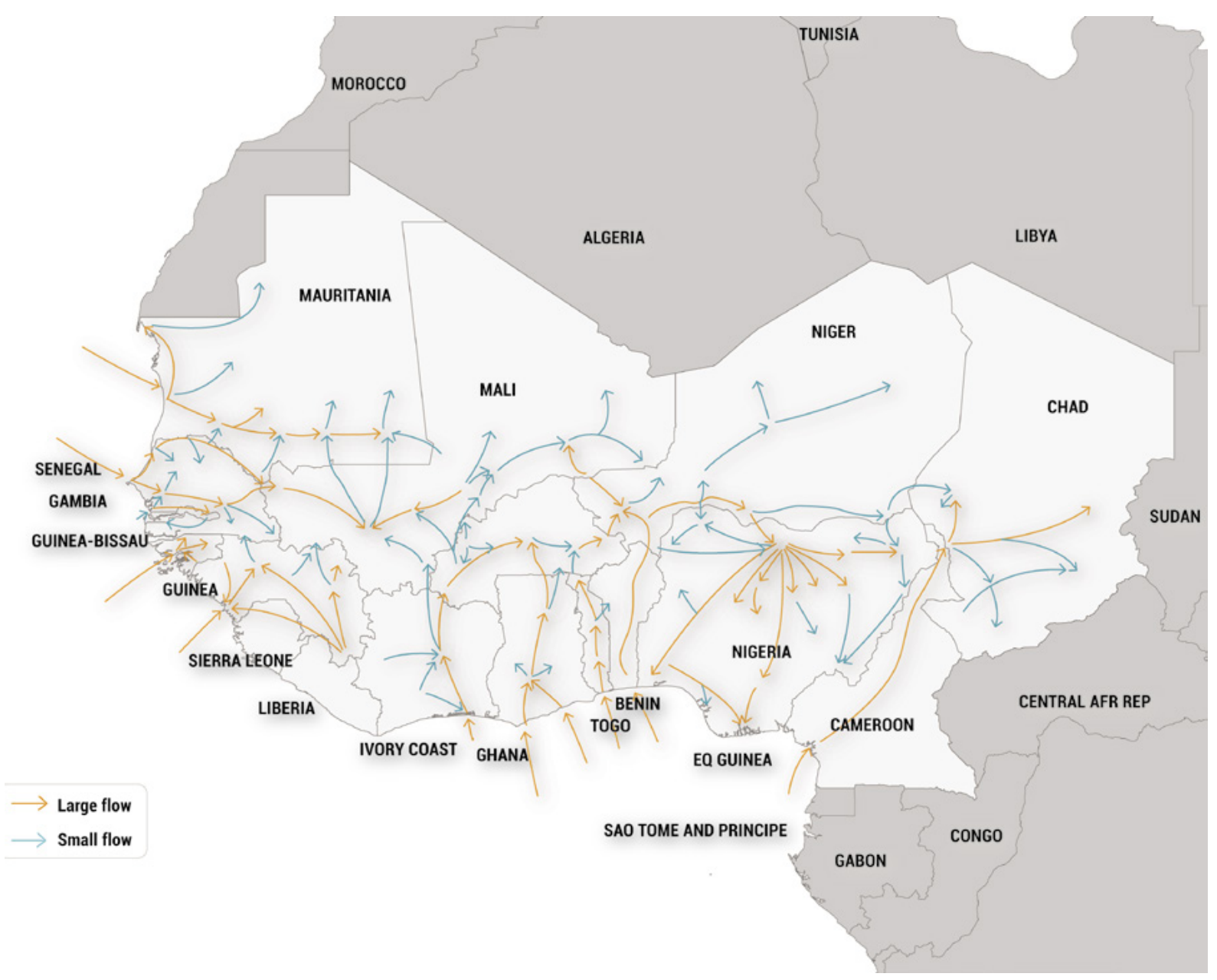

(1) Background and understanding

(2) Regional drivers

(3) Regional organisations

(4) Agro-pastoralism-based

(5) Grains-and-legumes-based

6 Rice-and-horticulture

6.1 Definitions

6.2 Demography and geography

6.3 Regional consumption and production trends

6.4 Livelihoods of producer communities

6.5 Production systems

6.6 Food system outcomes

6.7 Institutional drivers

6.8 Risks and resilience

6.9 The COVID-19 pandemic

6.10 Agency and development interventions

6.11 Summing up References

(7) Coastal maritime fisheries

and an uncertain business environment (low quality control, little protection of both farmers and millers by state institutions). Millers have tried to improve their grip on the supply chain by controlling production (or sometimes starting proper production units), which can work well but has led in several cases to land acquisitions and conflicts with farmers (Soullier et al. 2020).

Most current intraregional trade is for imported rice. The biggest producers (Nigeria, Mali, Guinea) hardly export rice. ${ }^{25}$ Nigeria is keen in protecting its domestic production. The common external tariff (CET) is designed as an instrument to strengthen the common market and to harmonise taxes between ECOWAS members. Import tariffs varied from 50 percent or higher (in Nigeria) to 10 percent or less in 2010-2015. Since 2015 it has been possible to place rice in the highest tariff band of 35 percent, which could increase intraregional trade and enhance the competitiveness of production. ECOWAS members maintained lower tariffs of 5 or 10 percent (Hathie 2016). The value-added taxes still differ by country
(8) Tropical mixed tree and food crops systems

(9) Toward enhanced resilience 
(from 0 to 18 percent). These low barriers do not hamper rice imports.

Overall vegetable production finds its destination in nearby markets. The gross value of primary vegetables (dry/shallot onions, peppers, tomatoes, potatoes/sweet potatoes, okra) was estimated at $\$ 8.3$ billion in 2016 (and around $\$ 4.7$ billion for fresh vegetables), with Niger representing $\$ 1.8$ billion and Mali, $\$ 1.4$ billion (and $\$ 360$ million for fresh vegetables). Besides in Nigeria, with $\$ 3.7$ billion for vegetables and $\$ 3.6$ billion for fresh vegetables, production is concentrated in the Sahel (Niger and Mali, as well as Burkina Faso and Senegal for tomatoes or leafy vegetables) and near urban markets in coastal countries (Ghana, Côte d'Ivoire) (figure 6.2). Dry and shallot onions are a main export crop for Niger. ${ }^{26}$ Its value chains have conquered market segments with specialised varieties, such as violets de Galmi and Goulbi onions in Niger. Tomatoes and leafy vegetables from Burkina Faso are exported to Côte d'Ivoire and Ghana. One obstacle is the high transport costs, due to red tape and border delays, which heavily affect perishable products. Storage and conservation are major issues, and up to 40 percent in losses has been reported (AFC 2015).

Horticulture cash crops such as onion, tomatoes, and potatoes have a fate similar to that of rice. Despite steadily rising production, local horticulture crops also face competition from cheap imports.

Domestic production is insufficient to cover demand throughout the year, even in some Sahel countries. Production is not protected, and it suffers from inefficiencies. However, tomato production in Senegal offers one of the few examples of industrial horticultural processing (AFC 2015; Fall, David-Benz, and Huat 2010). ${ }^{27}$

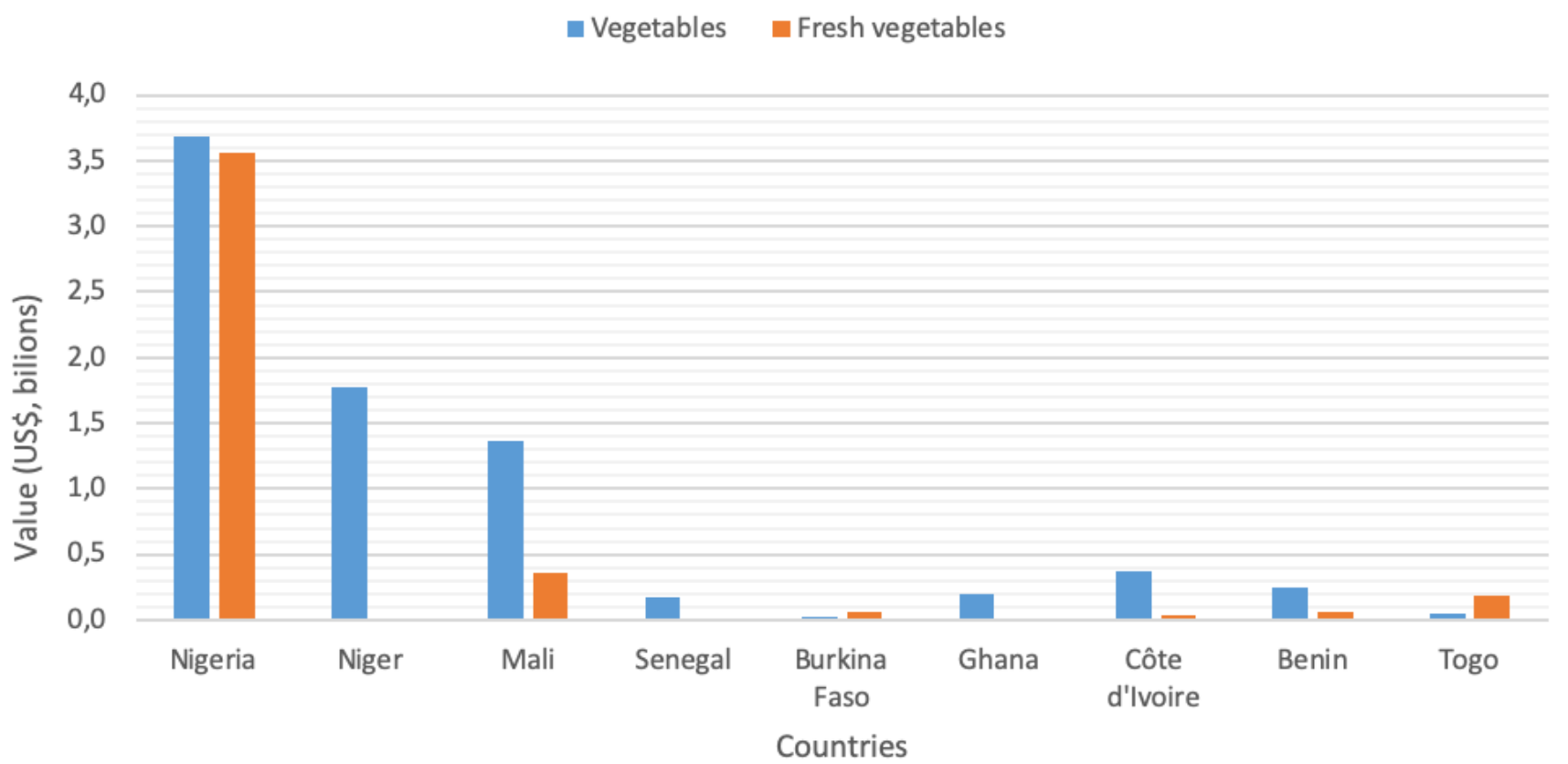

Figure 6.2 Value of Horticulture Production in West Africa, 2016

Source: FAOSTAT, Food and Agriculture Organisation, Rome (accessed August 31, 2020).

Note: European decimal in Y axis (,). Data for Burkina Faso appear to be too lower than expected.

(1) Background and understanding

(2) Regional drivers

(3) Regional organisations

(4) Agro-pastoralism-based

(5) Grains-and-legumes-based

6 Rice-and-horticulture

6.1 Definitions

6.2 Demography and geography

6.3 Regional consumption and production trends

6.4 Livelihoods of producer communities

\subsection{Production systems}

6.6 Food system outcomes

6.7 Institutional drivers

6.8 Risks and resilience

6.9 The COVID-19 pandemic

6.10 Agency and development interventions

6.11 Summing up References

(7) Coastal maritime fisheries

8 Tropical mixed tree and food crops systems

9 Toward enhanced resilience 
6.6.3 Environmental sustainability

Irrigation areas are notorious freshwater consumers. Rice fields use total seasonal water inputs up to two to three times higher than those for other cereals. ${ }^{28}$ Producing 1 kilogram of paddy rice can require up to 2.5 cubic meters of water (all outflows of evapotranspiration, seepage, and percolation)..$^{29}$

Improving farming or irrigation techniques and varieties might lower the water footprint, but the impact will remain high compared to that of rain-fed produce. Soil salinisation is a recurrent risk in big irrigation schemes and their downstream areas in the region's drylands.

Several policy documents emphasise the high irrigation potential of West African lowlands, less than 15 percent of which are currently used (DARD 2019; DAEWR 2012). The high water use requirements of irrigation systems might reduce the expected land expansion potential in the Sahel. In Mali, for instance, FAO estimated that irrigated-flooded agriculture is responsible for 94 percent of water demand (without counting hydroelectricity). ${ }^{30}$ Yet, in normal years, Mali's total water demand/availability rate can reach moderate stress levels (10-20 percent). According to Auclair and Lasserre $(2013,11)$,

the annual withdrawal at the Markala dam for the Office du Niger amounts to 2.6 billion cubic meters, which is modest compared to the average flow of the river (46 billion cubic meters) at this point. In addition, during low water periods, water withdrawals represent between 50 and 80 percent of the river flow. (translation by author)

This negatively affects water availability in downstream river valleys and flood plains. Burkina Faso has similar estimates. There,

irrigation represents 75 percent of consumptive demand, contributing to moderate stress level water rates in normal years (World Bank 2017).

Rice and horticulture crops may sustain rural development and food security, but their environmental and social impacts can be ambiguous. Both can provide options for sustainable intensification. According to $\operatorname{GRiSP}(2013,93)$,
Rice is... well adapted to flooded lowland ecosystems where the soils are least fragile and best able to support continuous cultivation. The development of profitable lowland rice technologies is therefore a central element in strategies to induce farmers to reduce pressure on... degraded uplands by shifting cultivation to lowland ecosystems. Relative to other cereals, rice also responds more to improved management and to higher inputs of nutrients, water control, and labour, and is thus favoured as production systems intensify.

Yet rice and horticulture have encroached on wetlands (including Ramsar sites), on grasslands for livestock (such as the Niger River bourgoutières), and on water plains and ponds, which play a key role in livestock and fishing systems and have contributed to conflicts over land and water access. (For Senegal and Niger valleys and deltas, see Madgwick and Pearce [2017] and Bruckmann and Beltrando [2014]).

Rice affects the environment "by releasing or sequestering gases or compounds that are active in the atmosphere or troposphere and by changing the chemical composition of the water flowing through rice fields" (GRiSP 2013, 24). Ammonia volatilisation is

the major pathway of nitrogen loss from applied nitrogen fertiliser in rice systems.... In tropical transplanted rice, nitrogen losses... can be 50 percent or higher .... Of the three main greenhouse gases, rice production sequesters carbon from carbon dioxide and likely increases emissions of nitrous oxide and methane, though by how much is not reliably known. (GRiSP 2013, 24-25)

The literature mostly concerns Asian ecosystems. Specific information on soil organic carbon stocks in West African ecosystems is less widely available. Carbon stocks in the Sahel may lie between 40 and 80 tons per hectare. ${ }^{31}$ The emissions depend on too many contextual factors to give detailed figures for West Africa. In general, using organic manure increases methane emissions. Flooding the soil sustains methane emissions (while midseason drainage might help, rain-fed environments have lower emission rates than continuous irrigated environments). Trost et al. $(2013,2)$ found that for 22 irrigation areas in various regions,
(1) Background and understanding

(2) Regional drivers

(3) Regional organisations

(4) Agro-pastoralism-based

(5) Grains-and-legumes-based

Rice-and-horticulture

6.1 Definitions

6.2 Demography and geography

6.3 Regional consumption and production trends

6.4 Livelihoods of producer communities

6.5 Production systems

6.6 Food system outcomes

6.7 Institutional drivers

6.8 Risks and resilience

6.9 The COVID-19 pandemic

6.10 Agency and development interventions

6.11 Summing up References

(7) Coastal maritime fisheries

(8) Tropical mixed tree and

8 food crops systems

9 Toward enhanced resilience 
(1) the influence of irrigation is strongly dependent on climate and initial soil organic carbon content. For instance, irrigation of cultivated desert soils led to an average increase of $90 \%$ to over $500 \%$ of soil organic carbon. (2) Irrigation of semiarid regions increases soil organic carbon by $11 \%$ to $35 \%$. (3) No consistent effects of irrigation were observed in humid regions. In many cases, $\mathrm{N}_{2} \mathrm{O}$ emissions increase after precipitation or irrigation. (4) Comparison of $\mathrm{N}_{2} \mathrm{O}$ emissions from irrigated and non-irrigated fields shows that availability of reactive nitrogen compounds controls increased $\mathrm{N}_{2} \mathrm{O}$ emissions under irrigation, in most cases. Here, increases of about $50 \%$ to $140 \%$ in $\mathrm{N}_{2} \mathrm{O}$ emissions were reported.

6.6.4 Equity and inclusion

There are few aggregated data at the West African level. The most recent ones are taken from surveys in four irrigation areas: in Mali (Office du Niger and Office du Sélingué), Burkina Faso (Bagré area), and Senegal (Anambé) (Bazin et al. 2017; Dixon and Holt 2010; ENSAN 2018). Without forgetting that each site has its specificities, there is a series of commonalities. Poverty among households persists, but irrigation areas also have a relatively large category of middle- or medium-size farmers. While 30-50 percent of households remain poor or very poor and food insecure, 35-50 percent belong to the middle group, which may fall below the poverty line in bad years but generally is food secure. There is a small group of better-off households, between 5 and 20 percent. A high proportion of households in the poor groups (around 10 percent for the very poor) are female headed.

Because all have access to irrigated land, the differences reside in household size and number of hectares that can be cultivated, as well as in available assets/equipment and livestock. The importance of diversification as sign of wealth and off-farm income has already been outlined in section 6.4. Interdependence is another feature, which shows differentiation among households. According to Dixon and Holt $(2010,15)$, reporting on Mali,

The poorest households receive payment in-kind for work carried out for the middle and better-off. Under this type of arrangement wealthier households normally pay labourers using grain from their harvests. In all zones the poor and very poor receive some of their annual food requirement from a combination of loans and gifts in-kind, given by the middle and better-off households. The loans are commonly taken during the hard hunger months when poor households are most dependent on the market and staple food prices are high. They are repaid after the harvest when the economic situation of these households has improved.

For the FHs, excluding the small external group of city-based "new actors" who invest with capital obtained from other sources than farming, land fragmentation is the main obstacle. For example, farmers in Mali and Senegal saw their family land in irrigation systems decline from 4-8 hectares to 2 hectares or less (Brondeau 2019; SWAC/OECD 2011; Williams et al. 2020). New land attributions are less than 0.5 hectares, which risks confining new FHs in a poverty trap, unable to rise above subsistence levels.

The previous section on environmental sustainability stressed the effects of agricultural encroachment on forestlands and rangelands and to a lesser extent in coastal areas on mangroves. This could have negative effects on livelihoods of agro-pastoralists and fishing people. Policy discourses of the early twenty-first century on new, necessary investments in agriculture favored in many cases land acquisitions and speculations by companies and city-based elites (see section 6.2). Such activities were focused on irrigation schemes, often at the expense of local farmer communities. Intracommunity acquisitions of irrigated lands also occur in developed lands or irrigation schemes, as well as in village lowlands-the latter of which predominantly affects women (see section 6.8).

\subsection{Institutional drivers}

Rice is high on the national and regional agendas of West African governments and ministries of agriculture and has been linked to policies on irrigated agriculture that also include horticulture and industrial crops. Large-scale irrigation schemes or areas have state offices or agencies, and some of them are sufficiently large and
(1) Background and understanding

(2) Regional drivers

(3) Regional organisations

(4) Agro-pastoralism-based

(5) Grains-and-legumes-based

Rice-and-horticulture

6.1 Definitions

6.2 Demography and geography

6.3 Regional consumption and production trends

6.4 Livelihoods of producer communities

6.5 Production systems

6.6 Food system outcomes

6.7 Institutional drivers

6.8 Risks and resilience

6.9 The COVID-19 pandemic

6.10 Agency and development interventions

6.11 Summing up References

(7) Coastal maritime fisheries

8 Tropical mixed tree and

8 food crops systems

9 Toward enhanced resilience 
powerful enough to have some autonomy on implementing policies. The Office du Niger in Mali is a classic example. Horticulture gets less attention in agricultural institutions, except in Niger and Senegal, where farmers, private processors, and traders have promoted value chains, such as for onion and tomato, and have encouraged state institutions and development projects to pay attention to vegetables. Confronted by persisting economic inefficiencies of large irrigation schemes, as well as the cumulative potential of numerous small-scale irrigation sites, government and donor agencies have given attention to different forms of irrigation after 2010 (Sahel Irrigation Initiative 2017) (see also Dittoh et al. 2013; Namara and Sally 2014; Van der Wijngaart 2019).

There are too many initiatives and programs to cite, most of which got a boost after the 2008 food crisis. A few key ones are the "Offensive Riz" of ECOWAS, which tries to federate multiple rice development initiatives, and the 2017 Strategic Framework for Agricultural Water in the Sahel (or L'Initiative pour l'irrigation du Sahel), which has a broader focus on all irrigation products (Sahel Irrigation Initiative 2017). Rice institutes such as AfricaRice have made progress in delivering adapted inputs, production, and conservation techniques for different ecosystems (except mangrove and floating rice). Institutes and favourable policies are less visible for horticulture, though the World Vegetable Centre is part of existing International Crops Research Institute for the Semi-Arid Tropics (ICRISAT) stations and is conducting programs for different commodities.

Except for Ghana, Togo, Liberia, and Sierra Leone, most West African countries have rice farmers with a relatively strong unionist tradition. Their unions and associations belong to the strongest farmer and civil organisations in the countries. In Ghana and Nigeria, production and commercialisation can be organised around millers. Rice farmers have worked on stronger regional representation, such as through the rice platform Cadre Régional de Concertation des Organisations de Producteurs de Riz created by national rice farmer associations. The platform is member of the regional 'Network of Farmers Organisations and Agricultural Producers in West Africa' (or ROPPA), which is well-recognised by regional and national government agencies. Still, as young organisations, these diverse farmers associations and unions have to cover a wide range of topics and be present at the local, regional, and national levels. Another critical issue is that the big producers and millers from the irrigation schemes dominate in national associations and unions at the expense of rain-fed rice farmers, most of whom are women.

Many local farmers associations composed of women are emerging in horticulture, while men lead the trade organisations are led by men. The strength of these organisations depends on context: they are relatively strong in Niger (such as ANFO and FCMN for onions) and in Senegal (such as CNCFTI for tomatoes), while they are less visible elsewhere. There is no specific representation at the regional level.

\subsection{Risks and resilience}

The significant production increase was driven by extension of rice areas. Yield gains and improved productivity have contributed less, supposedly because of low adoption of improved varieties and lack of good quality seed, low use of inputs and low adoption of good agricultural practices ${ }^{32}$ The lack of economic incentives also constrains the adoption of innovations requiring capital investments. Countries have improved services for seeds, inputs, plant protection, and production techniques and related technologies. There is improved support from state institutes (national agricultural research, AfricaRice, World Vegetables Centre) and from farmers and practitioners-for example, the 'system of rice intensification' (SRI) and onion varieties in Niger. ${ }^{33}$ Progress is related to availability of and access to services as well as knowledge and awareness of more sustainable or climate smart production, that is more adapted to the context under which households apply practices and technologies (see also section 6.7).

FHs face increasing land fragmentation and smaller plots. They are confronted as well by land pressure and tenure insecurity. ${ }^{34}$ In lowland and small-scale subsystems, local authorities and male village leaders make the decisions about managing land and infrastructure for land and water distribution and retention. The
(1) Background and understanding

(2) Regional drivers

(3) Regional organisations

(4) Agro-pastoralism-based

(5) Grains-and-legumes-based

Rice-and-horticulture

6.1 Definitions

6.2 Demography and geography

6.3 Regional consumption and production trends

6.4 Livelihoods of producer communities

6.5 Production systems

6.6 Food system outcomes

6.7 Institutional drivers

6.8 Risks and resilience

6.9 The COVID-19 pandemic

6.10 Agency and development interventions

6.11 Summing up References

(7) Coastal maritime fisheries

8 Tropical mixed tree and

8 food crops systems

9 Toward enhanced resilience 
same male leaders also make decisions about externally funded projects with development agencies. The interests of female farmers are not well represented, though women play a central role in rice and horticulture in rain-fed systems. In some places, external (project) interventions and investments have caused struggles over distribution and redistribution of land and rights, with the risk of capture by male local elites. In many other areas, women still master rice and horticulture production and processing.

National state agencies or offices decide on irrigation scheme investments, often using donor funds. Besides rehabilitation, investments can be used to develop production on perimeters in undeveloped areas to meet political promises to boost production and attract external investors. However, these plans sometimes clash with customary tenure rules over the presumed undeveloped lands, which are already used by communities for dryland farming and livestock keeping. Generally, government agencies will assume control of tenure to allocate plots in developed land. External investors or "new actors" place claims on irrigated land reaching thousands of hectares. In addition, intracommunity acquisitions of irrigated lands also occur. This may lead to inequalities. Transparent allocation of the irrigated plots is a challenge when decisions are made over access and user rights.

Rice research institutes have made progress in improving varieties (such as New Rice for Africa, or NERICA) (upland rice included) and in adapting production and storage methods to local contexts.

Public and private investments target irrigated production. However, similar to the context of mangrove and deepwater rice areas, many remote upland and lowland rice areas are not covered by either services or research. These are focused on irrigated areas, and the bias of irrigation schemes prevails.

6.8.1 Climate resilience

Rice-and-horticulture-based food systems take a particularly ambivalent place in assessments on the potential and vulnerability of West African agriculture and livestock raising. As for other systems, because of their dependence on river water and rain, the irrigated lowland and horticulture subsystems are exposed to the effects of climate variability. As underlined in section 6.6 , irrigated agriculture has a high water footprint. Nevertheless, since supply comes from canalised surface water and groundwater, the effects may be less directly perceptible or more long term than in rain-fed systems. Water availability or stress depends as much on existing infrastructure (water retention, canalisation) as on management capacities for irrigation schemes and for the wider water basins (including land and forest preservation).

At the same time, irrigated agriculture is presented in policy documents as one of the main interventions to reduce climate vulnerability (Namara and Sally 2014; Sahel Irrigation Initiative 2017; Van der Wijngaart et al. 2019). Especially in the Sahel countries, national and regional policies, such as the Comprehensive Africa Agriculture Development Programme (CAADP) and New Partnership for Africa's Development (NEPAD), emphasise the importance of irrigation development. According to Namara and Sally $(2014,342)$,

Despite the effects of climate change and climate variability, by and large, irrigation development in West Africa is not yet limited by physical water scarcity and the potential for further development exists, especially if the requisite investments are made available.

In other words, the irrigated lowland and horticulture subsystems may be resilient at microscale because they can rely on largely available water reserves. For the moment, in principle, the subsystems can cope with current climate change. Their resilience depends more heavily on other environmental and socioeconomic parameters.

There are important nuances. First, the region lacks reliable data about water resources, especially about groundwater:

There is little quantitative information on groundwater resources in Africa, and groundwater storage is consequently omitted from assessments of freshwater availability.... There are very few groundwater systems in the Sahel where both the recharge and discharge components of the groundwater balance have been determined... Although there are several
(1) Background and understanding

(2) Regional drivers

(3) Regional organisations

(4) Agro-pastoralism-based

(5) Grains-and-legumes-based

Rice-and-horticulture

6.1 Definitions

6.2 Demography and geography

6.3 Regional consumption and production trends

6.4 Livelihoods of producer communities

6.5 Production systems

6.6 Food system outcomes

6.7 Institutional drivers

6.8 Risks and resilience

6.9 The COVID-19 pandemic

6.10 Agency and development interventions

6.11 Summing up References

(7) Coastal maritime fisheries

8 Tropical mixed tree and

8 food crops systems

9 Toward enhanced resilience 
global remote sensing based and/or modelled rainfall dataset available, only a very limited number of high quality observed rainfall data is available. (Van der Wijngaart et al. 2019, 23) 35

Better monitoring and data sets are required to affirm or add nuance to these statements on high water reserves. Water demand and availability rates already regularly reach moderate stress levels in most Sahel countries. Second, abundant water use may hamper other systems. High water withdrawal of irrigation dams can negatively affect water availability in downstream river valleys and flood plains. Rice and horticulture have encroached on strategic areas for livestock and fishing production systems, making them more vulnerable to climate shocks.

Third, Sylla et al. (2018) pose several scenarios for temperature rise. They summarise the situation as follows:

changes in crop water demand, irrigation water need, water availability and the difference between water availability and irrigation water needs, here referred as basin potential, are presented for ten major river basins covering entire West Africa. Under the $2{ }^{\circ} \mathrm{C}$ scenario, crop water demand and irrigation water needs are projected to substantially increase with the largest changes in the Sahel and Gulf of Guinea respectively. At the same time, irrigation potential, which is directly controlled by the climate, is projected to decrease even in regions where water availability increases. This indicates that West African river basins will likely face severe freshwater shortages thus limiting sustainable agriculture. We conclude a general decline in the basin-scale irrigation potential in the event of large-scale irrigation development under $2^{\circ} \mathrm{C} \mathrm{global} \mathrm{warming.} \mathrm{Reducing} \mathrm{the} \mathrm{warming} \mathrm{to} 1.5^{\circ} \mathrm{C}$ decreases these impacts by as much as 50 percent, suggesting that the region of West Africa clearly benefits from efforts of enhanced mitigation. (Sylla et al. 2018, 1)

6.8.2 Economic resilience

Production costs in most West African countries can compete with imported rice costs. The Observatory of International Rice Statistics (OSIRIZ) concluded that "despite the relatively low productivity, production costs in West African countries are comparable to those of the major producing countries in the world" (DAEWR, 2020, 5). These production costs are between $\$ 180$ and $\$ 220$ per ton of paddy versus $\$ 130$ in Vietnam, $\$ 190$ in Thailand, and $\$ 225-\$ 300$ in the United States and Brazil (AFC 2015; DAEWR 2012; SWAC/OECD 2011). However, the Global Water Initiative West Africa noted that large scale irrigation schemes are expensive and the costs of highly engineered systems can be substantial (Bazin et al. 2017):

economic analyses indicate that average costs are around $\$ 8,000$ USD per hectare and may rise to $\$ 20,000$ USD per hectare, but the question of whether these investments give a viable economic return is often open. Many of the economic studies currently available are pan-African and lack the specificity required to inform national-level decision-making. ${ }^{36}$

Namara and Sally $(2014,265)$ reported, "One recurrent problem highlighted in all the countries was the inadequate attention paid to the maintenance of infrastructure. The unfortunate consequence is the relatively rapid degradation of the systems, often built at a very high investment cost," rising to CFAF 10 million, or $\$ 20,000$, per hectare. In three irrigation schemes (Mali, Burkina Faso, and Senegal), rice production costs varied between $\$ 340$ and $\$ 750$ per hectare, wherein hired labour and services were the determinative cost factors (Bazin et al. 2017) (see also Manikowski and Strapasson 2016). It raises the question of why relatively little is invested in appropriate services and financing for FHs compared to the infrastructure investment and maintenance costs.

The competitiveness of domestic rice production depends on more than the cost efficiency of farmers. Production costs in most countries can compete with imported rice costs. Competitiveness can be adversely affected by postharvest operations, which do not allow domestic products to match the quality of imported rice in homogeneity or cleanness. One obstacle to formal market access is quality, which has gained more attention in research in recent years. Value chain upgrading by semi-industrial and industrial milling progresses timidly but steadily. Postharvest losses in rice quality are variable-between 6 and 50 percent-while quantitative losses due to poor handling and storage can be as high as 14 percent in West Africa. ${ }^{37}$
(1) Background and understanding

(2) Regional drivers

(3) Regional organisations

(4) Agro-pastoralism-based

(5) Grains-and-legumes-based

Rice-and-horticulture

6.1 Definitions

6.2 Demography and geography

6.3 Regional consumption and production trends

6.4 Livelihoods of producer communities

6.5 Production systems

6.6 Food system outcomes

6.7 Institutional drivers

6.8 Risks and resilience

6.9 The COVID-19 pandemic

6.10 Agency and development interventions

6.11 Summing up References

(7) Coastal maritime fisheries

8 Tropical mixed tree and

8 food crops systems

9 Toward enhanced resilience 
6.8.3 Sociopolitical and food access resilience

Rice has gradually become a staple food since 1975, and therefore a key product in food security policy throughout West Africa. The temptation to count on rice imports is high, given the ease of procuring supplies of homogeneous, well-cleaned rice. However, the 2007-08 global financial crisis and the ensuing social unrest clearly underscore the vulnerability of this approach. The financial crisis led to an increased prevalence of severe food insecurity in West Africa, where urban households in high-consumption countries were spending 20-25 percent of their income on rice. Further, the impact of rising global price pressure on poverty is significant.

This urban-biased approach did not necessarily favor poor people (Lançon and Mendez del Villar 2014). The policy demonstrates a strategic risk, as many clear warning signs in the early twenty-first century indicated that the global market supply would become increasingly difficult. Only 6-8 percent of global production was available for export, so at the slightest mishap, producing countries would first ensure the food security of their own population. Decreased rice exports from Asian countries was a trigger for the soaring prices and unrest in Africa in 2008 (Lançon and Mendez del Villar 2014; SWAC/OECD 2011). Since 2010 several initiatives have been developed to boost rice production, but ECOWAS market policies hardly protect domestic production from imports (see sections 6.6.2 and 6.10).

\subsection{Food system impacts of and responses to} the COVID-19 pandemic

Interviews with key experts indicated that impacts of COVID-19related restrictions have had, to date, limited impact on the production of rice and vegetables. However, supply chains for farming inputs are directly impacted by COVID-19-related trade restrictions, as shipments and lorries become stuck due to closed borders and health checks. This is especially problematic for countries that largely depend on external markets for seeds, fertilisers, and the import of rice and fish, as well as to some extent milk powder, poultry, and vegetables.
One short-term indirect impact is that overall consumer prices are increasing. Market forces have already driven up the price, while some traders see rent-seeking opportunities by creating more scarcity. In the long run, potential disruptions of inputs such as seeds and fertiliser in domestic markets could continue to raise consumer prices and could result in decreasing domestic production of rice and vegetables (Thurlow 2020).

As of 2020, the availability of staple foods like rice was stil sufficient for big producers such as Mali, Côte d'Ivoire, and the Southwest Atlantic countries, as well as Niger, which consumes relatively small amounts. However, a recent investigation of countries' rice self-sufficiency status by AfricaRice showed that countries like the Gambia, Ghana, and Senegal have self-sufficiency ratios of 60 percent or less. Price shocks will therefore be more severe for these countries as they still largely depend on Asian exports to meet the gaps between production and consumption. Nevertheless, in the 2008 global food crisis, many consumers compensated for rice with coarse grains (maize, sorghum, millet), of which there was sufficient domestic production.

As many of these rice-producing countries largely rely on external markets, key informants identify several short- and long-term leverage points for resilience, including subsidising and controlling retail prices to contain the increase in consumer prices, monitoring local and imported rice stocks, and promoting regional trade and cooperation (Thurlow 2020). Over the longer term, key informants confirm tendencies such as promotion or protection of local rice, accessibility of quality seed and inputs, availability of basic infrastructure for postharvest processing and packaging, and improvement of water control through various forms of irrigation (next to large-scale irrigation).

\subsection{Agency and development interventions}

Policies promoting rice paint an ambiguous picture. After the 2008 food crisis, countries developed proactive or more structural policies to stimulate local rice and horticulture production through input subsidies, new or rehabilitated irrigation schemes, and adaptation
(1) Background and understanding

(2) Regional drivers

(3) Regional organisations

(4) Agro-pastoralism-based

(5) Grains-and-legumes-based

Rice-and-horticulture

6.1 Definitions

6.2 Demography and geography

6.3 Regional consumption and production trends

6.4 Livelihoods of producer communities

6.5 Production systems

6.6 Food system outcomes

6.7 Institutional drivers

6.8 Risks and resilience

6.9 The COVID-19 pandemic

6.10 Agency and development interventions

6.11 Summing up References

(7) Coastal maritime fisheries

8 Tropical mixed tree and

8 food crops systems

9 Toward enhanced resilience 
of research and more extension services. Large-scale irrigation is one of the solutions favoured by countries and donors in order to face the challenges of food security and of risk management of climate unpredictability. In 2013, Sahel countries committed to invest 7 billion USD to extend irrigation with 600,000 ha, among others by development of new areas often associated with large dams (cf. Dakar Declaration on Irrigation). ${ }^{38}$

Development banks, the World Bank, and agencies such as AFD and MCC cofinance large-scale irrigation schemes. Donor agencies are noticing that "given the high costs and under-performance of the parastatal irrigation schemes,... farmer-private irrigation approaches are gaining ground" (C. de Fraiture in Namara and Sally $2014,2)$. There is indeed still sufficient room for growth, but projections of the enormous potential of irrigation areas might be lowered or become more complex if the water footprints and

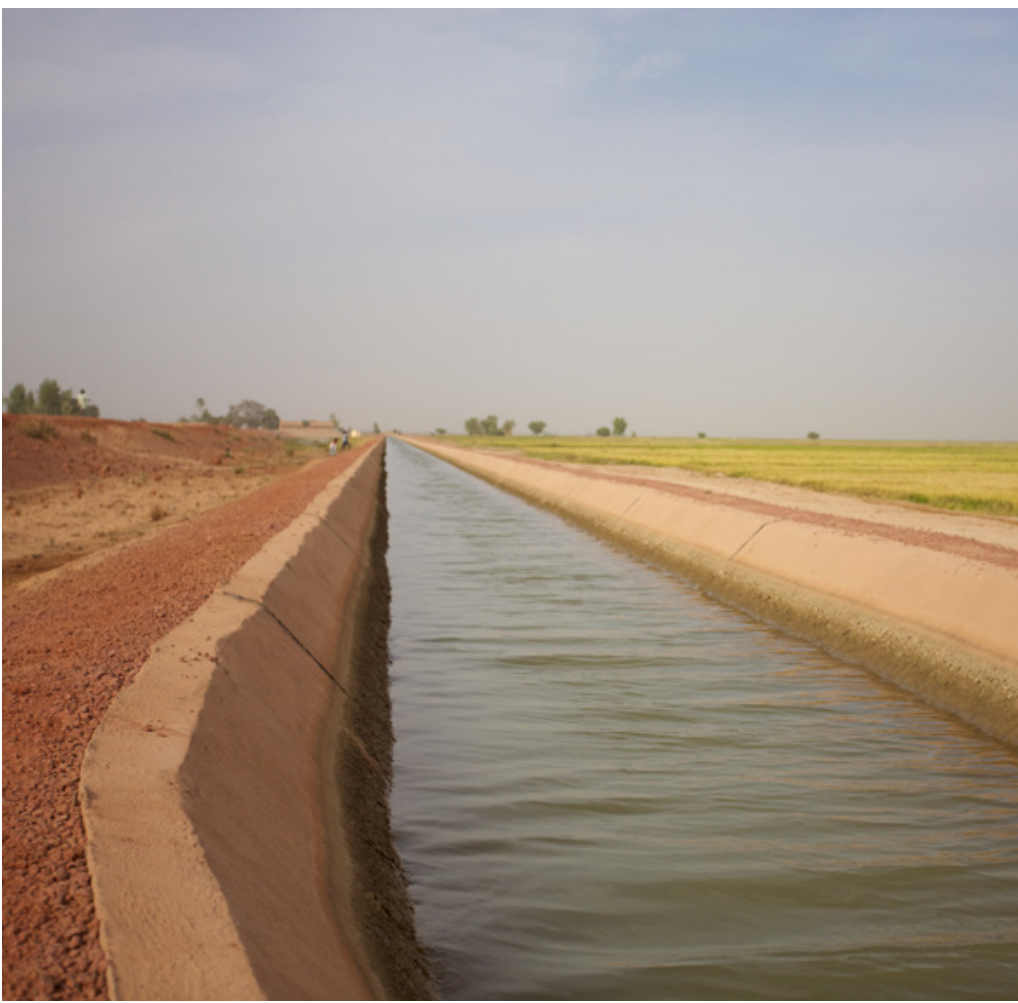

environmental costs are taken into account. This shift in attention by donors is a response to the potential of the many relatively small inland valley and floodplains irrigation systems. Investments are relatively low cost and spread easily. Agencies such as GIZ and the World Bank support small-scale irrigation development for horticulture, and some major programs exist in Niger, Mali, and Burkina Faso.

ECOWAS and WAEMU remain hesitant to protect the common market through stronger import barriers (DARD 2019; SWAC/OECD 2011), though farmer and development organisations have pled a case for these since 2015, including application of a higher CET (Hathie 2016). This could hamper domestic production and upgrading of value chains for rice and for vegetable commodities, such as onions and potatoes.

Proactive government policies supported by donor agencies have been well received by farmer and development organisations. They tend to remain focused on production (Hathie 2016) and follow an irrigated specialised, rice production model that only partly corresponds with the diversification strategy used by many FHs.

These include households in large-scale irrigation systems, which help a broad range of rain-fed and irrigated produce across seasons. This phenomenon partly explains the struggles between $\mathrm{FHs}$ and industrial millers in contract farming because their income strategies might not converge.

Besides services and knowledge, investment and adoption are a function of the wider spectrum of market incentives, risk management, labour force planning, and on- and off-farm opportunities. Development programs may not always take into account that productivity increases and technological improvements should fit into the available financial resources, broader production goals, assets, and diversified market orientations of different types of FHs (Bazin et al. 2017; Guèye 2014). Umbrella farmer organisations have pled the case for matching development incentives with different household strategies. This has led to an offering of more diverse programs, though within government circles a bias toward large-scale irrigation schemes and dams persists. ${ }^{39}$
(1) Background and understanding

(2) Regional drivers

(3) Regional organisations

(4) Agro-pastoralism-based

(5) Grains-and-legumes-based

Rice-and-horticulture

6.1 Definitions

6.2 Demography and geography

6.3 Regional consumption and production trends

6.4 Livelihoods of producer communities

6.5 Production systems

6.6 Food system outcomes

6.7 Institutional drivers

6.8 Risks and resilience

6.9 The COVID-19 pandemic

6.10 Agency and development interventions

6.11 Summing up References

(7) Coastal maritime fisheries

8 Tropical mixed tree and

8 food crops systems

9 Toward enhanced resilience 
Rain-fed and small-scale irrigated rice and horticulture remain the realm of women, who might receive support from numerous NGOs, but whose voices are hardly heard in state initiatives and umbrella farmers organisations. Because of potential scale and productivity, development discussions on upgrading value chains are reasonably oriented toward semi-industrial and industrial rice milling and processing. Such an orientation risks unnecessarily classifying artisanal processing and storage as marginal or only fit for lowquality rice and vegetables. It may fail to look at possible improvements in such value chains in processing, hygiene, and storage. For now, these artisanal chains remain responsible for the bulk of supply.

\subsection{Summing up: toward leverage points for future interventions}

The West Africa region shows a potential of hundreds of thousands of hectares of irrigable land that can be still exploited in several rice and horticulture subsystems. But the available surface and groundwater resources and the production and irrigation costs, rather than for instance land, are the limiting factors for expansion of irrigated farming. Better assessment is needed of the potential for development of the multiple small-scale lowland subsystems for rice and horticulture, weighing their benefits against the existing bias to support large-scale irrigation schemes. Since the lowland areas are not undeveloped lands, careful policy attention must be given to land tenure security for farmers and other water user groups in the irrigation areas, as well as in upstream and downstream areas. For land tenure security in general, several national, regional, and continental policies have indicated that work is needed to have clearer criteria for eligibility, stricter oversight of land allocation, and accountability in land use, such as respect for the conditions of contract, respect for tenure rights, and better compensation of land losses. This could improve productivity and equity in irrigation schemes and inland valleys.

There has been extensive and successful research on productivity and technologies for different rice subsystems and, to a lesser degree, horticulture crops. These studies come from several angles, including conventional research stations and institutes as well as practitioners and farmers. The System of Rice Intensification is based on farmers' experiences, which could be better assessed and validated in formal policies. Collabouration and exchange platforms can be instrumental.

Rice and horticulture crops are embedded in broader production systems of FHs and of men- or women-led production, with each type having distinctive livelihood strategies. Diversification, including irrigated and rain-fed produce and on- and off-farm opportunities, is as important as sustainable intensification, for example. Diversification is as much a part of these strategies in rice-and-horticulture-based systems as in other food systems. Development programs can better take into account the different livelihood strategies adapted to specific needs of households and of men or women.

Domestic rice can compete with imported rice in production costs. If its quality is more tailored to urban consumer preferences, its market share will grow considerably. This also holds true for the main horticulture crops. Rice in Mali and onions from Niger already showcase the potential. Competitiveness of domestic rice and horticulture crops depends to a large extent on whether local production can match import quality in terms of homogeneity and cleanness. Some countries have a high comparative demand advantage (the Southwest Atlantic coast, Mali) because of culturally embedded preferences for local rice with specific physical properties (size, parboiling, shape, uniformity). Besides a focus on technologies and varieties to increase production, quality issues and specific demand (cultural preferences) can receive more attention in research and in standards. Besides standard boards, industry bodies and farmers organisations can play a crucial role in improving standards.

Farmers' reserves and stocks are sometimes larger than assumed, and local rice and vegetables find outlets in numerous informa processing and trade channels. Semi-industrial and industrial milling is rising timidly, mainly in coastal countries. Given the various demands and numerous production basins and markets, artisanal and semi-industrial models do not necessarily compete and serve
(1) Background and understanding

(2) Regional drivers

(3) Regional organisations

(4) Agro-pastoralism-based

(5) Grains-and-legumes-based

Rice-and-horticulture

6.1 Definitions

6.2 Demography and geography

6.3 Regional consumption and production trends

6.4 Livelihoods of producer communities

6.5 Production systems

6.6 Food system outcomes

6.7 Institutional drivers

6.8 Risks and resilience

6.9 The COVID-19 pandemic

6.10 Agency and development interventions

\subsection{Summing up}

References

(7) Coastal maritime fisheries

8 Tropical mixed tree and

8 food crops systems

9 Toward enhanced resilience 
their own market segments. Local artisanal milled rice and vegetables continue to serve the bulk of the markets and are often the realm of women. Industrial milling can grow if production projections become more realistic (there is often milling overcapacity), contract terms are clearer or more adapted to farmers' production strategies, and the business environment is more favourable in terms of quality control and protection of both farmers and millers by state institutions.

Enforcement of ECOWAS policies, such as application of the CET and reducing border restrictions, is important to protect internal regional markets. If trends in consuming and producing rice and some vegetables continue, populations will become chronically dependent on the world market. This poses a genuine threat to food security since future price increases and volatility can affect both urban and rural, wealthier and poorer households. This highlights the need to boost local production and create market access. Most stakeholders are aware of the threat and opportunity a common market would bring.

Notes

1 Mangrove swamp rice may be part of marine coastal fisheries as well (see chapter 7).

2 Available data vary. Because of atomised production, there are only rough estimations of rain-fed or small-scale production and of people involved. Data from DARD (2019), Geo-Rf.net, FAOSTAT, and The World bank.

3 These and other sources, such as Namara and Sally (2014), report deals of hundreds of thousands of hectares of irrigated lands (developed or, more frequently, scheduled) leased to companies and national elites.

4 On average, in West Africa rice consumption can rise to 40 kilograms per capita per year, while millet, sorghum, and maize each lie between 25 and 35 kilograms per capita per year.

5 "Sorghum-millet has fallen by $12 \mathrm{~kg}$ per capita, and their share in cereals used as food from $62 \%$ in the early 1970 s to $50 \%$ in the early 1990 s. In contrast, the share of rice in cereals consumed grew from $15 \%$ to $25 \%$ over the same period, and from $12 \%$ to $18 \%$ in calorie terms from the 1960 s to the end of the 1990s" (DARD 2019,). Data also from FAOSTAT, Food and Agriculture Organisation, Rome (accessed June 30, 2020).
6 See also www.fao.org.

7 Data from FAOSTAT, Food and Agriculture Organisation, Rome (accessed June 30, 2020); AfricaRice database, CGIAR, Abidjan, Côte d'Ivoire (accessed June 30, 2020). See also DAEWR (2012).

8 Data also from FAOSTAT, Food and Agriculture Organisation, Rome (accessed June 30, 2020).

9 Unliked white polished riced, brown rice retains the bran layer, which contains many vitamins and minerals as well as fiber. Parboiling before milling allows a portion of the vitamins and minerals to be retained in polished rice (GRiSP 2013). White rice is less nutritious than millet and sorghum, but unlike in South and East Asia, it has not replaced these grains. Until now, coarse grains have been retained in standard meals. See www.icrisat.org.

10 Data from FAOSTAT, Food and Agriculture Organisation, Rome (accessed June 30, 2020); AfricaRice database, CGIAR, Abidjan, Côte d'Ivoire (accessed June 30, 2020); FEWS NET Data Centre, USAID, Washington, DC (accessed June 30, 2020). See also Soullier et al. (2020), DARD (2019), and Van der Wijngaart et al. (2019).

11 FAOSTAT, Food and Agriculture Organisation, Rome (accessed August 31, 2020)

12 This estimate includes microscale irrigation and peri-urban farming.

13 The data regroup a variety of products and are biased by mass (million tons). Monetary values would show other figures between the commodities and the countries.

14 Proper estimations with figures from AFC (2015) and FAOSTAT, Food and Agriculture Organisation, Rome (accessed June 30, 2020).

15 DARD (2019), GRiSP (2013), and FAOSTAT, Food and Agriculture Organisation, Rome (accessed June 30, 2020).

16 GRiSP (2013) and FAOSTAT, Food and Agriculture Organisation, Rome (accessed June 30, 2020).

17 No specific data available. Office du Niger mentions over 400,000 tons per year.

18 See FEWS NET reports on zoning and livelihoods. On Mali, see also Dixon and Holt (2010).

19 Surveys (WFP, FAO, FEWS NET) use harmonised food frameworks and scores, especially in the Sahel.

20 DARD (2019) and AfricaRice database, CGIAR, Abidjan, Côte d'Ivoire (accessed June 30, 2020).

21 Expressed as imported rice / (production + import). Demand $=$ food consumption + seed + stocks + feed.
(1) Background and understanding

(2) Regional drivers

(3) Regional organisations

(4) Agro-pastoralism-based

(5) Grains-and-legumes-based

Rice-and-horticulture

6.1 Definitions

6.2 Demography and geography

6.3 Regional consumption and production trends

6.4 Livelihoods of producer communities

6.5 Production systems

6.6 Food system outcomes

6.7 Institutional drivers

6.8 Risks and resilience

6.9 The COVID-19 pandemic

6.10 Agency and development interventions

\subsection{Summing up}

References

(7) Coastal maritime fisheries

8 Tropical mixed tree and

8 food crops systems

9) Toward enhanced resilience 
22 See www.aphlis.net. Other researchers estimate that qualitative losses could be as high as 50 percent.

23 Data in this section from FAOSTAT, Food and Agriculture Organisation, Rome (accessed August 31, 2020).

24 See also Hathie (2016).

25 All kinds of cross-border trade takes place. Farmers themselves also trade rice to neighbouring countries, such as in the case of Mali in 2015 (pers. comm. by Seydou Keita of Rice Producers Platform PNPR undersigned). Data from DARD (2019) and FEWS NET Data Centre, USAID, Washington, DC (accessed August 31, 2020).

26 Data are lacking for several products, such as for tomatoes and onions in Burkina Faso and onions in Mali.

27 For more on tomato production in Senegal.

28 Calculated as rainfall plus irrigation but excluding capillary rise, which is rarely quantified.

29 See ricetoday.irri.org

30 See www.fao.org

31 See, for example, carbon projections and atlas.

32 Numerous reports mention this: "Average crop yields in all cases are well below the potential achievable due to a shortage of irrigation water, inadequate application of fertilisers and pesticides, and limitations due to soil and crop-specific factors" (Williams et al. 2020).

33 See sriwestafrica.org.

34 See documents.

35 On Burkina Faso, see World Bank (2017).

36 See documents.

37 See www.aphlis.net.

38 See www.icid.org. See also www.iied.org. For information on dams in Niger, see www.worldbank.org and www.ipsnews.net.

39 Relations between farmers and state agencies and offices can be more ambiguous. One reason is that in the recent past the latter have authorised large land acquisitions for external new actors, which, according to various farmer organisations and NGOs, were concluded at the expense of farmer communities.

\section{References}

AFC (Agriculture and Finance Consultants). 2015. Rapport thématique sur les filières en agriculture irriguée au Sahel, Initiative pour l'Irrigation au Sahel. Bonn, Germany: AFC.

Auclair, A., and F. Lasserre. 2013. "Aménagements, politiques et conflits sur I'eau en Afrique de I'Ouest." VertigO 13 (2): 13994. https://doi.org/10.4000/ vertigo.13994.

Bazin, F., I. Hathie, J. Skinner, and J. Koundouno, eds. 2017. Irrigation, Sécurité alimentaire et pauvreté. Leçons tirées de trois grands barrages en Afrique de l'Ouest. London: International Institute for Environment and Development (IIED)/ International Union for Conservation of Nature (IUCN).

Brondeau, F. 2019. "The Office du Niger: An Agropole Project for Food Security in Mali?" Cybergeo: European Journal of Geography 2018: 870.

Bruckmann, L., and G. Beltrando. 2014. "L'agriculture irriguée et les cultures de décrue dans la moyenne vallée-oasis du Sénégal : dualité ou complémentarité ?". Article presented at Oases in the Globalization: Ruptures and Continuities, Paris, December 16-17, 2013.

Bush, J. 2018. "Paniers de dépenses minimum sectoriels, Etude de résilience HEA." HEA Sahel, March 5, 2018.

DAEWR (Department of Agriculture, Environment and Water Resources). 2012. Accelerating the ECOWAP/CAADP Implementation: Strategic Policy Paper on the Regional Offensive for Sustainable Rice Production in West Africa. Abuja, Nigeria: CEDEAO/ECOWAS.

DARD (Directorate of Agriculture and Rural Development). 2019. The ECOWAS Rice Fact Book, 2019. Abuja, Nigeria: ECOWAS.

Deininger, K., and D. Byerlee, with J. Lindsay, A. Norton, H. Selod, and M. Stickler. 2011. Rising Global Interest in Farmland: Can It Yield Sustainable and Equitable Benefits?. Washington, DC: World Bank.

Dittoh, S., M. Bhattarai, and M. Akuriba. 2013. "Micro Irrigation-Based Vegetable Farming for Income, Employment and Food Security in West Africa." In Global Food Security: Emerging Issues and Economic Implications, 177-99. Tamale, Ghana: Nova Science.

Dixon, S., and J. Holt. 2010. Livelihood Zoning and Profiling Report: Mali, A Special Report by the Famine Early Warning Systems Network. Bamako, Mali: FEG Consulting/ United States Agency for International Development (USAID)/ Famine Early Warning Systems Network (FEWS NET).

Fall, A., H. David-Benz, and J. Huat. 2010. "Tomate locale et production de concentrés : la force des contrats entre paysans et industrie." In L'agriculture sénégalaise à l'épreuve du marché, Chapter 8 , edited by G. Duteurtre, M. D. Faye, and P. N. Dieye. Paris: Karthala.
(1) Background and understanding

(2) Regional drivers

(3) Regional organisations

(4) Agro-pastoralism-based

(5) Grains-and-legumes-based

Rice-and-horticulture

6.1 Definitions

6.2 Demography and geography

6.3 Regional consumption and production trends

6.4 Livelihoods of producer communities

6.5 Production systems

6.6 Food system outcomes

6.7 Institutional drivers

6.8 Risks and resilience

6.9 The COVID-19 pandemic

6.10 Agency and development interventions

\subsection{Summing up}

\section{References}

(7) Coastal maritime fisheries

8 Tropical mixed tree and

8 food crops systems

9 Toward enhanced resilience 
Guèye, B. 2014. Specialisation or Diversification? Divergent Perspectives on Rice Farming in Three Large Dam-Irrigated Areas in the Sahel. London: IIED. GRiSP (Global Rice Science Partnership). 2013. Rice Almanac. 4th ed. Los Baños, Philippines: Global Rice Science Partnership, International Rice Research Institute.

Hathie, I. 2016. "Politiques d'autosuffisance en riz en Afrique de I'Ouest Quels acquis, quelles limites et quels débats ?". In Bulletins de synthèse Souveraineté Alimentaire, no. 23. Paris: Inter-réseaux Développement Rural.

Hilhorst, T., and J. Nelen. 2012. "Domestic Land Acquisitions in West Africa: The Rush for Farmland by Urban 'Businessmen.'" In Handbook of Land and Water Grabs in Africa, Foreign Direct Investment and Food and Water Security, Chapter 2.5, edited by J. A. Allen. London: Routledge.

Lançon, F., and P. Mendez del Villar. 2014. "Le marché rizicole ouest-africain et la sécurité alimentaire : leçons et perspectives après la flambée des prix de 2008." In Déméter 2014 : économie et stratégies agricoles, 227-45. Paris: Club Déméter/ CIRAD.

Madgwick, F. J., and F. Pearce, eds. 2017. Water Shocks: Wetlands and Human Migration in the Sahel. Ede, the Netherlands: Wetlands International.

Manikowski, S., and A. Strapasson. 2016. "Sustainability Assessment of Large Irrigation Dams in Senegal: A Cost-Benefit Analysis for the Senegal River Valley." Frontiers in Environmental Science 4: 18.

Namara, R. E., and H. Sally, eds. 2014. Proceedings of the Workshop on Irrigation in West Africa: Current Status and a View to the Future Ouagadougou, Burkina Faso, December 1-2, 2010. Colombo, Sri Lanka: International Water Management Institute (IWMI)

Papazian, V. 2012. "Les investissements agricoles massifs en Afrique, moteurs du développement ?" In Regards sur la Terre. Développement, alimentation environnement : changer l'agriculture ?, edited by P. Jacquet, R. Pachauri, and L. Tubiana. Paris: Armand Colin.

Sahel Irrigation Initiative. 2017. Cadre Stratégique pour I'Eau Agricole au Sahel. Ouagadougou, Burkina Faso: CILSS/ECOWAS/UEMOA.

Soullier, G., M. Demont, A. Arouna, F. Lançon, and P. Mendez del Villar 2020. "The State of Rice Value Chain Upgrading in West Africa." Global Food Security 25: 100365. Montpellier, France: Elsevier

SWAC/OECD (Sahel and West Africa Club Secretariat, Organisation for Economic Co-operation and Development). 2011. "The 2008 Rice Crisis: Shock and New Challenges." West African Challenges 2: 1-11. Paris: OECD.

Sylla, M. B., J. S. Pal, A. Faye, K. Dimobe, and H. Kunstmann. 2018. "Climate Change to Severely Impact West African Basin Scale Irrigation in $2{ }^{\circ} \mathrm{C}$ and $1.5^{\circ} \mathrm{C}$ Global Warming Scenarios." Scientific Reports 8: 14395.
Thurlow, James. 2020. COVID-19 lockdowns have imposed substantial economic costs on countries in Africa. In COVID-19 and global food security, eds. Johan Swinnen and John McDermott. Part One: Food security, poverty, and inequality, Chapter 4, Pp. 23-25. Washington, DC: International Food Policy Research Institute (IFPRI)

Trost, B., A. Prochnow, K. Drastig, A. Meyer-Aurich, F. Ellmer, and M. Baumecker. 2013. "Irrigation, Soil Organic Carbon and N2O Emissions. A review." Agronomy for Sustainable Development 33 (4): 733-49.

Van Der Wijngaart, R., J. Helming, C. Jacobs, P. A. Garzon Delvaux, S. Hoek, and S. Gomez y Paloma. 2019. Irrigation and Irrigated Agriculture Potential in the Sahel: The Case of the Niger River Basin: Prospective Review of the Potential and Constraints in a Changing Climate. Luxembourg City, Luxembourg: Office of the European Union.

Wannehain, H., and P. Janin. 2012. "Commercialisation des récoltes et disponibilités céréalières des producteurs dans deux 'zones greniers' du Mali." Cahiers Agricultures 21 (6): 455-64. Montpellier, France : CIRAD.

Williams, T. O., J.-M. Faurès, R. Namara, and K. Snyder. 2020. "Large-Scale Irrigated Farming System: The Potential and Challenges to Improve Food Security, Livelihoods and Ecosystem Management." In Farming Systems and Food Security in Africa: Priorities for Science and Policy under Global Change, edited by J. Dixon, D. P. Garrity, J,-M. Boffa, T. Olalekan Williams, and T. Amede. New York: Routledge.

World Bank. 2012. "Annex 1: The Rice Value Chain." In Growing Africa: Unlocking the Potential of Agribusiness. Washington, DC: World Bank.

World Bank. 2017. Amélioration de la connaissance et de la gestion des eaux au Burkina Faso : Rapport de synthèse. Washington, DC: World Bank.

Food security surveys by National institutes of Early Warning Systems and World Food Program:

ENSAN. 2013. Enquête Nationale sur la Sécurité Alimentaire et la Nutrition ENSAN 2013, Données primaires collectées en juin 2013. Early Warning System-Système d'Alerte Précoce (EWS-SAP). Dakar, Senegal: SE/CNSA (Secrétariat Exécutif du Conseil National à la Sécurité Alimentaire)/ WFP/ UNICEF/ FAO/ OMS.

ENSAN. 2018. Enquête Nationale sur la Sécurité Alimentaire et la Nutrition, Septembre 2018, ENSAN Mali, Rapport de Synthèse. Early Warning SystemSystème d'Alerte Précoce (EWS-SAP). Bamako, Mali: Mali Food Security Cluster.

VIA, 2015. Enquête Conjointe sur la Vulnérabilité à l'Insécurité Alimentaires des Ménages au Niger (Décembre 2010 - Janvier 2015). Système d'Alerte Précoce et de Prévention des Catastrophes (SAP/PC). Niamey, Niger: INS (Institut National des Statistiques)/ WFP/ PNUD/ FAO/ Save the Children/ FEWS-Net.
(1) Background and understanding

(2) Regional drivers

(3) Regional organisations

(4) Agro-pastoralism-based

(5) Grains-and-legumes-based

Rice-and-horticulture

6.1 Definitions

6.2 Demography and geography

6.3 Regional consumption and production trends

6.4 Livelihoods of producer communities

6.5 Production systems

6.6 Food system outcomes

6.7 Institutional drivers

6.8 Risks and resilience

6.9 The COVID-19 pandemic

6.10 Agency and development interventions

\subsection{Summing up}

\section{References}

(7) Coastal maritime fisheries

8 Tropical mixed tree and food crops systems

9) Toward enhanced resilience 


\section{Annex 6A Statistics on Rice and Vegetables}

80

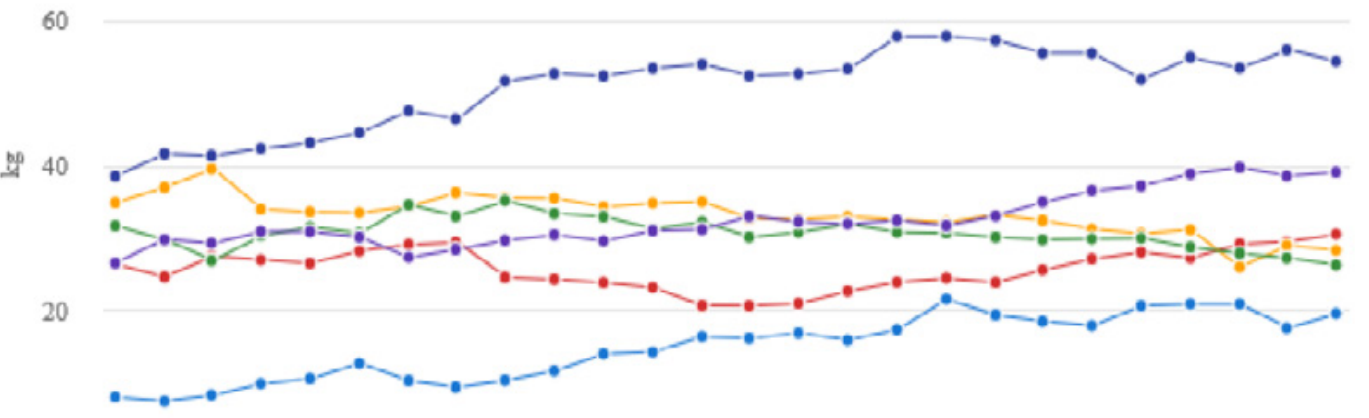

1990

1995

2000

2005

2010

Figure 6A.1 Food Supply Per Capita of Vegetables and Cereals in West Africa, 1988-2013

Source: FAOSTAT, Food and Agriculture Organisation, Rome (accessed August 27, 2020).

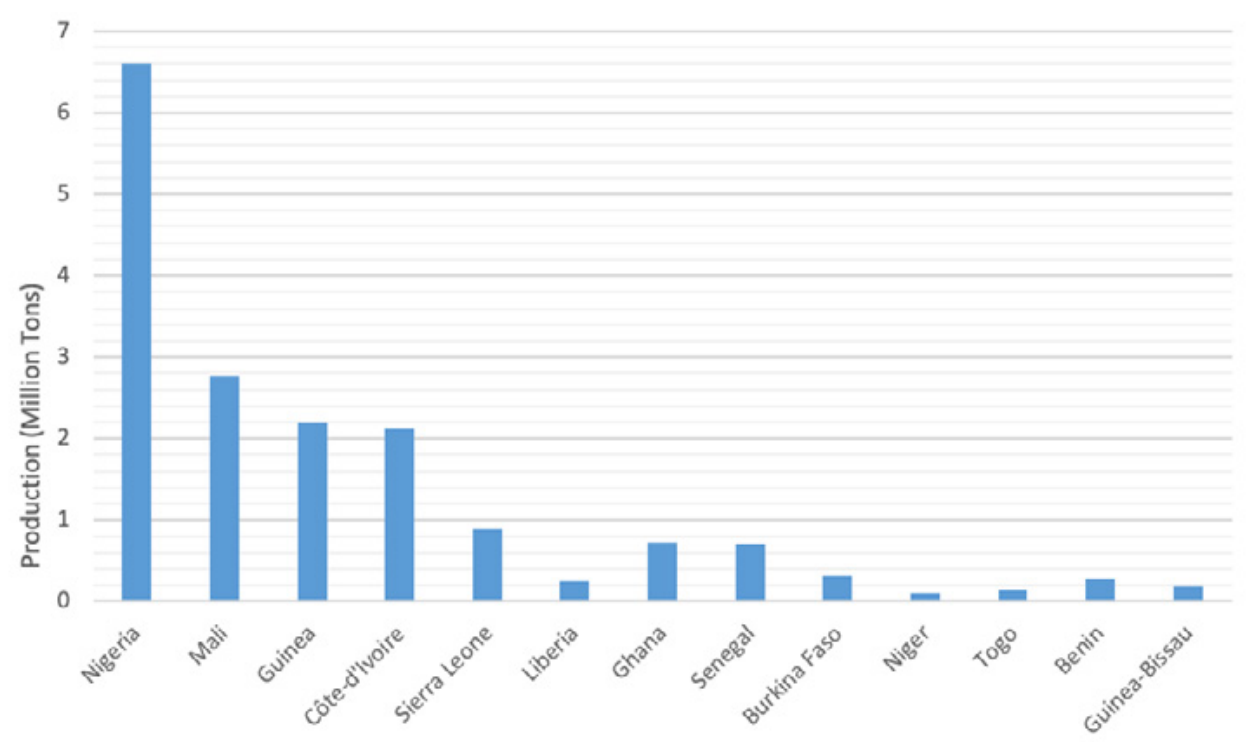

Countries
-- Western Africa

Food supply quantity $(\mathrm{kg} / \mathrm{capita} / \mathrm{yr})$

Wheat and products

Western Africa

Food supply quantity (kg/capita/yr)

Millet and products

- Western Africa

Food supply quantity (kg/capita/yr)

Rice and products

-- Westem Africa

Food supply quantity (kg/capita/yr)

Maize and products

Food supply quantity (kg/capita/yr)

Sorghum and products

- Westem Africa

Food supply quantity (kg/capita/yr)

Vegetables
(1) Background and understanding

(2) Regional drivers

(3) Regional organisations

(4) Agro-pastoralism-based

(5) Grains-and-legumes-based

6 Rice-and-horticulture

6.1 Definitions

6.2 Demography and geography

6.3 Regional consumption and production trends

6.4 Livelihoods of producer communities

6.5 Production systems

6.6 Food system outcomes

6.7 Institutional drivers

6.8 Risks and resilience

6.9 The COVID-19 pandemic

6.10 Agency and development interventions

\subsection{Summing up}

\section{References}

(7) Coastal maritime fisheries

(8) Tropical mixed tree and

food crops systems

9) Toward enhanced resilience

Figure 6A.2 Paddy Rice Production in West Africa, 2017 


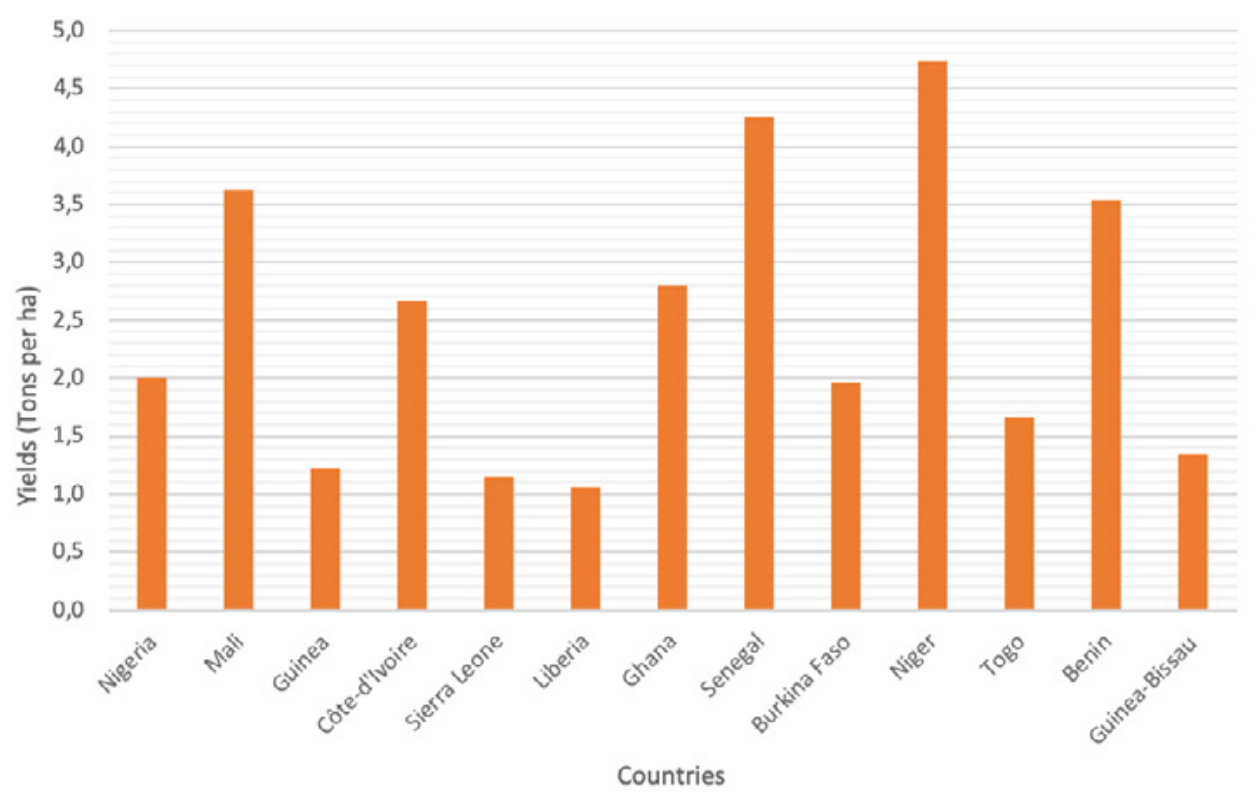

Figure 6A.3 Paddy Rice Yield in West Africa, 2017

Sources: FAOSTAT (August 2020).

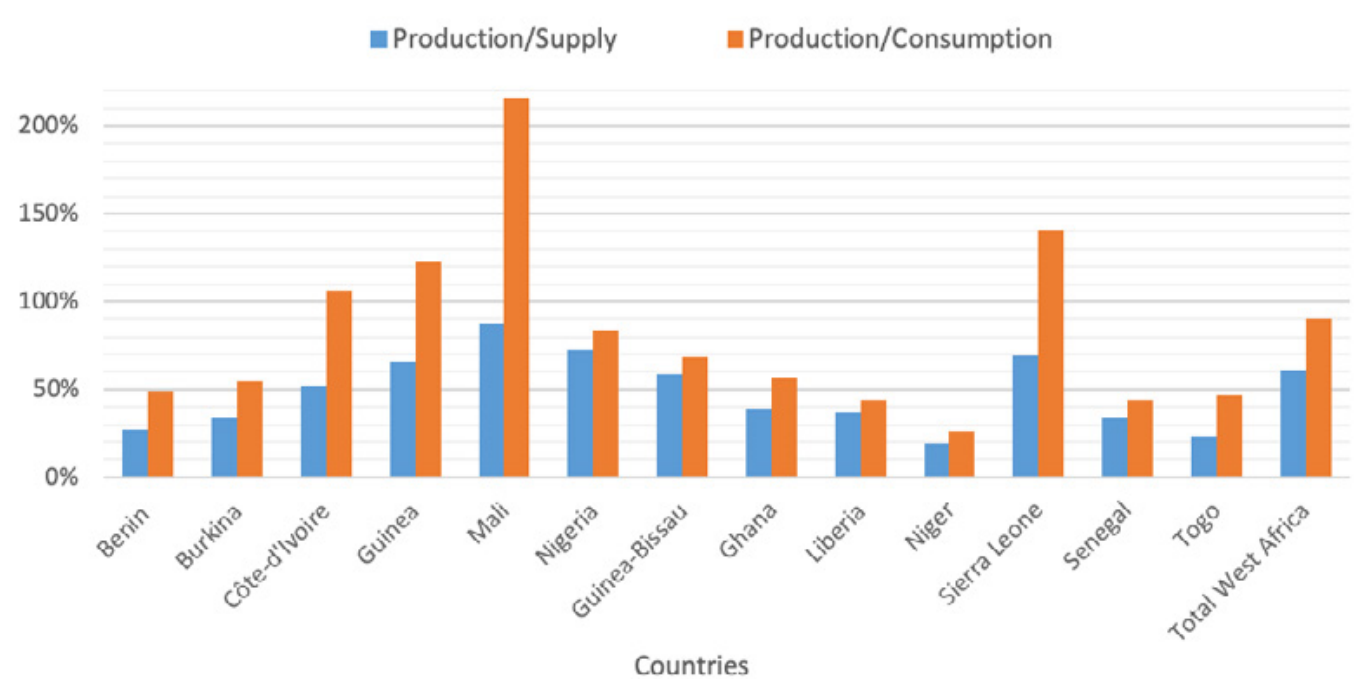

Figure 6A.4 Self-Sufficiency Rates for Rice in West Africa, 2017

Source: DARD 2019.
(1) Background and understanding

(2) Regional drivers

(3) Regional organisations

(4) Agro-pastoralism-based

(5) Grains-and-legumes-based

6 Rice-and-horticulture

6.1 Definitions

6.2 Demography and geography

6.3 Regional consumption and production trends

6.4 Livelihoods of producer communities

6.5 Production systems

6.6 Food system outcomes

6.7 Institutional drivers

6.8 Risks and resilience

6.9 The COVID-19 pandemic

6.10 Agency and development interventions

\subsection{Summing up}

\section{References}

(7) Coastal maritime fisheries

(8) Tropical mixed tree and food crops systems

9 Toward enhanced resilience 


\section{Coastal maritime fisheries food system}

By Froukje Kruijssen

\subsection{Definitions}

7.2 Demography and geography

$\underline{7.3 \text { Regional consumption and production trends }}$

7.4 Livelihoods of producer communities

\subsection{Production systems}

7.6 Food system outcomes

7.7 Institutional drivers

7.8 Risks and resilience

7.9 Food system impacts of and responses to the COVID-19 pandemic

7.10 Agency and development interventions

7.11 Summing up: toward leverage points for future interventions

References

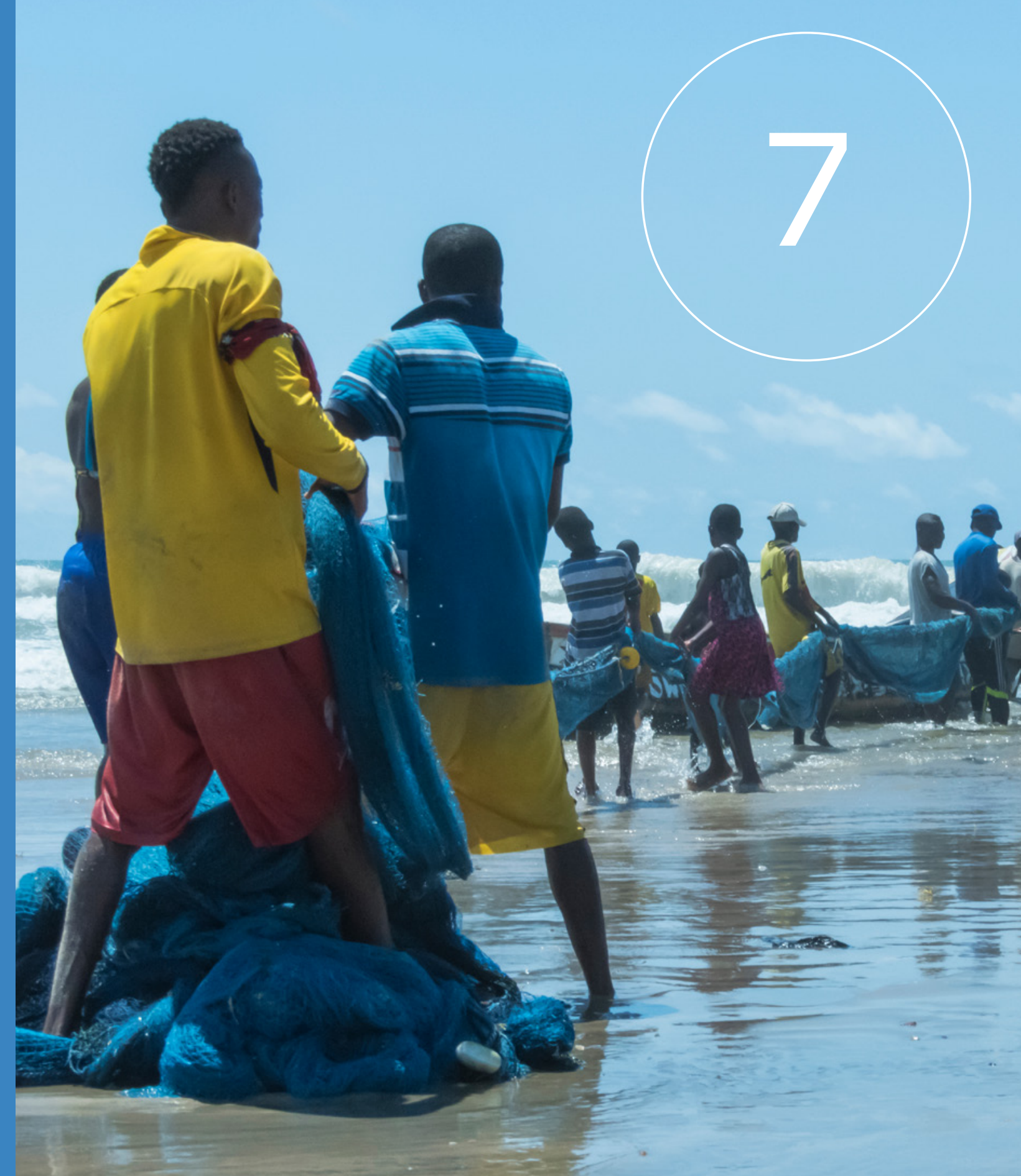

\section{$\bullet-$}


This chapter contains a description and an analysis of food systems based on fisheries and the catch, trade, processing, and

consumption of maritime fisheries products. This mostly excludes inland fisheries, aquaculture, and fish from imports, though some data presented here will refer to fish in general, as disaggregated data on marine fish alone is often lacking. The types of species and products may vary among different systems, but fish from marine and inland capture fisheries and aquaculture interact within food systems and influence each other in terms of price. The chapter has 11 sections. The first defines the coastal maritime fisheries food system, followed by a discussion of its demography, location, and importance to livelihoods. Section 7.3 describes trends in consumption and production, and section 7.4 details the livelihoods of people living in this food system. Section 7.5 covers the maritime fisheries production system, and section 7.6 addresses multiple food system outcomes. Section 7.7 highlights important institutiona drivers of changes in the system, while section 7.8 identifies trends, risks, and systems resilience, followed by an analysis of food system impacts of the COVID-19 pandemic in section 7.9. Section 7.10 contains an examination of past agency and development efforts to influence the coastal maritime fisheries food system and lessons for the future. The final section outlines some conclusions about leverage points for enhanced resilience of the coastal maritime fisheries food system.

\subsection{Definitions}

Coastal maritime fisheries are usually defined as all fisheries within exclusive economic zones (EEZs). EEZs are areas extending up to 200 nautical miles from a country's coastline that are reserved for that respective country and governed by the United Nations Convention on the Law of the Sea (UNCLOS) (see map 7.1). Under UNCLOS, countries have sovereign rights to explore, exploit, conserve, and manage the natural resources within their EEZ.

Fisheries and fleets in these coastal zones range from artisanal or small-scale boats to large-scale industrial vessels using a wide variety of fishing gear and practices. The fish caught are used for many purposes by both proximate and distant users. Fish is of key importance for household subsistence, and is heavily traded, reaching both urban and rural consumers at the local, national, regional, and global levels. These consumers gain access to a wide variety of marine products through a vast number of formal and informal markets and trading routes. Fish from coastal marine sources may be used to produce fish meal or fish oil, which are then used as ingredients in animal feeds. The coastal marine fisheries therefore provide food security, nutrition, employment, and income through a wide range of different roles in the value chain.

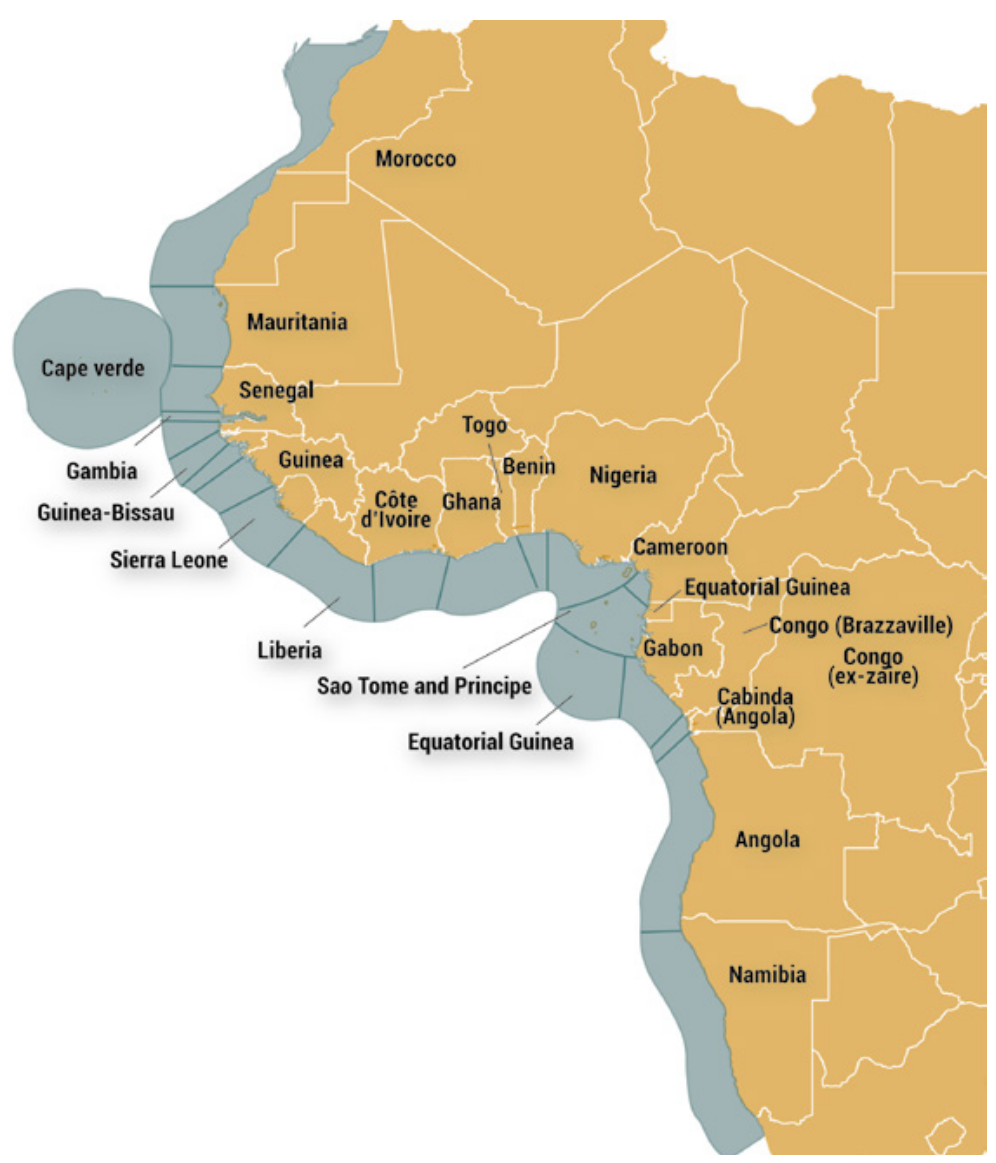

Map 7.1 Geographical Distribution of the West African Coastal Maritime Fisheries Food System (EEZ)

Source: Belhabib, Greer and Pauly, 2018
(1) Background and understanding

(2) Regional drivers

(3) Regional organisations

(4) Agro-pastoralism-based

(5) Grains-and-legumes-based

6) Rice-and-horticulture

7 Coastal maritime fisheries

7.1 Definitions

7.2 Demography and geography

7.3 Regional consumption and production trends

7.4 Livelihoods of producer communities

7.5 Production systems

7.6 Food system outcomes

7.7 Institutional drivers

7.8 Risks and resilience

7.9 The COVID-19 pandemic

7.10 Agency and development interventions

7.11 Summing up References

(8) Tropical mixed tree and

food crops systems

9 Toward enhanced resilience

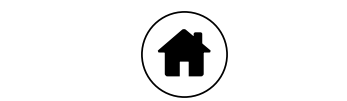




\subsection{Demography and geography}

The West African coastal zone land area is a little over 1 percent of the region's total land area, but over 7 percent of the region's population (over 28 million people in 2019) live in this zone. ${ }^{1}$ This reflects a general global trend that coastal zones attract people because of their rich resources, access to marine trade and transport, and recreational or cultural activities (Neumann et al. 2015). ${ }^{2}$ In West Africa in particular, coastal marine fisheries play an important role in providing income and livelihoods.

People in West African fishing communities rely on livelihood diversification but also use migration as a livelihood strategy since fish migratory patterns lead to seasonal variation in West African fisheries (Njock and Westlund 2010). Several complementary types of migration patterns can be discerned in West Africa based on temporal and geographic characteristics, including international and internal migration, as well as short-term, seasonal, long-term, and permanent migration. These migration patterns have important social implications. They have been associated with sexually transmitted diseases such as HIV/AIDS, which has been shown to be higher than the national average in many fishing communities, and with early school leaving due to school-age children accompanying their parents to locations lacking access to schools. Fishing migrants both contribute to the local economies they migrate to and compete for local jobs. One result is that they suffer from mistrust, discrimination, marginalisation, and conflict. Strong data on fisheries-related migration in West Africa are lacking, but case study evidence suggests that migrants from other countries make up as much as 95 percent of the fisher population in Côte d'Ivoire, 86 percent in Cameroon, and 33 percent in Mauritania (Njock and Westlund 2010).

\subsection{Regional consumption and production trends}

Fish is of key importance to food and nutrition security in West Africa, serving as an important source of key micronutrients (especially vitamin A, calcium, iron, selenium, and zinc), essential fatty acids (in particular omega-3s), and protein (Kawarazuka and Béné 2010, 2011). Micronutrient deficiencies occurring during the first 1,000 days of life increase the risk of infant and child mortality in the short term and restrict the cognitive development, schooling, and earning potential of children in the long term (Mulder, King, and Innis 2014) Fish is also of major importance for maternal health during pregnancy and is recognised for its beneficial heart-health properties

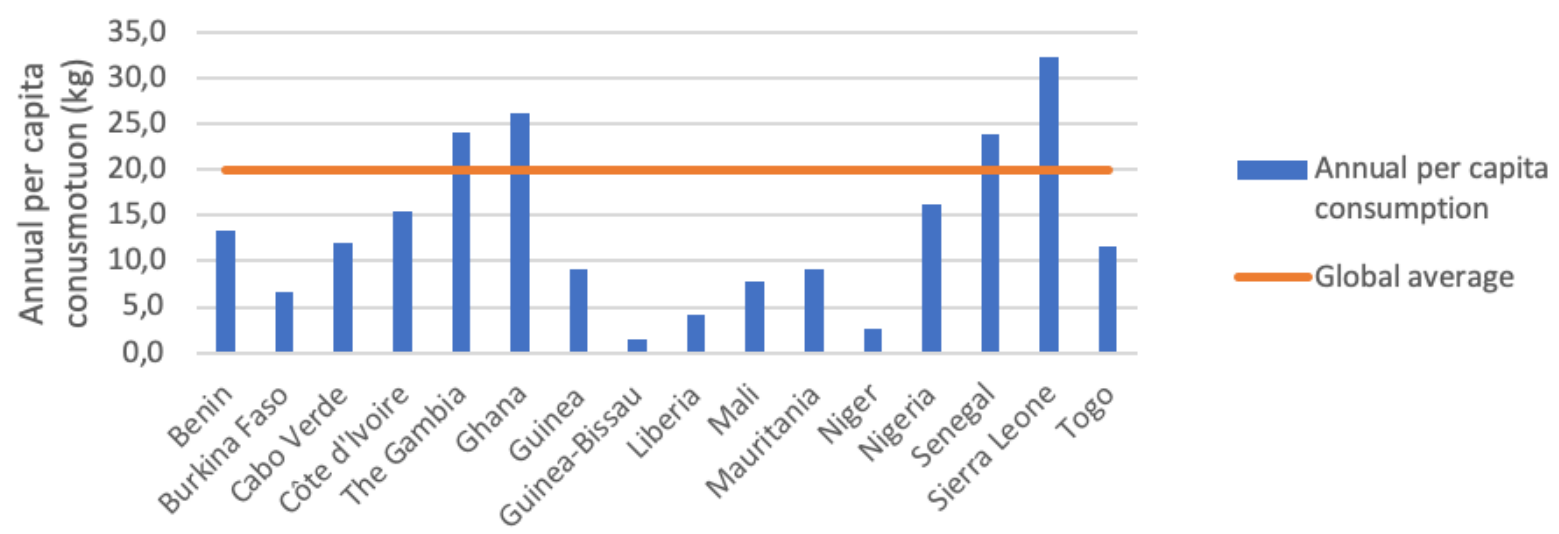

(1) Background and understanding

(2) Regional drivers

(3) Regional organisations

(4) Agro-pastoralism-based

(5) Grains-and-legumes-based

6) Rice-and-horticulture

7 Coastal maritime fisheries

7.1 Definitions

7.2 Demography and geography

7.3 Regional consumption and production trends

7.4 Livelihoods of producer communities

7.5 Production systems

7.6 Food system outcomes

7.7 Institutional drivers

7.8 Risks and resilience

7.9 The COVID-19 pandemic

7.10 Agency and development interventions

7.11 Summing up References

Tropical mixed tree and

8 food crops systems

9 Toward enhanced resilience

Figure 7.1 Annual Per Capita Fish Consumption in West Africa, 2013

Source: FAOSTAT, Food and Agriculture Organisation, Rome (accessed March 6, 2020). 
(Connor 2000). Despite the important role of fish in nutrition and health, nutritional considerations are generally not well integrated into fisheries' strategies, and fish are not integrated into food and nutrition security policies (Thilsted et al. 2016) and literature and policy discussions related to food systems (Tezzo et al. 2020).

Globally, fish accounted for about 17 percent of animal protein intake in 2015. However, in some West African countries such as the Gambia, Senegal, Sierra Leone, and Ghana, this figure was over 50 percent (FAO 2018). Figure 7.1 shows the variation in per capita annual fish consumption in West Africa, ranging from 1.4 kilograms in Guinea-Bissau to 32.3 kilograms in Sierra Leone. This includes fish from coastal marine fisheries and from other sources such as inland fisheries, aquaculture, and imported fish. Only the Gambia, Ghana, Senegal, and Sierra Leone are above the global average of 20 kilograms per capita per year (FAO 2018).

Fish, as well as plants, provide a reliable source of omega-3 fatty acids. Yet, only Cape Verde, the Gambia, and Senegal have achieved recommended levels of omega-3 fatty acids (figure 7.2) (Micha et al. 2014). Given the relatively low levels of fish

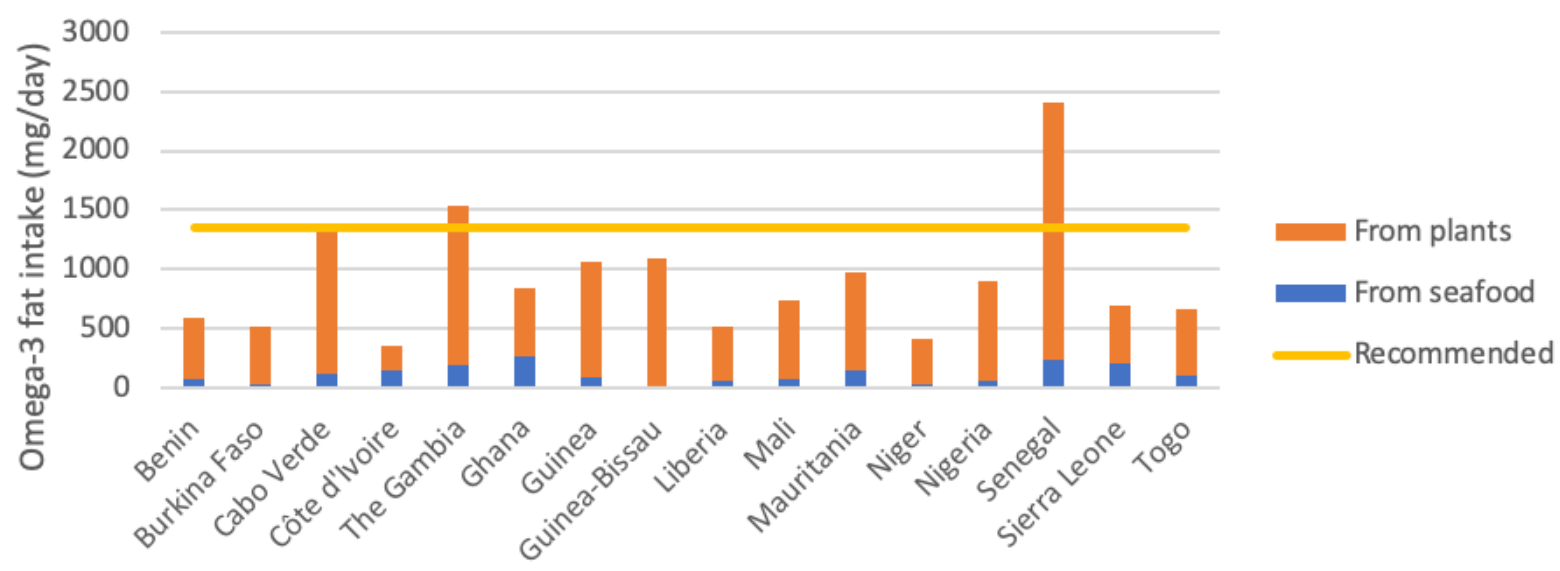

Figure 7.2 Daily Intake of Omega-3 Fatty Acids from Seafood and Plants in West Africa, 2010 Source: Micha et al. 2014.

Note: The recommended level for adults was computed as an average of the recommended daily intake of 1,600 milligrams for men and 1,100 milligrams for women. consumption per capita, there is scope for increased fish consumption to boost these levels in most West African countries. At the same time, it should be noted that environmental and ecological traits have an effect on nutrient content of marine finfish species (Hicks et al. 2019). Fish from the West African coastal zone contain relatively high levels of calcium, iron, and zinc and lower levels of omega- 3 fatty acids compared to species from cold thermal regimes.

Within countries, fish consumption is uneven as a result of differences in income distribution, cultural preferences, and logistics (Gordon et al. 2013). While there has been limited research in the West Africa region on the variation of fish consumption between rural and urban settings, a review of consumption studies from across Africa suggests that urban dwellers generally have higher levels of expenditure on meat and fish, as well as a higher level of consumption, than people in rural areas (Chauvin, Mulangu, and Porto 2012; Romanik 2008). Further, urban dwellers have a higher reliance on purchased food versus self-production (Chauvin,

Mulangu, and Porto 2012). While there are limited data on West Africa as a whole, evidence from individual countries shows the
(1) Background and understanding

(2) Regional drivers

(3) Regional organisations

(4) Agro-pastoralism-based

(5) Grains-and-legumes-based

6) Rice-and-horticulture

7 Coastal maritime fisheries

7.1 Definitions

7.2 Demography and geography

7.3 Regional consumption and production trends

7.4 Livelihoods of producer communities

7.5 Production systems

7.6 Food system outcomes

7.7 Institutional drivers

7.8 Risks and resilience

7.9 The COVID-19 pandemic

7.10 Agency and development interventions

7.11 Summing up References

(8) Tropical mixed tree and food crops systems

9 Toward enhanced resilience 
importance of fish for food security. In Ghana, for example, fish is available throughout the country at relatively low prices and may be purchased in relatively small quantities, making it accessible for low-income consumers, who spend over 25 percent of their food expenses on fish (Hasselberg et al. 2020). There is also differentiation between wealth groups in the types of species they purchase: whereas low-income consumers prefer cheaper smoked sardines, wealthy consumers buy larger and more expensive fish such as tilapia. There is also strong seasonal variation in the supply of fish. For example, in Ghana, marine fish are readily available during the two upwelling seasons and less accessible in the other months (Hasselberg et al. 2020).

Fish consumption may be at risk with declining fish supplies and growing populations. Drivers for increased demand for fish include growing populations, rising urbanisation, and increasing incomes (Béné et al. 2015). All these drivers are on an upward trend in West Africa. Population growth in West African countries has been among the highest in Africa (ADB 2018), and the region's urbanisation rate has been estimated at 32 percent (OECD 2011). ${ }^{3}$ Per capita income in West Africa has also increased significantly over the past decades (ADB 2018). This means that fish demand in West Africa will rise significantly in the near future. Several projections of the extent of this rise have been made but account for population growth only (see Béné et al. 2015). The actual growth in demand is likely to be much higher. These projections suggest that the African continent will become much more dependent on fish imports, from 14 percent in 2000 to 34 percent in 2030 (World Bank 2013).

The availability of fish for human consumption depends on the fisheries' resources and competing uses. When caught by industrial fishing fleets, most small pelagic fish, which are rich in macro- and micronutrients, are converted into fish meal and oil as ingredients for aquaculture, livestock, and chicken feed (Isaacs 2016). This raises important questions for food and nutrition security (Béné et al. 2015), as aquaculture tends to convert wild fish into farmed fish, which is inefficient, particularly for the carnivorous species (Boyd et al. 2007), and to feed more prosperous consumers elsewhere (Troell et al. 2014). A 2019 report on the fish meal and fish oil sector in Mauritania, Senegal, and the Gambia concluded that the share of fish diverted from direct human consumption has been increasing, even though globally it has been decreasing. The report raises concerns about the lack of transparency in the sector as well as the low share of fish offal use and high use of fish suitable for human consumption as a key component of fish meal, an ingredient for livestock and aquaculture feeds.

\subsection{Livelihoods of producer communities}

Coastal communities' livelihoods are highly diverse, and households are often involved in both land and marine and freshwater activities (Cinner and Bodin 2010). A study across 12 USAID Feed the Future target countries (given their food insecurity), including Ghana and Senegal, showed that in 10 out of 12 countries, fish-dependent households also rely on farm-based livelihood strategies and use similar land areas for agriculture as non-fish-reliant households (Fisher et al. 2017). This portfolio of both fish- and terrestrial-based food security strategies within households and communities is, however, often unrecognised in food security programmes (Fisher et al. 2017). The two types of activities are interlinked, as both rely on using natural resources. Both are also interlinked by environmental considerations, and land use change and nutrient management on land directly affect pollution at sea and the health of marine ecosystems, coral reefs, and marine health and fisheries (Klein et al. 2012). Understanding how the different ecosystems function and interact is therefore important for long-term sustainability of both systems (Klein et al. 2012).

\subsection{Production systems}

West African coastal fisheries encompass two so-called large marine ecosystems: the Canary Current, which comprises the region between Morocco and Guinea-Bissau, and the Guinea Current, which includes the rest of the West African coast. Mangrove forests and wetlands are important coastal ecosystems that collectively represent 15 percent of the world's mangrove area and provide important breeding grounds for many fish and shrimp species (IUCN 2016).
(1) Background and understanding

(2) Regional drivers

(3) Regional organisations

(4) Agro-pastoralism-based

(5) Grains-and-legumes-based

6) Rice-and-horticulture

7 Coastal maritime fisheries

7.1 Definitions

7.2 Demography and geography

7.3 Regional consumption and production trends

7.4 Livelihoods of producer communities

\subsection{Production systems}

7.6 Food system outcomes

7.7 Institutional drivers

7.8 Risks and resilience

7.9 The COVID-19 pandemic

7.10 Agency and development interventions

7.11 Summing up References

(8) Tropical mixed tree and 8 food crops systems

9 Toward enhanced resilience

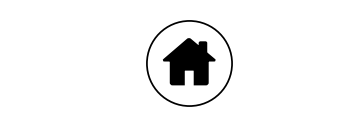


Over 450 fish species are exploited by the artisanal and industrial sectors across the region. Major species groups include the small pelagic species, such as European pilchard (Sardina pilchardus); sardinellas (Sardinella spp.); European anchovy, jacks, and horse mackerels; and African croakers, squids, cuttlefish, and hakes (Merluccius spp.) (Belhabib, Greer, and Pauly 2018). Official data reported by member states to the FAO suggest that marine capture fisheries from the Eastern Central Atlantic fishing area, which covers West Africa and part of Central Africa from the North of Morocco up to the Democratic Republic of the Congo, including the EEZ and the oceanic areas, equaled 5.5 million tonnes in 2018 (FAO 2020a) and on average just over 4 million tonnes annually in the period 200514 (FAO 2018). However, the official data generally underestimate the catch from small-scale artisanal fisheries and omit discarded bycatch and illegal, unreported, and unregulated (IUU) catch (Pauly and Zeller 2016). Total artisanal and industrial catches in West Africa's EEZs were estimated at 5.6 million tonnes per year in 2010, with 61 percent of that caught by industrial fishing vessels, based on a catch reconstruction method (Belhabib, Greer, and Pauly 2018).
Coastal marine fisheries in West Africa are complemented by inland (freshwater) capture fisheries and both marine and inland aquaculture. Marine capture fisheries are, however, by far the most important for fish production, contributing 71 percent in volume, followed by inland fisheries (19 percent) and inland aquaculture (10 percent) in 2018 according to the official data. ${ }^{4}$ While this reflects the general importance of marine capture fisheries for most West African countries, there is substantial variation across countries, both in terms of absolute volume of marine capture production (figure 7.3) and its share in overall fish production (figure 7.4). Landlocked countries obviously do not have any marine capture fisheries production. Nigeria has the highest overall volume of fish production by combining marine capture, inland capture, and inland aquaculture. Mauritania follows in total fish production, almost exclusively from marine capture. Other countries have less than half of Mauritania's production. Nigeria, Mali, and Ghana in particular report substantial volumes of inland capture fisheries, while only Nigeria and Ghana register significant volumes of aquaculture production.

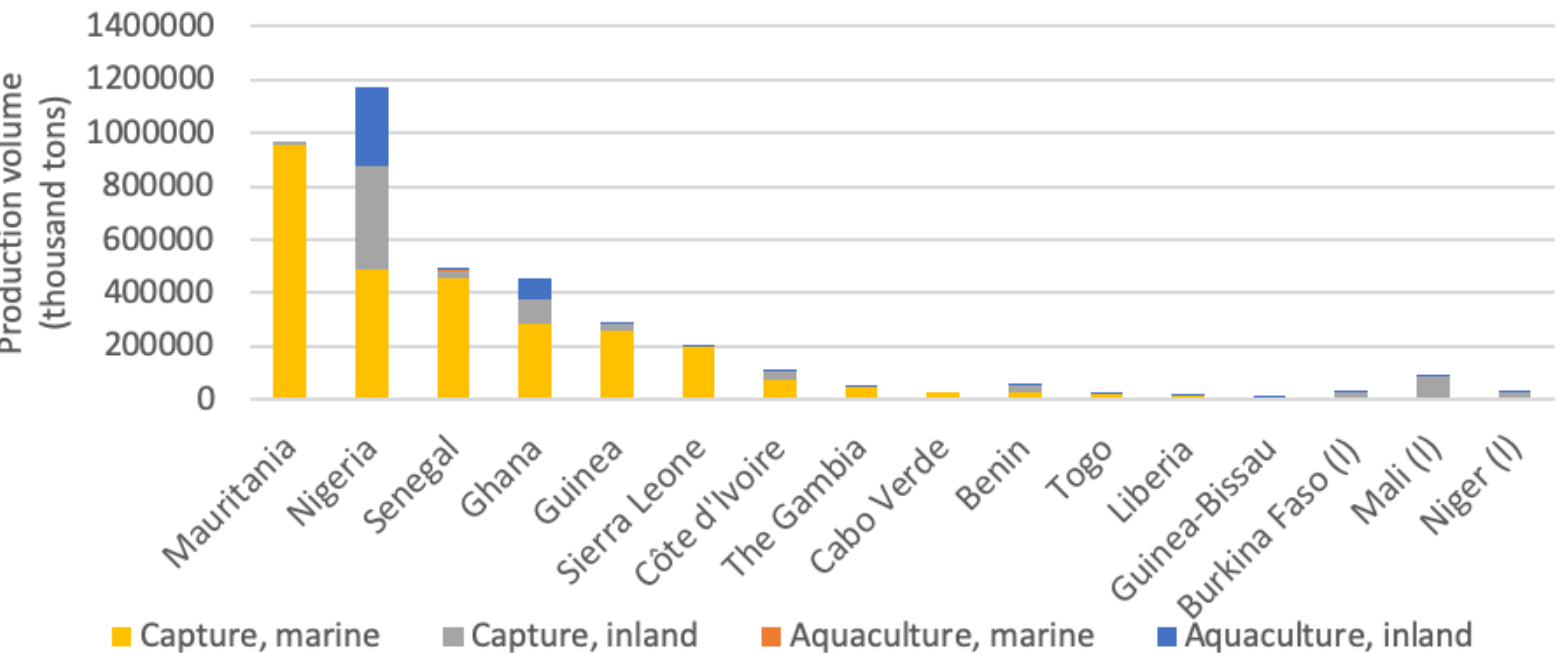

Figure 7.3 Volume of Fish Production by Source (thousand tonnes), 2018

Source: FISHSTAT, Food and Agriculture Organisation, Rome (accessed March 6, 2020).

Note: Countries are ordered by absolute volume of marine capture fisheries production. Landlocked countries are marked (I).

(1) Background and understanding

(2) Regional drivers

(3) Regional organisations

(4) Agro-pastoralism-based

(5) Grains-and-legumes-based

6) Rice-and-horticulture

7 Coastal maritime fisheries

7.1 Definitions

7.2 Demography and geography

7.3 Regional consumption and production trends

7.4 Livelihoods of producer communities

7.5 Production systems

7.6 Food system outcomes

7.7 Institutional drivers

7.8 Risks and resilience

7.9 The COVID-19 pandemic

7.10 Agency and development interventions

7.11 Summing up References

(8) Tropical mixed tree and food crops systems

9 Toward enhanced resilience 


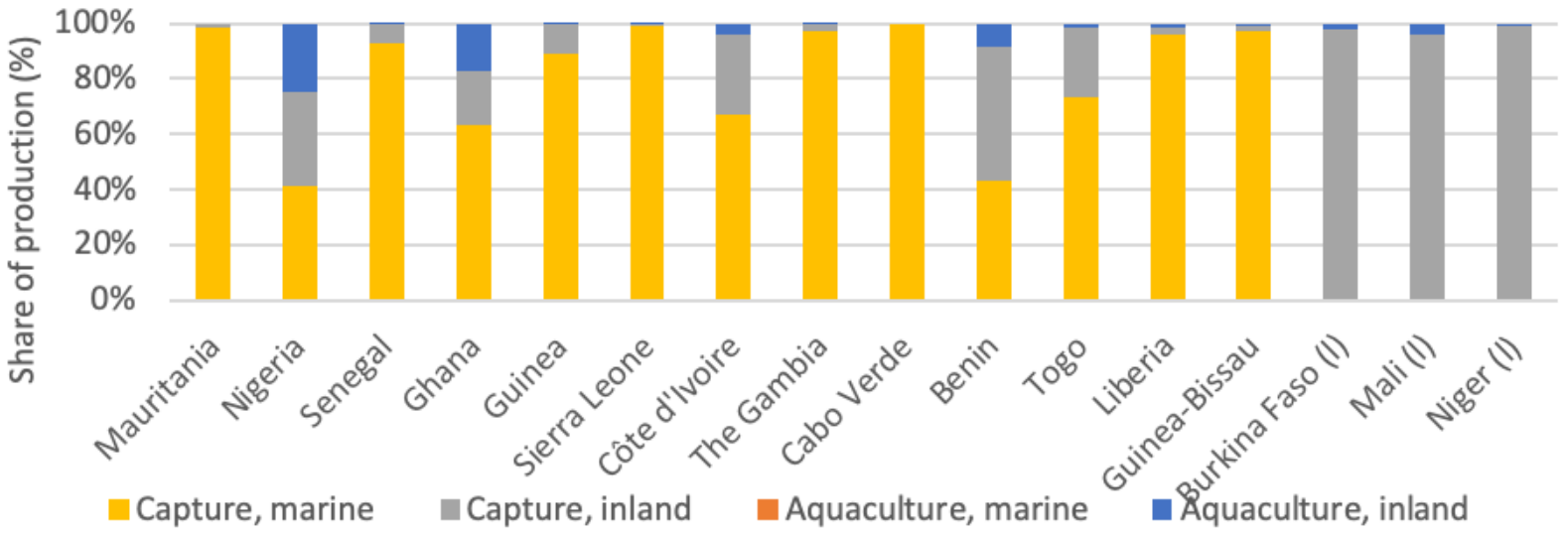

Figure 7.4 Shares of Sources in Total Fish Production (\%), 2018

Source: FISHSTAT, Food and Agriculture Organisation, Rome (accessed March 6, 2020).

Note: Countries are ordered by absolute volume of marine capture fisheries production. Landlocked countries are marked (I).

The size of the West African artisanal marine fishing fleet, including subsistence fishing, has increased rapidly since the 1970s. In 2010 the fleet was estimated at over 250,000 vessels, about half of which were motorised. They generated $\$ 3.6$ billion annually, almost entirely for local economies. The industrial fleet, however, grew until 2003 and then declined. It was estimated at 3,300 boats in 2010, dominated by demersal and shrimp trawlers ( 64 percent of industrial vessels), followed by small pelagic purse seiners and tuna long-liners and purse seiners (about 23 percent each) (Belhabib, Greer, and Pauly 2018). Foreign operators dominate the industrial sector and as little as 4 percent of the value of fish caught benefits West African countries, with most fish exported (Belhabib, Greer and Pauly 2018)

\subsection{Food system outcomes}

7.6.1 Household food and nutrition security

There is well-established evidence of the high nutritional value of finfish in particular through its supply of essential nutrients and micronutrients (fatty acids; vitamins D, A, and B; and minerals such as calcium, phosphorus, iodine, zinc, iron, and selenium). Fish therefore plays an important role in tackling multiple micronutrient deficiencies for poor people. Such evidence is mainly from studies in Asia and, to a lesser extent, developing countries elsewhere, particularly Africa (Bené et al. 2016). Fishing households consume relatively more fish than other households (Gomna and Rana 2007). Yet, there is no evidence that this leads to a higher nutritional status. Even in the case of higher nutritional status, higher cash income - for instance, from selling fish - may be more determining than the availability of fish (Béné et al. 2016).

We were unable to find specific representative data on the food and nutrition security status of households in West African fishing communities specifically. Given that cash income to is an important determinant for nutritional status, we use income as a proxy for food security (Belhabib, Sumaila, and Pauly 2015). Estimations made based on data from various sources indicate that fishers' daily income diminished in 4 out of 11 West African countries for which data is available. Fishers income remained (almost) constant in 3 countries and increased in 4 countries (Table 7.1). Fisher's income in Guinea, Guinea Bissau, and Togo is under or on the nationally set poverty line, and under or very close to the international poverty line of US\$1.25. In Ghana, fishers' incomes are also close to the
(1) Background and understanding

(2) Regional drivers

(3) Regional organisations

(4) Agro-pastoralism-based

(5) Grains-and-legumes-based

6) Rice-and-horticulture

7 Coastal maritime fisheries

7.1 Definitions

7.2 Demography and geography

7.3 Regional consumption and production trends

7.4 Livelihoods of producer communities

7.5 Production systems

7.6 Food system outcomes

7.7 Institutional drivers

7.8 Risks and resilience

7.9 The COVID-19 pandemic

7.10 Agency and development interventions

7.11 Summing up References

Tropical mixed tree and

food crops systems

9 Toward enhanced resilience

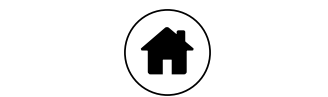




\begin{tabular}{|c|c|c|c|c|c|c|c|}
\hline & $\begin{array}{r}\text { Year data } \\
\text { past; present }\end{array}$ & $\begin{array}{r}\text { Fishers income } \\
\text { past } \\
(\$ / \text { day })\end{array}$ & $\begin{array}{r}\text { Fishers income } \\
\text { present } \\
(\$ / \text { day) }\end{array}$ & $\begin{array}{r}\text { Fishers income } \\
\text { change } \\
(\$ / \text { day })\end{array}$ & $\begin{array}{r}\text { National poverty } \\
\text { line present } \\
(\$ / \text { day })\end{array}$ & $\begin{array}{r}\text { Ratio fishers } \\
\text { income present/ } \\
\text { NPL }\end{array}$ & $\begin{array}{r}\text { Ratio fishers } \\
\text { income present/ } \\
\text { IPL (\$1.25) }\end{array}$ \\
\hline Benin & $1994 ; 2010$ & 5.7 & 5.7 & 0 & 2.5 & 2.3 & 4.6 \\
\hline Cabo Verde & $-; 2010$ & N/A & 35.3 & N/A & 1.1 & 32.1 & 28.2 \\
\hline Côte d'Ivoire & $1994 ; 2010$ & 9.5 & 5.9 & -3.6 & 1.1 & 5.4 & 4.7 \\
\hline The Gambia & $1994 ; 2010$ & 4.9 & 19.4 & 14.5 & 2 & 9.7 & 15.5 \\
\hline Ghana & $1977 ; 2010$ & 6.9 & 1.5 & -5.4 & 0.7 & 2.1 & 1.2 \\
\hline Guinea & $1990 ; 2000$ & 2.1 & 1.7 & -0.4 & 2.7 & 0.6 & 1.4 \\
\hline Guinea Bissau & $1993 ; 2010$ & 0.6 & 0.6 & 0 & 1.1 & 0.5 & 0.5 \\
\hline Liberia & -; 2010 & N/A & 5.9 & N/A & 1.3 & 4.5 & 4.7 \\
\hline Mauritania & $1994 ; 2002$ & 3.0 & 3.1 & 0.1 & 0.9 & 3.4 & 2.5 \\
\hline Nigeria & $1974 ; 2010$ & 0.2 & 3.8 & 3.6 & 1.6 & 2.4 & 3.0 \\
\hline Senegal & $1974 ; 1994$ & 7.6 & 13.5 & 5.9 & 1.5 & 9.0 & 10.8 \\
\hline Sierra Leone & $1974 ; 2010$ & 5.8 & 18.0 & 12.2 & 1.3 & 13.8 & 14.4 \\
\hline Togo & $1994 ; 2010$ & 4.6 & 2.3 & -2.3 & 2.2 & 1.0 & 1.8 \\
\hline
\end{tabular}

Table 7.1 Fishers' Income and Income Change (US\$/day) in West Africa and Incomes Compared to the National and International Poverty Lines (Ratio)

Source: Belhabib, Sumaila and Pauly, 2015

Note: Estimates of the landed are calculated as the product of the reconstructed small-scale catch (Belhabib, Sumaila and Pauly, 2015) and the ex-vessel price (from Sumaila et al., 2007, Swartz et al., 2013). Net income (i.e., total revenue minus total cost), is used to calculate fishers income, and has been converted to current prices using the Consumer Price Index. The column year data indicates the year the data originate from for the calculations of the past and present fishers incomes. Numbers in red indicate a decline in income (Fishers income change), or a present fishers income that is below the national poverty line (Ratio Fishers income present/NPL) or international poverty line (IPL) of US\$1.25. Numbers in orange indicate incomes that are very close it the national or international poverty line.

international poverty line. In these same countries fishers incomes have also declined or remained the same. With increasing pressure on the fisheries, this indicates that in some West African countries, the food and nutrition security status for people in fishing communities is under significant threat.

7.6.2 Income, trade, and employment

Recent data on the contribution of fisheries to GDP in West Africa is lacking. World Bank (2012), often cited in many recent publications (such as Cai, Huang, and Leung 2019) puts the contribution of fisheries to GDP in the West African region at 4.1 percent, including both production and postharvest activities, with production contributing 57 percent and the postharvest sector (including fish processing and marketing), 43 percent (Kébé and Tallec 2006). This includes the inland fisheries sector. The overall annual contribution of artisanal coastal fisheries in West Africa has been estimated at $\$ 3.6$ billion annually (Belhabib, Greer, and Pauly 2018). ${ }^{5}$

Payments made by distant countries to gain access rights to fish in the West African countries' EEZs also contribute to West African economies. Although the exact contribution is difficult to establish, the annual value of the fisheries agreement between African states and the EU for the entire Atlantic Ocean has been estimated at $€ 159$ million and with non-EU states, $€ 140$ million (de Graaf and Garibaldi 2014). These figures go beyond West Africa alone to include all African countries along the Atlantic coast. However, the fisheries
(1) Background and understanding

(2) Regional drivers

(3) Regional organisations

(4) Agro-pastoralism-based

(5) Grains-and-legumes-based

6) Rice-and-horticulture

7 Coastal maritime fisheries

7.1 Definitions

7.2 Demography and geography

7.3 Regional consumption and production trends

7.4 Livelihoods of producer communities

7.5 Production systems

7.6 Food system outcomes

7.7 Institutional drivers

7.8 Risks and resilience

7.9 The COVID-19 pandemic

7.10 Agency and development interventions

7.11 Summing up References

(8) Tropical mixed tree and

8 food crops systems

9 Toward enhanced resilience 
agreements are considered to be nontransparent and have fees that are too low (Belhabib et al. 2015). Much of the catch is processed directly onboard foreign fishing vessels and is directly exported, so it does not benefit West African employment or food security.

Fish from West African countries is sold both locally and nationally and is exported to other parts of the West African region, to other parts of Africa, and to other continents. Overall, in 2019 the West African region exported about half of its fish exports in terms of value to Europe, 23 percent to other West African countries,

21 percent to Asia, and only 4 percent to the rest of Africa, based on statistics from ITC trade maps (figure 7.5 ).

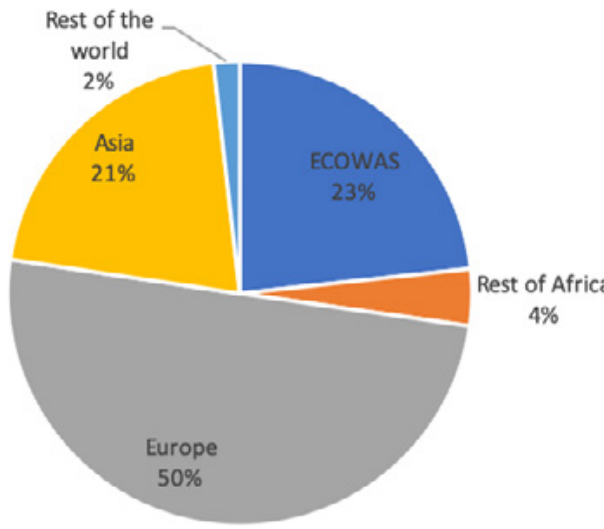

Figure 7.5 Exports from West Africa by Region (Percentage of total exports), 2019

Source: ITC Trade Map database, International Trade Centre, Geneva (accessed June 15, 2020).

African countries also import fish from outside the region, especially frozen fish. A wide range of fish products are traded to different types of consumers. For example, a mapping of domestic fish trade flows in Côte d'Ivoire (map 7.2) shows different kinds of fish products from the coastal and inland freshwater fisheries flowing to all parts of the country and to neighbouring countries. At the same time, fish are imported formally or informally by land from neighbours or from outside the region in frozen form (Ayilu et al. 2016).
The whole African continent is a net importer of fish by volume but a net exporter by value, which means it exports fish of higher value, in particular to Europe, and imports lower-value products (FAO 2020a). West Africa differs in this respect, as the overall trade balance is positive by volume and value. ${ }^{6}$

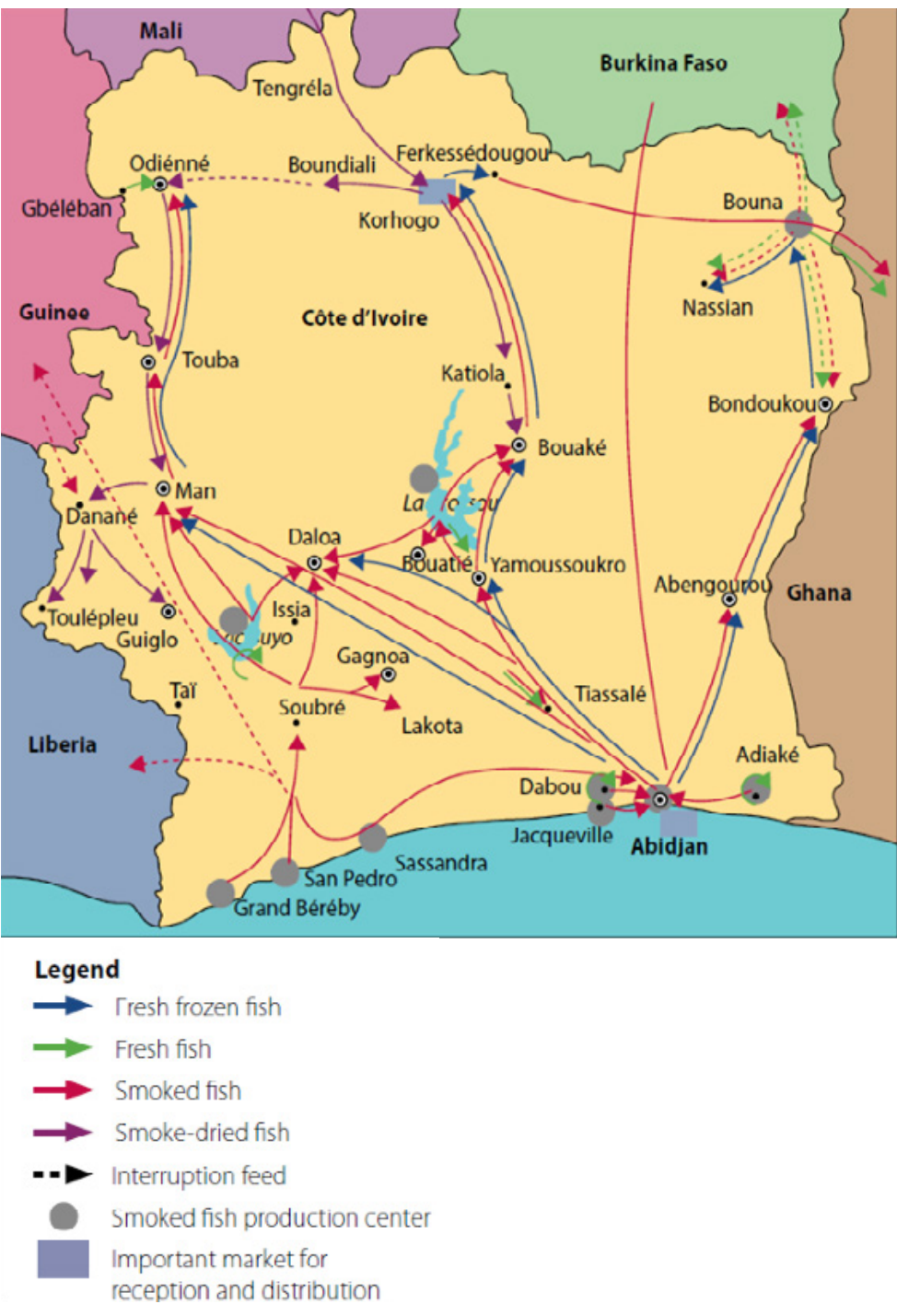

Map 7.2 Domestic Fish Trade Flows in Côte d'Ivoire, 2016 Source: Ayilu et al. 2016.
(1) Background and understanding

(2) Regional drivers

(3) Regional organisations

(4) Agro-pastoralism-based

(5) Grains-and-legumes-based

6) Rice-and-horticulture

7 Coastal maritime fisheries

7.1 Definitions

7.2 Demography and geography

7.3 Regional consumption and production trends

7.4 Livelihoods of producer communities

7.5 Production systems

7.6 Food system outcomes

7.7 Institutional drivers

7.8 Risks and resilience

7.9 The COVID-19 pandemic

7.10 Agency and development interventions

7.11 Summing up References

(8) Tropical mixed tree and food crops systems

9 Toward enhanced resilience

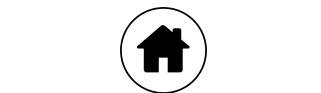




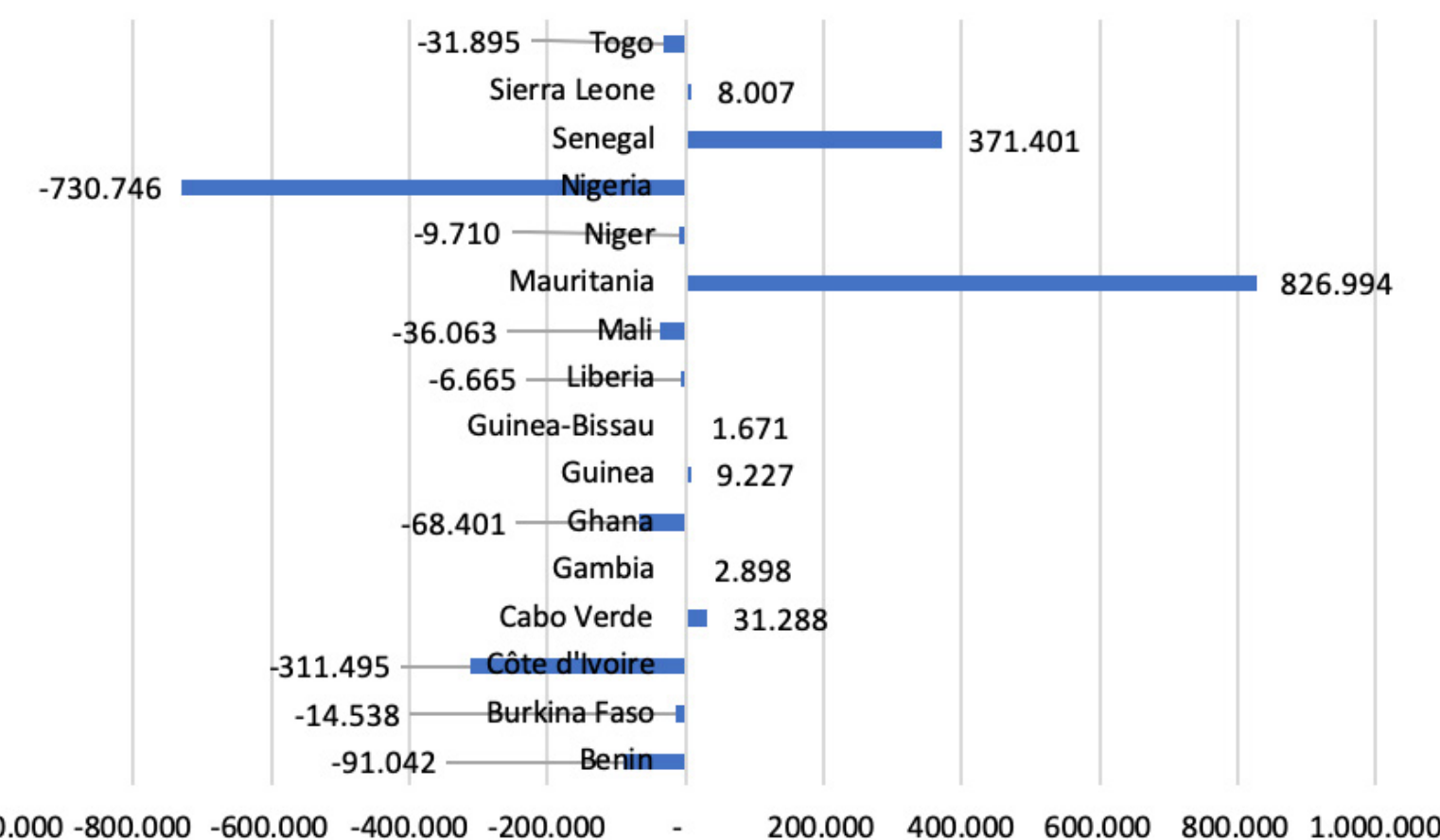

$-1.000 .000-800.000-600.000-400.000-200.000$

Figure 7.6 Value of Fish Trade Balance (thousand US\$), 2017

Source: FAOSTAT, Food and Agriculture Organisation, Rome (accessed March 6, 2020).

Figure 7.6 provides an overview of the value of the fish trade balance of West African countries. Fish trade data are not reported by source of fish, so this figure includes fish from inland fisheries and aquaculture. Although half of the 16 countries have a positive trade balance, it is only substantial for Mauritania and Senegal. By contrast, Côte d'Ivoire and Nigeria have especially large negative fish trade balances in terms of value.

These official trade figures exclude the informal cross-border trade in the West African region. This trade concerns mainly processed products from the artisanal sector, especially small pelagic fishery products $^{7}$ (Tall n.d.). There are no reliable estimates of this crossborder fish trade, but many sources indicate it is significant (Ayilu et al. 2016). Some projects have attempted to map the internal flows of fish in the West African region as a whole or within and from specific West African countries. ${ }^{8}$ Map 7.3 provides one of the most recent attempts at mapping West African fish trade flows.

An estimated 90 percent of traded fish and 70-80 percent of fish consumed in West Africa is smoked (Adeyeye and Oyewole 2016 Ayilu et al. 2016). Canning is uncommon as it is expensive and there are no canning facilities in West Africa (Isaacs 2016). Cold storage is still lacking in many places, and smoking and drying (and to a lesser extent salting) are common practices to enhance shelf life. The economic and nutritional value of fish may be affected by the process of landing, handling, and processing. Fish in general, and small pelagic fish with their high fat content in particular, spoil easily. Losses along fish value chains can therefore be high.

Evidence on postharvest fish losses from low-income countries is scant and highly variable in the methods and approaches used to
(1) Background and understanding

(2) Regional drivers

(3) Regional organisations

(4) Agro-pastoralism-based

(5) Grains-and-legumes-based

6) Rice-and-horticulture

7 Coastal maritime fisheries

7.1 Definitions

7.2 Demography and geography

7.3 Regional consumption and production trends

7.4 Livelihoods of producer communities

7.5 Production systems

7.6 Food system outcomes

7.7 Institutional drivers

7.8 Risks and resilience

7.9 The COVID-19 pandemic

7.10 Agency and development interventions

7.11 Summing up References

8 Tropical mixed tree and food crops systems

9 Toward enhanced resilience 


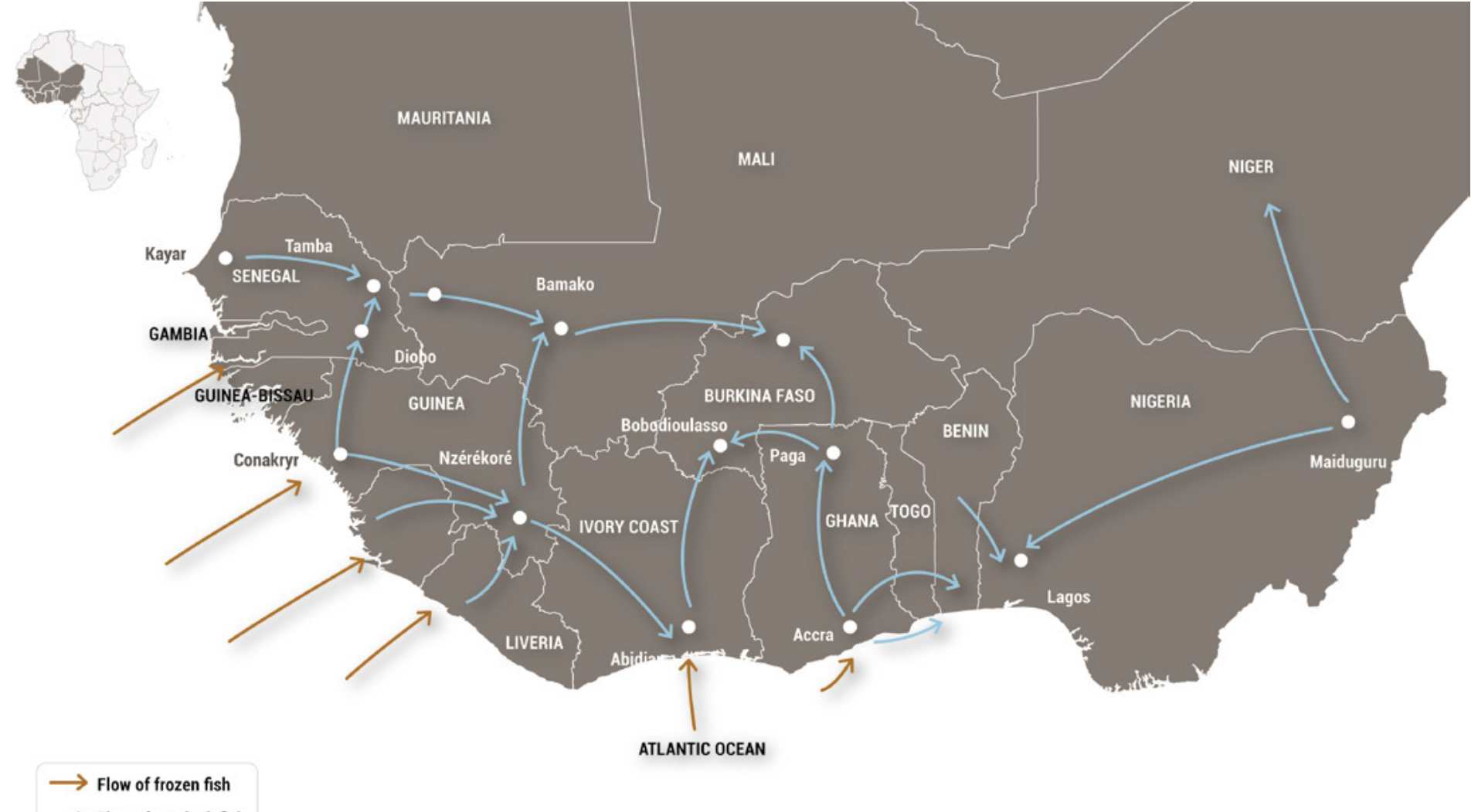

$\longrightarrow$ Flow of smoked fish

Map 7.3 Fish Trade Flow in the West African Region

Source: Ayilu et al. 2016

estimate these losses (Kruijssen et al. 2020), but it is clear that losses can be significant. In Ghana, for example, physical losses at production (landing) level for purse seine fisheries were estimated at 16-20 percent of total weight (Akande and Diei-Ouadi 2010), with losses of 3-17 percent for the entire smoked fish value chain (Diei-Ouadi et al. 2015).

Apart from physical losses, economic and nutritional outcomes may also be affected when quality is reduced. Nutritional losses, such as the loss of crude protein and fatty acids, may be a result of

smoking, freezing, or storage (Kruijssen et al. 2020). Food safety is also of concern as a wide range of acute health issues such as diarrhoea can occur along with long-term effects, such as chronic disorders of the kidneys, heart, eyes, and brain. Unsafe food therefore poses a threat to public health and local economies (Roesel et al. 2015). Most of the burden of foodborne diseases results from zoonoses, or microbes transmitted from animals to humans, caused by bacteria or parasites. While these hazards may be significant, they do not necessarily translate into real risk. For example, studies of shellfish in Côte d'Ivoire and smoked fish in Ghana found that microbes were present in the raw product in the market but not in the cooked end product (Roesel et al. 2015).
(1) Background and understanding

(2) Regional drivers

(3) Regional organisations

(4) Agro-pastoralism-based

(5) Grains-and-legumes-based

6) Rice-and-horticulture

7 Coastal maritime fisheries

7.1 Definitions

7.2 Demography and geography

7.3 Regional consumption and production trends

7.4 Livelihoods of producer communities

7.5 Production systems

7.6 Food system outcomes

7.7 Institutional drivers

7.8 Risks and resilience

7.9 The COVID-19 pandemic

7.10 Agency and development interventions

7.11 Summing up References

8 Tropical mixed tree and food crops systems

9 Toward enhanced resilience 
There are no recent specific estimates of overall employment in the coastal marine fisheries sector in West Africa. Estimates of overall direct and indirect employment in the fisheries sector in West Africa, including jobs in fishing, processing, marketing, and equipment repair, are at 7 to 12 million jobs, either full-time, part-time, or seasonal. This is based on official statistics combined with several assumptions, outlined as follows. Employment in the primary fisheries sector (marine and inland) was listed at slightly over 5 million jobs in 2018 for all of Africa, based on official data reported by member states to the FAO (2020a). These statistics also suggest that West African marine capture production contributed about 28 percent in volume to overall African capture (marine and inland) fisheries production. ${ }^{9}$ Employment in the primary fisheries sector is assumed proportionate to volume, which yields a figure of 1.4 million jobs in the primary sector for West Africa. Official production statistics likely underestimate real catch. Using a catch reconstruction method (see section 7.3; Pauly and Zeller 2016) and average crew size per boat, the number of people employed in West African marine small-scale fisheries was estimated to be about 70 percent higher than official figures (Belhabib, Sumaila, and Pauly 2015). This would mean that employment in the primary sector is almost 2.4 million jobs. This figure obscures significant variation between countries. In GuineaBissau, Guinea, and Ghana, for example, primary fisheries may employ up to 20 percent of the national labour force and 25 percent of the coastal population (Belhabib, Sumalia and Pauly 2015).

Estimates for employment generated further down the value chain, such as in processing (mainly drying and smoking) and marketing and in ancillary activities such as equipment repair in West Africa, are lacking. However, research suggests that employment

generated by small-scale marine fisheries in the secondary sector is two to four times the number of direct jobs. ${ }^{10}$ This would mean that indirect employment in West African coastal fisheries could generate between 4.8 million and 9.6 million jobs. Overall, this suggests that the primary and secondary coastal marine fisheries sector in West Africa generates 7-12 million jobs.
7.6.3 Environmental sustainability

The availability of fish from coastal marine capture fisheries depends on its environmental sustainability. Globally, over 35 percent of assessed coastal marine fish stocks are overexploited, mostly in developing coastal states and island nations (FAO 2020a). For the Eastern Central Atlantic, 57 percent of assessed stocks were estimated to be biologically sustainable in 2017 . The remainder was overfished, ranking the area as the fifth worst among the 15 fishing areas identified by the FAO (2020a). An IUCN assessment of 1,288 species in marine waters from Mauritania to Angola showed that 51 species were threatened or near threatened, with 39 of these caught for both industrial and small-scale fisheries. Many of these species are staple food sources for West Africans (IUCN 2016). Overfishing is not the only concern for healthy fish stocks: pollution from activities such as oil drilling, coastal development, poor waste management, and agricultural runoff negatively affect coastal ecosystems (Béné et al. 2015)

Fisheries subsidies, or financial payments from public entities to the fishing sector, have been widely identified as a major driver for overexploiting fisheries resources (Sumaila et al. 2016). Globally, two-thirds of fisheries subsidies are provided by developed countries, and they most likely benefit large-scale fisheries (Sumaila et al. 2016). Yet some subsidies aim to promote fishery resource conservation and management, though these are much smaller than subsidies promoting exploitation.

Apart from overfishing, the fisheries sector itself also has many other negative environmental impacts such as bycatch, the destruction of the seabed with certain fishing methods, marine debris, and the use of illegal and harmful fishing practices such as poison and explosive fishing. In addition, the sector emits GHGs through the use of fuel for fishing vessels. It has been estimated that globally in 2011 fisheries generated about 4 percent of the GHGs generated by food production (Parker et al. 2018). Although data from artisanal fisheries are lacking, it is likely that artisanal fisheries contribute far less than industrial fleets. The decline in fish stocks as a result of overfishing and climate change is likely to result in more GHG emissions from both artisanal and industrial sectors, as they may adapt by expanding fishing grounds (Belhabib, Lam, and Cheung 2016).
(1) Background and understanding

(2) Regional drivers

(3) Regional organisations

(4) Agro-pastoralism-based

(5) Grains-and-legumes-based

6) Rice-and-horticulture

7 Coastal maritime fisheries

7.1 Definitions

7.2 Demography and geography

7.3 Regional consumption and production trends

7.4 Livelihoods of producer communities

7.5 Production systems

7.6 Food system outcomes

7.7 Institutional drivers

7.8 Risks and resilience

7.9 The COVID-19 pandemic

7.10 Agency and development interventions

7.11 Summing up References

(8) Tropical mixed tree and

8 food crops systems

9 Toward enhanced resilience 
Secondary environmental effects of the coastal fisheries are the use of large amounts of firewood, charcoal, and coal for the purpose of smoking fish. This results in unsustainable harvesting of firewood, high levels of $\mathrm{CO}_{2}$ emissions, and drudgery from collecting firewood (Abanda et al. 2015). In addition to environmental problems, both processing and consuming smoked fish have been associated with health risks. For example, fish processors that use firewood for smoking or drying are exposed to higher carbon monoxide levels and other pollutants. Exposure to woodsmoke is strongly associated with respiratory diseases, high blood pressure, esophageal cancer, low birth weight, and under-five mortality (Bede-Ojimadu and Orisakwe 2020). Smoked fish consumers are exposed to high levels of polycyclic aromatic hydrocarbons (PAHs), a group of chemical compounds with carcinogenic properties that accumulate in fish when it is dried or smoked (Tongo, Ogbeide, and Ezemonye 2017). ${ }^{11}$

Another occupational health risk in the fisheries sector is the chance of accidents at sea during fishing trips, especially in the artisanal sector. Data from Senegal in 2017 showed that 92 accidents occurred at sea in that year, resulting in 140 deaths, mostly of artisanal fishermen. This represented a 63 percent increase from 2016 , with material damages estimated at over $\$ 200,000.12$ Reasons for the increase could be that fishers venture farther out at sea to compensate for declining catches and there are more unpredictable weather events due to climate change.

7.6.4 Equity and inclusion

Women in West Africa make up only 5 percent of those involved in small-scale fisheries and gleaning (catch) (Harper et al. 2020). Yet women play a much larger role in postharvest activities as processors and retailers (Weeratunge, Snyder and Sze 2010). In some West African countries, such as Ghana, some women own and rent out small-scale fishing boats and provide credit to fishers. Togo has examples of women providing credit to fishermen, which comes with social prestige (Frangoudes and Gerrard 2019). Women may contribute almost half of overall (direct and indirect) employment (Kelleher et al. 2012), though there is high variation in their involvement in different countries, ranging from 9 percent in Senegal to 40 percent in Ghana to 73 percent in Nigeria (Kelleher et al. 2012). However, fish trade and processing may be the only option some women have in coastal communities, especially when they are migrants or immigrants, such as in Cote d'Ivoire (Frangoudes and Gerrard 2019).

However, as is the case elsewhere in the world, women's role in fisheries is often underrecognised, which results in women in fisheries having fewer rights than men (Frangoudes and Gerrard 2019). They also often lack political attention, and women's role in fisheries food systems is often not well reflected in fisheries policies and management Weeratunge, Snyder and Sze 2010). From the second half of the last decade, some progress has been made. For example, the Ghana fisheries sector adopted a national gender mainstreaming strategy in 2016. An important aspect of such efforts needs to be challenging of cultural norms about women's role in fisheries, policies that fully take women into consideration, and efforts to disseminate sustainable fisheries practices to reach women (Torell et al. 2019). Apart from their role in fisheries management, women's fisheries activities are also found to disproportionately contribute to household food security because women's personal income from fishing activities is more likely to be used to purchase food and support other household expenses. In addition, women are more likely to withhold sales of fish for household consumption (Torell et al. 2019).

\subsection{Institutional drivers}

Fisheries governance is considered a key enabling factor in safeguarding the sustainability of capture fisheries and their economic and social benefits (World Bank 2009). Fisheries governance in West Africa takes place at multiple levels. At the continental level, the African Union Commission (2014) developed the Pan-African Fisheries and Aquaculture Policy Framework and Reform Strategy. Joint efforts are important, as African fisheries have a high degree of interconnectedness of ecosystems and cross-border employment and trade.

There is general agreement that inadequate collabouration between countries contributes to high incidence of IUU fishing (box 7.1) (African Union Commission 2014). At the West African regional
(1) Background and understanding

(2) Regional drivers

(3) Regional organisations

(4) Agro-pastoralism-based

(5) Grains-and-legumes-based

6) Rice-and-horticulture

7 Coastal maritime fisheries

7.1 Definitions

7.2 Demography and geography

7.3 Regional consumption and production trends

7.4 Livelihoods of producer communities

7.5 Production systems

7.6 Food system outcomes

7.7 Institutional drivers

7.8 Risks and resilience

7.9 The COVID-19 pandemic

7.10 Agency and development interventions

7.11 Summing up References

Tropical mixed tree and

8 food crops systems

9 Toward enhanced resilience 
level, the Subregional Fisheries Commission and the Fisheries Committee for the West Central Gulf of Guinea have also been put in place to improve collabouration across borders. The ECOWAS Coastal and Marine Resources Management Centre is the

implementation centre for monitoring coastal and marine resources

\section{Box 7.1 IUU Fishing in West Africa}

Illegal, unreported, and unregulated (IUU) fishing poses a major threat to West African fisheries. Illegal fishing activities include, for example, underreporting fishing effort, gearrelated offenses (such as illegal mesh size and illegal gear), fishing in a prohibited zone, registered vessels fishing without a license or with forged documents, and unauthorised entry into EEZs (Doumbouya et al. 2017). According to data from the Sea Around Us database, the Gambia, Guinea, GuineaBissau, Mauritania, Senegal, and Sierra Leone are particularly vulnerable to IUU fishing due to their weak monitoring, control, and surveillance (MCS) systems (Doumbouya et al. 2017). This is caused by a lack of human resources, inadequate financial investment in MCS, and a lack of cooperation between countries in the region (Okafor-Yarwood 2019).

Offenders are mostly from non-African countries, such as China, Russia, and several European nations. However, some neighbouring West African countries engage in IUU fishing (Petrossain and Clarke, 2020). Losses from IUU fishing to West African countries were estimated at $\$ 1.8$ billion in 2010 and $\$ 2.3$ billion in 2015 , of which only $\$ 13.8$ million was recovered through fines through MCS systems. The impact of IUU fishing on small-scale fishing communities is also significant, in particular for offenses such as catching juvenile and prohibited species and fishing in prohibited zones such as artisanal areas (Doumbouya et al. 2017). Not only has IUU fishing had negative effects through economic losses, but it also has been suggested that there is a correlation between IUU fishing and the incidence of piracy (Denton and Harris 2019). management in the ECOWAS region. It uses satellite data to manage fisheries resources and early warning information on ocean conditions. It implements the 'Monitoring for Environment and Security in Africa' (MESA) programme, which aims to enhance coastal monitoring to reduce IUU fishing practices. ${ }^{13}$

National fisheries policies, legislation, surveillance systems, and fisheries comanagement have been organised with varying degrees of investment and effectiveness. Comanagement is a participatory management model that promotes the joint management of fisheries resources by direct users, governments, and other stakeholders (d'Armengol et al. 2018). In West Africa, fisheries comanagement has originated from a process of decentralising government policies and international pressure toward democratisation in formulating fisheries policy objectives. Issues that have limited the success of fisheries comanagement in Africa include stringent institutional arrangements that limit participation, a lack of transparency, limited willingness and trust among governments to relinquish control of the resources to other actors, and poor human, technical, and financial resources (Khan, Mikkola, and Brummett 2004). Fisheries comanagement is becoming more widespread in West Africa, but there is great variation across countries in the degree of participation it involves. For most countries, comanagement is limited to consultation in forming policies and laws. In Senegal it includes only concessions for managing fisheries infrastructure. In Equatorial Guinea it is limited to information delivery. Comanagement in the Democratic Republic of the Congo is nonexistent (Franz, Smith, and Westlund 2019). ${ }^{14}$

At the global level, fisheries are governed by the fishing provisions of UNCLOS, the international agreement with the legal framework within which all activities on the oceans and seas must be carried out. There is also the 1995 Code of Conduct for Responsible Fisheries, which establishes nonmandatory principles and standards for conserving, managing, and developing all fisheries. There are also Voluntary Guidelines for Securing Sustainable Small-Scale Fisheries in the Context of Food Security and Poverty Eradication (SSF guidelines; FAO 2015). The SSF guidelines are meant to be a tool to guide policy dialogue, processes, and action at all levels. Further, they are an instrument to empower small-scale fishing
(1) Background and understanding

(2) Regional drivers

(3) Regional organisations

(4) Agro-pastoralism-based

(5) Grains-and-legumes-based

6) Rice-and-horticulture

7 Coastal maritime fisheries

7.1 Definitions

7.2 Demography and geography

7.3 Regional consumption and production trends

7.4 Livelihoods of producer communities

7.5 Production systems

7.6 Food system outcomes

7.7 Institutional drivers

7.8 Risks and resilience

7.9 The COVID-19 pandemic

7.10 Agency and development interventions

7.11 Summing up References

(8) Tropical mixed tree and

8 food crops systems

9 Toward enhanced resilience

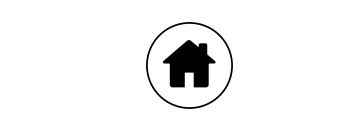


communities to participate in decision-making processes and assume responsibilities for sustainable use of fishery resources, with the ultimate purpose of securing sustainable small-scale fisheries for food security and poverty reduction (FAO 2015)

However, governance of the West African fisheries is still considered weak, with limited capacity, skills, and resources for the monitoring and surveillance of fisheries activities. The Economist Intelligence

Unit (EIU) Coastal Governance Index ranks 20 countries based on a measurement of the extent of governmental regulation and management for coastal areas. Nigeria is the only West African country included in the index (South Africa is the only other African country). In 2019 it ranked 19 out of 20, with a score of 48.7 out of 100 (EIU 2019). A strong correlation has been found between the Coastal Governance Index score and the Human Development Index (EIU 2019).

The perceived weakness of fisheries governance leads to limitations in the national and regional fisheries management efforts and results in a high level of IUU fishing (IUCN 2016). Research capacity to conduct stock assessments is also limited, which means there are limited quality data available to utilise for fisheries management efforts. Some marine protected areas (MPAs) have been established in the region, but their number is considered insufficient (IUCN 2016).

\subsection{Risks and resilience}

West African coastal marine fisheries are under pressure because of intense legal and illegal harvesting of marine resources, pollution, and degradation due to economic activities on land and at sea (Stewart et al. 2010) and because of climate change (Cinner et al. 2010). IUU fishing, and overfishing in general, severely hamper the sustainable management of marine ecosystems and therefore pose a threat to their sustainability in the future (Agnew et al. 2009). Some estimate that in West African waters as much as 40 percent of fish is caught illegally, the highest level globally (Agnew et al. 2009). To promote resilience, a network of MPAs has been designated in the region since the early twentieth century, managed by national institutions and in some cases by communities to conserve natural resources and habitats and promote local development. However, these MPAs mostly have not achieved the conservation objectives because of a lack of human resources and institutional capacities and communication within the network (Failler et al. 2020).

Coastal and marine pollution affect the structure and function of phytoplankton, zooplankton, and benthic and thereby have important effects on ecosystems and fisheries (Islam and Tanaka 2004). The primary category of marine pollutants is fertilisers and agrochemicals from agriculture, which are estimated to cause about 50 percent of the total pollution of surface water (Islam and Tanaka 2004). Other major pollutants are domestic, municipal, and industrial waste and sewage sludge; oil pollution from spills; and heavy metals and synthetic organic compounds from industry, plastics, and sediment. Although there are few data and scant literature on this topic in the West African coastal areas, researchers have concluded that globally most fisheries have been damaged to varying degrees and that the situation is more critical in fisheries that are already overexploited or otherwise vulnerable, such as those off the West African coast (Islam and Tanaka 2004).

These issues coupled with the expected increase in demand for fish due to population growth, urbanisation, and rising incomes in West Africa (see section 7.3) will put significant pressure on the marine fisheries food system. Aquaculture already supplies more than half of fish used for direct human consumption, and some suggest it could meet global demand (FAO 2020a). However, fish farming in many West African countries has been slow to develop. West Africa had an officially reported production of about 385,000 tonnes in 2018 , equivalent to 0.3 percent of global aquaculture production and less than 10 percent of overall official West African fish production (capture and aquaculture, or about 6 percent based on the figures from the catch reconstruction method) (see section 7.3). ${ }^{15} \mathrm{~A}$ recent study on the potential of development of shellfish and seaweed marine aquaculture concluded that given environmental, socioeconomic, and human health factors, there is only modest opportunity for it in the West African region

(Theuerkauf et al. 2019). Also, the fish species commonly produced
(1) Background and understanding

(2) Regional drivers

(3) Regional organisations

(4) Agro-pastoralism-based

(5) Grains-and-legumes-based

6 Rice-and-horticulture

7 Coastal maritime fisheries

7.1 Definitions

7.2 Demography and geography

7.3 Regional consumption and production trends

7.4 Livelihoods of producer communities

7.5 Production systems

7.6 Food system outcomes

7.7 Institutional drivers

7.8 Risks and resilience

7.9 The COVID-19 pandemic

7.10 Agency and development interventions

7.11 Summing up References

Tropical mixed tree and

8 food crops systems

9 Toward enhanced resilience

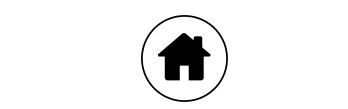


in aquaculture have less nutritional value than fatty marine fish from capture fisheries (Belton and Thilsted 2014).

\subsubsection{Climate resilience}

Climate change poses a significant threat to West African fisheries and the livelihoods that depend on them for food and income by affecting distribution, abundance, and productivity of fish species. Projections from 2013 based on a bioclimatic model of future distribution and maximum fisheries catch potential of fish and invertebrates in West African waters indicate a 21 percent decline in annual landed value, a 50 percent decline in fisheries-related jobs, and a total annual loss of $\$ 311$ million in the West African economy by 2050 (Lam et al. 2013). This represented 10 percent of the 2013 economic value, but because it was based on official fisheries statistics, it is most likely a significant underestimation of the economic loss. In addition, climate change is expected to increase the risk of floods in low-lying coastal areas (Adelekan and Fregene 2015).

Free et al. (2020) conclude that realistic climate-adaptive fisheries management could mitigate many of the potential negative impacts of climate change on human society. Reforms that are believed to achieve this include the following. First, the implementation of best practices in fisheries management will increase the resilience of

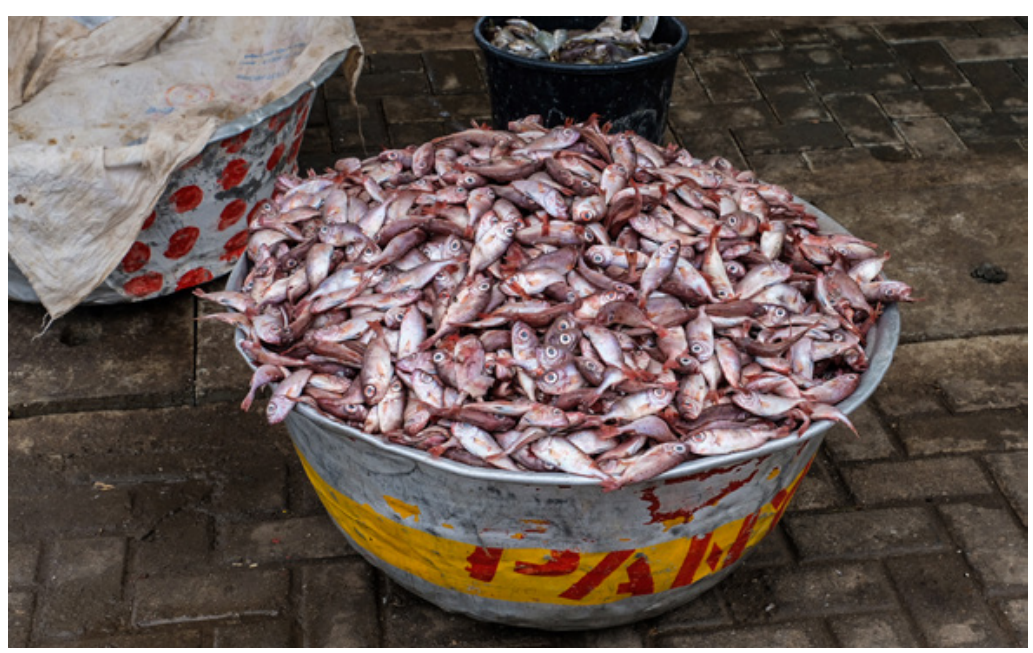

fisheries against climate change. Second, the use of different types of modelling, forecasting, and scenario building tools and near real-time data, and the development of rules that are robust to changing environmental conditions, can facilitate the

implementation of dynamic, flexible, and forward-looking fisheries management. Third, better sharing of data and collabourative management will foster international cooperation that is needed to accommodate fish stocks that move between jurisdictions as a result of climate change. Finally, promoting policies that facilitate income diversification, asset enhancement, improved multilevel fisheries governance, and increased mobility, will build socioeconomic resilience in fishing communities (Free et al. 2020).

7.8.2 Economic resilience

Based on an analysis of the Volta and Mekong basins, small-scale fishers may be more exposed and sensitive to shocks and risks than other socioeconomic groups due to their dependency on unpredictable fisheries resources and other socioinstitutional factors such as their level of debt and dependence on capital assets. Further, they are seen to have low adaptive capacity (Béné and Friend 2011). Small-scale fishing enterprises also often lack safety nets due to lack of access to traditional financial services, such as savings, credit, and insurance (Pomeroy et al. 2020). This gap is filled by informal lenders, in particular other actors in the fish value chain, whose services are often characterised by high costs, nontransparent finance conditions, and lack of records that allow fishing enterprises to build a financial profile necessary for access to formal finance (Pomeroy et al. 2020).

While West Africa has been lagging behind East Africa in terms of financial inclusion, the region is starting to catch up. For example, Ghana is becoming a frontrunner in terms of users of mobile money (in 2017, 58 percent of adults had access to a bank account) (Demirgüç-Kunt et al. 2018). Yet according to World Bank's Global Findex database, in the majority of West African countries the share of adults that had a bank account in 2017 was still well below the average in Sub-Saharan Africa. ${ }^{16}$ There are no specific data for financial inclusion of small-scale fishers in West Africa; however, as indicated, it is likely that access for this group is even lower (Pomeroy et al. 2020).
(1) Background and understanding

(2) Regional drivers

(3) Regional organisations

(4) Agro-pastoralism-based

(5) Grains-and-legumes-based

6) Rice-and-horticulture

7 Coastal maritime fisheries

7.1 Definitions

7.2 Demography and geography

7.3 Regional consumption and production trends

7.4 Livelihoods of producer communities

7.5 Production systems

7.6 Food system outcomes

7.7 Institutional drivers

7.8 Risks and resilience

7.9 The COVID-19 pandemic

7.10 Agency and development interventions

7.11 Summing up References

(8) Tropical mixed tree and

8 food crops systems

9 Toward enhanced resilience

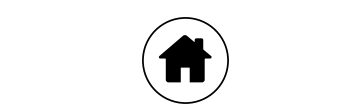


7.8.3 Sociopolitical resilience

As described, resilience in small-scale fisheries is defined by socioinstitutional factors such as economic exclusion, social marginalisation, class exploitation, and political disempowerment (Béné 2003). A major factor for many West African fisheries is the lack of organisation and political representation for small-scale fishers and other actors in this food system. For example, an analysis in Ghana found that although at the national level there were many bodies with influence on fisheries livelihoods, most of those had a broader rural community remit. By contrast, at the district level fisheries were seen as a "problematic" subsector peripheral to their main priorities, while at the micro level, few community-based organisations were found within the fishery (Lewins 2004). This lack of representation means that fisheries' specific concerns may not be well-represented when policies are being formulated.

\subsubsection{Food access resilience}

Coastal marine fishing communities mainly depend on fisheries for accessing food through fishing and income from fishing including processing activities. These communities have always had to deal with variabilities on seasonal and interannual scales, which have affected fish stocks and opportunities to fish. They now face new challenges because of climate change, with effects such as increased frequency of floods, coastal erosion, and sea level rise. Livelihoods coping strategies indicate how fishing communities deal with temporarily or sustained limited access to food (Perry and Sumaila 2007).

Besides the diversification of income sources, livelihood strategies of fishing households include exploiting fish and other coastal resources, such as mangrove and salt, more intensively at local scales (USAID 2017). As for fishing, the coping strategies may include temporal regional migration. This not only includes seasonal or permanent migration of communities and households to other fishing areas but also migration of fishermen to regions where they offer their skills for contract fishing to processing factories, such as in Mauritania. Their remittances, sent through informal channels, complement incomes from the households in their communities of origin for necessities such as food, shelter, and health care (Zickgraf et al. 2016).
7.9 Food system impacts of and responses to the COVID-19 pandemic

Globally, fisheries activities declined during the COVID-19 crisis both because of restrictions on people's movement, curfews, and a ban on fisheries in some countries, as well as because of closure of markets (FAO 2020b). ${ }^{17}$ Recommendations to prevent the spread of COVID-19, such as face masks and physical distancing, have been difficult to apply on fishing vessels and in fish markets. The negative impact was immediately felt by households dependent on artisanal fisheries, which are less resilient and have few financial buffers to bridge a period with reduced or no income. Industrial fisheries were similarly affected and reduced their activities. At the same time, there is some evidence of an increase in IUU fishing, while in other locations declines in fishing pressure, particularly by industrial fleets, may allow fish stocks to recover, which could have positive effects for the artisanal sector (Bennett et al. 2020).

Movement restrictions enforced during the COVID-19 crisis led to an interruption or strong disruption of supply chains and closure of markets. This specifically impacted the fish smokers and transporters, most of whom are women. In addition, fishers and fish processors and vendors, like all workers in the informal sector, have been exposed to a greater risk of infection, as they are in close contact with others at all stages of the value chain. Processing enterprises in coastal areas reduced or even seized production as exports were hampered. Supplies to the food service sector (restaurants and hotels) were also severely affected. Local alleviation of mobility restrictions have meant that activities in local supply chain are picking back up, but the export market may be affected for a longer period.

At the time of writing, there was still limited concrete evidence of the effect of COVID-19 on the consumption and nutrition of fishing and fish trading populations. In coastal areas, early information indicates that consumers from coastal cities such as Dakar experienced improved access to fish that were formerly exported while Sardinella prices rapidly increased. (Sardinella congregate far from the shore in open water and were inaccessible to artisanal fisherman due to COVID-19 prevention measures.) In Mauritania,
(1) Background and understanding

(2) Regional drivers

(3) Regional organisations

(4) Agro-pastoralism-based

(5) Grains-and-legumes-based

6) Rice-and-horticulture

7 Coastal maritime fisheries

7.1 Definitions

7.2 Demography and geography

7.3 Regional consumption and production trends

7.4 Livelihoods of producer communities

7.5 Production systems

7.6 Food system outcomes

7.7 Institutional drivers

7.8 Risks and resilience

7.9 The COVID-19 pandemic

7.10 Agency and development interventions

7.11 Summing up References

(8) Tropical mixed tree and

8 food crops systems

9 Toward enhanced resilience 
overproduction without marketing possibility led to the free distribution of fish to the population. Inland consumers experienced extreme difficulty in accessing fish products due to the supply chain disruptions. This directly threatened the nutritional status of vulnerable families. Mobility restrictions are slowly being released, alleviating the phenomena. Global export restrictions, if they last, might affect international prices and retail prices, which needs to be monitored in order to be confirmed by data.

Bennett et al. (2020) suggest a number of potential responses for the fisheries sector, some of which suggestions are summarised here. Governments can put in place targeted economic relief packages, aid, and loan forgiveness for small-scale fishers and fish workers, prioritising reopening of fisheries where possible, and putting measures in place such as purchasing seafood for institutional markets (for example, hospitals). NGOs can mobilise resources and funding to support coastal community partners, assist in monitoring COVID-19 impacts to small-scale fisheries, support responsible market development, and improve coordination of initiatives. Donors are urged to allow flexibility with already allocated funds and to redirect future funding toward building long-term resilience to future shocks. The private sector, in particular seafood businesses, can support small-scale fishers and coastal communities, ensure the health and safety of their workers, and confirm sourcing is done from small-scale fisheries suppliers.

\subsection{Agency and development interventions}

The most prominent changes in the fisheries development sector have been in the general trend toward conceptualising "responsible fisheries" through a set of nonbinding instruments that provide a framework of core principles and measures (see section 7.5; Ahmad 2020) and the push for a human rights-based approach (Willmann et al. 2017). The popular concept of socioecological resilience is a form of systems thinking that acknowledges the importance of understanding the interactions between social and ecological systems and addresses the ability of these systems to absorb or adapt to shocks (for a review, see Kawarazuka et al. 2017). It recognises that human activities and ecological systems interact, which makes it more important to support local management institutions and local resource users to adapt to changes (Kawarazuka et al. 2017). This is also reflected in investments in fisheries development projects. Institutions such as the World Bank have shifted from projects that have a narrow focus on infrastructure development for the fisheries sector alone toward more holistic and "softer" approaches such as stakeholder engagement (Blandon 2018). For fishing communities engaged in small-scale fisheries, this also means a broader focus on diversification and resilience.

These trends in the context of coastal marine fisheries have also become known as the "blue economy paradigm." This paradigm describes creating a sustainable ocean economy, which is "when economic activity is in balance with the long-term capacity of ocean ecosystems to support this activity and remain resilient and healthy" (EIU 2015, 7). On the one hand, the paradigm is about protecting and restoring the existing ocean resources, including coastal ecosystems such as coral reefs and mangroves. On the other hand, this refers to benefitting from opportunities for enhanced or new sustainable economic activity derived from the ocean, such as offshore renewable energy production, monetising the value of coastal carbon stocks into carbon finance markets, creating more sustainable aquaculture, and fostering ecotourism (EIU 2015). It has been suggested that the West African region contains 7.97 million hectares of mangroves, seagrass, and salt marshes, together storing over 1.8 billion tonnes of carbon, mainly located in seven West African countries. Therefore, securing private sector payments for blue carbon could be viable for some West African countries (Bryan et al. 2020).

\subsection{Summing up: toward leverage points for future interventions}

It is clear that a large number of people in West Africa depend on coastal marine fisheries for their livelihoods and food and nutrition security. This dependence - linked with persistent weaknesses in fisheries governance for monitoring and surveillance and facilitating comanagement, as well as unconducive fisheries agreements and
(1) Background and understanding

(2) Regional drivers

(3) Regional organisations

(4) Agro-pastoralism-based

(5) Grains-and-legumes-based

6) Rice-and-horticulture

7 Coastal maritime fisheries

7.1 Definitions

7.2 Demography and geography

7.3 Regional consumption and production trends

7.4 Livelihoods of producer communities

7.5 Production systems

7.6 Food system outcomes

7.7 Institutional drivers

7.8 Risks and resilience

7.9 The COVID-19 pandemic

7.10 Agency and development interventions

\subsection{Summing up}

References

(8) Tropical mixed tree and

8 food crops systems

9) Toward enhanced resilience 
fisheries subsidies for industrial fleets - results in overexploitation of resources and degradation of marine ecosystems. It is further exacerbated by external drivers such as a fast-growing West African population, urbanisation, increasing incomes, and climate change and terrestrial and marine activities that cause pollution. A specific external driver is illegal intrusion of extraregional fishing fleets from foreign countries and unfavourable fishing agreements (such as with the EU), which constrain local value creation.

There are a number of key entry points to enhance the coastal fisheries resilience:

- The interactions of terrestrial and marine activity and the diversity of coastal livelihoods strongly suggest that an integrated coastal food systems perspective that simultaneously addresses the management and sustainability of fisheries and farms is required for sound food security policies (Fisher et al. 2017). This means integrating fisheries, farming and livestock policies, and activities to ensure that fisheries are considered part of a wider livelihood package and that effects of terrestrial activities on marine resources are considered.

- Fisheries need to be further integrated into national food security and nutrition policies, as these policies are often more focused on terrestrial-based foods.

- It is important to ensure that women are fully recognised for their role in the fisheries food system and that gender dimensions are integrated into policies.

- While strengthening institutions for fisheries management has been a focus for many years, further support at the local, national, and regional levels is needed to make fisheries management more effective to protect and rehabilitate the fisheries ecosystem and resources.

- This should include the strengthening of capacity for improved collection and reporting of data on production, consumption, and trade.

- Further downstream in the chain, improved postharvest handling and processing could support reduction of waste and losses, maintaining food safety and reducing health risks from smoked products.

- The potential of inland fisheries and aquaculture needs to be reviewed, taking into account lessons learned from past interventions in these domains.

- Greater adaptive capacity is required at different scales to manage climate change risks and improve resilience. This includes developing community-based and institutional capacities, such as improved weather information.

- Economic resilience can be improved by addressing barriers to financial inclusion such as addressing financial literacy, de-risking financial institutions, conducting financial data collection, and providing of a range of financial services besides credit (Pomeroy et al. 2020).

- Innovative "blue economy" options, such as blue carbon and offshore renewable energy production, could be further explored.

Notes

1 Based on data from Neumann et al. (2015) and Population Estimates and Projections database, World Bank, Washington, DC (accessed November $6,2020)$.

2 Definitions of coastal zones on land differ depending on the analysis. One commonly used definition is low-elevation coastal zones (LECZs), defined as "the contiguous and hydrologically connected zone of land along the coast and below $10 \mathrm{~m}$ of elevation" (Neumann et al. 2015, p.1).

3 High variation exists across countries, with urbanisation ranging from 16 percent in Niger to 46 percent in Senegal. The coastal countries appear to have higher urbanisation rates than the landlocked countries. Seven coastal countries have urbanisation rates close to or above 40 percent, while those for some of the landlocked Sahel countries are below 25 percent (OECD 2011).

4 FISHSTAT, Food and Agriculture Organisation, Rome (accessed March 6, 2020).

5 ITC Trade Map database, International Trade Centre, Geneva (accessed June 15, 2020).

6 Data from 2018, FAOSTAT, Food and Agriculture Organisation, Rome (accessed March 6, 2020).

7 Key trade routes include Ghana to Togo and Benin for smoked sardinella/ anchovy and cured freshwater fish; Côte d'Ivoire to Burkina Faso for smoked sardinella; Sierra Leone to Guinea and Liberia for smoked sardinella and bonga; the Gambia to Guinea and Senegal for smoked bonga and skates; the Gambia to Ghana for dried shark products; Mali to Burkina Faso, Côte d'Ivoire, Niger, and Nigeria for cured freshwater fish; Senegal to Cameroon, Congo, Côte d'Ivoire, Gabon, Ghana, Guinea, Nigeria, Togo, Benin, Zaire, and Mali for smoked/dried salted marine fish; and Benin to Nigeria for smoked catfish and bonga.
(1) Background and understanding

(2) Regional drivers

(3) Regional organisations

(4) Agro-pastoralism-based

(5) Grains-and-legumes-based

6) Rice-and-horticulture

7 Coastal maritime fisheries

7.1 Definitions

7.2 Demography and geography

7.3 Regional consumption and production trends

7.4 Livelihoods of producer communities

7.5 Production systems

7.6 Food system outcomes

7.7 Institutional drivers

7.8 Risks and resilience

7.9 The COVID-19 pandemic

7.10 Agency and development interventions

\subsection{Summing up}

References

(8) Tropical mixed tree and

8 food crops systems

9 Toward enhanced resilience

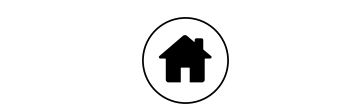


8 See Ayilu et al. (2016), ICSF (2002), and product trade maps from FEWS NET. For Sierra Leone.

9 FISHSTAT, Food and Agriculture Organisation, Rome (accessed March 6, 2020).

10 For different estimates, see Kelleher et al. (2012) and Teh and Sumaila (2013)

11 An improved kiln, which uses the so-called FAO-Thiaroye technique

(FTT), has been developed by FAO and was shown to reduce PAHs in smoked fish to safe levels (see: Bomfeh, K., L. Jacxsens, W. K. Amoa-Awua, I.

Tandoh, E. O. Afoakwa, E. G. Gamarro. and B. De Meulenaer. (202019).

"Reducing Polycyclic Aromatic Hydrocarbon Contamination in Smoked Fish

in The Global South: A Case Study of an Improved Kiln in Ghana." Journal of the Science of Food and Agriculture, 99 (12):, 5417--5423.

12 Although data on accidents and fatalities are not readily available, data came from the Directorate for the Monitoring and Protection of Senegalese Fisheries.

\section{See www.ecowas.int}

14 Based on a report from a regional consultation on West African fisheries held in 2018.

15 FISHSTAT, Food and Agriculture Organisation, Rome (accessed March 6, 2020).

16 Global Findex database, World Bank, Washington, DC (accessed March 6,2020 ).

17 Diverse sources, from the FAO to international media, have been used. An interview with Dr. Papa Gora, executive director of the Reseau sur les Politique de Pêche en Afrique de l'Ouest (REPAO), completed the data collection.

\section{References}

Abanda, F. H., M. B. Manjia, E. Cole, and B. Mempouo. 2015. "The Potential of Efficient Improved Mud-Brick Cookstove in Cameroon: An Exploratory Study." Environmental Management and Sustainable Development 4 (1): 106

ADB (African Development Bank). 2018. West Africa Economic Outlook 2018. Abidjan, Côte d'Ivoire: ADB.

Adelekan, I., and T. Fregene. 2015. "Vulnerability of Artisanal Fishing Communities to Flood Risks in Coastal Southwest Nigeria." Climate and Development 7 (4): 322-38.
Adeyeye, S. A. O., and O. B. Oyewole. 2016. "An Overview of Traditional Fish Smoking in Africa." Journal of Culinary Science \& Technology 14 (3): 198-215. https://doi.org/10.1080/15428052.2015.1102785.

African Union Commission. 2014. Policy Framework and Reform Strategy for Fisheries and Aquaculture in Africa: Creating a Conducive and Enabling Environment for the Fish Sector to Create Equitable, Social and Economic Development in Africa. Lusaka, Zambia: African Union Commission / NEPAD Agency.

Agnew, D. J., J. Pearce, G. Pramod, T. Peatman, R. Watson, J. R. Beddington, and T. J. Pitcher (2009). "Estimating the Worldwide Extent of Illegal Fishing." PLOS ONE 4 (2): e4570.

Ahmad, M. Z. 2020. "The Evolution of International Fisheries Law and Policy Framework: A Paradigm Shift towards Responsible Fisheries." Journal of International Studies 7: 51-81.

Akande, G. R., and Y. Diei-Ouadi. 2010. Post-harvest Losses in Small-Scale Fisheries: Case Studies in Five Sub-Saharan African Countries. FAO Fisheries and Aquaculture Technical Paper 550. Rome: FAO.

Ayilu, R. K., T. O. Antwi-Asare, P. Anoh, A. Tall, N. Aboya, S. Chimatiro, and S. Dedi. 2016. Informal Artisanal Fish Trade in West Africa: Improving CrossBorder Trade. Penang, Malaysia: WorldFish.

Bede-Ojimadu, O., and O. E. Orisakwe. 2020. "Exposure to Wood Smoke and Associated Health Effects in Sub-Saharan Africa: A Systematic Review." Annals of Global Health 86 (1): 32.

Belhabib, D., K. Greer, and D. Pauly. 2018. "Trends in Industrial and Artisanal Catch per Effort in West African Fisheries." Conservation Letters 11 (1): e12360.

Belhabib, D., V. W. Lam, and W. W. Cheung. 2016. "Overview of West African Fisheries under Climate Change: Impacts, Vulnerabilities and Adaptive Responses of the Artisanal and Industrial Sectors." Marine Policy 71, 15-28.

Belhabib, D., U. R. Sumaila, V. W. Lam, D. Zeller, P. Le Billon, E. A. Kane, and D. Pauly. 2015. "Euros vs. Yuan: Comparing European and Chinese Fishing Access in West Africa." PLOS One 10: e0118351.

Belhabib, D., U. R. Sumaila, and D. Pauly. 2015. "Feeding the Poor: Contribution of West African Fisheries to Employment and Food Security." Ocean \& Coastal Management 111: 72-81.

Belton, B., and S. H. Thilsted. 2014. "Fisheries in Transition: Food and Nutrition Security Implications for the Global South." Global Food Security 3 (1): 59-66.

Béné, C. 2003. "When Fishery Rhymes with Poverty: A First Step beyond the Old Paradigm on Poverty in Small-Scale Fisheries." World Development 31 (6): $949-75$
(1) Background and understanding

(2) Regional drivers

(3) Regional organisations

(4) Agro-pastoralism-based

(5) Grains-and-legumes-based

6) Rice-and-horticulture

7 Coastal maritime fisheries

7.1 Definitions

7.2 Demography and geography

7.3 Regional consumption and production trends

7.4 Livelihoods of producer communities

7.5 Production systems

7.6 Food system outcomes

7.7 Institutional drivers

7.8 Risks and resilience

7.9 The COVID-19 pandemic

7.10 Agency and development interventions

\subsection{Summing up}

\section{References}

Tropical mixed tree and

8 food crops systems

9 Toward enhanced resilience 
Béné, C., R. Arthur, H. Norbury, E. H. Allison, M. Beveridge, S. Bush, L. Campling, W. Leschen, D. Little, D. Squires, S. H. Thilsted, M. Troell, and M. Williams. 2016. "Contribution of Fisheries and Aquaculture to Food Security and Poverty Reduction: Assessing the Current Evidence." World Development 79: 177-96.

Béné, C., M. Barange, R. Subasinghe, P. Pinstrup-Andersen, G. Merino, G. Hemre, and M. Williams. 2015. "Feeding 9 Billion by 2050 - Putting Fish Back on the Menu." Food Security 7: 261-74.

Béné, C., and R. M. Friend 2011. "Poverty in Small-Scale Fisheries: Old Issue, New Analysis." Progress in Development Studies 11 (2): 119-44.

Bennett, N. J., E. M. Finkbeiner, N. C. Ban, D. Belhabib, S. D. Jupiter, J. N. Kittinger, S. Mangubhai, J. Scholtens, D. Gill, and P. Christie. 2020. "The COVID-19 Pandemic, Small-Scale Fisheries and Coastal Fishing Communities" Coastal Management 48(4), 336-47.

Blandon, A. 2018. "A Sea Change: Unpacking the Different Conceptualisations of Fisheries Development in Easter Africa." Master's thesis, Stockholm Resilience Centre.

Boyd, C. E., C. Tucker, A. McNevin, K. Bostock, and J. Clay. 2007. "Indicators of Resource Use Efficiency and Environmental Performance in Fish and Crustacean Aquaculture." Reviews in Fisheries Science 15: 327-60.

Bryan, T., J. Virdin, T. Vegh, C. Y. Kot, J. Cleary, and P. N. Halpin. 2020. "Blue Carbon Conservation in West Africa: A First Assessment of Feasibility." Journal of Coastal Conservation 24 (1): 8.

Cai, J. N., H. Huang, and P. S. Leung. 2019. Understanding and Measuring the Contribution of Aquaculture and Fisheries to Gross Domestic Product (GDP). FAO Fisheries and Aquaculture Technical Paper 606. Rome: FAO.

Chauvin, N. D., F. Mulangu, and G. Porto. 2012. "Food Production and Consumption Trends in SubSaharan Africa: Prospects for the Transformation of the Agricultural Sector." Working Paper 2012-011, Regional Bureau for Africa, United Nations Development Programme, New York.

Cinner, J. E., and Ö Bodin. 2010. "Livelihood Diversification in Tropical Coastal Communities: A Network-Based Approach to Analyzing 'Livelihood Landscapes."' PLOS ONE 5 (8): e11999.

Cinner, J. E., T. R. McClanahan, N. A. Graham, T. M. Daw, J. Maina, S. M. Stead, A. Wamukota, K. Brown and Ö Bodin. 2012. "Vulnerability of Coastal Communities to Key Impacts of Climate Change on Coral Reef Fisheries." Global Environmental Change 22 (1): 12-20.

Connor, W. E. 2000. "Importance of n-3 Fatty Acids in Health and Disease." American Journal of Clinical Nutrition 71 (1): 171S-75S.

d'Armengol, L., M. P. Castillo, I. Ruiz-Mallén, and E. Corbera. 2018. "A Systematic Review of Co-managed Small-Scale Fisheries: Social Diversity and Adaptive Management Improve Outcomes." Global Environmental Change 52: 212-25.

de Graaf, G., and L. Garabaldi. 2014. The Value of African Fisheries. FAO Fisheries Circular 1093. Rome: FAO.

Demirgüç-Kunt, A., L. Klapper, D. Singer, S. Ansar, and J. Hess. 2018. "The Global Findex Database 2017: Measuring Financial Inclusion and the Fintech Revolution". Washington, DC: World Bank.

Denton, G. L., and J. R. Harris. 2019. "The Impact of Illegal Fishing on Maritime Piracy: Evidence from West Africa." Studies in Conflict \& Terrorism, $1-20$.

Diei-Ouadi, Y., B. Komivi Sodoke, Y. Ouedraogo, F. Adjoa Oduro, K. Bokobosso, and I. Rosenthal. 2015. Strengthening the Performance of Postharvest Systems and Regional Trade in Small-Scale Fisheries: Case Study of Post-harvest Loss Reduction in the Volta Basin Riparian Countries. Fisheries and Aquaculture Circular 1105. Rome: FAO.

Doumbouya, A., O. T. Camara, J. Mamie, J. F. Intchama, A. Jarra, S. Ceesay, A. Guèye, D. Ndiaye, E. Beibou, A. Padilla, and D. Belhabib. 2017. "Assessing the Effectiveness of Monitoring Control and Surveillance of Illegal Fishing: The Case of West Africa." Frontiers in Marine Science 4: 50.

EIU (Economist Intelligence Unit). 2015. "The Blue Economy: Growth, Opportunity and a Sustainable Ocean Economy." Briefing Paper Prepared for the World Ocean Summit 2015, EIU, London.

EIU (Economist Intelligence Unit). 2019. Coastal Governance Index 2019. London: EIU.

Failler, P., G. Touron-Gardic, B. Drakeford, O. Sadio, and M. S. Traoré. 2020 "Perception of Threats and Related Management Measures: The Case of 32 Marine Protected Areas in West Africa." Marine Policy 117: 103936.

FAO. 2015. Voluntary Guidelines for Securing Sustainable Small-Scale Fisheries in the Context of Food Security and Poverty Eradication. Rome: FAO.

FAO. 2018. The State of World Fisheries and Aquaculture 2018: Meeting the Sustainable Development Goals. Rome: FAO.

FAO. 2020a. The State of World Fisheries and Aquaculture 2020 Sustainability in Action. Rome: FAO.

FAO. 2020b. Summary of the Impacts of the COVID-19 Pandemic on the Fisheries and Aquaculture Sector: Addendum to the State of World Fisheries and Aquaculture 2020. Rome: FAO.

Fisher, B., R. Naidoo, J. Guernier, K. Johnson, D. Mullins, D. Robinson, and E. H. Allison. 2017. "Integrating Fisheries and Agricultural Programs for Food Security." Agriculture \& Food Security 6 (1): 1.
(1) Background and understanding

(2) Regional drivers

(3) Regional organisations

(4) Agro-pastoralism-based

(5) Grains-and-legumes-based

(6) Rice-and-horticulture

7 Coastal maritime fisheries

7.1 Definitions

7.2 Demography and geography

7.3 Regional consumption and production trends

7.4 Livelihoods of producer communities

7.5 Production systems

7.6 Food system outcomes

7.7 Institutional drivers

7.8 Risks and resilience

7.9 The COVID-19 pandemic

7.10 Agency and development interventions

\subsection{Summing up}

\section{References}

(8) Tropical mixed tree and

8 food crops systems

9 Toward enhanced resilience

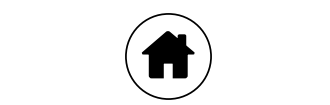


Frangoudes, K., and S. Gerrard. 2019. "Gender Perspective in Fisheries: Examples from the South and the North." In Transdisciplinarity for SmallScale Fisheries Governance, 119-40. Cham, Switzerland: Springer.

Franz, N., H. Smith, and L. Westlund, eds. 2019. Towards the Implementation of the SSF Guidelines in West and Central Africa. FAO Fisheries and Aquaculture Proceedings 62. Rome: FAO.

Free, C. M., T. Mangin, J. G. Molinos, E. Ojea, M. Burden, C. Costello, and S. D. Gaines. 2020. "Realistic Fisheries Management Reforms Could Mitigate the Impacts of Climate Change in Most Countries." PLOS ONE 15 (3): e0224347.

Gomna, A., and K. Rana, K. 2007. "Inter-household and Intra-household Patterns of Fish and Meat Consumption in Fishing Communities in Two States in Nigeria." British Journal of Nutrition 97 (1): 145-52.

Gordon, A., C. Finegold, C. C. Crissman, and A. Pulis. 2013. Fish Production, Consumption and Trade in Sub-Saharan Africa: A Review Analysis. Penang, Malaysia: WorldFish.

Harper, S., M. Adshade, V. W. Lam, D. Pauly, and U. R. Sumaila. 2020 "Valuing Invisible Catches: Estimating the Global Contribution by Women to Small-Scale Marine Capture Fisheries Production." PLOS ONE 15 (3): e0228912.

Hasselberg, A. E., I. Aakre, J. Scholtens, R. Overå, J. Kolding, M. S. Bank, A. Atter, and M. Kjellevold. 2020. "Fish for Food and Nutrition Security in Ghana: Challenges and Opportunities." Global Food Security 26: 100380.

Hicks, C. C., P. J. Cohen, N. A. Graham, K. L. Nash, E. H. Allison, C. D'Lima D. J. Mills, M. Roscher, S. H. Thilsted, A. L. Thorne-Lyman, and M. A. MacNeil. 2019. "Harnessing Global Fisheries to Tackle Micronutrient Deficiencies." Nature 574 (7776): 95-98.

Isaacs, M. 2016. "The Humble Sardine (Small Pelagics): Fish as Food or Fodder." Agriculture \& Food Security 5 (1): 27.

Islam, Md. S., and M. Tanaka. 2004. "Impacts of pollution on coastal and marine ecosystems including coastal and marine fisheries and approach for management: a review and synthesis." Marine pollution bulletin 48(7-8): 624-49.

IUCN (International Union for Conservation of Nature). 2016. Red List of Marine Bony Fishes of the Eastern Central Atlantic. Gland, Switzerland: IUCN.

Kawarazuka, N., and C. Béné. 2010. "Linking Small-Scale Fisheries and Aquaculture to Household Nutritional Security: An Overview." Food Security 2: 343-57.

Kawarazuka, N., and C. Béné. 2011. "The Potential Role of Small Fish in Improving Micronutrient Deficiencies in Developing Countries: Building the Evidence." Public Health Nutrition 14 (20): 1-12.
Kawarazuka, N., C. Locke, C.M. McDougall, P. Kantor, and M. Morgan. 2017. "Bringing analysis of gender and social-ecological resilience together in mall-scale fisheries research: Challenges and opportunities". Ambio 46(2): 201-13.

Kébé, M., and F. Tallec. 2006. Contribution of Fisheries Sector to National Economies (West and Central Africa. Sustainable Fisheries Livelihoods Programme (SFLP) in West Africa. Cotonou, Benin: Impression AGCom.

Kelleher, K., L. Westlund, E. Hoshino, D. Mills, R. Willmann, G. de Graaf, and R. Brummett. 2012. Hidden Harvest: The Global Contribution of Capture Fisheries. Washington, DC: World Bank.

Khan, A. S., H. Mikkola, and R. Brummett. 2004. "Feasibility of Fisheries Comanagement in Africa." NAGA Worldfish Centre Quarterly 27 (1 \& 2): 60-64.

Klein, C. J., S. D. Jupiter, E. R. Selig, M. E. Watts, B. S. Halpern, M. Kamal, C. Roelfsema, and H. P. Possingham 2012. "Forest Conservation Delivers Highly Variable Coral Reef Conservation Outcomes." Ecological Applications 22 (4): 1246-56.

Kruijssen, F., I. Tedesco, A. Ward, L. Pincus, D. Love, and A. L. ThorneLyman. 2020. "Losses and Waste in Fish Value Chains: A Review of the Evidence from Low and Middle-Income Countries." Global Food Security 26: 100434.

Lam, V. W. W. W. Cheung, W. Swartz, and U. R. Sumaila. 2012. "Climate Change Impacts on Fisheries in West Africa: Implications for Economic, Food and Nutritional Security." African Journal of Marine Science 34 (1): 103-17.

Lewins, R. 2004. "The Sustainable Livelihoods Approach: The Importance of Policies, Institutions and Process." In Poverty and Small-scale Fisheries in West Africa, edited by A. E. Neiland and C. Béné, 37-45. Dordrecht, the Netherlands: Springer.

Micha, R., S. Khatibzadeh, P. Shi, S. Fahimi, S. Lim, K. G. Andrews, R. E. Engell, J. Powles, M. Ezzati and D. Mozaffarian. 2014. "Global, Regional, and National Consumption Levels of Dietary Fats and Oils in 1990 and 2010: A Systematic Analysis Including 266 Country-Specific Nutrition Surveys." British Medical Journal 348: g2272.

Mulder, K. A., D. J. King, and S. M. Innis. 2014. "Omega-3 Fatty Acid Deficiency in Infants before Birth Identified Using a Randomized Trial of Maternal DHA Supplementation in Pregnancy." PLOS ONE 9 (1): e83764.

Neumann, B., A. T. Vafeidis, J. Zimmermann, and R. J. Nicholls. 2015. "Future Coastal Population Growth and Exposure to Sea-Level Rise and Coastal Flooding: A Global Assessment." PLOS ONE 10 (3): e0118571.

Njock, J. C., and L. Westlund. 2010. "Migration, resource management and global change: experiences from fishing communities in West and Central Africa". Marine Policy 34(4: 752-60.
(1) Background and understanding

(2) Regional drivers

(3) Regional organisations

(4) Agro-pastoralism-based

(5) Grains-and-legumes-based

(6) Rice-and-horticulture

7 Coastal maritime fisheries

7.1 Definitions

7.2 Demography and geography

7.3 Regional consumption and production trends

7.4 Livelihoods of producer communities

7.5 Production systems

7.6 Food system outcomes

7.7 Institutional drivers

7.8 Risks and resilience

7.9 The COVID-19 pandemic

7.10 Agency and development interventions

\subsection{Summing up}

\section{References}

Tropical mixed tree and

food crops systems

9 Toward enhanced resilience

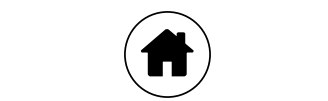


OECD (Organisation for Economic Co-operation and Development). 2011. "West African Urbanisation Trends." West African Futures, no. 1: 1-8.

Okafor-Yarwood, I. 2019. "Illegal, Unreported and Unregulated Fishing, and the Complexities of the Sustainable Development Goals (SDGs) for Countries in the Gulf of Guinea." Marine Policy 99: 414-22.

Parker, R. W., J. L. Blanchard, C. Gardner, B. S. Green, K. Hartmann, P. H. Tyedmers, and R. A. Watson 2018. "Fuel Use and Greenhouse Gas Emissions of World Fisheries." Nature Climate Change 8 (4): 333.

Pauly, D., and D. Zeller. 2016. "Catch Reconstructions Reveal That Global Marine Fisheries Catches Are Higher Than Reported and Declining." Nature Communications 7: 1-9.

Perry, I., and U. R. Sumaila 2007. "Marine Ecosystem Variability and Human Community Responses: The Example of Ghana, West Africa." Marine Policy $31(2): 125-34$

Petrossian, G. A., and R. V. Clarke. 2020. "Disaggregating Illegal Fishing Losses for the 22 Countries of the West African Coast." Maritime Studies, August 2, 2020, 1-11. https://doi.org/10.1007/s40152-020-00197-9.

Pomeroy, R., C. Arango, C. G. Lomboy, and S. Box. 2020. "Financial Inclusion to Build Economic Resilience in Small-Scale Fisheries." Marine Policy 118 103982.

Roesel, K., D. Grace, K. Makita, B. Boufoh, E. Kangethe, L. Kurwijila, S. Henderickx, C. McCrindle, K. Tano-Debrah, G. Zewede, and H. Matusse. 2015. "Hazards Do Not Always Translate into Risks." In Food Safety in Informal Markets - Animal Products in Sub-Saharan Africa, edited by K. Roesel and D. Grace, 31-44. Abingdon, Oxon, United Kingdom: Routledge.

Romanik, C. T. 2008. An Urban-Rural Focus on Food Markets in Africa. Washington, DC: Urban Institute.

Stewart, K. R., R. L. Lewison, D. C. Dunn, R. H. Bjorkland, S. Kelez, P. N. Halpin, and L. B. Crowder. 2010. "Characterizing Fishing Effort and Spatial Extent of Coastal Fisheries." PLOS ONE 5 (12): e14451.

Sumaila, U. R., V. Lam, F. Le Manach, W. Swartz, and D. Pauly. 2016. "Global Fisheries Subsidies: An Updated Estimate." Marine Policy 69: 189-93.

Tall, A. (n.d.). "Obstacles to the Development of Small Scale Fish Trade in West Africa." OceanDocs.

Teh, L. C., and U. R. Sumaila. 2013. "Contribution of Marine Fisheries to Worldwide Employment." Fish and Fisheries 14 (1): 77-88.

Tezzo, X., S. R. Bush, P. J. M. Oosterveer, and B. Belton. 2020. "Food System Perspective on Fisheries and Aquaculture Development in Asia." Agriculture and Human Values 2020, 18-18.
Theuerkauf, S. J., J. A. Morris Jr., T. J. Waters, L. C. Wickliffe, H. K. Alleway, and R. C. Jones. 2019. "A Global Spatial Analysis Reveals Where Marine Aquaculture Can Benefit Nature and People." PLOS ONE 14 (10): e0222282.

Thilsted, S. H., A. Thorne-Lyman, R. Subasinghe, P. Webb, J. R. Bogard, M. J. Phillips, and E. H. Allison 2016. "Sustaining Healthy Diets: The Role of Capture Fisheries and Aquaculture for Improving Nutrition in the Post-2015 Era." Food Policy 61: 126-31. .

Tongo, I., O. Ogbeide, and L. Ezemonye. 2017. "Human Health Risk Assessment of Polycyclic Aromatic Hydrocarbons (PAHs) in Smoked Fish Species from Markets in Southern Nigeria." Toxicology Reports 4: 55-61.

Torell, E., D. Bilecki, A. Owusu, B. Crawford, K. Beran, and K. Kent. 2019. "Assessing the Impacts of Gender Integration in Ghana's Fisheries Sector." Coastal Management 47 (6): 507-26.

Troell, M., R. L. Naylor, M. Metian, M. Beveridge, P. H. Tyedmers, C. Folke, K. J. Arrow, S. Barrett, A. Crépin, P. R. Ehrlich, A. Gren, N. Kautsky, S. A. Levin, K. Nyborg, H. Österblom, S. Polasky, M. Scheffer, B. H. Walker, T. Xepapadeas, and A. de Zeeuw.2014. "Does Aquaculture Add Resilience to the Global Food System?" Proceedings of the National Academy of Sciences 111 (37): 13257-63.

USAID (United States Agency for International Development). 2017.

Evaluation de la vulnérabilité au changement climatique dans les régions de la mangrove en Sierra Léone. Rapport abrégé Mali 2017. Washington, DC: USAID.

Weeratunge, N., K. A. Snyder, and C. P. Sze 2010. "Gleaner, fisher, trader, processor: understanding gendered employment in fisheries and aquaculture." Fish and Fisheries 11(4): 405-20.

Willmann, R., N. Franz, C. Fuentevilla, T. F. McInerney, and L. Westlund. 2017. "A Human Rights-Based Approach to Securing Small-Scale Fisheries: A Quest for Development as Freedom." In The Small-Scale Fisheries Guidelines, edited by S. Jentoft, R. Chuenpagdee, M. Barragán-Paladines, and N. Franz, 15-34. Cham, Switzerland: Springer.

World Bank. 2009. PROFISH Global Program on Fisheries: Reforming Fisheries and Aquaculture for Global Benefits - Evaluation Report. Washington, DC: World Bank.

World Bank. 2012. Hidden Harvest: The Global Contribution of Capture Fisheries. Washington, DC: World Bank.

World Bank. 2013. Fish to 2030: Prospects for Fisheries and Aquaculture. Agriculture and Environmental Services Discussion Paper 3. Washington, DC: World Bank.

Zickgraf, C., S. Vigil, F. de Longueville, P. Ozer, and F. Gemenne. 2016. "The Impact of Vulnerability and Resilience to Environmental Changes on Mobility Patterns in West Africa." KNOMAD Working Paper 14, World Bank, Washington DC.
(1) Background and understanding

(2) Regional drivers

(3) Regional organisations

(4) Agro-pastoralism-based

(5) Grains-and-legumes-based

6) Rice-and-horticulture

7 Coastal maritime fisheries

7.1 Definitions

7.2 Demography and geography

7.3 Regional consumption and production trends

7.4 Livelihoods of producer communities

7.5 Production systems

7.6 Food system outcomes

7.7 Institutional drivers

7.8 Risks and resilience

7.9 The COVID-19 pandemic

7.10 Agency and development interventions

7.11 Summing up

\section{References}

(8) Tropical mixed tree and

8 food crops systems

9 Toward enhanced resilience

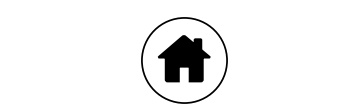




\section{Tropical mixed tree and food crops systems}

By Verina Ingram

\subsection{Definitions}

8.2 Demography and geography

8.3 Regional consumption and production trends

$\underline{8.4 \text { Livelihoods of producer communities }}$

8.5 Production systems

8.6 Food system outcomes

8.7 Institutional drivers

8.8 Risks and resilience

8.9 Food system impacts of and responses to the COVID-19 pandemic

$\underline{8.10 \text { Agency and development interventions }}$

8.11 Summing up: toward leverage points for future interventions

References

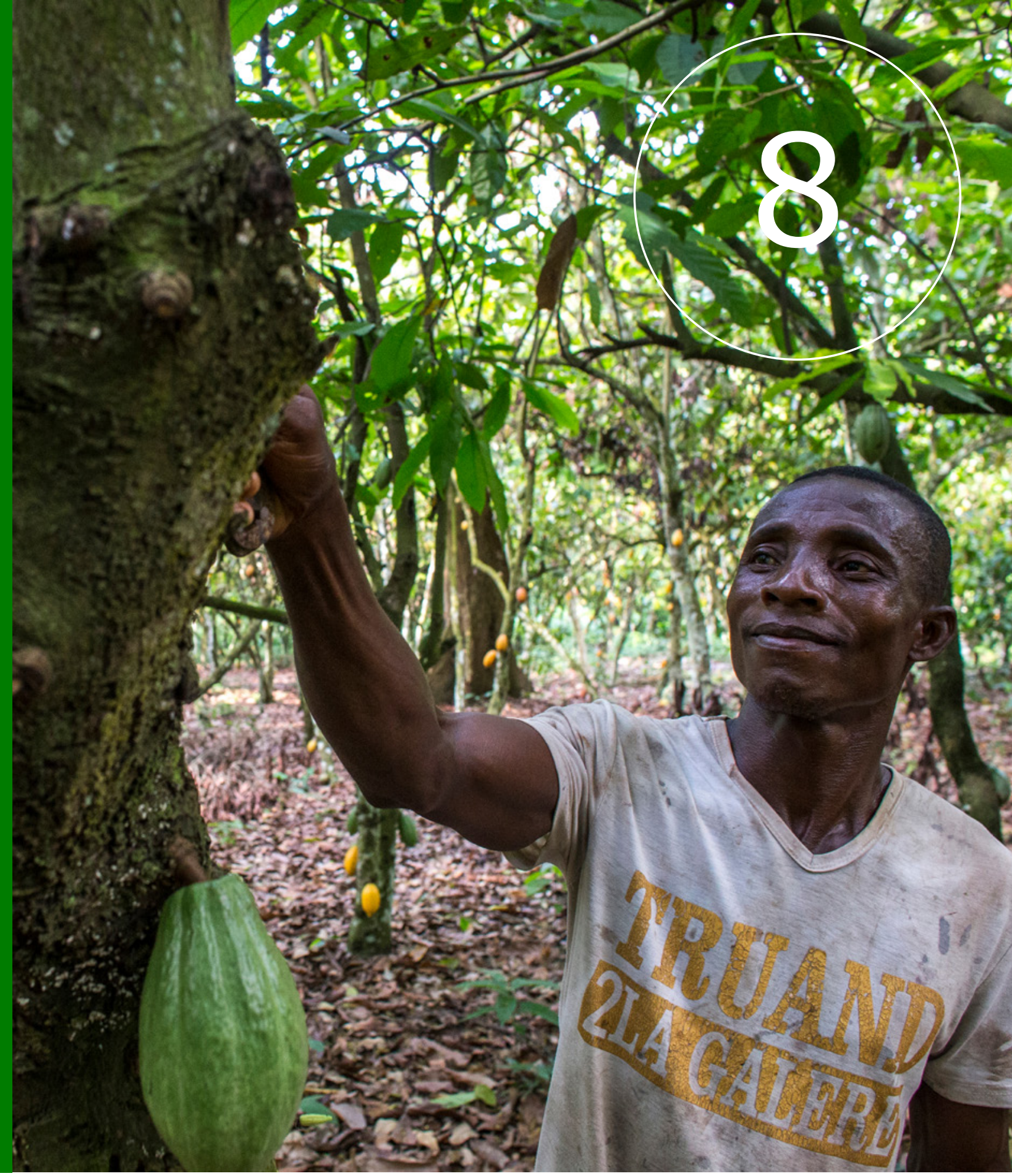

\section{$\rightarrow-$}


This chapter contains a description and analysis of food systems based on tropical mixed tree and food crops production, trade, processing, and consumption. The chapter has 11 sections. The first defines these food systems, followed by a discussion of their demography and locations. Section 8.3 describes trends in consumption and production, and section 8.4 addresses the livelihoods of people living in this food system. Section 8.5 covers production systems, and section 8.6 addresses multiple food system outcomes. Section 8.7 highlights important institutional drivers of particular changes in the system, while section 8.8 identifies trends, risks, and systems resilience, followed by an analysis of food system impacts of the COVID-19 pandemic in section 8.9. Section 8.10 contains an examination of past agency and development efforts to influence tropical mixed tree and food crop systems and lessons for the future. The final section outlines some conclusions about leverage points for enhanced resilience of tropical mixed tree and food crop systems.

\subsection{Definitions}

West African tropical mixed tree and food crop systems can be viewed from both a plot and a farm perspective. They comprise varying proportions of the following:

- Tree crops, including cocoa, coffee, rubber, oil palm, cashew, and citrus in both the lowland and highland areas. These are the principal source (at least 50 percent) of household revenue, and households view them as the most important crop (Bymolt, Laven, and Tyszler 2018).

- Subsistence food starchy staple crops, mainly cassava, plantain, maize, cocoyam, yam, beans, sweet potato, and taro in separate plots or intercropped in both the lowlands and highlands (Bymolt, Laven, and Tyszler 2018).

- Food crops for both subsistence use and cash, especially market vegetables (leafy greens, onions, chilis, herbs) and legumes (peas, beans).

- Indigenous and exotic trees used for nonfood cash and subsistence multipurposes such as construction, tools, medicine, and wood fuel (sometimes with multiple parts used, such as timber, fruits, nuts, bark, roots, and leaves). They are often intercropped in agroforestry and extensively managed food and farm systems - for example, rotating fallows, with long-term fallows having characteristics of secondary forests.

- Livestock, with small ruminants, goats, and chickens in lowlands and cows in highland areas (Smith 1991).

In these food systems, other income sources often contribute to household income and support the mixed tree and food crops farming systems, especially given that cash crop harvests and subsequent income flows are highly seasonal. Examples include household consumption and sale of forest (timber and nontimber) products for food and other uses and income from farm labour and off-farm work. Tropical mixed tree and food crop systems generally consist of several plots with different rotating mixes of annual crops, perennial tree crops and fallows, or swiddens forming intercropped ${ }^{1}$ and agroforest ${ }^{2}$ or tree-based systems. These systems have often developed from clearing natural forests for agriculture, with specific indigenous tree species deliberately left and maintained as part of these systems (Wiersum 1997). Many factors $^{3}$ combine to determine the extent to which these systems form mosaics in forested areas and to which forests (secondary or primary) are maintained or deforestation, degradation, or reforestation occurs (Fairhead and Leach 1995, 1998; Rudel 2013).

Two broad mixed tree and food crops systems exist in tropical West Africa based on their geographic agroecological climatic zone:

- Lowland humid tree farming systems are dominated by high-density cash-crop exotic tree species such as cocoa, rubber, palm oil, ${ }^{4}$ coffee, and citrus.

- Highland forest perennial systems have planted high-density exotics such as arabica coffee, citrus, and eucalyptus and traditional indigenous cash-generating food trees such as cola, palms, and nonfood species like bamboo and raffia, along with staple crops such as maize, potatoes, sweet potatoes, and livestock.

These mixed tree and food crop food systems include associated value chains, institutions, and agencies specific to these systems They also contribute to the diets of nonfarmer consumers locally and internationally. The food system characteristics and internal
(1) Background and understanding

(2) Regional drivers

(3) Regional organisations

(4) Agro-pastoralism-based

(5) Grains-and-legumes-based

6) Rice-and-horticulture

(7) Coastal maritime fisheries

Tropical mixed tree and food crops systems

8.1 Definitions

8.2 Demography and geography

8.3 Regional consumption and production trends

8.4 Livelihoods of producer communities

8.5 Production systems

8.6 Food system outcomes

8.7 Institutional drivers

8.8 Risks and resilience

8.9 The COVID-19 pandemic

8.10 Agency and development interventions

8.11 Summing up References

9 Toward enhanced resilience 
logic with extensive global feedback loops between its components mean that vulnerability and resilience are both responses to internal and external shocks. Given this context, mixed tree and food crop systems are defined as follows:

food systems based on entwined farm-forest production systems, livelihoods, and markets, where products from trees are produced in mixed farming systems and forest

environments ${ }^{5}$ that contain other tree and agricultural crops and livestock used for household consumption and sale in consumer and industrial markets.

\subsection{Demography and geography}

The lowland humid tree farming systems are present from Côte d'Ivoire to Ghana and from Nigeria and Cameroon to Gabon, with smaller pockets in Congo and Angola, largely in the humid zone, shown in maps 8.1 (orange outline) and 8.2. The highland forest perennial systems are found in the Guinea Highlands (GuineaSierra Leone-Liberia), Niger River area, Nigerian and Cameroon Highlands, and the central Adamawa Plateau, Bight of Benin, and Massif de Bongos (Central African Republic-Sudan-northern Congo), shown in map 8.1 (blue outline).

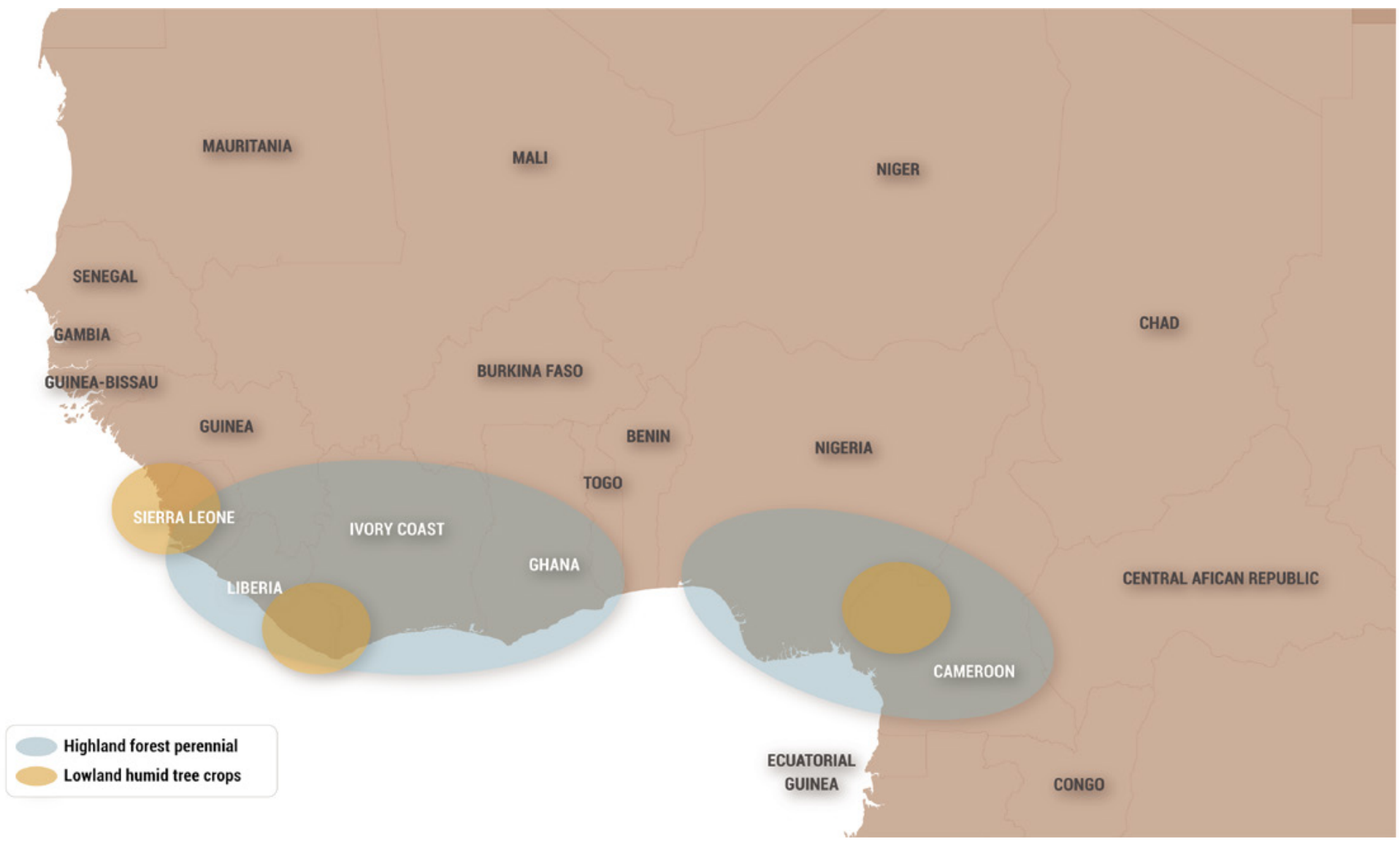

Map 8.1 Mixed Tree and Food Crops Systems in West Africa Source: Dixon et al. 2020. 


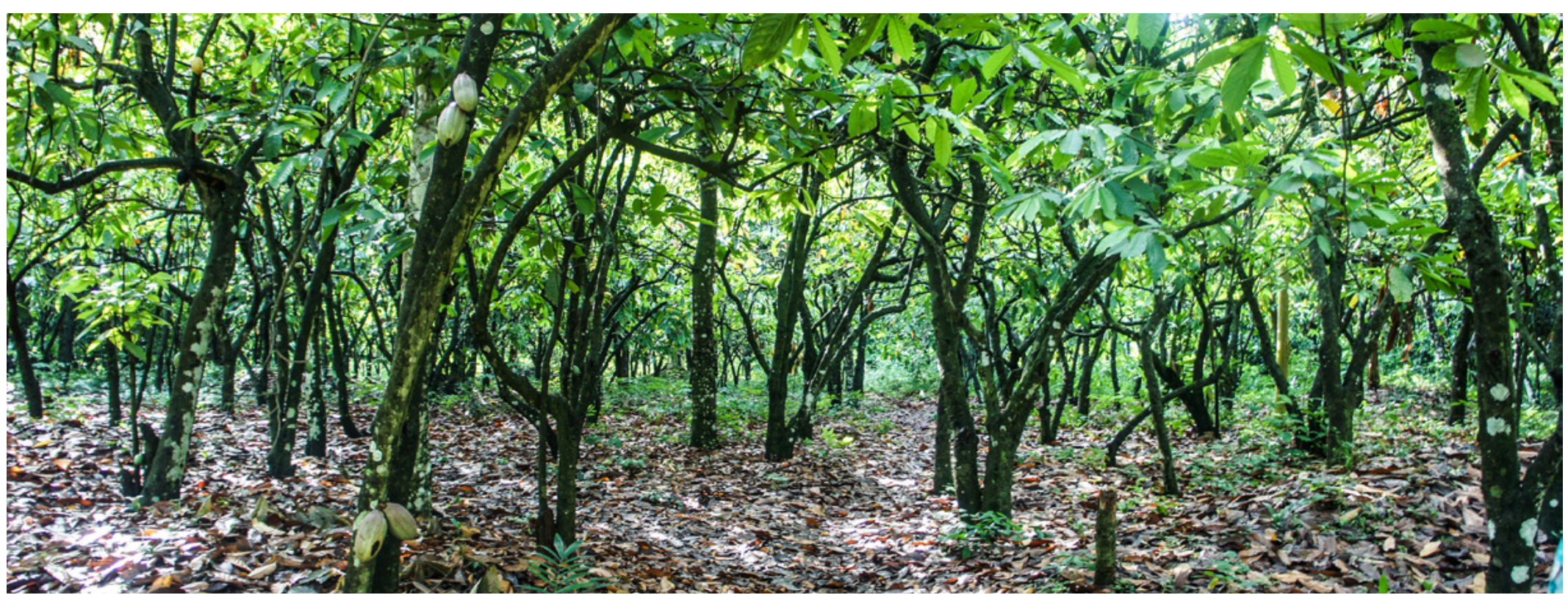

An estimated 30 million farmers on 64 million hectares practiced lowland humid tree farming systems in Sub-Saharan Africa in 2015, most in West Africa (Dixon et al. 2020). These systems are situated in the humid lowlands in West and Central Africa. Yet the competitive pressures of global markets limit the extent of this system to places where (1) relatively efficient marketing systems link tree crop producers to those markets and (2) land tenure combined with access to large-scale foreign investment capital, technology, farm inputs, and labour enables this system (Dixon et al. 2020). In 2000 the scale of this system was estimated at 73 million hectares ( 3 percent of the Sub-Saharan African total), which accounted for 10 million hectares ( 6 percent) of total cultivated area due to extensive fallows and supported an agricultural population of nearly 25 million (7 percent of the Sub-Saharan total) (Dixon et al. 2001). Lowland humid systems are situated in some of the most densely populated areas in West Africa, with between 200 and 1,000 persons per square kilometer.

Data on the extent of highland forest perennial systems for West Africa do not exist. In 2015 the Africa-wide highland mixed system hosted 73 million people on about 53 million hectares of land, with medium to high population density (200-500 persons per square kilometer) and high poverty rates, with about 37 percent of the population living on an income of less than $\$ 1.25$ per day (Dixon et al. 2020). Endowed with high agroecological potential, the highland perennial farming system makes a large contribution to West African economies and food security despite its limited geographic area. With declining farm sizes and less fallowing due to demographic pressure, the system's opportunities for intensification, income growth, and livelihood diversification are largely defined by its integration into national markets (Dixon et al. estimated to occupy 1 percent of land area and account for 8 percent of the total cultivated area (Dixon et al. 2001). In 2001 this system was known as the highland temperate farming system and occupied 2 percent of the Sub-Saharan Africa land area and accounted for 6 million hectares (4 percent) of cultivated area, supporting a large agricultural population of 28 million (7 percent of the total) (Dixon et al. 2001). 2020). In 2000, for all Sub-Saharan Africa, these systems were
(1) Background and understanding

(2) Regional drivers

(3) Regional organisations

(4) Agro-pastoralism-based

(5) Grains-and-legumes-based

6) Rice-and-horticulture

(7) Coastal maritime fisheries

Tropical mixed tree and food crops systems

8.1 Definitions

\subsection{Demography and} geography

8.3 Regional consumption and production trends

8.4 Livelihoods of producer communities

8.5 Production systems

8.6 Food system outcomes

8.7 Institutional drivers

8.8 Risks and resilience

8.9 The COVID-19 pandemic

8.10 Agency and development interventions

8.11 Summing up References

9) Toward enhanced resilience 


\subsection{Regional consumption and production trends}

The economic value of trade in some of the major cash crops and associated value chains from these mixed farming systems is shown in table 8.1 .

\begin{tabular}{|c|c|c|c|c|c|c|c|c|c|}
\hline $\begin{array}{l}\text { Tree } \\
\text { cash } \\
\text { crops }\end{array}$ & $\begin{array}{l}\text { Major producing } \\
\text { countries in } \\
\text { West Africa }\end{array}$ & System & $\begin{array}{l}\text { Production/ } \\
\text { yield, } 2018 \\
\text { (tons) }\end{array}$ & $\begin{array}{l}\text { Area, } \\
2018 \\
\text { (ha) }\end{array}$ & $\begin{array}{l}\text { Export } \\
\text { quantity, } \\
2017 \text { (tons) }\end{array}$ & $\begin{array}{l}\text { Exports value, } \\
2017 \text { (US\$, } \\
\text { thousands) }\end{array}$ & $\begin{array}{l}\text { Percentage } \\
\text { global } \\
\text { production }(\%)\end{array}$ & $\begin{array}{l}\text { Type of } \\
\text { value } \\
\text { chains }\end{array}$ & $\begin{array}{l}\text { Value chain } \\
\text { consumer types } \\
\text { and regions }\end{array}$ \\
\hline Avocado & $\begin{array}{l}\text { Cameroon, Côte } \\
\text { d'Ivoire, Ghana }\end{array}$ & $\begin{array}{l}\text { Highland } \\
\text { and } \\
\text { lowland }\end{array}$ & 47,369 & 7,683 & 767 & $\$ 56$ & $12.8 \%$ (Africa) & $\begin{array}{l}\text { Local, } \\
\text { regional, and } \\
\text { international }\end{array}$ & Consumer \\
\hline Baobab & Senegal & Lowland & $4,469,168$ & 886,997 & 450 & & & $\begin{array}{l}\text { Local and } \\
\text { regional }\end{array}$ & $\begin{array}{l}\text { Consumer food } \\
\text { and nonfood }\end{array}$ \\
\hline Cashew & $\begin{array}{l}\text { Benin, Burkina } \\
\text { Faso, Côte d'Ivoire, } \\
\text { Ghana, Mali, Nigeria }\end{array}$ & Lowland & $1,525,827$ & $2,901,825$ & 35,334 & $\$ 153,182$ & $38 \%$ (Africa) & $\begin{array}{l}\text { Local and } \\
\text { international }\end{array}$ & Consumer \\
\hline Oranges & $\begin{array}{l}\text { Benin, Côte d'Ivoire, } \\
\text { Guinea, Ghana, } \\
\text { Nigeria }\end{array}$ & $\begin{array}{l}\text { Highland } \\
\text { and } \\
\text { lowland }\end{array}$ & $1,174,893$ & 57,597 & 9,100 & $\$ 1,966$ & & $\begin{array}{l}\text { Local and } \\
\text { international }\end{array}$ & Consumer \\
\hline Cocoa & $\begin{array}{l}\text { Cameroon, Côte } \\
\text { d'Ivoire, Ghana, } \\
\text { Nigeria }\end{array}$ & Lowland & $3,364,818$ & $7,191,243$ & $2,843,202$ & $\$ 7,401,600$ & $65.6 \%$ (Africa) & International & $\begin{array}{l}\text { Consumer, } \\
\text { industrial }\end{array}$ \\
\hline Coffee & $\begin{array}{l}\text { Cameroon, Côte } \\
\text { d'Ivoire, Sierra } \\
\text { Leone }\end{array}$ & $\begin{array}{l}\text { Highland } \\
\text { and } \\
\text { lowland }\end{array}$ & 184,204 & 786,944 & 60,651 & $\$ 90,363$ & $14 \%$ (Africa) & International & $\begin{array}{l}\text { Consumer, } \\
\text { industrial }\end{array}$ \\
\hline Dates & $\begin{array}{l}\text { Benin, Cameroon, } \\
\text { Mali }\end{array}$ & Lowland & 43,742 & 16,466 & 2,271 & $\$ 507$ & $38 \%$ (Africa) & Local & Consumer \\
\hline Karite & $\begin{array}{l}\text { Benin, Burkina Faso, } \\
\text { Ghana, Mali, Nigeria }\end{array}$ & Lowland & 496,667 & 570,228 & 265,344 & $\$ 27,901$ & $\begin{array}{l}100 \% \\
\text { (West Africa) }\end{array}$ & $\begin{array}{l}\text { Local and } \\
\text { international }\end{array}$ & $\begin{array}{l}\text { Industrial } \\
\text { (nonfood and } \\
\text { food), consumers }\end{array}$ \\
\hline Kola nuts & $\begin{array}{l}\text { Côte d'Ivoire, } \\
\text { Ghana, Guinea, } \\
\text { Nigeria }\end{array}$ & Lowland & - & - & 26,051 & $\$ 3,496$ & & $\begin{array}{l}\text { Local and } \\
\text { regional }\end{array}$ & Consumer \\
\hline Mango & $\begin{array}{l}\text { Côte d'Ivoire, Mali, } \\
\text { Niger, Nigeria, } \\
\text { Senegal }\end{array}$ & $\begin{array}{l}\text { Highland } \\
\text { and } \\
\text { lowland }\end{array}$ & $2,562,304$ & 514,949 & 87,033 & $\$ 108,585$ & $11 \%$ (Africa) & International & Consumer \\
\hline $\begin{array}{l}\text { Oil palm } \\
\text { fruit }\end{array}$ & $\begin{array}{l}\text { Cameroon, Côte } \\
\text { d'Ivoire, Ghana, } \\
\text { Nigeria, Sierra } \\
\text { Leone }\end{array}$ & Lowland & $14,926,119$ & $4,164,684$ & - & - & $8.4 \%$ (Africa) & Local & $\begin{array}{l}\text { Consumer } \\
\text { manufacturing } \\
\text { (food and } \\
\text { nonfood) }\end{array}$ \\
\hline Rubber & $\begin{array}{l}\text { Côte d'Ivoire, } \\
\text { Liberia, Nigeria }\end{array}$ & Lowland & 717,737 & 780,357 & 802,432 & $\$ 1,088,893$ & $5.6 \%$ (Africa) & International & $\begin{array}{l}\text { Industrial (nonfood } \\
\text { and food), } \\
\text { consumers }\end{array}$ \\
\hline
\end{tabular}

(1) Background and understanding

(2) Regional drivers

(3) Regional organisations

(4) Agro-pastoralism-based

(5) Grains-and-legumes-based

6) Rice-and-horticulture

(7) Coastal maritime fisheries

Tropical mixed tree and food crops systems

8.1 Definitions

8.2 Demography and geography

8.3 Regional consumption and production trends

8.4 Livelihoods of producer communities

8.5 Production systems

8.6 Food system outcomes

8.7 Institutional drivers

8.8 Risks and resilience

8.9 The COVID-19 pandemic

8.10 Agency and development interventions

8.11 Summing up References

9) Toward enhanced resilience

Table 8.1 Production and Trade Values for Tree Food Cash Crops in West Africa

Source: FAOSTAT, Food and Agriculture Organisation, Rome (accessed June 16, 2020). 
Data on the number of people employed in each crop are generally lacking, except for cocoa, which is the crop with the largest land area coverage in West Africa and accounts for the largest share of exports. In Ghana 800,000 people were active in the cocoa sector in 2014, accounting for 50 percent of national employment, with a value of $\$ 2$ billion in 2017, equivalent to 30 percent of GDP. In 2017 in Côte d'Ivoire, cocoa was estimated to account for 75 percent of national employment, 15 percent of GDP, and 50 percent of export receipts (Vigneri and Kolavalli 2018).

Figure 8.1 shows how cash crops from these systems have been important since the 1960s. Cocoa has consistently been the major cash crop from these systems that is produced and exported from West Africa. Since the mid-1980s, cocoa, karite, cashew, and avocado production has tripled. Baobab exports were permitted to the EU as a "novel food" in 2008 and to the United States in 2009 and have increased globally since baobab has been promoted as superfood (CBI 2020). Regional trade in traditional tree crops from

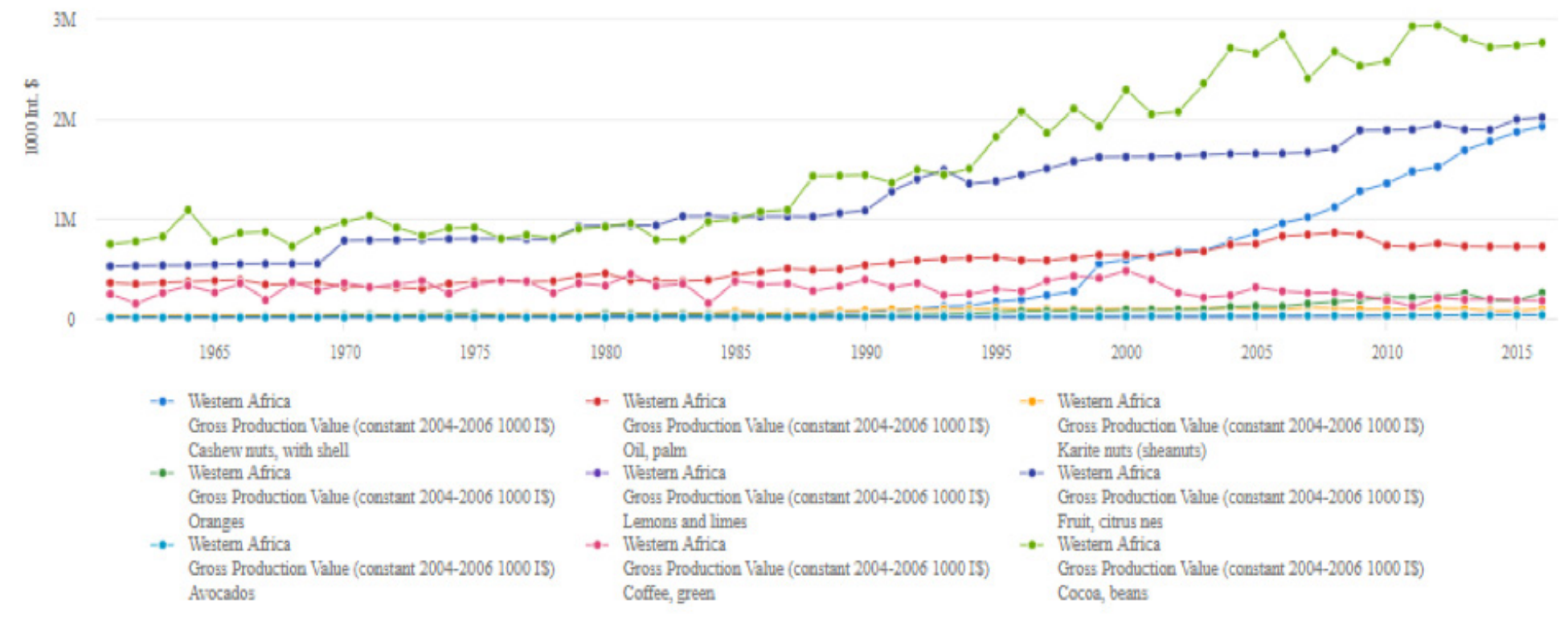

Figure 8.1 Gross production value of West African Agricultural Production of Tree Crops, 1961-2016 Source: FAOSTAT, Food and Agriculture Organisation, Rome (accessed June 16, 2020). the highland and lowland systems such as baobab, cola, and safou has been established for a long time but is largely unrecorded in international or national statistics (Ingram et al. 2012; Lescuyer et al. 2016).

Associated value chains of traditional foods (such as cola nuts) and nonfood cash crops from these systems include wood fuel, medicines, and construction materials. Despite the importance of forest products for multiple uses but especially indigenous "traditional" food in West Africa (Falconer and Koppell 1990), data on the values sold locally, nationally, and internationally are generally lacking and are not systematically updated (Ingram 2011; Ingram et al. 2012). For example, in Cameroon nontimber forest products (NTFPs) - the majority of which are foods - were valued between $\$ 21$ million and $\$ 23$ million in 2008-09 (Ingram 2009). About 38 percent of vegetal NTFPs are used as food, with an annual economic value for 16 of these foods estimated at $\$ 64.7$ million in 2016 , representing 0.2 percent of the GDP of the country, with at least 283,000 people
(1) Background and understanding

(2) Regional drivers

(3) Regional organisations

(4) Agro-pastoralism-based

(5) Grains-and-legumes-based

(6) Rice-and-horticulture

(7) Coastal maritime fisheries

Tropical mixed tree and food crops systems

8.1 Definitions

8.2 Demography and geography

\subsection{Regional consumption} and production trends

8.4 Livelihoods of producer communities

8.5 Production systems

8.6 Food system outcomes

8.7 Institutional drivers

8.8 Risks and resilience

8.9 The COVID-19 pandemic

8.10 Agency and development interventions

8.11 Summing up References

9 Toward enhanced resilience 
involved (Awono et al. 2016). There are many more people involved in hunting and NTFP sectors than in the formal sectors, though these jobs are seldom comparable in terms of time spent, working conditions, and social protection (Lescuyer et al. 2016).

Examples from across West Africa highlight how the food system continuum from farms to fallows and forests generates both food and income used to buy food. For example, in southern Niger the jujube (Ziziphus mauritiana) and desert date (Balanites aegyptiaca) value chains involved 3,044 people, particularly women, with an estimated 39 tons of jujube and 27 tons of desert date fruit collected in 2017 (Moussa et al. 2020) and the ditax (Detarium senegalense) seed value chain in Togo generated $\$ 59$ per year on average for harvesters (Dangbo et al. 2019).

\subsection{Livelihoods of producer communities}

Mixed tree and food crops livelihoods are based on the household as the production and decision unit for farming, sales, investments, and so on. A household 6 and the larger community are often interlinked, as household members work on the family farm and on each other's farms, often as groups, to collect forest products, mainly in the peak harvest seasons.

Traditionally, household members' livelihood strategies have been characterised by a distribution of tasks and income. In general, men have long been oriented toward cash crops such as coffee, cocoa, rubber, and others (Boffa 2000; Rocheleau and Edmunds 1997). However, few crops can be defined clearly as only "men's" or "women's" crops (Doss 2002). Clearing forestland, hunting, and creating certain high-value forest products are generally considered male tasks that require deciding which native trees are maintained or felled for mixed tree and food crops systems (Quisumbing et al. 2001). Cash crop trade is mainly the responsibility of adult men. Women help with weeding, harvesting, and transporting from farm to household or market and are involved in subsistence crops trade surpluses in nearby food markets (Colfer, Basnett, and Elias 2016). Women generally focus on subsistence crops, collecting firewood (from forests, farm, and fallows), and staple crops, but there are variations across countries and ethnic groups, often depending on if women are culturally permitted to own and manage productive capital such as livestock (Colfer, Basnett, and Elias 2016). Surpluses may be sold by women to generate additional income, with men and women usually having different expenditure patterns (Edame et al. 2011; Ingram et al. 2016; Kiewisch 2015; Oluyole 2011). Young people also are involved in farm labour. However, with current population growth, many youths have left the production system, though they remain part of the extended family.

Child and slave labour in food systems, particularly in cocoa, is an issue in some West African countries (Carter 2017; U.S.

Department of State 2016). Child labour ${ }^{7}$ is driven by low incomes, limited employment and labour options, and a complex relationship between household wealth, demographics, and availability of family labour. Other drivers of child and slave labour include a country's agricultural dependency, social norms, and lack of higher returns to basic schooling.

The ability to earn a living income ${ }^{8}$ from tree cash crops, particularly for cocoa farmers in Ghana and Côte d'Ivoire, has become a development focus. In these systems, tree cash crops are preferred to other crops as they provide a better income than other farming systems (Bymolt, Laven, and Tyszler 2018). Yet the interactions between prices and public and private sector initiatives to enable, or disenable, farmers to earn a living income has increasingly been scrutinised. The living income for March 2020 was $\Phi 1,683$ per month ( $\$ 312$ ) (Anker and Anker 2020), and in rural cocoa-growing areas of Côte d'Ivoire the living income in 2017 was CFAF $3,759,281(\$ 6,517)$ per year for a typical male-headed household (up to 4 hectares of productive land) with 3.5 adults and 3.5 children (Tyszler, Bymolt, and Laven 2018).

Land tenure is still mainly customary, though there is increasing privatisation (Chauveau 2007), and has a major influence on what is farmed and who owns the resulting food and revenues from food cash crops (Bandiaky-Badji 2011; Berry 2009; Fenske 2011). Absentee ownership (city-based investors and elites) is growing in importance, putting farm and trade decisions outside farm managers' sphere of influence (Woods 2004). While national
(1) Background and understanding

(2) Regional drivers

(3) Regional organisations

(4) Agro-pastoralism-based

5) Grains-and-legumes-based

(6) Rice-and-horticulture

(7) Coastal maritime fisheries

Tropical mixed tree and food crops systems

8.1 Definitions

8.2 Demography and geography

8.3 Regional consumption and production trends

8.4 Livelihoods of producer communities

8.5 Production systems

8.6 Food system outcomes

8.7 Institutional drivers

8.8 Risks and resilience

8.9 The COVID-19 pandemic

8.10 Agency and development interventions

8.11 Summing up References

9) Toward enhanced resilience 
populations continue to grow, in general, rural areas are depopulating as people move to urban areas in search of paid employment, education, and other opportunities. However, in some areas of Côte d'Ivoire and Burkina Faso, patterns of counter-

urbanisation have occurred, such as where the level of urbanisation is decreasing (Beauchemin 2011). Household and some trade linkages between rural and urban areas based on family networks are strong, affecting cash remittances and transfers, food sharing, and sourcing and investment in food systems (Djurfeldt 2015).

In Côte d'Ivoire, Burkina Faso, Sierra Leone, Nigeria, and Liberia (Berry 2009; Maconachie et al. 2006; Nyame 2011; Richards 2005), violent conflicts have led to internal and regional migration, increased competition and new land claims and politics, changing customary rules governing access to land, illegal appropriation of protected areas, migrant farmers settling into new area, and the new practice of mixed tree and food crops farming systems (with less shade cover and different intercropping practices) (Aderinto 2013; Amanor 2012; Mitchell 2011, 2012). These conflicts have, to varying extents, been attributed to conflicts over resources (Flores 2004).

Since the 1970s, the capacity of mixed tree and food crops systems to absorb shocks and adapt to external drivers has changed (Hirons et al. 2018; Kiewisch 2015; Monastyrnaya et al. 2016; Papaioannou 2016; Tyszler, Bymolt, and Laven 2018). Changes have occurred that generally have negative livelihoods impacts, though some societal groups have seen positive impacts. These changes are due to growing social differentiation and inequalities between groups (such as on the basis of ethnicity, indigenous/migrant status, or gender) because of combinations of "wicked problems" and other factors. These include increasing poverty through fragmentation, decreasing farm sizes, and reduced land access in some areas; migration to urban areas confounding farm labour shortages and labour rights; climate change affecting crop production; market shocks with extreme fluctuations in commodity prices (Böwer, Geis, and Winkler 2007; Dupraz and Postolle 2013); violent conflicts and disease, such as the Ebola outbreaks in Côte d'Ivoire, Liberia, Sierra Leone, and Democratic Republic of Congo (Figuié 2016; Maconachie et al. 2006; Mitchell 2011; Witteveen et al. 2016) and more recently COVID-19 (Arouna et al. 2020; Siche 2020).

\subsection{Production systems}

Most of the tropical mixed tree and food crops systems were introduced in the late 1800s and promoted by colonial governments as larger-scale plantations with some smallholder growers. Following independence, they took off as major smallholder systems heavily supported by the independent governments, with the planted areas increasing in both household and national economic importance (Wessel and Quist-Wessel 2015).

Cash crops in the food system such as coffee, cocoa, palm oil, cashew, and karite are grown mostly for export but also for domestic consumption, where they are sold mainly to processing plants. The area under cash crops in Sub-Saharan Africa is much smaller than that under food crops (de Graaff, Kessler, and Nibbering 2011). Cash crops have been viewed as threats to food crop production, as they compete for the same resources. Cash crops generate income for inputs into food crops for subsistence use, and cash crops can be grown in rotation or intercropped with food crops to boost food crop production (Boffa 2000; de Graaff, Kessler, and Nibbering 2011; Dixon et al. 2020).

These mixed tree and food crops farming systems are highly diverse and heterogenous. They are based on a continuum from farm to fallows to forests (Halewood et al. 2014; Koffi 2016; Lourme Ruiz, Dury, and Martin-Prével 2016; Roussel 1994). Besides the cash crops, most contain food crops and generally lesser proportions of plants and animals (bushmeat), used both for household subsistence and for income generation. Uses include medicine, energy from woody or animal-based biomass (fuelwood and charcoal), construction (timber, bamboo, raffia, and other palms), utensils, and cultural, religious, or spiritual uses. These systems are thus about food crops but also provide other food and nonfood products and ecosystem services (Bayala et al. 2011; Bymolt, Laven, and Tyszler 2018; Ingram et al. 2012; Ingram, van den Berg, et al. 2018; Klöpffer and Curran 2014).

These tropical mixed tree and food crop systems are distinguished by different socioeconomic, sociocultural, and agronomic features:
(1) Background and understanding

(2) Regional drivers

(3) Regional organisations

(4) Agro-pastoralism-based

5) Grains-and-legumes-based

6) Rice-and-horticulture

(7) Coastal maritime fisheries

Tropical mixed tree and food crops systems

8.1 Definitions

8.2 Demography and geography

8.3 Regional consumption and production trends

8.4 Livelihoods of producer communities

8.5 Production systems

8.6 Food system outcomes

8.7 Institutional drivers

8.8 Risks and resilience

8.9 The COVID-19 pandemic

8.10 Agency and development interventions

8.11 Summing up References

9 Toward enhanced resilience 
- Some people self-identify by their main cash crop, such as cacao or coffee, even if they live in towns as absentee landowners outside the physical farming system and farming is managed by labourers or tenants. Profits are distributed based on traditional input systems (time, labour, and other farm inputs).

- Farmers may have commodity market contractual

arrangements, such as with regular buyers (commercial and cooperatives), or they may be out-growers ${ }^{9}$ or contract farmers (for palm oil, cocoa, or coffee). The arrangement determines profits, inputs, and farming practices (Smalley 2013).

Economically, mixed tree cash crop systems differ from other local food and farming systems in their greater reliance on cash crops to provide household income and therefore access local and imported foods for their consumption, such as rice and cereals (Gockowski 2020).

- Sharecropping land tenure arrangements are common, where access to land, costs, and profits and sometimes inputs are divided in different proportions (such as the abunu, abuna, and abusa systems in Ghana and cocoa and oil palm systems in Côte d'Ivoire) (Bergert 2000; Quaye et al. 2015).

- Diverse, heterogenous farm sizes are characteristic of smallholders and larger-scale systems. Lowland tree crop plot and farm systems tend to be small scale, about 2-2.5 hectares on average for cocoa farms, though larger farms up to 20 hectares or more exist (Bymolt, Laven, and Tyszler 2018; Ingram, Waarts, and van Rijn 2018). Farm and fallow plot systems vary widely in size, with a range of tree products harvested for use and sale within a radius of several kilometers to around 60 kilometers for wildlife hunting in open-access forest areas (Boffa 1999; Fa and Brown 2009; Kalinganire et al. 2007).

- Three main plant nutrient management systems are used (Dixon et al. 2020). The forest rent subsystem (FRS) relies on the inherent stock of plant nutrients in both soil and forest biomass and is mainly used by smallholders. The smallholder intensified subsystem (SIS) maintains nutrient balances by incorporating external inputs (mineral fertilisers, organic fertiliser, or animal manure). A third subsystem is the large-scale monospecies industrial plantation subsystem (IPS), which is heavily capitalised and focused on profit more than the typical smallholder system who focus on subsistence crops and incomes. Some smallholders also have smaller monospecies tree crop plots, such as cocoa, coffee, rubber, and oil palm in the humid forest areas; eucalyptus and cola nuts in the highlands; or cashew, eucalyptus, citrus, guava, and mango in the Sahel (Bayala et al. 2011; Olaniyi 2010). These plots have very heterogenous input systems, from no inputs to highly intensive input use.

\subsection{Food system outcomes}

8.6.1 Household food and nutrition security

Food security and insecurity depend on farm and household characteristics. High levels of crop diversity are inherent in the lowland humid and highland forest systems to enable these systems to meet household food consumption needs year-round and provide nutritional security for some farming households (box 8.1). However, for many households with specific socioeconomic (for example, income allocation), farm, and demographic characteristics (related to gender and intrahousehold dynamics), both individual and household resilience is lower. For example, around half of farmers studied in countries in the lowland humid zones had high risk of food and nutritional insecurity (Edame et al. 2011; Kiewisch 2015; Kuwornu and Amegashie 2013; Oluyole 2011). Surpluses and cash crops support the households in purchasing food that is not grown on-farm or collected in the forest systems.

In cash crop systems, such as cocoa in Côte d'Ivoire, income allocation and intrahousehold dynamics affect seasonal household resilience and food security. As women's and men's incomes are separate and destined for different purposes in the household, the fact that men's income is often earmarked for individual spending creates problems for households particularly in the lean season, with increased joint decision-making in the interests of the household seen as a key factor to ameliorate insecurity (Kiewisch 2015).

Diets based on the foods these systems supply depend on what they produce and purchases of local and imported foodstuffs, though purchases depend on access to markets/food, distance, poverty, and so on (Edame et al. 2011; Kiewisch 2015; Oluyole
(1) Background and understanding

(2) Regional drivers

(3) Regional organisations

(4) Agro-pastoralism-based

(5) Grains-and-legumes-based

6) Rice-and-horticulture

(7) Coastal maritime fisheries

Tropical mixed tree and food crops systems

8.1 Definitions

8.2 Demography and geography

8.3 Regional consumption and production trends

8.4 Livelihoods of producer communities

8.5 Production systems

8.6 Food system outcomes

8.7 Institutional drivers

8.8 Risks and resilience

8.9 The COVID-19 pandemic

8.10 Agency and development interventions

8.11 Summing up References

9 Toward enhanced resilience 
Box 8.1 Outcomes of Mixed Tree and Food Crops Systems for Subsistence Use

Lowland humid tree farming systems provide a wide range of foods for household consumption that contribute to food and nutritional security. For example, in a broad sample of 3,000 households, 90 percent produced cocoa in Ghana compared to 69 percent in Cote d'Ivoire (Bymolt, Laven, and Tyszler 2018). Up to 25 other crops were also grown on the farms. Cassava and plantains were the second-most cultivated crops due to their dual role as food and cash crops. A variety of crops, such as chili, yam, eggplant, okra, tomatoes, and groundnuts, are frequently produced. Vegetables are produced on small plots, while large plots produce staple crops such as maize, rice, and yam. The use of multipurpose shade trees providing a range of food and other products is common but varies significantly in both coffee and cocoa systems (Bisseleua et al. 2013; Herzog 1994; Ruf 2011).

Highland forest perennial systems provide a range of foods for household consumption. Both surpluses and cash crop commodities are sold. Yields per hectare for the main food crops are generally low, but there are considerable differences in yield output among farmers depending on their strategies, inputs, management, and sociocultural demography (Degrande et al. 2006; Yengoh 2012).

2011). It also depends on the extent to which food is harvested from forests that form part of the food systems, as household food for different household members is often foraged by women and children from fallows and open-access forested environments near these farming systems (Gbetnkom 2009; Nikiema 2005; Powell et al. 2015; Sunderland et al. 2013). Fallows and forested areas have traditionally been an important source of animal protein in the form of bushmeat and fish, though supply has rapidly declined to crisis levels since the 1980 s due to overhunting, land use change, changing agricultural practices such as shorter fallow rotation periods; this has not been offset by the supply of alternative cheap protein sources (Bennett et al. 2007; Brashares et al. 2004; Van Vliet et al. 2012). Bushmeat bans in Sierra Leone and Guinea due to the Ebola virus, while intended as health measures, unintendedly decreased protein consumption in the humid forest areas (Bonwitt et al. 2018). Forests also supply fuelwood, which affects food and nutritional security and health (Jin et al. 2017). The biodiversity of farms, fallows, and wider forested areas has been associated with the food and nutritional security of farmer households (Sunderland 2011). Some of the main cash crops grown, such as coffee and cocoa, are not consumed by the producers, so they only contribute to household food security through the income they generate (Achterbosch et al. 2014).

8.6.2 Income, trade, and employment

These mixed farming systems produce both major food crops for sale, minor food cash crops, and subsistence foods, and the surpluses may be sold. For example, box 8.1 shows that in Ghana and Côte d'Ivoire up to 25 other crops are also grown on the farms and provide 10-69 percent of household income (Bymolt, Laven, and Tyszler 2018). The main tree cash crops, however, are generally the source of most household income. For example, an estimated 78 percent of household income in Ghana comes from cocoa compared to 90 percent in Côte d'Ivoire (Fountain and Hütz-Adams 2018) and 75 percent of income of rural populations in the humid zone of Cameroon (Mukete et al. 2018). In Liberia, 38 percent of household income comes from food crop sales and 39 percent from tree crops (cocoa, rubber, coffee) (Kolleh 2016).

Nearly all households in the lowland humid system have multiple income sources, and multiple household members typically engage in income-generating activities - for example, to support households in Ghana and Côte d'Ivoire (table 8.2) (Bymolt, Laven, and Tyszler 2018). On average, in 2016 a cocoa household in Ghana generates cocoa revenues of $\$ 1,885$ per year, or a net income of $\$ 1,510$ from cocoa after accounting for input and hired labour costs. In Ghana, the average cocoa-based farming household earns $\$ 2,487$ per annum from all income sources, equivalent to $\$ 6,784$ purchasing power parity (PPP) (2016). In Côte d'Ivoire, an average cocoa household income generates cocoa revenues of $\$ 2,029$ and a net cocoa income of $\$ 1,908$. In Côte d'Ivoire, the average
(1) Background and understanding

(2) Regional drivers

(3) Regional organisations

(4) Agro-pastoralism-based

(5) Grains-and-legumes-based

6) Rice-and-horticulture

(7) Coastal maritime fisheries

Tropical mixed tree and food crops systems

8.1 Definitions

8.2 Demography and geography

8.3 Regional consumption and production trends

8.4 Livelihoods of producer communities

8.5 Production systems

8.6 Food system outcomes

8.7 Institutional drivers

8.8 Risks and resilience

8.9 The COVID-19 pandemic

8.10 Agency and development interventions

8.11 Summing up References

9 Toward enhanced resilience 
household income of $\$ 2,900$ is equivalent to $\$ 7,429$ PPP (2016). Thus, despite the emphasis on cash crops, especially cocoa, poverty among cocoa farmers in Côte d'Ivoire and Ghana is common (Bymolt, Laven, and Tyszler 2018).

The level of farming intensification also affects incomes (Cerda et al. 2014). In other countries producing these cash crops, such as Liberia and Sierra Leone, large-scale plantations and out-grower schemes create different income dynamics with mixed tree and food crops systems (rubber, cocoa, and coffee), accounting for 34 percent of agricultural GDP in 2009. Cocoa, the second-most important export crop after rubber, provided income for an estimated 11 percent of the rural agricultural population in 2012, and coffee, 5 percent, together accounting for around 17 percent of total employment (Schroth et al. 2015). A typical smallholder cocoa farm in West Africa yields 650 kilograms per hectare per year, generating $\$ 2,000$ to $\$ 3,000$ a year (ICCO 2007), although loweryielding countries such as Cameroon, Nigeria, Sierra Leone, and Libera generate less than Ghana and Côte d'Ivoire (Hütz-Adams et al. 2016).

\begin{tabular}{lrrrr} 
& Cocoa & $\begin{array}{r}\text { Ghana } \\
\text { Noncocoa } \\
\text { farming }\end{array}$ & $\begin{array}{r}\text { Côte d'Ivoire } \\
\text { farming }\end{array}$ & $\begin{array}{r}\text { Noncocoa } \\
\text { farming }\end{array}$ \\
\hline $\begin{array}{l}\text { Average percentage of } \\
\text { household income from } \\
\text { different sources }\end{array}$ & $61 \%$ & $10 \%$ & $66 \%$ & $5 \%$ \\
\hline $\begin{array}{l}\text { Average percentage of } \\
\text { household income from } \\
\text { sale of other crops }\end{array}$ & $20 \%$ & $56 \%$ & $24 \%$ & $69 \%$ \\
\hline $\begin{array}{l}\text { Average household net } \\
\text { cocoa income for cocoa } \\
\text { farming households } \\
\text { (US } \$ \text { /farm) }\end{array}$ & $\$ 1,510$ & & & \\
\hline $\begin{array}{l}\text { Average household total } \\
\text { incom } \text { from }\end{array}$ & & & & \\
\hline
\end{tabular}

income from all sources

(all households)

(2016 US\$/household)

Table 8.2 Incomes for Cocoa and Mixed Farming Households in Côte d'Ivoire and Ghana, 2016

Source: Bymolt, Laven, and Tyszler 2018.
On a national level, cash crops contribute to food security through exports that generate foreign currency and income to import food or invest in domestic production (Achterbosch et al. 2014). The area taken by specific food crops, nonfood crops, and cash crops in these systems is dynamic, even though they are perennial tree systems, which generally have longer maturity, investment, rotation, and renewal periods than other perennial crops. Both the number of farmers in these systems per country and the numbers of farmers associated with food cash crops and land area are notoriously difficult to estimate (Dixon et al. 2001, 2020; Gockowski 2020). For the West African Highlands, recent data are difficult to find. In the lowland humid zone, there are an estimated 1.5 to 2 million West African cocoa farmers on 4.5 million farms (Cocoa Action 2018; Fountain and Hütz-Adams 2018; Wessel and Quist-Wessel 2015).

As these systems produce food mainly for household consumption, food cash crops, and nonfood products (consumed mainly in other geographies), there may be trade-offs between the impacts of food and nonfood cash crop production, such as cocoa and coffee in the humid systems (Amanor 2012; Dupraz and Postolle 2013;

Kugelman and Levenstein 2013). As cash crops bring substantial wage and employment opportunities to rural economies and households, albeit characterised by fluctuations, over time cash crops can stimulate agricultural innovation by raising capital for agricultural investment and accelerating the buildup of institutions that enable further commercialisation. The trade-off, however, is that for cash crops to be successful, economic and environmental risks linked to cash crops must be prevented or limited. This may require risk coping to balance the benefits and risks of cash crop and food crop production in their cropping decisions to sustain their livelihood and food security (Achterbosch et al. 2014).

The cash crops in mixed food systems supply products to global consumers, mainly in the global north, with many showing increasing growth in international trade. The nominal export revenues of cash crops have shown considerable growth since the 1970 s, both in terms of value and quantity. Yet highly fluctuating prices can create volatility in export value, and while exports have increased since the 1990s, the dollar value has fluctuated, making the context volatile for individual farmers (Achterbosch et al. 2014).
(1) Background and understanding

(2) Regional drivers

(3) Regional organisations

(4) Agro-pastoralism-based

(5) Grains-and-legumes-based

(6) Rice-and-horticulture

(7) Coastal maritime fisheries

Tropical mixed tree and food crops systems

8.1 Definitions

8.2 Demography and geography

8.3 Regional consumption and production trends

8.4 Livelihoods of producer communities

8.5 Production systems

8.6 Food system outcomes

8.7 Institutional drivers

8.8 Risks and resilience

8.9 The COVID-19 pandemic

8.10 Agency and development interventions

8.11 Summing up References

9 Toward enhanced resilience 
These farming systems also produce a range of nonfood crops including wood fuel, medicines, tools, and construction materials (Nikiema 2005) as well as ecosystem services (Dumont et al. 2014; Vaast and Somarriba 2014). There are trade-off outcomes in terms of household incomes, human health, and food and nutritional security between some of the products and services produced in these systems. These trade-offs occur at different scales, such as intrahousehold, community, and ecological systems. For example, the costs of, the use of different types of, and the availability of wood fuel from the food systems also affect human health and food and nutritional security (Jin et al. 2017).

8.6.3 Environmental sustainability

The cash crops integral to the tropical mixed tree and food crops systems, which have explicit market values, act as strong incentives to overexploit the systems and degrade forest ecosystem products such as wood, fiber, and food, and services such as water purification, disease vector control, and pollination (Cohen et al. 2012). As a result, reported environmental outcomes include the following:

\section{- Farmers' expansion into secondary and primary forests to} gain new land and overcome soil fertility issues has resulted in significant degradation and loss of forest environments in which these systems are embedded (Kroeger et al. 2017; Ruf and Schroth 2004; Ruf and Zadi 1998). These forested areas themselves can provide a wide range of food and nonfood products and ecosystem services to farmers and other stakeholders (Bayala et al. 2014; Cohen et al. 2012).

- Soil erosion and degradation and resulting decreased soil fertility (and biodiversity loss) occur with intensive cash crop systems and higher input uses (Buerkert and Hiernaux 1998; Tondoh et al. 2015).

- Overharvesting of forest products results in decreased natural regeneration rates of native crop species such as baobab (Schumann et al. 2010, 2011) and shea trees (Boffa 2000) and decreased species diversity in both forest and fallows (Kalinganire et al. 2007). Overharvest increases with trade and when combined with other pressures.

- Although mixed tree and food crops systems can also support reforestation, even though their expansion contributes to deforestation, their sustainability strongly depends on the type of farming system adopted, such as monoculture, full sun or shade, or agroforestry systems.

- Crop intensification ${ }^{10}$ elsewhere may prevent further deforestation, but it potentially creates greater input costs, crop diseases, environmental pollution, and human health. Intensification of some cash crops has been supported in other regions, such as oil palm in Indonesia and coffee and cocoa in Latin America. Many West African governments still see this as an option, such as promoting oil palm expansions via large plantations and smallholders in Liberia, Sierra Leone, and Cameroon. Evidence that substantial intensification and productivity increases can be made without negative environmental impacts in cocoa and coffee production is weak (Waarts et al. 2019)

- The effect of intensifying farming systems (such as full sun versus more extensive shade, monocultures versus intercropping, agroforestry, and mixed cropping) on the quality, quantity, diversity, and duration of ecosystem services suggest that mixed farming systems host higher levels of biodiversity and provide more and higher levels of ecosystem services (Dumont et al. 2014; Vaast and Somarriba 2014; Wade et al. 2010).

8.6.4 Equity and inclusion

In much of rural West Africa land ownership, farming systems, and business are differentiated based on age, gender, and sometimes ethnic customs. Thus, the food systems can have inequitable outcomes and exclusion. Because men generally decide which trees are maintained or felled in mixed systems (Doss 2002; Quisumbing et al. 2001) and they conduct cash crop farming and trade, they determine benefits and if and how these are distributed in the household. The majority of cocoa and coffee farmers in West Africa are male, though there are some areas in Ghana, Côte d'Ivoire, Cameroon, and Nigeria where women (in their own right or as widows) own and run cash crop farms and trade (see Bymolt, Laven, and Tyszler 2018; Ingram, van Rijn, et al. 2018; Kiewisch 2015). Women benefit more from trade in subsistence crops surpluses (Colfer, Basnett, and Elias 2016). However, as the value of products such as cocoa and karite have increased and trade has become globalised, men have entered the value chains (Ingram et
(1) Background and understanding

(2) Regional drivers

(3) Regional organisations

(4) Agro-pastoralism-based

(5) Grains-and-legumes-based

6) Rice-and-horticulture

(7) Coastal maritime fisheries

Tropical mixed tree and food crops systems

8.1 Definitions

8.2 Demography and geography

8.3 Regional consumption and production trends

8.4 Livelihoods of producer communities

8.5 Production systems

8.6 Food system outcomes

8.7 Institutional drivers

8.8 Risks and resilience

8.9 The COVID-19 pandemic

8.10 Agency and development interventions

8.11 Summing up References

9 Toward enhanced resilience 
al. 2015, 2016). Young people generally have insufficient capital and rights to buy or accumulate land.

\subsection{Institutional drivers}

There have been and continue to be differing roles and ideologies of producer and consumer country governments in interventions and policies regarding cash crop commodities. National governments have provided varying levels of services to farmers, particularly since the 1950s, with the aim of exponentially increasing cash crop tree systems. In the 1990s and first decade of the twenty-first century, governments focused on crops seen as central to national economic growth or export revenues. The government authorities involved have included those responsible for agriculture, research, extension services, and trade in the highest-value cash crops, such as the Cameroon National Cocoa and Coffee Board, the Ghana Cocoa Board, Côte d'Ivoire's Conseil Café Cacao, and the Nigerian Export Promotion Council.

Intergovernment networks and associations have supported the economic interests of producer countries for the major cash crops. In 2019 an alliance between the two major global cocoa producers - Côte d'Ivoire and Ghana - was formed, dubbed the COPEC (cocoa cartel), potentially with Nigeria and Cameroon. On a regional level, financial institutions such as the African Union, African Development Bank, Common Fund for Commodities, and World Bank have long supported cash crop production systems via grants and loans. Internationally active organisations include the International Cocoa Organisation (ICCO) and the Alliance of Cocoa Producing Countries

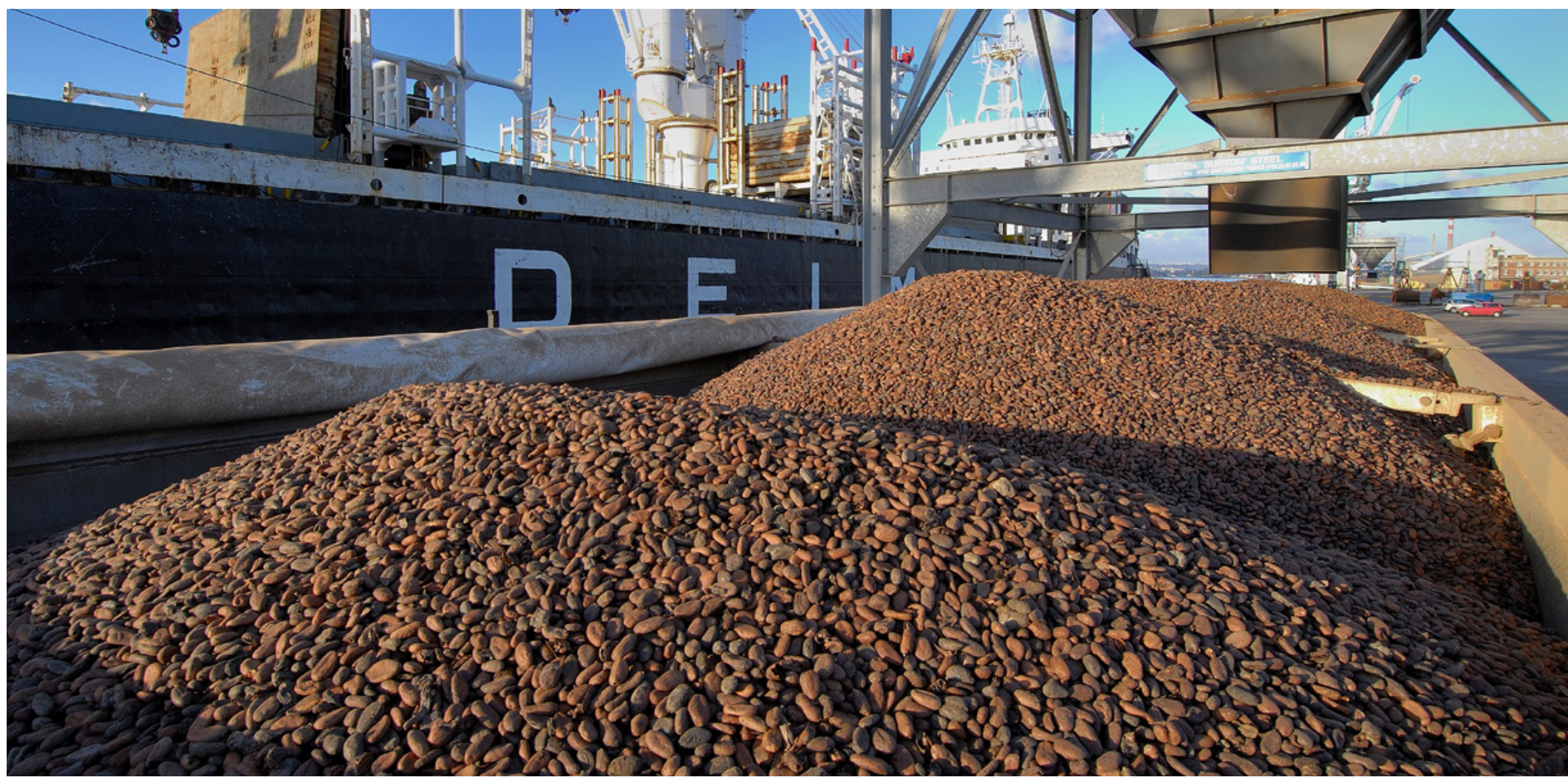

(1) Background and understanding

(2) Regional drivers

(3) Regional organisations

(4) Agro-pastoralism-based

(5) Grains-and-legumes-based

6) Rice-and-horticulture

(7) Coastal maritime fisheries

Tropical mixed tree and food crops systems

8.1 Definitions

8.2 Demography and geography

8.3 Regional consumption and production trends

8.4 Livelihoods of producer communities

8.5 Production systems

8.6 Food system outcomes

8.7 Institutional drivers

8.8 Risks and resilience

8.9 The COVID-19 pandemic

8.10 Agency and development interventions

8.11 Summing up References

9 Toward enhanced resilience 
(COPAL) - an intergovernmental organisation founded in 1962 by Ghana, Nigeria, Brazil, Côte d'Ivoire, and Cameroon.

The African Continental Free Trade Area (AfCFTA) has sought to integrate Africa's markets and facilitate regional trading after July 1 2020 by creating new impetus for investment, trade, and industrialisation. Farmer cooperatives, unions, and associations associated with the main cash crops have risen and fallen, their fortunes and roles fluctuating according to political interest by governments, the international community, and the private sector since the 1950s (Tiffen et al. 2004; Young, Sherman, and Rose 1981). They have voiced and supported farmers' interests to different extents but have largely acted as channels to aggregate production for sale to exporters and traders. There are a limited number of weak national and international umbrella organisations such as the World Cocoa Producers Organisation.

Several networks and platforms seek to promote and represent entire value chains, such as the Global Shea Alliance and the African Baobab Alliance, and national level sector associations such as Cameroon's Cocoa and Coffee Interprofessional Board. Strong, generally active, and well-funded private-sector organisations represent the main export crop traders, manufacturers-processors, and exporters on the regional, national (for example, the Cocoa Association of Nigeria), or international level (such as the World Cocoa Foundation). Many of the larger buyers in cocoa, coffee, rubber, and shea have corporate responsibility programs and projects to support the large number of local licensed agents and buyers, known as "buy'am-sell'ams" (both local companies and international traders), which generally maintain a low profile and do not engage in collective, associated actions due to high levels of competition in the sector.

International NGOs, such as the VOICE Network, Oxfam, and Solidaridad, and networks such as the International Cocoa Initiative have been active since mid- 2000 on cocoa, focusing the attention of consumers, traders, and consumer country governments on the living, working, and environmental conditions under which these crops are grown. They have also called attention to the impacts of government, private, and development projects and initiatives, such as voluntary certification, and have been involved in and have funded studies and projects on child labour, deforestation, poverty, and living income.

\subsection{Risks and resilience}

Soil fertility and soil degradation pose a risk to the productivity of the main cash crops due to degraded soils and trends toward more intensive farming practices, which deplete soil nutrients and require costly external inputs (Adejuwon and Ekanade 1988; de Graaff, Kessler, and Nibbering 2011; Hartemink 2003; Tondoh et al. 2015).

There is considerable diversity between individual countries with respect to their focus on increasing cash and subsistence crop production to keep up with population growth. Differences relate to increasing the area under cultivation, farm regeneration and support, and measures to increase crop yields (de Graaff, Kessler, and Nibbering 2011). There are uncoordinated and differing cash crop policies by countries in West Africa, and between producer and consumer countries, and between takeholders in the food systems and value chains. Many producer countries have a cash-crop commodity focus (eg on cocoa), with ineffective, uncoordinated, and duplicated interventions between different crops and countries (Capillo and Somerville-Large 2020; Waarts et al. 2019). A risk of the commodity cash crop trend is that ensuring sustainable livelihoods taking into account entire farming systems and addressing trade-offs does not happen. For example, specialising in cocoa or coffee can pose a risk of not growing food for one's own consumption (Achterbosch et al. 2014) but can also improve food security, as has been found among East African coffee farmers (Kuma et al. 2019).

Human disease outbreaks, such as Ebola and COVID-19, negatively affect the harvest and transport of crops to consumption areas as well as outputs and incomes (FAO 2016).

Trade-offs between cash crop intensification and ecosystem services present a risk to the integrity of these systems and outcomes and the role of interventions to mitigate farming practices such as
(1) Background and understanding

(2) Regional drivers

(3) Regional organisations

(4) Agro-pastoralism-based

(5) Grains-and-legumes-based

6) Rice-and-horticulture

(7) Coastal maritime fisheries

Tropical mixed tree and food crops systems

8.1 Definitions

8.2 Demography and geography

8.3 Regional consumption and production trends

8.4 Livelihoods of producer communities

8.5 Production systems

8.6 Food system outcomes

8.7 Institutional drivers

\subsection{Risks and resilience}

8.9 The COVID-19 pandemic

8.10 Agency and development interventions

8.11 Summing up References

9) Toward enhanced resilience 
agroforestry (Vaast and Somarriba 2014), afforestation (Jagoret et al. 2012), voluntary standards certification (Ingram, Waarts, and van Rijn 2018), and traditional ecological knowledge (Assembe Mvondo et al. 2009).

Farmer vulnerability and resilience can be seen at different levels in food systems, such as at the household, social and trading community, landscape, and ecosystem levels. These are affected by land and markets, which are generally governed by a mix of statutory and customary rules and institutions, with many farmers lacking secure land tenure rights and feeling unclear about the formal rules to profitably access commodity markets. Vulnerability and resilience are also affected by farmers' autonomy and freedom to choose farming and livelihood strategies, particularly when they are "locked in" or dependent upon tree crops (with long maturation and life spans) and their associated trading systems (Ingram, Waarts, and van Rijn 2018; Vicol et al. 2019).

Trade-offs affecting resilience occur at the farm, household, and macroeconomic levels. Conflicting agricultural and trade policies have stimulated tree cash crop production (in terms of desired production, yields, and incomes) over subsistence crop production (Boffa 2000; Dixon et al. 2020; Gockowski 2020; Kalinganire et al 2007), affecting the diversity, extent, and quality of ecosystem services provided by differing ratios of native and exotic trees and crops.

Other factors affecting resilience include access to knowledge, technology, and capital, enabling sustainable crop production and yield increases on the same land area (de Graaff, Kessler, and Nibbering 2011; Waarts et al. 2019). The extent of collabouration and coordination between farmers and stakeholders in the food system and associated value chain can increase farmer resilience. Coordination can develop from different, sometimes competing or conflicting motivations, which serve to increase resilience. For example, traders and buyers seek to secure supplies of quality cash crops in their supply chain and are sensitive to corporate reputation risk, as many cash crops are in the public eye and are high on trade, aid, and development agendas, such as coffee, cocoa, and oil palm (Waarts et al. 2019). There is also increasing attention by origin, producer country governments and consumer country governments to the role of cash crops in agricultural and land tenure reforms.

\subsubsection{Climate resilience}

Climate variability is expected to impact the cocoa and coffee sectors in West Africa by changing the humid climate in which these crops thrive. The area suitable for cocoa production is predicted to decrease significantly. In some areas, longer or more intense dry seasons may adversely affect production, while, conversely, increases in rainfall and/or humidity levels in other areas may create ideal conditions for the spread of cocoa pests and diseases (Läderach et al. 2013; Schroth et al. 2015). Ultimately, climate change threatens the health and nutrition of farmers who depend on income from cash crops (Läderach et al. 2013; Schroth et al. 2015).

Studies have identified the areas most at risk and the options for mitigation, such as adopting climate smart agriculture (CSA) practices that foster resilience to climate change while sustainably increasing crop productivity. The private sector and academia have been playing an increasing role in supporting the adaptation of agriculture to climate change threats, introducing high-yielding, early-maturing, drought-resistant varieties of crops and assessing the resilience of shaded agroforestry cocoa compared to full sun systems (preliminary studies show that, counterintuitively, shaded systems are more resilient) (Abdulai et al. 2018). They have also studied farmer behaviors and adopting mitigation and adaptation to climate change, such as using science-based management of productive resources (land, soil, and water), improving the storability and transportability of foods to reduce food waste and loss, and coinvesting in measures to enable farmers and the industry to adapt to pressures from climate change.

\subsubsection{Economic resilience}

The economic resilience of farmers in these systems has been affected by vicious cycles of labour shortage leading to low production, and resulting emigration, which poses a risk to maintain these systems (de Graaff, Kessler, and Nibbering 2011). Farmers are affected by the inability of current global commodity market actors, institutions, and governments in consumer and producer
(1) Background and understanding

(2) Regional drivers

(3) Regional organisations

(4) Agro-pastoralism-based

(5) Grains-and-legumes-based

6) Rice-and-horticulture

(7) Coastal maritime fisheries

Tropical mixed tree and food crops systems

8.1 Definitions

8.2 Demography and geography

8.3 Regional consumption and production trends

8.4 Livelihoods of producer communities

8.5 Production systems

8.6 Food system outcomes

8.7 Institutional drivers

\subsection{Risks and resilience}

8.9 The COVID-19 pandemic

8.10 Agency and development interventions

8.11 Summing up References

9 Toward enhanced resilience 
countries to balance supply and demand, leading to price fluctuations (Squicciarini and Swinnen 2016). Cash crop prices also do not incorporate externalities such as ecosystem degradation to reflect their "true price" (Waarts et al. 2019). Continued and new violent conflicts in the region can disrupt these systems, such as in Cameroon, Nigeria, Burkina Faso, and Côte d'Ivoire, leading to further food insecurity (Flores 2004).

\subsubsection{Sociopolitical resilience}

Long-term increased production of major cash crops is set against cyclical market boom and busts, which have short- and longer-term interlinked repercussions for prices, livelihoods, land area in production and associated deforestation, and switches to other cash crops (Clough, Faust, and Tscharntke 2009; Ruf and Siswoputranto 1995). Farmers increasingly depend on a smaller, more consolidated number of major global traders and manufacturers, exacerbating unequal power status in the global cocoa and, to a lesser extent, coffee value chains (Fountain and Hütz-Adams 2018; Ingram, van Rijn, et al. 2018). This is related to a focus of traders, governments, and some support organisations on one dominant crop rather than on interlinked food, farm, and product socioecological systems (Waarts et al. 2019).

There is a risk that increasing competition and concentration pressures on commodity prices, current national and global agricultural policies, and neoliberal market reforms to steer land use practices will result in further dispossession of some mixed food system smallholders. Here some food cash crops, such as cocoa, are replaced by nonfood crops (mainly rubber and palm oil), and customarily owned land is purchased for conversion to large-scale industrial estate production. Termed the "land grab debate"

(Amanor 2012; Kugelman and Levenstein 2013), multiple outcomes can occur - decreasing access to and dispossession of land,

decreased access to value chains, and changes in the quantity and type of crops and food grown for international markets - with implications for the local food supply. Related is a cash crop-food sovereignty risk, which may occur when long-term food security depends on food imports rather than on domestic production, with barriers to sheltering production from world price fluctuations and unfair trading (Dupraz and Postolle 2013).

\subsubsection{Food access resilience}

Food accessibility, or the capacity to have sufficient physical and economic resources to obtain appropriate foods for a nutritious diet, is another determinant of food security. Two accessibility indicators - average income levels measured by the size of GDP per capita and good road networks - provide an indication of the likelihood of economic access to food markets by households (FAO 2017). Given the context in which tropical mixed tree and food crops are grown, suggests that households and communities should have relatively high food access resilience. However, when examining the livelihood practices, institutions, knowledge, and beliefs in Ghanaian cocoa communities, characteristics of resilience can be contradictory across different spatial, temporal, and social scales, highlighting the importance of attending to social differentiation among communities (Hirons et al. 2018).

\subsection{Food system impacts of and responses to the COVID-19 pandemic}

Key informants indicated that, by mid-2019, disruption to the production of cocoa was limited since the main harvest period for West African countries ended in March 2020, just before the major outbreak of COVID-19. Farmers were able to harvest their produce before the coronavirus hit West Africa. In case some of the production was not sold, the cocoa production could be stored for a long period. This has provided farmers some flexibility as restrictions in transportation have been extended. However, if the outbreak forces governments to extend measures for a couple more months or if a second wave starts during the next harvest season, the livelihoods of farmers could be affected by COVID- 19 .

Attention should be paid to the fact that Ghana and Côte d'Ivoire together represent over 60 percent of the total world cocoa production. In case COVID-19 further emerges in these countries and forces governments to scale up measures such as stricter curfews or lockdown of ports, cocoa production might be harmed, which could cause shortages in international markets (CBI 2020).
(1) Background and understanding

(2) Regional drivers

(3) Regional organisations

(4) Agro-pastoralism-based

(5) Grains-and-legumes-based

6) Rice-and-horticulture

(7) Coastal maritime fisheries

Tropical mixed tree and food crops systems

8.1 Definitions

8.2 Demography and geography

8.3 Regional consumption and production trends

8.4 Livelihoods of producer communities

8.5 Production systems

8.6 Food system outcomes

8.7 Institutional drivers

8.8 Risks and resilience

8.9 The COVID-19 pandemic

8.10 Agency and development interventions

8.11 Summing up References

9 Toward enhanced resilience 
Exports to international markets have seemed to operate as usual Other than a short two-week period when some ports adjusted to lockdown, the cacao sector has not had any supply chain issues in West Africa due to COVID-19. Whereas some fresh food products are transported mainly by plane, most cacao exports are ocean shipments. In the first few months, no scarcity of containers was reported; hence travel restrictions have affected the cacao sector to a lesser extent (CBI 2020).

The supply chain demand for cocoa might affect farmers in production countries. Some chocolate factories in Europe, North America, and China had to close in the second and early third quarters of 2020 due to lockdowns and infections. This affected the supply chain demand and hence might have implications for prices.

Furthermore, tree and food crops that are sold on domestic markets could face challenges in transportation. The transportation of crops from the producing to consuming regions could be made difficult by travel bans, lockdowns, and curfews. In Ghana and Côte d'Ivoire, the main cities were in lockdown for several months, and transportation of fresh food products was harmed.

Palm oil is both produced and consumed in West African countries Next to consumption of domestic trade, cross-border regional and international trade between countries also takes place. Worldwide travel restrictions might affect the consumption of both regionally and internationally produced palm oil, resulting in less availability of palm oil in the local market and rising local prices.

Children may be significantly affected due to the temporary closure of schools, as they not only miss their daily school meals, which could increase food insecurity, but also may be asked to help out in the field since they are at home. During the 2013 Ebola virus disease outbreak, the closure of schools caused an increase in child labour on cocoa farms in Sierra Leone, Liberia, and Guinea.

In the first few months of the COVID-19 pandemic, there were no reports of significant changes in the consumption patterns and nutritional status of households in this food system.

\subsection{Agency and development interventions}

Recent intensification versus diversification debates by major commodity sector stakeholders in crop sectors such as cocoa and coffee could affect incomes and support given to small-scale cash crop farmers (Bymolt, Laven, and Tyszler 2018; Ingram, van Rijn, et al. 2018). This parallels a new focus on the living income of some cash crop farmers and relations between commodity buying and consumer price, production, and interventions. There is also growing realisation among value chain stakeholders of the links between low health and nutrition impacting the productivity of farming systems and we'll bring of farmers (Aginam et al. 2019; Larson et al. 2005).

The long-term impact of the massive, historic rates of deforestation in West Africa has included negative impacts on food security in terms of food quantity, diversity, and nutritional quality as access to bushmeat (Bennett et al. 2007) and plant-based food sources and fuelwood have decreased (Catarino et al. 2019; Powell et al. 2013). A major conservation concern involves the expansion of the area for cash crops, leading to a focus on how to save the last forests, particularly poorly enforced protected areas (Kroeger et al. 2017; Ruf and Schroth 2004; Ruf and Zadi 1998). One discourse addresses the colonial economics of cash crop farming given issues of land tenure security and access to land, increasing fragmentation and decreasing farm sizes, and the roles of the state and private sector in maintaining these inequities due to market protection and market-based policies on land and commodities (Oomes et al. 2016; Squicciarini and Swinnen 2016; Vellema et al. 2016).

Public-private-NGO partnerships have increasingly focused on some of the dominant tree-based cash crops (coffee, cocoa, palm oil), including voluntary certification and support programs for farmers, which were focused initially on productivity and more recently diversification. There is interest in increasing resilience by learning from traditional crop systems and traditional ecological knowledge with a focus on smallholders in cocoa, palm oil, and coffee (Carrere 2010; Jagoret et al. 2012; Potter 2015).
(1) Background and understanding

(2) Regional drivers

(3) Regional organisations

(4) Agro-pastoralism-based

5) Grains-and-legumes-based

6) Rice-and-horticulture

(7) Coastal maritime fisheries

Tropical mixed tree and food crops systems

8.1 Definitions

8.2 Demography and geography

8.3 Regional consumption and production trends

8.4 Livelihoods of producer communities

8.5 Production systems

8.6 Food system outcomes

8.7 Institutional drivers

8.8 Risks and resilience

8.9 The COVID-19 pandemic

8.10 Agency and development interventions

8.11 Summing up References

9) Toward enhanced resilience 
Increasing cooperation among local farmer communities, national authorities, and international organisations on interventions that use agroforestry - a land management practice where trees are grown around or among crops or pastureland - can be instrumental in overcoming barriers to expand agroforestry systems in the region (Tschora and Cherubini 2020).

\subsection{Summing up: toward leverage points for future interventions}

As smallholder commodity farms in these systems are highly heterogenous and their systems are highly diverse, with personal factors that influence farmers' behavior and crop choices, a tailored approach to interventions is needed. Mixed systems policies and interventions must take into account farmers' aspirations, needs, opportunities, and perceptions of risks and resilience. Policy makers must identify and analyze farmers' socioeconomic, demographic, and farm system characteristics and needs prior to implementing interventions.

Farmers who cannot earn more than a living income from their cash crop farming systems need alternatives, such as employment opportunities, so that they can move away from agriculture when land reforms are implemented. Farmers remaining in agriculture should have the opportunity to increase farm size through appropriately implemented land reforms. Such farmers should obtain support in land use change if they are situated in areas affected strongly by climate change. Such support should take into account the entire farm, not just the commodity field. When identifying farmers who can or cannot be lifted out of poverty by agriculture-based interventions, swift and effective decisions need to be made on where and how to invest time and funds. In this way, policies and programs can be implemented more cost-effectively, and farmers can avoid frustration, as well as any time and costs associated with nonadoption.

Interventions targeting major cash crops need to focus on both prices and productivity and address substitution between crops. Price increases of the cash crop commodities grown in these systems can play an important role in alleviating poverty among farmers but require supply management and government interventions in consumer and producer countries to ensure a sustainable, stable long-term income impact without negative effects on forests and biodiversity. Sustainable productivity increases of generally low-yielding smallholder grown cash crops suggest that interventions that focus on increasing productivity may also play a role in contributing to farmers' incomes and sparing land for personal and local food production.

More recognition is needed of the trade-offs between food and nutritional security, income, and environmental outcomes at different scales (household, community, and landscape) and interventions that focus on nonfood cash crops have on foods consumed by farmers. More attention is needed on the fact that that interventions already involve multiple stakeholders in the systems (value chain actors and public-private partnerships, governments, development organisations, NGOs, farmers associations, and communities). Designing and implementing effective and efficient interventions must take into account multiple pathways. Learning from experiences from different countries with similar mixed tree crop systems (such as in Brazilian, Indonesian, and Ethiopian coffee and cocoa farm systems) and looking at other tree crop commodities - could be valuable to show what works and also what interventions have failed.

Although much of the deforestation driven by the tropical mixed tree and food crop systems is now decades old, preventing further deforestation is a priority for hotspots and new frontiers, such as Sierra Leone, Liberia, and Guinea, which still have high rates of forest cover. Leverage points include producer country governments identifying hotspots and frontiers of direct and indirect cash crop commodity-based deforestation; strict enforcement of protected areas with moratoria on agriculture where needed; and convening multistakeholder platforms, landscape initiatives, and partnerships. Addressing the issue of customary and statutory tenure of lands subject to deforestation by commodities is difficult but essential in countries where good governance practices are not present. Interventions that focus on plot or farm scale also need to take into account the management and governance at a landscape and
(1) Background and understanding

(2) Regional drivers

(3) Regional organisations

(4) Agro-pastoralism-based

5) Grains-and-legumes-based

6) Rice-and-horticulture

(7) Coastal maritime fisheries

Tropical mixed tree and food crops systems

8.1 Definitions

8.2 Demography and geography

8.3 Regional consumption and production trends

8.4 Livelihoods of producer communities

8.5 Production systems

8.6 Food system outcomes

8.7 Institutional drivers

8.8 Risks and resilience

8.9 The COVID-19 pandemic

8.10 Agency and development interventions

8.11 Summing up References

9 Toward enhanced resilience 
ecosystem scale level of forested environments (Asubonteng et al. 2020).

Agroforestry can be an option to secure food security and codeliver a range of environmental benefits. More agroforestry (as opposed to single-crop farms and plantations) can offer multiple-win solutions to address major local and global environmental challenges. In shaded agroforest plantations for cocoa, coffee, oil palm, banana, and citrus in tropical humid West Africa, synergies have been found between rural development and adaptation benefits. But there is no clear relationship between biodiversity and carbon storage, and a trade-off occurs between high carbon stocks and crop yields. Trade-offs can be minimised by using a mix of tree species that store medium carbon stocks and enhance yields, soil fertility, and climate resilience. In general, plant functional diversity (in other words, a balanced mix of shade trees, fruit trees, palms, and bananas) could be a key feature of successful agroforestry systems. Agroforestry tree coproducts (such as for fodder and medicinal uses) can also be diversified sources of income for local farmers. The large-scale deployment of agroforestry in West Africa could sequester up to 135 megatons of $\mathrm{CO}_{2}$ per year over two decades (Tschora and Cherubini 2020).

Notes

1 Intercropping refers to growing two or more crops in proximity and simultaneously in the same plot, mainly to produce a greater yield on a given area by using of resources or ecological processes otherwise not utilised by a single crop.

2 Agroforestry refers to agriculture that incorporates trees and to landuse systems and technologies where woody perennials (trees, shrubs, palms, bamboos, and so on) are deliberately used on land management units as agricultural crops or animals in some form of spatial arrangement or temporal sequence (FAO 2015).

3 Factors include population density, national economic dependence upon (small-scale) agriculture or petroleum and minerals, cultural habits, alternative fuel sources to wood energy, remoteness from markets and infrastructure, and steepness of slopes in the highland areas (Fairhead and Leach 1995, 1998; Rudel 2013).

4 Although the oil palm (Elaeis guineensis) is technically a palm, not a tree, and is indigenous to West and Central Africa, commercial varieties are cultivated in many farming systems.
5 Defined as land spanning more than 0.5 hectares with trees higher than 5 meters and a canopy cover of more than 10 percent, or trees able to reach these thresholds in situ. This does not include land that is predominantly under agricultural or urban land use (FAO 2010).

6 Defined as people who for most of the time live together under the same roof and eat from the same pot.

7 According to the International Labour Organisation (ILO 2013), child labour refers to a subset of children's work (sometimes called employment or economic activity) that is injurious, negative, or undesirable to children and should be targeted for elimination. Three international conventions - the UN Convention on the Rights of the Child, ILO Convention No. 182 ("Worst Forms of Child Labour Convention"), and ILO Convention No. 138 ("Minimum Age Convention") - provide the main legal standards. These form the basis for child labour legislation enacted by signatory countries.

8 Living income is defined as the net annual income required for a household in a place to afford a decent standard of living for all members of that household. Elements of a decent standard of living include food, water, housing, education, health care, transportation, clothing, and other essential needs, including provision for unexpected events.

9 An out-grower is a farmer or landholder engaged in a contractual partnership with a company for the production of agricultural or forest products for trade.

10 Higher levels of inputs enable higher productivity on the same land area.

\section{References}

Abdulai, Issaka, Philippe Vaast, Munir P. Hoffmann, Richard Asare, Laurence Jassogne, Piet Van Asten, Reimund P. Rötter, and Sophie Graefe. 2018.

"Cocoa Agroforestry Is Less Resilient to Sub-optimal and Extreme Climate Than Cocoa in Full Sun." Global Change Biology 24 (1): 273-86.

Achterbosch, Thom J., Siemen van Berkum, Gerdien W. Meijerink, H. Asbreuk, and D. A. Oudendag. 2014. Cash Crops and Food Security: Contributions to Income, Livelihood Risk and Agricultural Innovation. Wageningen, the Netherlands: LEI Wageningen Research University.

Adejuwon, J. O., and O. Ekanade. 1988. "A Comparison of Soil Properties under Different Landuse Types in a Part of the Nigerian Cocoa Belt." Catena 15 (3-4): 319-31.

Aderinto, Saheed. 2013. "Where Is the Boundary? Cocoa Conflict, Land Tenure, and Politics in Western Nigeria, 1890s-1960." Journal of Social History 47 (1): 176-95.
(1) Background and understanding

(2) Regional drivers

(3) Regional organisations

(4) Agro-pastoralism-based

(5) Grains-and-legumes-based

6) Rice-and-horticulture

(7) Coastal maritime fisheries

Tropical mixed tree and food crops systems

8.1 Definitions

8.2 Demography and geography

8.3 Regional consumption and production trends

8.4 Livelihoods of producer communities

8.5 Production systems

8.6 Food system outcomes

8.7 Institutional drivers

8.8 Risks and resilience

8.9 The COVID-19 pandemic

8.10 Agency and development interventions

\subsection{Summing up}

References

9 Toward enhanced resilience 
Aginam, Obijiofor, Robyn Alders, Kerry Arabena, Conor Ashleigh, Brigitte Bagnol, Kirsten Black, Yngve Braaten, Sean Coogan, Angus Dawson, and Chris Degeling. 2019. One Planet, One Health. Sydney: Sydney University Press.

Amanor, Kojo Sebastian. 2012. "Global Resource Grabs, Agribusiness Concentration and the Smallholder: Two West African Case Studies." Journal of Peasant Studies 39 (3-4): 731-49.

Anker, Richard, and Martha Anker. 2020. "Living Income March 2020 Update: Rural Ghana Cocoa Growing Areas of Ashanti, Central, Eastern and Western." Series 1, Report 2, Report 2, May 5, 2020. ISEAL Alliance

Arouna, Aminou, Guillaume Soullier, Patricio Mendez del Villar, and Matty Demont. 2020. "Policy Options for Mitigating Impacts of COVID-19 on Domestic Rice Value Chains and Food Security in West Africa." Global Food Security 26: 100405

Assembe Mvondo, S., Abdon Awono, Verina Ingram, Guillaume Lescuyer, Jolien Schure, Denis Sonwa, and Olufunso Somorin. 2009. L'état de l'art de bois d'énergie en RDC: Analyse institutionelle et socio économique de la filière bois d'énergie. Yaoundé, Cameroon: CIFOR / Projet Makala.

Asubonteng, Kwabena O., Karin Pfeffer, Mirjam A. F. Ros-Tonen, Isa Baud, and Daniel T Benefoh. 2020. "Integration Versus Segregation: Structural Dynamics of a Smallholder-Dominated Mosaic Landscape under Tree-Crop Expansion in Ghana." Applied Geography 118: 102201

Awono, A., R. Eba'a Atyi, D. Foundjem-Tita, and Patrice Levang. 2016 "Vegetal Non-timber Forest Products in Cameroon, Contribution to the National Economy." International Forestry Review 18 (1): 66-77.

Bandiaky-Badji, Solange. 2011. "Gender Equity in Senegal's Forest Governance History: Why Policy and Representation Matter." International Forestry Review 13 (2): 177-94

Bayala, Jules, Antoine Kalinganire, Zac Tchoundjeu, Fergus Sinclair, and Dennis Garrity. 2011. "Conservation Agriculture with Trees in the West African Sahel - A Review." ICRAF Occasional Paper 14. Mali: ICRAF

Bayala, Jules, J. Sanou, Z. Teklehaimanot, A. Kalinganire, and S. J. Ouédraogo. 2014. "Parklands for Buffering Climate Risk and Sustaining Agricultural Production in the Sahel of West Africa." Current Opinion in Environmental Sustainability 6: 28-34.

Beauchemin, Cris. 2011. "Rural-Urban Migration in West Africa: Towards a Reversal? Migration Trends and Economic Situation in Burkina Faso and Côte d'Ivoire." Population, Space and Place 17 (1): 47-72.

Bennett, Elizabeth L., Eric Blencowe, Katrina Brandon, David Brown, Robert W. Burn, Guy Cowlishaw, Glyn Davies, Holly Dublin, John E. Fa, and E. J. Milner-Gulland. 2007. "Hunting for Consensus: Reconciling Bushmeat Harvest, Conservation, and Development Policy in West and Central Africa." Conservation Biology 21 (3): 884-87.
Bergert, Daniel L. 2000. "Management Strategies of Elaeis guineenis (Oil Palm) in Response to Localised Markets in South Eastern Ghana West Africa." Master of Science in Forestry thesis. Michigan Technological University.

Berry, Sara. 2009. "Property, Authority and Citizenship: Land Claims, Politics and the Dynamics of Social Division in West Africa." Development and Change 40 (1): 23-45.

Bisseleua, Hervé, Bertin Daghela, Daniel Fotio, Alain Didier Missoup Yede and Stefan Vidal. 2013. "Shade Tree Diversity, Cocoa Pest Damage, Yield Compensating Inputs and Farmers' Net Returns in West Africa." PLOS ONE 8 (3)

Boffa, Jean Marc. 1999. "Agroforestry Parklands in Sub-Saharan Africa." In FAO Conservation Guide, 34. Rome: FAO.

Boffa, Jean Marc. 2000. "West African Agroforestry Parklands: Keys to Conservation and Sustainable Management." Unasylva 200 51: 11-17.

Bonwitt, Jesse, Michael Dawson, Martin Kandeh, Rashid Ansumana, Foday Sahr, Hannah Brown, and Ann H. Kelly, 2018. "Unintended Consequences of the 'Bushmeat Ban'in West Africa during the 2013-2016 Ebola Virus Disease Epidemic." Social Science \& Medicine 200: 166-73.

Böwer, Uwe, André Geis, and Adalbert Winkler. 2007. "Commodity Price Fluctuations and Their Impact on Monetary and Fiscal Policies in Western and Central Africa." ECB Occasional Paper 60. Frankfurt am Main, European Central Bank.

Brashares, Justin S., Peter Arcese, Moses K. Sam, Peter B. Coppolillo, Anthony R. E. Sinclair, and Andrew Balmford. 2004. "Bushmeat Hunting, Wildlife Declines, and Fish Supply in West Africa." Science 306 (5699): 1180-83.

Buerkert, Andreas, and Pierre Hiernaux. 1998. "Nutrients in the West African Sudano-Sahelian Zone: Losses, Transfers and Role of External Inputs." Zeitschrift für Pflanzenernährung und Bodenkunde 161 (4): 365-83.

Bymolt, R., A. Laven, and M. Tyszler. 2018. Demystifying the Cocoa Sector in Ghana and Côte d'Ivoire. Amsterdam: KIT.

Capillo, Antonio, and Naomi Somerville-Large. 2020. Cocoa Sustainable Livelihoods Landscape Study: Côte d'Ivoire and Ghana. A Critical Review of Initiatives across the Cocoa Sector That Aim to Achieve Sustainable Livelihoods for Cocoa Farmers and Their Communities in West Africa. London: Fairtrade Foundation \& Mondelez International.

Carrere, Ricardo. 2010. "Oil Palm in Africa: Past, Present and Future Scenarios." WRM Series on Tree Plantations 15: 111.

Carter, Becky. 2017. "Prevalence and Impacts of Child Labour in Agriculture." K4D Helpdesk Report. Brighton, UK: Institute of Development Studies.
(1) Background and understanding

(2) Regional drivers

(3) Regional organisations

(4) Agro-pastoralism-based

(5) Grains-and-legumes-based

6) Rice-and-horticulture

(7) Coastal maritime fisheries

Tropical mixed tree and food crops systems

8.1 Definitions

8.2 Demography and geography

8.3 Regional consumption and production trends

8.4 Livelihoods of producer communities

8.5 Production systems

8.6 Food system outcomes

8.7 Institutional drivers

8.8 Risks and resilience

8.9 The COVID-19 pandemic

8.10 Agency and development interventions

\subsection{Summing up}

References

9 Toward enhanced resilience 
Catarino, Luís, Maria M. Romeiras, Quintino Bancessi, Daniel Duarte, Diana Faria, Filipa Monteiro, and Margarida Moldão. 2019. "Edible Leafy Vegetables from West Africa (Guinea-Bissau): Consumption, Trade and Food Potential." Foods 8 (10): 493

CBI (Centre for the Promotion of Imports). 2020. "The European Market Potential for Baobab." In Market Information: Natural Ingredients for Health Products. Den Haag: CBI, Ministry of Foreign Affairs.

Cerda, Rolando, Olivier Deheuvels, David Calvache, Lourdes Niehaus, Yara Saenz, Justine Kent, Sergio Vilchez, Alejandra Villota, Carlos Martinez, and Eduardo Somarriba. 2014. "Contribution of Cocoa Agroforestry Systems to Family Income and Domestic Consumption: Looking Toward Intensification." Agroforestry Systems 88 (6): 957-81.

Chauveau, Jean-Pierre. 2007. Changes in Customary Land Tenure Systems in Africa. London: IIED.

Clough, Yann, Heiko Faust, and Teja Tscharntke. 2009. "Cacao Boom and Bust: Sustainability of Agroforests and Opportunities for Biodiversity Conservation." Conservation Letters 2 (5): 197-205.

Cocoa Action. 2018. Cocoa Farming. An Overview London. London: World Cocoa Foundation.

Cohen, Mathew J., Danielle King, Sharlynn Sweeney, Gemma Shepherd, and Mark Brown. 2012. "Ecosystems Services and Rural Livelihoods in the Sahel: Environmental Accounting and Wealth Surveys-Summary for Decision Makers." Malta: UNEP.

Colfer, Carol J. Pierce, Bimbika Sijapati Basnett, and Marlène Elias. 2016. Gender and Forests: Climate Change, Tenure, Value Chains and Emerging Issues. London: Earthscan.

Dangbo, Fifonsi Ayélé, Kossi Adjonou, Kouami Kokou, and Juergen Blaser. 2019. "The Socioeconomic Contribution of Detarium senegalense Seeds to Rural Livelihoods in Togo (West Africa)." International Journal of Biological and Chemical Sciences 13 (3): 1582-95.

De Graaff, Jan, Aad Kessler, and Jan Willem Nibbering. 2011. "Agriculture and Food Security in Selected Countries in Sub-Saharan Africa: Diversity in Trends and Opportunities." Food Security 3 (2): 195-213.

Degrande, Ann, Kathrin Schreckenberg, Charlie Mbosso, Paul Anegbeh, Victoria Okafor, and Jacques Kanmegne. 2006. "Farmers' Fruit Tree-Growing Strategies in the Humid Forest Zone of Cameroon and Nigeria." Agroforestry Systems 67 (2): 159-75.

Dinar, Ariel, Rashid Hassan, Robert Mendelsohn, and James Benhin. 2012. Climate Change and Agriculture in Africa: Impact Assessment and Adaptation Strategies. London: Routledge.

Dixon, J., D. P. Garrity, J.-M. Boffa, T. O. Williams, T. Amede, C. Auricht, R. Lott, and G. Mburathi. 2020. Farming Systems and Food Security in Africa.
Priorities for Science and Policy under Global Change. Oxon, New York: Earthscan Routledge.

Dixon, John, Aidan Gulliver, David Gibbon, and Malcolm Hall. 2001. Farming Systems and Poverty. Improving Farmers' Livelihoods in a Changing World. Rome: FAO.

Djurfeldt, Agnes Andersson. 2015. "Urbanisation and Linkages to Smallholder Farming in Sub-Saharan Africa: Implications for Food Security." Global Food Security 4: 1-7.

Doss, Cheryl R. 2002. "Men's Crops? Women's Crops? The Gender Patterns of Cropping in Ghana." World Development 30 (11): 1987-2000.

Dumont, E. Smith, Guy-Modeste Gnahoua, L. Ohouo, Fergus L. Sinclair, and Philippe Vaast. 2014. "Farmers in Côte d'Ivoire Value Integrating Tree Diversity in Cocoa for the Provision of Ecosystem Services." Agroforestry Systems 88 (6): 1047-66.

Dupraz, C. Laroche, and Angèle Postolle. 2013. "Food Sovereignty and Agricultural Trade Policy Commitments: How Much Leeway Do West African Nations Have?" Food Policy 38: 115-25.

Edame, Greg E., A. B. Ekpenyong, William M. Fonta, and E. J. C. Duru. 2011. "Climate Change, Food Security and Agricultural Productivity in Africa: Issues and Policy Directions." International Journal of Humanities and Social Science 1 (21): 205-23.

Fa, John E., and David Brown. 2009. "Impacts of Hunting on Mammals in African Tropical Moist Forests: A Review and Synthesis." Mammal Review 39 (4): $231-64$

Fairhead, James, and Melissa Leach. 1995. "False Forest History, Complicit Social Analysis: Rethinking Some West African Environmental Narratives." World Development 23 (6): 1023-35.

Fairhead, James, and Melissa Leach. 1998. Reframing Deforestation: Global Analyses and Local Realities with Studies in West Africa. Cambridge: Cambridge University Press.

Falconer, Julia, and Carla R. S. Koppell. 1990. The Major Significance of "Minor" Forest Products. The Local Use and Value of Forests in the West African Humid Forest Zone. Rome: FAO.

FAO (Food and Agriculture Organisation). 2010. Global Forest Resources Assessment 2010. Rome: FAO.

FAO (Food and Agriculture Organisation). 2012. Forest Resources Assessment 2015. Terms and Definitions. Working Paper 180 Rome: FAO.

FAO (Food and Agriculture Organisation). 2017. Africa Regional Overview of Food Security and Nutrition. The Challenges of Building Resilience to Shocks and Stresses 2016. Accra, Ghana: FAO.
(1) Background and understanding

(2) Regional drivers

(3) Regional organisations

(4) Agro-pastoralism-based

(5) Grains-and-legumes-based

(6) Rice-and-horticulture

(7) Coastal maritime fisheries

Tropical mixed tree and food crops systems

8.1 Definitions

8.2 Demography and geography

8.3 Regional consumption and production trends

8.4 Livelihoods of producer communities

8.5 Production systems

8.6 Food system outcomes

8.7 Institutional drivers

8.8 Risks and resilience

8.9 The COVID-19 pandemic

8.10 Agency and development interventions

\subsection{Summing up}

References

9 Toward enhanced resilience 
FAO (Food and Agriculture Organisation) and CIRAD. 2016. Impact of the Ebola Virus Disease Outbreak on Market Chains and Trade in Agricultural Products in West Africa. Dakar, Senegal: FAO.

Fenske, James. 2011. "Land Tenure and Investment Incentives: Evidence from West Africa." Journal of Development Economics 95 (2): 137-56.

Figuié, Muriel. 2016. Impact of the Ebola Virus Disease Outbreak on Market Chains and Trade of Agricultural Products in West Africa: Report for FAO REOWA (Resilience, Emergencies and Rehabilitation in West Africa). Rome: FAO.

Flores, Margarita. 2004. "Conflicts, Rural Development and Food Security in West Africa." FAO, ESA Working Paper No. 04-02, FAO, Rome.

Fountain, Antonie, and Friedel Hütz-Adams. 2018. 2018 Cocoa Barometer. The Voice Network.

Gbetnkom, Daniel. 2009. "Forest Depletion and Food Security of Poor Rural Populations in Africa: Evidence from Cameroon." Journal of African Economies 18 (2): 261-86.

Gockowski, Jim. 2020. "The Tree Crop Farming System. Stagnation, Innovation and Forest Degradation." In Farming Systems and Food Security in Africa: Priorities for Science and Policy under Global Change, p $282-$ 317 edited by J. Dixon, D. P. Garrity, J.-M. Boffa, T. O. Williams, T. Amede, C. Auricht, R. Lott, and G. Mburathi, 573pp. Oxon, New York: Earthscan Routledge.

Halewood, M., J. J. Baidu-Forson, E. Clancy, and R. S. Vodouhe. 2014. "La coopération pour le meilleur usage possible des ressources phytogénétiques en Afrique de l'Ouest et centrale: un impératif régional. Bioversity International, Rome".

Hartemink, Alfred E. 2003. Soil Fertility Decline in the Tropics: With Case Studies on Plantations. Wallingford, Cabi.

Herzog, F. 1994. "Multipurpose Shade Trees in Coffee and Cocoa Plantations in Côte d'Ivoire." Agroforestry Systems 27 (3): 259-67.

Hirons, M., E. Boyd, C. McDermott, R. Asare, A. Morel, J. Mason, Y. Malhi, and K. Norris. 2018. "Understanding Climate Resilience in Ghanaian Cocoa Communities - Advancing a Biocultural Perspective." Journal of Rural Studies 63: 120-29.

Hütz-Adams, Friedel, Claudia Huber, Irene Knoke, Pedro Morazán, and Mara Mürlebach. 2016. Strengthening the Competitiveness of Cocoa Production and Improving the Income of Cocoa Producers in West and Central Africa. Bonn, Germany: Südwind.

International Cocoa Organisation Cocoa Board (ICCO). 2007. "Sustainable Cocoa Economy: A Comprehensive and Participatory Approach." Presented at the Consultative Board on the World Cocoa Economy 12th meeting.
2007)Ingram, Verina. 2009. "NTFPs in the Congo Basin." In The Forests of the Congo Basin, State of the Forest 2008, edited by C. de Wasseige, D. Devers, P. Marcken, R. Eba'a Atyi, R. Nasi, and P. Mayaux, 159-172. Yaoundé, Cameroon: Congo Basin Forest Partnership.

Ingram, Verina. 2011. "Non-timber Forest Products from the Cloud Forests of the Cameroon Highlands." In Mountain Forests in a Changing World: Realizing Values, Addressing Challenges, edited by Martin Price, Geors Gratzer, Lalisa Alemayehu Duguma, Thomas Kohler, Daniel Maselli, and Rosalaura Romeo, 42. Rome: FAO/MPS \& SDC.

Ingram, Verina, Merel Haverhals, Sjoerd Petersen, Marlene Elias, Bimbika Sijapati Basnett, and P. Sola. 2016. "Gender and Forest, Tree and Agroforestry Value Chains." In Gender and Forests: Climate Change, Tenure, Value Chains and Emerging Issues, edited by Carol J. Pierce Colfer, Bimbika Sijapati Basnett, and Marlène Elias, p221-242. New York: Taylor and Francis.

Ingram, Verina, Ousseynou Ndoye, Donald Midoko Iponga, Julius Chupezi Tieguhong, and Robert Nasi. 2012. "Non Timber Forest Products: Contribution to National Economy and Strategies for Sustainable

Management." In The Forests of the Congo Basin. State of the Forest 2010 edited by C. de Wasseige, P. de Marcken, N. Bayol, F. Hiol Hiol, P. Mayaux, B. Desclée, R. Nasi, A. Billand, P. Defourny, and R. Eba'a, 276. Luxembourg: Office des publications de I'Union Européenne.

Ingram, Verina, Jolanda van den Berg, Mark van Oorschot, Eric Arets, and Lucas Judge. 2018. "Governance Options to Enhance Ecosystem Services in Cocoa, Soy, Tropical Timber and Palm Oil Value Chains." Environmental Management 62 (1): 128-42.

Ingram, Verina, Fedes van Rijn, Yuca Waarts, and Henk Gilhuis. 2018. "The Impacts of Cocoa Sustainability Initiatives in West Africa." Sustainability 10 (11): 42-49.

Ingram, Verina, Yuca Waarts, and Fedes van Rijn. 2018. "Cocoa Sustainability Initiatives: The Impacts of Cocoa Sustainability Initiatives in West Africa." In Achieving Sustainable Cultivation of Cocoa, edited by Pathmanathan Umaharan, Vol 5. Cambridge, UK: Burleigh Dodds.

Ingram, V. J., E. L. Yago-Quattara, Abraham Lartey, Diana Mogre, Jo Wijnands, and Jolanda van den Berg. 2015. Gender Dynamics in Cashew and Shea Value Chains from Ghana and Burkina Faso. Wageningen, the Netherlands: LEI Wageningen Research University.

Jagoret, Patrick, Isabelle Michel-Dounias, Didier Snoeck, Hervé Todem Ngnogué, and Eric Malézieux. 2012. "Afforestation of Savannah with Cocoa Agroforestry Systems: A Small-Farmer Innovation in Central Cameroon." Agroforestry Systems 86 (3): 493-504.

Jin, Sooyeon Laura, Jolien Schure, Verina Ingram, and II Byoung. 2017. Sustainable Woodfuel for Food Security. A Smart Choice: Green, Renewable and Affordable. Rome: FAO.
(1) Background and understanding

(2) Regional drivers

(3) Regional organisations

(4) Agro-pastoralism-based

(5) Grains-and-legumes-based

(6) Rice-and-horticulture

(7) Coastal maritime fisheries

Tropical mixed tree and food crops systems

8.1 Definitions

8.2 Demography and geography

8.3 Regional consumption and production trends

8.4 Livelihoods of producer communities

8.5 Production systems

8.6 Food system outcomes

8.7 Institutional drivers

8.8 Risks and resilience

8.9 The COVID-19 pandemic

8.10 Agency and development interventions

\subsection{Summing up}

References

9 Toward enhanced resilience 
Kalinganire, A., J. C. Weber, A. Uwamariya, and B. Kone. 2007. "Improving Rural Livelihoods through Domestication of Indigenous Fruit Trees in the Parklands of the Sahel." Fruit Trees 10: 186-203.

Kiewisch, Elizabeth. 2015. "Looking within the Household: A Study on Gender, Food Security, and Resilience in Cocoa-Growing Communities." Gender \& Development 23 (3): 497-513.

Klöpffer, Walter, and Mary Ann Curran. 2014. LCA Compendium: The Complete World of Life Cycle Assessment. London: Springer.

Koffi, Christophe. 2016. "Contribution des ressources arborées à la sécurité alimentaire des populations rurales dans le sud-Ouest du Burkina Faso dans un contexte de variabilité climatique." Paris: AgroParisTech, 280 p. Thèse de doctorat : Science de l'environnement.

Kolleh, Randolph Reagan. 2016. "Determinants of Farmers' Participation in Agricultural Production Cooperatives and Impact of Cooperative Membership on Farm Income in Liberia." Doctoral Dissertation M.Phil. Department of Agricultural Economics, Agribusiness, and Extension, College of Agriculture and Natural Resources, Kwame Nkrumah University of Science and Technology

Kroeger, Alan, Haseebullah Bakhtary, Franziska Haupt, and Charlotte Streck. 2017. Eliminating Deforestation from the Cocoa Supply Chain. Washington, DC: World Bank.

Kugelman, Michael, and Susan L. Levenstein. 2013. "The Global Farms Race: Land Grabs, Agricultural Investment, and the Scramble for Food Security." Island Press: Washington DC

Kuma, Tadesse, Mekdim Dereje, Kalle Hirvonen, and Bart Minten. 2019. "Cash Crops and Food Security: Evidence from Ethiopian Smallholder Coffee Producers." Journal of Development Studies 55 (6): 1267-84.

Kuwornu, John K. M., and Ditchfield P. K. Amegashie. 2013. "Analysis of Food Security Status of Farming Households in the Forest Belt of the Central Region of Ghana." Russian Journal of Agricultural and Socioeconomic Sciences 13 (1): 26-42.

Läderach, Peter, A. Martinez-Valle, Götz Schroth, and N. Castro. 2013.

"Predicting the Future Climatic Suitability for Cocoa Farming of the World's Leading Producer Countries, Ghana and Côte d'Ivoire." Climatic Change 119 (3-4): 841-54.

Larson, Bruce, Samuel Asuming-Brempong, Daniel Sarpong, Henry AnimSomuah, and Sydney Rosen. 2005. "Household Health and Cocoa Production: A Baseline Survey of Smallholder Farming Households in Western Region, Ghana." Health and Development Discussion Paper 6. Boston: Centre for International Health and Development, Boston University School of Public Health.
Lescuyer, G., R. Eba'a Atyi, Robert Nasi, and T. Fomete Nembot. 2016. "Valuing the Cameroonian Forest." International Forestry Review 18 (s1): $1-3$.

Lourme Ruiz, Alissia, Sandrine Dury, and Yves Martin-Prével. 2016.

"Consomme-t-on ce que l'on sème? Relations entre diversité de la production, revenu agricole et diversité alimentaire au Burkina Faso." Cahiers Agricultures 25:160033. DOI: 10.1051/cagri/201603

Maconachie, Roy, Tony Binns, Paul Tengbe, and Reynold Johnson. 2006. "Temporary Labour Migration and Sustainable Post-Conflict Return in Sierra Leone." GeoJournal 67 (3): 223-40.

Mitchell, Matthew I. 2011. "Insights from the Cocoa Regions in Côte d'Ivoire and Ghana: Rethinking the Migration-Conflict Nexus." African Studies Review 54 (2): 123-44

Mitchell, Matthew I. 2012. "The Political Economy of Migration and Conflict in Ghana's Cocoa Regions: Enduring Peace or Deepening Cleavages?" Pape presented at the Canadian Political Science Association Annual Meeting, Edmonton, Canada, 2012

Monastyrnaya, Elena, Jonas Joerin, Evans Dawoe, and Johan Six. 2016 Assessing the Resilience of the Cocoa Value Chain in Ghana. Zurich: Swiss Federal Institute of Technology.

Moussa, Massaoudou, Tougiani Abasse, Habou Rabiou, Moussa Aboubacar, and Larwanou Mahamane. 2020. "Analysis of the Fruit Value Chain of Two Priority Food Woody Species of Central Southern Niger, West Africa." Open Journal of Forestry 10 (3): 277.

Mukete, Ngoe, Zhou Li, Mukete Beckline, and Bobyeg Patricia. 2018. "Cocoa Production in Cameroon: A Socioeconomic and Technical Efficiency Perspective." International Journal of Agricultural Economics 3 (1): 1.

Nikiema, Albert. 2005. Agroforestry Parkland Species Diversity: Uses and Management in Semi-arid West-Africa (Burkina Faso). PhD thesis. Wageningen: Wageningen University

Nyame, Frank K. 2011. "New Regionalisms, Micro-Regionalisms, and the Migration-Conflict Nexus: Evidence from Natural Resource Sectors in West Africa." In The Ashgate Research Companion to Regionalisms,375. Ashgate.

Olaniyi, O. J. 2010. "Factors Influencing Adoption of Rubber-Based Techniques among Small-Holder Farmers in Delta State, Nigeria." Journal of Food, Agriculture \& Environment 8 (2): 391-94.

Oluyole, K. A. 2011. "Food Security Status among Cocoa Growing Households in Ondo and Kwara States of Nigeria: A Discriminant Analysis Approach." African Journal of Food, Agriculture, Nutrition and Development 11 (7): 5646-60
(1) Background and understanding

(2) Regional drivers

(3) Regional organisations

(4) Agro-pastoralism-based

5) Grains-and-legumes-based

(6) Rice-and-horticulture

(7) Coastal maritime fisheries

Tropical mixed tree and food crops systems

8.1 Definitions

8.2 Demography and geography

8.3 Regional consumption and production trends

8.4 Livelihoods of producer communities

8.5 Production systems

8.6 Food system outcomes

8.7 Institutional drivers

8.8 Risks and resilience

8.9 The COVID-19 pandemic

8.10 Agency and development interventions

\subsection{Summing up}

References

9 Toward enhanced resilience 
Oomes, N., B. Tieben, A. Laven, Ties Ammerlaan, Romy Appelman, Cindy Biesenbeek, and Eelco Buunk. 2016. Market Concentration and Price Formation in the Global Cocoa Value Chain. Amsterdam: SEO.

Papaioannou, Kostadis J. 2016. "Climate Shocks and Conflict: Evidence from Colonial Nigeria." Political Geography 50: 33-47.

Potter, Lesley. 2015. Managing Oil Palm Landscapes: A Seven-Country Survey of the Modern Palm Oil Industry in Southeast Asia, Latin America and West Africa. Bogor: CIFOR.

Powell, Bronwen, Amy Ickowitz, Stepha McMullin, Ramni Jamnadass, Christine Padoch, Miguel Pinedo-Vasquez, and Terry Sunderland. 2013. "The Role of Forests, Trees and Wild Biodiversity for Nutrition-Sensitive Food Systems and Landscapes." Expert background paper for the International Conference on Nutrition, FAO, Rome, 2013.

Powell, Bronwen, Shakuntala Haraksingh Thilsted, Amy Ickowitz, Celine Termote, Terry Sunderland, and Anna Herforth. 2015. "Improving Diets with Wild and Cultivated Biodiversity from across the Landscape." Food Security 7 (3): 535-54.

Quaye, Wilhelmina, Richard Ampadu, Justina Onumah, and Atsu Titiati. 2015. "Does the Current Land Tenurial Arrangement in Ghana Incentivise Adoption of Environmentally Sustainable Cocoa Production Practices? A Case Study of Four Selected Cocoa Growing Districts in Ghana." African Journal of Science, Technology, Innovation and Development 7 (4): 265-75.

Quisumbing, Agnes R., Ellen Payongayong, J. B. Aidoo, and Keijiro Otsuka. 2001. "Women's Land Rights in the Transition to Individualized Ownership: Implications for Tree-Resource Management in Western Ghana." Economic Development and Cultural Change 50 (1): 157-81.

Richards, Paul. 2005. "To Fight or to Farm? Agrarian Dimensions of the Mano River Conflicts (Liberia and Sierra Leone)." African Affairs 104 (417): 571-90.

Rocheleau, Dianne, and David Edmunds. 1997. "Women, Men and Trees: Gender, Power and Property in Forest and Agrarian Landscapes." World Development 25 (8): 1351-71.

Rousseau, Karen, Denis Gautier, and D. Andrew Wardell. 2015. "Coping with the Upheavals of Globalization in the Shea Value Chain: The Maintenance and Relevance of Upstream Shea Nut Supply Chain Organisation in Western Burkina Faso." World Development 66: 413-27.

Roussel, Bernard. 1994. "Usages, perception et gestion des jachères: comparaison entre une région sèche et une région humide de l'Afrique de I'Ouest." Journal d'agriculture traditionnelle et de botanique appliquée 36 (1): 29-43
Rudel, Thomas K. 2013. "The National Determinants of Deforestation in SubSaharan Africa." Philosophical Transactions of the Royal Society B: Biological Sciences 368 (1625): 20120405

Ruf, François Olivier. 2011. "The Myth of Complex Cocoa Agroforests: The Case of Ghana." Human Ecology 39 (3): 373.

Ruf, François, and Götz Schroth. 2004. "Chocolate Forests and Monocultures: A Historical Review of Cocoa Growing and Its Conflicting Role in Tropical Deforestation and Forest Conservation." In Agroforestry and Biodiversity Conservation in Tropical Landscapes, 107-34. Washington, DC: Island Press.

Ruf, François, and P. S. Siswoputranto. 1995. Cocoa Cycles: The Economics Of Cocoa Supply. Woodhead Publishing-Elsevier.

Ruf, François, and Honoré Zadi. 1998. "Cocoa: From Deforestation to Reforestation." First international workshop on sustainable cocoa growing. Smithsonian Institute. s.I. : Smithsonian Institute, 29 p. Workshop on Sustainable Cocoa Growing. 1, Panama City, Panama, 29 March 1998/3 April 1998.

Schroth, Götz, Peter Läderach, Armando Isaac Martínez Valle, and Christian Bunn. 2015. "Climate Vulnerability and Adaptation of the Smallholder Cocoa and Coffee Value Chains in Liberia." Working Paper No. 134. Copenhagen, Denmark: CGIAR Research Program on Climate Change, Agriculture and Food Security (CCAFS); International Fund for Agricultural Development (IFAD).

Schumann, Katharina, Rüdiger Wittig, Adjima Thiombiano, Ute Becker, and Karen Hahn. 2010. "Impact of Land-Use Type and Bark-and Leaf-Harvesting on Population Structure and Fruit Production of the Baobab Tree (Adansonia digitata L.) in a Semi-arid Savanna, West Africa." Forest Ecology and Management 260 (11): 2035-44.

Schumann, Katharina, Rüdiger Wittig, Adjima Thiombiano, Ute Becker, and Karen Hahn. 2011. "Impact of Land-Use Type and Harvesting on Population Structure of a Non-timber Forest Product-Providing Tree in a Semi-arid Savanna, West Africa." Biological Conservation 144 (9): 2369-76.

Siche, Raúl. 2020. "What Is the Impact of COVID-19 Disease on Agriculture?" Scientia Agropecuaria 11 (1): 3-6

Smalley, Rebecca. 2013. "Plantations, Contract Farming and Commercial Farming Areas in Africa: A Comparative Review." LACA Working Paper 055, PLAAS, Brighton, UK.

Smith, O. B. 1991. "Small Ruminant Feeding Systems for Small Scale Farmers in Humid West Africa." In The Complementarity of Feed Resources for Animal Production in Africa, In Joint Feed Resources Network Workshop on the Complementarity of Feed Resources for Animal Production in Africa, Gaborone (Botswana), 4-8 Mar 1991. ILCA, 1992.
(1) Background and understanding

(2) Regional drivers

(3) Regional organisations

(4) Agro-pastoralism-based

(5) Grains-and-legumes-based

6) Rice-and-horticulture

(7) Coastal maritime fisheries

Tropical mixed tree and food crops systems

8.1 Definitions

8.2 Demography and geography

8.3 Regional consumption and production trends

8.4 Livelihoods of producer communities

8.5 Production systems

8.6 Food system outcomes

8.7 Institutional drivers

8.8 Risks and resilience

8.9 The COVID-19 pandemic

8.10 Agency and development interventions

\subsection{Summing up}

References

9 Toward enhanced resilience 
Squicciarini, Mara P., and Johan Swinnen. 2016. The Economics of Chocolate. Oxford, UK: Oxford University Press.

Sunderland, Terry. 2011. "Food Security: Why Is Biodiversity Important?" International Forestry Review 13 (3): 265-74

Sunderland, Terry, Bronwen Powell, Amy Ickowitz, Samson Foli, Miguel Pinedo-Vasquez, Robert Nasi, and C. Padoch. 2013. "Food Security and Nutrition. The Role of Forests," Discussion paper, Centre for International Forestry Research (CIFOR), Bogor, Indonesia.

Tiffen, Pauline, Jacqui MacDonald, Haruna Maamah, and Frema Osei-Opare. 2004. "From Tree-Minders to Global Players: Cocoa Farmers in Ghana." In Chains of Fortune Linking Women Producers and Workers with Global Markets, 11-44. London: Commonwealth Secretariat.

Tondoh, Jérôme Ebagnerin, François N'guessan Kouamé, Arnauth Martinez Guéi, Blandine Sey, Armand Wowo Koné, and Noël Gnessougou. 2015. "Ecological Changes Induced by Full-Sun Cocoa Farming in Côte d'Ivoire." Global Ecology and Conservation 3: 575-95.

Trémolières, Marie, and Olivier Walther. 2017. Cross-Border Co-operation and Policy Networks in West Africa. Paris: OECD.

Tschora, Héloïse, and Francesco Cherubini. 2020. "Co-benefits and Trade-offs of Agroforestry for Climate Change Mitigation and Other Sustainability Goals in West Africa." Global Ecology and Conservation 22: e00919.

Tyszler, Marcelo, Roger Bymolt, and Anna Laven. 2018. Analysis of the Income Gap of Cocoa Producing Households in Côte d'Ivoire: Comparison of Actual Incomes with the Living Income Benchmark. Amsterdam: KIT.

U.S. Department of State. 2016. Trafficking in Persons Report. Washington, DC: U.S. Department of State, Office to Monitor and Combat Trafficking in Persons.

Vaast, Philippe, and Eduardo Somarriba. 2014. "Trade-offs between Crop Intensification and Ecosystem Services: The Role of Agroforestry in Cocoa Cultivation." Agroforestry Systems 88 (6): 947-56.

Van Vliet, Nathalie, Ole Mertz, Andreas Heinimann, Tobias Langanke, Unai Pascual, Birgit Schmook, Cristina Adams, Dietrich Schmidt-Vogt, Peter

Messerli, and Stephen Leisz. 2012. "Trends, Drivers and Impacts of Changes in Swidden Cultivation in Tropical Forest-Agriculture Frontiers: A Global Assessment." Global Environmental Change 22 (2): 418-29.

Vellema, Sietze, Anna Laven, Giel Ton, and Sander Muilerman. 2016. "Policy Reform and Supply Chain Governance." In The Economics of Chocolate,228. Oxford Scholarship Online. DOI: 10.1093/ acprof:0so/9780198726449.001.0001

Vicol, Mark, Niels Fold, Bill Pritchard, and Jeffrey Neilson. 2019. "Global Production Networks, Regional Development Trajectories and Smallholder
Livelihoods in the Global South." Journal of Economic Geography 19 (4): 973-93.

Vigneri, Marcella, and Shashi Kolavalli. 2018. Growth through Pricing Policy: The Case of Cocoa in Ghana. Rome: FAO.

Waarts, Y., V. Jansen, V. Ingram, M. Slingerland, F. van Rijn, G. Beekman J. Dengerink, J. van Vliet, E. Arets, M. Sassen, J. Guijt, and S. van Vugt. 2019. A Living Income for Smallholder Commodity Farmers and Protected Forests and Biodiversity: How Can the Private and Public Sectors Contribute? Wageningen, the Netherlands: Wageningen Research University.

Wade, Amy S. I., Alex Asase, Paul Hadley, John Mason, Kwesi OforiFrimpong, David Preece, Nat Spring, and Ken Norris. 2010. "Management Strategies for Maximizing Carbon Storage and Tree Species Diversity in Cocoa-Growing Landscapes." Agriculture, Ecosystems \& Environment 138 (3-4): 324-34.

Wessel, Marius, and P. M. Foluke Quist-Wessel. 2015. "Cocoa Production in West Africa: A Review and Analysis of Recent Developments." NJASWageningen Journal of Life Sciences 74: 1-7.

Wiersum, Kornelis Freerk. 1997. "Indigenous Exploitation and Management of Tropical Forest Resources: An Evolutionary Continuum in forest-People Interactions." Agriculture, Ecosystems \& Environment 63 (1): 1-16.

Witteveen, L. M., Margriet Goris, Rico Lie, and V. J. Ingram. 2016. Kusheh, na minem Fatu, en mi na koko farmer. Hello, I Am Fatu and I Am a cocoa farmer: A Digital Farmer Field School for Training in Cocoa Production and Certification in Sierra Leone. Wageningen, the Netherlands: Wageningen Research University Science Shop.

Woods, Dwayne. 2004. "Predatory Elites, Rents and Cocoa: A Comparative Analysis of Ghana and Côte d'Ivoire." Commonwealth \& Comparative Politics 42 (2): 224-41.

Yengoh, Genesis T. 2012. "Determinants of Yield Differences in Small-Scale Food Crop Farming Systems in Cameroon." Agriculture \& Food Security 1 (1): 19.

Young, Crawford, Neal P. Sherman, and Tim H. Rose. 1981. Cooperatives \& Development: Agricultural Politics in Ghana and Uganda. Madison, WI: University of Wisconsin Press.
(1) Background and understanding

(2) Regional drivers

(3) Regional organisations

(4) Agro-pastoralism-based

(5) Grains-and-legumes-based

(6) Rice-and-horticulture

(7) Coastal maritime fisheries

Tropical mixed tree and food crops systems

8.1 Definitions

8.2 Demography and geography

8.3 Regional consumption and production trends

8.4 Livelihoods of producer communities

8.5 Production systems

8.6 Food system outcomes

8.7 Institutional drivers

8.8 Risks and resilience

8.9 The COVID-19 pandemic

8.10 Agency and development interventions

\subsection{Summing up}

References

9 Toward enhanced resilience 


\section{Toward enhanced resilience of West African food systems}

By Bart de Steenhuijsen Piters, Joost Nelen, Verina Ingram, Bertus Wennink, and Fabien Tondel

\subsection{Demography and geography}

9.2 Food systems outputs: production and economic value

9.3 Constraints and drivers of food system change 9.4 Impacts of disease and responses affecting system vulnerability and resilience

\subsection{Food systems resilience}

9.6 Leverage points for enhancing food systems resilience

9.7 Potential roles for regional organisations

\subsection{Conclusions}

References

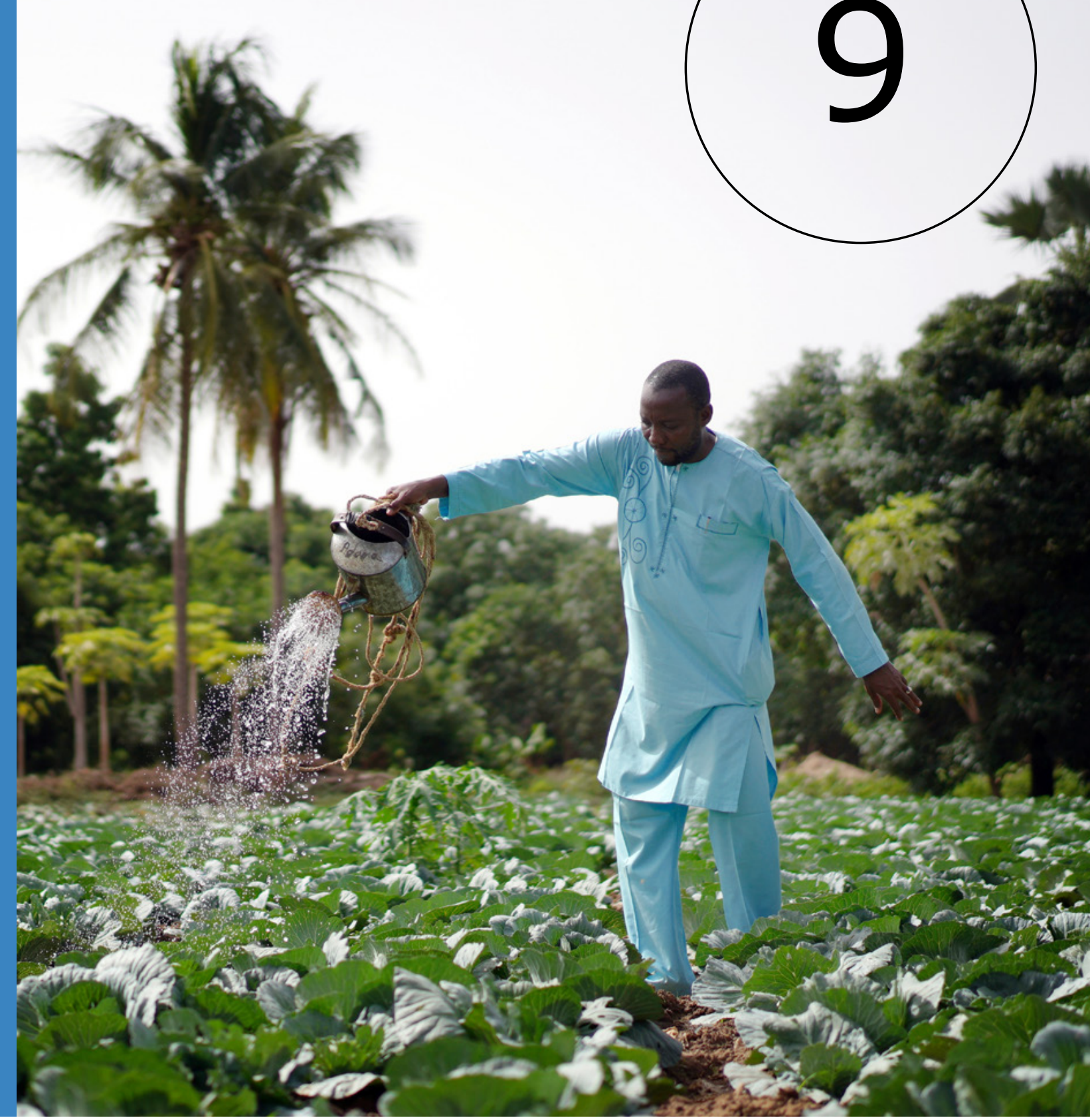


In this study, five food systems were selected to highlight and reflect important food system dynamics in the West African region (figure 9.1). This chapter begins with a summary and comparison of general features of the five food systems and continues with further analysis of their internal dynamics and ability to absorb shocks and disturbances.

Food system resilience
Climate resilience
Economic resilience
Sociopolitical resilience
Food access resilience

Figure 9.1 Food System Resilience and Intrasystem Disparities

\subsection{Demography and geography}

In total an estimated 173-193 million people inhabit West African food systems, which is 47-52 percent of the total population of West Africa (estimated at 367 million in 2015). These food systems cover all the major geographies embracing the major ecosystem and climatic zones in West Africa.

Agro-pastoralism-based food systems cover the Sahel areas of West Africa, as well as major parts of the Sahara and Sudan zones. The Sudano-Sahelian area overlaps with other food systems, and agro-pastoralists have a variable set of land tenure rights on these areas. Mobility for production and marketing is a key issue. In particular, poorer segments of pastoralist communities and young people are migrating to other areas and urban centres in search of more sustainable livelihoods.
The mixed-grains-and-legumes-based food system in the SudanoSahelian zone covers Mali, Burkina Faso, Niger, and Senegal, as well as northern parts of Guinea, Ghana, Togo, and Côte d'Ivoire. This food system interacts in various ways with the agro-pastoralism food systems, both in terms of reciprocity through exchanges of produce and other items such as manure as well as conflicting interests. In the southern parts of the system (toward the Guinean zones), there is still land available for expansion. In the other parts, due to scarcity of suitable land for agriculture and fragmentation of land tenure, there is a net outward migration, mainly of young people.

Rice-and-horticulture-based crops are included in four of the food systems, in which their production plays an important, but not always dominant, role. As such, it is important to distinguish between rain-fed upland rice, rain-fed lowland rice and vegetables, irrigated lowlands for rice and vegetables, and mangrove and floating rice. These production systems are geographically dispersed across West Africa, while the large lowland irrigation areas are concentrated in the Sahel.

The coastal maritime fisheries food system covers the whole of the West African coast and includes all fishing populations. The tropical mixed tree and food crop systems cover the mixed tree and food crop lowland and highland systems and represent the largest population of the food systems analyzed in this study (table 9.1).

a $\quad$ Millet $=14.9$ million ha (including Sahel zone); maize $=11.5$ million ha (including Guinean zone); sorghum = 14.7 million ha; cowpea $=10.7$ million ha.

b Lowland humid tree farming systems. Data on the extent of highland forest perennial systems for West Africa does not exist.
(1) Background and understanding

(2) Regional drivers

(3) Regional organisations

(4) Agro-pastoralism-based

(5) Grains-and-legumes-based

6) Rice-and-horticulture

(7) Coastal maritime fisheries

(8) Tropical mixed tree and

8 food crops systems

9 Toward enhanced resilience

\subsection{Demography and} geography

9.2 Food systems outputs

9.3 Constraints and drivers

9.4 Impacts

9.5 Food systems resilience

9.6 Leverage points

9.7 Potential roles for regional organisations

9.8 Conclusions References

\begin{tabular}{llllll} 
& $\begin{array}{l}\text { Agro-pastoralism- } \\
\text { based food systems }\end{array}$ & $\begin{array}{l}\text { Mixed-grains-and-legumes- } \\
\text { based food system in the } \\
\text { Sudano-Sahelian zones }\end{array}$ & $\begin{array}{l}\text { Rice-and- } \\
\text { horticulture-crops- } \\
\text { based food systems }\end{array}$ & $\begin{array}{l}\text { Coastal maritime } \\
\text { fisheries food system }\end{array}$ & $\begin{array}{l}\text { Tropical mixed } \\
\text { tree and food crop } \\
\text { systems }\end{array}$ \\
\hline Population (millions) & $17-25$ & 30 & $18-24$ & $7-12$ & $30 \mathrm{~b}$ \\
\hline Area (ha, millions) & - & $52^{\mathrm{a}}$ & $\begin{array}{l}\text { Rice: } 9.0 \\
\text { Vegetables: } 4.4\end{array}$ & $\begin{array}{l}<1 \text { percent of total } \\
\text { area in West Africa }\end{array}$ \\
\hline
\end{tabular}

Table 9.1 Population and Area of the Five Food Systems. Sources: All references and data sources can be found in the respective chapters. 


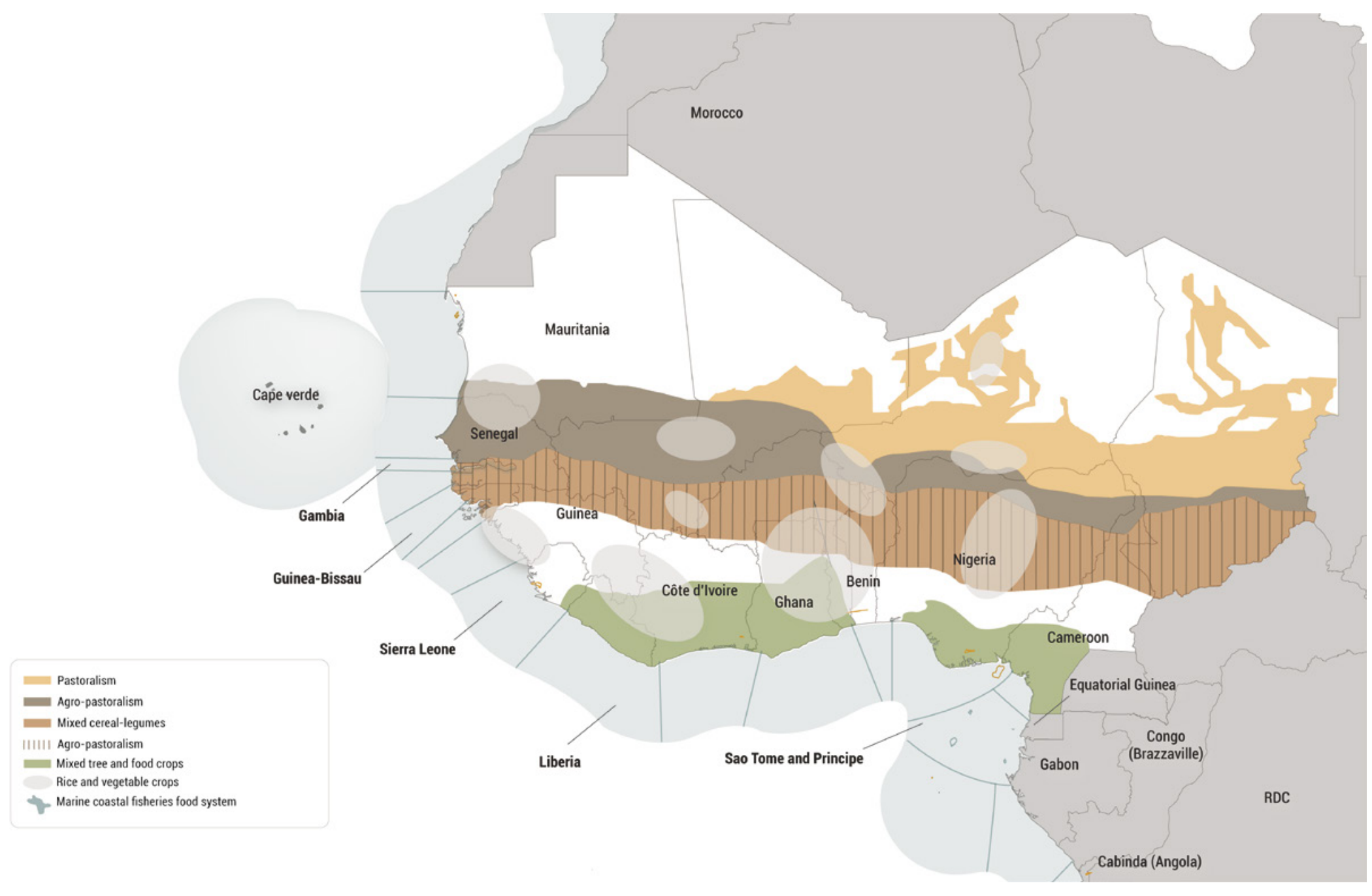

Map 9.1 The Five Food Systems

\subsection{Food systems outputs: production and} economic value

\subsubsection{Food production}

All five food systems produce a wide variety of crops, tree products, fish, and livestock, but each is dominated by one or more food products that are produced for home consumption and trade. The latter mainly serves to supply urban and semi-urban consumers and, in some systems, constitutes cash crops for producers, which contribute to the diets of consumers globally.

Approximately 70 percent of all meat consumed in West Africa originates from the agro-pastoralism-based food system. For dairy products, the contribution lies between 80 percent for rural
(1) Background and understanding

(2) Regional drivers

(3) Regional organisations

(4) Agro-pastoralism-based

(5) Grains-and-legumes-based

(6) Rice-and-horticulture

(7) Coastal maritime fisheries

8 Tropical mixed tree and

8 food crops systems

9 Toward enhanced resilience

9.1 Demography and geography

9.2 Food systems outputs

9.3 Constraints and drivers

9.4 Impacts

9.5 Food systems resilience

9.6 Leverage points

9.7 Potential roles for regional organisations

9.8 Conclusions References 
households in the Sahel to 20 percent or less in cities and coastal areas. This cross-border trade contributes 12-19 percent of GDP to Sahelian countries. The coastal maritime fisheries food system is an important contributor to per capita fish consumption, which ranges from 1.4 kilograms in Guinee-Bissau to 32.3 kilograms in Sierra Leone. Yet, most countries still have levels of omega-3 intake far below those recommended.

Table 9.2 suggests that the economic value of fish trade outstrips that of traded animal products by agro-pastoralists by a factor 7 to 8. But it is highly likely that the value of registered livestock trade is significantly underestimated, as most transactions take place informally. In 2018 Burkina Faso, Mali, and Niger together supplied an estimated 65 percent of West Africa's millet, 60 percent of the cowpea, 40 percent of the sorghum, and 25 percent of the maize production. The tropical mixed tree and food crop food systems produce a wide variety of food traded locally and to urban areas, though data showing the value and volume of the tubers, legumes, seeds/nuts, and fruits is lacking.

a Data include Nigeria.

b Millet, sorghum, maize, and cowpea production for 2018 of Burkina Faso, Mali, and Niger. c All data include Nigeria. Data concerning irrigated rice is in milled equivalents. Rain-fed upland and lowland rice taken into account in other systems.

The total for all milled rice was around 13 million tons in 2018 .

d Trade in central basin from Sahel to coast. No reliable data available.

e The total value of domestic rice was around $\$ 5.2$ billion, and the value of vegetables was around \$8.3 billion in 2016 .

f Cocoa from Ghana, Côte d'Ivoire, Cameroon, and Nigeria.

These data indicate that West Africa is to a large extent selfsufficient in its main food supplies. This may not reflect annual variations, related, for example, to climate variability and economic shocks, which may cause periodic regional food deficits. Regional production, processing, and trade are very important contributors to GDP but at household level are also significant sources of income to people operating in food production and food value chains.

9.2.2 Food and nutrition security

This section contains a comparison of indicators of food and nutrition security of producer communities and other people dependent on food systems. Table 9.3 highlights that in all food systems, significant numbers of households are experiencing

\begin{tabular}{|c|c|c|c|c|c|}
\hline & $\begin{array}{l}\text { Agro-pastoralism- } \\
\text { based food systems }\end{array}$ & $\begin{array}{l}\text { Mixed-grains-and-legumes- } \\
\text { based food system in the } \\
\text { Sudano-Sahelian zones }\end{array}$ & $\begin{array}{l}\text { Rice-and- } \\
\text { horticulture-crops- } \\
\text { based food systems }\end{array}$ & $\begin{array}{l}\text { Coastal maritime } \\
\text { fisheries food } \\
\text { system }\end{array}$ & $\begin{array}{l}\text { Tropical mixed tree } \\
\text { and food crop systems }\end{array}$ \\
\hline Major food products & $\begin{array}{l}\text { Cattle and small } \\
\text { ruminant products }\end{array}$ & $\begin{array}{l}\text { Coarse grains, legumes, and } \\
\text { rice }\end{array}$ & Rice and vegetables & Fish & $\begin{array}{l}\text { Seeds/nuts, fruits, } \\
\text { tubers, and legumes }\end{array}$ \\
\hline $\begin{array}{l}\text { Total annual production } \\
\text { (megatons or number of } \\
\text { animals raised) }\end{array}$ & $\begin{array}{l}\text { Cattle: } 78 \text { million } \\
\text { Small ruminants: } 285 \\
\text { milliona }^{\text {a }}\end{array}$ & $\begin{array}{l}\text { Coarse grains: } 16.8 \text { million MT } \\
\text { Legumes: } 3.2 \text { million } \text { MT }^{\mathrm{b}} \\
\text { Rain-fed rice: } 4.7 \text { million MT }\end{array}$ & $\begin{array}{l}\text { Irrigated rice: } 18.5 \\
\text { million } \mathrm{MT} \\
\text { Vegetables: } 26.4 \\
\text { million } \mathrm{MT}^{\mathrm{c}}\end{array}$ & $\begin{array}{l}\text { Fish: } \\
\text { 2,85 million MT }\end{array}$ & $\begin{array}{l}\text { Tubers: } \\
\text { Legumes: } \\
\text { Rain-fed rice: } 5.7 \text { million } \\
\text { MT } \\
\text { Seeds/nuts: } \\
\text { Fruits: }\end{array}$ \\
\hline $\begin{array}{l}\text { Total annual economic } \\
\text { value of traded products }\end{array}$ & At least $€ 400^{d}$ & $\begin{array}{l}\text { Coarse grains: } € 14-18 \\
\text { Legumes: } € 0.4-0.8\end{array}$ & $\begin{array}{l}\text { Rice: } € 3,700 \\
\text { Vegetables: _e }\end{array}$ & $€ 3,000$ & Approx. $€ 7,800^{f}$ \\
\hline
\end{tabular}

$(€$, millions)

Table 9.2 Production and Economic Value per Food System

Sources: All references and data sources can be found in the respective chapters. 


\begin{tabular}{|c|c|c|c|c|c|}
\hline & $\begin{array}{l}\text { Agro-pastoralism- } \\
\text { based food systems }\end{array}$ & $\begin{array}{l}\text { Mixed-grains-and-legumes- } \\
\text { based food system in the } \\
\text { Sudano-Sahelian zones }\end{array}$ & $\begin{array}{l}\text { Rice-and- } \\
\text { horticulture-crops- } \\
\text { based food systems }\end{array}$ & $\begin{array}{l}\text { Coastal maritime } \\
\text { fisheries food } \\
\text { system }\end{array}$ & $\begin{array}{l}\text { Tropical mixed tree } \\
\text { and food crop systems }\end{array}$ \\
\hline $\begin{array}{l}\text { Frequency of food } \\
\text { insecurity in population }\end{array}$ & $24 \%-30 \%$ & $5 \%-19 \%$ & $7 \%-19 \%$ & $16 \%-36 \%$ & $6 \%-18 \%$ \\
\hline $\begin{array}{l}\text { Chronic malnutrition } \\
\text { (rate of stunting by } \\
\text { height for children under } \\
\text { five) }\end{array}$ & $25 \%-45 \%$ & $20 \%-30 \%$ & $20 \%-30 \%$ & $25 \%-35 \%$ & $18 \%-30 \%$ \\
\hline $\begin{array}{l}\text { Severe malnutrition (rate } \\
\text { of wasting, weight for } \\
\text { length, of children under } \\
\text { five) }\end{array}$ & $8 \%-14 \%$ & $5 \%-10 \%$ & - & - & - \\
\hline
\end{tabular}

Table 9.3 Food and Nutrition Insecurity by Food System

Sources: Data from World Bank Open Data, World Bank, Washington, DC (accessed August 31, 2020). Combined with country livelihood reports from FEWS NET Data Centre, USAID, Washington, DC (accessed August 31, 2020), and country assessments.

chronic and absolute food insecurity. Chronic insecurity affects around 25 percent of households in at least three systems. The percentage of stunted children varies between food systems and countries, with the highest prevalence in Niger (40 percent). The high rates of child stunting across all five food systems indicate the severity and impacts of food insecurity irrespective of the food system. Chronic and incidental food insecurity does not affect all households and individuals in the food systems equally, as these phenomena are highly correlated with gender and socioeconomic disparity.

a Moderate-to-severe levels according to CARI.

9.2.3 Environmental sustainability and economic inclusivity Three out of five food systems have a high negative impact on biodiversity due to the expansion of production systems into forest and savannah areas or into wetlands. Three food systems show positive impacts on carbon sequestration. The mixed tree and food crops system in the humid tropical rainforests has more positive impacts than annual production systems, though negative impacts are associated with expansion into forest areas and the use of industrial chemicals (table 9.4).

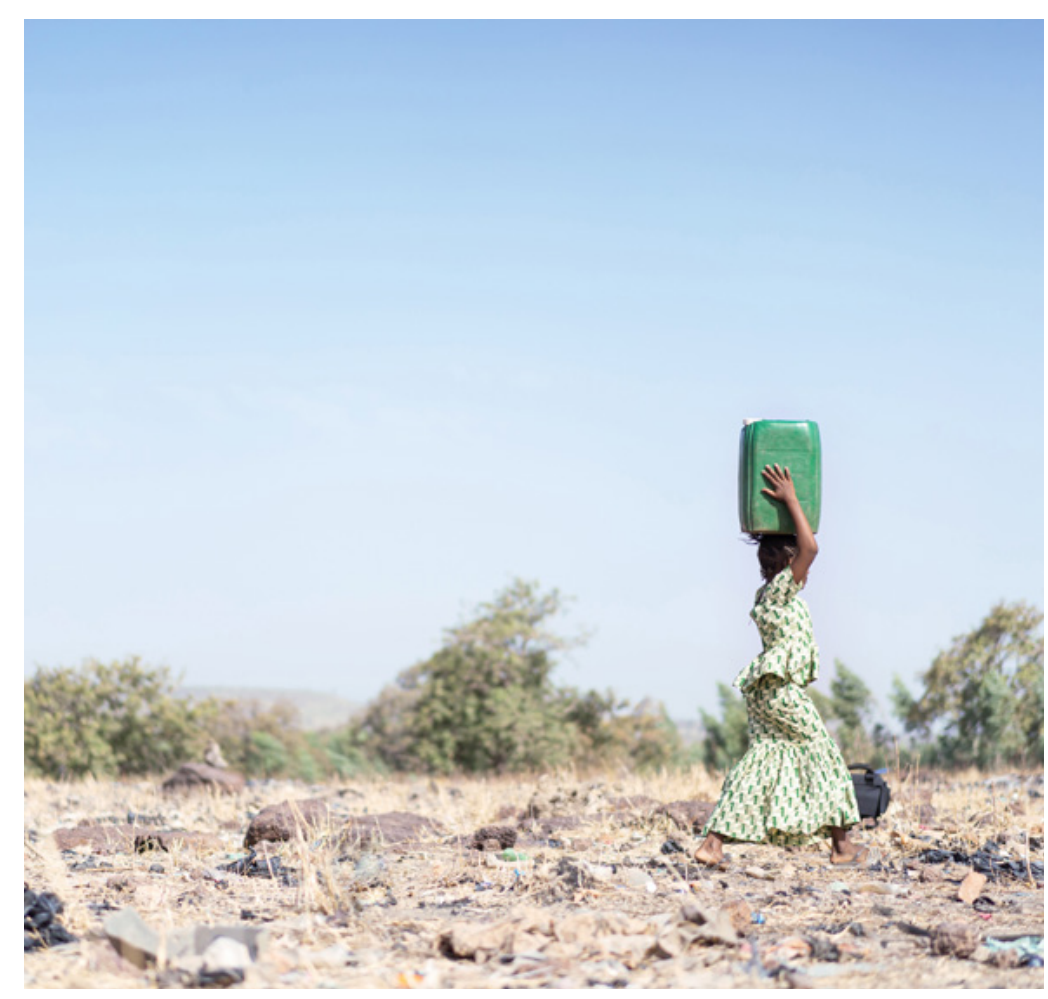

(1) Background and understanding

(2) Regional drivers

(3) Regional organisations

(4) Agro-pastoralism-based

(5) Grains-and-legumes-based

6) Rice-and-horticulture

(7) Coastal maritime fisheries

(8) Tropical mixed tree and

8 food crops systems

9 Toward enhanced resilience

9.1 Demography and geography

9.2 Food systems outputs

9.3 Constraints and drivers

9.4 Impacts

9.5 Food systems resilience

9.6 Leverage points

9.7 Potential roles for regional organisations

9.8 Conclusions References 


\begin{tabular}{|c|c|c|c|c|c|}
\hline & $\begin{array}{l}\text { Agro-pastoralism- } \\
\text { based food systems }\end{array}$ & $\begin{array}{l}\text { Mixed-grains-and-legumes- } \\
\text { based food system in the } \\
\text { Sudano-Sahelian zones }\end{array}$ & $\begin{array}{l}\text { Rice-and- } \\
\text { horticulture-crops- } \\
\text { based food systems }\end{array}$ & $\begin{array}{l}\text { Coastal maritime } \\
\text { fisheries food } \\
\text { system }\end{array}$ & $\begin{array}{l}\text { Tropical mixed tree } \\
\text { and food crop systems }\end{array}$ \\
\hline $\begin{array}{l}\text { Soil and water } \\
\text { conservation }\end{array}$ & No negative impacts & Medium negative impacts & High negative impacts & $\begin{array}{l}\text { Limited negative } \\
\text { impacts }\end{array}$ & Positive impacts \\
\hline Carbon sequestration & Positive contribution ${ }^{a}$ & No contribution & $\begin{array}{l}\text { Small positive } \\
\text { contribution }^{\mathrm{b}}\end{array}$ & No contribution & Positive contribution ${ }^{c}$ \\
\hline $\begin{array}{l}\text { Greenhouse gas } \\
\text { emissions }\end{array}$ & Limited contribution & Limited contribution & High contribution & No contribution & No contribution ${ }^{c}$ \\
\hline Biodiversity conservation & No negative impacts & High negative impacts & High negative impacts & $\begin{array}{l}\text { High negative } \\
\text { impacts }\end{array}$ & Positive impacts $^{d}$ \\
\hline
\end{tabular}

Table 9.4 Environmental sustainability per food system

a Livestock are responsible for emissions, which are neutralised (positive balance) by maintenance of savannah grass vegetation and soils.

b In the Sahel, compared to in neighbouring dry areas, irrigated lands stock considerably more carbon. Emissions are mainly nitrogen $\left(\mathrm{N}_{2} \mathrm{O}\right)$. In humid environments, coastal countries' contribution is very limited.

c As compared to annual cropping systems. Possibly negative compared to forest due to clearance.

d Associated with expansion into rainforest areas.

The rice-and-vegetable-based food system in the deltas has negative environmental impacts due to high water use, expansion into vulnerable ecosystems, and high use of industrial chemicals. The mixed-grains-and-legumes-based food system in the SudanoSahelian zones shows high variations within the system related to environmental impacts, with limited negative impacts on soil fertility when measures are applied for soil conservation and soil nutrient management. Higher negative impacts are observed when farmers lack the assets for investing in soil fertility maintenance. Moreover, cotton is the biggest input and pesticide user in the region, followed by irrigated rice.

The economic inclusivity of the five food systems is exhibited in table 9.5. Women have limited access to production assets in the agro-pastoralism-based food systems, though they can dispose of the most prominent asset, cattle. Income disparities between pastoralist households are important, and evidence indicates that they are increasing. The most important asset, livestock, is being progressively concentrated in the hands of a minority of owners (absentee agrobreeders), and impoverished pastoralist families merely manage herds, owning only a small part.

Women in the three sedentary agriculture-based food systems are generally excluded from commodity production and benefits, with the exception of rain-fed rice and vegetables, and provide a major labour input during the growing season. They are often entitled to grow, process, and trade food crops, but their access to production assets is often constrained. This is a general feature observed across sedentary agricultural food systems in West Africa. The maritime fisheries food system is not different in terms of excluding women from primary fishing activities, but women are very well represented in processing and other value chain activities, often having accumulated capital through which they have achieved boat ownership and secured their supplies of fish. As such, in the maritime fisheries food system, women have a higher economic and social status as compared to women in the other four systems.
(1) Background and understanding

(2) Regional drivers

(3) Regional organisations

(4) Agro-pastoralism-based

(5) Grains-and-legumes-based

6) Rice-and-horticulture

(7) Coastal maritime fisheries

(8) Tropical mixed tree and

8 food crops systems

9 Toward enhanced resilience

9.1 Demography and geography

9.2 Food systems outputs

9.3 Constraints and drivers

9.4 Impacts

9.5 Food systems resilience

9.6 Leverage points

9.7 Potential roles for regional organisations

9.8 Conclusions References 


\begin{tabular}{|c|c|c|c|c|c|}
\hline & $\begin{array}{l}\text { Agro-pastoralism- } \\
\text { based food systems }\end{array}$ & $\begin{array}{l}\text { Mixed-grains-and-legumes- } \\
\text { based food system in the } \\
\text { Sudano-Sahelian zones }\end{array}$ & $\begin{array}{l}\text { Rice-and- } \\
\text { horticulture-crops- } \\
\text { based food systems }\end{array}$ & $\begin{array}{l}\text { Coastal maritime } \\
\text { fisheries food system }\end{array}$ & $\begin{array}{l}\text { Tropical mixed tree } \\
\text { and food crop systems }\end{array}$ \\
\hline $\begin{array}{l}\text { Women as } \\
\text { economic actors }\end{array}$ & $\begin{array}{l}\text { Exclusion from } \\
\text { livestock meat } \\
\text { Inclusion in artisanal } \\
\text { dairy processing and } \\
\text { trade }\end{array}$ & $\begin{array}{l}\text { Exclusion from net benefits of } \\
\text { commodity production } \\
\text { Inclusion in food crop } \\
\text { production, processing, and } \\
\text { trade }\end{array}$ & $\begin{array}{l}\text { Exclusion from semi- } \\
\text { industrial processing } \\
\text { and regional trade } \\
\text { Inclusion in small-scale } \\
\text { vegetables and rice } \\
\text { production, processing, } \\
\text { and marketing }\end{array}$ & $\begin{array}{l}\text { Exclusion in fishing } \\
\text { operations } \\
\text { Inclusion in boat } \\
\text { ownership, processing, } \\
\text { and trade }\end{array}$ & $\begin{array}{l}\text { Exclusion from net } \\
\text { benefits of commodity } \\
\text { production mainly due } \\
\text { to land and cash crop } \\
\text { customary tenure } \\
\text { Inclusion in food crop } \\
\text { production and trade }\end{array}$ \\
\hline $\begin{array}{l}\text { Household } \\
\text { income disparity }\end{array}$ & $\begin{array}{l}\text { Increasing disparities } \\
\text { due to accumulation } \\
\text { of livestock and } \\
\text { limitation of access } \\
\text { to natural resources; } \\
\text { absentee owners } \\
\text { increase household } \\
\text { disparities. }\end{array}$ & $\begin{array}{l}\text { Increasing disparities due to lack } \\
\text { of access to production assets } \\
\text { by poorer segments and their } \\
\text { increasing dependence on off- } \\
\text { farm income opportunities }\end{array}$ & $\begin{array}{l}\text { Increasing disparities } \\
\text { due to lack of access } \\
\text { to production assets } \\
\text { by poorer segments } \\
\text { and focus on off-farm } \\
\text { income opportunities }\end{array}$ & $\begin{array}{l}\text { Income differences } \\
\text { between boat owners and } \\
\text { workers/crew }\end{array}$ & $\begin{array}{l}\text { Increasing disparities } \\
\text { due to lack of access } \\
\text { to production assets by } \\
\text { poorer producer and } \\
\text { focus on off-farm income } \\
\text { opportunities }\end{array}$ \\
\hline $\begin{array}{l}\text { Opportunities for } \\
\text { youth }\end{array}$ & $\begin{array}{l}\text { Limited opportunities, } \\
\text { with young people } \\
\text { used as herders and } \\
\text { a net outflux of young } \\
\text { people }\end{array}$ & $\begin{array}{l}\text { Limited opportunities due to } \\
\text { land tenure and inheritance, } \\
\text { resulting in fragmentation of } \\
\text { land } \\
\text { Increasing opportunities } \\
\text { in agribusiness and food } \\
\text { processing but limited access to } \\
\text { finance }\end{array}$ & $\begin{array}{l}\text { Limited opportunities } \\
\text { due to limited } \\
\text { land tenure and } \\
\text { inheritance, resulting in } \\
\text { fragmentation of land }\end{array}$ & $\begin{array}{l}\text { Limited opportunities in } \\
\text { maritime fisheries } \\
\text { Increasing opportunities } \\
\text { in fish farming if } \\
\text { supported by access to } \\
\text { funding, training, and } \\
\text { technical assistance }\end{array}$ & $\begin{array}{l}\text { Limited opportunities } \\
\text { due to land tenure and } \\
\text { inheritance, resulting in } \\
\text { land size fragmentation }\end{array}$ \\
\hline
\end{tabular}

Table 9.5 Economic Inclusivity by Food System

An overall striking feature is that the vast majority of food products in all systems are the outcomes of family farming. Industrialised capital-intensive farming is rare and limited to a small group of monoculture cash crops in the tree crop areas and irrigated schemes. If possible, the farming households opt for a wide range of produce. Diversification is considered a sign of wealth and contributes to resilience. Households generally recognise and make trade-offs between growing sometimes risky cash crops and food production for subsistence use, with surpluses sold in local markets.

Household income disparities are great across the four land-based agriculture food systems, with a class of subsistence and market- oriented households capable of feeding their families and accumulating capital. The share of self-provisioning of food is highest for the wealthier ones. All household categories are in some way oriented at self-provisioning and commercialisation. The differences are more in their degree of subsistence and market orientation. A heterogeneous majority of more subsistence-oriented households depends on, besides crops and livestock, seasonal or off-farm labour and other economic activities for income generation. The proportion by household class fluctuates, very generally, around 10 percent for commercial, 10-20 percent for emerging/ semicommercial, and 80-70 percent for semisubsistence households (Woodhill 2020). There is growing evidence that
(1) Background and understanding

(2) Regional drivers

(3) Regional organisations

(4) Agro-pastoralism-based

(5) Grains-and-legumes-based

6) Rice-and-horticulture

(7) Coastal maritime fisheries

(8) Tropical mixed tree and

8 food crops systems

9 Toward enhanced resilience

9.1 Demography and geography

\subsection{Food systems outputs}

9.3 Constraints and drivers

9.4 Impacts

9.5 Food systems resilience

9.6 Leverage points

9.7 Potential roles for regional organisations

9.8 Conclusions References 
commercial and emerging households, together accounting for a maximum of 30 percent of the population, are producing the vast majority of traded food surpluses to urban markets. These households are procuring farm inputs and are main users of both public and private agricultural service delivery. However, as the level of mechanisation remains limited, they depend on the supply of labour force from semisubsistence households.

Young people in the four land-based food systems encounter major obstacles as emerging farmers due to late inheritance and

fragmentation of land. Once land is inherited, it proves too small for generating a living income from agriculture in regions with high population pressure and land saturation.

\subsection{Constraints and drivers of food system change}

The five food systems face multiple constraints that affect their integrity, productivity, and resilience. Land-based food systems are all constrained by increasing fragmentation of farm size. Climate change negatively affects four out of five food systems. Increasing socioeconomic disparities are observed across all five food systems. Competing claims and conflicts over resource use are prominent constraints in the agro-pastoralism-based food systems and mixedgrains-and-legumes-based food system in the Sudano-Sahelian zones. Trade barriers internal to the region (livestock products) and unrestricted imports (rice) are constrains associated with nonimplementation of ECOWAS regional trade policies.

Changes in the agro-pastoralism-based food systems occur as a function of regional demographic drivers, including population growth, encroachment on pastoral resources and areas (by agriculture, mining, and settlements) and growing urban demand for animal products. Over 70 percent of all livestock products consumed in West Africa originate from agro-pastoralism in Sahelian countries. The shares for dairy products lie between 80 percent in rural Sahel to 20 percent or less in cities and coastal areas. So far, these have coped with the growing demand by expanding herd sizes, intensifying trade and, by extension, livestock keeping in more humid Sudan areas. However, nontariff restrictions hamper intraregional trade and cheap imports of meat, mainly poultry and milk powder, supply increasingly urban consumers with affordable meat and dairy products. Expansion of land cultivated by sedentary farmers in Sahel as well as Sudan zones and related water use limit progressively pastoralist access to grazing areas, corridors, and water resources. This phenomenon is further aggravated by extensive land and water resource acquisitions by urban investors in pastoral areas, such as has been observed in Niger. The two expansions into land formerly used by pastoralists lead to increasing conflicts between land users. Urban investors also affect the integrity of the agro-pastoralism-based food systems by accumulating large herds. Finally, an important driver of system change includes asymmetry between national policies that limit cross-border transhumance.

\section{Drivers of changes in the mixed-grains-and-legumes-based}

food system in the Sudano-Sahelian zones include population pressure, increasing urban and rural demands for food, and land degradation and fragmentation. Farmers have responded to increased food demands mainly by expanding areas under cultivation. This is still possible in the southern Sudan zones. Where expansion is restricted due to scarcity of fallows, farmers take steps toward intensification when the required technologies are available and accessible, or they become further marginalised as agricultural producers. The latter group turns to wage labour and other economic opportunities to secure minimal levels of income. Disparities between households are increasing, excluding especially women and youths from access to primary sources of production. Conflicts with other land users are on the rise, contributing to significant human insecurity. Despite a West African regional market with no formal cross-country trade barriers for agricultural products, trade between ECOWAS member states remains hindered by restrictive national policies and informal customs procedures. Artisanal processing of food crops, mainly women's business, has always existed, and semi-industrial processing for urban markets is on the rise though is still small-scale. High transaction costs because of failing transport and energy infrastructure as well as limited private investment impede going to scale (table 9.6).
(1) Background and understanding

(2) Regional drivers

(3) Regional organisations

(4) Agro-pastoralism-based

(5) Grains-and-legumes-based

6) Rice-and-horticulture

(7) Coastal maritime fisheries

(8) Tropical mixed tree and

8 food crops systems

Toward enhanced resilience

9.1 Demography and geography

9.2 Food systems outputs

9.3 Constraints and drivers

9.4 Impacts

9.5 Food systems resilience

9.6 Leverage points

9.7 Potential roles for regional organisations

9.8 Conclusions References 


\begin{tabular}{|c|c|c|c|c|}
\hline $\begin{array}{l}\text { Agro-pastoralism-based food } \\
\text { systems }\end{array}$ & $\begin{array}{l}\text { Mixed-grains-and-legumes- } \\
\text { based food system in the } \\
\text { Sudano-Sahelian zones }\end{array}$ & $\begin{array}{l}\text { Rice-and-horticulture- } \\
\text { crops-based food } \\
\text { systems }\end{array}$ & $\begin{array}{l}\text { Coastal maritime } \\
\text { fisheries food system }\end{array}$ & $\begin{array}{l}\text { Tropical mixed tree and food } \\
\text { crop systems }\end{array}$ \\
\hline $\begin{array}{l}\text { Reduced cross-border mobility } \\
\text { and trade barriers }\end{array}$ & $\begin{array}{l}\text { Fragmentation of farm size } \\
\text { and absence of suitable land } \\
\text { for expansion }\end{array}$ & $\begin{array}{l}\text { Access to sustainable } \\
\text { water resources and high } \\
\text { water use footprints }\end{array}$ & $\begin{array}{l}\text { Overfishing and coastal } \\
\text { pollution }\end{array}$ & $\begin{array}{l}\text { Environmental and ecosystem } \\
\text { services degradation; trade-offs } \\
\text { between crop intensification and } \\
\text { ecosystem services }\end{array}$ \\
\hline $\begin{array}{l}\text { Progressive limitation in access } \\
\text { to grazing land and water } \\
\text { resources }\end{array}$ & $\begin{array}{l}\text { Increasing socioeconomic } \\
\text { and gender disparities and } \\
\text { declining yields by poorer } \\
\text { segments }\end{array}$ & $\begin{array}{l}\text { Bias on and maintenance } \\
\text { of large-scale irrigation } \\
\text { schemes }\end{array}$ & $\begin{array}{l}\text { Human health risks } \\
\text { associated with smoking } \\
\text { fish }\end{array}$ & $\begin{array}{l}\text { Uncoordinated policies and } \\
\text { interventions-price versus } \\
\text { productivity and unbalanced } \\
\text { supply and demand }\end{array}$ \\
\hline $\begin{array}{l}\text { Climate change impacts on } \\
\text { quality of grazing land and } \\
\text { availability of water }\end{array}$ & $\begin{array}{l}\text { Climate change impacts on } \\
\text { rainfall intensity and duration } \\
\text { of rainy season }\end{array}$ & $\begin{array}{l}\text { Processing and value } \\
\text { chain inefficiencies and } \\
\text { losses }\end{array}$ & $\begin{array}{l}\text { Increasing socioeconomic } \\
\text { and gender disparities } \\
\text { and no investment } \\
\text { opportunities by poorer } \\
\text { segments }\end{array}$ & $\begin{array}{l}\text { Climate changes affecting } \\
\text { productivity }\end{array}$ \\
\hline $\begin{array}{l}\text { Violence, displacement, and } \\
\text { militarisation }\end{array}$ & $\begin{array}{l}\text { Lack of off-farm economic } \\
\text { opportunities for poorer } \\
\text { segments, youths, and women }\end{array}$ & $\begin{array}{l}\text { Land acquisitions by } \\
\text { external actors and } \\
\text { conflicts with other land } \\
\text { and water users }\end{array}$ & $\begin{array}{l}\text { Climate change impacts } \\
\text { on fish stocks and } \\
\text { unpredictability of weather, } \\
\text { affecting human safety }\end{array}$ & Low labour productivity \\
\hline $\begin{array}{l}\text { Increasing socioeconomic } \\
\text { and gender disparities and no } \\
\text { investment or diversification } \\
\text { opportunities by poorer segments }\end{array}$ & $\begin{array}{l}\text { Conflicts with other users of } \\
\text { land and water resources }\end{array}$ & $\begin{array}{l}\text { Liberalised ECOWAS } \\
\text { trade policies and urban } \\
\text { consumer bias in imports } \\
\text { (low CETs) }\end{array}$ & $\begin{array}{l}\text { Value chain inefficiencies } \\
\text { resulting in food waste }\end{array}$ & $\begin{array}{l}\text { Landgrabs, socioeconomic and } \\
\text { gender disparity, and exclusion } \\
\text { of the poorest from access to } \\
\text { land }\end{array}$ \\
\hline
\end{tabular}

(1) Background and understanding

(2) Regional drivers

(3) Regional organisations

(4) Agro-pastoralism-based

(5) Grains-and-legumes-based

6) Rice-and-horticulture

(7) Coastal maritime fisheries

8 Tropical mixed tree and

8 food crops systems

9 Toward enhanced resilience

9.1 Demography and geography

9.2 Food systems outputs

9.3 Constraints and drivers

9.4 Impacts

9.5 Food systems resilience

9.6 Leverage points

9.7 Potential roles for regional organisations chain inefficiencies and losses. Liberalised ECOWAS rice import policies (low barriers/tariffs) have had effects on price regimes and negative impacts on domestic production. On average, 40 percent of West Africa's consumer demand for rice is met by imports.

The coastal maritime fisheries food system is driven by three important phenomena: ecosystem health and fisheries management; climate change, possibly causing up to a 21 percent decline in landed value by 2050; and population growth, urbanisation, and rising incomes, increasing demand for fish. Whereas population growth, urbanisation, and rising incomes

incentivise the fish industry, the other two phenomena impose
9.8 Conclusions References merely complementing domestic supply deficits; consumption depends on availability and accessibility, urban and cultural preferences, and import policies. Governmental interventions, including input subsidy, public extension services, and development and rehabilitation of irrigation areas, are positive drivers behind increased production. This has led to the expansion of rice-growing areas instead of higher productivity per unit land. This expansion causes high infrastructure and environmental costs. Artisanal 
constraints to sustainable increase in maritime fish catches in the coastal countries.

The tropical mixed tree and food crops systems are driven by increasing global demand for cash crops, changing traditional food systems and increasing farmer dependence, climate change affecting productivity and the extent of current major production areas, changing urban-rural relations, population growth and land use pressuring and degrading ecosystem fertility, and calls for corporate social responsibility in the cash crop commodity value chains by Western consumers.

Common denominators among drivers of change in West African food systems are population growth and developing consumer markets, land scarcity and declining soil fertility, and natural resource conflicts. Gender inequality and socioeconomic disparities are present, to various degrees, among all food systems.

Functioning regional markets, be they regulated by ECOWAS

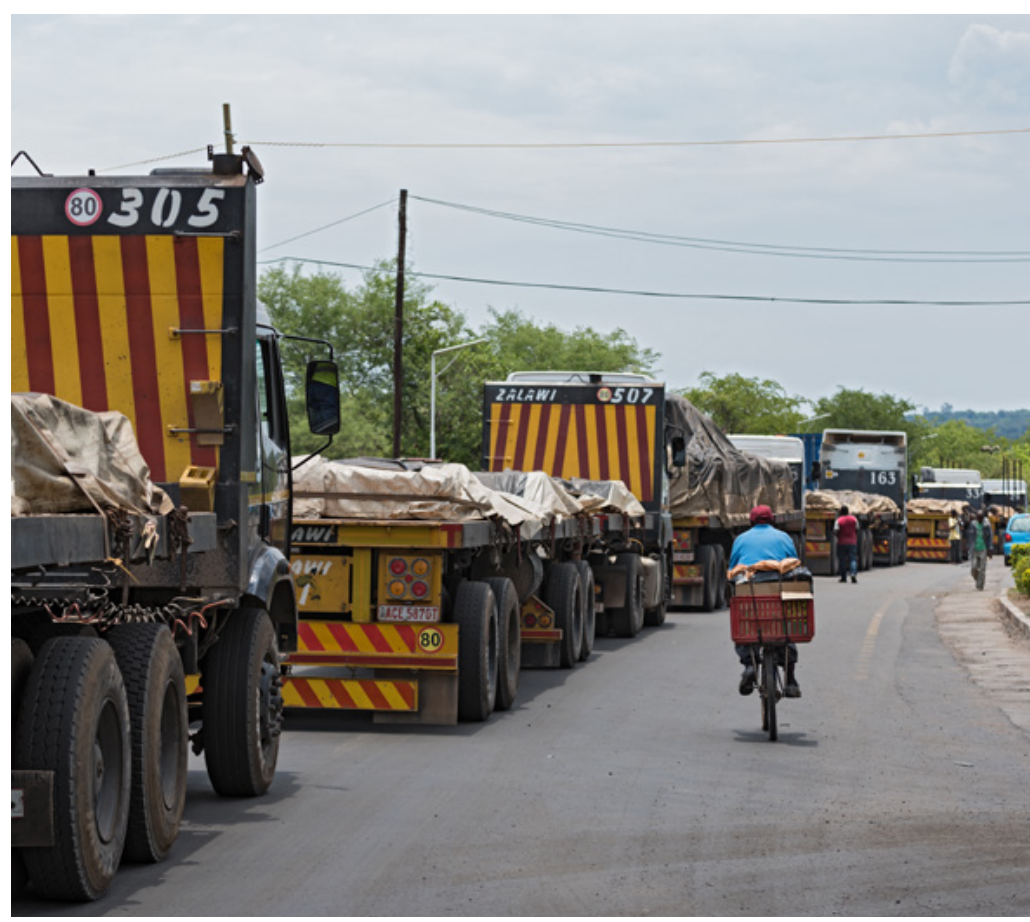

agreements and national policies or addressed through informal networks, are key drivers of food system changes in West Africa.

Without denying the necessity that production follow rising demand these trends call for greater attention to the postharvest segments of the food chains: conservation, wholesaling, and retailing. They also underline the importance of national and ECOWAS policies on a wider range of strategic foods. In other words, public concerns about food insecurity can no longer be restricted to the staple grains (rice, coarse grains), though these account for a major share of caloric intake. Tubers and plantains, legumes, animal products (meat, dairy, fish), oils, and fruits and vegetables now play a strategic role from a nutritional, economic, and cultural point of view (see chapter 2 ).

\subsection{Impacts of disease and responses affecting} system vulnerability and resilience

West Africa has a history of debilitating and lethal infectious human diseases-in the past, Spanish flu and more recently HIV/AIDS, H1N1, Ebola, and COVID-19-and increasingly severe plant and animal diseases and pests (such as locusts) in part linked to climate change. These negatively affect food system vulnerability and resilience (FAO 2015). Most countries in West Africa also are affected by the multiple burden of malnutrition, with undernutrition coexisting with overweight or obesity, and rising levels of dietrelated noncommunicable diseases (FAO 2015).

In West Africa the apparent stability of HIV/AIDS prevalence rates in the 1990 s turned out to be a misconception, with rates increasing in the first decade of the twenty-first century after an initial decline as countries and regions took different response strategies. The impacts of HIV/AIDS include rural poverty, decreased mobility, and increased vulnerability due to loss of agricultural skills and knowledge, shortage of labour, loss of productive generation, weakening of institutional rural and agricultural capacity, and exacerbation of gender inequalities (FAO 2003). HIV/AIDS continues to be a threat. In Senegal, for example, economic access has been found to be the strongest predictor of severe food insecurity, and
(1) Background and understanding

(2) Regional drivers

(3) Regional organisations

(4) Agro-pastoralism-based

(5) Grains-and-legumes-based

6) Rice-and-horticulture

(7) Coastal maritime fisheries

(8) Tropical mixed tree and

food crops systems

Toward enhanced resilience

9.1 Demography and geography

9.2 Food systems outputs

9.3 Constraints and drivers

\subsection{Impacts}

9.5 Food systems resilience

9.6 Leverage points

9.7 Potential roles for regional organisations

9.8 Conclusions References 
poorly controlled HIV transmission has been found to be the strongest predictor of malnutrition (Benzekri et al. 2017).

Interventions to address food insecurity differ from those targeting malnutrition and are not well coordinated, with urban and rural areas requiring different interventions to be effective (Benzekeri et al. 2017).

The Ebola virus is estimated to have affected half a million people with severe food insecurity, mainly in the three worst-hit West African countries-Guinea, Sierra Leone, and Liberia-in the period 2013-16. The disease affected both health and human productivity and seriously disrupted economic activities as a result of restrictions imposed on movement and trade to limit disease transmission. The Reduced Coping Strategies Index (rCSI) has been used to measure the frequency and severity of the mechanisms households employ when faced with food shortages, such as skipping meals. Results showed that during the height of the pandemic, households resorted to more frequent or severe negative strategies to cope with the effects of price increases, loss of wages, disruptions to trade (both imports and exports), and inability to produce food (WFP 2017). Lessons from the Ebola outbreak were that the disease increased food insecurity, but not substantially so, and that food insecurity happened as easily in rural areas as in urban ones (Hatlebakk 2020). The Ebola epicentres had higher food insecurity than surrounding areas, and as the disease continued to spread, markets began operating at reduced capacity, with health care workers also at much higher risk of infection (Sauvage-Mar 2020).

The COVID-19 pandemic affecting West Africa since March 2020 is the most recent example of how a pandemic impacts food systems in multiple ways and on multiple levels. Travel restrictions became a widespread measure in response to COVID-19. International borders were closed throughout West Africa, including suspensions of international flights. Moreover, domestic movement in many countries was also limited as people were requested to keep travel to the minimum necessary. This has had implications for people who travel from farms to markets and vice versa. As of May 2020, West African countries had begun to ease the restrictions in movement. Burkina Faso, Cote d'Ivoire, Gabon, Guinea, and Senegal were the first countries to ease or lift curfews and lockdowns (Thurlow 2020).
The food service sector faced difficulties due to national government measures to reduce the spread of the coronavirus. In most countries, traditional urban retail food markets closed for a while and reopened after strict measures were introduced. However, in some cases the food markets stayed open, such as in Benin and Mali. Restaurants and bars were shut down in most countries, though others were more lenient such as Benin.

Throughout West Africa, schools closed due to the COVID-19 pandemic. Gradually, however, countries started to reopen their schools at the local level. On June 1, 2020, Niger became the first West African country to reopen all schools at the national level. As of August 2020, the measures and health impacts of COVID-19 had had limited effect on primary production, market linkages, and consumption and nutritional status. In the short term, restrictions on movement directly influenced many steps in agricultural value chains. As regional trade and migration of people and livestock are key features of West African food systems, mobility restrictions disrupted the availability of the agricultural labour force, livestock, agricultural inputs (such as seeds and fertiliser), and transportation of agricultural output. As most fresh produce, meat, and other perishable products are usually transported at night due to daytime heat, curfews made the transportation of these products impossible, and health checkpoints contributed to the loss and waste of food products.

In the first few months of the COVID-19 outbreak, farming production and productivity were affected to a lesser extent. In the rural areas, farmers continued their daily business as usual. However, where international borders were closed for longer periods, this affected demand for agricultural export commodities, such as the import of agricultural inputs like seeds and fertiliser, which potentially hurt agricultural productivity (FAO 2020).

Moreover, governments may be forced to cut agricultural expenses to cover the costs of fighting COVID-19. Smallholder farmers who depend on government subsidies could face difficulties in the harvest season (WFP 2020. Food transportation restrictions, such as food trucks not being allowed to enter distribution centres, ports, or markets, and reductions in air freight led to difficulties in food reaching domestic and international markets and affected the
(1) Background and understanding

(2) Regional drivers

(3) Regional organisations

(4) Agro-pastoralism-based

(5) Grains-and-legumes-based

6) Rice-and-horticulture

(7) Coastal maritime fisheries

(8) Tropical mixed tree and

8 food crops systems

Toward enhanced resilience

9.1 Demography and geography

9.2 Food systems outputs

9.3 Constraints and drivers

\subsection{Impacts}

9.5 Food systems resilience

9.6 Leverage points

9.7 Potential roles for regional organisations

9.8 Conclusions References 
short-term income of farmers and traders (WFP 2020). The WFP (2020) observed increasing food prices in Chad, Ghana, Mauritania, Niger, Nigeria, Senegal, and Sierra Leone due to transportation problems for imported food items and some domestic food products not reaching urban areas, which affected the food availability of urban consumers. In April 2020, there was a decline in food availability in Ghana, Mauritania, Niger, Nigeria, Senegal, and Sierra Leone. Although food stores and supermarkets remained open in many countries, in some countries the larger open-air markets were closed, which especially affected people working in the informal food service sector, who have few social protections (FAO 2020; WFP 2020).

Women are particularly well represented in the informal food service sector, so they may struggle to maintain their families if they cannot perform their jobs in this sector. Women are involved in all stages of the food value chain but work mainly as street vendors. There are no social protections for the women working in the informal food service sector, which could worsen their economic situation (OECD 2020;).

Infectious diseases such as HIV/AIDS, Ebola, and COVID-19 show how declines in income and unemployment can lead to decreases in the purchasing power of people and reduce the budget available for food. This harms food security and food diversity intake.

Diseases further aggravate people's nutritional status. For example, in December 2019, before the beginning of the COVID-19 pandemic, 9.4 million people required emergency food assistance, a figure that was expected to increase to 17 million at the end of the lean season (OECD 2020). Lessons learned from diseases in the last two decades suggest that food stocks that can be harvested year round, such as live animals and robust staple foods, appear to constitute a reserve in times of crisis, implying that governments should monitor food production with help of local extension services. Food aid and cash transfers may be necessary where interventions against diseases lead to lack of incomes and lockdowns of local food markets (Hatlebakk 2020). Online surveying technologies appear useful in monitoring, with West Africa learning faster than any other area due to the lethal impact of Ebola (Sauvage-Mar 2020). Highly infectious diseases, such as Ebola, and the responses to it led to disruptions across the food chain with long-term systemwide impacts on food security and nutrition (Kodish et al. 2019; Sauvage-Mar 2020). Culturally appropriate social and behavior change communications were a critical response component for improving health, nutrition, and hygiene-related behaviors through community engagement (Kodish et al. 2019).

Disease and malnutrition are intertwined, with malnutrition becoming more frequent due to droughts and water scarcity, diminishing dietary diversity, reducing food consumption and leading to water contamination. Moreover, higher exposure to infectious diseases as well as population displacement are associated with impoverishment and changes in consumption habits (UN 2010).

\subsection{Food systems resilience}

The agro-pastoralism-based food systems have proven to be intrinsically climate resilient, provided their mobility is maintained, land and water access over a wide, connected range of areas is secured, and they can stock or destock their herds at favorable terms. Intrinsic resilience is created by external factors that reduce access to grazing and refuge areas and mobility, which undermines pastoralists' anticipation to agroclimatic shocks. From this perspective, the system has reached its limits in the Sahara-Sahelian zones, and pastoralists have widened their scope in the past decades to southern Sudan areas, where they have to share natural resources with users of other systems, who can also own and keep livestock. This results in frequent competing claims over natural resource use, which negatively affects food systems resilience. As urban consumer demand for livestock products continues to increase with rising population and purchasing power by the middle class, these systems are also economically resilient, provided that ECOWAS cross-border trade agreements are respected.

However, agro-pastoralism-based food systems show less sociopolitical resilience, as threats of civil conflict, lack of political representation, and national policies to restrict free border passage increase. The latter may have major repercussions for the integrity
(1) Background and understanding

(2) Regional drivers

(3) Regional organisations

(4) Agro-pastoralism-based

(5) Grains-and-legumes-based

6) Rice-and-horticulture

(7) Coastal maritime fisheries

8 Tropical mixed tree and

8 food crops systems

Toward enhanced resilience

9.1 Demography and geography

9.2 Food systems outputs

9.3 Constraints and drivers

9.4 Impacts

9.5 Food systems resilience

9.6 Leverage points

9.7 Potential roles for regional organisations

9.8 Conclusions References 
of agro-pastoralism-based food systems, with potentially significant impacts on production and trade. This will affect pastoralist

households' access to adequate food, as well as urban consumer access to livestock products. Gender, socioeconomic, and generational disparities are important, creating intrasystem tensions and net out-migration of people.

\section{The mixed-grains-and-legumes-based food system in the} Sudano-Sahelian zones is predominantly rain-fed and has become vulnerable to climate variability because of land degradation, including declining soil fertility and vegetation, and reduction of forest-rangeland reserves. Exceptions are smallholder lowland rice and vegetable production in depressions where water is accumulated and retained for longer periods, and the last land reserves in the most humid Sudan areas (southern Mali, Burkina Faso, and Senegal, and northern Guinea, Côte-d'Ivoire, Ghana, and Togo). Due to its diversified food production and progressive increases in urban consumer demand for grains and pulses, the system is economically resilient, with very limited disturbances imposed by fluctuations in global food markets. However, a considerable portion of the mainly subsistence-oriented farmer households depends on the local food markets for their food supply. Here, an exception is made by import markets for industrial inputs, which may vary and translate into price fluctuations.

Gender disparities result in unequal access to benefits from agriculture. Young people are severely constrained in their access to land and, hence, seek other economic activities, such as mining, or migrate to urban centres. Farming communities are increasingly represented by their organisations, which enhances their sociopolitical resilience, but they often struggle to become economically viable. People are affected in specific areas by rising conflicts and influx of displaced people.

In principle, West Africa has enough land potential to raise production of rice and vegetables in different production systems. The limiting factor of the rice-and-horticulture-based food systems in irrigated lowlands is their dependency on water resources and on their management. Irrigated agriculture is by far the greatest consumer of available renewable water sources, which will reach their availability limit before 2030. Access to water is increasingly contested, and fluctuations in rainfall may affect net availability of water. Rain-fed or small-scale irrigated lowland rice and vegetables have less constraints, and their production by smallholders may offer significant opportunities for increasing domestic production while increasing the climate resilience of these production systems. Regional research and development platforms, farmers organisations, and private traders have contributed to adapted production techniques and small investments. As consumer demands for rice continue to increase, the main obstacle to more economic resilience is unrestricted imports of rice. Options to enhance economic resilience include implementation of national and ECOWAS trade policies.

The coastal maritime fisheries food system is facing less predictable weather conditions, affecting the safety of fishermen and their climate resilience. The system is under pressure because of intense legal and illegal harvesting of marine resources, pollution, and degradation due to economic activities on land and at sea. A large number of people depend on coastal marine fisheries for their livelihoods and food and nutrition security. This dependence, linked with persistent weaknesses in fisheries governance for monitoring and surveillance and facilitating comanagement, as well as unconducive fisheries agreements and fisheries subsidies for industrial fleets, has resulted in overexploitation of resources and degradation of the marine ecosystems. Fishing communities are generally fragmented and not sociopolitically resilient enough to address these negative effects. The system is neither environmentally nor economically resilient and cannot absorb more people in the nearby future unless the negative effects of industrial fleets are reduced, responsible fisheries practices are adopted, and new avenues such as fish farming are explored. The latter could add substantial resilience to the system while having the potential to include more households. Women have historically strong positions in the system and will benefit from these new economic opportunities, which will enhance the food access resilience of households. But experiences with introducing fish farming in West Africa show only modest successes. These, together with other failures, must be analyzed and understood before considering interventions for upscaling.
(1) Background and understanding

(2) Regional drivers

(3) Regional organisations

(4) Agro-pastoralism-based

(5) Grains-and-legumes-based

(6) Rice-and-horticulture

(7) Coastal maritime fisheries

Tropical mixed tree and

8 food crops systems

Toward enhanced resilience

9.1 Demography and geography

9.2 Food systems outputs

9.3 Constraints and drivers

9.4 Impacts

9.5 Food systems resilience

9.6 Leverage points

9.7 Potential roles for regional organisations

9.8 Conclusions References 
Households in the tropical mixed tree and food crops systems are affected by land tenure systems and markets. In all areas, rising pressure and higher land values undermine local or customary tenure regimes, with the risk of reducing the wide range of access and property rights to mere private ownership and titles. Most countries have legislation that recognises different rights, common pool resources, and livestock mobility, but practice often shows otherwise. The commons (forestlands, rangelands, wetlands) face an uncertain fate. They are exposed to land acquisitions, and few sanctions are taken against land speculation. Secondary rights holders such as women, pastoralists, and migrants risk being excluded from key resources to balance the trade-offs of investing and specialising in price-volatile cash crops versus food crop production. Because of these factors, the majority of households in this food system are not economically resilient and therefore vulnerable to external economic shocks and climate shocks, which affect cash crop productivity directly and indirectly, such as through pests and diseases. Trade-offs are observed between further market integration through crop intensification and the diversity, extent, and quality of ecosystem services. The food access resilience of the poorer and more vulnerable farmers segment, such as with small farm sizes and low capital, is also threatened due to vulnerability to external economic shocks.

\subsection{Leverage points for enhancing food systems} resilience

Leverage points for enhancing food systems resilience are very diverse, depending on the specific dynamics of each system.

As mobility is key to the rationale of the agro-pastoralism-based food systems, opportunities for enhancing their environmental and economic resilience are found in pro-pastoralist national legislation and ECOWAS common market policies. In other words, as pastoralism is inherently sustainable and uses the natural resources of the Sahara-Sahelian zones more optimally than any other system, protection is key. However, growth is at its limits and is mainly found in Sudano-Sahelian zones, where agro-pastoralists cohabit with people in other systems. Encroachment by sedentary farmers and large land accumulations by urban investors create stress on agro-pastoralism-based food systems. These current and potential conflicts must be deescalated and mediated between all parties affected, resulting in more inclusive land tenure and land use agreements. Food and nutrition security has to be tackled as much from the angle of the available forage base of livestock (and access to resources) as from the accessibility to staple crops and nutritious food. There has been substantial growth in livestock trade. Opportunities for women must be explored, such as by developing the dairy sector. In the end, if demographic growth continues at the same rate, the system cannot contain the increasing number of people.

Leverage points for enhancing the resilience of the mixed-grainsand-legumes-based food system are regional platforms of private-sector farmers organisations and government institutions for lobbying and advocacy for agricultural, agribusiness, and agri-food policies. Regional research and development platforms could contribute to more environmental resilience through the development and upscaling of climate smart crop and livestock varieties and sustainable intensification practices. Yet, consumer demands must be leading these innovations in production.

Semisubsistence households will require low-capital innovations that support their dietary requirements instead of market demands. These households and the many young people who depend on labour markets for income generation will benefit from employment opportunities in emerging staple food processing value chains and improvements in labour conditions. Related leverage points to achieve such resilience could include private sector development, such as processing industries, service sector development, and the strengthening of labour unions and farmers organisations. Protection of the commons and de-escalating conflicts with other natural resource users need to be highly prioritised in order to create more conducive and peaceful conditions. The last land reserves in more humid Sudan areas must be carefully managed. Specialised ECOWAS commissions (agricultural and trade policies) could be beneficial in coordinating national policies and wellinformed public investments.
(1) Background and understanding

(2) Regional drivers

(3) Regional organisations

(4) Agro-pastoralism-based

(5) Grains-and-legumes-based

6) Rice-and-horticulture

(7) Coastal maritime fisheries

(8) Tropical mixed tree and

8 food crops systems

Toward enhanced resilience

9.1 Demography and geography

9.2 Food systems outputs

9.3 Constraints and drivers

9.4 Impacts

9.5 Food systems resilience

9.6 Leverage points

9.7 Potential roles for regional organisations

9.8 Conclusions References 
Analysis of the rice-and-horticulture-based food systems in irrigated lowlands, with reference to other food systems in which rice and vegetables are produced, clearly indicates that increasing consumer demands will continue driving West Africa's rice production. Experiences during the COVID-19 pandemic have showcased again, as in 2008, that dependency on rice import results in consumer vulnerability to market volatility. Projections of increased consumer demand combined with reducing dependency on imports for strategic food items like rice further support regional rice production policies. To date, ECOWAS's liberal trade policy has constrained this goal but has the potential to become a positive driver of food systems change. The highest potential for enhancing production of rice and vegetables is found in the rain-fed lowlands and small-scale schemes. These have fewer negative impacts on the environment while generating income for large numbers of men and women. Support of localised rice processing and more efficient rice and vegetable value chains will have positive impacts on employment creation and reduction of food losses.

Enhanced environmental resilience of the coastal maritime fisheries food system can be achieved by limitation of annual catch, improved fishery practices, and enhanced conservation of fish populations, including maritime controls of international fishing vessels and offshores as well as conservation of mangrove and other fish nursery areas. These will require adequate policies, strengthening institutions, and financially supporting reinforcement capacities. As these measure will allow for the regeneration of fish populations and balanced catches, they will also limit industrial fisheries, economic benefits for fishing populations, and the absolute availability of fish for human consumption. In order to strengthen the socioeconomic resilience of the system, responsible fisheries practices and, if feasible, sustainable fish farming will have to be strongly promoted among fishing communities. This will increase affordable and (if well processed) safe fish supplies to urban consumers, favoring women, who to date are responsible for most fish trade in West Africa. Additional positive effects can be achieved through vegetable protein production for sustainable fish feed, increasing employment and income opportunities for smallholders.
Given the diversity of the tropical mixed tree and food crops systems, policies and interventions must take into account contextual and personal factors influencing farmers' behavior and crop choices in the mixed systems, living incomes from cash crops, and the governance of the wider forest environments these systems are embedded in. Interventions for the major cash crops need to focus on both prices and productivity and address substitution between crops. It is essential to recognise food and nutritional security, income, and environmental outcomes at different scales of trade-off between food and nonfood cash crops and consumed foods from the systems. Enhancing the socioeconomic-political resilience of producer organisations and positive producer-oriented policy and regulatory framework nationally and internationally could have a positive impact on market regulation in terms providing more voice and bargaining power in terms of prices and traded volumes, thus creating more long-term economic stability.

\subsection{Potential roles for regional organisations}

As highlighted, food systems are geographically dispersed across West Africa and have many cross-border characteristics, whether looking at agro-pastoral production systems, cereals and other staple foods, linkages between rural and urban markets, the movement of people to seek employment or escape drought, or fisheries in regional waters. At the same time, chronic or acute food insecurity has different effects across populations depending on location, while environmental sustainability, and especially access to water resources, relies on transboundary resources. The COVID-19 pandemic also raises challenges that require coordinated responses from countries to ensure that people and goods can continue to move across borders. All of this highlights the potential role of regional organisations to share information, guide member state policies, coordinate actions by national actors, and sometimes carry out collective action, such as joint responses to food crises due to climate shocks.

In some respects, West Africa is well endowed with regional organisational structures to help manage the cross-border aspects of food systems. The multifunctional ECOWAS, has a core mandate
(1) Background and understanding

(2) Regional drivers

(3) Regional organisations

(4) Agro-pastoralism-based

(5) Grains-and-legumes-based

(6) Rice-and-horticulture

(7) Coastal maritime fisheries

(8) Tropical mixed tree and

8 food crops systems

Toward enhanced resilience

9.1 Demography and geography

9.2 Food systems outputs

9.3 Constraints and drivers

9.4 Impacts

9.5 Food systems resilience

9.6 Leverage points

9.7 Potential roles for regional organisations

9.8 Conclusions References 
in the areas of agriculture, regional trade, industrialisation, and other sectors less directly relating to food systems such as peace and security or water and energy. The region also has specialised agencies such as CILSS to provide data and monitor agricultural production, trade, and food security conditions as an input supporting food policy making. CILSS's information system on cross-border food commodity trade flows and trade barriers is a valuable tool for this function that should be sustained.

Formally, ECOWAS has some areas of competence that can contribute to building resilience in regional food systems. By facilitating intraregional trade, it can provide incentives for investment in cross-border supply chains for both staple foods and value-added products and in the short run help mitigate production shocks by enabling the movement of agri-food products between surplus and deficit areas in the regional market. Having put in place a policy framework in which it has promoted certain sectors (rice and livestock in particular), ECOWAS has the institutional capacity to promote the development of diversified value chains, including fruits, vegetables, and pulses. The framework of the CET and more broadly the ECOWAS Common Trade Policy may offer opportunities to improve the stability of the regional market and provide incentives for producers in import-competing sectors (rice, dairy, poultry, and others). The significant progress made on the establishment of a regional food reserve for emergency needs indicates the possibility of collective action and solidarity in ECOWAS. With its implementing agency, the Regional Agency for Agriculture and Food (ARAA), ECOWAS may also support actors and territories in adjusting to the rapid transitions taking place in regional food systems, particularly in the agro-pastoral system, where it is increasingly difficult for small-scale producers and youths to sustain their livelihoods.

However, the formal role of these regional organisations must be understood alongside the informal rules of the game that shape how food systems operate in reality. State-business relations, rent seeking, and rent distribution often shape what regional agendas are implemented and how, with variations across food systems depending on how national elites view their interests. As such, regional agreements and strategies are often frustrated at the

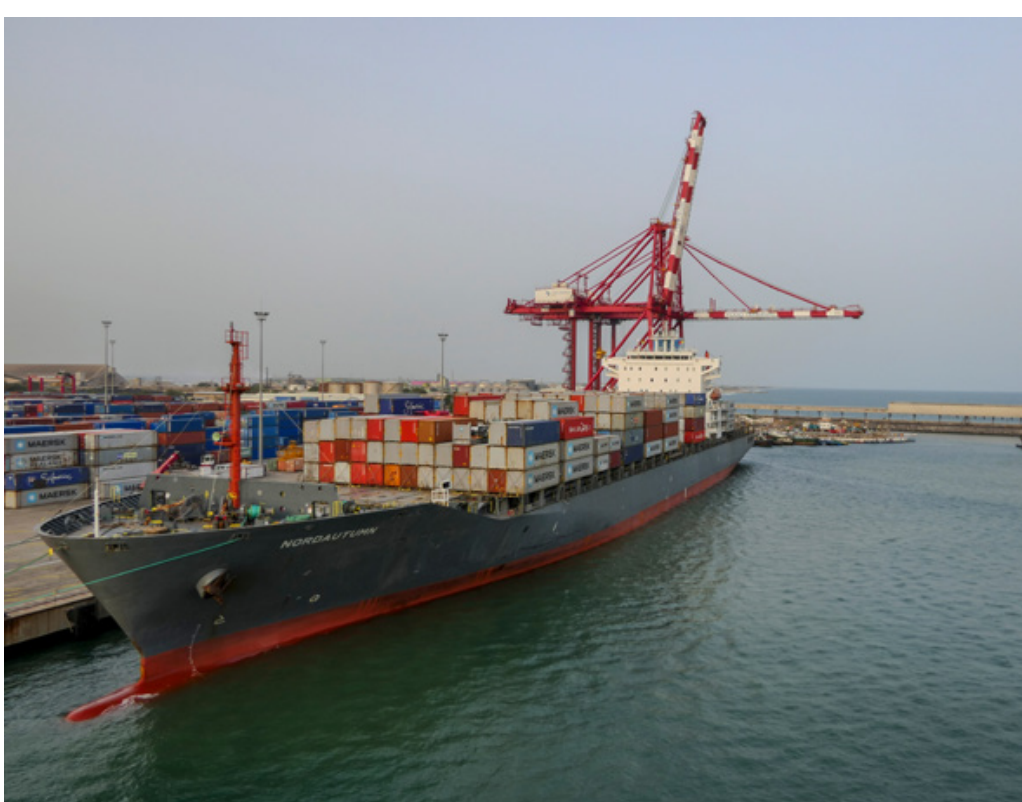

(1) Background and understanding

(2) Regional drivers

(3) Regional organisations

(4) Agro-pastoralism-based

(5) Grains-and-legumes-based

(6) Rice-and-horticulture

(7) Coastal maritime fisheries

(8) Tropical mixed tree and

8 food crops systems

Toward enhanced resilience

implementation stage, where national interests run counter to regional agreements, even though they are agreed on by heads of state. For example, whereas national policies often hinder the movement of livestock across borders, these policies also offer little protection against the influence of the international markets in the rice sector (price volatility and low-quality imported rice competing with locally produced rice). Similarly, the implicit objective in ECOWAP of exploiting comparative advantages, developing complementary production and logistic capabilities, and facilitating trade among ECOWAS countries has rarely gained traction among national actors, who have often prioritised the same sectors. Initiatives to build the adaptation and resilience of regional food systems and agri-food markets, and to strengthen coordination between countries in responding to food crises and acute malnutrition, must therefore seek to understand the often deeply embedded factors that determine the strategies pursued by various actors and their operations and how regional policies play out in practice. What appear as inefficiencies may nonetheless serve specific purposes, where existing barriers to cross-border trade and cooperation similarly serve the interests of some actors.
9.1 Demography and geography

9.2 Food systems outputs

9.3 Constraints and drivers

9.4 Impacts

9.5 Food systems resilience

9.6 Leverage points

9.7 Potential roles for regional organisations

9.8 Conclusions References 
This is not to undermine the importance of regional organisations, which often still carry a high level of political legitimacy. Rather, they should be involved with an understanding of their limitations while also seeking where national political and economic interests align to allow for collective action at the regional level. Given its convening power, ECOWAS can contribute to sustained dialogue among different categories of actors (including the powerful ones with vested interests) and between policy sectors (especially agricultural and trade policies) to identify the most beneficial measures.

\subsection{Conclusions}

The following conclusions are drawn from these findings and identification of leverage points for enhanced food systems resilience:

1 Despite promising data on domestic production, malnutrition persists in all food systems. Consumer demands for food have risen gradually over the past decades in West Africa and are projected to rise further due to increasing population, income, and economic growth. Food systems have kept pace with these increasing demands through higher domestic production and imports. In general terms-and most specifically with reference to coarse grains, tubers, legumes, and ruminant meat-most demand has been met through domestic and regional production. Important exceptions are rice, dairy, and poultry, though West African food systems have adequate potential to meet consumer demand for these products.

Although the food supply looks positive in absolute numbers, these figures do not explain the high rate of malnutrition observed among the various populations of West Africa. The numbers are alarming in terms of persistent undernutrition and rising levels of obesity. High rates of child stunting across all five food systems indicate the severity of food insecurity irrespective of the food system. Undernutrition and foodborne disease prevalence are explained by food system outcomes in terms of the affordability, accessibility, and safety of food. In other words, undernutrition is also an expression of socioeconomic poverty and is strongly associated with highly accentuated social disparities and the agroeconomic exclusion of people, notably women, observed across West Africa. Food safety issues and postharvest losses are observed in many food value chains, notably fresh vegetables and animal products (dairy and fish). These health risks hamper the consumption of the more diverse foods needed for healthy diets.

\section{Important threats to food system resilience are economic} shocks, sociopolitical instability, climate change and socioeconomic disparity. Food systems of West Africa differ significantly in their response to these threats. Food systems that depend on global markets, such as rice and poultry, and export-oriented cash crops, such as cotton, cacao, and palm oil (as drivers of mixed-crop systems), are more vulnerable to economic shocks than food systems that depend on informal, domestic, and regional markets, such as livestock products, coarse grains, and pulses. In contrast, food systems that are based on the extraction of food from natural resources, such as fisheries and pastoralism, are less resilient to climate variation when their historically evolved production systems are constrained by new drivers of change, such as industrial fisheries, encroachment on pastoral lands, and national policies restricting pastoralist mobility. Secured access to key natural resources is a prerequisite for the survival of the systems (see also conclusion 5 )

Two systems show greater climate resilience due to access to widely available natural resources. In some countries, the mixed-grain-and-legumes-based system can still expand to the southern Sudan areas, which are the last abundant land reserves with relatively low population density. The rice-andhorticulture-based systems can build on largely available surface water and groundwater reserves to sustain current irrigated lowland systems. However, there are important nuances: expansion to and clearance of Sudan areas is already taking place in an unsustainable way, at the expense of forest resources, meaning the region's real water potential is unknown
(1) Background and understanding

(2) Regional drivers

(3) Regional organisations

(4) Agro-pastoralism-based

(5) Grains-and-legumes-based

6) Rice-and-horticulture

(7) Coastal maritime fisheries

(8) Tropical mixed tree and

8 food crops systems

Toward enhanced resilience

9.1 Demography and geography

9.2 Food systems outputs

9.3 Constraints and drivers

9.4 Impacts

9.5 Food systems resilience

9.6 Leverage points

9.7 Potential roles for regional organisations

9.8 Conclusions References 
and possibly overestimated. Lastly, these two systems risk encroaching on the other systems and increasing their exposure to climate events and economic shocks.

\section{People's security is the most important condition for} improving food systems resilience. Regional conflict hampers the safe and efficient flow of crop and livestock products, as well as wage labourers seeking opportunities elsewhere. There is much debate about the root causes of conflict in the Sahel region, but there is general agreement that land and water scarcity, combined with deteriorating natural resource management agreements between users, has contributed much to the current situation. In spite of ample progress in terms of natural resource legislation and decentralisation of government, enforcement has been weak, resulting in a status quo of competing claims on natural resources and confusion about rights among users. Moreover, local governments have not been sufficiently empowered, in terms of capacities and financial resources, which has limited their ability to intervene or provide community services. For these reasons, the authority of local governments has eroded over time, resulting in lack of a social contract and, in particular situations, a vacuum of power. Resolving conflict and addressing its root causes should be a top priority when pursuing enhanced food systems resilience. mobilising community agencies, enforcing municipalities to reestablish social contracts, and addressing land tenure issues in cooperation with interest groups are among the most prominent and urgent interventions required.

\section{All five food systems contribute substantial volumes of} crop, fish, and livestock products to regional food

markets. These contributions have secured consumer access to a diversity of locally produced food. Most food systems represent ample opportunities for sustainable intensification of food production, while room for extension of land for agriculture, both crop and livestock production, has become very limited, with the exception of two systems (see conclusion 3). Until recently, farmers and livestock keepers mainly opted for extension of land under cultivation and, to a lesser extent, of herd sizes. Large-scale successes in increasing yields have remained limited, with the exception of some pulses/legumes and grains (maize and rice). Two dominant drivers are behind increasing crop and livestock production. First, a minority of commercially oriented farmers and cattle owners are capable of investing accumulated capital in land and herd extension. Until recently, land extension was (and in some cases still is) more remunerative than intensification. Second, growing consumer demand is communicated through value chain agents to producers. Key catalysts of farm and livestock investment include assured markets for crop and livestock products and their farm gate prices. In order to meet future demand for food, farmers must invest in sustainable intensification to reduce currently observed yield gaps. The agroservices required, such as farm inputs and farm advice, can be obtained through private-sector value chain agents.

\section{Family farms still constitute the backbone of all food}

systems. This includes the more specialised systems, such as rice-and-horticulture-based systems, fisheries, and agropastoralism-based systems. Corporate capital-intensive farming is rare and appears only in specific cases, such as in industrial irrigation schemes. Commercial - mainly informal - value chains, supplying the urban centres with food, include an estimated 30-40 percent of rural households, depending on the system and area. The other approximately 80-70 percent of households are engaged in seasonal/wage labour or other petty business for income generation, complemented with crop production and livestock keeping for self-provisioning. These households only bring produce to the market in situations of immediate cash needs or exceptional cases of access production. Currently, earnings from local wage labour and remittances from seasonal and regional migration to areas with demand for cheap labour are the most common tools households use to respond to food and nutrition insecurity. As such, these households are frequently net consumers of locally produced food. There is a strong interdependence between the different household types within, and sometimes between, systems. Poorer households sell their labour and/or depend on loans and gifts of wealthy households, while the latter need additional labour in peak times.
(1) Background and understanding

(2) Regional drivers

(3) Regional organisations

(4) Agro-pastoralism-based

5) Grains-and-legumes-based

6) Rice-and-horticulture

(7) Coastal maritime fisheries

(8) Tropical mixed tree and

food crops systems

Toward enhanced resilience

9.1 Demography and geography

9.2 Food systems outputs

9.3 Constraints and drivers

9.4 Impacts

9.5 Food systems resilience

9.6 Leverage points

9.7 Potential roles for regional organisations

9.8 Conclusions References 
In the short run, no significant shifts in economic development are foreseen in West Africa, such as creating new manufacturing and services industries that absorb massive numbers of workers. Thus, solutions to improve the livelihoods of poorer rural households must be sought in more enumerative labour and more diverse, sustainable farming for self-provisioning and selling of surplus in times of overproduction. The latter differs from more commercial farming in terms of extensive capital and labour practices but is geared toward securing access to diverse food year-round. The agroservices needed to achieve these objectives must be subsidised from public sources.

\section{The coastal maritime fisheries food system has very low} resilience. The coastal maritime fisheries food system differs from the four other systems as it depends most heavily on vulnerable natural resources that cannot be replaced or completed by additional sources. (This is also true, to a lesser degree, of pastoralism.) Although the system is an important regional supplier of fish, it has reached its limit and cannot be further intensified without incremental damage to the fish reserves. The system does not produce significant volumes of food products other than fish for consumer markets. Thus, this food system presents limited resilience in terms of its capacity to absorb environmental shocks and new generations of fishermen, and its communities have low levels of agency in terms of political influence. Marine fish populations need preservation, and sustainable fisheries practices must be promoted. Laws and agreements on foreign fishing operations require more effective endorsements. Researchers should investigate whether the economic resilience and equity of the system can be improved by introducing new modes of fish production, such as fish farming. Considering the projected increase in consumer demand for fish, many more people, including women and youths, can make a living out of fish production. But experiences to date with introducing fish farming in West Africa have shown only modest successes. These successes, together with the failures, need to be analyzed before considering interventions for upscaling.

\section{Regional markets are key to improving economic} resilience. Functioning regional markets are conducive to efficient trade flows, lowering transaction costs while protecting domestic production against market distortions triggered by the volatility of global food markets. Because of asymmetrical supply/demand in large areas, intraregional trade is crucial to satisfy rising demand. ECOWAS has made good progress with policies for establishing regional markets, enhancing the free flow of goods between countries, and regulating the import of products from global markets. However, despite this progress, endorsement of trade agreements and application of instruments such as CETs have been weak. The application of higher CETs on imports of strategic food such as rice, milk powder, or poultry might propel domestic production and trade. Until now, ECOWAS states have decided to keep such imports at the lower tariffs of 5 or 10 percent, which hardly prevents disturbances of domestic production by imports.

8 Trade restrictions negatively affect the resilience of food systems. Historically, the people of West Africa have traded their products across the region, and current national boundaries, drawn under colonial rule, have not significantly changed this dynamic. Even when nations decide to close their borders, they remain permeable to informal trade flows. Yet, such restrictions impose transaction costs, making regional food products much more expensive than needed and reducing their competitiveness with foreign imports. These restrictions neither serve producers, who are limited in their offset on local markets of their production, nor help poorer urban consumers access basic food ingredients for healthy diets. Trade restrictions also negatively affect the resilience of food systems in economic terms and increase system vulnerability to unforeseen shocks that cannot be absorbed through regional displacement of food stocks and surpluses. Cross-border mobility is an essential part of agro-pastoralism-based food systems, which require seasonal transhumance and transport of animals to regional consumer markets. This implies that ECOWAS regional trade policy and agreements need to be endorsed.
(1) Background and understanding

(2) Regional drivers

(3) Regional organisations

(4) Agro-pastoralism-based

(5) Grains-and-legumes-based

6) Rice-and-horticulture

(7) Coastal maritime fisheries

(8) Tropical mixed tree and

8 food crops systems

9 Toward enhanced resilience

9.1 Demography and geography

9.2 Food systems outputs

9.3 Constraints and drivers

9.4 Impacts

9.5 Food systems resilience

9.6 Leverage points

9.7 Potential roles for regional organisations

9.8 Conclusions References 
9 The COVID-19 pandemic is a wake-up call for economic and food access vulnerability. The pandemic has had, to date, variable impacts on food systems. Food systems that are dependent on global markets have proven less resilient, and hence more vulnerable, to economic shocks. The pandemic has renewed debates on the importance of domestic and regional food markets. There are clear opportunities for import substitution to have positive economic and social impacts for rain-fed rice, peri-urban vegetables, poultry, dairy, grains and legumes, and fish.

\section{Informal trade channels are the heart of the West African} food trade. Throughout the region's informal food economies, trade channels connect remote rural areas to a wide range of small towns within and between countries. This trade is responsible for the bulk of food trade in West Africa for grains, livestock, fruits, and vegetables and even for regulated products such as rice. Modern retail is rising in the capitals and big cities but is in general still modest. After state withdrawal in the 1980s and 19990s, mostly informal trade networks took over cereal commercialisation and proved their ability to keep pace with rising food demand. The food chains are not merely "short," since trade can have regional dimensions; livestock markets can go from the deep Sahel to coastal markets. Further, certain cereal and livestock markets have already existed for many decades. Women occupy a dominant place as farmers, traders, and processors. In most countries, the informal economy employs the majority of the nonfarming workforce and contributes substantially to GDP.

However, there is little social security in the informal economy. The question of food quality and hygiene is crucial in both formal and informal trade circuits. Farmers and traders cope with inefficiencies while having little access to working capital. The importance of the informal economy for food supply and for employment is not in question; rather, the discussion must focus on interventions that could be helpful to improve it. Decentralised governments can be instrumental in giving incentives, such as improved storage and market infrastructure, access to energy, hygiene measures, and incentives for private- sector financing of working capital for small and medium-sized enterprises.

11 Food systems differ in their resilience to climate shocks. Such shocks are not new, and many populations have developed coping mechanisms when confronted with natural shocks. But the frequency and severity of these shocks have increased, which has reduced household resilience through the depletion of capital reserves and food stocks. Moreover, crop production and livestock-keeping practices and the innovation capacity of producers cannot keep pace with climate changes. This constraint is amplified by other food system bottlenecks, such as declining soil fertility, land and water scarcity, and food system drivers such as increased demands for food and income from agriculture. These challenges can only be addressed by matching the innovation capacity of producers with regional research capacity, together seeking climate smart responses to production constraints.

12 Nutrition is key to food systems resilience. Chronic inadequate diets, leading to micronutrient deficits, affect more people's health in West Africa than seasonal low calorie intake. This trend is pervasive in urban and rural environments. The discourse around development and food insecurity has shifted toward nutrition, though national policies and interventions still focus on staple crops and production quantities. There are some important technical interventions, such as enriching cereals, but these alone will not make the difference. More important are the current efforts of policy makers and agricultural researchers to expand perspectives on food security (such as extending nutrition questions from the health and food aid sectors to agriculture), change and target education (such as for women in agricultural households), and include vegetables, dairy, meat, and fish in agricultural policies for food and nutrition security.

13 Regional organisations can enhance the resilience of food systems. In particular, they can build on the emerging track record of ECOWAS in establishing a regional agricultural policy framework and coordinating responses to regional food crises. Technical organisations such as CILSS have extensive
(1) Background and understanding

(2) Regional drivers

(3) Regional organisations

(4) Agro-pastoralism-based

(5) Grains-and-legumes-based

(6) Rice-and-horticulture

(7) Coastal maritime fisheries

(8) Tropical mixed tree and

8 food crops systems

Toward enhanced resilience

9.1 Demography and geography

9.2 Food systems outputs

9.3 Constraints and drivers

9.4 Impacts

9.5 Food systems resilience

9.6 Leverage points

9.7 Potential roles for regional organisations

9.8 Conclusions References 
experience in providing knowledge, advice, and coordination support for the implementation of programs to improve food security and manage climate risks. Yet, regional cooperation in West Africa still depends mainly upon the interests of national actors, which greatly limits what regional organisations can actually do beyond formal regional policies and agreements. To promote food systems resilience, for which many factors are locally specific, care must be taken in formulating regional interventions, notably at the ECOWAS level. Such interventions should build on regional policy and programmatic experiences with proven traction among member states, be it in the fields of agri-food trade, research and innovation, transboundary natural resources management, or social protection. Where there is traction for regional action, supporting the development of existing regional institutions, policy instruments such as the ARAA, and networks of nonstate actors should be the preferred approach to ensure the sustainability of outcomes.

\section{References}

Benzekri, N. A., J. F. Sambou, B. Diaw, E. H. I. Sall, F. Sall, A. Niang, S. Ba, N. F. N. Guèye, M. B. Diallo, S. E. Hawes, and M. Seydi. 2017. "The Dimensions of Food Insecurity and Malnutrition among People Living with HIV in Senegal, West Africa." AIDS Care 29 (12): 1510-16.

Dinesh, Dhanush, Bernard Bett, Randall Boone, Delia Grace, James Kinyangi, Johanna Lindahl, Chadag Vishnumurthy Mohan, Julian Ramirez-Villegas, Timothy Robinson, Todd Rosenstock, Julian Smith, and Philip Thornton. 2015. Impact of Climate Change on African Agriculture: Focus on Pests and Diseases. Gaborone, Botswana: CCARDESA.

FAO (Food and Agriculture Organisation). 2003. The Impact of HIV/AIDS on Agriculture and Food Security: Mitigating the Impact of HIV/AIDS on Food Security and Rural Poverty. Rome: FAO.

FAO (Food and Agriculture Organisation). 2015. Regional Overview of Food Insecurity Africa. Rome: FAO.

FAO. 2020. Addressing the impacts of COVID-19 in food crises | AprilDecember 2020: FAO's component of the Global COVID-19 Humanitarian Response Plan. Rome.

Hatlebakk, M. 2020. Corona and Food Security in Poor Countries. CMI Brief 4. Bergen, Norway: CMI
Kodish, S. R., F. Bio, R. Oemcke, J. Conteh, J. M. Beauliere, S. Pyne-Bailey, F. Rohner, I. Ngnie-Teta, M. B. Jalloh, and J. P. Wirth. 2019. "A Qualitative Study to Understand How Ebola Virus Disease Affected Nutrition in Sierra Leone: A Food Value-Chain Framework for Improving Future Response Strategies." PLOS Neglected Tropical Diseases 13 (9): e0007645.

Sauvage-Mar, M. 2020. "How To Apply Lessons Learned from the Ebola Response to COVID-19." Crisis Response, International Development Research, April 6, 2020

Thurlow, James. 2020. COVID-19 lockdowns have imposed substantial economic costs on countries in Africa. In COVID-19 and global food security, eds. Johan Swinnen and John McDermott. Part One: Food security, poverty, and inequality, Chapter 4, Pp. 23-25. Washington, DC: International Food Policy Research Institute (IFPRI)

UN (United Nations). 2010. Food and Nutrition Security in West Africa: Opportunities and Challenges. Supplement on the 11th Annual ECOWAS Nutrition Forum. SCN NEWS No. 38. Geneva: WHO.

UN (United Nations). 2020. UN Secretary-General's policy brief: The impact of COVID-19 on women

WFP (World Food Programme). 2017. Impact of West Africa Ebola Outbreak on Food Security and Staple Food Prices. Rome: WFP.

WFP. 2020. COVID 19 situation reports. Updates on actions taken by the World Food Programme (WFP) in response to the novel Coronavirus (COVID-19) pandemic.

Woodhill, J., S. Hasnain, and A. Griffith. 2020. Farmers and food systems: What future for small-scale agriculture? Environmental Change Institute, University of Oxford, Oxford.
(1) Background and understanding

(2) Regional drivers

(3) Regional organisations

(4) Agro-pastoralism-based

(5) Grains-and-legumes-based

6) Rice-and-horticulture

(7) Coastal maritime fisheries

(8) Tropical mixed tree and

food crops systems

9 Toward enhanced resilience

9.1 Demography and geography

9.2 Food systems outputs

9.3 Constraints and drivers

9.4 Impacts

9.5 Food systems resilience

9.6 Leverage points

9.7 Potential roles for regional organisations

9.8 Conclusions

References 


\section{Acknowledgements}

As with any study of this scope, there are many people whom we would like to thank. Without their noteworthy contributions this

study would simply not have been possible. First, the authors would like to thank The Netherlands Ministry of Foreign Affairs that

provided, through the Netherlands Food Partnership, funding to this study. We acknowledge additional financial support and guidance by the World Bank, including through comments from Tobias Baedeker, Sebastian Heinz, Katrina Brandon and James Tefft. Other people who contributed to the research include Herman Brouwer, Gonne Beekman, Annabelle Daburon and Deborah Bakker. Many people in West Africa have been consulted or have contributed in various ways, for which we would like to express our gratitude. We are grateful to Fernanda Rubiano for having created supportive visuals and Zayd Abdulla and Dina Towbin \& Associates LLC for editing the text.
(1) Background and understanding

(2) Regional drivers

(3) Regional organisations

(4) Agro-pastoralism-based

(5) Grains-and-legumes-based

6) Rice-and-horticulture

(7) Coastal maritime fisheries

8 Tropical mixed tree and food crops systems

9 Toward enhanced resilience 


\section{Colophon}

Bart de Steenhuijsen Piters, Joost Nelen, Bertus Wennink, Verina Ingram, Fabien Tondel, Froukje Kruijssen and Jenny Aker 2021. West African food system resilience. Wageningen,

Wageningen Economic Research, Report 2021-006. 184 pages.; 37 fig.; 14 tab.; 12 maps; 489 ref.

\section{Photography}

Tremens Productions / Shutterstock.com (p.14)

Anton Ivanov / Shutterstock.com (p.20)

Fabian Plock / Shutterstock.com (p.32)

ymphotos / Shutterstock.com (p.76)

Agarianna76 / Shutterstock.com (p.82)

Hector Conesa / Shutterstock.com (p.85)

Gerhard Pettersson / Shutterstock.com (p.114)

GODONG-PHOTO / Shutterstock.com (p.137)

Photoagriculture / Shutterstock.com (p.149)

Rainer Lesniewski / Shutterstock.com (p.171)

ambient_pix / Shutterstock.com (p.177)

Others: Shutterstock.com, Wageningen University \& Research

\section{Design}

Wageningen University \& Research, Communication Services

This report can be downloaded for free at

https://doi.org/10.18174/543127 or at

www.wur.nl/economic-research.

This research was carried out by Wageningen Economic Research in collaboration with the Royal Tropical Institute (KIT) and European Centre for Development Policy Management (ECDPM). The research was co-funded by the Netherlands Food Partnership and with contributions from the World Bank.

(C) 2021 Wageningen Economic Research PO Box 29703,

2502 LS Den Haag, T +31 7033583 30,

E communications.ssg@wur.nl, wur.eu/economic-research.

Wageningen Economic Research is part of

Wageningen University \& Research.
(1) Background and understanding

(2) Regional drivers

(3) Regional organisations

4 Agro-pastoralism-based

C Wageningen Economic Research, part of Stichting Wageningen Research, 2021

The user may reproduce, distribute and share this work and make derivative works from it. Material by third parties which is used in the work and which are subject to intellectual property rights may not be used without prior permission from the relevant third party. The user must attribute the work by stating the name indicated by the author or licensor but may not do this in such a way as to create the impression that the author/licensor endorses the use of the work or the work of the user. The user may not use the work for commercial purposes.

Wageningen Economic Research accepts no liability for any damage resulting from the use of the results of this study or the application of the advice contained in it.

Wageningen Economic Research is ISO 9001:2015 certified.

Wageningen Economic Research 2021-006

Project code 2282300349
(5) Grains-and-legumes-based

(6) Rice-and-horticulture

(7) Coastal maritime fisheries

8 Tropical mixed tree and food crops systems

9 Toward enhanced resilience 